\title{
WAVES OF THE SEA AND OTHER WATER-WAVES
}

\section{VAUGHAN CORNISH}




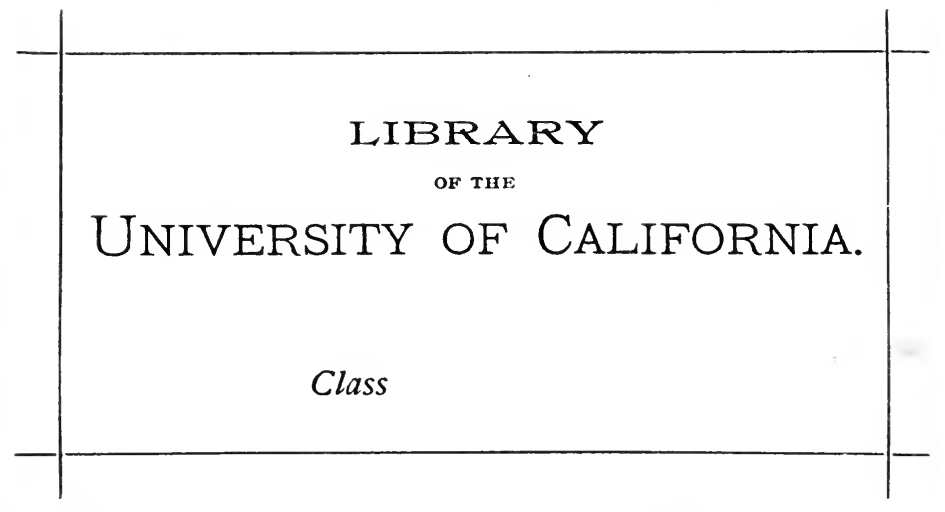


Digitized by the Internet Archive in 2007 with funding from Microsoft Corporation 


\section{WAVES OF THE SEA}




\section{BY THE SAME AUTHOR.}

\section{The Panama Canal and its Makers.}

With a Map and 63 Illustrations from the Author's Photographs.

\section{Large Crown 8vo, cloth, 5.}

"It is a pleasure to have a book on the Panama Canal by an English observer. Mr. Cornish is both qualified and independent. He has produced an admirable description, suited for the general reader, lucid, not overloaded with technicalities, of the right length, yet comprehensive." Daily Chronicle.

"The author of this concise account of the history, the progress, and the possibilities of a gigantic enterprise is to be congratulated on the skilful manner in which he has compressed an enormous amount of information and many valuable opinions and observations into a very small space." -Standard.

LONDON: T. FISHER UNWIN. 


\section{WAVES OF THE SEA}

AND OTHER WATER WAVES

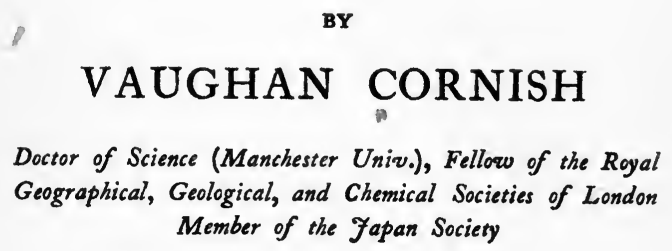

WITH 50 PHOTOGRAPHS TAKEN BY THE AUTHOR

T. F ISHER U N W I N

LONDON : ADELPHI TERRACE

LEIPSIC: INSELSTRAS'SE 20

1910 


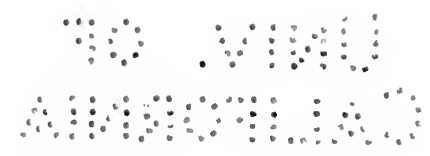

(All rights reserved.) 


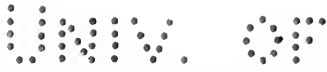

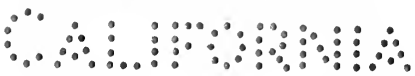




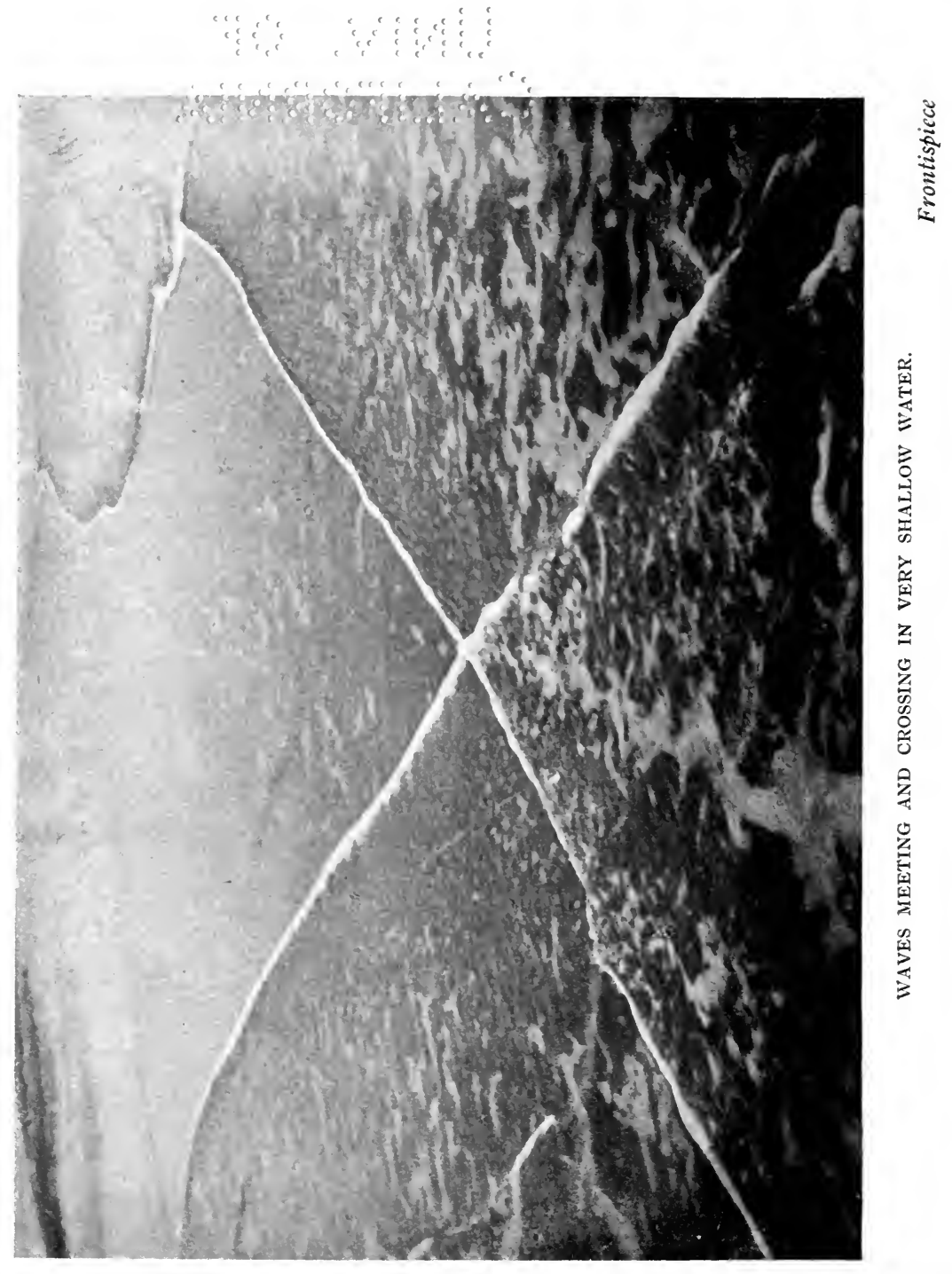


TO

SIR CLEMENTS R. MARKHAM, K.C.B., F.R.S.

VICE-PRESIDENT AND PAST PRESIDENT

OF THE

ROYAL GEOGRAPHICAL SOCIETY

IN TOKEN OF

SINCERE REGARD AND VENERATION

I DEDICATE THIS BOOK

V. C. 



\section{P R E F A C E}

Most of us have felt the fascination of a wave. The waves of the sea, which are the prototype of all the phenomena which we now call waves, are perhaps the most fascinating of all. Great as is the beauty of their form, the mystery of their motion is the greater charm. For while they move they live and have a being, which, like our own, is but momentarily associated with the matter of which they are formed. The wave preserves its individuality, its recognisable though not unchanging form, its energy, partly active, partly in reserve, whilst its material substance is constantly rejected and renewed. Of all manifestations of the inorganic world it is most like a living being. Yet when we watch it to its end we find none of the sad accompaniments of the exhaustion of life. It is most beautiful at the last, as it culminates to its fall and breaks in seething foam.

There are two aspects of sea waves which particularly attract our admiration. The first is that 
of a storm at sea, the second is the surf which comes in during calm weather upon a shore facing the open ocean, the breakers booming like minute guns. The first indicates the fury of the wind, but it is the second which we almost instinctively recognise as affording the best index of the greatness of the expanse of water.

These things, and others of a like nature, I have watched for many years, and I have set down in this book what I have been able to add to former knowledge.

I have written to inform the mind, not to stir the imagination. The appearances are familiar and recurrent, and I do not attempt to recall them by much word-painting, but the precise observation and measurement of waves, and the discovery of the mode of their production, are matters of difficulty, and to these I have given myself.

My investigations on water waves have been prosecuted during the last fifteen years. They have been made in many parts of the world, which I have visited principally for the study of surface waves of different kinds. The chief results as far as they relate to water waves are contained in this volume, which contains also a critical examination of observations made by a number of seamen and others upon the size and speed of ocean waves. 
Most of Part III., relating to tidal bores and other waves in rivers, was published in the Geographical Journal and in Engineering in 1906, but Parts I. and II., which relate to waves of the sea, are new, and were written in 1909- Io.

Side by side with the observations of water waves, I have during the same period (i.e., since I 895 ) been investigating the progressive transverse ridges which are produced in sand and snow by the action of water or wind, and I have made observations upon earthquakes and other wavephenomena which come within the province of physical geography. These I intend to publish later.

August, г9ro.

VAUGHAN CORNISH. 



\section{CONTENTS}

\section{PART I}

ON THE SIZE AND SPEED OF DEEP-SEA WAVES

CHAPTER I

Introduction-Waves on ponds-Waves on lakes-Coniston

Water-Lake of Geneva-Lake Superior-Waves in semi-enclosed seas-Western Mediterranean-China Sea

\section{CHAPTER II}

Observations of waves on the North Atlantic-Conclusion as to height of North Atlantic waves-Waves on the North Pacific-The effective length of fetch of strong winds on the North Atlantic Ocean-The numerical relation between the length of fetch of wind and height of storm-waves-Waves on the South Atlantic and Southern Indian Oceans-Waves on the South Pacific Ocean-The discrepancy between wave-lengths determined respectively by simultaneous and by successive observation of wave-crests . . .

\section{CHAPTER III}

The wave-length of the swell which reaches the shore after storms-The height of the swell at sea during storms -The co-existence of waves of different lengths-The give and take between air and water in the development of waves 


\section{CHAPTER IV}

The velocity of the wind at sea-The numerical relation between velocity of wind and average height of waves -The relation between the velocity of the wind and the velocity of the waves-The connection between the rate of progress of cyclones and the character of the waves-The effect of squalls and gusts upon waves-On wave-fronts in a veering wind, and on the irregularity of the waves in the region of the Trade winds-The observed profile of waves at sea-The mountainous appearance of waves

\section{PART II}

ON THE ACTION OF SEA WAVES TO TRANS. PORT SHINGLE, SAND, AND MUD

\section{CHAPTER V}

On the depth to which wave-agitation extends, and on the transport of fine mud-The action of waves to drive shingle shorewards-The effect of percolation to promote the building-up of beaches-The movement of sand by waves-The undertow .

\section{CHAPTER VI}

On the actions which determine the 'longshore transport of beach shingle-On the causes which give rise to an arrangement of pebbles according to their sizes along the Chesil Beach and certain other beaches-On the production and maintenance of the Shambles sand-bank near Portland-The formation of patches of shingle upon 2 sandy beach by the action of breakers . 


\section{PART III}

ON STATIONARY AND PROGRESSIVE WAVES IN RIVERS

\section{CHAPTER VII}

The flood-wave of rivers-The roll-wave in the Tees-In the Ure-In the Nikko torrent-On the advance of a flood over dry ground

\section{CHAPTER VIII}

Tidal bores-Wave-length of the Severn bore-On the want of concordance between height of tide and height of bore, and on the conditions which determine the starting-point of the bore

\section{CHAPTER IX}

Cinematographing the Severn bore .

\section{CHAPTER $\mathrm{X}$}

Stationary or standing waves-Cross-stream progressive waves: observations in Niagara River.

\section{CHAPTER XI}

On streams which flow as a series of roll-waves-Observations on a conduit from Territet to Glion-Observations on the conduit of the Grünnbach (Merlingen, Thunersee) -Observations on the conduit of the Guntenbach (Gunten, Thunersee)

\section{CHAPTER XII}

The sounds of running water-The gushing motion of cataracts-Conical structures produced by the breakup of a waterfall-The wave-track of a ship . 


\section{LIST OF ILLUSTRATIONS}

PLATES.

WAVES MEETING AND CROSSING IN VERY SHALLOW WATER

Frontispiece PAGE

A MODERATE GaLE IN THE MEDITERRANEAN

From S.S. Orizaba. Height of camera 22 feet.

A STRONG GaLE IN THE NORTH ATLANTIC

From S.S. Ivernia. Height of camera 40 feet.

HEAVY SWELL IN THE NORTH ATLANTIC . . $\quad 5^{\text {I }}$

WAVES AND SWELL IN THE NORTH ATLANTIC - $\quad 57$

UNDULATING HORIZON OF A ROUGH SEA • • • 65

WEATHER IN THE NORTH ATLANTIC. * . $\quad$ II5

THE PROFILE OF BREAKING WAVES AT EASTBOURNE • I43

WAVES BREAKING ON A SHINGLE BEACH • . . I5I

A WAVE BEFORE AND AFTER BREAKING • • • $\quad$ I55

WAVE BURSTING AGAINST A VERTICAL WALL $\quad$ - $\quad$ I59

BREAKER AND BORES ON A FLAT SHORE . . . . 163

THE FRINGE OF FOAM LEFT BY THE BORE UPON A FLAT SHORE $\cdot \quad$. $\quad . \quad$. $\quad . \quad$. 167 
PAGE

WAVES APPROACHING ONE ANOTHER IN VERY SHALLOW

WATE

WAVES SHOWN BY DISTORTED REFLECTION OF MASTS

(KINGSTON, JAMAICA) • $\quad$ - $\quad . \quad$ - $\quad$ I77

SHINGLE RIDGES

I8I

THE ENCROACHMENT OF SHINGLE (SLAUGHDEN, NEAR ALDE-

BURGH, SUFFOLK)

- 185

STONES ON THE BEACH NEAR CHESILTON AND THE GRA-

DATION OF STONES FROM BURTON BRADSTOCK TO

CHESILTON

- 195

SHORE BETWEEN EAST END OF CHESIL BEACH AND

BLACKNOR POINT

SAND BROUGHT BACK AFTER A STORM AND SAND DRIFTED

ALONGSHORE

201

SHINGLE SORTED FROM SAND BY THE WASH OF A HEAVY SWELL (BRANKSOME CHINE, NEAR BOURNEMOUTH) 。

REMOVING SHINGLE AFTER A HEAVY SWELL, BEFORE THE

SAND IS BROUGHT BACK IN CALMER WEATHER

CHEVRON-SHAPED PATCH OF SHINGLE FORMED BY THE

WASH OF THE SWELL ON A SANDY SHORE (BOSCOMBE)

THE COURSE OF THE RIVER SEVERN FROM GLOUCESTER

TO THE SEVERN TUNNEL

- 233 


\section{LIST OF ILLUS'TRATIONS}

THE BORE ON THE SHALLOWS OF DENNY ROCK, AND AFTER

REACHING DEEPER WATER

THE NOOSE SANDBANK

CINEMATOGRAPHS OF THE BORE APPROACHING STONEBENCH 255

CINEMATOGRAPHS OF THE BORE ON REACHING STONEBENCH 259

BORE VIEWED FROM BEHIND AFTER PASSING STONEBENCH 263

STATIONARY WAVES CAUSED BY A WEIR ON THE RIVER

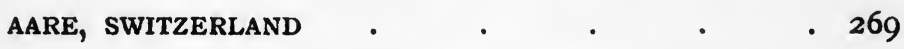

BIRD'S-EYE VIEW OF WAVES IN WHIRLPOOL RAPIDS, NIAGARA 275

LEAPING WAVE, WHIRLPOOL RAPIDS, NIAGARA $\quad$ • 279

WAVES IN WHIRLPOOL RAPIDS, NIAGARA • • • $\quad 285$

WAVES IN A RAPID ON THE ST. LAWRENCE, TAKEN GOING

DOWN-STREAM IN A STEAMER • • • • • $\quad 289$

ROLL-WAVES IN THE GRÜNNBACH CONDUIT, LOOKING UP-

STREAM -

- 303

ROLL-WAVE LEAPING THE OUTFALL OF THE GRÜNNBACH CONDUIT .

ROLLWAVES IN THE GRÜNNBACH CONDUIT, LOOKING

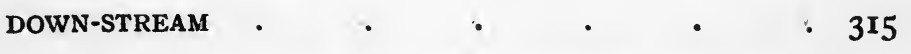

OUTFALL OF THE GUNTENBACH AT THE WAVE-TROUGH, AND

(A FEW SECONDS LATER) AT THE WAVE-CREST 
THE GUNTENBach With TWo Roll-waves .

THE GUNTENBACH WITH TWO ROLL-WAVES.

UPPER PART OF FALLS AT NIAGARA, SHOWING UNBROKEN WATER

NIAGARA FALLS, SHOWING FLEECY APPEARANCE PRODUCED BY THE BREAKING OF THE FALLING WATER .

THE BREAKING WATER OF NIAGARA FALLS, TAKEN FROM

S.S. MAID-OF-THE-MIST

FALLS OF THE TSCHINGELBACH, BURGLAUENEN • • 343

WATER ROCKETS PROJECTED UPWARDS FROM THE FOOT

OF THE HORSESHOE FALLS, NIAGARA • • • 347

WAVE-TRACK OF STEAMER ON THUNERSEE, SHOWING

THWART-SHIP AND DIVERGING WAVES . . $35^{\mathrm{I}}$

WAVE-TRACK OF STEAMER ON CONISTON WATER, SHOWING

INTERFERENCE BANDS BETWEEN DIVERGING WAVES OF

THE BOW AND STERN SERIES . $\quad . \quad \cdot \quad \cdot 355$

WAVE-TRACK OF STEAMER ON CONISTON WATER, SHOWING INTERFERENCE BANDS AND DOUBLE-CRESTED DIVERGING WAVES

WAVE-TRACK OF STEAMER ON LAKE LEMAN - $36 \mathbf{r}$

WAVE-TRACK OF STEAMER ON LAKE LEMAN, SHOWING, ON THE LEFT, THE INNER BOUNDARY OF GROUP OF DIVERGING WAVES 


\section{LIST OF ILLUSTRATIONS}

FIGURES IN THE TEXT.

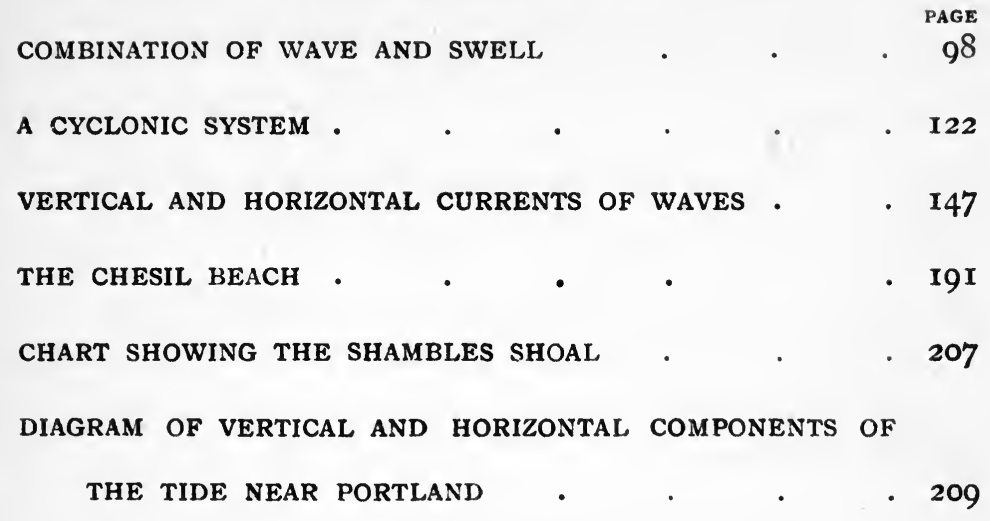



PART I

ON THE SIZE AND SPEED OF DEEPSEA WAVES 



\section{CHAPTER I}

Introduction-Waves on ponds-Waves on lakes-Coniston Water-Lake of Geneva-Lake Superior-Waves in semienclosed seas-Western Mediterranean-China Sea.

\section{Introduction}

MEASUREMENTS of waves at sea by means of the eye are not susceptible of great accuracy; but the irregularity of the waves themselves is so considerable, especially in their most important condition, which is during storms, that it is more useful to measure many waves somewhat roughly than to obtain (even if it be possible) the precise measurement of a few. The advantage of the mere number of observations does not, however, apply when we. pass from rough measurements by careful observers to mere guessing at the dimensions of waves as seen from on board ship. Measurements of the height of waves, for instance, taken in the usual way by finding the height above the ship's waterline from which a neighbouring wave-crest just intercepts the horizon, are believed to be accurate 
to within I foot in 10 when made by a practised observer. This was the estimate of the late Lieutenant Paris, of the French Navy, for his observations, and the late Lord Kelvin informed me that he relied upon his own measurements to the same extent. When, however, an unpractised observer, judging merely by the look of things from the deck of a ship, guesses the height and length of waves, it is possible for him to err much more widely than he would on the land, where he stands on a firm platform, with objects of known size in the neighbourhood to afford a scale. The rolling of the ship, in particular, alters the apparent direction of the vertical so as to mislead the judgment as to height. It is difficult to say how widely these guesses may depart from fact, but I do not think it unlikely that waves 20 feet high may, according to the circumstances, be guessed by unpractised or careless observers at anything from 10 to 30 feet. This is a range of error of roo per cent. as against the 10 per cent. of the practised observer. While, therefore, in dealing with the data before me, I have been anxious to obtain numerous records, I have been still more anxious not to include any which might belong to the category. of misleading guesses. As far as possible, I have relied upon figures in which the observer has ex- 


\section{AND OTHER WATER WAVES}

plained his method of measurement, and detailed the attendant circumstances of wind, weather, and environment. This may have led to the rejection for the purpose of this book of good measurements, but the importance of all measurements or estimates of the size of sea waves being accompanied by a statement of the method of observation and the attendant circumstances cannot be too strongly emphasised.

The relation between the wave-length in deep water and the period (or time which elapses between the passage of a fixed point by two succeeding wave-crests) has been calculated mathematically, and verified by observation. I have, therefore, in what follows applied the formula thus obtained, viz.:

$$
\text { Wave length }=5 \frac{1}{8} \times \text { square of period, }
$$

to obtain the wave-length when only the period has been measured. In all cases, however, the reader is informed which observation was made, that of length or period.

\section{WAVES ON PONDS}

As the sea is always heaving with the disturbance due to former winds, the commencement of the wave-making action of wind is best observed 
on smaller sheets of water. In a rock pool, 20 feet in diameter, under High Peak, Sidmouth, Devon, I have measured waves of $I$ inch wave-length at the windward end, and $4 \frac{1}{8}$ inches at the leeward end, the wind having the force of a gale. Thus if we take the average length of the waves to be $2 \frac{1}{2}$ inches, there was in this small pool a series of ninety, consecutive waves, the longest of which was I -6oth of the length of the series.

On the Round Pond in Kensington Gardens, London, 670 feet in diameter, the water on an absolutely still day has a glassy surface, but any breath of air sufficient to be felt upon the cheek is enough to ruffle its surface and to do away with the mirror-like reflection. It will then be seen that the area of ruffled water has been instantaneously covered with an almost uniform pattern of little waves about an inch in length from crest to crest. As the minutes pass during which the breeze continues, the height and length of the waves to leeward increases, but those on the windward edge of the ruffled water remain of the original size. Soon the whole pond, except a few feet at the windward end, is covered with waves travelling before the wind whose size increases regularly from the windward to the leeward shore. The maximum size attained at the latter place depends to some 
extent upon the strength of the wind, but even in a whole gale (October 6, I 90 I) the little breakers on the shelving lee shore followed one another at intervals of only I second. I The wave-length was not measured, but appeared to be about 3 feet. The whole of this effect was soon produced, being a matter of minutes; the height of the waves quickly diminished when the wind lulled, and could be seen to increase instantaneously when squalls occurred, the height increasing by a considerable fraction during a squall lasting four minutes.

If we take the greatest length of waves observed in the Round Pond on the day referred to as 3 feet, and adopt the simple mean of the shortest ( $\mathrm{I}$ inch) and the longest ( 36 inch) wave as the average wave-length for the pond during a gale, we find that there is then a series of 436 consecutive waves, of which the longest is $1-223$ rd of the length of the series, or of the length of fetch of the wind, or of the length of run of the waves.

On the Serpentine Water in Hyde Park, a much larger pond, the shape of which, however, is not favourable to the development of waves, I measured those produced in a strong SW. breeze, going out

I The calculated length of a I-second wave in deep water is 5 feet. The velocity of the wind in London was 50 statute miles per hour. 
in a boat not very far from the lee end, where I was sure of a sufficient depth of water for the purpose. Measurements with a wooden rule repeated during the course of half an hour gave 3 feet wave-length and a height from trough to crest of about 2 inches.

In ponds, therefore, we see that when the wind raises waves at all they must be numerous, and that even the longest must be a small fraction of length of the series, and that the fraction decreases as the length of the pond increases. The steepness of the waves formed by wind upon ponds is also found to be small as compared, for instance, with the waves which may sometimes be seen caused by obstructions in a river. Thus the height of the waves in the Serpentine was only I-I 8th of their length.

\section{WAVES ON LAKES}

\section{Coniston Water}

We now proceed to observations on a larger sheet of water, the Lake of Coniston, or Coniston Water, in Lancashire. They were taken near the upper end of the lake, at a distance of 7 statute miles from the lower end. The sheet of water is narrow and nearly straight, the lower end about 
S. by .W. from the upper. When the wind blew up the lake with the force of half a gale I found that the waves near the upper end succeeded each other at intervals of 2 seconds, corresponding to a wavelength in deep water of 20 feet. At a later date Mr. Hamil, a seaman of experience, and captain of the steam gondola which plies on the lake, sent me the following observations which he made upon the larger waves produced in a whole gale of wind.

On September 3, I902, at 8 a.m., there was a light wind blowing up the lake, i.e., from the south. At ro a.m. it rose to a gale, the wind shifting to a little $\mathrm{W}$. of S. Mr. Hamil timed the waves at Yewdale Beck, near the upper end of the lake, with the following results :

Waves passing point of observation. Waves breaking on beach.

\begin{tabular}{|c|c|c|c|c|c|c|c|c|}
\hline I0.30 a.m. & ... & 27 & per & nute & .. & \\
\hline $\mathrm{I} 0.32$ a.m. & ... & & & & $\ldots$ & 24 & er & inute \\
\hline I I.o a.m. & $\ldots$ & 23 & $"$ & $" 1$ & $\cdots$ & & & \\
\hline II.2 a.m. & ... & & & & ... & 22 & $n$ & $"$ \\
\hline I I.30 a.m. & ... & $2 I$ & $"$ & $"$ & $\cdots$ & & & \\
\hline I I.32 a.m. & $\ldots$ & & & & $\cdots$ & 20 & $"$ & $" n$ \\
\hline 12.0 a.m. & $\cdots$ & 2 I & $"$ & $"$ & $\cdots$ & & & \\
\hline I2.2 a.m. & ... & & & & $\cdots$ & 20 & $"$ & $"$ \\
\hline
\end{tabular}

Thus the period appeared to be constant after I I.30 a.m. -i.e., an hour and a half after the gale commenced. The length of wave in deep water corresponding to the observed period of 3 seconds 
is 46 feet. The distance from the lower end of the lake being 7 statute miles, or 36,960 feet, the length attained by the waves is I-803rd of this distance. If we take the average length of the series of waves as 23 feet (since when they commence their length is very small), the number of waves in series from end to end of the lake was 1,608 .

The wind conditions were similar to those described for the Round Pond at Kensington and for the Rock Pool at Sidmouth. Thus we see that the length of the storm-waves is increased when the length of the sheet of water is increased, but more slowly.

The above, however, are not the greatest waves which can be formed on Coniston Water, although they are probably about as large as are formed in ordinary gales. The following observations supplied to me by Mr. Hamil illustrate the way in which waves larger than ordinary are produced. They indicate a fact (which we shall find illustrated later when dealing with the great waves of high southern latitudes-e.g., between the Cape of Good Hope and Australia) that the wave-raising power of wind is much greater when operating upon water already in waves than upon nearly smooth water.

Mr. Hamil finds that the largest waves on 
Coniston Water are only formed when, after about three days of steady wind blowing along the length of the lake has produced a steady " run " of waves, it comes on to blow very hard in the same direction. Under such circumstances he recorded, near the upper end, a wave-length of 65 feet and a height of 5 feet. These measurements were made against the side of the steam gondola. He relies upon the length to less than 5 feet either way-i.e., is sure that the waves were more than 60 and less than 70 feet long. The determination of height he found more difficult. The wave-length attained under these somewhat rare conditions was I -569 th of the length of the whole series. The length of wave was 13 times the height. Assuming the same steepness of water for ordinary gales as for the above unusual storms, the height of wave corresponding to the wave-length of 46 feet would be $3 \frac{1}{2}$ feet, and this, I suppose, is seldom much exceeded on Coniston Water.

\section{The Lake of Geneva}

On Lake Leman, or the Lake of Geneva, Dr. F. A. Forel records during storms wave-periods of 4.7 seconds at Morges and 5.0 at the town of Geneva. The longest run which a wave could have before reaching Morges is 27 statute miles, 
and the calculated wave-length in deep water for a period of 4.7 seconds is I I 3 feet. The length of run possible at the town of Geneva, which is situated at the lower extremity of the lake, is 43 statute miles, and the wave-length corresponding to a period of 5 seconds is 128 feet. At Morges, therefore, the length of the storm-waves was I-I26I of the length of the series and at Geneva I-I774. If we suppose the wind blowing down the lake, and at the Geneva end making waves I 28 feet long, then if we take as before the average length of waves on the lake to be one-half as long, the number of the waves in the series, from end to end of the lake, is 3,548 .

The following heights of waves on the lake are recorded by Thos. Stevenson I as having been observed by Buckie at the distances stated from windward shore, viz. :

Height of Wave

in feet.

$7.0 \quad \cdots$

$7.0 \quad \cdots$

8.0

8.0
Length of Fetch in miles.

... $3 \mathbf{I}$

... 38

... 38

... 40

I Vide article, "Harbours," "Encyclopædia Britannica," 9th edition. Of all the bodies of water cited by Stevenson in his table of the increase of height with length of fetch, the Lake of Geneva is the only one which is wholly enclosed. Many of the others are, moreover, shallow or affected by strong currents. 


\section{AND O'THER WA'TER WAVES}

The greatest length (calculated from the observed period) is $\mathrm{I} 5.4$ times the greatest height.

\section{Lake Superior}

On Lake Superior waves have been carefully measured from the shore by Colonel D. D. Gaillard, Corps of Engineers, U.S.A. For the size of the waves out in the deep water of the lake, he has, however, had to obtain evidence from the captains of vessels. He writes : I

"As the result of inquiries of vessel captains who have navigated Lake Superior for many years, and who have, in some cases, made a special note of the fact that in unusually severe storms the horizon could not be seen from the wheelhouse when the ship was in the trough of the sea, on account of adjacent wave-crests, it seems probable that during unusually severe storms upon Lake Superior, which occur only at intervals of several years, waves may be encountered in deep water of a height of from 20 to 25 feet and a length of 275 to 325 feet."

He adds that the waves on Lake Superior are larger than occur on any other of this chain of great lakes.

I "Wave Action in Relation to Engineering Structures" (Washington Government Printing Office, 1904), p. 82. 
In the Duluth Canal at the western end of Lake Superior Colonel Gaillard during I9O I and I 902 frequently measured waves 200 feet in length, occasionally 250 , and once 275 feet, in a depth of not more than 27 feet of water. The velocity of such waves is reduced in water of this depth and they close in upon one another, their wavelength diminishing. The measurements taken by Colonel Gaillard in somewhat shallow water therefore show that the estimates of wave-length made by the captains of vessels were not excessive, and that we may safely say that a length of 300 feet is attained during exceptionally severe storms by the waves of Lake Superior. The possible length of fetch of wind and length of run of the waves at Duluth is 298 statute miles or 259 nautical miles, so that the greatest wave-length is $1-5248$ th of the length of the lake, and if the average wave-length of the series be I 50 feet, there would be 10,496 successive waves simultaneously between windward and leeward shore. Thus again we find the steady growth of wave-length with the length of the sheet of water, the increase of wave-length taking place, however, more slowly.

Taking the height of the waves during severe storms on this lake as $22 \frac{1}{2}$ feet and their length as 300 , we find that the length is 13.3 times the 
height, which is nearly the same as that ( 13 ) found for an exceptional storm on Coniston Water.

WAVES IN SEMI-ENCLOSED SEAS OF, CONSIDERABLE DEPTH

\section{Waves in the Western Mediterranean}

The Western Mediterranean is about $\mathrm{I}, 000$ statute miles from east to west, but its area is somewhat broken up by islands. The depths are great and the tidal currents small, so that observations of waves are useful for the determination of dimensions due to the mere action of wind on deep water.

On April 7, I 899, I sailed from Marseilles at 4 p.m. on the Orient liner Orizaba, bound for Naples, the weather being fair. Next morning, the 8th, when nearing the Straits of Bonifacio, there was a heavy sea directly following the ship, the wind having risen during the night and having now the force of a moderate gale. The waves were not running in a single series of parallel ridges, but with a good deal of crossing, and the characteristic feature of the scene was the number of bursting billows of more or less pyramidal form produced by the meeting at an acute angle of waves running not quite in the same direction, 
These waves, curling over in a cusp and breaking, flecked the surface of deep blue water with white foam which reflected the bright beams of the sun shining through the spray. I set myself to measure the height of these waves at the times of their greatest elevation. Standing on the bulwark rails of the spar deck, while holding to the steel uprights which supported the promenade deck, I found that my eye was on a level with the crests of the highest waves when 22 feet above the flotation line. The position of the latter I obtained from the commander, who informed me that its then position was 3 feet below the Plimsoll mark. The height of the deck above the Plimsoll mark was known from the scale plan of the ship. The ship did not pitch, and her rolling was so slow that it was fairly easy to make the observation when on an even keel. Thus the height from trough to crest of the pyramidal waves, which were the characteristic waves of the day, was ascertained with some approach to accuracy to be 22 feet.

I desired to ascertain the length of the waves, which were travelling in the same direction as the ship, but as usual was unable to watch a wavecrest running the whole length of the vessel. The length between two convexities near the ship's side, viewed simultaneously, I judged to be 


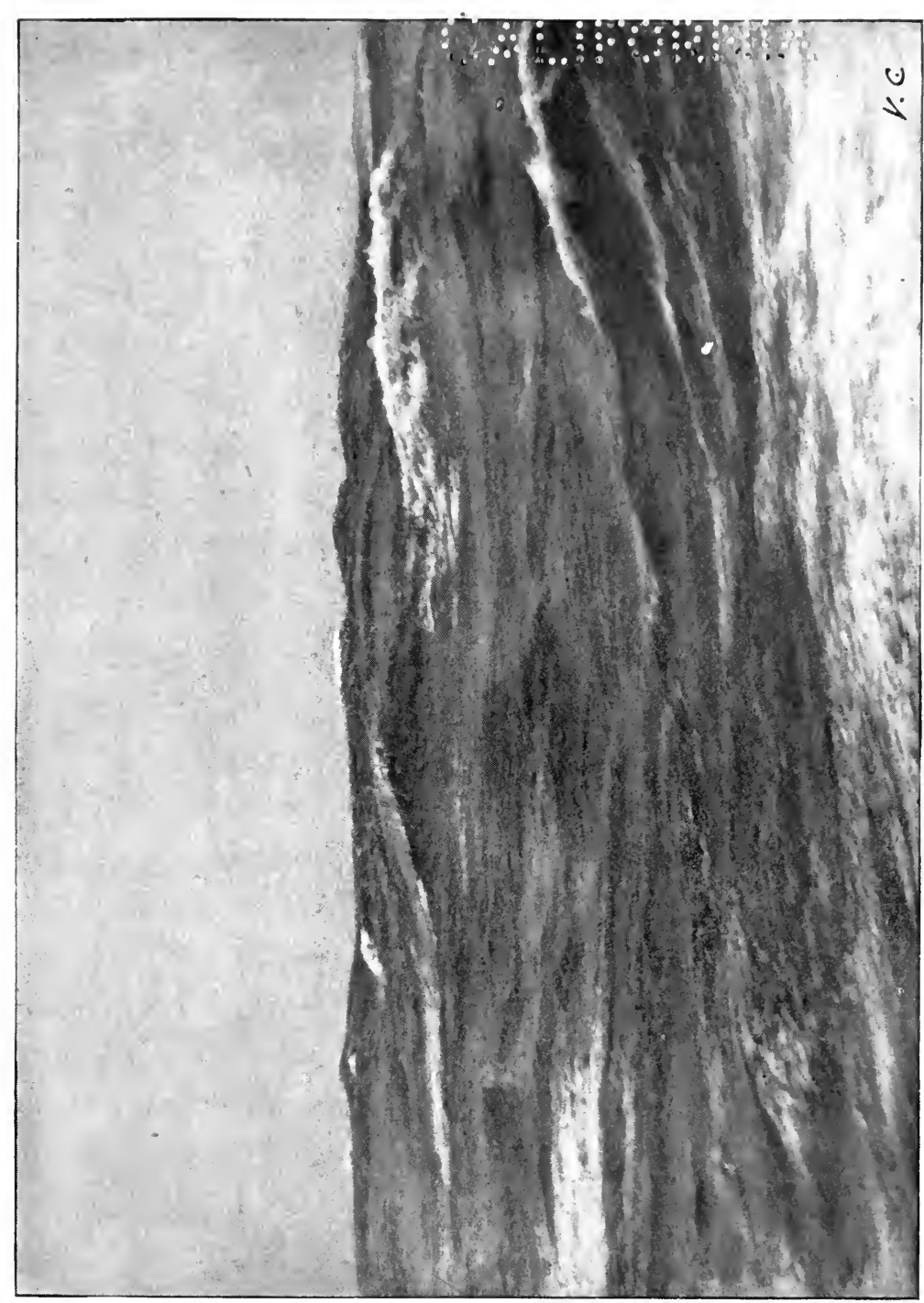

1 


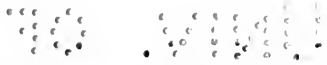

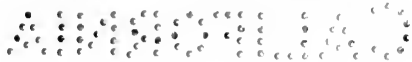

$$
\begin{aligned}
& \bullet
\end{aligned}
$$


I 30 feet, using the length of the promenade deck as standard of measurement. This estimate is quite out of harmony with the successive observation of following waves. The speed of the vessel was I 4 knots and the waves travelled past the ship at a very considerable speed. They succeeded one another at an average interval of 17 seconds. This determination by itself does not permit the wave-length to be calculated from a simple formula, ${ }^{\mathrm{I}}$ but it is satisfied by a true period of 8 to 9 seconds with length of 328 to 4 I 5 feet. Seven seconds (with a wave-length 250 feet) is definitely too small, and Io seconds (with wave length $5 \mathrm{I} 2 \mathrm{feet}$ ) is definitely too much. It is quite inconsistent with a length of I 30 feet, which corresponds to a speed of only I 5 knots, which is scarcely greater than that of the ship, and it seems likely that this estimate of the wave-length was in fact due to the transverse waves caused by the ship's own motion, which for her then speed of I 4 knots have a length of I I o feet.

It appears, therefore, that the average wavelength was not less than 328 feet (an 8-seconds wave).

The wind was westerly, and the sea-room about

I It can be calculated, however ; see Monthly Chart, North Atlantic, September, 1909, published by the Meteorological Committee. 
300 statute or 260 geographical miles. This distance from the windward shores is the same as the maximum possible on Lake Superior, but the area of the Western Mediterranean is many times greater. The height which I observed in the Western Mediterranean in a moderate gale (speed of wind estimated by the captain of the vessel at 30 miles per hour) is the same as that recorded for gales of exceptional severity upon Lake Superior, in which the velocity of the wind would not be less than 53 miles an hour. The height, therefore, attained by the largest waves in very severe storms in the Western Mediterranean must be greater. The storms of the Gulf of Lions situated to the westward of my place of observation are notorious for their severity and for the dangerous sea which rises. Admiral W. H. Smyth, in his book upon the Mediterranean, ${ }^{\mathrm{I}}$ writes that in the worst weather in the Gulf of Lions the waves attain a height which cannot be much less than 30 feet. Perhaps we may interpret this as meaning that they cannot be less than 27 to 28 feet.

\section{Waves in the China Sea}

The China Sea is a body of water lying between the mainland of Asia and the open Pacific, from × Quoted by Cialdi, "Motolondoso del Mare." 
which it is screened by the Philippine Archipelago and other islands. The uninterrupted expanses of water are greater than in the Western Mediterranean. The following observations were made by the late Lieutenant Paris, of the French Navy, whose careful methods of work will be described later. Off Cape Varella, in a violent storm from the north-east which lasted several days, the highest wave was $2 \mathrm{I} .3$ feet and the average wave-length 328 feet. The sea-room to windward was about 750 statute or 650 geographical miles. Thus the difference in the sizes of waves in great lakes and in the much larger semi-enclosed seas respectively is less than we should have expected from the observed difference between their size in the smaller and in the larger lakes. We find, however, a great increase when we go from the semi-enclosed seas to the open oceans. ${ }^{I}$

I In the Caribbean Sea also, where I have made five voyages, the waves are not quite like those of the open ocean. Between Colon and Kingston they have a clear run of more than 500 nautical miles in the direction of the prevailing $\mathrm{NE}$. wind, which blows strongly. The waves, which I have seen attain a height of above 20 feet during ordinary strong Trade winds, remind one more of those of the Mediterranean than of the Atlantic, and there is an absence of the long swell accompanying the rough sea.which is characteristic of the open ocean. 


\section{CHAPTER II}

Observations of waves on the North Atlantic-Conclusion as to height of North Atlantic waves-Waves on the North Pacific-The effective length of fetch of strong winds on the North Atlantic Ocean-The numerical relation between the length of fetch of wind and height of storm-wavesWaves on the South Atlantic and Southern Indian Oceans -Waves on the South Pacific Ocean-The discrepancy between wave-lengths determined respectively by simultaneous and by successive observation of wave-crests.

\section{Waves on the North Atlantic Ocean}

I Now pass on to the records of storm-waves on the North Atlantic Ocean. One of the best is that of the Rev. William Scoresby, ${ }^{\mathrm{I}}$ which I give almost in his own words.

The height of the waves was recorded on the east-bound voyage from America to England on board the s.S. Hibernia. The construction of the ship afforded several platforms of known elevation above the water-line. On March 5, 1848, the ship

I British Association Meeting of 1850, Report, published 185I, Part II., pp. 26-3I. 
was in latitude $51^{\circ} \mathrm{N}$. and longitude $38^{\circ} 50^{\prime} \mathrm{W}$., the wind about WSW., and the ship's course true $\mathrm{N} .52^{\circ} \mathrm{E}$. By sunset of the previous day the wind was blowing a hard gale, which continued with heavy squalls during the night, so that all sail was taken in except a storm stay-sail forward. The barometer, which had stood at 29.50 inches at 8 p.m. on the previous day, had fallen to 28.30 inches by ro a.m. on the 5 th. On the afternoon of this day, Dr. Scoresby took up his post of observation on the saloon deck, which gave an elevation of the eye 23 feet 3 inches above the water-line. He found, however, that every approaching wave intercepted the horizon, so that from this position he could decide little except that the average height, reckoned from trough to crest, was more than 24 feet. $\mathrm{He}$ therefore ventured upon the paddle-box, which was about 7 feet higher, giving an eye elevation of 30 feet 3 inches. This level was well maintained during the moments of actual observation, because the whole of the ship's length ( 220 feet) was clear within the trough of the wave when the next following crest was at its greatest apparent height, and the ship at these moments was on an even keel. From this position quite one half of the waves which overtook and passed the ship were above the level 
of the observer's eye. Sometimes a crest extending in a ridge 100 yards long would be from $2^{\circ}$ to $3^{\circ}$ above the invisible horizon. This Dr. Scoresby says would give a height from trough to crest of more than 40 feet, but I confess I regard this rather as a guess than a measurement. Sometimes, he says, the crossing of two wave-crests would send up a sharp peak of water to a height which he believed to be 50 or 55 feet, or the crest of a breaking wave would shoot up to a similar height. The average height of the waves during the observations on March $5^{\text {th }}$ was more than 30 feet.

On the following day, when, the wind being less violent, the waves had subsided to an average height of 26 feet and were more regular, Dr. Scoresby determined the wave-length in the following indirect manner. The waves overtook the ship every I 6.5 seconds and each wave took 6 seconds to run the whole 220 feet of the ship's length. Then the distance between two succeeding wavecrests as thus observed was :

$$
220 \times \frac{\mathrm{r} 6 \cdot 5}{6}=605 \text { feet ; }
$$

but the ship was not running in exactly the same direction as the waves, and a line from crest to 
crest measured at right angles would of course be shorter. Making due allowance for the observed angle, the true wave-length was determined to be 560 feet.

So far Dr. Scoresby.

I proceed to consider the position of his vessel at sea so as to be able to compare the sea-room with that possible on Lake Superior, which we have stated to be (at Duluth) 259 nautical miles.

At noon on March 5 th, the day when the waves were highest, the vessel was about 600 geographical miles from the coast of Newfoundland, the direction from which the wind blew, and by 4 o'clock in the afternoon 36 miles farther from this, the nearest shore. At noon on the 6th the distance from shore was about 800 geographical miles. If the highest waves were measured at $4 \mathrm{p} . \mathrm{m}$. on the

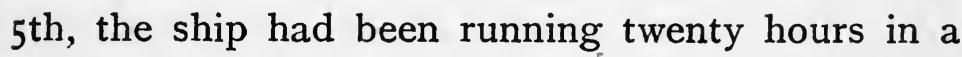
hard gale, and was i 80 geographical miles from the point where the full force of the gale first struck her. The cyclone was, presumably, travelling in the same general direction as the ship, but how close to the shore the westerly wind first attained the force of a gale we do not know. This much is certain, that where the waves attained an average height of more than 30 feet, and an occasional maximum estimated at more than 40 , the sea-room 
or stretch of water to windward I was 600 geographical miles or more, as compared with the 259 geographical miles which is the maximum amount of sea-room possible upon Lake Superior, where we have accepted $22 \frac{1}{2}$ feet as the height of waves in exceptionally severe storms.

The wave-length of 560 feet 2 was measured on the Atlantic with a sea-room of 800 geographical miles as compared with the 300 feet of Lake Superior with a possible sea-room of 259 geographical miles.

The length of the waves on March 6th was 21.6 times as great as the height, but on the previous day they must have been steeper.

We will next consider the case of another strong gale in the North Atlantic with sea-room of at least 1,000 instead of 600 geographical miles, in which we shall find that the waves are of about the same height as in the last case.

The waves in question were observed by myself on December 7, 1900, when outward bound from Liverpool to Boston by the Cunard S.S. Ivernia.

I The "room" which concerns a navigator is more often that to leeward, but the expression for space to windward is useful for our purpose.

2 From the building line in Bond Street to the front of the Royal Geographical Society's House, I, Savile Row, is the length of a Io-second wave, $5^{\text {I } 2}$ feet. 


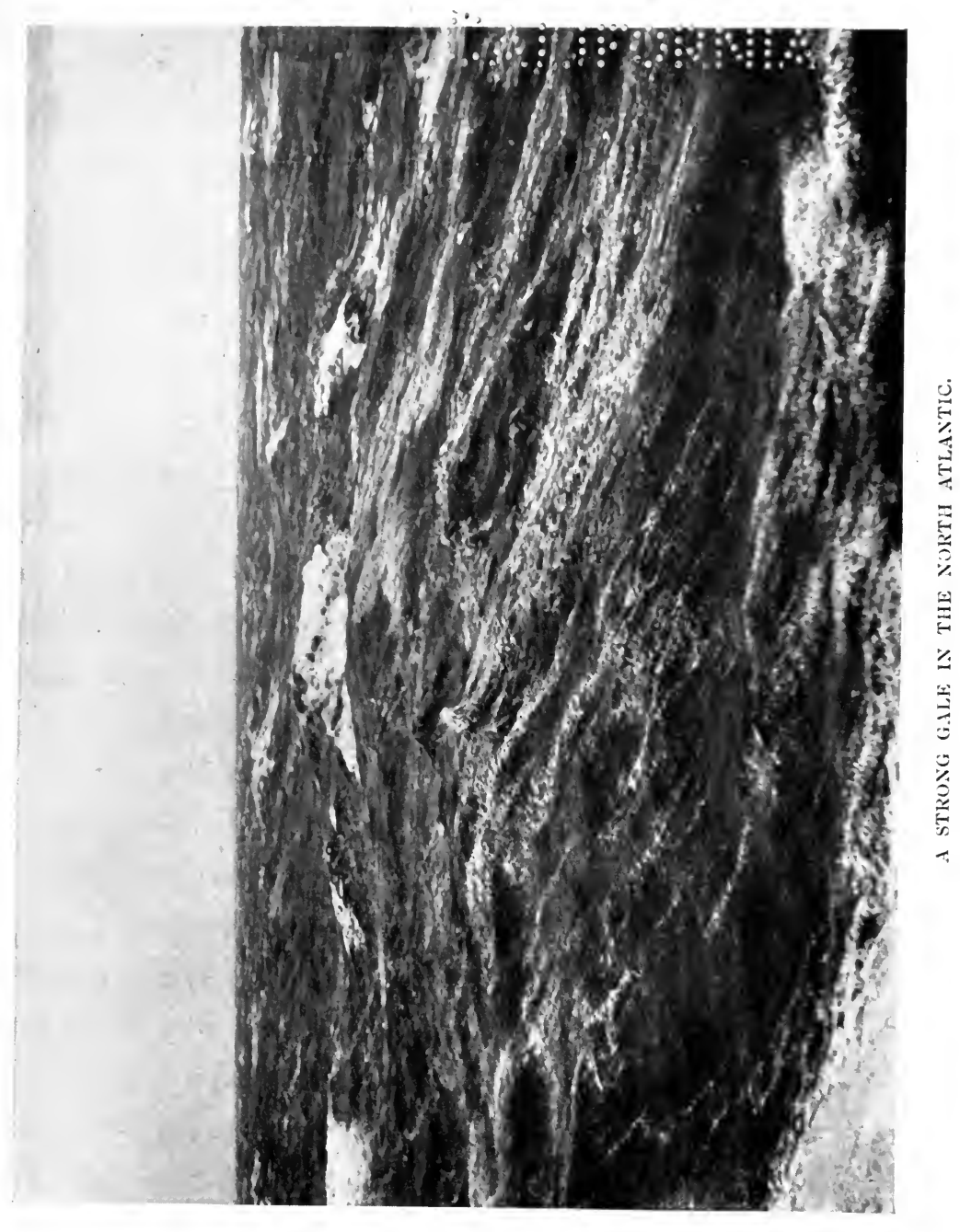




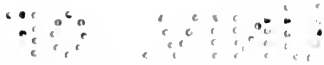

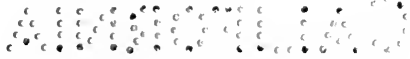


Leaving Queenstown on the morning of the $5^{\text {th }}$, we met a rather heavy swell on our westerly course, which continued and somewhat increased during the 6th. We drove into a strong gale that night, and the highest waves which I saw during the voyage were on the morning of the 7 th. The force of the wind on that day was logged as 9 on Beaufort's scale of $0-12$, the number 9 being called " a strong gale." We continued to drive through a gale during the whole of the 7 th, 8th, and 9th, the winds varying from $\mathrm{S}$. by $\mathrm{W}$. on the morning of the 7 th to WNW., always therefore producing a head sea, at first on the port, afterwards on the starboard. The morning of the 7 th (bar. 29. I 5 inches) was the only time during the three days when the waves were " running true"-i.e., in long parallel ridges exactly at right angles to the wind, of which ridges six or seven were simultaneously visible when looking upwind from the weather side of the ship. There was no long, flat swell noticeable, neither were there minor waves of such prominence as to distract attention from the principal waves. In the course of eleven voyages across the Atlantic this is the only occasion on which I have seen this "regular sea" during a storm, and the waves were the highest which I have ever observed in a storm. Our noon position 
was N. $50^{\circ} 56^{\prime}$, W. $25^{\circ} .33^{\prime}$, so that the distance from the Newfoundland Banks was about I,000 geographical miles. This was the direction in which we were steaming and apparently the direction from which the bad weather was coming. The wind, however, came from a direction in which there was no land for 2,000 geographical miles. I was able to judge the height of the waves more readily than usual on account of several favourable circumstances. The ship, though pitching, did not roll, being heeled over to starboard at a moderate angle, which did not vary. Stationing myself amidships, I was subject to neither pitching nor rolling, but merely to a lift and fall as each of the large waves passed beneath us. The two promenade decks afforded platforms which happened to be at just the right altitudes for judging the height of the usual, and of the maximum, waves respectively. The altitude of these decks above the water line of the ship I obtained from the scale section of the ship in charge of the chief engineer. The heeling over of the ship was measured, and its amount allowed for, on the assumption that the height of the deck above the water was reduced, on the lee side, to the full extent possible. The height of the waves is recorded as equal to the height of the eye above the ship's water-line, where they just topped 


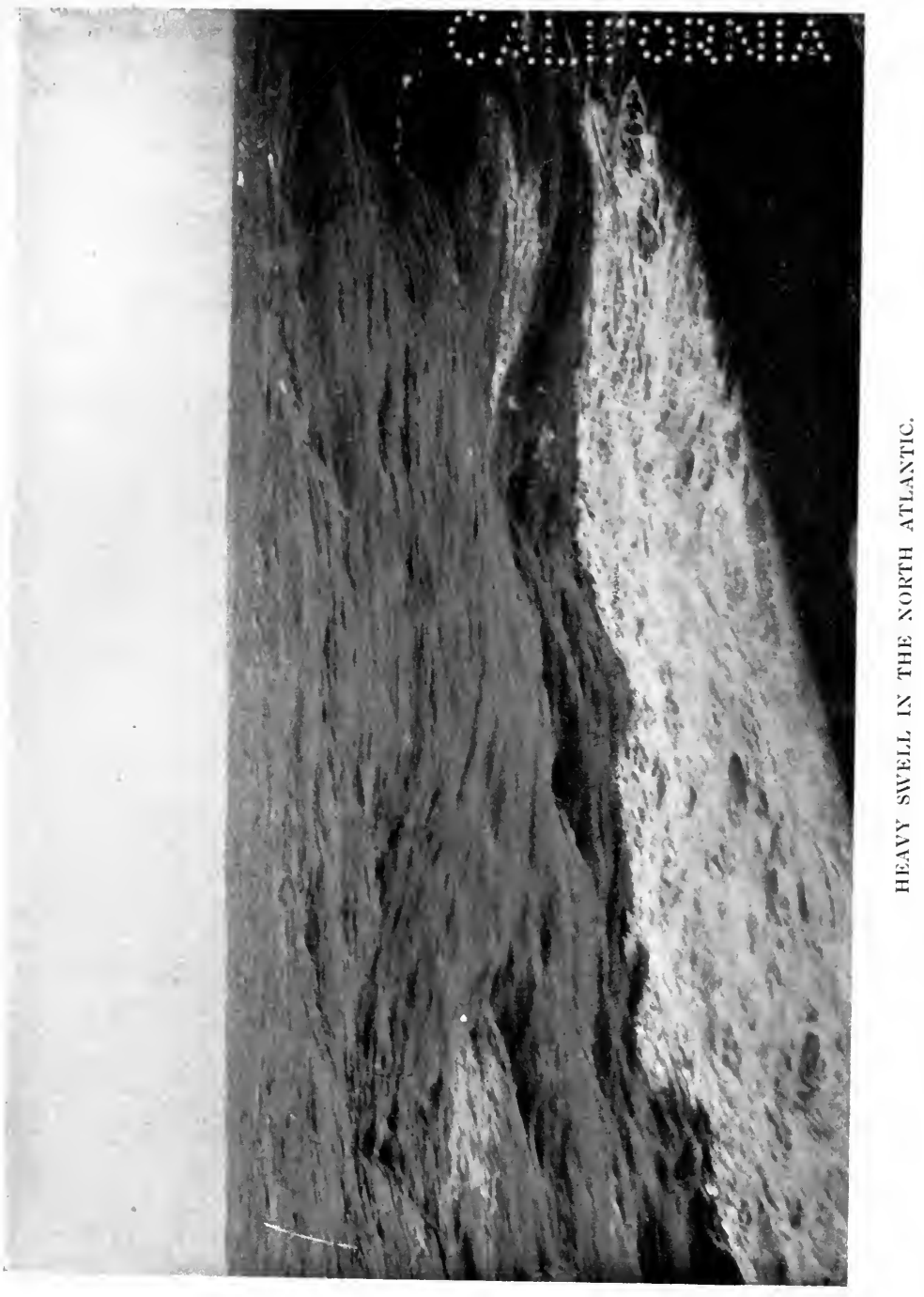




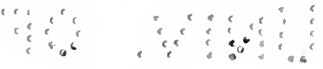

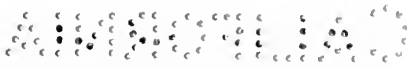


the horizon, nothing being added for the small amount by which they actually exceeded the height of the eye. Thus, when observing on the lower deck, I found that the waves commonly attained 29 feet, and from the upper deck that they occasionally attained 43 feet. My lower platform was about the same altitude as Dr. Scoresby's highest position, and my estimate of the height of the ordinary waves is about the same as his. I had the advantage, however, of a second and higher platform, which brought me on a level with the highest waves. Their height as measured by me from this point of vantage is practically the same as that guessed by Dr. Scoresby from his lower platform. The force of the wind was about the same in both cases, his determination with 600 geographical miles sea-room, mine with I,000 miles.

Next day, December 8, I 9oo, the wind had shifted to WNW. with force 8 (a "fresh gale "); the waves were irregular and not so high, and again on the 9th, with wind SWi. of the same strength, there was an irregular sea with no very high waves, though they were magnificent from the tumult of their headlong rush and the white fury of the broken water. The sea was, indeed, covered with spume and veiled in spindrift. A small schooner sighted 
in the afternoon was running before the storm under a minimum of sail, and rolling very heavily. From on board this vessel such waves would tower above the horizon, but none were as high as 30 feet. The position of our ship on the 9th was not far S. and E. of that of Dr. Scoresby's ship when he measured the 560-feet wave-length.

Although the higher platform of my larger vessel gave me an advantage for the measurement of the highest waves, her great length, and the structure of the upper works usual on modern liners, made it very difficult for me, unassisted, to measure wavelength. I have found the same difficulty every time I have been at sea, as I have always voyaged in ships measuring from nearly 500 to 600 feet in length. It has usually happened that when there were large regular waves their course made a considerable angle with that of the ship, and even when the waves ran more nearly in our own direction, it was generally impossible for me to watch the wave-crest during the whole of its passage along the length of the ship. I have, therefore, been generally reduced to judging the wave-length in terms of the known length of the ship from the simultaneous position of two crests. The length of the Ivernia is 600 feet, and the regular waves which we encountered in the strong gale of Decem- 
ber 7 th I judged by the above method to be about 350 feet in length.

I have never yet seen storm-waves on the North Atlantic in which the distance between the wavecrests, viewed simultaneously, appeared to me nearly as long as the 6oo-feet ships on which I have voyaged, nor, indeed, any which appeared more than 400 feet in length. This was the apparent distance between crests during a heavy swell without wind which I observed from the Red Star S.S. Vaterland in March, I901, east-bound in N. Lat. $48^{\circ} 30^{\prime}$, W. Long. $21^{\circ} 40^{\prime}$.

The second, and latest, opportunity which I have had of measuring very large waves on the North Atlantic was on board the Atlantic Transport Company's s.s. Minnehaha, east-bound from New York to Southampton, on February 9, 1907, in N. Lat. $48^{\circ} 54^{\prime}$, W. Long. I $8 \circ 20^{\prime}$. There was only a moderate breeze from $\mathrm{NW}$., but a huge north-westerly swell came upon us at about $45^{\circ}$ abaft the beam. The vessel did not pitch, her slow and stately rolling motion was perfectly rhythmical and regular, and in the absence of strong wind observation was unusually easy. It was evident from the great height of the swell that we were only just outside the storm area, and this conclusion was confirmed by a wireless message received 4 
during the day from the White Star s.s. Cedric to the northward of us reporting that she was in a strong NW. gale. Standing on the lower promenade deck, one long ridge after another obscured a considerable arc of the horizon after passing beneath the ship, and continued so to obscure it when at a distance estimated at 400 to 600 feet from us. I allowed 2 feet as a minimum estimate for the excess of height above my eye, based on an observation made a short time before. The observation was simply this, that when sitting in my deck chair I had seen a wave similarly obscure the horizon, and on my rising at once, the horizon remained obscured. The increase in the elevation of eye upon rising was found afterwards to be 2 feet.

The roll of the ship at the time of the obscuration of the leeward horizon was in each case to the weather side, so that the deck on the lee side was tilted upwards. The amount of the tilt was measured for several rolls, which were quite regular, and assuming that the full amount ought to be added to the deck height, I obtained 2 feet so to add. I was standing during the observations, and my eye-height is 5 feet 9 inches, or say $5 \frac{1}{2}$ feet, so that there is altogether $9 \frac{1}{2}$ feet to add to the height of the deck. This, measured with a heavy 


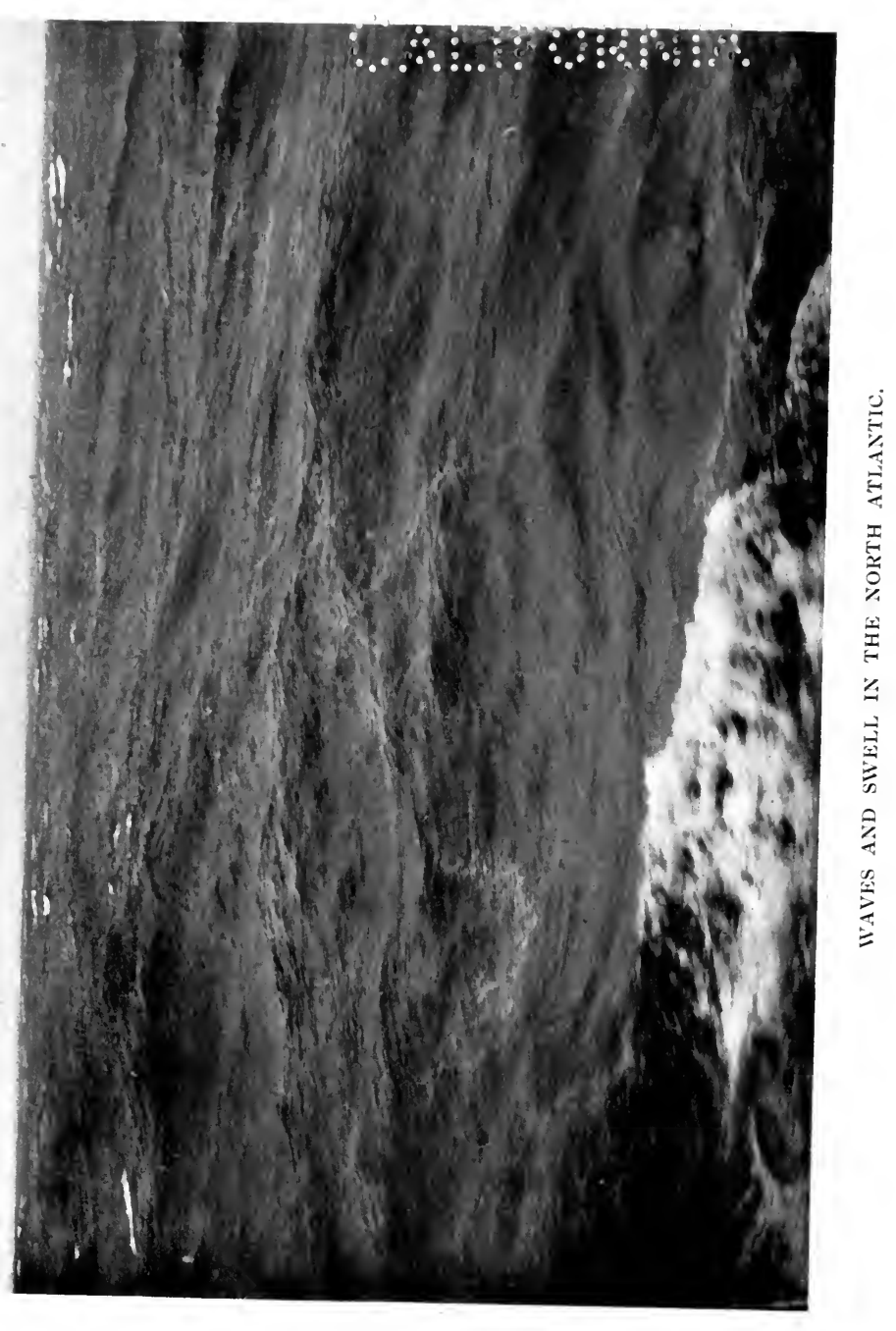




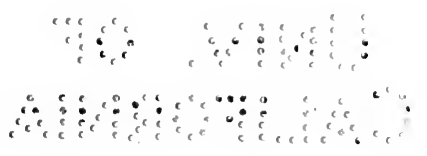


rope hung over the lee side, I found to vary with the oscillations of the ship and of the water from $29 \frac{1}{2}$ to $33 \frac{1}{2}$ feet, giving an average of $31 \frac{1}{2}$ feet for smooth water. Two days later, with lighter bunkers, the height above the smooth water of the Solent was found by the rope to be $32 \frac{1}{2}$ feet.

Taking, therefore, the height of the deck at the time of observation as $3 \mathrm{I} \frac{1}{2}$ feet, the height of the waves which repeatedly passed us was:

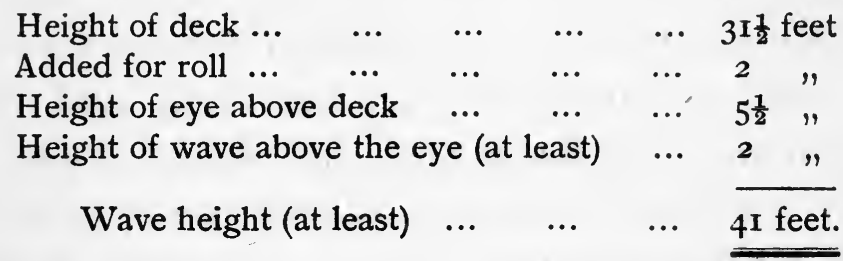

Whilst this is 2 feet less than that determined for the highest waves during the strong gale of December 7, 1900, there was much less variation in size from one wave to another, and the average height in this north-westerly swell was no doubt quite as great as that during the strong southerly gale.

The sea-room on February 9, 1907, reckoned from the coast of Greenland-the direction of the wind-was about I, I oo geographical miles, and from the Newfoundland Banks to the westward about I, 200 . 
Conclusion as to Height of North Atlantic Waves

Thus concordant observations indicate that anywhere in the North Atlantic with sea-room of from 600 up to certainly 1,000 and perhaps 2,000 miles the height of the large waves during ordinary strong gales is practically constant, being not less than 43 feet. $^{\mathrm{I}}$

With regard to the height which is momentarily attained by peaks of water shooting upwards where waves cross, the late Lord Kelvin informed me that he had measured one 60 feet high, and this measurement confirms the concordant guesses of several officers on North Atlantic liners whom I have consulted on the subject. I have not myself seen anything nearly so high.

Accounts not infrequently appear in the newspapers of some great wave encountered by the fast Atlantic liners. These are sometimes reported as 80,90 , and even 100 feet high. This height invariably relates to the altitude above the flotation line of the superstructures which have been deluged with water. This is not, properly speaking, the height of a wave, but merely the height to which a body of water is thrown when a wave breaks on board. This increases with the speed of the ${ }^{x}$ See Note on p. ${ }^{3} 8$. 
ship, which dips her bows into the rising billow in a head sea. The recorded heights also tend to increase as the ships are built of larger dimensions, on account of the fact that the greater height of the navigation bridge and wheel-house allows the attainment of a greater altitude to be recorded with certainty. The wheel-house of the Lusitania, e.g., is 80 feet, or rather more, above the flotation line.

\section{Waves on the North Pacific Ocean}

The North Pacific Ocean has a breadth of open and deep sea about twice as great as that of the North Atlantic. The passage from Victoria, B.C., to Yokohama is about 4,000 geographical miles, as compared with the 3,000 from Liverpool to New York. This route is traversed by a number of liners similar to the medium-sized Atlantic liners. I made this passage once, east-bound from Yokohama to Seattle, in fair weather, when we only encountered a moderate swell similar to that met with in similar weather in the same latitudes on the Atlantic. The great circle course which is followed took us as far north as Lat. $49^{\circ} 40^{\prime}$. I had opportunities during this long voyage of collecting opinions upon the size of the waves on this route as compared with those of the North Atlantic and of the Southern Ocean from seamen who knew all three. The late 
Dr. Elgar, F.R.S., designer of the Campania, who was also a passenger, gave his views. There was a complete consensus of opinion-

First, that the type of storm was the same as on the North Atlantic routes.

Second, that the storm-waves on the Pacific route were certainly not higher than those on the Atlantic, and I did not gather that they were any longer. They were said to be as irregular as those of the North Atlantic and not to "run true" as the waves do in the steadier winds of the Southern Ocean, a circumstance which was attributed to the storm being generally of the rotatory character, with a fairly rapid change in the direction of the wind. I conclude from this evidence that the greater size of the ocean does not in this case lead to the development of greater storm-waves than those of the North Atlantic.

Thus I have not found in northern latitudes any increase of height of storm-waves beyond a distance of 600 geographical miles from the windward shore. Nevertheless the size of waves observed by Scoresby is not nearly equalled in enclosed seas of 500-700 miles in breadth.

I attribute the difference to a smaller size of cyclonic systems on the semi-enclosed seas. ${ }^{\mathrm{I}}$

× Cf. A. Buchan, "Meteorology," " Encyclopædia Britannica," $9^{\text {th }}$ edition. 
On the Effective Length of Fetch of Strong Winds on the North Atlantic Ocean

The volume of charts illustrating the weather in the North Atlantic from December I 8, I 898, to February I 5, I 899,' ${ }^{\prime}$ provides detailed and reliable information as to the effective length of fetch of winds in that ocean. The storms were of unusual strength and persistence, so that the charts give us maximum values. The positions and distances stated below are measured from the charts. At noon, January I, I 899, a west wind of force 7-8 of Beaufort's scale and upwards (i.e., in no place less than a moderate gale) is shown to obtain from N. $49^{\circ}, \mathrm{W} \cdot 40^{\circ}$ to N. $49^{\circ}, \mathrm{W} .60^{\circ}$, a distance of I,300 geographical miles or rather more. But, in order that the waves at the lee end should be reinforced by those at the weather end of the strip, time must be allowed for the travel of the waves. Waves of about 8 seconds period would be prevalent in such winds, and we will consider their movement. Their speed is $8 \times 3=.24$ knots, and even when going as forced waves before the wind they will only travel 576 geographical miles in 24 hours. Now, an examination of the charts for Decem-

x Charts illustrating weather of the North Atlantic Ocean in the winter of $1898-9$, Met. Council, rgor. 
ber 3 Ist and for January 2nd shows that on neither day was there so long a strip of water simultaneously subject to west wind of force 7-8 as on January Ist. Therefore the apparent length of fetch on that day never became effective. But we see on comparing the chart of December 3 Ist with that of January Ist that a strip of 550 geographical miles was continuously subject to west wind of force 7-8 for 24 hours, and towards the end of this period this was the effective length of fetch of the wind for 8-second waves, and for any swifter waves which the force of the wind may have been capable of producing.

At noon on January I o, 1899 , winds of Beaufort force 7-8 with direction a little $\mathrm{W}$. of $\mathrm{N}$. prevailed from N. $47^{\circ}$, W. $46^{\circ}$ to N. $48^{\circ}$, W. $32^{\circ}$, a distance of 600 geographical miles. On the previous day (January 9th) at noon the wind was blowing in the same direction between the same two positions, with a force of 9-12, so that for 24 hours there were winds of constant direction, with a force varying from a moderate gale to a hurricane, simultaneously and continuously affecting the water over a stretch of 600 geographical miles. Towards the end of the period, therefore, there was an effective length of fetch of wind of 600 geographical miles for all waves of rather more than 8 seconds period. 


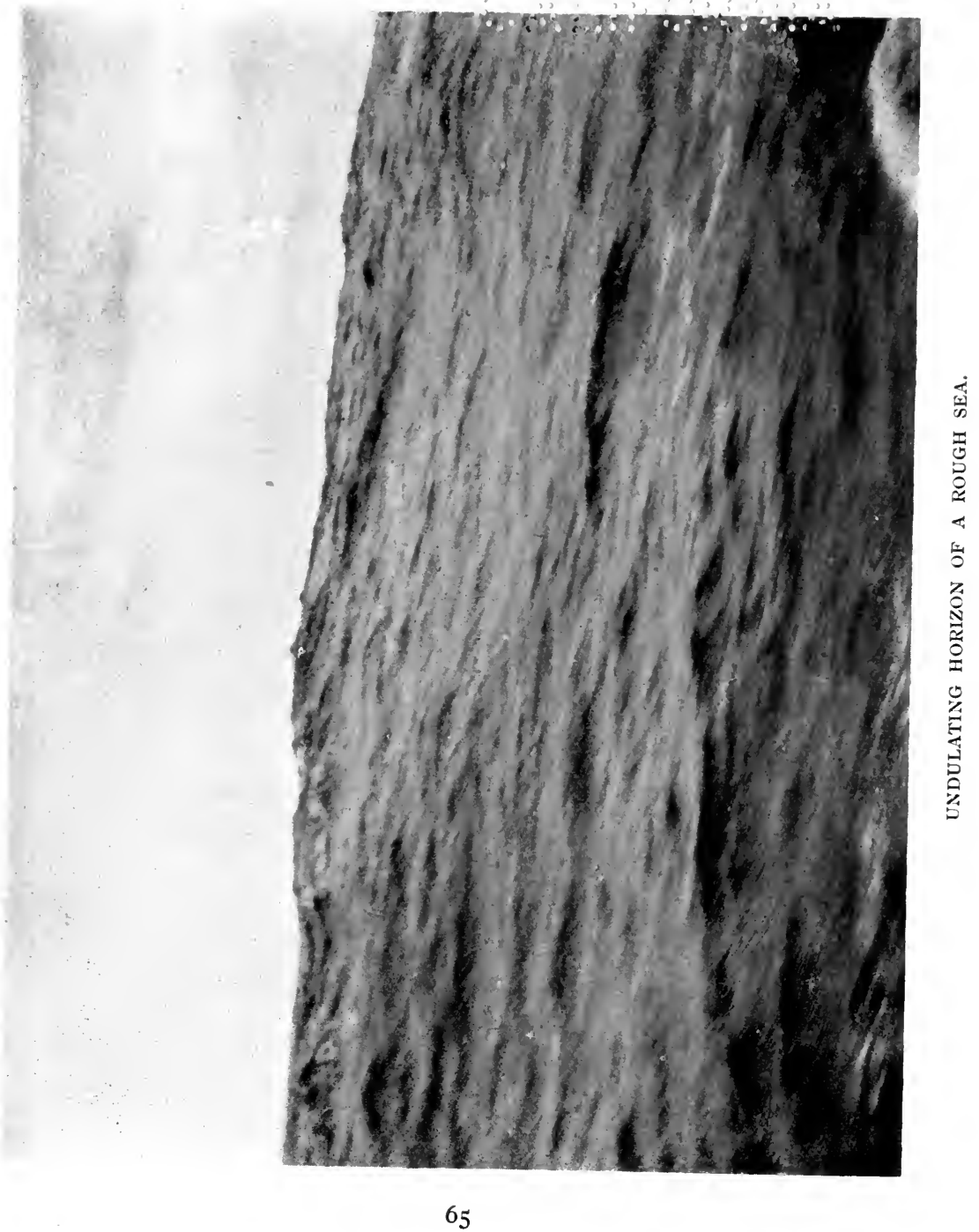




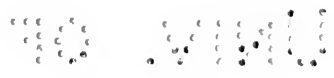

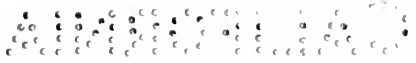


Throughout the whole of the nine weeks of exceptionally stormy weather which is covered by these charts I cannot be sure of any greater effective length of fetch of wind than 600 geographical, or 700 statute, miles. This is the wave-making length of wind-fetch for the North Atlantic which we have to compare with the 259 geographical or 289 statute miles of Lake Superior. The wavemaking effect of a strip of wind of 600 geographical (700 statute) miles long on the mid-Atlantic is, however, increased by the swell which is always entering at the weather end. This result agrees with the conclusion already arrived at that Scoresby observed, at 600 geographical miles from the windward shore, waves of the greatest height producible in the Atlantic by the then force of wind.

\section{The Numerical Relation between Length of Fetch of Wind and Height of Storm-waves}

Thomas Stevenson's empirical formula (height of wave in feet $=1.5 \times$ square root of length of fetch in geographical miles) was shown by him to apply to distances of rather more than I oo geographical miles. Colonel Gaillard observed waves 23 feet high in the Duluth Canal with a length of fetch of 259 nautical miles, the height calculated from Stevenson's formula being 24 . I feet. The same 
formula gives 36.75 feet for 600 geographical miles from the windward shore, which is in fair agreement with Scoresby's observations on March 5, 1848 (see ante, p. 42).

Waves on the South Atlantic and Southern Indian Oceans

Sailors agree that storm-waves are seen in their fullest and most typical development in those Southern latitudes where the ocean uninterruptedly encircles the globe. They are observed from ships which go round the Cape of Good Hope, and by those which go round Cape Horn. I proceed to the observations made by the late Lieutenant Paris, ${ }^{1}$ of the French Navy, in I 867, when proceeding by the corvette Dupleix to the China station via the Cape of Good Hope. The Dupleix was a sailing vessel with auxiliary steam. She ran before a prolonged westerly gale during the last days of October, I 867, having passed the Agulhas Bank, but being still west of the Island of St. Paul. The vessel seems, therefore, to have been somewhere between $40^{\circ}$ and $80^{\circ} \mathrm{E}$. Long. and about $40^{\circ} \mathrm{S}$. Lat. After this storm the vessel proceeded northwards under steam through the calms of Capricorn,

${ }^{x}$ See Revue Maritime et Coloniale, vol. xxxi. (1870), pp. II I127, "Observations sur l'État de la Mer." 
accompanied by a swell from the south-west. Lieutenant Paris made regular observations of waves during the whole of this voyage, and when cruising in the seas of China and Japan, but his opportunities of measuring large ocean waves occurred only in the southern ocean, and principally during the storm above referred to. For obtaining data as to the size of full-grown storm-waves from his valuable paper, we are, in fact, almost restricted to a single day's observations, but the value of this day's work is greatly enhanced by his daily practice in observing. His method, as he explicitly states, is that of Dr. Scoresby, the wave-lengths being usually obtained by noting the time occupied by the wave in running the length of the ship combined with the interval elapsing between the arrival of the waves. The height he calculates as equal to that of the eye when the -wave just obscures the horizon; but his observations in this respect are superior to Dr. Scoresby's, for, by nimbly running up or down the shrouds, he got on a level with each succeeding wave, and was not reduced to Scoresby's expedient of guessing the height above him of the largest waves. His results are as follows. On October 25th, I 867 , between the Cape of Good Hope and the Islands of St. Paul and Amsterdam, during a strong gale 
from the north-west with violent snow squalls, he measured at different times of the day 30 waves which averaged 29.5 feet in height, and of these 6 succeeded one another in a procession, all the members of which were of equal height, viz., 37.7 feet (II.5 metres). Later in the day he saw waves which he says were " certainly higher" than these, but he was not at the time so placed as to be able to measure them. Their height, we may safely conclude, was not less than 40 feet and probably a little more. Several sailors on board who had been much at sea had never seen waves so high. They occurred on what appears to have been the fourth day of the gale, but the narrative is not quite clear upon this point.

It will be noticed that both in average and extreme height the results are practically the same as were obtained during strong gales in the North Atlantic by Scoresby on March 5, I 848, and by myself on December 7, I900.

The waves were, however, much longer in the Southern Ocean, the greatest average on any day being $77 \mathrm{I}$ feet, with not a few of 900, and several waves surpassing I,3 I 2 feet (400 metres) in length. Scoresby, measuring in the same indirect way, found the Atlantic waves 560 feet long.

Although at the outset of our discussion of the 
relation between the size of waves and the size of the basin in which they were formed, I used either observed lengths, or lengths calculated from the period, according to which were available, I find that in observations from shipboard in the open ocean there is in this matter a troublesome discrepancy. Most of the "wave-lengths" given in published records such as those of Scoresby and Paris were not really observed as an apparent distance separating two ridges of water viewed simultaneously, but are deduced by calculation from observed speeds. The speed is obtained in the way described by Dr. Scoresby, viz., the observation of the time taken by a wave-crest to run the length of the ship, combined with the interval between the arrival of two wave-crests, the speed of the ship being known. When the ship is broadside on to the waves their apparent period should enable one to calculate at once the wave-length. I found, however, when observing at sea, that the length so calculated was much greater than the apparent distance between successive convexities of the water's surface. I have also found that many officers on the Atlantic liners disclaim ever having witnessed in the North Atlantic waves of the great lengths which are measured indirectly by systematic observers from the observed speeds of, and 
the interval of time between, successive waves. The discrepancy I suppose to be in some way connected with the fact that in a storm there are always waves of different length and speed running in the same direction. The waves made by the ship, which are stationary with respect to the ship herself, also I think produce a confusing effect on the direct method of estimation by increasing the height of the progressive waves at certain definite positions. I do not think it desirable to set aside either mode of observation, and in what follows I shall record both. The reader will in consequence find that, while the records of heights provide consistent numbers which are comparatively easy to interpret, the records of length are more confused.

Lieutenant Paris remarks of the great series of six waves above described that, as they passed, they left the ship, which was 230 feet long, in a valley "a cable's length" (6oo feet) across.

The following is a case of a great wave-length recorded by direct observation in the same part of the ocean, viz., on the route from the Cape of Good Hope to Australia. Major Leonard Darwin, who communicated the facts to me, was on this voyage in a vessel 400 feet long, when they fell in with a gale of such unusual severity that the 
Captain went twelve hours out of his course in order to partly avoid its fury. Major Darwin made a special effort to judge the distance separating crest from crest of the great rollers, and came to the conclusion that it was three times as great as the ship's length-i.e., I,200 feet. Thus we see that if we compare the wave-lengths, calculated from the velocity of the waves, as observed between the Cape of Good Hope and Australia with those obtained by the same process in the North Atlantic, the Southern Ocean has much the longer waves, and, again, if we compare the eyeestimated length in the Southern Ocean with that in the North Atlantic, the Southern Ocean has also much the longer waves.

The following observations by Captain Hugh F. David, of the White Star S.S. Corinthic, ${ }^{1}$ were made during August, 1907, somewhere between S. Lat. $45^{\circ} 30^{\prime}$, E. Long. $6 I^{\circ}$ and S. Lat. $46^{\circ} 45^{\prime}$, E. Long. $98^{\circ} 25^{\prime}$. This is between the Island of St. Paul and Kerguelen Island, and about 600 geographical miles farther south than the position where Lieutenant Paris made the observations above described. The direction of the wind was westerly, and its greatest force was logged as 9,

× Letter to Captain Campbell Hepworth, R.N.R., of the Meteorological Office, and log of the Corinthic. 
which on the Beaufort scale of $\mathrm{O}-\mathrm{I} 2$, is equivalent to a wind-velocity of 44 statute or 38.2 geographical miles per hour, and is termed " a strong gale." An interesting photograph was taken at the after-end of the promenade deck, with camera 26 feet above the sea level, showing a neighbouring wave following the ship and eclipsing the distant horizon. Captain David writes:

"With regard to the lengths and heights of the waves at the time of the photograph, I did take quite a few observations, more particularly of the heights, which ranged from 38 to 45 feet, though I have a vivid recollection of one which I think was quite 50 feet in height. Standing on bridge at 50 feet above sea level, the crest of this wave appeared level with the eyes of jigger rigging just before ship's stern commenced to rise. The height of rigging from the horizontal line drawn from bridge rail to jiggermast taken from scale slightly exceeds 50 feet. This was, of course, an exceptional wave, and I felt quite glad when it passed without doing any damage. Referring to their length from crest to crest, I would not be quite so definite, though an average would be about 600 to 750 feet during the worst part of the storm and indeed afterwards." (The length of the Corinthic is 500 feet.) 
In the absence of any statement to the contrary it may be safely concluded that the wave-length was judged by eye, not determined by indirect measurements as in the cases of Paris and Scoresby, eye estimation of the distance between two crests simultaneously observed being the almost universal practice of officers on the bridge. Thus this length for Southern (Indian) Ocean of 6oo750 feet should be compared with my eye estimate of 350-400 feet for similar weather in the North Atlantic, and not with Scoresby's indirect measurement there of a length of 560 feet.

Captain Percy Howe, who has voyaged on the same route, informs me that between the Cape of Good Hope and Adelaide he was in 1907 subject to a gale of 2 I days' duration, from July I 5 th to August 5th, much the most prolonged which he has ever experienced. During the most violent parts of the storm the waves which passed the ship obscured his horizon when the ship was on an even keel. His eye-height on the bridge of the Owestry Grange was 45 feet, so that the waves exceeded this height. The ship's length was 480 feet, and she was wholly within the trough of the waves, the length of which he estimates at 750 feet. These estimates, which are almost the same as Captain David's, are for a part of the same series of exceptional storms. 


\section{Waves on the South Pacific Ocean}

Leaving now that part of the Southern Ocean which is on the routes from the Cape of Good Hope to Australia and New Zealand, we will examine records from the Cape Horn route from New Zealand to Europe, which touches higher latitudes.

The following observations for height were given me by Mr. G. T. Ogilvie. He came home (eastbound) by this route in I 880 on a I,300-ton ship, with a length of 230 feet. Whenever it blew hard he used to get into the mizzen rigging and sight on to the horizon from various heights. Near Cape Horn, and therefore more than $53^{\circ} \mathrm{S}$. of the Equator, in a full gale blowing from about SW., he estimated the highest wave as 2 feet above his plane of observation, which, on the Captain's estimate, was then 40 feet above the water-line, making a total wave-height of 42 feet. Waves 30 feet high were comparatively common. He thought he saw one or two rollers not less than 45 feet in height from trough to crest, and possibly 48 feet, but attaches little weight to the figures for the altitude of a wave apparently so far above the line of sight.

The following observations by the Hon. Ralph 
Abercromby ' relate to waves observed in the South Pacific Ocean on a voyage between New Zealand and Cape Horn on S.S. Tongariro in 1885 . On July 16 th the ship was in S. Lat. $55^{\circ}$, W. Long. $105^{\circ}$, in a hard gale from SW. The waves were the largest seen on the voyage. For the measurement of their height he used a $4 \frac{1}{2}$-inch aneroid barometer with a very open scale divided to . O I inch. He found (on the assumption that a difference in .OOI inch in the aneroid reading was equivalent to a change of I foot in level) that in passing from trough to crest the greatest lift experienced by the aneroid in the cabin was 40 feet. This was a solitary instance. The next greatest was 30 feet. Now, on a previous day, he had found by measurement with a piece of string that, when the wave-crest passed the cabin, the porthole was 6 feet nearer the water than it was at the trough of the wave. Assuming the same difference to hold during the day of heavier sea, he adds 6 feet to the lift of 40 feet in order to obtain the total height of the greatest wave, which he therefore considers to have been 46 feet. $\mathrm{He}$ reckons the liability to error of the aneroid reading at 2 to 2.5 feet, and that of the measurement

I Phil. Mag., April, 1888 (vol. xxv., 5th series), "Observations on the Height, Length, and Velocity of Ocean Waves." 
of water-level by the string at not less than 2 feet either way. Thus, his determination of a single wave-height of 46 feet may really be due to a wave of anything from $4 \mathrm{I} \frac{1}{2}$ feet to $50 \frac{1}{2}$ feet in height, and therefore, as is the case with so many other measurements in storms at sea, can only be taken actually to establish a wave-height of a little more than 40 feet. Dr. G. Schott, using a sensitive aneroid with microscopic reading, recorded a maximum wave-height of 39.4 feet in the South (Atlantic) Ocean.

On the Discrepancy between Wave-lengths determined respectively by Simultaneous and by Successive Observation of Wave-crests

On March I 5, I903, I was on the S.S. Hitachi, of the Nippon Yusen Kaisha, in N. Lat. 280 26', E. Long. I $25^{\circ} 53^{\prime}$, bound for Kobe, from Hongkong. The position is in the East China Sea, which is here only partially. screened from the open Pacific by the Loo-choo Islands. We encountered in the afternoon a heavy northerly swell, which met the ship at an angle estimated by eye at $45^{\circ}$. One crest was at the stern when the next following was at the bow, and, knowing the length of the ship, the true distance from crest to crest, reckoned at right angles to the course of the waves, was 
known to be 280 feet. But the interval between the arrival of the waves was $8 \frac{1}{2}$ seconds, and, as the vessel was travelling in a direction somewhat opposed to the direction of the waves, the true wave-period must have been somewhat greater. An $8 \frac{1}{2}$-seconds wave has a length in deep water of 370 feet and a 9-seconds wave of 4 I 5 feet.

Assuming the determination of the period to be fairly accurate, as the observation is an easy one, and the application of the mathematical formula to be valid, as there is every reason to suppose, we must seek some reason why the apparent wavelength should be quite 90 feet less than the true.

Two possibilities suggest themselves. The first is that minor sea-waves are noticed in the simultaneous observations of wave-crests, but are passed over by the eye when watching the progress of the more rapidly moving crests of the principal sea-waves.

The second possibility is that the shortening of apparent wave-length was due to the increased height of the sea-waves in the vicinity of the bow and the stern of the vessel. A large vessel proceeding at a fair speed-in the above case a vessel of about 6,400 tons going at 12 knots-produces a short, steep wave, several feet high, at the bow, and a similar one at the stern. In smooth water 
these are stationary relatively to the ship, and have a constant height. In a slight head sea, however, the stationary bow-wave is replaced by an intermittent wave, rising up, when the sea-wave meets the bow, and subsiding at the trough of the sea-waves. In a heavy head sea the ship's own bow-wave becomes inconspicuous, but, nevertheless, contributes as much as before to the total height of the sea-waves as they reach the bow and the stern. Now, looking aft, the steeper ship-wave will maintain the apparent crest of the flatter sea-wave for some distance after the crest of the true sea-wave has passed. Conversely, looking forward, the steep bow-wave will cause an anticipation of the true crest of the advancing, flatter sea-wave. Consequently the above measurement of wave-length by simultaneous position of crests along the ship's side was too small by twice the distance through which the steeper ship-wave shifted the position of the combined wave-crest. ${ }^{1}$

Where the sea waves are large and regular and long, and the ship small and slow, this error is least. With a moderate sea and a large and swift ship the error is greatest.

Officers of the Atlantic liners generally estimate

x The presence of ship's waves need not affect the determination of wave-length from observed velocity, for the interval between the arrival of a sea-wave at stern and bow is the same as if there were no ship-wave. 
wave-length by the position of crests with relation to the bow and stern of the vessel. Thus, when sailing by the Allan liner Tunisian, in $190 \mathrm{I}$, the chief officer informed me that in a storm in the Atlantic the ship generally "took three waves," which means that when one crest is at the bow and another at the stern there would be a third crest between. In other words, there would be two sea-waves to the ship's length. The Tunisian is 520 feet long, which would make the apparent wave-length 260 feet.

In my endeavours to get at the truth about the dimensions of sea-waves, I have done three things : first, made measurements myself ; second, examined the records of measurements made by others; third, consulted officers on all ships by which I have travelled as to what their experience leads them to suppose the height and length of waves to be. Now, the officers of the Merchant Service have far more experience of weather in the open oceans than most naval officers, for ships of war keep mostly to the vicinity of land. $A$ fortiori their experience is far greater than that of landsmen such as myself. On the other hand, those to whom I have spoken on the subject have not actually made measurements. The result of my three lines of inquiry is as follows:

As regards the height of waves, the general 
opinion of the officers of the Merchant Service accords with remarkable closeness with the measurements which have been made by Dr. Scoresby, Lieutenant Paris, Captain David, and Mr. Ogilvie. My own measurements confirm both, as far as the heights of waves in the North Atlantic are concerned. "About 40 feet" for the fairly frequent larger waves in an ordinary North Atlantic storm is the general verdict of the officers on the liners, and they are generally prepared to concede a few feet more for waves in exceptional storms, especially in the region of westerly winds in the Southern Ocean. From the records discussed in detail above I find that the larger waves in ordinary North Atlantic storms attain 43 feet and in exceptional storms both here and in the South Indian Ocean attain, and perhaps surpass, 45 feet. The possibility of an occasional peak of water shooting up to a height of 60 feet before breaking is sometimes admitted, but those whom I have consulted generally feel that there is little to be gained by guessing at the figures applicable to such circumstances when they have had no reliable standard of measurement.

In the matter of wave-length in the North Atlantic, however, I find the general opinion of officers on the liners to be that 600 feet would be an enormous wave-length, and, if intended as an 
average, and not merely the distance between a single pair of crests in a confused sea, would not be met with there in ordinary storms.

Such a sea, in which a large ship of 500 feet long running directly before the wind is left, time after time, within the trough of the wave, they have only witnessed in the Southern Ocean, particularly in the part east of the Cape of Good Hope, where the sea is more regular and is probably longer than that near Cape Horn, though perhaps not higher.

Thus, it is only in the Southern Ocean, particularly in the eastern parts, where the waves are not only large but regular, that the officers' estimate of wave-length agrees with the measurements from speed and periodic time.

I have not yet traversed the Southern Ocean, but in my efforts to judge wave-length from on board ship in the Irish Channel, the Mediterranean, East China Sea, Caribbean, North Pacific, and North Atlantic I almost despaired of getting any results worth recording on account of the discrepancies above described. It seems as if the measurements from velocity and period were a nearer representation of the natural state of the sea than those gained by officers from their experience on the bridge. Yet the latter must not be lightly dismissed, and more attention should 
be given to unravelling this part of the subject. My explanation of the systematic effect of the ship's waves to shorten the apparent wave-length I believe to be an important part of the whole explanation, but it may not be the sole cause.

It is possible that the observed elevation of the wave-crest above the ship's flotation line is sometimes increased on account of the presence of a ship-wave tending to make the recorded heights of waves too great, especially when observed from large, fast ships.

On the other hand, a large vessel, among waves shorter than herself, neither rises to the crests nor sinks to the troughs, so that in observations such as my own on the Minnehaha and the Ivernia the recorded height of the wave-crest above the stillwater-line of the ship is probably less than the height above the trough.

Thus, these two possible sources of error tend to neutralise each other, and as the heights recorded by eye on large ships agree with those recorded on smaller ones, and both are in accordance with aneroid determinations, as far as these have been carried, we may regard them as probably free from any large systematic error such as that which the ship-wave, and perhaps other superposition, introduces in one of the methods of measuring wave-lengths. 


\section{CHAPTER III}

The wave-length of the swell which reaches the shore after storms-The height of the swell at sea during stormsThe co-existence of waves of different lengths-The give and take between air and water in the development of waves.

The Wave-length of the Swell which reaches the Shore after Storms

WHEN the waves produced upon the deep sea run into water of which the depth is less than $I-4$ th the wave-length, theory shows that their speed is reduced 6.7 per cent., and when the depth is no more than I-8th of the wave-length their speed is only 4 -I 1 oths of what it was in deep water.' This reduction of speed goes on as the wave approaches the shelving shore. Finally, in water of which the depth is only a small fraction of the original wave-length, the wave-speed is the same in all cases, no matter what was the original speed and wave-length in deep water. This progressive

× Vide Sir G. G. Stokes' "Admiralty Manual," I 886. 
change of speed causes the wave-crests to close up, so that the space separating them gets less and less as they approach the shore, but the interval of time between the arrival there of successive crests is unchanged. Consequently, by timing the arrival of a number of breakers, or the passage of a fixed point by a number of waves just before breaking, we know at once the period of these waves, not only as we see them in shallow water, but as they were in water so deep that the wave disturbance did not reach nearly to the bottom. From the period we can calculate the speed in deep water by the mathematical theory of waves, using the formula :

Period (in seconds) $=$ speed of wave in feet per second $\div 5 \frac{1}{8}$ (nearly), or, more roughly :

Period (in seconds) $=$ speed of wave in knots per hour $\div 3$; and we can calculate the wave-length for deep water thus :

Square of period $=$ length of wave $\div 5 \frac{1}{8}$.

The breakers which arrive somewhat irregularly during storms do so at intervals which, as far as I have noticed them, do not differ much from the intervals observed on board ship in the deep sea during storms; but after storms the period of the 
breakers is sometimes much greater. Now, this means that their wave-length in deep water was much greater than that observed during storms at sea, and that the speed in deep water of these subsequent waves was also much greater than that of the waves then observed. But when the wind no longer acts upon the water, there is no agent to accelerate the waves. Theoretically, they should travel by gravity at the same speed as that which the action of the wind has induced, or, if there be any change of speed while in deep water, it could only be some very gradual diminution. A real increase in the speed of transmission may be pronounced with confidence to be an impossibility in the absence of any new source of energy.

The only possible explanation, therefore, is that the waves of longer period which come in upon the shore after storms are present, but escape observation, during storms at sea. Not only so, but they have attracted comparatively little attention from on board ship even after storms.

The following observations of the swell, following a westerly storm, were made by myself at Branksome Chine, on the Dorsetshire coast, between Bournemouth and Poole. The storm had been violent and long at Bournemouth, and the weather in the Atlantic exceptionally stormy. 
On the morning of December 29, I 898, the wind, now light, having drawn more to the north, the sky was brighter and the weather pleasant, as it generally is here when the wind blows from the north-west after the passing of a storm from the Atlantic. At I I a.m. an unusually heavy surf came rolling in upon the sandy beach, the waves maintained unbroken almost to the shore by the action of the off-shore breeze, which, at Branksome Chine, always favours the production of a wellformed breaker.

At I I a.m. came four large breakers at the following intervals, viz.:

$22,18,20$, average 20 seconds.

They were followed by an almost smooth sea ; and then, after a short time, came a second series of four large breakers at the following intervals, viz.:

$$
\text { I6, 22, I9, average I9 seconds. }
$$

At I I.25 a.m. a fine series of seven breakers, arrived at the following intervals, viz. :

$$
2 \mathrm{I}, 17,22,23,23,20 \text {, average } 2 \mathrm{I} \text { seconds. }
$$

I did not notice any minor waves between the members of the series.

At I I.35 a.m. a set of six breakers came at the following intervals, viz.:

$$
\text { I6, 19, 25, 16, 24, average } 20 \text { seconds. }
$$


And at I I.5O a.m. a set of seven breakers at the following intervals, viz.:

I7, 2I, I6, 22, 23, I8, average 19.5 seconds.

The general average of the periods of the five sets of waves is 19.9 seconds.

Later in the day large breakers followed one another in continuous succession without the occurrence of any smooth water, and for three-quarters of an hour I noted, watch in hand, a succession of 139 consecutive breakers, occurring at the following intervals, viz. (reading from left to right) :

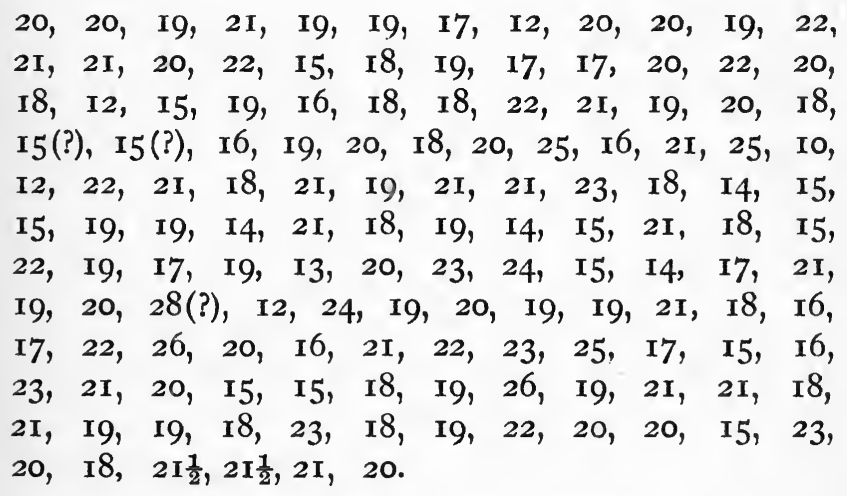

The average interval was I 9 seconds, and this determination is accurate to a degree not attained by observations from moving ships. The recorded intervals between the successive breakers probably vary more than the real intervals, because if the 
observer is too late in his determination of the time of breaking for any wave, he not only makes that interval too long, but the next too short. Thus we see that we had here a fairly uniform series of waves whose average period, I 9 seconds, shows that their velocity, when in deep water, was 57 knots, or 66.5 statute miles, per hour, and their average wave-length $\mathrm{I}, 850$ feet $\mathrm{s}$

It was not easy to make exact comparison between the height of these breakers and those which I have seen at Branksome Chine during storms, for the latter break farther out and in deeper water. However, the impression conveyed to the eye is that there is no very great difference between the heights of the breakers above the water in front of them in the two cases. Branksome Chine is sheltered from the west by the promontory called Purbeck Island, so that the waves of westerly gales and the swell which follows are both reduced by change of direction in rounding the promontory. If, however, we recall to mind the numerous references in nautical writings to the great breakers which come in during calm weather upon oceanic islands and other shores directly exposed to the ocean, we shall recognise that their

x This is about equal to the distance from Park Lane to Devonshire House, measured along Piccadilly. 
height must be of the same order of magnitude as that of the breaking waves of storms.

On December 29, I 898 , in N. $47^{\circ}$, W. I $9^{\circ}$, waves 45-52 feet high were reported from s.s. St. Simon. In absence of details I have not used these in the above records of height of waves, but I take them here to calculate a maximum length of storm-wave in the Atlantic during the exceptionally wild weather prevailing at the time of my observation at Branksome. We have already seen that when the length of waves is determined in the manner which gives the highest values (viz., by recording speed and period of arrival from on board ship), maximum waves of 40 feet are associated in the North Atlantic with lengths not more than 600 feet, or fifteen times the height. The corresponding length for a height of 45 feet is 675 feet, and for 52 feet, 780 feet. The latter is a figure probably considerably in excess of the real average wave-length during the storm, for which 600 to 700 feet would be a more likely estimate. Nevertheless, if we took the excessive value of 780 feet for the average length of the storm-waves, this would be less than one-half the average length of the swell observed at a distance.

On February I, I899, I recorded at the same place a swell of even longer period. The day 
was calm, after some days of light winds from north and east. A heavy swell began to come in upon the shore at about I I a.m., and between 3 and 4 p.m. I timed the arrival of twelve successive breakers, between which the eleven intervals were as follows :

\section{$23,23,22,22,22,23,21,24,24,22,22$, average $22 \cdot 5$ seconds.}

This is the longest period which I have ever observed for a group of waves. It was noted at the time as a good observation-i.e., the determination of the times was rendered easy by the regularity in the form and progress of the waves. Multiplying the period by three, we obtain with sufficient accuracy the speed in deep water, expressed in knots, which is therefore 67.5. This multiplied by 7-6 gives the speed in statute miles per hour, viz., 78.75. The corresponding wave-length in deep water is 2,594 feet. Although observed in the English Channel, it is an accepted view that such a swell is due to an Atlantic storm. The period is almost twice as great as that ( I I.7 seconds) recorded by Dr. Scoresby in the storm of March 5-6, I 848, and the speed therefore is likewise nearly twice as great. In a later chapter an account will be given of the probable origin of this set of breakers and of the distances they had travelled (see p. I i 8 ). 
On September 16, 1900, in fine weather at Branksome Chine, I heard the boom of surf, and, looking from my window, timed a set of wellformed though not large breakers at the following intervals, viz. :

$$
18,17,19,23,19,21 \text {, average } 19.5 \text { seconds. }
$$

The following observation of a swell from the Atlantic was made on the north coast of Ireland, near the Giant's Causeway, in the autumn of 1870 , by the late Sir G. G. Stokes.' One morning a grand surf came rolling in. There had been, some days before, a long succession of heavy gales in the North Atlantic. The period determined from different sets of six or eight waves was 17 seconds. The average difference between the mean periods of the different sets of waves was only about $1-5$ th of a second. The differences between the periods of individual waves is not recorded, but would, of course, be much greater. Somewhat later the period sank to 16 seconds, in the latish afternoon to 14 , and next day to I 3 . The surf was highest for the 17 -second period. During several other summers, when Sir G. G. Stokes spent a month or two on that coast, he never saw anything so striking.

× Discussion in Section A, British Association, Dover, 1899, on a paper by the present author. 
Some interesting deductions can be made from the above record.

The mean between the period at commencement ( 7 seconds) and that next day ( 13 seconds) is I 5 seconds; and in 24 hours 5,760 waves of this period would have discharged themselves upon the shore. The length of a 15 -second wave is 1,153 feet, so that 5,760 such waves in series would occupy a space of 1,090 geographical miles. The length of the waves at the front of the group was I,48 I feet, and of those at the rear 866 feet. If we suppose the waves travelling freely after the storm, the rate of progress of the group, if reckoned by that of a I 5-second wave, would be, not 45, but $22 \frac{1}{2}$ knots, ${ }^{1}$ so that the advance per 24 hours would be 540 geographical miles, and the interval between the storms and the arrival of the swell was "some days."

The character of the group of waves at the moment when the storm ceased must have been

I Vide Nature, vol. xvi., I877, p. 343, for Osborne Reynolds on the relation between group-velocity and wave-velocity in deep water. In deep water a group of trochoidal waves travelling freely under the action of gravity advances at half the speed of the individual waves. If we follow the motion of the first wave of the group, we shall find that it dies out, and the wave behind it has now taken the lead. If, on the other hand, we watch the last wave of the group, we shall soon find that another one has appeared behind it, and the sum total of these 


\section{AND O'THER WATER WAVES}

very different from that at the end of their long journey. In the first place, the waves which would have been noticed and measured from ship-board would have comprised none of the length of even the shortest seen at the Giant's Causeway. They. would have been the waves from 400 to 600 feet long, with periods of less than I I seconds, and they could not have arrived at the Giant's Causeway until later. But when they did arrive-as arrive they must-it is evident that they gave rise to no remarkable breakers, for the surf was decreasing

two effects may be represented by the following scheme, in which we take the front wave and place it at the back :-

$$
\begin{aligned}
& \text { I } 234567 \\
& 7123456 \\
& 6712345 \\
& 567 \text { I } 234 \\
& 4567 \text { I } 23 \\
& 34567 \text { I } 2 \\
& 234567 \text { I } \\
& \text { I } 234567 \text {. }
\end{aligned}
$$

In each succeeding horizontal row the individual waves have moved forward two places, but the group has advanced only one. The late J. Scott Russell's early recognition of two wave velocities appears to have been forgotten. $\mathrm{He}$ says, in his Report on Waves, B. A. meeting at York, I844: "I have found that the motion of propagation of the whole group is different from the apparent motion of wave transmission along the surface; that in the group whose velocity of oscillation is as observed, 3.57 feet per second, each wave having a seeming velocity of 3.57 , the whole group moves forward in the direction of transmission with a much slower velocity." 
as the period decreased, and observations were discontinued when the period was i 3 seconds. Theory shows that when deep-sea waves are left to themselves, the time which they take to flatten out so as to become invisible is proportional to the square of the wave-length. ${ }^{r}$ Hence the longer waves are more permanent. Again, waves of all lengths are reduced to the same small speed by the time they break upon the shore; so that waves originally long and swift are shut up, or telescoped, to a much greater extent than the slower ones, and they undergo in the process a correspondingly greater increase in height. On both accounts, therefore, the height of the breakers given by the swifter waves is increased out of all proportion to their original height during the storm.

\section{The Height of the Swell at Sea during Storms}

I shall now attempt to arrive at some conclusion as to the height during storms of the waves longer than those then measured, or that part of the wave-disturbance which is termed then, and afterwards, "the swell." On board ship during storms the swell is felt in the movement of the vessel more distinctly than it is seen, but it often can be perceived as a sort of broad band, lighter

- Vide J. Boussinesq, Comptes Rendus, cxxi. 
or darker, where the whole group of shorter waves seems slightly raised, and this broad, heaved-up piece seems to travel with great speed, like the shadow of a scudding cloud.

To take the example afforded us by Sir G. G. Stokes' observation, let us think of the group of waves which he observed as they were when the wind first dropped, and think of them first apart from the shorter waves with which they were then really associated. They were not then a band I, I 00 miles broad of almost perfectly harmonic undulations with length from 866 feet to I,48 I feet, but a much narrower band in which the water undulated with less regular motion, the surface having a less regular form'. I shall take the average period of undulation of the water in this band as I 5 seconds, and the wave-length, therefore, as I, I 50 feet. This part of the total wave-disturbance I call the swell, and I inquire, What was the height of the swell? Now, the height of the principal waves shorter than the swell, i.e., the dominant, or storm waves, we know fairly well from the preceding records. Most of them were 30 feet high, with fairly frequent larger individuals of 40 feet, and some of them were not much more than 20 feet high.

The diagram shows how such a condition can 

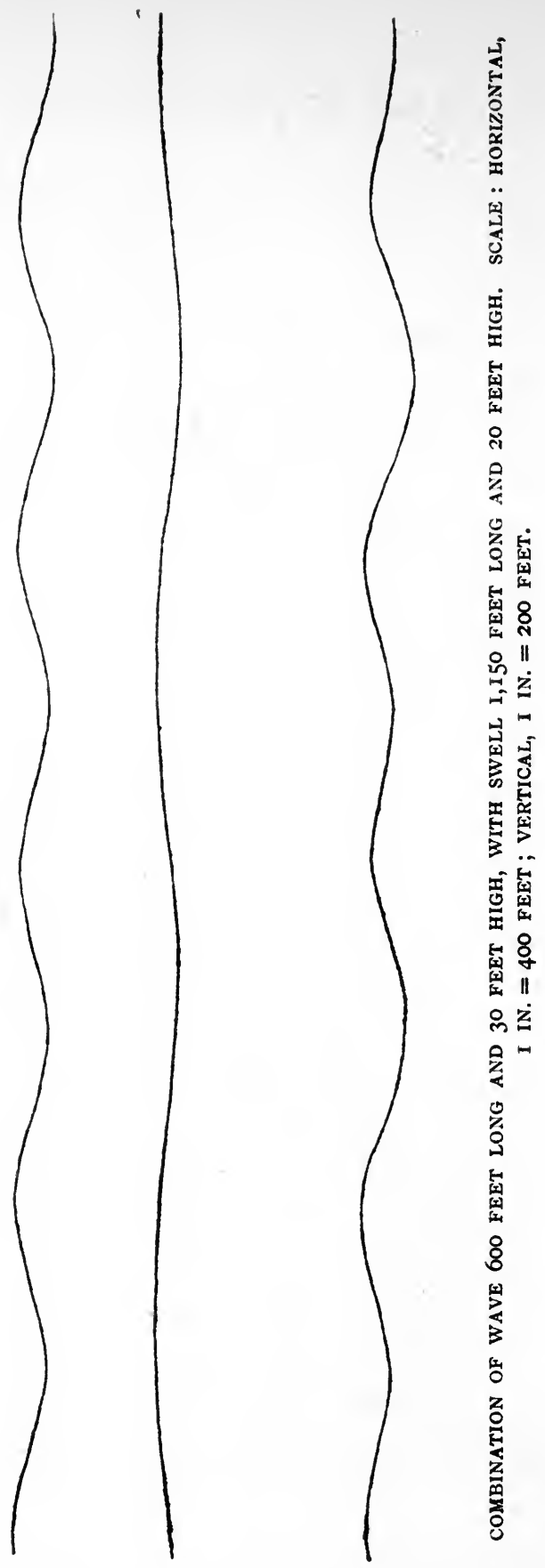


\section{AND O'THER WATER WW WES}

be represented by replacing the theoretically infinite number of wave-lengths by two, which I call the storm-wave, or the dominant wave, and the swell, the former 30 feet high and the latter 20 . The lengths arbitrarily chosen are 600 feet for the former and I, I 50 for the latter. It will be noticed that the combined wave in the third line represents fairly well the appearance of a tolerably regular sea, and it would do so still better if the curves had been drawn in the form of a trochoid instead of a curve of sines, which makes the trough similar to the crest.

Measuring from left to right, the vertical distance from each crest to the trough next on the right is :

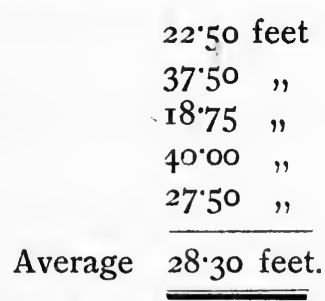

The average, if carried on through the whole gamut of the combined wave, would be $30-i . e$., the same as the height of the dominant or stormwave. Thus, in the above example we have a range of observed wave-height from rather less than 20 feet up to 40 feet. This result, corresponding to the heights observed by me in the storm of 
December 7, 1900, is due to a swell of two-thirds the height of the storm-wave and nearly double its length, the hypothetical height of the swell being 20 feet. This, however, is not an observation but a case chosen for examination.

On June Io, I 885, Abercromby, using an aneroid as already described, observed individual wave-heights of $26,21,23.5$, and 26 feet (average 24), but obtained an absolute difference of level between lowest trough and highest crest (not, however, one of those recorded above) of 35 feet.

$$
\begin{aligned}
& \text { Let } x=\text { height of storm-waves, } \\
& \text {,y = height of swell, } \\
& \text { Then } x+y=35 \text { feet ; }
\end{aligned}
$$

and, as we saw from the diagram referred to above-

$$
x=24 \text { (the average apparent height), }
$$

therefore-

$$
y=35-24=\mathrm{II} \text { feet. }
$$

This recorded case, therefore, is consistent with an amplitude of swell nearly one half as great as that of the storm-wave which dominates the eye. Had I not drawn for myself combined curves to test the effect produced by combining together undulations of a certain length with others nearly twice as long, I should not have supposed it possible to obscure a longer undulation of such considerable amplitude. 


\section{AND O'THER WATER W AVES, $10 \mathrm{t}$}

The diagrams, which I published in Knowledge in I $90 \mathrm{I}$, and afterwards in the Geographical Journal, May, 1904, show what is geometrically and numerically possible in the way of such obscuration. The observations made on the north coast of Ireland by Sir G. G. Stokes (as well as my own observations) show how necessary it is to allow for the presence with the storm-waves of longer waves of considerable amplitude. Abercromby's single observation supplies a confirmation of the apparently somewhat extreme case shown in the figure given on p. 98. It is, however, much to be desired that further observations similar to those of Abercromby should be obtained, for it must be confessed that it is a narrow foundation upon which to build.

On the Co-existence of Waves of Different Lengths

In studying deep-sea waves one is often called upon to decide whether to fix the attention upon the actual surface of irregular or complex form and deal with it as the concrete wave, or to think of this irregular wave as composed of, or resolved into, a number of simple harmonic waves each of regular form and of a different speed. As a matter of mathematics all irregular waves can be so re- 
solved, and the behaviour of the roughened sea, when the wind drops, exactly performs this act of analysis-i.e., of resolution into components. On account of this physical circumstance it is impossible to obtain a thoroughly satisfactory understanding of deep-sea waves as long as we restrict our mental view by the limitation of our eyesight, which generally shows us only one set of waves of somewhat irregular form running in any particular direction. Other sets of waves crossing these may be perceived by the eye, but for the present I am only concerned with those which run in one direction.

The following is a generalised description of what I actually see when the wind blows upon water.

I A curious condition occurs when two deep-sea swells meet one another from exactly opposite directions. I observed such a case from R.M.S.P. Atrato on June 27, 1910. We were bound for Barbados from Southampton, and had passed a few hours before St. Michael's, in the Azores. All the way out from the English Channel we had been accompanied by a north-westerly swell. From the Azores to Barbados the sea and swell were from a south-easterly and easterly direction. On the day in question the south-easterly swell met the northwesterly, both being of only moderate height. The appearance was that, again and again, a great round-topped billow formed, which did not travel, but (a furrow appearing along its summit) quickly became double-crested, the two crests then travelling away in opposite directions. 


\section{AND OTHER WA'TER WAVES 103}

First comes the simultaneous creation of a uniform pattern of minute waves all over the surface, then the growth of the waves to leeward, so that after a time there is a certain size of wave corresponding to the distance from the windward shore, which size is not afterwards exceeded. The growth of these larger waves at any place is accompanied by the failure and partial obliteration of the shorter waves which were there before, and this is due to the circumstance that the growth in height of the shorter waves is hampered by the vortex or eddy of the air caused by the largor series of waves. At each position there is finally a definite length of wave which is the dominant wave for that locality for the actual force of wind -i.e., the class of wave which so dominates the eye that any shorter wave there appears as a mere ripple upon its surface and any longer wave is only to be detected by the presence of a sort of heaving motion which runs through the whole system of the dominant waves. On small sheets of water, or near the windward shore at sea, this swell is insignificant, but as the length of fetch of the wind increases it becomes an important part of the whole disturbance. This fact is most easily understood if we consider what happens when the wind ceases and the waves are left to themselves. Travel over 
a considerable distance analyses the originally complex, irregular waves into series of simple, regular waves of graduated length. The longer and swifter are in front, the shorter and slower are in the rear. But this is not all, for the shorter components flatten out very quickly as they travel, whereas the longer components preserve their height with but little diminution for long distances. Consider now the effect of this upon the surfacewater at a place far distant from the windward shore. The short-length (and therefore shortperiod) waves will reach this place so flattened that they will produce no appreciable effect, and may, therefore, be regarded as not reaching it at all, and the water will heave with a long-period undulation, the surface exhibiting therefore only long, swift waves. Now, this gravitational travel, with its accompanying analysis of the wave-components, must go on in just the same way when the wind is blowing as it does after storms. Therefore at a considerable distance from the windward shore the state attained by the sea during a storm does not depend only upon what the wind does there, but also upon the transmission by gravity, independently of the wind, of the longer-period components of the irregular waves which the storm has created to windward. The greater the length 


\section{AND OTHER WATER WAVES 105}

of fetch the greater is the distance from which the surface-water draws the reinforcement of its long-period heaving, and the greater, therefore, is that part of the wave disturbance which is of greater wave-length than the dominant wave.

What, now, precisely is this dominant or stormwave, and how is it evolved? The answer is not difficult if we think of the mode of motion of the wind as it blows over the wave-water. There must be a continual give and take between the wind and the water, such that the air above tends to go into a regular series of travelling vortices or eddies, with long-extended horizontal axes, rolling along in the hollows between the crests of a regular series of travelling water-ridges. Above this series of travelling eddies the air must flow in undulating lines, the amplitude of the undulations diminishing with the height above the water-surface, so that at a considerable altitude the air flows in straight lines. When the sea has attained to an approximately steady wave condition under the action of the wind, there is superposed upon it a train of wind-eddies (and above them, aerial undulations), which are of regularly increasing size for a long distance from the windward shore. At each successive position as we recede from the windward shore there is a characteristic, and successively 
larger, size of dominant or storm-wave, and this is the wave of length identical with that of the air-eddy. These air-eddies, as has been already said, hamper the development of shorter waves whose full growth would require the existence of shorter air-eddies; but they have little effect upon the longer and flatter swell, which possesses great energy, stirs the water to considerable depths, and is continually reinforced by gravitational transmission from great distances. ${ }^{\text {T }}$ Thus it seems that in the attempt to extract precise and even numerical results for the visual observation of waves at sea, we may neglect that part of the wave disturbance which is of shorter wave-length than the dominant or storm-waves ("the waves" of common parlance), but that we must not ignore the swell, which is of greater wave-length.2

I I suspect the existence of another mechanism contributing to the same result. Referring once more to the swell running by gravity-suppose this to have attained a regular gradation of wave-length. Then each section will presumably be opaque to and absorb vibrations of its own period and transmit or be transparent to vibrations of greater period.

2 The theory of the action of wind to increase the height of waves already running before it is that the horizontal velocity of the air being greatest at the crest, the downward pressure of the atmosphere is least there. Conversely at the trough, where horizontal velocity is least, downward pressure is greatest. Hence the trough is pushed farther down and the crest is sucked up. 


\section{CHAPTER IV}

The velocity of the wind at sea-The numerical relation between velocity of wind and average height of wavesThe relation between the velocity of the wind and the velocity of the waves-The connection between the rate of progress of cyclones and the character of the waves-The effect of squalls and gusts upon waves-On wave-fronts in a veering wind, and on the irregularity of the waves in the region of the Trade winds-The observed profile of waves at sea-The mountainous appearance of waves.

\section{The Velocity of the Wind at Sea}

IN order to arrive at an opinion upon the relation between the velocity of the wind and the size and speed of the waves of the sea, we have to rely mainly upon the conventional numbers entered by the navigating officer in the ship's log, by which he expresses the force of the wind as he judges it to be. The watch on the bridge being of four hours' duration, the number generally represents the average force of the wind throughout this time. The connection between these conventional numbers and the velocity of the wind has been determined by experiments with anemometers. In the 
case of the ordinary cup-anemometer the number of revolutions recorded during "strong breeze," " moderate gale," \&c., had been compared with those obtained by whirling the instrument on a turn-table, by which means a counter air-current of known velocity is produced. The earlier experiments indicated that the number of revolutions of the standard cup-anemometer must be multiplied by three to give the velocity of the wind in statute miles per hour. More complete experiments, however, have shown that this "reduction factor" was much too high, and the factor, or multiplier, now adopted by meteorologists is 2.2. Hence the velocities of wind found in records of some years back are greatly in excess of the values now adopted. Wherever the actual logged number expressing the sailor's estimate of the force of the wind can be obtained, it is, however, easy to calculate anew the velocity of the wind in statute miles per hour, and this has been done in the present book. Thus the velocities of wind quoted by me as observed by Lieutenant Paris are not those stated by him in metres per second, but those recalculated from his logged numbers. The following table is taken from a paper ${ }^{\mathrm{I}}$ by $\mathrm{Mr}$. R. H.

I Q.F.R.M.S., Jan., I897, vol. xxii., No. IoI, pp. 24-55, and discussion on pp. 56-61. 


\section{AND O'THER WATER WAVES 109}

Curtis on "An Attempt to Determine the Velocity Equivalents of W.ind Forces Estimated by Beaufort's Scale."

The third column gives what is usually called the velocity of the wind, by which is meant its average velocity. But the velocity of the wind varies very rapidly. This is particularly noticeable when the wind is strong. Every gale is gusty and affected by squalls, and columns 4 and 5 show the average range of wind velocity, corresponding to each of the numbers or degrees of the Beaufort scale.

\begin{tabular}{|c|c|c|c|c|c|}
\hline Description. & & $\begin{array}{l}\text { Beaufort's } \\
\text { Number. }\end{array}$ & $\begin{array}{l}\text { Average Velocity } \\
\text { of Wind in Statute } \\
\text { Miles per Hour } \\
\text { or "the Velocity" } \\
\text { of the Wind. }\end{array}$ & $\begin{array}{l}\text { Average } \\
\text { Maximum } \\
\text { Velocity of } \\
\text { the Wind. }\end{array}$ & $\begin{array}{l}\text { Average } \\
\text { Minimum } \\
\text { Velocity of } \\
\text { the Wind. }\end{array}$ \\
\hline $\begin{array}{l}\text { Calm ... } \\
\text { Light air } \\
\text { Light breeze } \\
\text { Gentle breeze } \\
\text { Moderate breez } \\
\text { Fresh breeze } \\
\text { Strong breeze } \\
\text { Moderate gale } \\
\text { Fresh gale } \\
\text { Strong gale } \\
\text { Whole gale } \\
\text { Storm ... } \\
\text { Hurricane }\end{array}$ & $\begin{array}{l}\ldots \\
\ldots \\
\ldots \\
\ldots \\
\ldots \\
\ldots \\
\ldots \\
\cdots \\
\cdots \\
\cdots \\
\cdots \\
\cdots\end{array}$ & $\begin{array}{r}0 \\
1 \\
2 \\
3 \\
4 \\
5 \\
6 \\
7 \\
8 \\
9 \\
10 \\
11 \\
12\end{array}$ & $\begin{array}{r}2 \\
4 \\
7 \\
10 \\
14 \\
19 \\
25 \\
31 \\
37 \\
44 \\
53 \\
64 \\
77\end{array}$ & $\begin{array}{r}- \\
5 \\
9 \\
13 \\
18 \\
25 \\
33 \\
41 \\
47 \\
58 \\
73 \\
83 \\
?\end{array}$ & $\begin{array}{r}0 \\
3 \\
5 \\
7 \\
10 \\
14 \\
18 \\
22 \\
27 \\
31 \\
36 \\
45 \\
?\end{array}$ \\
\hline
\end{tabular}


The Numerical Relation between Velocity of Wind and Average Height of Waves

The heights of waves discussed in detail in preceding chapters are those produced when the wind has had opportunity to develop them fully, and most attention was given to the size of the maximum waves then produced. Circumstances frequently prevent the waves from attaining the full size which the velocity of the wind is capable of producing, of which fact examples were noted in my voyage on the Ivernia ( $p$. 53). The numerical relation between the velocities of wind and average height of wave, obtained from the records of daily observations on long cruises, depends in part on cases where the velocity of wind has no physical relation to the height of the waves. Such averages, therefore, blur the truths, which the writer, as a student of physical geography, desires to elucidate. There is, however, a practical point of view from which these averages may be useful-that, viz., of the naval architect. As the ships which he designs may have to sail on any seas and to encounter all weathers, it is sometimes desirable to eliminate local conditions.

The tables given in my paper in the Geographical Journal, May, I904, show how closely con- 


\section{AND OTHER WATER WAVES 111}

cordant are the results from the data of Desbois, of Paris, and of Antoine, when recalculated by the modern reduction-factor of wind velocity. On an average the velocity of the wind in statute miles per hour was found to be 2.05 times the height of the wave in feet. Thus the average height of the waves in a whole gale, Beaufort's force 9, wind velocity 44 s.m.p.h., is :

$$
44 \div 2 \cdot 05=2 \mathrm{~s} \cdot 5 \text { feet. }
$$

As already explained, this average would be exceeded when the wind had full opportunity to do its work.

The Relation between the Velocity of the Wind and the Velocity of the Waves

The greatest average length of storm-waves on any one day recorded in the preceding pages is that observed by Lieutenant Paris, viz., 77 I feet, which corresponds to a wave velocity of 43 statute miles per hour. The average velocity of the wind, as re-calculated from the conventional number in Paris's table, was 46 statute miles per hour. The gale had lasted (or the ship, running before the wind, had been in it ) for four days, or, say, I oo hours. During the first day of the gale the wave-length was only $37 \mathrm{I}$ feet, corresponding to 
a speed of 30 statute miles per hour. Thus, during the first day the air blew over the travelling wavecrests at 16 statute miles per hour, and during the last day at 3 miles per hour.

During the storm in the Southern Indian Ocean (described on p. 73) Captain David, of the s.s. Corinthic, estimated the average length of the waves at about 675 feet, which corresponds to a wave velocity of 40 statute miles per hour. The wind was logged as 9 on Beaufort's scale, so that its average velocity must be taken as 44 statute miles per hour. The air, therefore, blew over the ridges of the travelling waves at an average speed of 4 statute miles per hour.

During the storm in the North Atlantic (described on p. 42) the wind was recorded by Scoresby on March 5th as a "hard gale," which I take to be the same as a " strong gale," number 9 on Beaufort's scale, corresponding to an average velocity of 44 statute miles per hour. Now, the average length of the waves measured by Scoresby on March 6th was 560 feet, corresponding to an average velocity of 38 statute miles per hour. The ship, which was running before the wind, had then been exposed to the gale for about 40 hours, but the force of the gale had by this time somewhat abated. When the gale was at its height 


\section{AND OTHER WATER WAVES 113}

the wind was therefore 6 s.m.p.h. swifter than the waves at their swiftest.

In the Mediterranean and other semi-enclosed seas, even where the water is deep, the length and speed of the waves are much less. Consequently the effective velocity of the wind, which maintains the eddy on the lee of the travelling ridges, is much greater.

In all the above cases, which are typical, the velocity of the storm-wave is a few miles per hour less than the velocity of the wind as averaged over a period of from 4 to roo hours.

The period of the swells which break upon our shores after storms shows that they travel when in deep water at much greater speeds than do the highest waves of storms. Thus the calculated speed of the unbroken series of 139 waves which I observed at Branksome Chine on December 29, I 898, was 66.5 statute miles per hour, and that of twelve successive waves observed on February $\mathbf{I}$, I 899, was 78.5 statute miles per hour. Other observations recorded at the same locality, of which particulars have already been given, show that velocities of between 68 and 78 statute miles per hour are normal, though not frequent, for breaking swells coming to our shores from the west after storms in the Atlantic. 
Many considerations crowd in upon the mind when we endeavour to reason upon the physical connection between the swells of this speed and the pressure of the wind during the storm. How far, for instance, can we regard the longest of these subsequent swells as having had an independent existence during the storm? For the present, at all events, I shall set aside such refinements, and simply consider the numerical speed-relation of the swiftest observed swells to the swiftest observed winds in the same part of the world, and see where this will lead us.

The storms in the North Atlantic during December, 1898, and January and February, I899, were of such exceptional violence that the Meteorological Council made them the subject of a special inquiry, which has beene mbodied in a valuable report, ${ }^{1}$ commenced by Lieut. C. W. Baillie, R.N., and completed by Commander Campbell Hepworth, R.N.R. The charts show that between December $25^{\text {th }}$ and 29 th very strong westerly winds prevailed between the Newfoundland Banks and the entrance to the English Channel. In the notes to these charts it is recorded that the velocity of the wind at Alnwick Castle, Northumberland,

I Charts illustrating the weather of the North Atlantic Ocean in the winter of 1898-9 (Meteorological Council, 1901). 

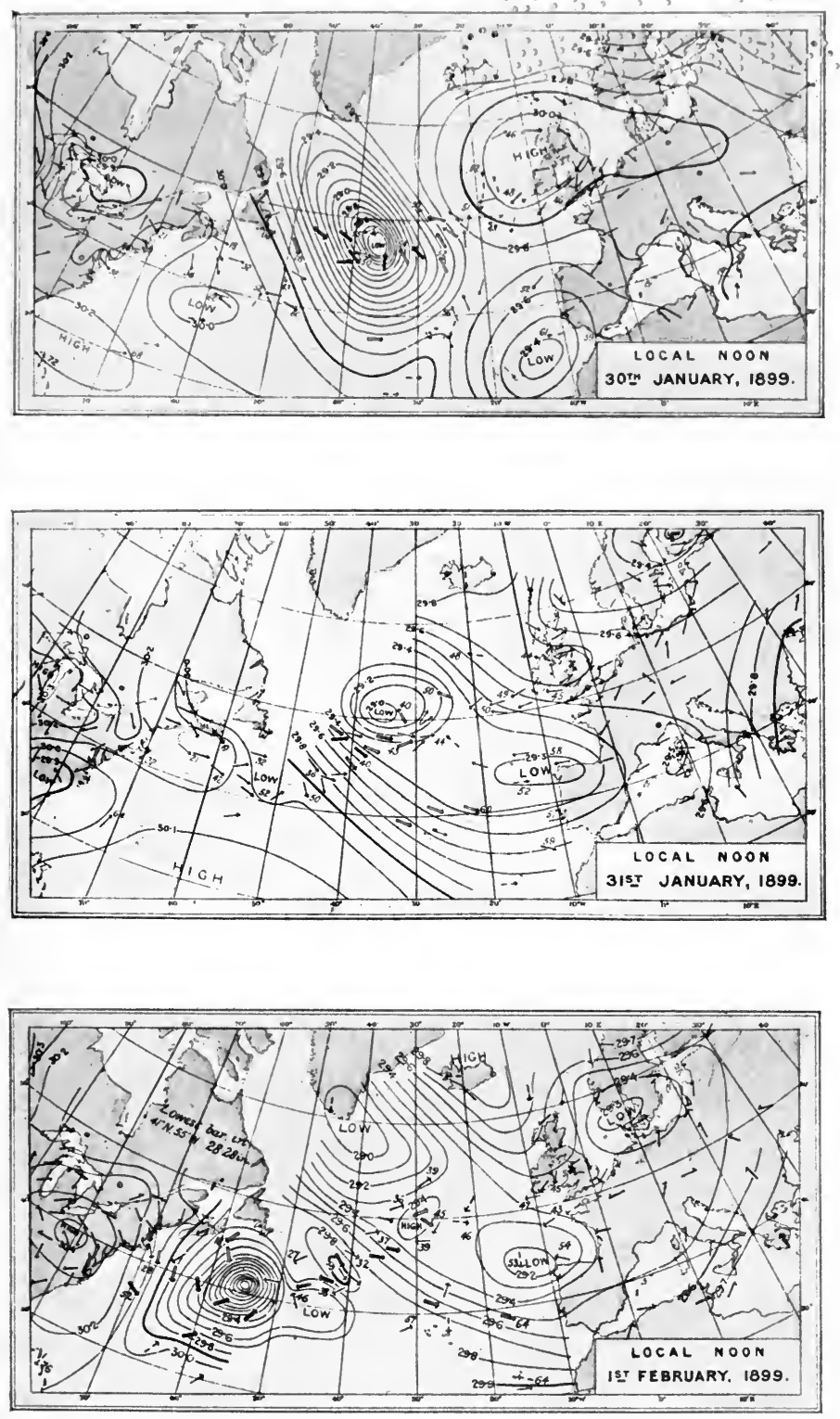

WEATHER IN THE NORTH ATLANTIC.

(From a report of the Meteorological Council, I90I.) 
क a

mingund 


\section{AND OTHER IVATER WAVES 117}

attained 77 statute miles per hour at ro p.m. on the 27 th, and 7 I statute miles per hour at 2 a.m. on the 28th. Beaufort's II-I 2 (i.e., 64-77 statute miles per hour) was recorded at sea in N. $49^{\circ}$, W. $35^{\circ}$, on 28 th, and N. $5^{\circ}$, W. I $9^{\circ}$, on $29^{\text {th }}$. Thus it is proved that the winds that blew had at times an average velocity 10 statute miles per hour greater than that of the swell observed at Branksome Chine on December 29th. I am not able, however, to derive the observed swell from the hurricane arrows shown on the charts for noon December 28th and 29th, for they are too far off for the swell, if travelling with the group velocity of 34 statute miles per hour, to reach Branksome Chine at the observed time. A feature of the chart for the 29th which is worth noticing is the existence of $\mathrm{W}$. and SW. winds of Beaufort's 9-10 (44-53 statute miles per hour) near the entrance to the English Channel. In the moderate depths of the Channel the speed of the swell must have been so reduced I that the observed velocity of wind on the morning of the 29 th was sufficient to exert pressure upon the swells. This may account for their reaching Branksome Chine with a height unusually great for this locality, and much greater

× The maximum speed of a wave in 20 fathoms is about 43 statute miles per hour. 
than the height of the swells observed on February Ist.

The charts throw a clearer light upon the swell observed at Branksome Chine on February ist. This had a period of $\mathbf{2 2 . 5}$ seconds, and therefore a speed in deep water of 78.5 statute miles per hour. A group of these swells travelling freely for a long distance under the action of gravity advances at 39.25 statute miles per hour. Now, the charts for the days January 29th to February Ist show Beaufort's I I - I 2 (64-77 statute miles per hour) only on January 3 oth, and the positions of the arrows showing force 9-10 on 3 Ist and Ist are too distant to affect the water at Branksome Chine on Ist. The cyclonic system of January 3oth half-way between North America and England is a very deep isolated depression, with wind of force II-I 2 in N. $45^{\circ}$, W. $41^{\circ}$, the direction of this wind being a little $\mathrm{S}$. of $\mathrm{W}$. This wind, and that a little in advance of the black arrow, would send a swell almost directly to the entrance of the English Channel. The distance of the straight run from N. $45^{\circ}$, W. $4 I^{\circ}$, to Cape La Hogue (which I shall take as the distance to Branksome Chine) is $28 \circ, 1,680$ geographical miles, I,960 statute miles. The difference of time between local noon January 30 th in W. $41^{\circ}$ and 


\section{AND OTHER WATER WAVES 119}

3 p.m. February ist at Branksome Chine (about W. $2^{\circ}$ ) is about 48 hours. The westerly swell at N. $45^{\circ}$, W. $41^{\circ}$, if starting at noon on January 3 oth, would reach Branksome Chine at the required time if it travelled at the speed of $1,960 \div 48=40.8$ statute miles per hour. Now the observed groupvelocity of the swells recorded at Branksome Chine on February Ist was 39.25 statute miles per hour. There is, therefore, strong ground for regarding that swell as being the result of the storm which occurred two days before at a distance of nearly 2,000 statute miles.

From Mr. F. J. Brodie's paper I on "The Prevalence of Gales on the Coasts of the British Isles during the Years 1871-1900" we learn that in the great storm of December 22, 1894, the wind had a velocity of not less than 53 statute miles per hour for 14 hours (as observed, of course, at a fixed station), 64 statute miles per hour for 9 hours, and 76 statute miles per hour for 2 hours. On January I 2, I 899, 53 statute miles per hour was maintained for 6 hours and 70-76 for I hour. The velocities attained in gusts are recorded in another paper.2 In January, I 899, a rate of 90 statute miles per hour was recorded at Southport

2 Symonds, Met. Mag., May, 1900. 
in one gust and between 80 and 90 in several others. The highest recorded velocity in any gust was that registered by a Dines' pressure tube anemometer at the Rousdon Observatory, South Devon, viz., I or statute miles per hour. The results may also be expressed in this way, viz., that, at a fixed station, a wind velocity of above 70 miles per hour has been maintained for as long as 2 hours, but velocities of from 80 to Ioo s.m.p.h. have only been maintained for minutes or seconds.

The greatest period of any short group of swells which I have observed is 22.5 seconds, with a speed, therefore, of 78.5 statute miles per hour. M. Bertin I says that 24 seconds (speed 84 statute miles per hour) is certainly beyond all observed periods in European waters. The greatest speed which I have observed in a group of many swells was 66.5 s.m.p.h. on December 29, I 898 . The greatest recorded average velocities of wind in that weather were 77 and 7 I s.m.p.h. on 27 th and 28 th of the same month.

The greatest speed which I have recorded for a group of a few swells is 78.5 s.m.p.h. on February I, I899. The greatest speed of wind x "Experimental Study of Waves," Inst. of Naval Architects, I873. 


\section{AND O'THER WA'TER WAVES 121}

in gusts during that weather was frequently 80 s.m.p.h., ranging up to 90 s.m.p.h. in one case. This was in January.

As far as the evidence goes in this difficult part of our subject, the indication is that the maximum average velocity of wind maintained for I hour is a few s.m.p.h. greater than the average maximum velocity of any long group of swells originating therefrom and forming breakers upon the shores of England. It is conceivable that shorter groups of greater speed may owe their origin to gusts, but during lulls these would be running against a current of air. The maximum recorded wind velocity in gusts in $1898-99$ was I I $\frac{1}{2}$ m.p.h. greater than that of the swiftest of the short groups of swells.

On the Connection between the Rate of Progress of Cyclones and the Character of the Waves

Strong winds in the North Atlantic are developed in that part of an area of low atmospheric pressure where the barometric gradient is steep. These atmospheric depressions are very frequently of the form and nature known as cyclones, of which the general character is that shown in the accompanying diagram. 
The oval indicates the area covered by the depression, the long arrow the direction of advance, the short arrows the direction of wind in certain parts of the cyclone. In the position marked A the direction of the wind is contrary to the direction of advance of the cyclone. Hence in this quadrant the cyclone is continually receding from the waves which its wind creates, and

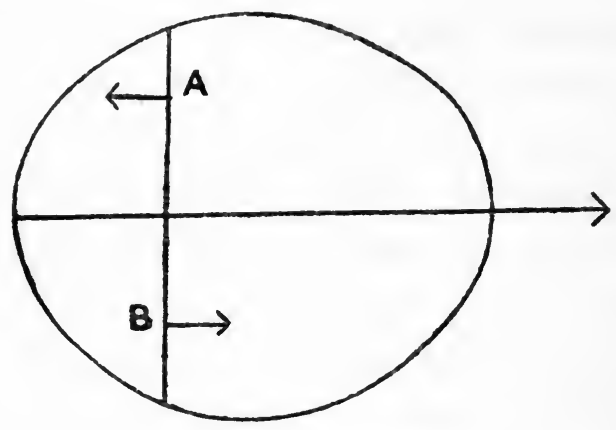

A CYCLONIC SYSTEM.

along the line of advance of this part we should not expect that there would be any great development of waves, even if the winds there were strong, which they are usually not. Obviously, for a given velocity of wind, the position most favourable to the development of waves is that where the direction of the wind coincides with the direction of advance of the cyclone. This is where the direction of 


\section{AND O'THER WATER WAVES 123}

the wind is shown by the arrow B. Here, moreover, at about 4-Ioths the distance from centre to edge, the strongest winds are usually developed. The line of advance of $\mathrm{B}$ will, therefore, be the line along which the greatest wavedevelopment will occur. There is not any constant relation between the rate of advance of a cyclone and the velocity of the winds locally developed within its area. Considering only the critical position $\mathrm{B}$ in the cyclone, the rate of advance of the cyclone is, from our present point of view, simply the rate of advance of the locus of the force which is there creating the waves; we have to do, in fact, with waves created by a travelling disturbance. Let us consider groups of simple harmonic waves of different lengths, and therefore different speeds, to be already formed and to be travelling together (and therefore superimposed upon one another) as forced waves pressed upon by the wind. This wind, however, in a progressive cyclone is a " travelling disturbance," and while it will, to some extent, increase all the waves beneath it which it can press upon at all, the waves which move slower than the travelling disturbance are being left behind all the time. On the other hand, all waves whose velocity is greater than that of the travelling disturbance run ahead of it, and are no longer subject 
to the reinforcing action of the wind. The waves whose speed is identical with that of the travelling disturbance will be continually subject to the reinforcing action of the wind during the whole lifetime of the cyclone. I think, therefore, that the wave-length of the principal, or dominant, or storm-wave generated in Atlantic storms should depend, not only upon the velocity of the wind, but also upon the rate of advance of the cyclone. It is, I believe, a matter of common remark that in some storms a short, steep sea is soon formed and in others a longer sea.

The general rate of advance of Atlantic storms towards our shores has been investigated, ${ }^{\mathbf{I}}$ and the figures are worth examining in connection with our subject. Storms advancing from points between WSW. and WNW. to ENE. and ESE. travel at an average speed of 28.9 statute miles per hour. Of the 264 storms examined, only 60 travelled at more than 35 statute miles per hour, and of these only io travelled at more than $52 \frac{1}{2}$ statute miles per hour.

It appears, therefore, taking the average of a large number of storms coming from the Atlantic, that waves travelling about 30 statute miles per

${ }^{\mp}$ Q.F.R.M.S., 1902, loc. cit. 
hour I (length 37 I feet) should enjoy special opportunities for development in depressions where the wind exceeds that velocity.

We see, therefore, that waves of $68-78$ statute miles per hour, which are the greatest speeds II have recorded for swells after Atlantic storms, would in almost all cases outrun them, even when the depression advances along a straight path. The reason that such waves are not developed to greater heights is, therefore, not only that the wind is, during most of the time, not strong enough, but also that the cyclones advance too slowly.

The above method of theoretical treatment is of only occasional application on account of the fact that there are generally several neighbouring cyclonic systems on the North Atlantic and that the actual winds are a compromise between them. Fortunately, the charts for December 27, 28, and 29, 1898 , enable us to examine an instance of this commoner condition. A series of cyclonic systems were following one another across the North Atlantic from S. of W: to $\mathrm{N}$. of $\mathrm{E}$., and strong westerly winds prevailed during the whole of these three days between N. $50^{\circ}, W^{i} .40^{\circ}$, and

- This is a wave of a little more than 8 seconds period. The 8 -seconds wave has a speed of about 28 statute miles per hour and a length of 328 feet. 
the entrance to the English Channel. The unusual force of Beaufort's II-I 2 was at local noon on December 28th recorded in the neighbourhood of N. $50^{\circ}, \mathrm{W} \cdot 37^{\circ}$, and not elsewhere, and on local noon December 29th in the neighbourhood of N. $49^{\circ}$, W. $19^{\circ}$, and not elsewhere. As the storm does not appear to have abated meanwhile, we may infer that the locus of the hurricane wind progressed continuously along this path of 840 statute miles in the course of these 23 hours. This is at the rate of 36.5 statute miles per hour. The average wind velocity for I I-I 2 is 70.5 statute miles per hour. Waves travelling at nearly this speed would be running on ahead all the time. The waves which would be all the time from noon December 28 th to December 29th subject to the maximum force of wind would be those with a speed of 36.5 statute miles per hour, and, therefore, with a length of about 558 feet. As they would be subject to an effective wind velocity of $70.5-36.5=34$ statute miles per hour, there would be a great deal of spraying from their crests.

Two hours at a fixed station is the greatest time recorded above for wind with an average velocity of more than 70 statute miles per hour. If the locus of that wind force were advancing at 36.5 


\section{AND OTHER WATER WAVES 127}

statute miles per hour, as in the above case, the length of fetch, or stretch of water, at any one time subject to this wind would be 73 statute miles, in which there would be a train of only 200 of the I,9 I 8 foot-waves.

It may in this connection be noted that in a gust lasting I minute, and in which the locus of application is advancing at the same rate $(36.5$ statute miles per hour), the length of fetch would be only about half a mile-i.e., less than two of the above wave-lengths. The absence of breakers with speeds nearly as great as the maximum wind speed of gusts may, therefore, be properly attributed as much to their insufficient length of fetch as to insufficient time of action.

The charts for February 2 and 3, 1899, in the publication of the Meteorological Council to which I have so often referred, afford an excellent example of a long-continued hurricane-force of wind which was stationary in position for 24 hours. After examining these two maps, I made the following note, viz:

"Maps for February 2nd and 3rd show hurricane-force (centre about N. $45^{\circ}$, W. $45^{\circ}$ ), with no appreciable length of fetch indicated, occupying almost the same considerable frontage for 24 hours. In this area must have been a 
very wild sea with the waves spraying very much, from which must have emerged a very long swell."

After making this memorandum I referred to the notes on page 6 of the publication, and found:

"On February 2nd .. . the Quernmore, in N. $4 I^{\circ}, W .46^{\circ}$, reported that during the storm the atmosphere was so heavily charged with spoondrift as to appear as a heavy snowstorm."

My reason for diagnosing an exceptional amount of spraying was that the locus of the hurricaneforce did not advance, so that the wind would not have been able to develop the longer waves.

\section{The Effect of Squalls and Gusts upon Waves}

On December 22, 1906, I was on board the Leyland S.S. Jamaican, bound for Puerto Colombia from Liverpool, in $\mathrm{N}$. Lat. $38^{\circ} 2 \mathrm{I}^{\prime}$, W. Long. $35^{\circ} 43$. There was a heavy sea and a moderate gale. At 4 p.m. a violent squall of wind, with rain, occurred, lasting about 4 minutes, which was accompanied by very big waves, and succeeded by comparatively calm water. I guessed the largest waves during the squall to be 7 feet higher than those which preceded or followed.

On the following day, December 23rd, we were in N. Lat. $35^{\circ} 47 \frac{1}{2}^{\prime}$, W. Long. $39^{\circ} 48^{\prime}$, with a 
strong breeze verging on a moderate gale-i.e., a wind velocity of about 28 statute miles per hour. At 3 p.m. there occurred a squall lasting 3 minutes, which converted a moderate to a large sea. I estimated that the height of the waves increased at least 2 feet per minute, finally attaining rather more than 20 feet. Not only did the waves increase in height, but the crests lengthened out transversely, so that the waves ran in longer and more regular ridges. The squall came from the starboard and abaft. Two minutes after it had passed us we were among waves no larger than before, but I could see a group of about four great ridges travelling away with the squall. The length of the waves, as judged by their appearance in relation to the ship's length, was never more than 200 feet. As has been already explained, this estimate is generally less than the measurements obtained by following the waves in their course.

In another squall, occurring at 5.2 p.m. and lasting 5 minutes, the height of the waves was perceptibly increased.

Next day, December 24th, we were in N. Lat. $33^{\circ} 38^{\prime}$, W. Long. $43^{\circ} 58^{\prime}$. The principal "waves" were mounds of water, produced by the crossing of two sets of waves. At 3.30 p.m. 
the wind began to fall, and at 4 p.m. the sea was slight, except for the occasional formation of a larger mound of water. At 4.55 p.m. a black being very dense and apparently rainy. The part. head. It reached from the horizon on one side of us to the horizon on the other side, the two ends being very dense and apparently rainy. The part of the cloud directly overhead was thin, and discharged only a few small drops of rain. The passage overhead of this central part was accompanied by only a slight additional breath of wind, but with it came a big swell, comprising I 2 or more large waves, and the ship, previously steady, began to roll heavily. In 5 minutes the cloud had passed, and in another Io minutes the sea had quite returned to its former state.

These observations relate to squalls occurring towards the end of stormy weather, coming upon a fairly large swell running in the same general direction as the wind. They show that (according to my guesses of height) a sudden increase of wind can restore the height of waves at the rate of $I$ or 2 feet per minute. They illustrate the fact that, when the system of travelling ridges is already formed, the wind, falling into eddies between them, has greater power to raise the crests and depress the troughs, a power of swift and immediate action 
which contrasts strongly with the slight power of the wind when blowing upon smooth water. My observations from the S.S. Jamaican relate, as I have said, to the action of squalls at the tail end of a storm.

Their action during the height of a storm is often to lower the waves. Thus, during my voyage from Liverpool to Boston on the Cunard S.S. Ivernia, December, I900, of which some particulars have already been given, I often saw the effect (which others have frequently described) of showers of spray from every wave-crest during each gust. The steepness and the slowness of the waves were such that the cohesion of the water at the crests could not resist any increase of the upward suction and the horizontal pressure there. Hence in the gusts the water was torn in showers of spray from the crests, falling finally, one must presume, mainly in the sheltered troughs, thus tending to flatten out the sea.

On March I I, I 90 I, on the Red Star S.S. Vaterland, east-bound from New York to Southampton, I saw the much greater lowering effect of a wind meeting the waves. We were in $\mathrm{N}$. Lat. $44^{\circ} 56^{\prime}$, W. Long. $36^{\circ} 54^{\prime}$, with a rough sea from the starboard, the waves occasionally rising above the horizon of our promenade deck. At about 4 p.m. 
the wind quite suddenly chopped round and blew from the opposite direction, meeting the waves in their advance. The ridges of the waves, as usual, were not uniform, but had, on the contrary, an undulating outline. The wind caught the higher portions, and bit huge pieces out of them which momentarily formed a milk-white cloud, which in its turn was quickly dissipated in spray.

On Wave-fronts in a Veering Wind, and on the Irregularity of the Waves in the Region of the Trade Winds

Wind is never really steady. Not only is it always more or less gusty, but it is always veering-i.e., changing its direction. Apart altogether from the progressive variation in the general direction of the wind which is characteristic of a cyclonic system, there is a rapid veering about a mean position, even in the Trades. The amount of this veering is sufficient to exercise an important effect upon the character of the waves and the appearance they present.

It results in the formation of waves running simultaneously in slightly different directions, and thus, even in the regions of the Trade winds, the open sea does not present a series of parallel ridges, 


\section{AND O'THER WATER WAVES 133}

each one of uniform height, with a lateral extension many times greater than the distance from crest to crest.

In 1907 I made the following observations on the want of regularity of waves created by the Trade winds. On January 8 th, en route from Colon to Kingston, Jamaica, in a strong NE. Trade wind, I estimated the height of the principal waves at I 5 feet. Their apparent length was about 200 feet. I noted at the time that this strong breeze had continued, to my knowledge, for eight days, and that for some days past there had been no increase either in the size of the waves or in their regularity, indicating, therefore, not only that the maximum size is soon attained (as M. Bertin ' has pointed out), but also that there is no continuous approximation towards regularity. The captain of the vessel (s.s. Jamaican) stated that on such a day as this the wind would not vary more than one point of the compass in the course of a fourhour watch, and this is reckoned a very steady wind. But one point of the compass is $11 \frac{1}{4}$ degrees of arc, which is a very appreciable angle. If one watches the arrow of a sensitive weathercock in a strong breeze, in our own country, it will be seen

" Memoir on the "Experimental Study of Waves," Inst. of Naval Architects, 1873 . 
that it never remains stationary for more than one or two seconds, but is continually shifting through a large angle.

Another cause can also be divined for the unlevel tops of the wave-ridges and their small lateral extension. This cause is a greater force of wind to right or left of the ship's course. Suppose, in the first place, that the ship is in a calm, and that to the starboard and in front there is a head wind blowing. Then a swell will spread out laterally from that area, meeting the ship obliquely on the starboard quarter. Secondly, if a lighter head wind be blowing where the ship is, the wind-waves will be crossed obliquely by this swell from the starboard, even though the wind there be blowing in the same direction as that where the ship is. The velocity of the wind being less where the ship is, it will not be able to regularise the obliquely-running, swifter swell.

The wind-formed waves which run in the most regular ridges (i.e., of the greatest lateral extension as compared to their wave length) are of two orders of magnitude. First, the small waves of a few feet in length and not more than one foot high; second, the large ocean waves. The regularity of the first is not affected by long-period veering of the wind, for they die out completely in 
the interval and fresh sets are formed. The regularity of the second is not visibly affected by shortperiod veering, being too massive. Waves of intermediate size are affected by both kinds of veering and several crossing sets are formed.

\section{The Observed Profile of Waves at Sea}

Both during a wind and in the case of a swell travelling calmly in deep water, the trochoid represents the apparent form of the wave much more nearly than the curve of sines, for it is easy to observe that the convex part of the wave has a steeper curve than the concave part, the crest being narrower than the trough. But, except in the case of a somewhat flat swell, the greater steepness of the front face of the wave is obvious to the eye, and most markedly so when the wind is blowing. Now, Sir G. G. Stokes found I that waves of permanent type in deep water, whatever be the order of approximation to which the calculation is pushed, must be symmetrical with respect to vertical planes passing through their ridges. I conclude, therefore, that steep waves at sea are never waves of permanent type. Again,

I "Math. and Phys. Papers," vol. i., p. 193, from Trans. Camb. Phil. Soc., vol. viii., p. 44I. 
both Stokes and von Helmholtz showed that for a single series of waves of permanent type the condition under which greatest steepness could be attained was that the speed of wind and wave should be equal.

Now, according to observation, the steepest wind-waves in deep water are formed where the speed remains small relatively to that of the winde.g., in lakes and small seas. Also in the Trades, where the wind is perpetual, there is no sign or symptom of an approach to the "highest wave" of Helmholtz and Stokes. I conclude, therefore, that observation indicates that under natural conditions of wind there is no tendency to progressive approximation towards the state of one set of waves of permanent type.

In this connection, I note that Professor Horace Lamb, who has investigated water-waves as a mathematician, writes I that "the possible form of waves of permanent type . . . is very interesting mathematically . . . but no reason has been given, so far as I know, why free water-waves should tend to assume a form consistent with permanence."

× Presidential Address, Section A, British Association, Cambridge Meeting, 1904 . 


\section{AND O'THER WATER WAVES 137}

On the Mountainous Appearance of Waves

The phrase "waves mountains high" has long given offence to literary landsmen, who quote measurements to show that waves are not even as high as hills. I have never met a seaman who either supposed or pretended that waves were as high as mountains, but there are conditions when waves look like mountains, or, at any rate, like large hills.

This happens when the majority of the crests rise well above the line of sight, especially if the atmosphere be rather thick, so that minute detail is obliterated. Four or five ridges, with the intervening three or four troughs, then fill all the space between the eye and the horizon. Being mounted on a deck, there is a feeling or impression that the horizon is at the distance which it would have on land with such an eye-elevation. This would mean a mile or more from ridge to ridge, which is ten times the actual distance; and the apparent height is consequently increased in the same ratio, making a wave of 40 feet look as high as a hill of 400 . I have seen, and recorded, ${ }^{\prime}$ a case where absence

× Geographical Fournal, Jan., 1900, "On Desert Sand-dunes Bordering the Nile Delta." 
of surface detail produced a somewhat similar illusion of great size among desert sand-dunes. Particularly when under a low sun they produced as great an impression of size as mountains thousands of feet high-i.e., of ten times their real height.

Note to PAge 60.

In storms of exceptional duration as well as of more than ordinary severity, such as are not encountered every year, the waves are somewhat higher. Thus in February, I9Io, the R.M.S.P. Oruba, between Southampton and Barbados, encountered waves which, from the account given me by Captain C. P. Langmaid, appear to have attained 45 feet. In March, 1904, Captain J. G. K. Cheret, on another of the R.M.S.P. steamers, encountered between Southampton and the Azores exceptional weather, of which he has given me an account. When he was on the bridge the waves frequently obscured the horizon at times when the ship was on an even keel, from which it appears that they surpassed 45 and may have attained 50 feet. 


\section{PART II}

ON THE ACTION OF SEA WAVES TO TRANSPORT SHINGLE, SAND, AND MUD 



\section{CHAPTER V}

On the depth to which wave-agitation extends, and on the transport of fine mud-The action of waves to drive shingle shorewards-The effect of percolation to promote the building-up of beaches-The movement of sand by waves-The undertow.

On the Depth to which Wave Agitation Extends, and on the Transport of Fine Mud

WHEN the surface of the deep sea is in waves, the agitation extends to some depth. For our notion of what goes on below the surface we have to depend mainly upon theory, observations being almost wholly wanting. According to theory, if there be one set of regular trochoidal waves running, the repeated motion of any particle of surface-water is a vertical circle.

In the upper half of the circle the motion of the particle is forwards-i.e., in the direction of advance of the wave. In the lower half it is backwards. Thus the return flow of the wave-water in a travelling wave is not a precise reversal of 
the onward flow, for it takes place at a lower level.

Below the surface trochoid are sub-surface trochoids, in which the diameter of the circle which the particles of water describe diminishes with increasing depth.

The diameter of the circle and the velocity of the oscillating currents diminish in geometrical progression as the depth increases in arithmetical progression, the diameters being halved for an additional depth of I-9th wave-length below the mid-level of the surface wave. Thus, at a depth equal to one wave-length, the diameter of the circle, and the velocity of the moving particle of water, is $I-512$ th of that at the surface. Thus, in the case of a wave with a length of 600 feet and a height from trough to crest at the sea's surface of 40 feet, the particles of water at a depth of 600 feet will revolve in a circle of 40 feet $\div 512=0.94$ inch diameter. The period of a 60o-foot wave is about I I seconds, and this is the time in which the particle at a depth of 600 feet would describe a circle of about $I$ inch diameter.

We have seen that waves of the greatest height are seldom more than 600 feet long in the North Atlantic, and it is seldom that very long swells, being much lower, would give a greater agitation 


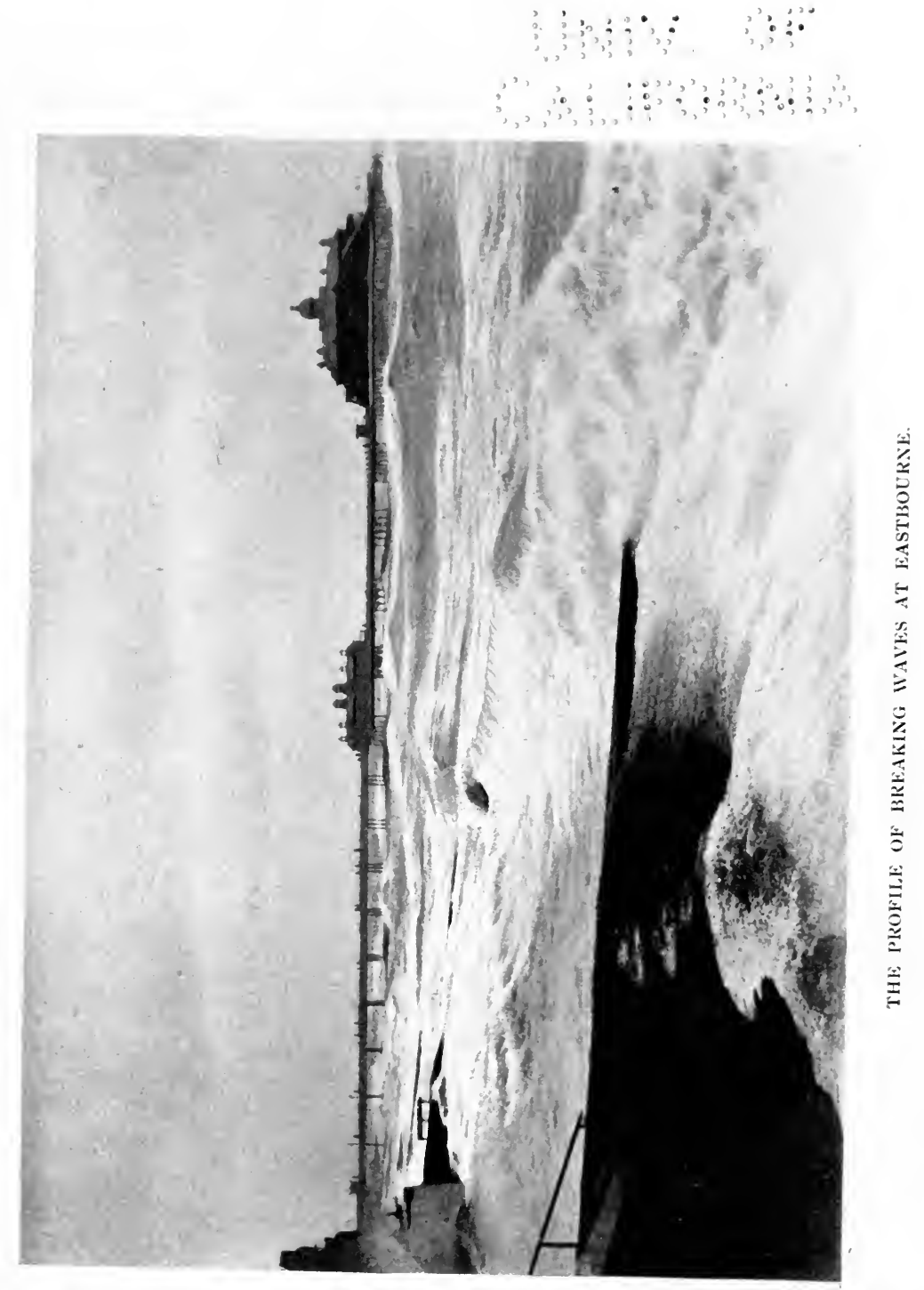




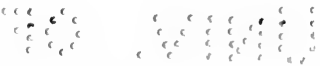

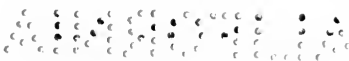


than this at a depth of 600 feet. The line of 600 feet, or Ioo fathoms, is a very important depth in the seas, for it is approximately that to which the edges of the continents are submerged. From this line the sea bottom descends abruptly to the vast depths of the great plains where the soundings are reckoned in thousands of fathoms.

At such depths the agitation caused by windwaves must be absolutely insensible, but within depths of 100 fathoms, i.e., on the continental platform, continual slight oscillations of I 0-20 seconds period, and even as little as I-inch amplitude, must exert an effect in hindering the deposition of the finest kinds of mud. Mud, or dust, when so finely divided that it settles through air or through water with indefinite slowness, only comes to rest where the fluid is free from agitation, unless some agency -e.g., chemical or electrical-precipitates the particles. Every student has noticed that it is not the exposed papers which he is handling frequently on his desk which become dusty, but those put away-e.g., on the top of a high bookshelf.

We may say with confidence, as a theoretical inference, that the agitation of wind-formed waves affects the bottom of the sea as far as the edge of the continental platform to such an extent as (in co-operation with tidal and other currents) to 
keep very fine mud moving about until it has an opportunity of subsiding over the edge of the continental shelf-in the absence, that is to say, of chemical or other coagulation of the fine particles into clots or lumps.

The Action of Waves to Drive Shingle Shorewards

It is matter of common experience that the stones brought on to the sea-shore (e.g., by the wasting of gravel cliffs or by the wash of stone-carrying torrents), though swept along the coast and thus distributed, are to a great extent rejected by the sea and piled up in a bank, so that some of the stones are only reached again by the largest waves at the times of high water of the greatest tides. Classifying the detritus brought to the sea-shore into three sorts, viz., shingle, sand, and mud, we may say that those parts of the sea bottom which are subject to wave disturbance afford no abiding place for either the first or the last.

We have seen how the mud travels on the whole in a direction contrary to that of the swell, which, having "felt the bottom," is advancing shorewards.

I now put forward a theory which I think shows that the oscillations of the bottom water where agitated by progressive waves has a proper action of its own to heave forward-i.e., in the direction 

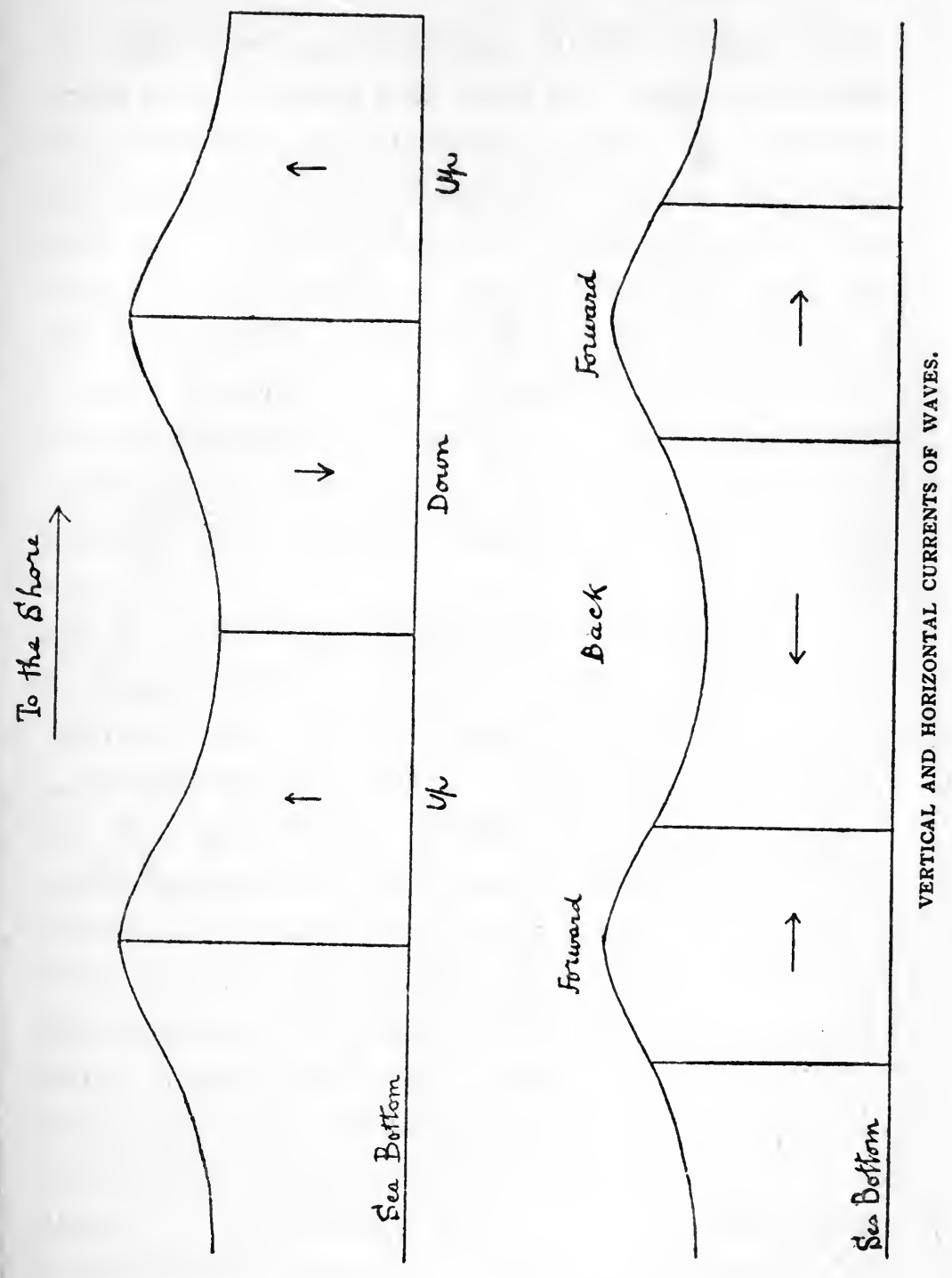
of the waves' motion-all detritus which they can wholly or partly lift from the bottom, but cannot maintain more than momentarily in suspension. I will first suppose the waves to be symmetrical, which is the condition least favourable to proving my case, and I will begin by supposing the bottom to be horizontal. The vertical currents are as shown in the first figure; i.e., an upward current begins when the trough passes and continues until the arrival of the crest, after which subsidence commences and continues until the next trough arrives.

The horizontal currents are as shown in the second figure. The shoreward current begins in the midst of the upward current. The material which has been raised by the upward current is caught thereby and heaved shoreward, and the shoreward current, acting after the commencement of the down current, continues to drive the material forward during the first part of its period of subsidence. The backward horizontal current then sets in when the water has been clarified from all coarser and rapidly subsiding materials, so that at its commencement it only finds fine material in suspension, which it carries backwards. During the last part of its period of action the backward horizontal current is accompanied by an upward 


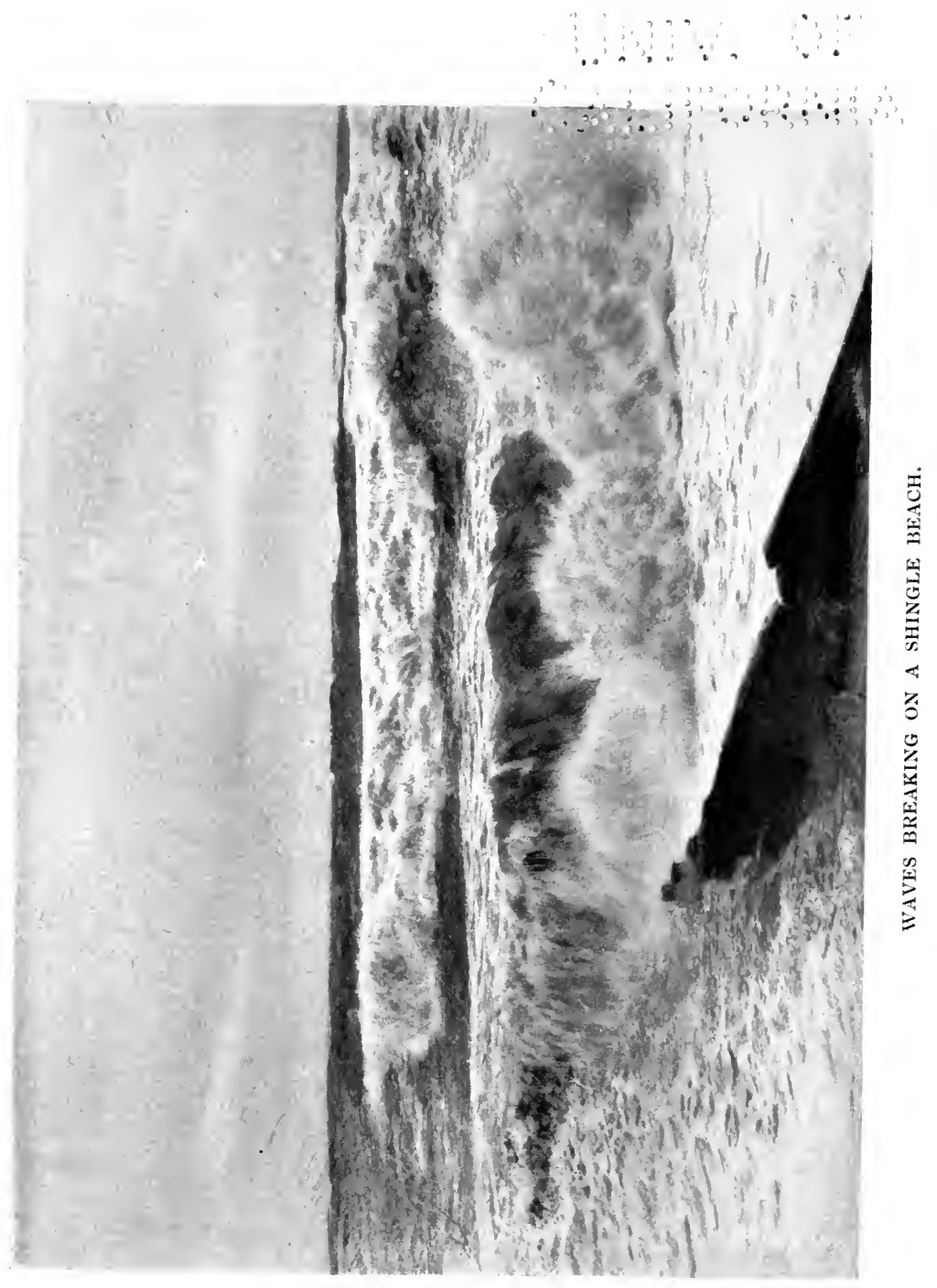




$$
\begin{aligned}
& \because \because, \quad \because: \div: \\
& \therefore\left\{\begin{array}{c}
0 \\
\vdots
\end{array}\right.
\end{aligned}
$$

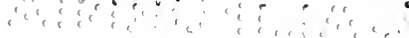


current, and coarser material begins to be carried backwards; but this backward movement is more than neutralised by the succeeding forward current, which has the advantage of acting upon material already suspended, or, in the case of large stones, already loosened from their anchorage.

Next, let us consider the case of waves approaching the breaking condition; and here I can rely upon personal observation, particularly upon the moderately flat, sandy shore between Bournemouth Pier and Branksome Chine, Dorset. When the wave is in this stage the front is much steeper than the back, the upward current (trough to crest) is short-lasting, but very violent. The reversal of horizontal current sets in very suddenly, the shoreward current attaining its maximum speed very. quickly, while the water is heavily charged with the coarser sediment. The change from shoreward to seaward current and from upward to downward current is, on the other hand, very gradual. At its commencement the seaward current is also very gentle, and it only attains great intensity just in time to have its effects upon the coarser sediments reversed by the sudden onset of the shore current which accompanies the advancing wavecrest.

When the wave actually breaks upon a bare 
shore there are two additions to its mode of shoreward action upon pebbles. In the first place, and obviously, the cataract which is discharged obliquely upon the ground drives pebbles forwards. In the second place, if we look at what happens just behind the fallen front, we see that, instead of subsidence and backward flow, there occur upwelling and shoreward flow. The reason is evidently that the head of water in front has been destroyed, the pressure is now from behind, and the breaking wave has, in fact, rolled over.

It is evident that this predominantly forward, or shoreward, action of nearly, and quite, breaking waves upon pebbles could be neutralised by setting the waves to roll the pebbles up a slope. There would be a slope of some particular steepness on which gravity would just neutraiise the forward action of the waves. ${ }^{1}$

Moreover, since the advantage of the forward action over the backward action so much depends upon quick subsidence of the particles, it appears a proper inference that upon a moderate seaward slope there will be a travel of large material shoreward, while material of a somewhat smaller size will merely oscillate.

I This is a reason against the construction of steep groynes. 

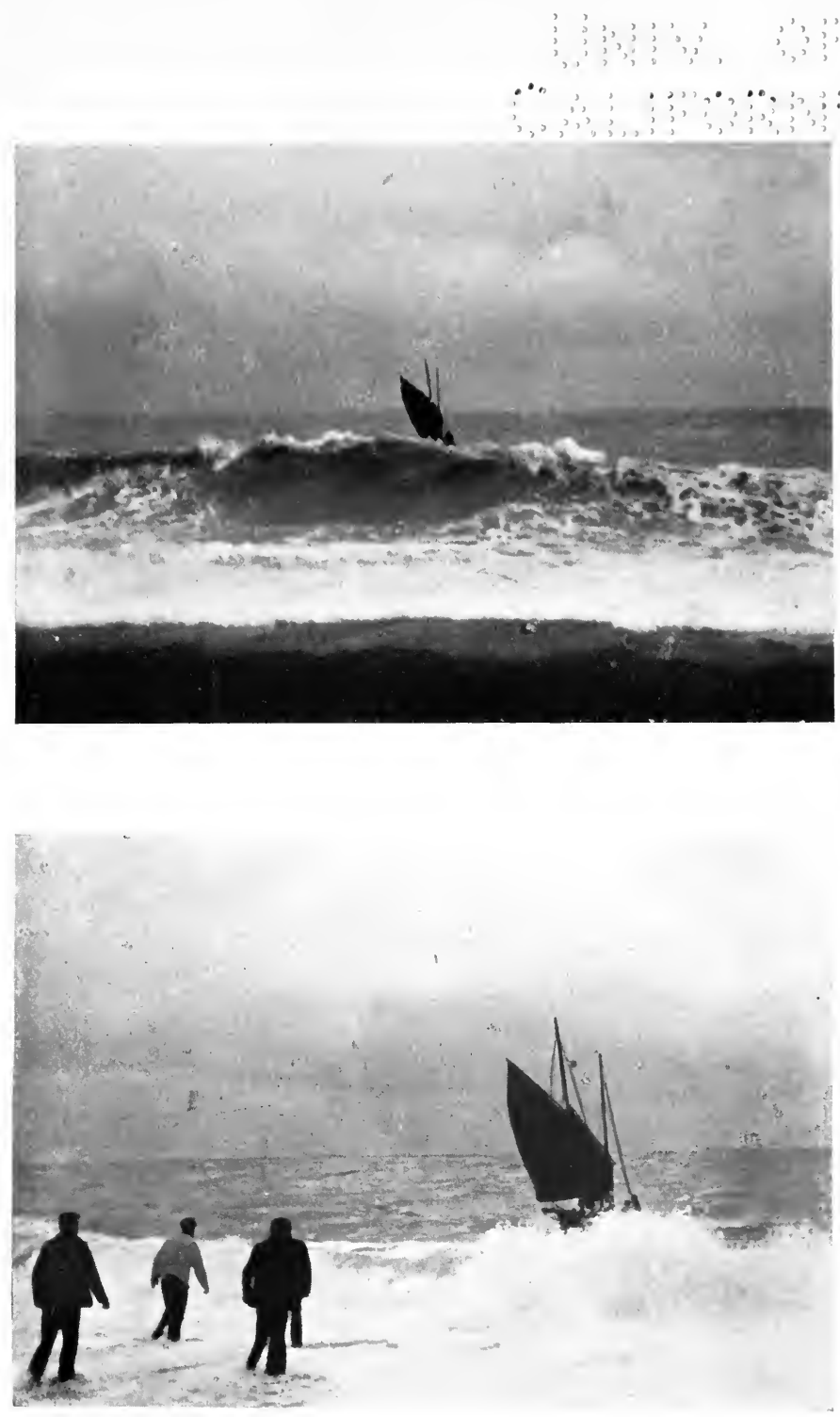

A WAVE BEFORE AND AFTER BREAKING.

I 55 


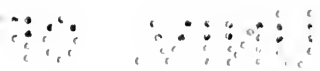

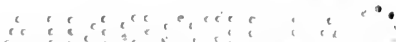

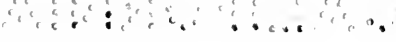


The Effect of Percolation to Promote the Building of Beaches

When I have watched the action of the breakers upon a natural sloping platform of hard rock, cut at the foot of a cliff, it has seemed to me that the stones thrown forward by the breaker roll down so freely in the backwash that a moderate slope is sufficient to return to the breaker as many stones as it rejects.

It is otherwise, however, when the shore is already covered with a sloping bank of shingle. The wash from the breaker, rushing up this bank in virtue of the speed with which it starts, travels over its surface, filling only the interstices between the upper layers of stones, and leaving the interstices of the greater part of the bank above the mean sea level unsaturated and void. When the wash of the breaker has reached its limit and the water begins to run downhill, a great part of it subsides through the interstices of the shingle instead of flowing as a surface-current, so that the latter is weakened in two ways. There is the diminution of momentum which lessens its power to roll stones down, and secondly there is the diminution of depth which results in the larger of these stones being only partly submerged. They are 
thus often stranded through loss of buoyancy. This stranding effect is seen best, however, in the wood, seaweed, corks, \&c., which are left in a marginal fringe at the furthest reach of the wash from the waves.

The proper effect of waves, when acting without complicating circumstances, upon a sufficient supply of shingle is to construct a bank or ridge upon the top of the beach, the face of which is of very steep and uniform slope. These banks are called Fulls, and are a characteristic feature whereever shingle beaches extend seawards upon our shores-e.g., at Dungeness.

\section{The Movement of Sand by Waves}

Sand neither remains suspended indefinitely, as mud, nor drops instantaneously, as shingle, but settles through water at a moderate rate, which for the beach sand at Branksome Chine, Dorset, is about 2 inches per second. Unlike fine mud, which the wave-water of the sea passes on to the great depths; unlike the shingle, which the waves reject upon the shore; the movement of the sand is very variable, changing more than that of the mud or shingle with the varying agitation of the sea. My own observations on seashore sand have been made on the coasts of England, Scotland, and Wales, but 

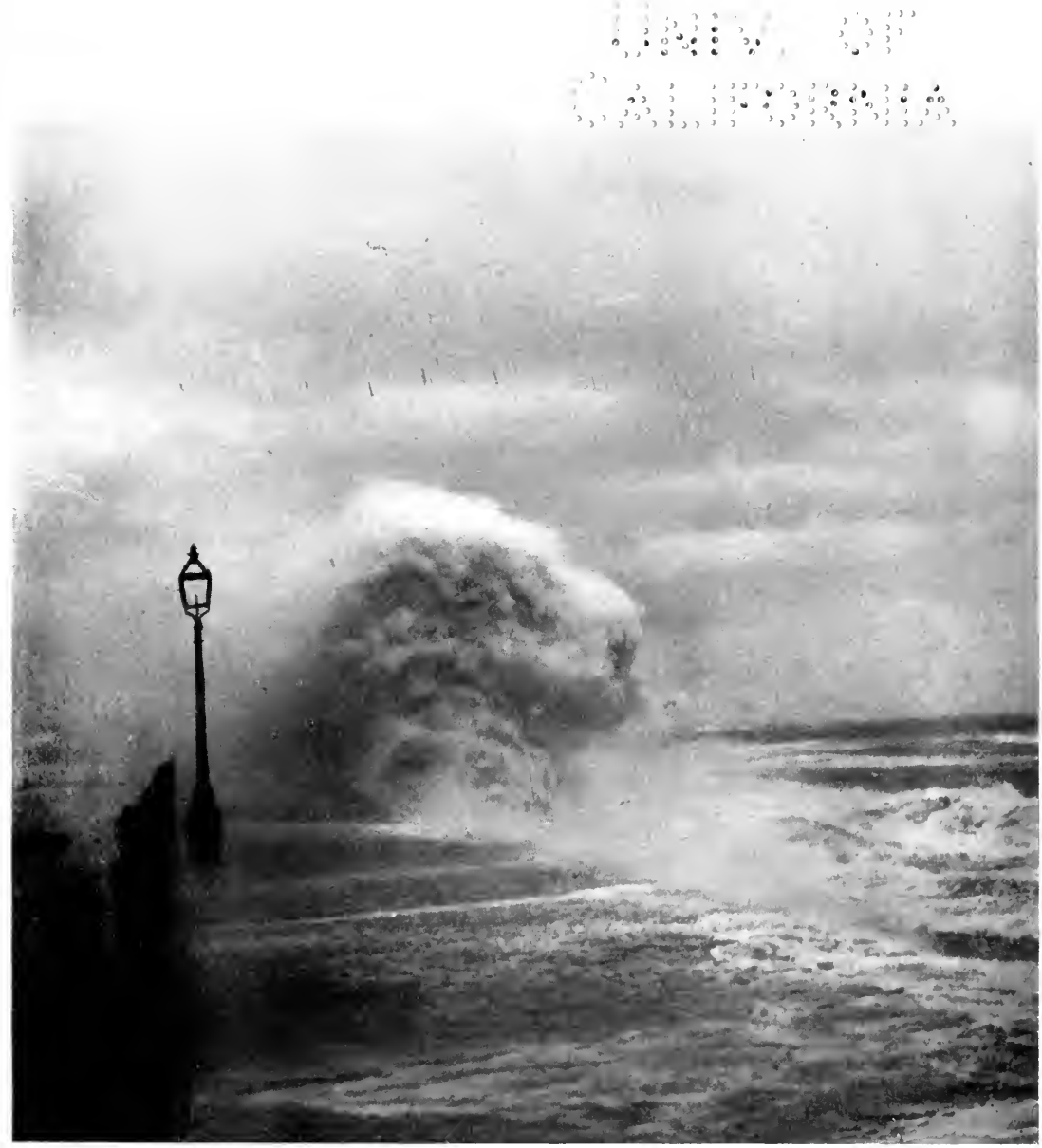

IVAVE BURSTING AGAINST A VERTICAL IVALL. 


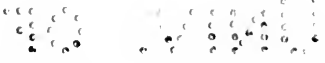

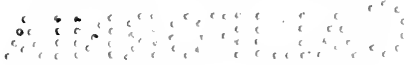


chiefly in the English Channel, and almost daily during some years on the beach near Branksome Chine, between Bournemouth and Poole Haven. They do not apply to lakes or tideless seas.

Usually the floor of our seas is covered with clean sand, from the lower parts of the beach which are uncovered daily by the recession of the tide, to depths as great as enable the bottom to be seen from a boat. In greater depths the sand dredged up is less clean and homogeneous. In addition to this covering of sand upon the floor of the shallow sea there are here and there great banks of sand rising nearly to the surface from water of some depth. Such are the Skerries Bank, east of Start Point (Devon) and the Shambles Shoal, east of Portland Bill (Dorset). Also, where shingle is not too abundant, the whole of the surface of the beach is often composed of sand (which buries the occasional stones). In such localities one may often see the breakers piling up a ridge of sand on the top of the beach in the manner already described for the shingle Fulls. The water does not, however, drain out of the sand-ridge so completely between waves, and the influence of percolation upon accumulation is, therefore, not so great as in the case of shingle, although it is still a main factor in the accumulation of the ridge at the summit of the beach. 
From time to time, and generally after storms of exceptional severity or long duration, or accompanied by high tides, the clean sand is wholly removed between the levels of high and low tide, and much is also removed at even lower levels. We then see during low tide the eroded rock which is the real floor of the foreshore. At high tide the sea, even if calm, then reaches its bounding cliffs, and we realise that the sandy covering of the foreshore, though generally there, is not a permanent deposit, but only a covering which is stripped off when the forces of the sea are really set to work.

After the beach has been stripped by storms near Branksome Chine the slope of the shore has been much reduced, and in the calm weather succeeding, especially with an off-shore wind, I have often watched the sand being brought back and piled up by the breakers in a sand Full, or ridge, often with a lagoon behind it at high tide. The waves have then the shoreward action on the sand which has already been described in the case of shingle, the settlement of the sand being, I presume, sufficiently rapid in the case of these small waves in the presence of little other agitation-as, e.g., of tidal or other currents. When the wind is off-shore there is probably a slight shoreward undertow assisting, as to which I shall have more to say. Apart from this, 


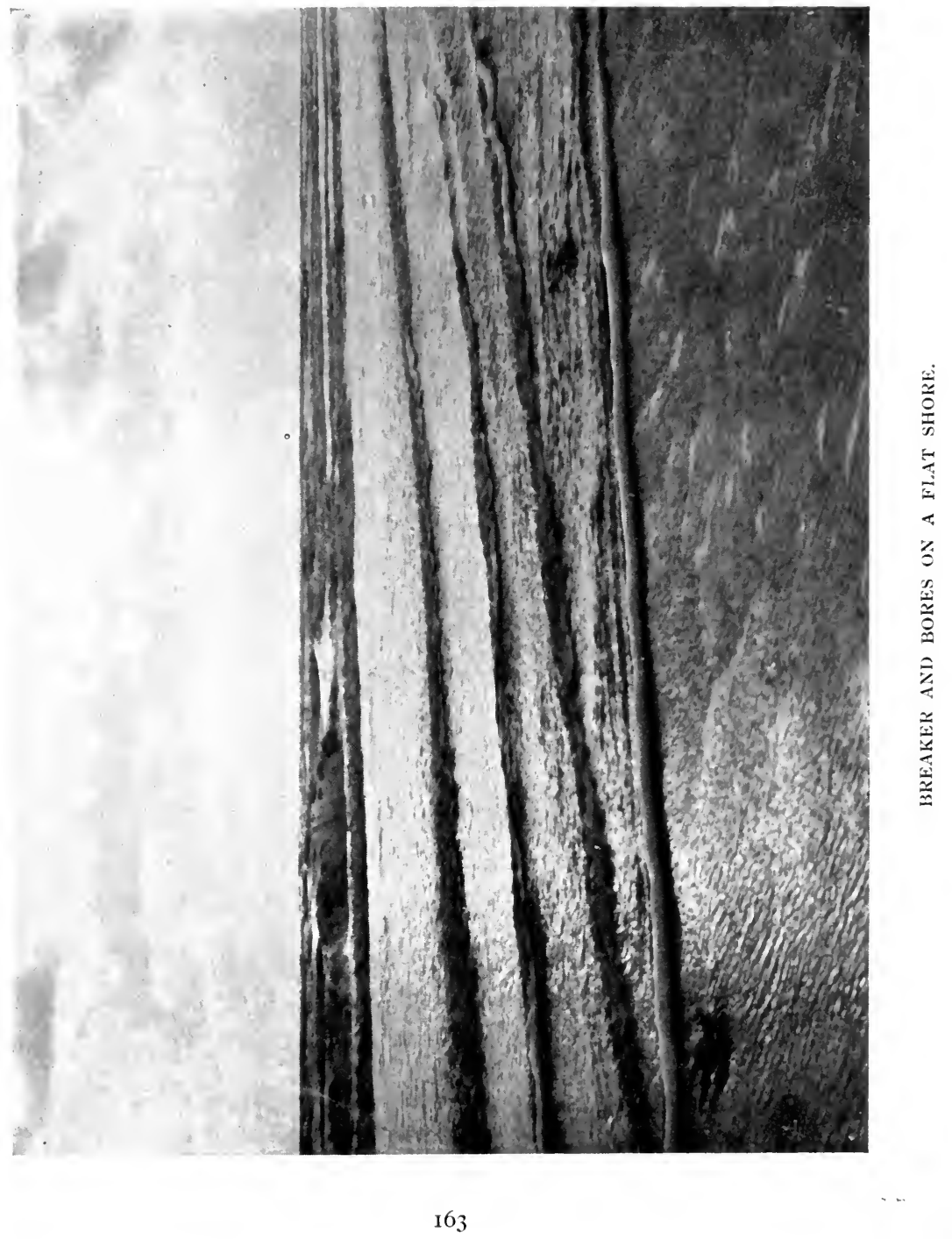




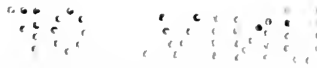

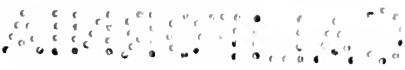




\section{AND OTHER WATER WAVES 165}

however, the mere action of a small swell from the offing appears to bring the sand in here when the slope of the shore has been reduced almost to nothing. The shoreward action does not then cease with the breaker; for the waves, breaking far out, produce another kind of wave, the bore, a wave of permanent form with a precipitous foaming front. There is always a procession of these in advance of the breaker-line, and they thin themselves from less and less to nothing as they advance to the shore. Sand-ripples over which they pass (when not wholly obliterated) are no longer symmetrical, but face shorewards, and, presumably, travel shorewards. The action of these waves upon quickly subsiding material is predominantly shorewards, being an exaggeration of that already described for waves about to break.

After a time of fair weather, a moderately sloping foreshore and a beach of clean sand is once more formed here, and equilibrium is re-established for such weather, the slope being a measure of the excess of shoreward over seaward action proper to the waves.

All this process which I have described differs, however, but little from that already specified for shingle, and the reader will naturally be more inquisitive as to the explanation of the reversal of this in prolonged rough weather. 
An important part of the explanation is in the seaward currents generated during such weather, with which I shall have to deal presently, and for the moment I will only specify that part of the mechanism of removal which is due to the waves considered as merely oscillating-i.e., without any resultant current. When the sea is very rough the agitation of the bottom-water is so violent that the sand cannot settle. It must be remembered that wherever there is a swirl of water with an upward velocity of even as little as 2 inches per second the sand cannot sink. Thus, as may be readily perceived by the eye, the rough water becomes turbid with the sand, as if the sand were so much mud, and the mechanism of shoreward transport of quickly subsiding particles no longer applies. The sand behaves, in fact, more like mud or dust, and (even if there were no seaward undertow or other seaward currents) it would tend to shift to deeper water where the bottom agitation is not too great to allow it to settle.

\section{On the Undertow}

At Branksome Chine there is a typical sandy shore of moderate slope, which is not exposed to strong tidal currents. The exposure is southerly, and there is a headland a few miles to the westward. 


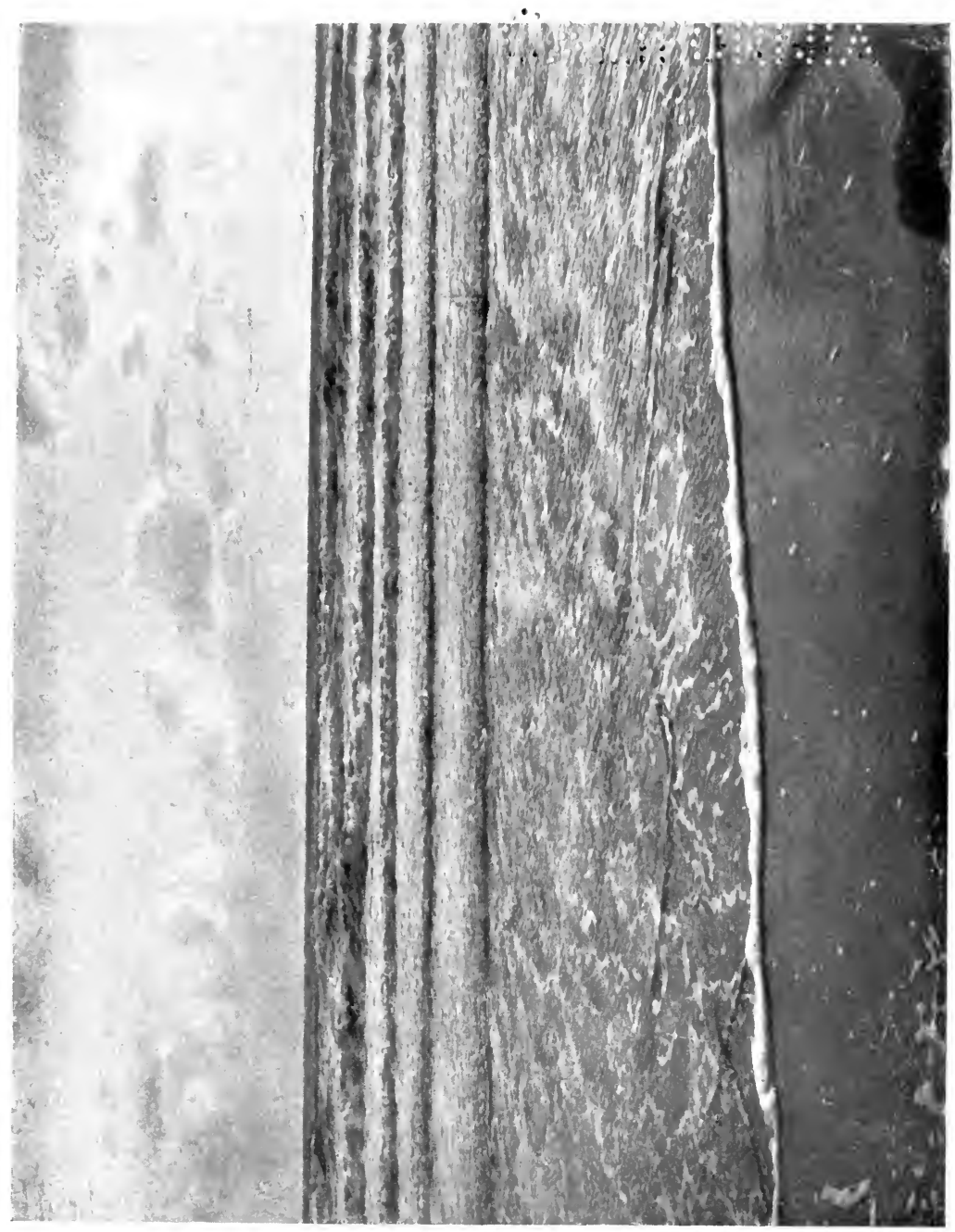

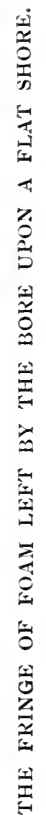




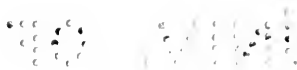

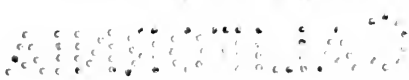




\section{AND OTHER WATER W AVES 169}

Thus in an ordinary, cyclonic storm, advancing from the Atlantic, the principal waves, rounding Old Harry Rocks to the westward, come in directly upon the shore with a south-westerly wind more or less behind them. In the clearingt weather which generally, follows, with north-westerly wind, the waves generated at a distance continue to advance upon the shore, but the wind is now against them, and spray is often torn from the crest of the breaker and driven seawards. Under these different conditions the position of the breakers is quite different. In the first case-i.e., with strong on-shore windthere is more than one line of breakers, but even the final line is situated far from the shore, and between it and the beach there is a somewhat numerous series of bores, or roll waves.

When, on the other hand, the wind is off-shore, with a rough sea in the offing, waves do not break until they come quite close to the beach. The breakers, moreover, curl over in a well-formed cusp and occasion a loud report. This noise is apparently due to the escape of the air which has been momentarily imprisoned when the cusp has curled over upon the front of the wave. Although they come so close to the shore before breaking, their height, reckoned above the antecedent trough, is sometimes as great as that of the breaking waves 
during the previous on-shore wind. I found that when the water was but little above my knees the crest of the wave about to break close by was considerably above my head, showing that the wave remained unbroken when the depth of water immediately in front was considerably less than the height of the wave from trough to crest. In a rough sea with on-shore wind the cusped breaking waves were formed much beyond the limit of a man's depth. These waves not only broke farther out, but also when the cusp was not perfectly formed. The upper part of the crest folded itself down upon the front face, becoming a mass of seething water, and the wave then travelled on as a bore with its head of froth. The motion in the frothing head was violently shorewards, and it was impossible to swim in it.

Many measurements have been made by engineers to determine the depth of water in which waves break. Very roughly the general result may be expressed by saying that the depth of water (reckoned from the undisturbed sea-level) is equal to the height of the crest above the trough. I shall not pause to discuss the somewhat unsatisfactory mode of expression, the point I wish to bring out being that the more those measurements have multiplied the clearer it has become that the 


\section{AND OTHER WATER WAVES 171}

ratio is not even approximately constant. It is quite different, not only for shores of different slopes, but also for a given shore it is quite different during on-shore and off-shore wind respectively. Thus Colonel D. D. Gaillard, U.S.A., found $\mathrm{I}$ that with a given locality and a given slope a wave broke in a depth of water equal to $1 \frac{1}{4}$ times its height when there was a strong wind blowing shorewards, while with an equally strong wind blowing off-shore the wave remained unbroken until the depth of the water was only $\frac{3}{4}$ of its height.

When there was no wind and the breakers were due solely to the ocean swell the wave broke in a depth of water equal to the height of the crest above the trough when the slope was $I$ in Ioo, but when the slope was $I$ in 12 the wave broke when the depth was more than twice the wave height.

The breaking of a wave is, of course, due to the water near the surface in the crest of the wave moving much more quickly forward than the water immediately below it. This condition must be reached sooner or later when ordinary waves from the deep sea advance in the continually shallowing water caused by a sloping bottom. On the

I "Wave Action in Relation to Engineering Structures," Washington, I904, Chapter VII. 
steeply sloping shore of a shingle beach at the highest level of the tide we can at any time see that strong rushes of water are poured back in a shallow sheet to the foot of the breakers. It is not difficult to understand that the effect on the bottom water just beyond the breaker of this strong intermittent current will be to diminish the velocity of the bottom current under the crests and increase the seaward velocity of the current under the troughs.

The more the shoreward bottom current is checked under the crests, the deeper will be the water in which the wave will break.

It is well established that wind at sea causes a current which is strong at the surface, but of which the intensity decreases rapidly with depth. Thus, quite apart from any slight translation of water which may be theoretically deduced for trochoidal waves, there is a surface drift in a storm at sea which has the following effect upon the oscillations of a particle of water at the surface, viz., at the end of each complete oscillation it has advanced in the direction of the wave when the wave is running before the wind. Thus, in an on-shore gale there is a surface drift, which takes place in jerks, towards the shore, and this goes on as long: as the gale endures. But the level of the 


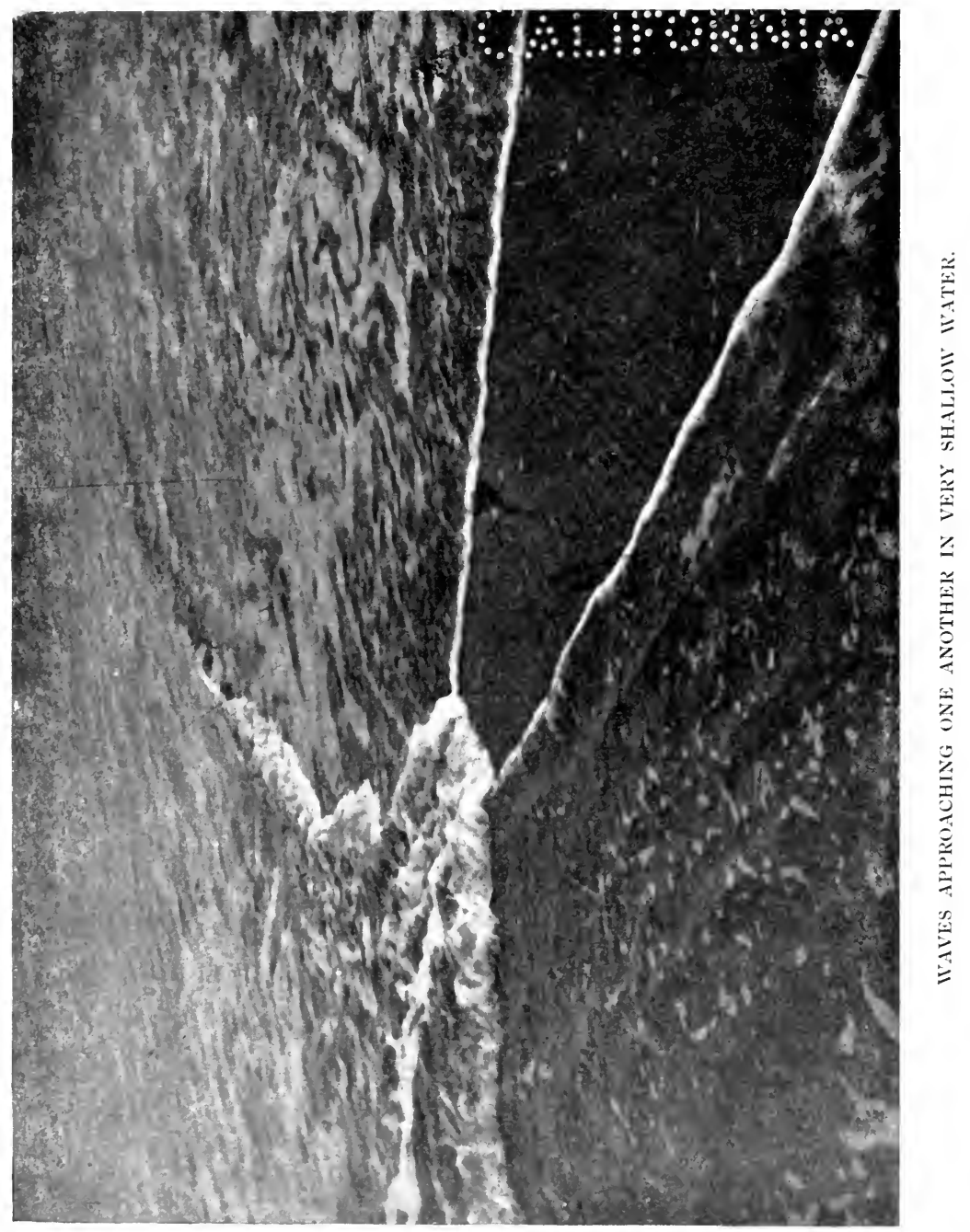




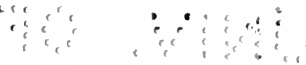

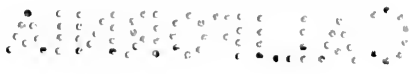




\section{AND OTHER WATER WAVES 175}

water does not rise proportionately to the amount driven shoreward, for a head of water accumulates which in time prevents a further rise. The surface drift, indeed, continues, but the undertow is increased, so that the amount of water receding from the shore is equal to that approaching it. In the case of a prolonged storm when the wind blows into a bay and there is a steep beach, it seems. quite possible that the undertow may be so strong that the bottom current is continuously seaward, although it would, no doubt, be jerky, the seaward motion being checked as each wave-crest passes. These are the conditions under which even shingle may travel seawards from the foot of the breaker.

If, however, there be no terminating cliff or seawall, so much of the shingle as is only reached by the extreme wash of the water discharged from the breaker will, I think, still be driven shoreward, owing to the effect of percolation.

That off-shore wind produces up-welling of water against a coast-line has been proved on the large scale by observations of temperature and salinity, and it follows that there must then be a sort of shoreward undertow. Its intensity must be much less than that of seaward undertow during on-shore winds, but it doubtless increases the normal shoreward action of the waves. 


\section{CHAPTER VI}

On the actions which determine the 'longshore transport of beach shingle-On the causes which give rise to an arrangement of pebbles according to their sizes along the Chesil Beach and certain other beaches-On the production and maintenance of the Shambles sand-bank near PortlandThe formation of patches of shingle upon a sandy beach by the action of breakers.

On the Actions which Determine the 'Longshore Transport of Beach Shingle

WHEN the sea is smooth, the shingle of our beaches lies undisturbed by the tidal currents. The 'longshore drift of beach shingle is therefore ultimately due to the wash of the breakers, and in order to judge of the effect of the tidal currents upon 'longshore drift, we have to consider how the motion of this wash-water is affected by them. Where the shingle beach is on a straight line of coast where the tidal current runs strongly past the shore while a fairly heavy surf is breaking, the appearances presented to the spectator on the shore are deceptive. The breakers discharging at right angles to the shore are noisy and conspicuous; the 


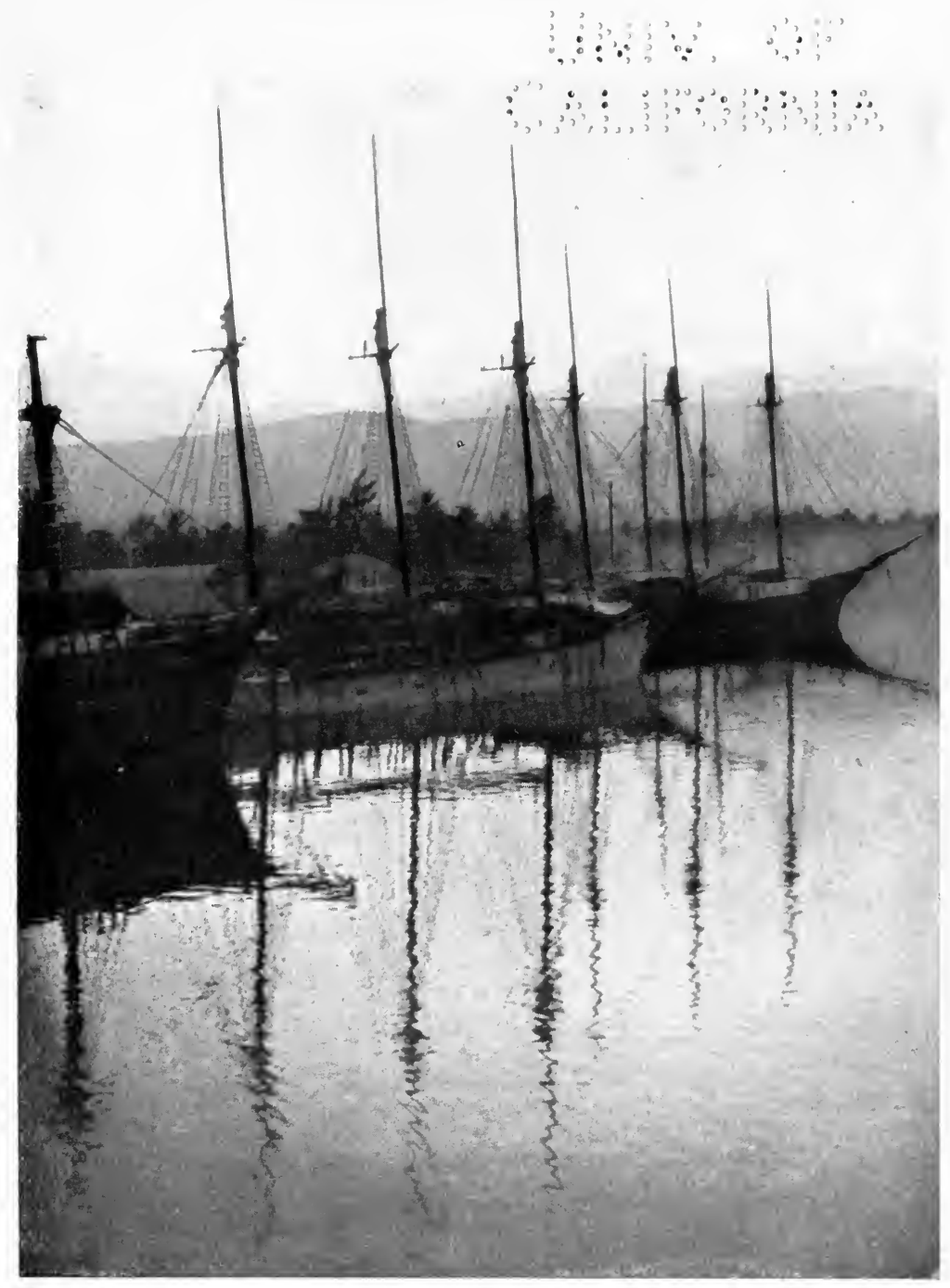

WAVES SHOWN BY DISTORTED REFLECTION OF MASTS (KINGSTON, JAMAICA). 


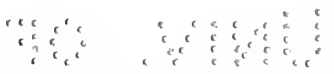

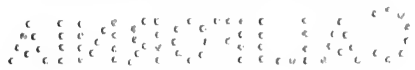




\section{AND OTHER WATER WAVES 179}

steady current parallel to the shore is silent and invisible. Yet all the water of the sea has this lateral drift, including the wash-water of the breaker. The motion of the stones which it then carries is not simply up and down, but a zigzag, the general direction of which is that of the current's motion.

Where small beaches are formed on the shores of torrential rivers, small progressive waves charge in upon them ; but here the current is more conspicuous than the wave, and I have then observed ripples in coarse sand facing the shore and impelled by the waves, whilst the coarse sand grains could be seen to travel much faster in the direction of the current than in that of the wave.

.When, at sea, the wind is obliquely on-shore there is not only a 'longshore current, producing the effect explained above, but waves also break obliquely. Their effect to drive shingle along the shore is then obvious to the eye. On a gently sloping sandy beach the waves running directly before the wind cross the swell coming in from the offing. Just at the breaker-line they combine with the swell and cause it to break sooner than it otherwise would. Thus a number of short, oblique breakers are produced where the crests coincide, and these drive sand along the shore. 
On a steeply sloping beach obliquely breaking waves are even more common and conspicuous. It is scarcely necessary to insist upon the fact that 'longshore drift due to wind will depend upon the length of fetch of the wind as well as upon its velocity, since large waves are only produced by the action of wind upon a long stretch of water.

The effect of the tides to determine the 'longshore drift of beach shingle by waves is, on the other hand, a complex matter, and it is of the highest importance that the general principles governing this effect should be definitely laid down. I will endeavour to do this for our own coasts.

Twice a day a current flows from the Atlantic Ocean into our narrow seas, and produces a rise of water-level there. Wherever the tide runs freely the currents follow the same rule as the forward and backward currents of the ordinary wind-waves of the sea, viz., when above the mean sea-level they are forward; when below mean sea-level, they are backward.

Thus, wherever the tide runs freely along a coast - e.g., on a straight shore or past a headlandthe current is what we may call up-channel during the whole time that the water is above mean sealevel. This means eastwards for the English 


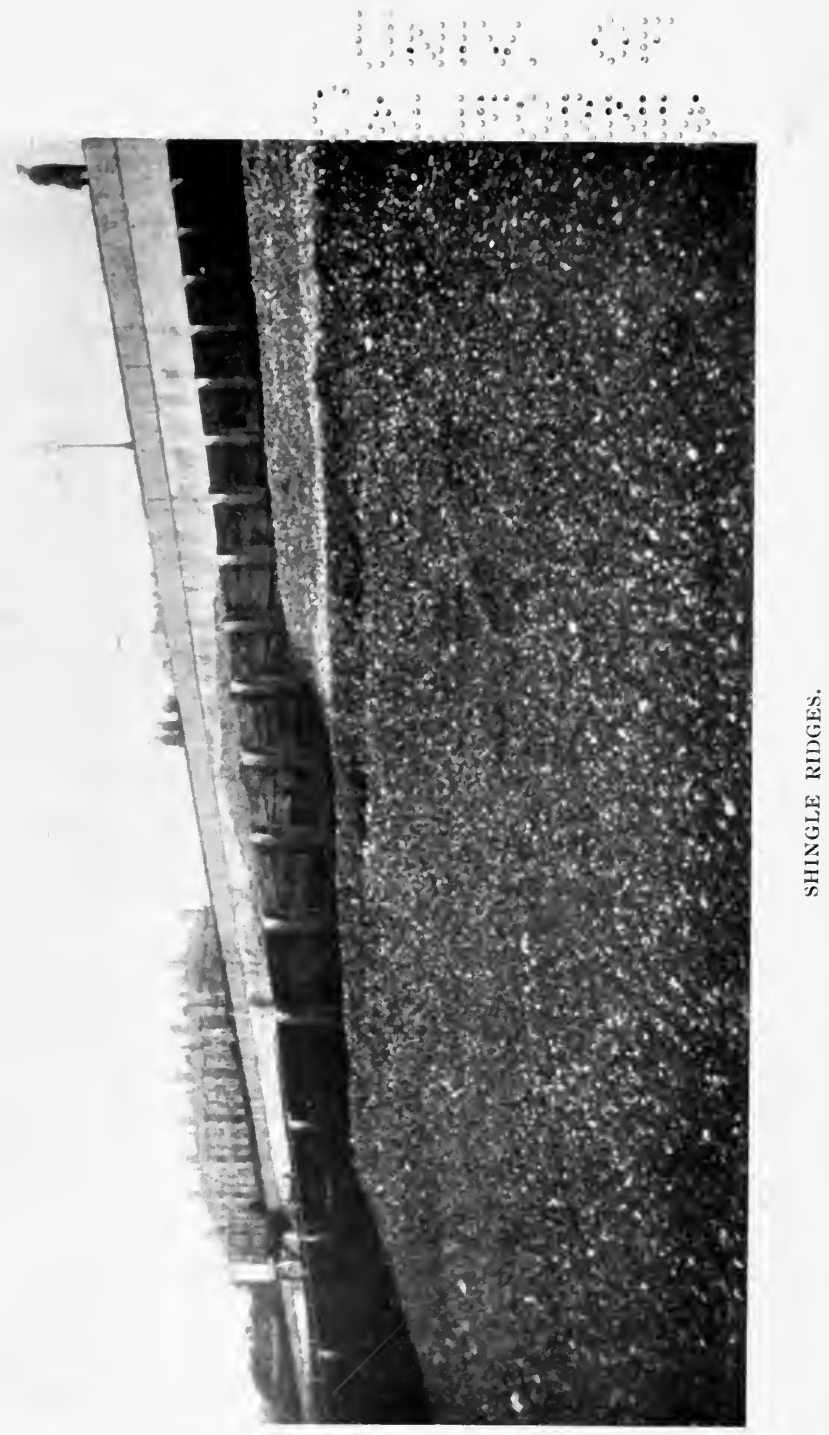


“光

$\therefore$ 


\section{AND OTHER WATER WAVES 183}

Channel. Now, wherever there is much shingle it accumulates mostly near the highest level reached by the wash from the breakers. In such situations, therefore, most of the shingle is out of reach of breakers during the outflowing current of the tide. Moreover, for the same roughness in the offing, the breakers are very much smaller when the water is below mean sea-level, on account of the gentler slope of this part of the beach. Thus it is evident that for straight coast and for headlands the effect of the tides (apart altogether from the wind-currents and from oblique waves) is to cause the waves to transport shingle predominantly in the direction of the inflowing current, or up-channel. The predominance should be most marked in the case of the larger shingle. This predominance is independent of any excess of speed of the inflow. current. Where the tide is impeded, the course of affairs is somewhat different. Thus, at the head of a bay or inlet, or where, at a nodal point, tidal currents from opposite directions have met, a " head" of water accumulates which stems the inflowing tidal current and causes the outflow to commence sooner than it otherwise would. The extreme case is that in which the outflow commences immediately the highest level is reached. In this case it is possible for the average water- 
level during the outflowing current to be the same as that during the inflowing current, so that the resulting 'longshore transport by waves running dead on shore may be nil, their effect during outflowing tide being equal and contrary to that during inflowing tide. Leaving out of account for the present the exceptional and rare positions where tidal nodes occur, we see from the above that the combined action of tides and onshore waves is to sweep shingle rapidly up-channel from all salient positions. In bays, the transport will be, on the whole, up-channel, but much more slowly, on account of the inflow and outflow currents of the tide occurring at more nearly equal levels. Thus, removal of shingle from headlands and accumulation in bays would still be general even if there were no co-operating causes, such as oblique waves and stronger currents.

Dr. Owens and Mr. Case, in their valuable book on " Coast Erosion and Foreshore Protection," have already called attention to the importance of the relation between the times of commencement of flood and ebb currents and the times of high and low water in connection with the littoral drift, and have cited the case of Southwold, Suffolk, where the upper part of the foreshore is only exposed to the flood current. I have worked out as above 


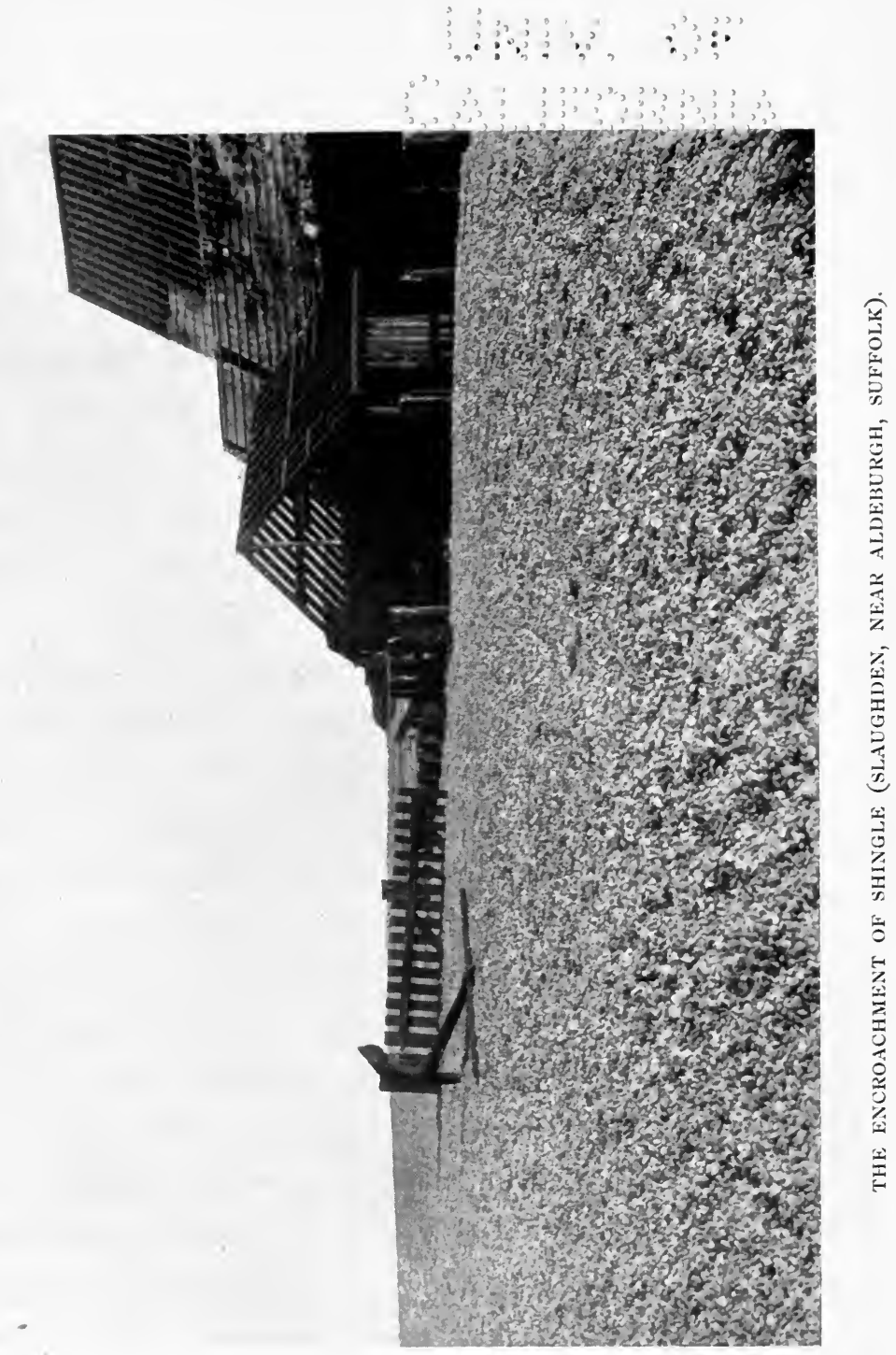




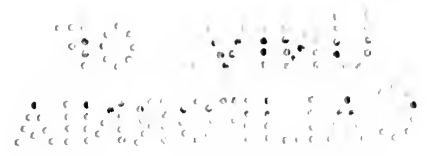

t 
the general law governing the application of their valuable suggestion.

In the case of our south coasts the general direction of the inflowing tidal current coincides with that of the greatest length of fetch and the strongest winds. Hence the effect of the above principle has been to a great extent overlooked there. Similarly, on our east coast the direction of the inflowing current is the same as the direction of the greatest length of fetch.

There is, however, one part of our coast which appears particularly suited to demonstrate the importance of the principle of high-level inflow: as contrasted with low-level outflow of tide as a controlling factor in the longshore transport of shingle. This is the coast of Cumberland, as to which the following evidence was given to the Coast Erosion Commission, ${ }^{\mathrm{x}}$ viz., that the current of the inflowing tide is from north to south, the prevailing wind from the south-west, and the travel of beach material from north to south as far as Morecambe Bay. Even if the bare statement that the prevailing wind is south-west should need some qualification, there is no question that the prevailing westerly winds, combined with the greater length of fetch to south-west, would produce the largest waves from that quarter.

× By Mr. G.IA. Abernethy, M.I.C.E. 
Here, therefore, we have a case in which the circumstances appear to show the operation of the high level of the inflowing tidal current to be predominant against the other factors of 'longshore transport.

With regard to the velocities attained by the tidal currents on our coasts, I am not aware that it is possible to declare that those during the inflowing tidal current are, on the whole, either greater or less than those of the outflowing tide, although it would probably not be difficult to cite local cases on both sides.

There remains a peculiarity of the inflowing tidal current, or part of it, which presumably assists in the transport of shingle. This has been pointed out by Mr. W. H. Wheeler, who says that the flood tide comes along in wavelets of its own making, whereas the waters of the ebb tide are essentially calm.

I have on one or two occasions noticed the effect in a narrow channel and on tidal rivers during the inflowing current. I do not know if it lasts during the whole period of the inflowing current, or if it only continues while the level of the water is rising. I do not think we have proofs as yet that the amount of transport due to this cause is considerable. 


\section{AND OTHER WATER WAVES 189}

On the Causes which give rise to an Arrangement of Pebbles according to their Size along the Chesil Beach and certain other Beaches

When considering on and off-shore action of waves, we have seen that a sorting of materials takes place. It is assisted by the seaward slope of the shore. In the arrangement of pebbles along a shore there is no such gravitational assistance in sorting, except such as is given after the arrangement is effected-e.g., by the greater steepness of a coarser beach. The origin of a longitudinal arrangement of pebbles on a tidal shore is therefore to be sought in the 'longshore action of the wash from the breakers during all the phases of the tide.

The effect of the action of the waves to determine the size of the shingle is, of course, best studied upon those parts of the shore where the beach is not supplied with new stones by wastage of cliffs at the back of the beach, or by a torrent entering the sea. In beaches replenished by 'longshore drift the replenishing material consists mainly of stones not easily broken into smaller fragments. The approximate permanence of such a beach, as a whole, is apt to mislead the observer into supposing the rate of 'longshore travel of individual 
stones to be much less than it really is. Mr. Nelson B. Richardson and I arranged an experiment upon the rate of travel of materials of which he has given a full account. ${ }^{1}$

On the beach opposite Fleet Coastguard Station, in a slight breeze from NNW., with breakers 2 feet high, and a current running eastwards at I foot per second, a brickbat, or half-brick, travelled 56 yards in $2 \frac{1}{4}$ hours. Supposing this wind to remain constant, the shingle would not travel westwards even when the current is running to the west. Therefore, allowing six hours out of every twelve for the east-running current, which is less than what it is, the brickbat would then travel from Bridport Harbour to Chesilton ( 18 miles) in 108 days. Given strong wind from the westwards, the time of transit would be very much less. Another brickbat travelled 574 yards to the eastward in 28 hours, which would make the time of travelling the 18 miles 142 days during fine weather. A stone, 4 inches long, which was caught by a wave, appeared to move more quickly than either of the brickbats; but even if the stones were moved somewhat more slowly than the brick-

I "An Experiment on the Movements of a Load of Brickbats deposited on the Chesil Beach," by Nelson B. Richardson, B.A. (Proceedings of the Dorset Field Club, vol. xxiii., 1902). 


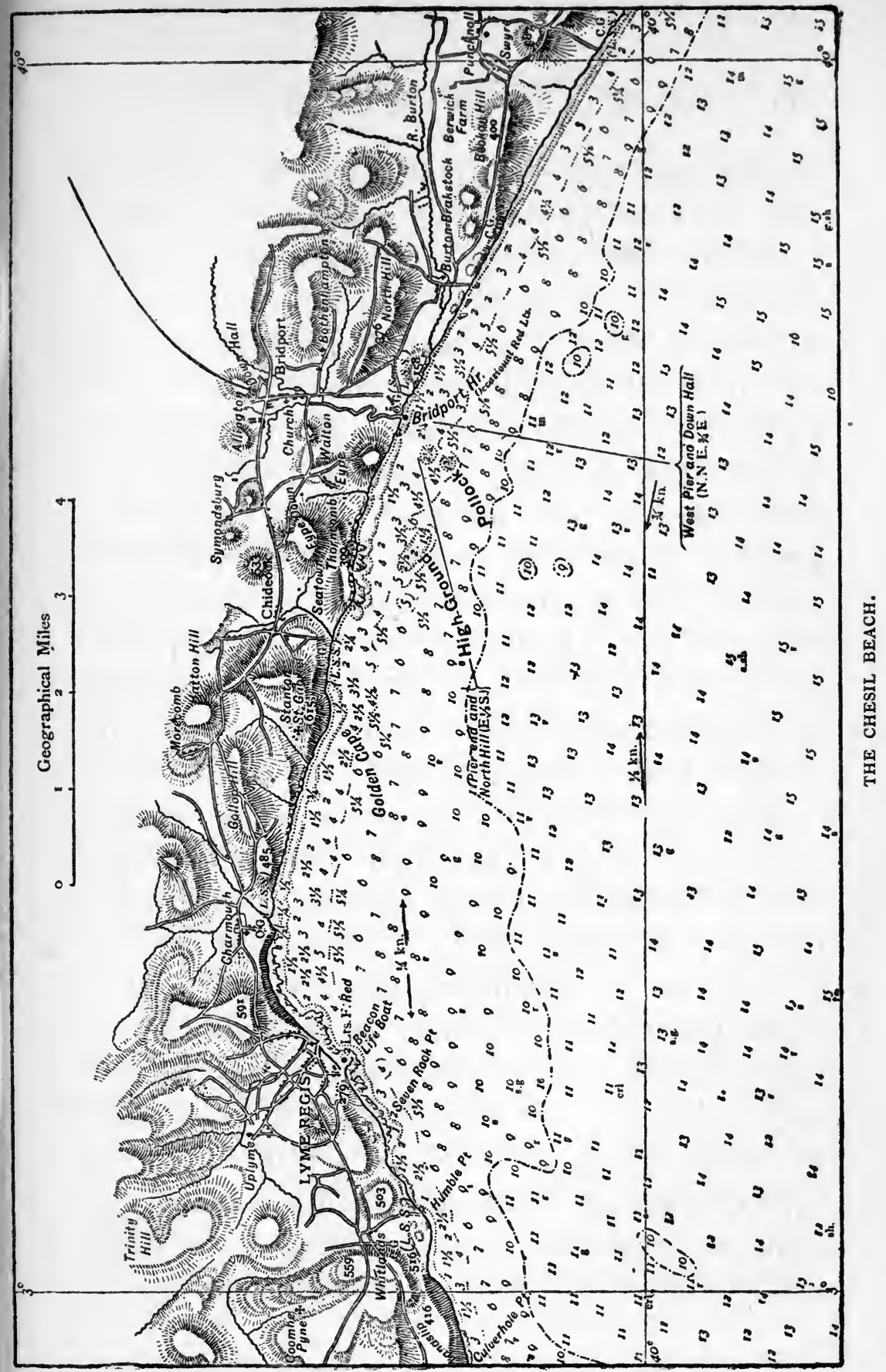


bats, yet the observation of the latter shows that with the ordinarily prevailing westerly winds a stone may travel from Bridport Harbour to Chesilton in a time to be reckoned in days, weeks, or months, and not in decades or centuries. When dealing with the arrangement by sizes of worn beach pebbles, we should therefore seek an explanation in the rapid shifting of the material and not in its relatively slow attrition. Thus I found the average weight of a pebble at Chesilton to be I $2.8 \mathrm{oz}$., and at Burton Bradstock, I 6 miles away, .028 oz.-i.e., 457 times smaller. Prestwich explained this difference of size on the supposition that the pebbles travelled from Chesilton towards Burton (and Bridport), and in transit were reduced from the size seen at the former to that seen at the latter place. Apart from the circumstance that all the known agencies are to make the principal travel in the opposite direction, let us see what his supposition would involve. It is useful to consider it because of its possible misapplication to other causes where it may be less easy to disprove. In the first place, it would mean an extraordinarily short life for a pebble. In the second place, it would involve the presence all along the beach of an enormous proportion of sharp. shingle-chips. My own observations lead me to 


\section{AND O'THER WATER WAVES 193}

think that the reduction in the size of pebbles is accomplished mainly by fracture. Although the principal pebble has its fractured surface rapidly smoothed and rounded, the sharpness of the chips tells the true tale. It is the same with wind-borne sands-the larger grains are the best rounded. If comminution really proceeded mainly by rubbing down, it would be the smaller particles which would be the best rounded.

I was fortunately able to observe on the Chesil Beach, in July, I 897, a part of the wave action by which the sorting of shingle is accomplished. I was on the beach opposite Chickerell when there was a light easterly wind, and the small breakers made by it were depleting the steep face of the beach. A glance at the map shows that wind from the east has a small length of fetch, and that the waves it makes cannot be very large anywhere on the beach, and, near Chesilton, must always be very small. The tide was falling at the time of my observation, and the shingle in the band of wet stones exposed above the waves was coarser than that out of their reach. It was evident that the backwash was removing the smaller pebbles and drifting them westwards, leaving the larger in their place.

The secret of the gradation of shingle upon beaches sheltered at one end from large waves 
is that whilst both large and small pebbles travel in the one direction before the big waves which come with great length of fetch, only the small pebbles are driven back by the small waves which come from the small length of fetch.

I took samples of the shingle all the way along the Chesil Beach in July, I 897 (see plate), and the following table shows their weights:

\begin{tabular}{|c|c|c|c|}
\hline Locality. & $\begin{array}{c}\text { Miles } \\
\text { from } \\
\text { Bridport } \\
\text { Harbour. }\end{array}$ & $\begin{array}{l}\text { Av. Weight } \\
\text { of a Pebble } \\
\text { in oz. }\end{array}$ & $\begin{array}{l}\text { Reference to } \\
\text { Photograph of Portions } \\
\text { of the Samples }\end{array}$ \\
\hline Cliff End, Burton Bradstock & 2 & $\cdot 028$ & $\begin{array}{l}\text { Group of stones } \\
\text { on left. }\end{array}$ \\
\hline Opposite Coastguard Station, & & & \\
\hline Puncknowll $\quad \ldots \quad \ldots$ & 5 & $\cdot 067$ & $\begin{array}{l}\text { Second from } \\
\text { left. }\end{array}$ \\
\hline 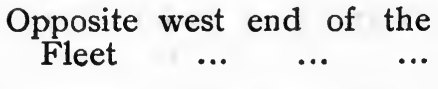 & 8 & 'III & Third from left. \\
\hline $\begin{array}{c}\text { Opposite Coastguard Station, } \\
\text { Langton Herring }\end{array}$ & II & •294 & Fourth from left. \\
\hline $\begin{array}{c}\text { Opposite Coastguard Station, } \\
\text { Chickerell... } \quad \ldots \quad \ldots\end{array}$ & I3 & 342 & Fifth from left. \\
\hline Opposite "Passage" & I6 & 783 & Sixth from left. \\
\hline $\begin{array}{l}200 \text { yards west of the Chisel- } \\
\text { ton end of the beach }\end{array}$ & 18 & $12 \cdot 800$ & Last on right. \\
\hline
\end{tabular}

As we go eastward for the first 16 miles, the weight of the pebbles is doubled every 2 miles, 


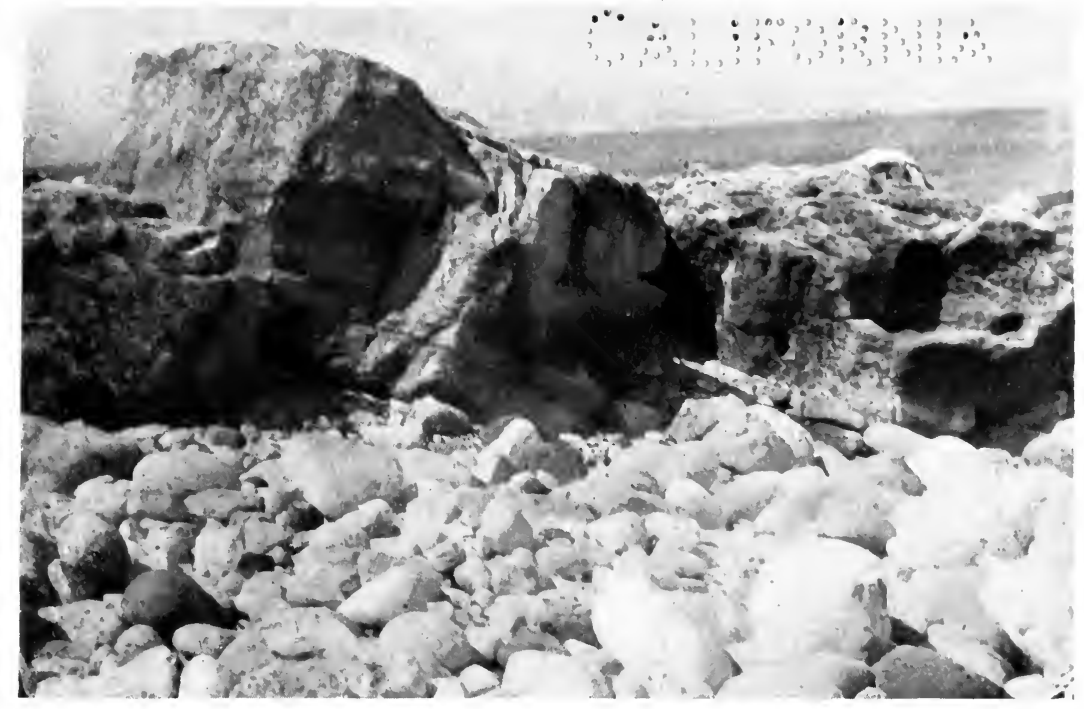

SHORE BETWEEN EAST END OF CHESIL BEACH AND BLACKNOR POINT.
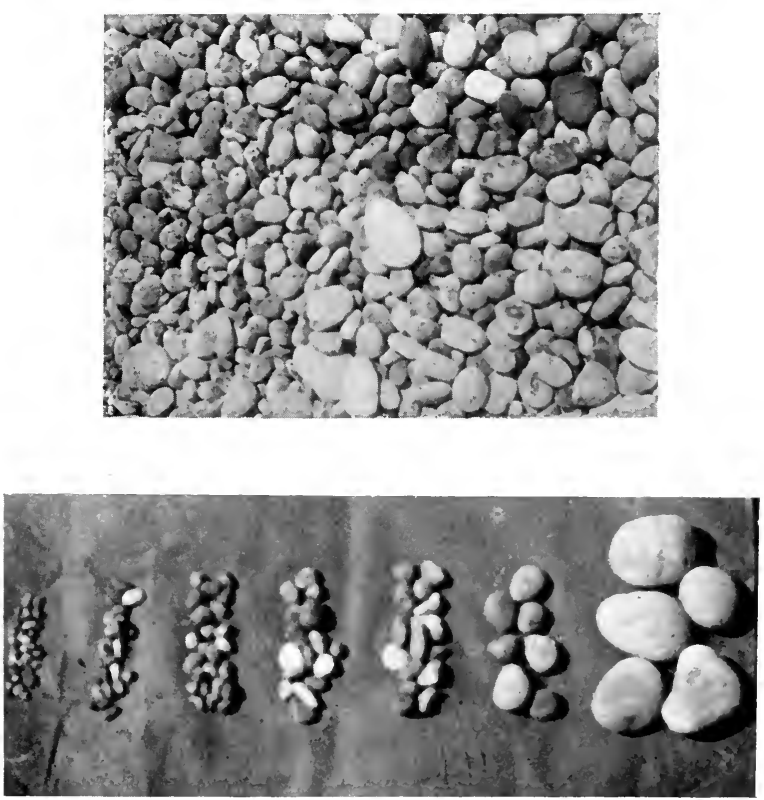

STONES ON THE BEACH NEAR CHESILTON AND THE GRADATION OF STONES FROM BURTON BRADSTOCK TO CHESILTON. 


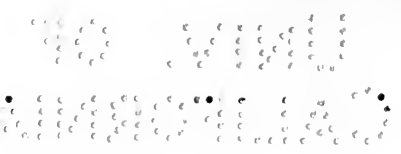


but in the last 2 miles it is doubled every $\frac{1}{4}$-mile.

Most of the beach is, in fact, composed of small shingle, but close under the eastern shelter of Portland Bill the shingle is large. At the Chesilton end the beach receives new material from the steep shore of Portland. It mostly consists of large stones of the Portland stone, which is derived partly from the waste of the steep shore but not a little largely from the foot of the tips of the stone from the great quarries on the summit. It is the larger fragments chiefly which reach the foot of the tips. A glance at the map shows that large waves can travel towards Chesilton, not only from the direction of Bridport Harbour, but from the direction of Portland Bill. I found many very large pebbles of Portland stone on the beach at and near Chesilton, which must have been driven there from the coast of the promontory by these large waves. But an examination of length of fetch on the map. shows at once that there can be no large waves to drive these great pebbles far along the beach to the westward. At Chesilton, or Chesil Cove, the direction of the shore changes through nearly a right angle. The corner is open directly to the south-west. The Cove is a focus towards which large breakers can and do come in winds from 
north-west to, say, south-by-west, and it is a pocket into which, if a large pebble be driven, it cannot escape in either direction.

Finally, we must not omit to notice the cooperation of the tides with the eastward drift along this beach. High water on days of full and new moon occurs at about $5 \frac{1}{2}$ hours at the Bill of Portland. But there is a strong outsetting current from the West Bay for 9 hours out of every 12, viz., from 2 hours to I I hours on the days of full and new moon. This comprises all the time when the water is above mean sea-level. Thus, even such waves as do run westward along the beach (especially near Chesilton) either have the tidal current against them or else are only beating against the lower part of the beach, where much of the shingle is out of their reach.

Before leaving the interesting subject of the arrangement of beach shingle, I will give some particulars of my, observations between Lyme and Bridport Harbour. Looking at the map, and at a map of the South Coast of England, we see that Lyme Bay is the largest bay on that coast, and that the sudden change in direction of the coast so as to face the south-west occurs, not at Bridport Harbour, but at Charmouth. It occurred to me, therefore, that Bridport Harbour was not the 


\section{AND OTHER WATER WAVES 199}

proper place from which to commence the study of the great accumulation of shingle, and I decided to supplement my observations by a visit to the shore between Lyme and Bridport Harbour. I went in a boat, rowing close under the shore, and landing from time to time. I found that the accumulation of beach material began at Charmouth. From thence to Golden Cap the size of the shingle and the height of the beach increase. Golden Cap is only slightly a promontory at high water, but there is a considerable ledge projecting above lowwater mark, so that on the whole its effect as a groyne is considerable. Eastward of Golden Cap there is a curved beach as far as the promontory of Thorncombe Beacon, which again is prolonged by a ledge of rocks above low-water mark. On this piece of coast we see again the increase of height of beach and size of shingle in the angle under the west side of the promontory. Close under the east side of the promontory the sea reached the cliffs at high water, ${ }^{\prime}$ but at low water there was exposed a firm bed of particles of the size of very coarse sand. This bed of material

r The same effect is seen on the lee side of groynes which have been built up to the highest reach of the waves, and erosion results. The groyne should be low enough to allow shingle to be washed freely over its shoreward end so that the foreshore on the lee side may be kept covered and protected. 
consisted of sharp angular fragments with cutting edges, as different in shape from the sand-grains of a sandy shore as from the large rounded pebbles on the west side of the promontory. The conclusion is obvious that they were the chips from the attrition of the large pebbles on the west side, which are banged against each other by the breakers at high tide. If the current be then running eastwards, as the general information on the chart indicates, there would be a strong undertow from this position with a horizontal circulation of water on the east of the promontory. Here, except in easterly winds (which are not prevalent during most of the year), the water is smooth and the chips deposit. A true beach, where the sea does not usually reach the land at high tide, begins again at Eype mouth with very small shingle. There is no natural promontory between here and Portland, but the solid western pier of Bridport Harbour has 14 feet of water against it at high water of spring tides, and projects nearly to lowwater mark. Close to the western side of this artificial promontory the shingle becomes much larger, whilst on the east side of the harbour it is again quite small. This is the situation usually. reckoned as the beginning of Chesil Beach, and from here to Chesilton the shingle gets coarser 


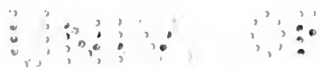
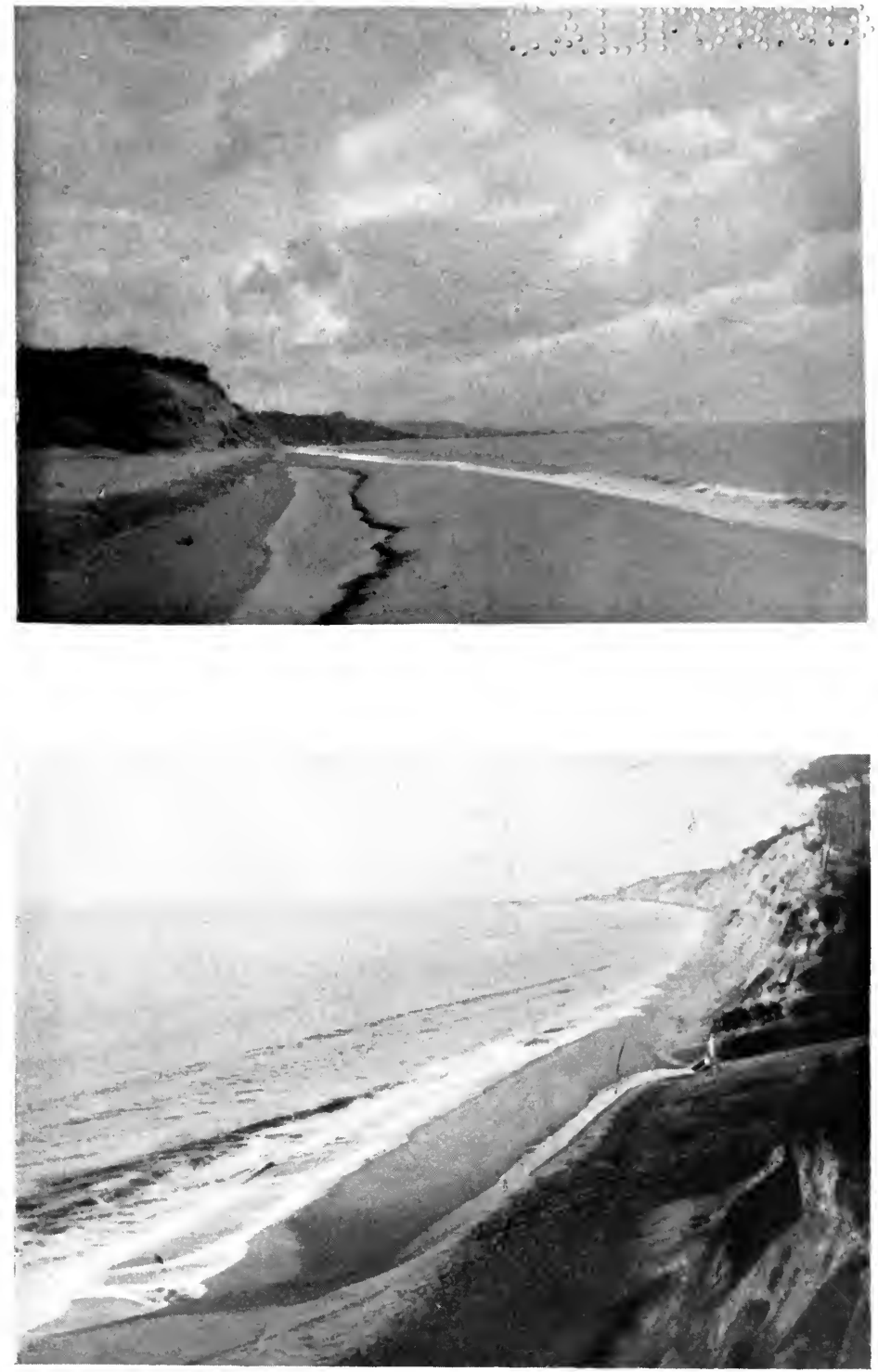

SAND BROUGHT BACK AFTER A STORI AND SAND DRIFTED ALONGSHORE. 201 


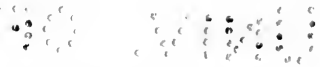

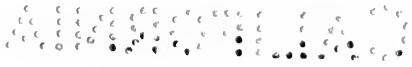




\section{AND O'THER WA'TER WAVES 203}

and the height of the beach greater. The increase in the size of the shingle, however, is for most of the way a very gradual process, becoming rapid only when near the shelter of the Portland promontory.

Thus I found that wherever there was shelter from the east there was a pocket filled by a high beach composed of large shingle. The arrangement is therefore due to the normal sorting action by the waves, in which the local tides happen to assist.

I have shown why the large stones collect at Chesilton, but I must add a word on the probable mode of removal from the steep shore in that agitated corner, of the large quantity of small angular fragments which are mixed up with the boulders between the end of the true Chesil Beach and Blacknor Point. There is little trace of them on the beach at Chesilton, and the bottom off there is a good holding anchorage of clay. A strong undertow setting towards Portland is a matter of local knowledge, and Captain King's " Pilot's Handbook for the English Channel" furnishes detailed information on the subject of the outsetting current. It runs for 9 hours out of every 12 (so long does it take to relieve by a narrow stream the water from the broad bay which has piled up in the Chesilton corner), and closely skirts the rocky shore, gradu- 
ally increasing in strength as it approaches the Bill, where it has acquired such velocity as to extend far beyond that point before it turns to the east. This tide out of the west bay acquires its greatest velocity when the tidal stream in this part of the English Channel is running to the eastward. While, therefore, the large shingle is driven to the focus of the waves at Chesilton, the smallest shingle, the sand, and chips are presumably removed by the undertow. What becomes of some of the material so removed is suggested in the section relating to the Shambles Shoal.

Marked gradation in size of shingle is a characteristic of beaches sheltered at one end by a natural or artificial groyne. I have not heard of conspicuous cases of such gradation on long beaches with a nearly uniform exposure-such, e.g., as that at Aldeburgh in Suffolk. This being so, my explanation of the grading as due to one-sided shelter would probably have found readier acceptance but for the attractions of a previous suggestion by Sir John Coode. He noticed that a large pebble isolated on a surface of small shingle was rolled about by the wash of the waves even when this travelled over the interlocked smaller pebbles without disturbing them. He said that large stones would travel quickly along the Chesil Beach from 
the westwards until they reached a bed of pebbles of the large size, when they interlock and cease to travel readily; and this, in his opinion, explained the accumulation of large stones at Chesilton. The observation, as far as a horizontal current of shallow water is concerned, is correct. It is a mode of motion readily seen in fine weather, and with water of a depth of $I$ or 2 inches. It is a mistake to suppose that what is then seen is a measure of the relative mobility of large and small shingle in really rough weather, and nearer the position where the wave breaks. Here, with a depth of many inches, or a foot or two, and with strong upward swirls, it is less easy to see the motion of individual stones, but there is no doubt that the smaller, loosened from their interlocking and lightened by the upward current, are driven about much more freely than the large stones. It is under such circumstances that most of the movement of shingle takes place.

What, however, I particularly wish to point out about Sir John Coode's theory of the Chesil Beach is not so much the partial truth of the observation as the logical error of supposing it to be an explanation of the origin of the observed grading. The logical error is this, that in order that the stones shall travel in the required manner we have 
to suppose the stones already arranged according to size along the beach. In other words, the results of the process must be already appreciable before it can commence to operate.

The most that can be claimed, therefore, would be that the process tends to preserve an arrangement already achieved by other means, and the considerations already advanced as to the action of upward currents in stormy weather show that even for this purpose the process is probably much less effective than observation in fine weather would lead one to suppose.

\section{On the Production and Maintenance of the Shambles Sand-bank near Portland}

The great heap of sand called "the Shambles" is similar in shape and situation to the banner cloud which is formed in the eddy of air on the lee side of an Alpine peak. The Bill of Portland, projecting outwards into the currents of the English Channel, corresponds to the mountain peak projecting upwards into the currents of the air. If the promontory of Portland were removed, the Shambles sand-bank would be washed away. If, on the other hand, the sand-bank were removed by dredging, the promontory of Portland remain- 


\section{AND O'THER WA'TER WAVES 207}

ing, I think it is very probable that a sand-bank would re-form in the same position.

When a small vessel is taken through the race on Portland Ledge during somewhat rough weather the decks are covered with sand deposited
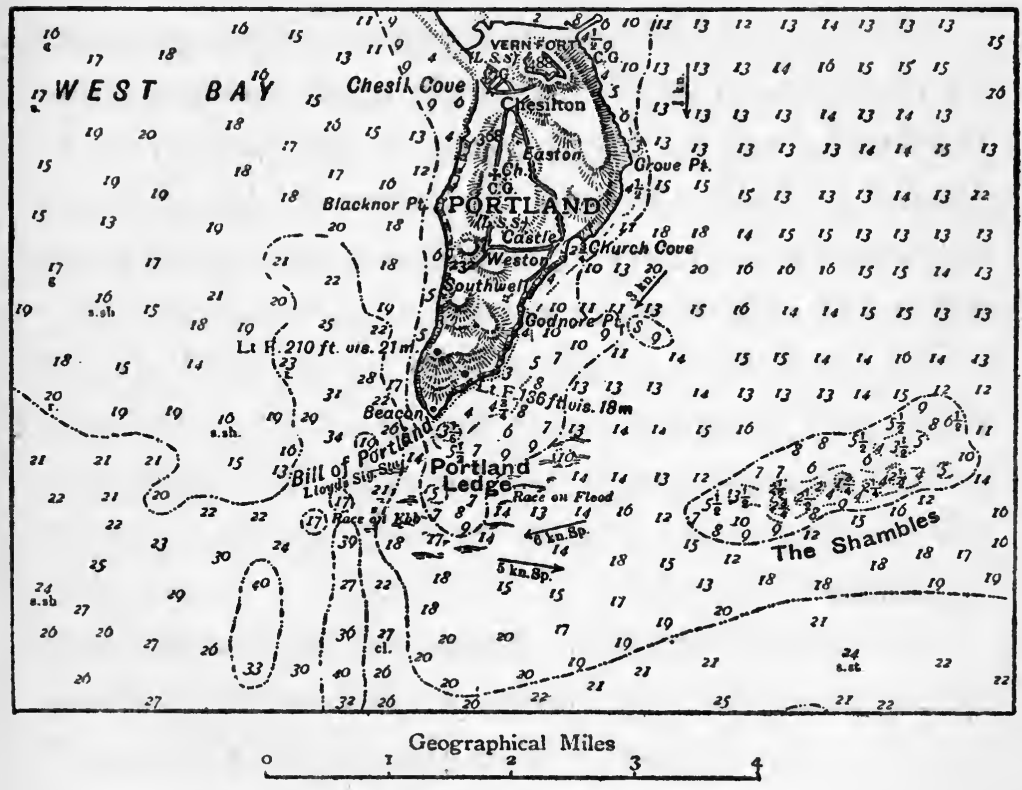

CHART SHOWING THE SHAMBLES SHOAL.

from the water which splashes over her. I have already shown that it is probable that the 9-hour outset from the West Bay removes shingle chips and sand from the Chesil Beach and the Portland cliffs, and I suppose the Shambles shoal to be 
maintained by this and other detritus settling from suspension in the repeated horizontal circulation of water eddying round a vertical axis on the east side of Portland.

The course of the currents is as follows: 1 The outset from the West Bay from 2 hours to I I hours on the days of full and new moon, having assumed its eastern course, rushes with great violence over Portland Ledge. High water at the Bill occurs at about $5 \frac{1}{2}$ hours $\mathrm{F}$. and $\mathrm{C}$. (i.e., on the days of full and new moon). At 6 hours 20 minutes this stream is met at right angles a short distance east of the ledge by a strong stream from East Portland Bay. This stream lasts for $9 \frac{1}{2}$ hours. "These united streams press on towards the Shambles, which they cross about east by north, running $3 \frac{3}{4}$ knots."

The bank, which is composed of coarse sand and gravel, rises suddenly on the south from the depth of $\mathrm{I}$ o fathoms. The approach on the north is more gradual. The streams run across the shoal at 3 to 4 knots during spring tides, and waves break heavily upon it. The surface is strongly. rippled, and the ridges are in motion even in fine weather. The shoal does not persist, there-

I See "The Pilot's Handbook for the English Channel," by Commander J. W. King, R.N., twelfth edition, 1893 . 
Outiet. from West Bay.
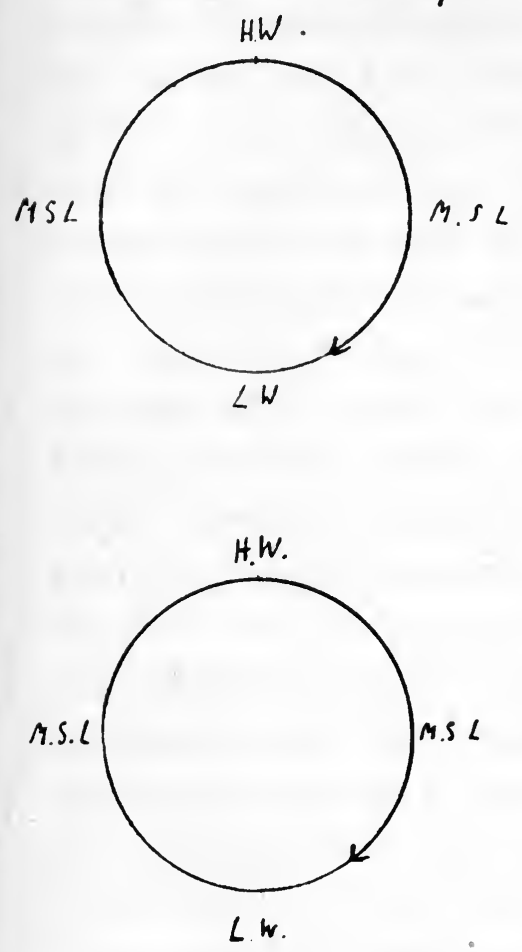

Goot-rumning Stieam af. Shanbles.
Outset from sat Bay.

. W. W.

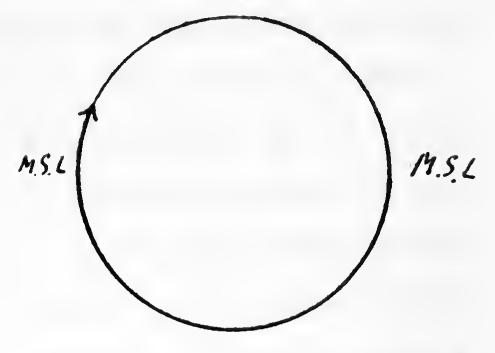

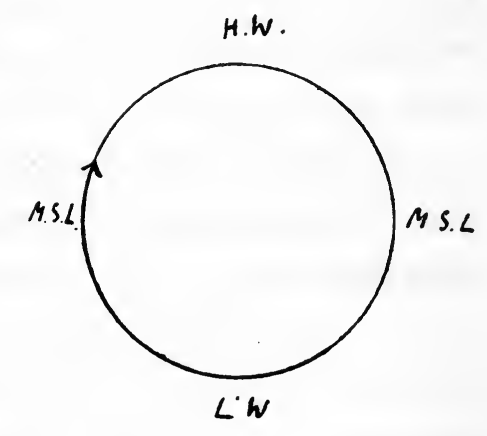

West-rumning Stream at Shanbles.

RELATION OF THE VERTICAL AND HORIZONTAL COMPONENTS OF THE TIDE NEAR PORTLAND. 
fore, on account of its enjoying shelter from disturbance. I suppose its maintenance to be due to horizontal circulation caused by meeting of two currents at right angles, this repetition of path giving time for the somewhat slow rate of subsidence of sand to take effect. High water at the Bill occurs in the middle of the 9 hours' outset from the West Bay, and less than an hour afterwards occurs the meeting at right angles with the outset on the east side of the Bill. Thus the presumed rotation is set up at the time of greatest wave action on the Chesil Beach, when the outset from the West Bay must be most heavily charged with sediment.

The outset from the East Bay of Portland presumably contributes sediment to the Shambles when the main tidal current is setting to the eastward. The tidal current sets westward at the Shambles at about I I hours F. and C.-i.e., about the time of low water and at the time of cessation of the outset from West Bay. The outset from the East Bay is then running, and continues to do so for another 5 hours-i.e., until 4 hours $\mathrm{F}$. and $\mathrm{C}$. That no shoal corresponding to the Shambles is formed by the west-flowing current on the west side of Portland Bill is to be ascribed largely to the lower water-level and consequent lesser wave action on the shores. 


\section{AND OTHER WATER WAVES 211}

In this connection the position of the Skerries Bank, north-east of Start Point, should be compared with that of the Shambles. Portland Bill terminates, on the eastern side, the largest bay, on our south coast. Start Point similarly terminates the second largest bay. On the up-channel side of each is a sand-bank, which, from its situation, and from the absence of a corresponding bank on the west of the promontory, suggests rather the continuous current of a river than the alternating currents of the tides. Of all the causes which produce this curious arrangement the relation of the time of turn of the tidal stream to the turn of the tidal level is, perhaps, the most important and the most likely to escape notice.

The accompanying diagrams show the relation between the times of the vertical and horizontal oscillations of the tide at Portland Bill.

The Formation of Patches of Shingle upon a Sandy Beach by the Action of Breakers

The surface of the beach at Branksome Chine is usually pure sand, but many stones derived from the wasting of the gravelly cliffs are buried beneath it. Under certain conditions the wash of the breakers begins to convert the sandy to a shingly 
beach, and the action often proceeds as far as the formation of isolated patches of shingle.

The occasion upon which I saw the process proceeding best was during a heavy swell succeeding a storm, when the wash of the breakers carried the sand away in suspension. The shingle remaining behind became concentrated in the mannerillustrated by the photographs. The plate facing p. 2 i 4 , from a photograph, taken on a later occasion, and about 4 miles farther east, shows more distinctly the characteristic wedge-shape of the isolated patches of shingle. If the process were to continue, these patches would coalesce into a single ridge of shingle. This sorting action of the waves is at once taken advantage of by builders or others requiring shingle, carts being sent to remove it before the smaller waves and offshore winds have again smothered it with sand. 

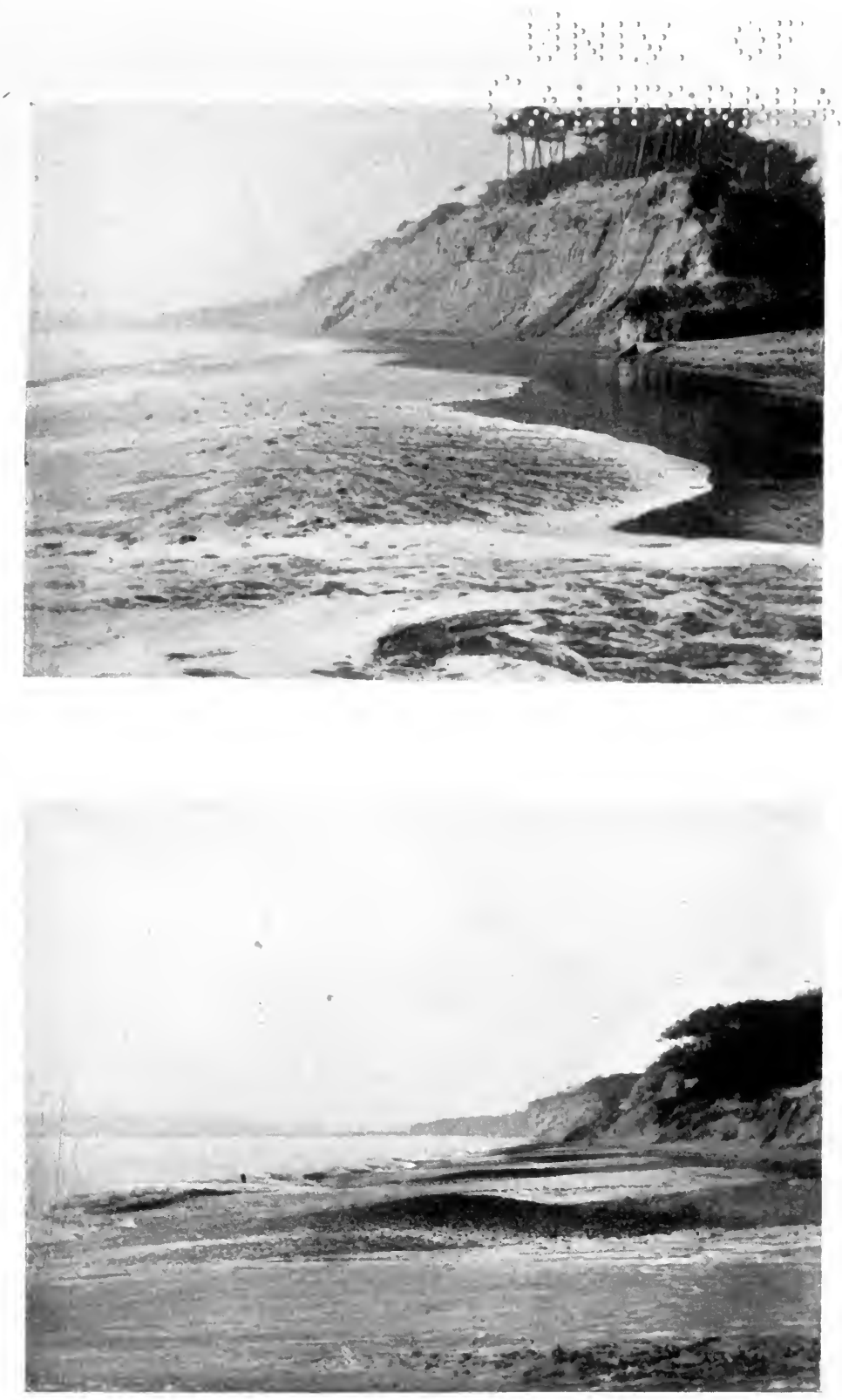

SHINGLE SORTED FRON SAND BY THE WASH OF A HEAVY SWELL (BRANKSOME CHINE, NEAR BOURNEMOUTH). 


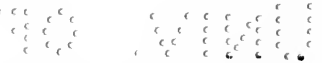

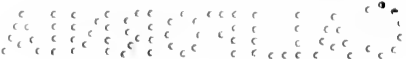




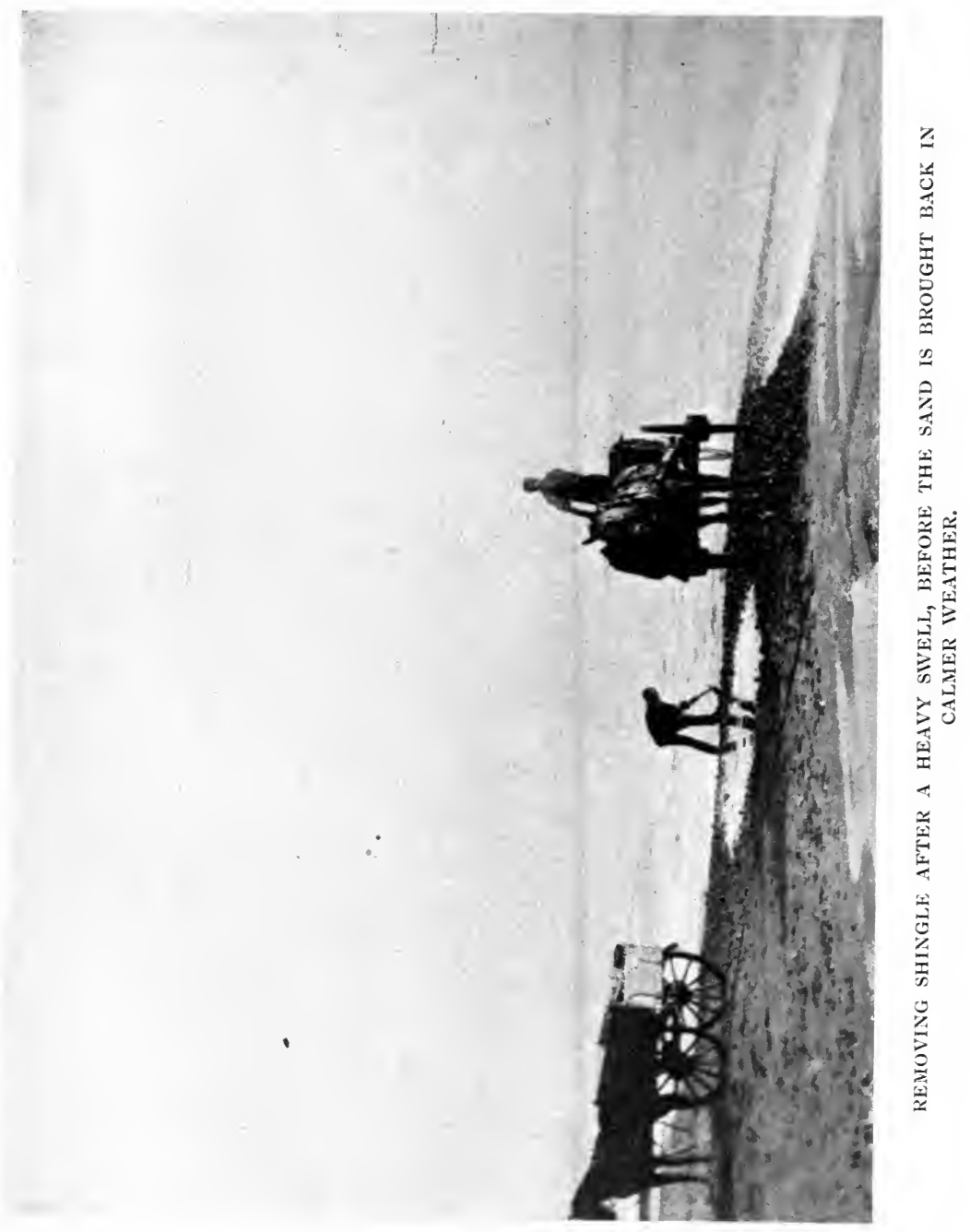




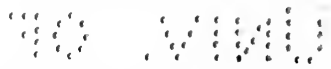

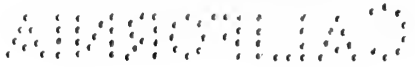




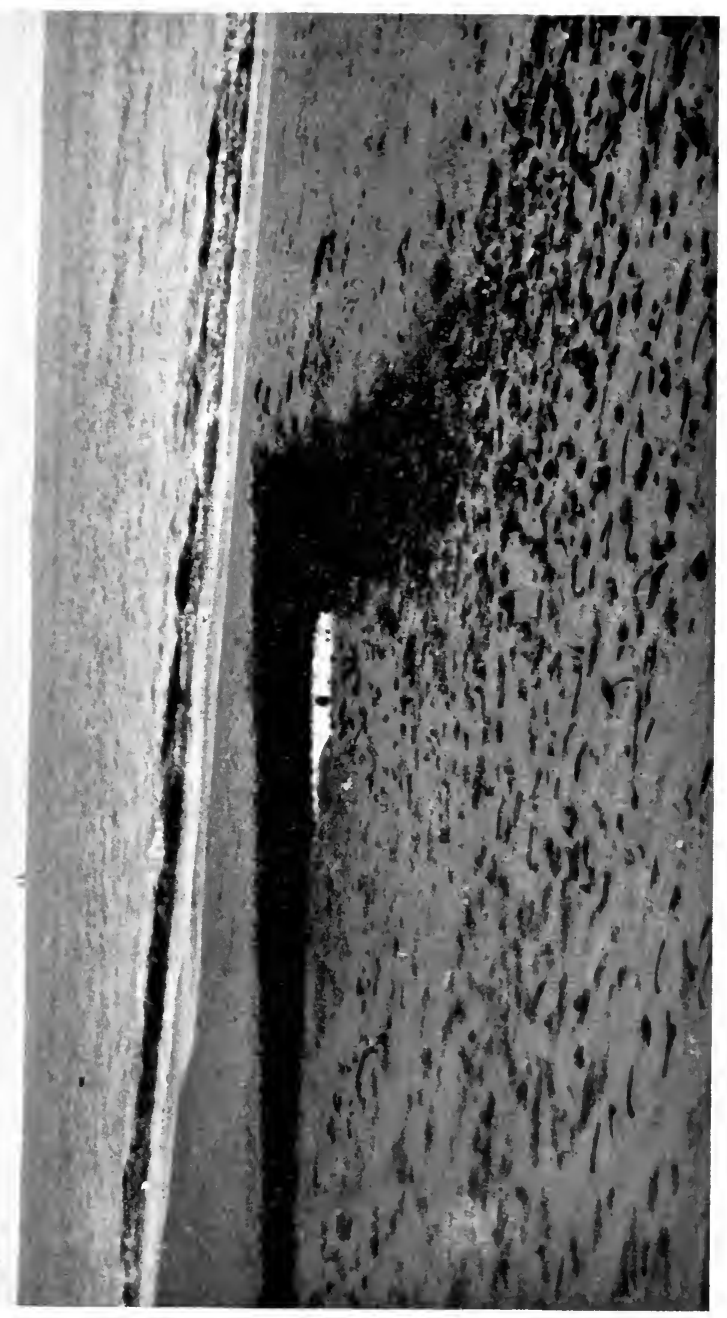

年

䌉

分

옹

武 잉

结

'

్ㅗㄴ

3

率 


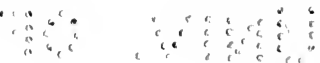

a 


\section{PART III}

ON STATIONARY AND PROGRESSIVE WAVES IN RIVERS 



\section{CHAPTER VII}

The flood-wave of rivers-The roll-wave in the Tees-In the Ure-In the Nikko torrent-On the advance of a flood over dry ground.

\section{On the Flood-waves of Rivers}

A PROGRESSIVE wave is not an obvious phenomenon in ordinary river floods; nevertheless, a careful consideration of the matter shows that wave-transmission is an important factor in the disposal of the flood-water of a river. Let us take the case of a river receiving an accession of water from a suddenly swollen tributary. The threatened congestion of water is avoided by wave-transmission down the main stream. The length of the wedge of newly added water is sufficient to originate a "long" wave, and the wavevelocity down-stream is therefore the greatest that is compatible with the depth, viz., the velocity, which a body would acquire if falling in vacuo, under the action of gravity, through a height equal to one-half the depth of the stream. If the calcu- 
lated velocity of a "long" wave in different depths of water be compared with the observed velocities of current in large rivers, it will be seen at once that the wave-velocities are many times greater than the velocities of the currents. Thus the floodwater obtains room for itself, not so much by rushing forward as by causing the waters for a long way in front to lift or swell slightly. The transmission of pressure through the current is so rapid that there is (except under special circumstances, to be described later) no visible wave, but the river lower down is found to be rising long before the arrival of the floating and suspended matter which accompanies the arrival of the actual waters of the flooded tributary. The speed at which this wave-transmission of the flood progresses down the channel is equal to :

Velocity of current plus velocity of "long" wave.

In the case, however, of a shrunken river flowing through alluvial soil the rate of advance of the " first rise" of water after a drought may be much diminished by the absorption of water by the porous ground over which the river has to spread.

When a river increases in depth in its lower reaches, the wave-velocity increases, and the amplitude of the wave is thereby dimin- 


\section{AND O'THER WA'TER WAVES 223}

ished, and the increasing width of the river further diminishes the amplitude of the wave. Thus the very perfection of the mechanism of wave-transmission down-stream in rivers usually prevents the accumulation of a wave-face sufficiently steep to be visible. The rise of a river before the arrival of the actual flood-water which originates the rise is, moreover, less obviously wavelike in character than the rise of level in a river due to the tide, for in the former the rise is accompanied by increased velocity, just as it would be if the river were running at a steady, but higher, level. In the case of the first rise of a river due to tide, however, there is a slackening of the current.

We see, therefore, that causes commonly cooperate to mask the progressive waves due to floods in non-tidal rivers.

In the upper reaches of certain rivers, however, the sudden arrival of a wall of water, travelling down-channel at a great speed, is a normal occurrence after heavy' rain in the hills where the river and its tributaries take their rise. Thus, on the River Tees, during one summer and autumn the roll-wave, as it is called, was seen on no less than six occasions by Mr. F. R. Glyn, F.R.G.S. The following description of the phenomenon is taken 
from a letter written by Mr. Glyn to the author, January I 4, 1902:

" This river [the Tees] has its source at the foot of Crossfell, in Westmorland, and with a considerable watershed is fed by mountain streams and a number of tributaries between Middleton and Crossfell, running through the extensive moors in that district.

" One of the peculiar characteristics of this river is the roll-wave, 2 feet or 3 feet high, which suddenly, and sometimes quite unexpectedly, comes down the river, filling from bank to bank the stream, which but a minute previously had, perhaps, been at low summer level. Many lives have in consequence been lost, while I personally experienced a most unpleasant sensation some years ago. I happened to be fishing for salmon from a dry rock in the centre of the river, some few miles below Barnard Castle, when I suddenly heard a rushing noise, as if the wind had suddenly risen and caused the branches of the trees to rustle. I looked up the river and saw the roll-wave almost upon me. Before I could get to land it had washed me several yards down, and but for a side stream that, fortunately, brought me to land, I should not have been able to record the facts. As it was, I lost my salmon-rod, cap, \&c., but was most thankful for such a providential escape. 
"It is at all times a naturally rapid river, winding its way over large masses of rock and boulder, and the most accomplished swimmer would have but little chance of saving himself.

" In the neighbourhood of Barnard Castle, a few miles below that town, we generally allow seven hours for the river to come down after rain in one's locality; and such calculations are very near the mark, but, of course, occasionally after heavy thunderstorms above Middleton and otherwise the wave descends without any warning whatever to anglers and others in the lower districts. As there is sometimes an entire absence of rain locally, these sudden and sometimes unexpected spates make the Tees in summertime dangerous even to the most experienced."

The Ure is somewhat similar in general character to the Tees. At Aysgarth it is well known to lovers of the picturesque on account of the beautiful Fall, or "Force." The pavement-like rock bed of the river outcrops horizontally, and the depth of the river is fairly uniform in cross-section, although longitudinally it consists of pools and shallows. The Tees also, where I have seen it near Barnard Castle, was of uniform depth (crosswise), owing to the nature of its bed of hard and homogeneous rock. I may note in passing 
that uniformity of depth across the stream is important for the preservation of a roll-wave. In a channel with deep longitudinal grooves and shallow shores such waves would change their direction and discharge laterally upon the shelving banks.

I have received the following account of the rollwave at Aysgarth from a resident at that place:

"The Aysgarth local name for a flood was 'spate' or 'freshet.' I was one evening in the middle of the river, about Ioo yards below the lower Force, fishing, when I heard a roar above, and presently a wall of water some 2 feet or 3 feet high came dashing over the fall. I, fortunately, gained the bank in time to see it rush past me, filling the bed, rushing madly over the boulder rocks, and spoiling my fishing. The rocks here are limestone, with great fissures and pot-holes. Below the Force is the great salmon-hole, the limit of the up-rushing fish.

"Above the lower Force the stream runs in reaches over shelving limestones from the second Force. At the foot of this there is a very deep hole. . . . Succeeding this Force the water comes beneath the picturesque bridge from the beautiful upper Force, a succession of ledges, forming holes beneath." 


\section{AND OTHER WATER WAVES 227}

The arrangement of a river in alternating pools and shallows is a condition theoretically favourable to the formation of such roll-waves as are described by these observers: The wave-velocity diminishing greatly where the bottom rises at the lower end of the pool, this section at first receives far more than it can pass on, so that the wave face, instead of being of infinitesimal gradient, becomes quite steep - a "wall" of water in appearance.

On entering a pool the wave may perhaps lose this form, commonly called a bore, and become a group of rounded swells, but on entering shallow water this will close up, and the front of the disturbance will be either a cusped wave, like a wave about to break upon the shore, or a solid wedge of foaming water-the bore proper-like those beautiful foaming ridges which come in upon a flat sandy shore when the great waves of a storm are breaking far out at sea.

Roll-waves are also reported as occurring in the Rhondda and the Taff Rivers in Wales. They are frequent in the rivers among the foothills of the Himalayas. They are also recorded from time to time as the result of an exceptional and solitary cause of flood in various parts of the world. Thus, during the great typhoon in the autumn of 1902 
a landslide from Mount Nantaisan in Japan caused a sudden efflux of water from Lake Chusenzi, which, combined presumably with the torrential rain, caused a wall of water many feet high to travel down the Nikko River, doing great damage to the celebrated Thousand Statues of Buddha on the right bank. Its speed was certainly very great, judging from the account which I received from the Japanese custodian of a tea-house on the right bank, which was at once swept away. The man himself had only just time to scramble up the hillside, although the situation allowed him a clear view for a considerable distance up-stream. The high-water mark of the flood was still visible on the hillside when I visited the locality a year afterwards.

In the account which Sir Samuel Baker gives of the coming down of the waters of the Atbara (vide "The Nile Tributaries"), the bed of the river appears to have been dry except for entirely isolated pools of large extent. The occurrence was at night, and no details are given of the appearance of the actual front of the flood as it advanced over the dry bed. The advance of the floodhead in such a case is not a simple case of wave-travel to which a definite speed is allotted in the theory of long waves, dependent upon the 


\section{AND OTHER WATER WAVES 229}

depth of water, for there is no water in front of the advancing wedge. The rate of encroachment would, in the above case, be somewhat reduced by the porosity of the soil over which the flood advanced.

Colonel Gaillard, U.S.A., informs me that he once saw the wave-front of a flood advancing along the dry bed of a canyon in Arizona. He estimated the depth of water at the crest of the wave at 25 feet and the horizontal distance from the advanced foot of the wave to this crest at about 300 feet. This space presented a series of frothy ridges. Perhaps these were a series of roll-waves over-riding one another. The mechanism can be imagined from that described later for the rollwaves of the Grünnbach conduit, where the larger waves, i.e., those which have deepest water at their crests, continually overtake the smaller ones. 


\section{CHAPTER VIII}

Tidal bores-Wave-length of the Severn bore-On the want of concordance between height of tide and height of bore, and on the conditions which determine the starting-point of the bore.

\section{On Tidal Bores}

THE time during which the tide flows in a river is less than that during which it ebbs, for during the flood tide the river quickly gathers an opposing " head" of water (both on account of the slope of its bed and of the diminution of its breadth) which reverses the tidal flow, so to speak, before its time. Conversely, the form of the channel as well as the momentum of the land water, or true river water, prolong the seaward flow of the ebbing tide. If the conditions be considered at different places successively farther up the river, it will be seen that this difference increases, the duration of flood tide being less and that of ebb tide greater at places higher up than at places lower down the river. When we reach the limit of tidal influence of the river the duration of 
flood tide is, of course, zero, and ebb goes on all the time. The phenomena are too extended in a horizontal direction, and the surface gradients of the water are, for the most part, too small for the eye to see the ebb and flow of the tidal river as a wave; but in a diagram, with the vertical scale much exaggerated, showing in profile the advance of the tide up the river, it appears in the form of a travelling wave, which becomes steeper as it advances up the river. If the course of the ebb tide down the river be similarly shown on a diagram, it will be seen that the front of the wave is never so steep as the front of the flood-tide wave becomes in the upper reaches of the tidal river. This is partly because at the commencement of ebb the river is full and the water deep, instead of being at its shallowest as at the commencement of the flood.

In many tidal rivers a visible wave with a very steep front, travelling up-stream, constitutes the "first rise" of the flood tide, which is sometimes referred to by boatmen simply as the "head" of the flood, but it has also specific names, such as the "Bore" and the "Aegir" (on the Trent). This phenomenon has long been accepted in works which deal with the theory of tides as being the steep face, or the steep part of the face, of the flood- 
tide considered as a single wave, although $\mathrm{Sir}$ G. H. Darwin has pointed out that theory serves rather to explain a rapid rise than an absolutely sudden one.

In the account which I have now to give of the tidal bore, as I have seen it in the River Severn, it will be found that it seems to have a wave-length insignificant in comparison with that of the tidal wave considered as a whole.

\section{Wave-Length of the Severn Bore}

The River Severn, which is tidal up to and beyond Gloucester, pursues below this city a sinuous course, similar to that of a non-tidal river in an alluvial plain. The gradient is at first slight, and the chief peculiarity of the bed is the occurrence at several places of ledges of rock lying. across the stream, which suddenly reduce its depth. Thus the depth at ordinary low water over the "Stonebench" is 3 feet, whereas the depth in the long pool below is I o feet. Denny Rock is another shallow, which has a deep reach above it. The character of the river changes somewhat near Priding, where sand-banks begin to be prominent at low water. Between Gloucester and Priding is the best part of the river for viewing the bore, 


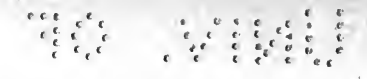

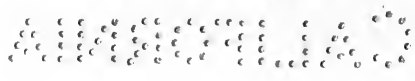


if the object be to see an imposing spectacle. The favourite spot, visited by crowds at the highest tides of spring and autumn, is Stonebench, and there are others similar to it, such as Denny. Rock. The phenomenon at Stonebench is very striking.

The wave slackens in speed when it comes to the shallowing water, increasing in height the while, and finally charges over the shoal with a rush of broken waters. I saw the phenomenon at Denny "Pill" (or Brook) on April 30, I 9oo. Here the wave, when first seen, was already in shoal water, and, at all events from my low point of sight, appeared solitary. It had a steep front, in places overfalling upon itself with foam (see Plate). As soon as it passed the place of observation it presented another appearance, viz., that of a group of smoothly-rounded waves (see Plate). Being on this occasion closely occupied with obtaining photographs, I did not observe this part of the phenomenon with undivided attention; but on a subsequent occasion (October 30, I 90 I), at Priding, I was able to observe carefully, and to photograph, a similar occurrence. The approaching bore, whatever wave disturbance may have been half-concealed behind, presented a face like the breaker of the seashore, and this was almost 
all that was noticeable from the front. But when the bore came opposite to me, the water being deeper below the part of the bank on which I stood, the steep, bold front was gone in an instant; a rounded wave or swell, followed by others of the like size and form, being immediately substituted, and the number of these swells rapidly increased, the group lengthening to leeward, so that in a few seconds I counted no less than sixteen of these large swells, ${ }^{1}$ forming a group of waves of remarkable appearance, which progressed, as a whole, with singular slowness, owing, I suppose, to the well-known circumstance that the speed of a group of waves (at least in deep water) is only half that of the individual wave. The above observation suggests important reflections upon the nature of the tidal bore. This term is by common consent employed to designate a steep-fronted wave, either overfalling or on the verge of breaking, constituting the first rise of the tide in a river or estuary. If it be actually a part of the

I These are often referred to as " ripples," but the etymology of the word indicates the propriety of restricting its use to little waves. Its use for waves of capillary size, as proposed by Lord Kelvin, may be conveniently extended in the case of other materials-e.g., sand and snow-to a small class of waves only affecting superficial strata, co-existing with larger waves capable of indefinitely great development. 


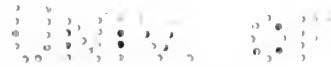

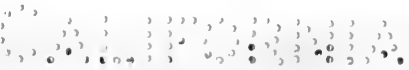
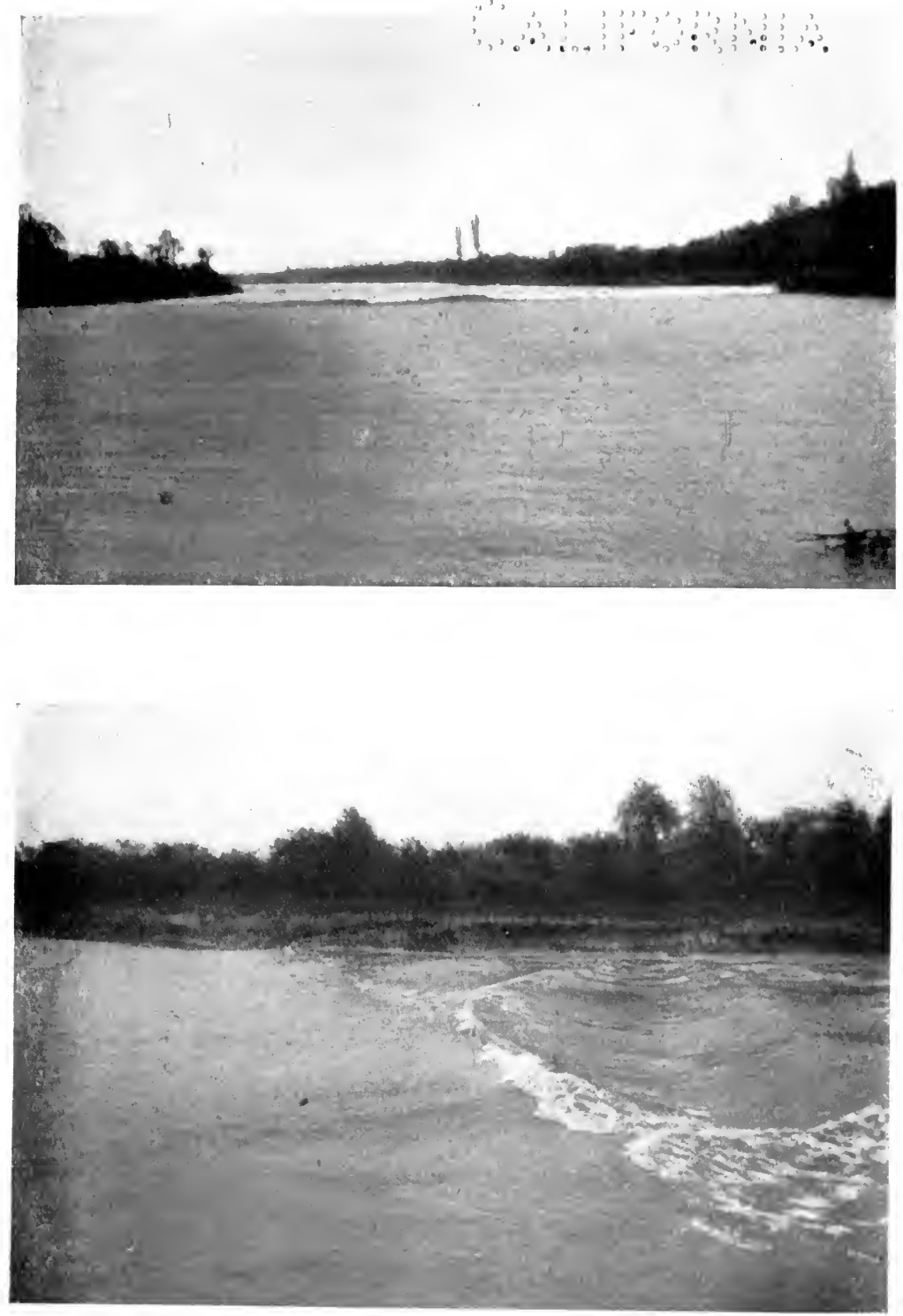

THE BORE ON THE SHALLOWS OF DENNY ROCK, AND AFTER REACHING DEEPER WATER. 


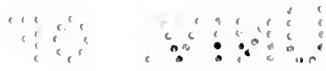

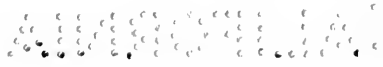




\section{AND O'THER WATER WAVES 239}

face or front slope of the whole flood tide regarded as one wave, then its length is indefinitely great as compared with the depth of the Severn at Priding, and the only change on entering slightly deeper water would be an increase of speed, accompanied by diminution of height and, perhaps, of steepness. There would be no resolution into a group of waves. It appears, on the contrary, that the greater part of the (no doubt complex) wave which was seen to approach Priding was " long," as regarded the shoal water, but " short" as regarded the deeper water.

From Priding or Framilode to Hock Crib, or Hock Cliff, as it is also called, is the last great horseshoe bend of the permanent banks of the Severn. Below Hock Cliff are the straight diverging banks, with a straight axis, which indicate the subordination of fluviatile to estuarine conditions. Already in the stretch from Framilode, past Newnham at the apex of the horseshoe bend, to Hock Cliff, we see the near approach of estuarine conditions in the rapid divergence of the banks, and in the sand-banks, dry before low water, which are here a feature of the river.

The bore at Newnham is a less imposing wave than in the narrower river from Denny to Stonebench, where the whole width of the channel is 
filled even at low water, and the bore, besides being much higher than at Newnham, reaches from bank to bank, and seems as if it would overwhelm everything in its course. Nevertheless, convenience of access, and the wide prospect of the river from the lovely Newnham churchyard, situated on a salient bluff at the bend in the river's course, combine to make this a favourite spot for viewing the approach of the bore. The first appearance of an advancing line of foaming water far down the river below Awre, at a distance of some miles, is indeed a most impressive sight.

I first saw the approaching bore from Newnham at the high tide of April 29, I 900 . Having descended to the ferry, I entered a boat and surmounted the wave just outside the projecting cliff, which makes a kind of harbour at the ferry. There was no change noticeable in the current when the boat rose to the bore, in the deep water, but after it was passed the boatman almost immediately brought the vessel to land with a few strong strokes, in order to avoid the tremendous current which quickly succeeded the passage of the wave.

The wave was not solitary, for after it passed the water flowed back from the shore, exposing many yards of tabular rocks which it had covered. It then surged up again, and during the rapid cur- 
rent above referred to the rise of level was continuous.

The second occasion on which I saw the bore from Newnham was on October 29, I901, after a summer when the river had been low owing to small rainfall, and at a time when the usual heavy. rains of autumn had not commenced. Although the tide was almost the highest of the year, the bore was a very small one. Stationing myself first in the churchyard, I noticed that the bore, which had been visible before entering the pool near Bullo, disappeared there except for some disturbance of reflection from the surface of the deep. water. I then ran down to the shore. On the shelving sand-bank which formed the left shore of the low-water channel the bore advanced as a crested wave of no great size, rolling over upon itself. As I watched this, my attention was caught by the sudden submergence of a stake near me, which I had noticed as being convenient for marking if there were any change of level before the arrival of the bore. I found, however, that the quick rise of water which covered the stake was the whole of the "bore" on this, the deeper, side of the river. There was here no steepfronted wave. Moreover, after this rise, there was a marked subsidence, so that the wave was not 
solitary. I obtained two photographs showing the level of the water when the bore was passing, and, a few seconds afterwards, during this subsidence.

On the Want of Concordance between Height of Tide and Height of Bore, and on the Conditions which Determine the Starting-point of the Bore

The capricious character of the tidal bore is one of the most interesting characteristics of this phenomenon in the Severn, and I suspect that it is capricious in other rivers also.

The disturbing cause lies in the sand-banks below Hock Cliff, and we will therefore now describe the character of the river or estuary below that point. The change which there commences is not only that which has been mentioned - the straight, diverging banks of the high-water channel, in place of winding, nearly parallel banks -but also a change of gradient. The low-water slope, which from Gloucester to Framilode is slight, becomes very steep below Hock Cliff, and continues of unusual steepness to the Sheperdine Sands. Below the Severn Bridge, which practically bounds the view down-stream from Hock Cliff, the steepness is slightly increased. Below the Sheperdine Sands to Aust the low-water gradient is again slight. 

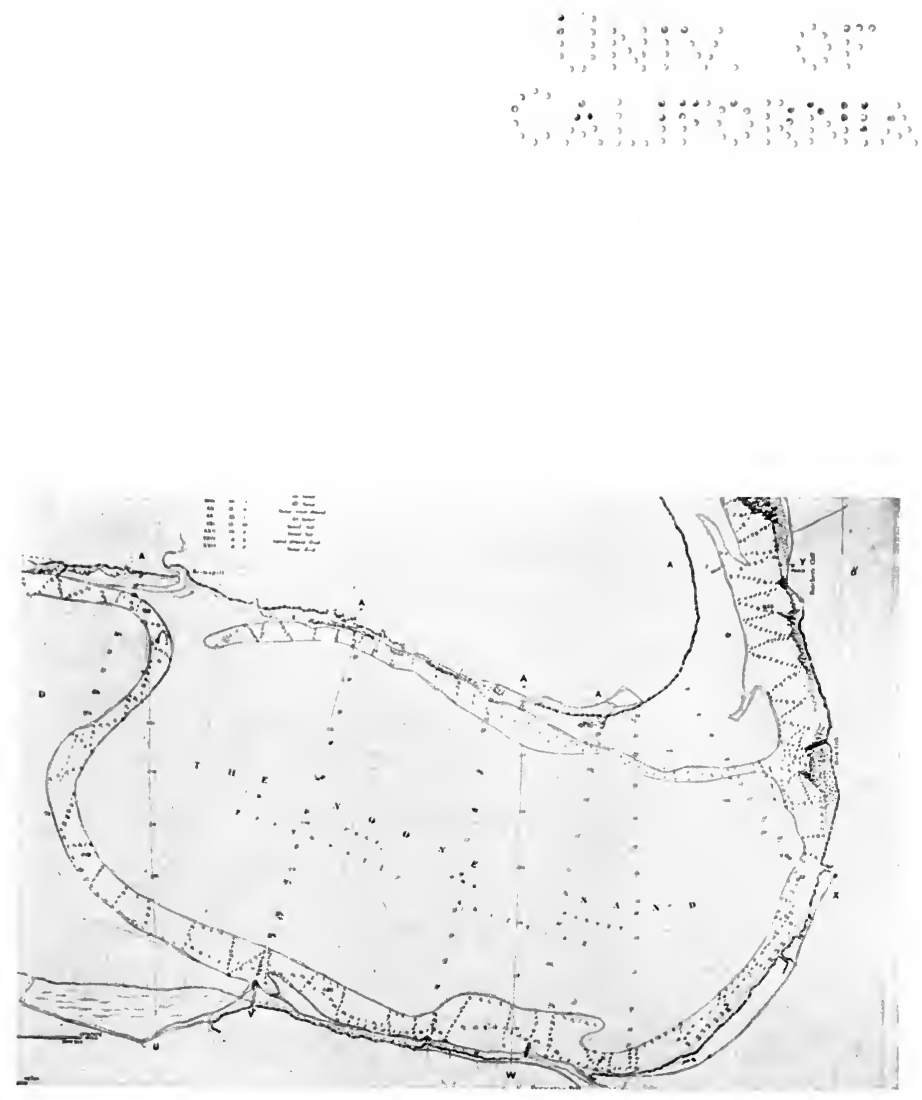

THE NOOSE SANDBANK 
$\because ; \quad ; \quad ; \quad=$

$\therefore \begin{aligned} & \therefore \\ & \therefore\end{aligned}$ 


\section{AND OTHER WATER WAVES 245}

It is between Hock Cliff and the Severn Bridge that the bore usually commences, according to all testimony. The river at low water below Hock Cliff continues to flow in a single channel, the position of which, however, is no longer fairly constant, as at Newnham, but depends greatly upon the quantity of land water. After a wet season it hugs the left bank, cutting a deep trough in the loose sands, and making as wide a bend as the permanent bank permits. This is the condition which, according to the testimony collected by the late Frank Buckland ${ }^{I}$ and also by myself, gives rise to a large bore at Newnham, about four miles farther up.

In dry seasons the channel, which contains all the water during most of the time of ebb and during the commencement of flood, lies much farther from the eastern shore, taking a straighter course. Presumably in this as in other cases which I have noticed elsewhere, the shorter course is due to the influence of the flood tide, which tends to flow in a chord of the arc made by the ebb, or river current. 2 After the dry season of the summer of I90I, the ebb was flowing in such a channel, far from the eastern shore and between perpen-

r "Log-Book of a Fisherman and Zoologist," I875.

"Geographical Fournal, August, 1901: "On Sand-waves in Tidal Currents." 
dicular cliffs of sand. When, at 8 a.m. on October 30, I90I, I stood in the slime at the foot of Hock Cliff, I saw the bore advancing from beyond Awre as a line of white breaking water, stretching quite across the channel, its summit being lower than the top of the cliffs of sand. The height of the wave seemed to be about 2 feet or $2 \frac{1}{2}$ feet. To the left of where I stood commenced the now disused channel following the east, or Frampton shore, which lower down became a deep trench. At 8.10 a.m. the bore, having reached the upper entrance to this channel, sent a wave swinging round to the east into it which travelled down as a bore, while the main bore passed me at 8. I 3 a.m., much diminished and enfeebled, on its way to Newnham. That the bore at the latter place would this morning be a feeble affair, as had been the case on the preceding evening, I could well believe when I saw how the "head of the flood" was squandering itself in driving another wave and stream of water down the Frampton Channel. Indeed, the fishermen tell me that sometimes a bore coming up this channel meets that which I saw travel down it, and that a boat which finds itself between them is in a dangerous predicament. At 8.35 a.m. I saw a small bore travelling across the sandbank which separates the Frampton Channel 
from the present, or Awre, channel travelling up-stream, and from the Frampton towards Awre Channel, which was not yet quite full. The arrival of this reinforcement completed the covering of the sandbanks, and a broad sheet of water lay stretched before me from shore to shore. At 8.39 a.m. the water was slack, or nearly so, and then commenced to flow up-stream towards Newnham, but no longer with a "head." Thus the first flow was retarded 26 minutes. The total rise of tide at Newnham would probably be lessened not at all, or very slightly, by the circulation which took place between Frampton and Awre.

As has been said, the Severn bore actually commences somewhere between Severn Bridge and Hock Cliff, according to concurrent testimony. Below Severn Bridge it is reliably reported that a bore sometimes makes an appearance in one or other of the low-water channels between sand-banks, but it vanishes again. Yet the low-water gradient of the river is not less, but rather greater, below Severn Bridge, and the rate of progress of "first rise" of tide from the Sheperdine Sands to Sharpness (a little below Severn Bridge) is even slower than from Sharpness to Hock Cliff. Why, then, does not the permanent bore originate between Sharpness and the Sheperdine Sands, especially as it is not 
far below this that there is the greatest tidal range (about 40 feet at springs)? It may occur to the reader that a long run is required under boreforming conditions before the bore becomes appreciable; but both theory and observation show it is not so. If the conditions for forming a bore be fulfilled, the wave attains a considerable size in a very short interval both of time and space.

An answer to the question, Why does the bore usually originate above and not below Severn Bridge?-i.e., in the upper, not the lower, half of the steep slope of the estuary-is afforded by the following observations made from the commanding elevation of the Severn Bridge ( 100 feet above low-water mark), on April 27, 1900, two days before the highest of this set of spring tides. At 3.43 p.m. the approach of the flood tide could be discerned by a change of appearance of the water, although there was no actual surface wave. It was 4.5 p.m. before the level of the water was rising at the bridge, so slow is the advance of the first rise. I was stationed near the west end of the bridge, where the principal low-water channel of the ebbing water lies. The flood tide did not force its way up this channel against the strong stream, but was pressed away towards the east, filling a swatchway, or blind channel, which led 
away to the east of a sand-bank called the Waveridge, or Waifridge. After working thus to its right until 4.30 p.m., with slow current but rapidly rising level, the flood tide, having filled the swatchway brim full, suddenly swept over the Waifridge Sand in a broad sheet of water, which poured over to the westward into the main channel.

The sands, which had been drying for several hours, were covered so suddenly that the imprisoned air spouted through the seething water.

It is evident that the presence of an alternative channel, open from below, prevented the formation of a bore in this case, just as at Hock Cliff the alternative channel, open from above, reduced the bore after it had been formed.

The flood tide goes the way of least resistance, and if it be free to circulate, it does not stem the ebbing stream and form a bore. The presence of alternative channels, which becomes more marked as we travel down-stream from Severn Bridge to. Sheperdine Sands, is in itself sufficient to explain the non-formation of a permanent bore in the lower portion of the steep slope of the estuary.

Near Beachly Point, just below the foot of the steep slope to which I have so frequently referred, I watched the commencement of a spring tide on April 28, 1900. The first rise was perfectly. 
calm, being unaccompanied by any wave or other commotion.

It remains to explain why the flood tide, at its first rise, preserves alternative channels in the lower part of the steep slope below Severn Bridge and not in the upper, or only to a limited extent, for on the absence of side channels depends the possibility of forming a bore where the other circumstances (shallowness and a fairly steep gradient) are present.

The sands which encumber the bed of the Severn from Hock Cliff to the Sheperdine Shoal are subject to arrangement and redistribution alternately by the waters which flow seaward and by those which flow landward. In the upper part of this region the sands are arranged so as to form a channel almost like that of a non-tidal river flowing in an alluvial plain. Particularly is this the case when the land water much predominates, as during neap. tides and after heavy rains. The ebbing stream, flowing continuously for many hours in its narrow winding channels, continually lowers its bed, scouring the sand from beneath and forming a channel which, at the time of first rise, has high, steep. banks. The first rise of the flood tide has therefore, as a rule, to make its way against this ebbing stream up the normal river channel which has been 
prepared for it. Then the bore is produced, and it is noteworthy in this connection that, according to the observation kindly communicated to me by Mr. D. Wintle, of Newnham-on-Severn, the bore is more marked there at the commencement of spring tides than after they have been running for some days.

In the lower reaches of the steep slope, and above Beachly Point, the land water forms a smaller proportion of the total, and the duration of the ebb is shorter. The sands, as they are at low water, are therefore not arranged so well to facilitate the run of the ebbing waters, their distribution, on the contrary, exhibiting certain features markedly favourable to the commencement of an upward flow. This change of conditions exhibits itself by the presence of swatchways, or by-channels, such as that above referred to.

How these are formed has been already indicated, and may now be further explained. The ebbing stream ponds back the flood, which consequently makes another way for itself through and across the sands. The relation of the two classes of channel due to ebb and flow respectively has been described by the author elsewhere.' Briefly, the low-water ebb channels are narrow, deep, and × Geographical Fournal, August, Igor. 
sinuous, those of the flood broader, shallower, and straighter. Tidal bores appear to be characteristic of rivers where there are drying sand-banks, and are perhaps only produced there in a part of the sandy estuary which has not yet settled down to a permanent form. The bore marks a struggle between flood or ebb which appears to be a transitory state of things, for in Professor Osborne Reynolds's model estuaries the bore disappeared in all cases when the sand-banks had attained their final form.

From the above it appears, when we study on the spot the conditions of a tidal bore as exhibited in the River Severn, that the phenomenon is somewhat more local and less general than the usual mathematical treatment of the subject would lead one to expect. The visible wave is not the steepening of the front of the tide as a whole, but the steepening of the front of the rising water in a short reach of the river. The observation above recorded of the multiplication of the wave on entering the water of moderate depth supports this view.

The tide presumably does not make its way steadily up a tortuous channel, its progress, on the contrary, being alternately checked and hastened. Even on an open coast the rise of the tide, as registered on the gauges, is markedly pulsative, 
the curve presenting "notches." These are a marked and disturbing feature of the records of tide-gauges, and positions are consequently chosen for their erection on the coasts where the uninterrupted run of the tide shall cause them to be as slight as possible. This pulsative rise of the tide is sometimes strikingly visible to the eye in situations where there is a considerable inflow over nearly flat sands. Thus, on the Anat sand-bank, on the left shore of the river mouth at Montrose, N.B., where I was standing at the turn of the tide on March I7, I900, the water came suddenly rushing in, filling up the hollows and threatening to cover the whole area. The rush, however, soon ceased, and the water then receded, leaving the sands bare once more; but only for one or two minutes, when another rush again occurred, and I do not think that the water subsequently retired.

In subsequent observations on the Severn and elsewhere it will be well to look out for this process, especially at places below the point of starting of the regular bore. It may be that these considerations help to explain the absolute suddenness of rise which constitutes the bore, and which, according to Sir G. H. Darwin, is not quite what is indicated by theory-that is to say, by the theory which regards the bore as the face of the tide-wave considered as a whole. 


\section{CHAPTER IX}

Cinematographing the Severn bore.

IN I90 I Mr. Charles Urban very kindly lent me a bioscope camera and the services of an operator for the purpose of cinematographing the Severn bore. The photograph was taken under my direction on September 29, I 90 I, and was shown at the meeting of the Royal Geographical Society on November $25^{\text {th. I }}$ I believe this is the first cinematograph of a tidal bore.

The cinematograph picture was taken at Stonebench, below Gloucester, which is distant 4 miles by road, reckoning from the cathedral. The tide was the third after full moon, and was not quite so high as that predicted for September 3oth, which was one of the four highest predicted tides of the year. After the dry summer the amount of land-water in the river was probably below the average, nevertheless, the low-water level was $\mathrm{I} \frac{1}{2}$ feet above that given as summer low water in Admiral Beechey's survey made in 1849 . The 

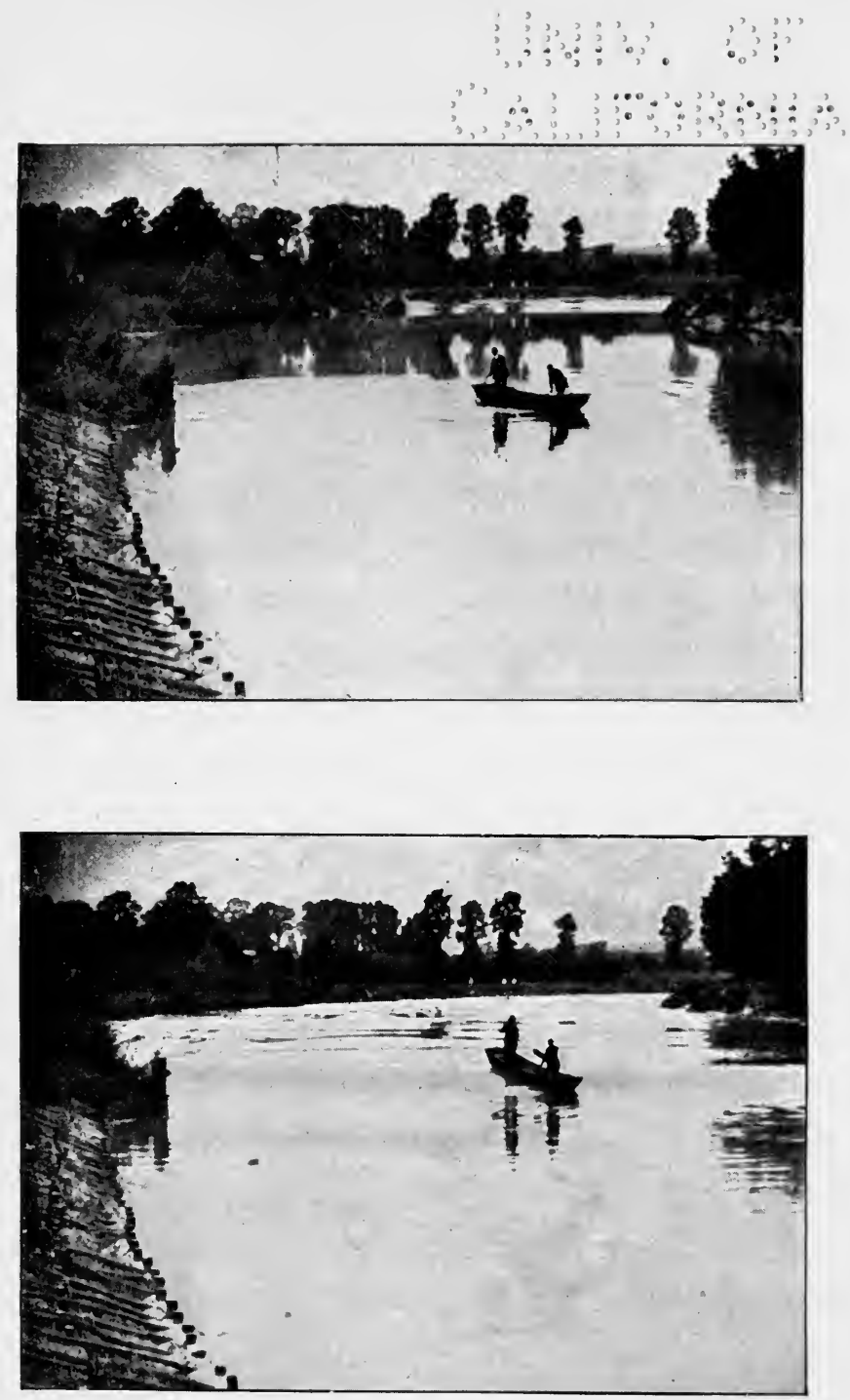

CINEMATOGRAPHS OF THE BORE APPROACHING STONEBENCH. 


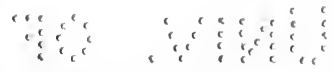

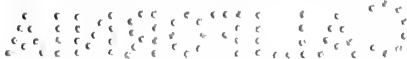


reason, no doubt, is that the spring tides had already begun to fill up the river. The camera was placed upon the left bank, as low down as was consistent with the safety of the instrument, and about 30 feet back from the submerged "Stonebench," so as to show the breaking of the wave where the water suddenly shallows from 6 or 7 to $2 \frac{1}{2}$ or 3 feet. A boat was engaged to meet the bore, and was anchored in deeper water at a suitable distance; and to obtain the scale a post near the left bank was measured, its top being found to be 58 inches above low water.

The bore was heard at 9 a.m., a few seconds before its appearance round the bend of the river, at a distance of 513 yards from the camera. The resurgings from the concave left bank had a fine effect, well reproduced when the film is shown upon the screen. The boat rode easily over the unbroken wave in about Io feet of water. The height of the wave there I estimated at from 3 feet to 3 feet 6 inches, and the height at the sides of the river 4 to 5 feet. At the jetty or breakwater, of which one post already referred to was visible beyond the osiers, the bore suddenly sent a sheet of water up to a height of 7 or 8 feet, but, recovering itself in a moment, the wave came on with a front still smooth and unbroken, its inverted 
image perfectly mirrored by the smooth water ahead of it. Then, on reaching the hidden Stonebench, the wave curled over in a beautiful scroll. But no stationary photograph can reproduce the effect which is given on the screen as the darkfronted curling wave rushes out of the picture, which is then immediately flooded with light, the bright clouds instead of muddy banks being now reflected by the smoother waters. The speed of the bore was about I $3 \frac{1}{2}$ statute miles per hour. The exposure of film was continued after the bore had passed in order to illustrate the after-rush of water, the speed of which was well shown by floating debris. 'A boat happened to come by, one of the occupants of which was gathering flotsam and jetsam, and the camera was then revolved so as to follow the boat as it passed. Owing to high osiers intercepting the view up-stream, it was not practical to cinematograph the bore from behind, as had been intended. High water occurred 56 minutes after the passage of the bore, the total rise being 8 feet $6 \frac{1}{2}$ inches. The height of the water then above ordnance datum was several feet higher than high water of even a 40-foot tide at Portishead. The current continued to flow up the river for 3 I minutes after high water.

The tidal bore in nature is not precisely repeated 

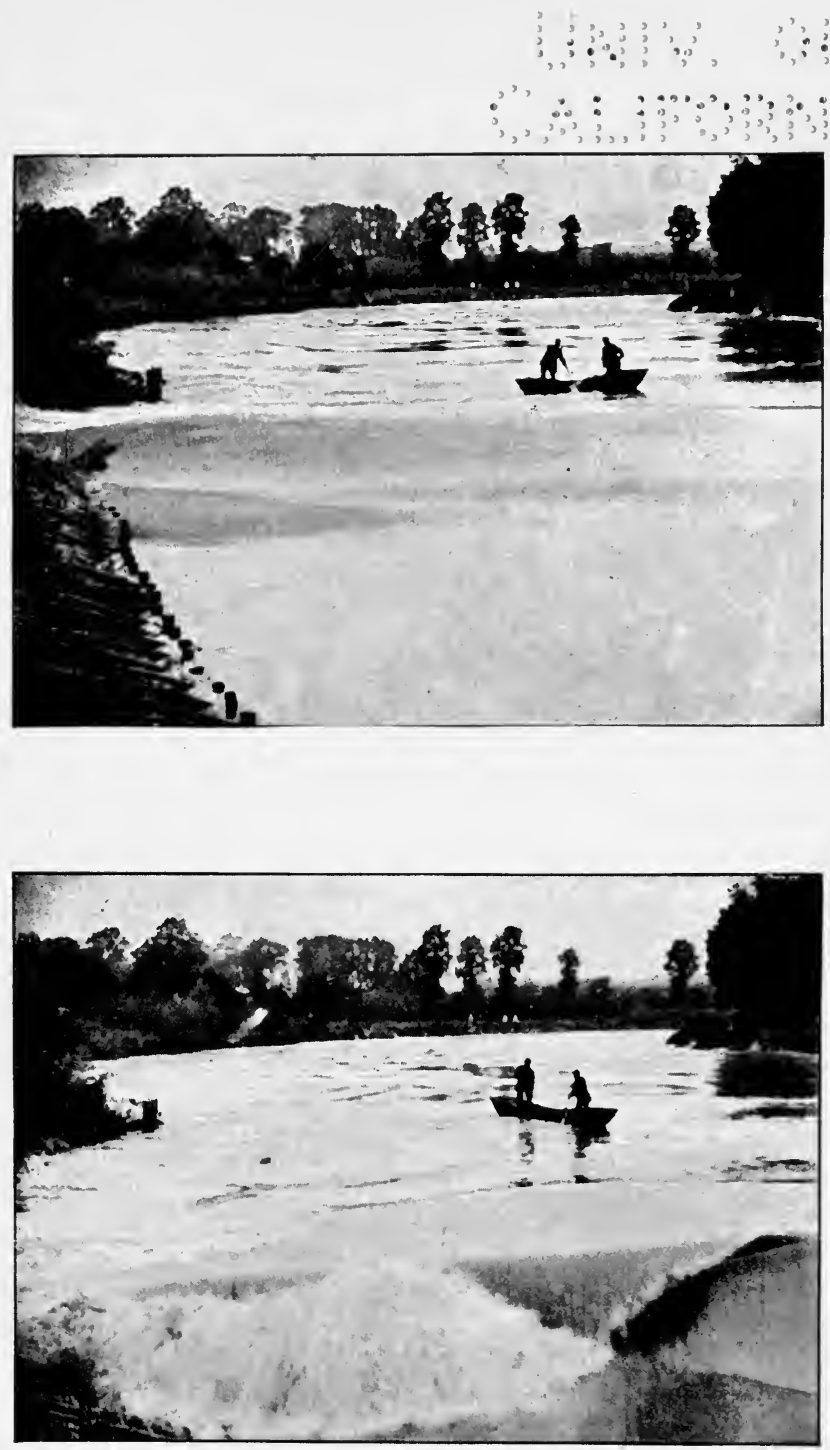

CINEMATOGRAPHS OF THE BORE ON REACHING STONEBENCH. 259 


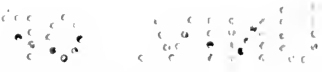

$$
\begin{aligned}
& \therefore \begin{array}{l}
\therefore \\
\because
\end{array}
\end{aligned}
$$




\section{AND OTHER WATER WAVES 261}

at succeeding tides, and in most rivers is not seen at every tide. The cinematograph representation, on the contrary, can be repeated on the screen as often as required, and with a delay of only one or two minutes while the film is being re-wound. At each repetition the observer can concentrate his attention upon one particular feature. In this way

I have seen several things on the picture which escaped my observation on September 29th. Measurements can also be made from the film, either in the hand or from its projection on the screen.

\section{Description of Plates.}

(The figures are enlargements from individual pictures upon the cinematograph film.)

Fig. I shows the bore in the distance as a bright band, where immediately before had been the dark image of bank and trees. The 5 -foot post is visible on the left, with its reflection below.

Fig. 2 shows the boat rising to the wave. The wave on the right of the boat cuts into two the reflection of the trees on the right bank. A comparison with Fig. I shows at once the turbulence of the water behind the bore. The alternation of wide bright bands with narrow dark bands parallel to the front of the bore indicates the character and position of the undulations behind it, whilst the confused reflection of light near the left bank indicates resurging therefrom. If the apparent heights of the banks in the two figures be measured, the level of the water will be found to have risen behind the bore.

Fig. 3 shows the wave as yet unbroken, but with steeper front, due to its approach to the shoal ; the inverted image is plainly visible. Measurement of the post from the picture shows that 
the water there is 2 feet 5 inches above the level of the river in front of the bore.

Fig. 4 shows the bore rushing over the Stonebench. The mean level of water at the post is 2 feet II inches above low water, but there is a noticeable difference of level at front and back of the post, indicated by a dark shadow on the picture. This shows that the current, which, shortly before the bore arrived, I found to be ebbing seawards at 0.8 mile per hour, is now making in the opposite direction with considerable strength. The boat remains in position, being anchored. 


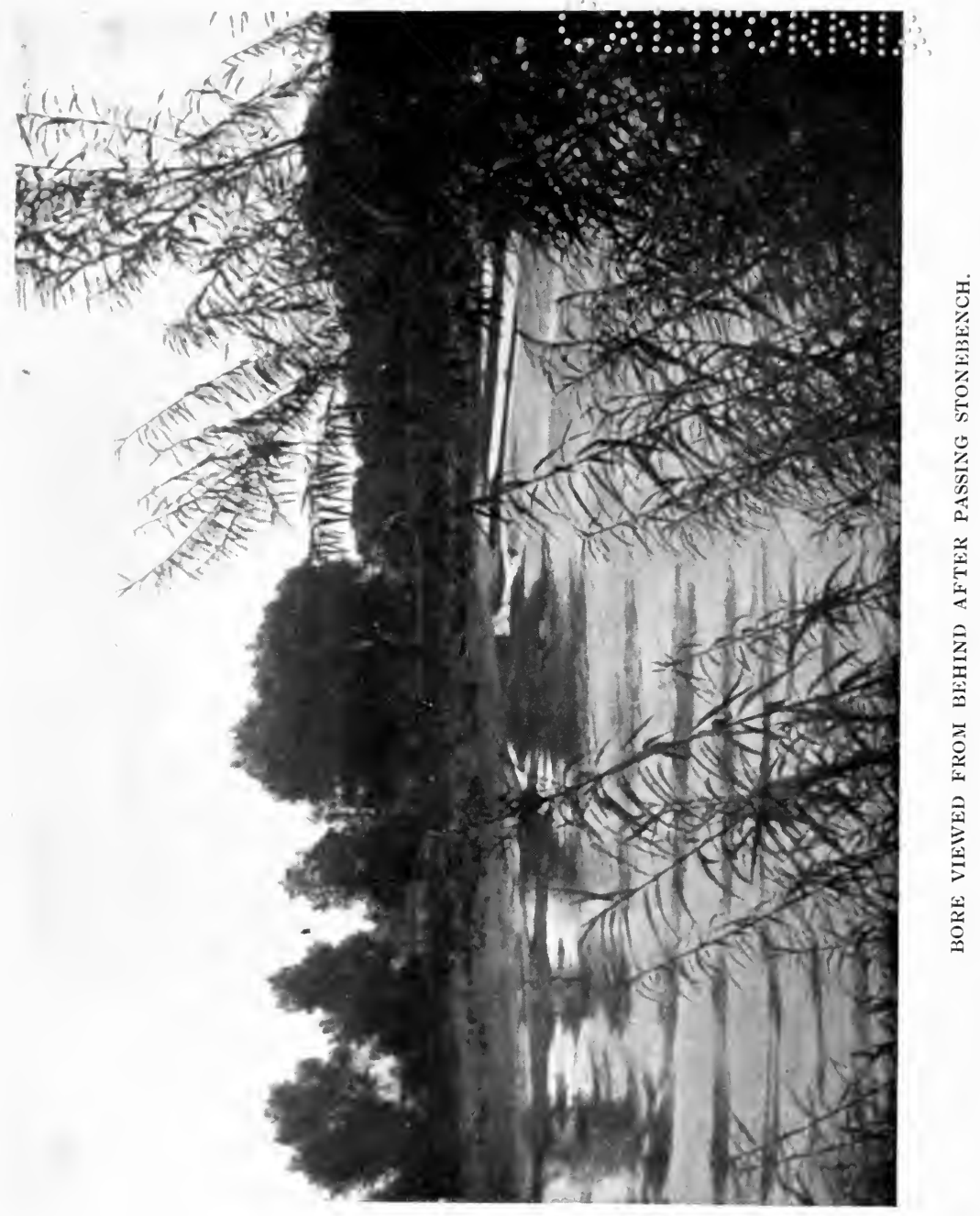




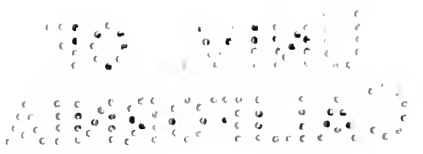




\section{CHAPTER $\mathrm{X}$}

Stationary or standing waves-Cross-stream progressive waves : observations in Niagara River.

\section{Stationary or Standing Waves}

ONE who observes the well-known waves of rapid, or rock-encumbered, rivers from the bank cannot fail to notice that whereas the shape of the corrugated surface is not very different from that of an agitated sea, yet there is this great difference, viz., that the river-waves maintain their position unchanged; and, partly for this reason, they are called stationary or standing waves. If a piece of stick be tossed upon the stream, its downstream motion over the corrugated surface will be seen to be alternately checked and accelerated as it reaches the crests and troughs respectively. Mathematically, this undulated river is regarded as a steady stream, flowing, say, to the right, with a train of waves travelling to the left at a speed 
equal to that of the stream.I This conception will be found very helpful to a proper understanding of the subject; and that it is no mere subtlety of thought is realised immediately by one who shall drift in a boat through such a train of waves. Dropping down-stream in this way on the ebbing tide between the piers of the Severn Bridge opposite Sharpness, my eyes were fixed upon the waves which combed over towards me. Almost at once the sense of drifting vanished, the boat seemed no longer to progress through rough water, but, on the contrary, to be at a standstill, whilst wave after wave charged past her.

In small streams it is not difficult to produce stationary waves by introducing a stone or boulder, or, better still, a transverse barrier which rises above the bottom sufficiently near to the

I An excellent illustration of a wave with a motion equal and opposite to that of the current is seen when one pours water into the centre of a flat-bottomed circular sitz-bath. The current flows outwards in all directions with diminishing velocity, and the water, resurging from the circumference, makes a breaking wave with a circular front facing the centre of the bath. As the depth of water behind the wave increases the velocity of the wave also increases, so that its front closes in towards the centre where the autflowing current is more rapid. The circle is presently reduced, at first slowly, afterwards more rapidly, so that only a small hole is left, and finally the wave closes in completely upon the down-pouring column of water. 
surface. A mound of water forms in the neighbourhood of the obstruction (its precise position relatively thereto depending upon the circumstances of depth and speed), and a hollow and a second crest, and then a third, a fourth, and so on, appear farther down-stream, a train of waves speedily being formed. If the obstruction be now dragged up-stream, the whole train of waves moves upstream with it, preserving their position relatively to one another (which is the second connotion of the epithet "stationary" as applied to them). In performing this simple experiment the close resemblance between the ordinary waves of rivers and ship-waves becomes at once apparent. The analogy is yet further brought home when one notices the waves formed by a model or toy vessel moored in a rapid stream. The familiar train of waves shown by a ship steaming through still water is here reproduced in the water which flows past the stationary vessel.

There are, however, considerable differences in the appearances usually presented by ship-waves and river-waves, which are due partly to the fact that the latter are produced by disturbances which affect the water throughout its whole depth, and the former are generally only superficial. Again, river-waves, when caused by a weir, extend in 
straight parallel ridges at right angles to the current, quite across the stream, a form very different from the wave-track of a ship.

A solitary boulder in mid-stream does, however, reproduce, very roughly, the wave-track of a ship, a series of waves being formed on either side, each wave inclined at an angle which appears to be about the same as in the case of ship-waves, viz., I $9 \frac{1}{2}{ }^{\circ}$ to the current, each succeeding wave projecting somewhat farther into the stream than its predecessor. There is generally but little indication visible of any system of transverse waves like the thwart-ship waves which are comprised between the diverging, or "échelon," waves of a ship's track.

When river-waves arise from the retardation caused by a rough bank, or where a stream narrows, or where it enters upon a different gradient, the wave-front is inclined to the bank. If the stream be wide, the oblique standing waves are of greater elevation near the bank, the height diminishing farther out, the centre of the river being smooth. If, however, the stream be narrow, the standing waves originating from the opposite banks are superposed in the centre of the stream, and the combined crests there have a greater amplitude than either separately. Thus the highest wave 


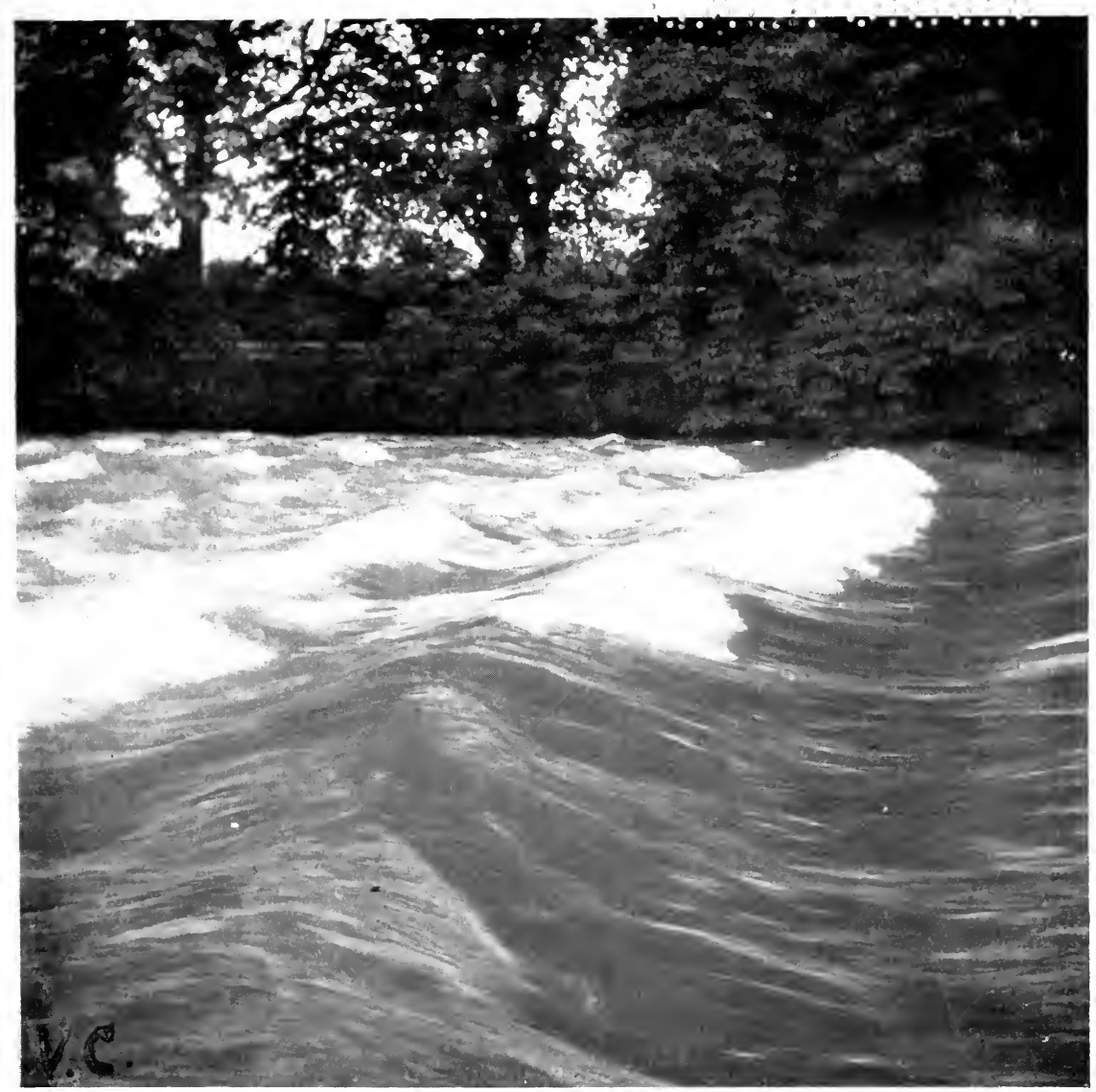

STATIONARY WAVES CAUSED BY A WEIR ON THE RIVER AARE, SIVITZERLAND. 269 


$$
\begin{aligned}
& \begin{array}{ccc}
\ddots & \cdots \\
\ddots & \ddots & \vdots
\end{array} \\
& \therefore \begin{array}{lll}
\therefore \\
\therefore
\end{array}
\end{aligned}
$$


is in this case found in the centre of the stream, as may be seen, for example, near the spot, called Bloody Run, opposite Foster's Flats, in the rapids between Niagara Whirlpool and Lewiston.

In 1896 I noticed some facts relating to waves in rivers of which I found no published explanation. The first was that the water of rivers, perticularly rapid mountain streams-e.g., at Meran, in the Tyrol-does not maintain a constant level at any fixed spot, but, on the contrary, oscillates perceptibly with a motion sufficiently rapid and short in period to be readily perceived by the eye. This indicated that there was something of the character of a progressive wave, but I could not at that time see any travelling wave.

The second observation was that the so-called stationary waves (e.g., on the Eisah, above Botzen, and at the Bingen Rapids, on the Rhine) were not perfectly stationary, but oscillated somewhat about a mean position. . Their most noticeable movement was that, from time to time, they charged somewhat rapidly a foot or two up-stream; and in this case the cusped waves broke as waves break on a sea-beach. It appeared to me that the second phenomenon was related to the first in the following way: granting that the "stationary" waves are travelling up-stream as fast as the current 
flows, then if the speed of the current be suddenly diminished, the speed of the waves will be too great, and they will charge up-stream. Thus, if the current be subject to fluctuation, as the first observation seemed to indicate, we should expect the "standing" waves to fluctuate about a mean position.

A third fact, also, best observed in mountain streams-e.g., the Lutschine, at Grindelwald, in Switzerland-was that in the shallows of little bays there was always a succession of progressive waves rushing towards the shore, as waves come in on a sloping sea-beach. These "rollers" in the little bays were evidently connected with the oscillation or throbbing of the stream. A long series of these "rollers" was timed just below Speybridge, near Grantown, N.B., when the "Galloping Spey" was swollen by melting snow and ice, in February, I 900 . They were only roughly periodic. They rolled in upon the shore in a direction about at right angles to the current-their direction being, of course, conditioned by the shallowing of the water; and it was of interest to observe that these waves rippled the sand at right angles to their motion, although the current drifted the sandgrains parallel to the ripple ridges.

Beyond the frequent repetition of these three 


\section{AND O'THER WA'TER WAVES 273}

observations in different rivers, I was not able to progress in this matter for some time. I determined, however, to see what I could learn of wave phenomena in rivers, particularly those connected with the pulsation or throbbing which I had noticed, by a visit to the River Niagara, where I thought I could see such things in their full and free development.

Cross-stream Progressive Waves. Observations in Niagara River

I arrived at Niagara Falls, N.Y., on July 8, I 903, accompanied by my wife, who has shared in all my travels in search of wave phenomena. The next three weeks were spent in observation between Niagara Falls and Lewiston, after which a voyage was made from Kingston, Ontario, to Montreal, passing through numerous falls and rapids on the St. Lawrence.

Above the Falls of Niagara the river is wide and generally shallow, flowing very swiftly on a considerable gradient over an uneven, rocky bottom. Between the American shore and Goat Island the water is shallowest. Above the bridge connecting them I was able to see waves progressing downstream which I thought "faced"-i.e., had their steeper face-turned down-stream and towards the 
shore, instead of up-stream and away from the shore, as the stationary waves are. The travelling waves were not conspicuous, however, and I was not able to detect similar ones (facing downstream) in the deep waters of the Whirlpool Rapids.

In the upper rapids of Niagara regular trains of waves are not prominent. The most noticeable waves are such as that beyond the last "Sister Island," where a huge mass of water surmounts a rocky protuberance, to leeward of which the water curls back in a fine cusp.

In a little sheltered channel among the islands, where the water flowed less tumultuously, much better examples could be seen of a regular train of waves. From Lunar Island I saw one of the cusped waves near the brink of the American Falls break periodically, thus :

In 57 seconds the wave broke 7 times;

, 62 " " " 8 "

corresponding to periods of 8.14 and 7.77 seconds respectively. This is in the same part of the river where I observed the progressive waves. I postpone until another section the account of certain phenomena of the actual falls, and, passing by without remark the 2-mile stretch of deep water 


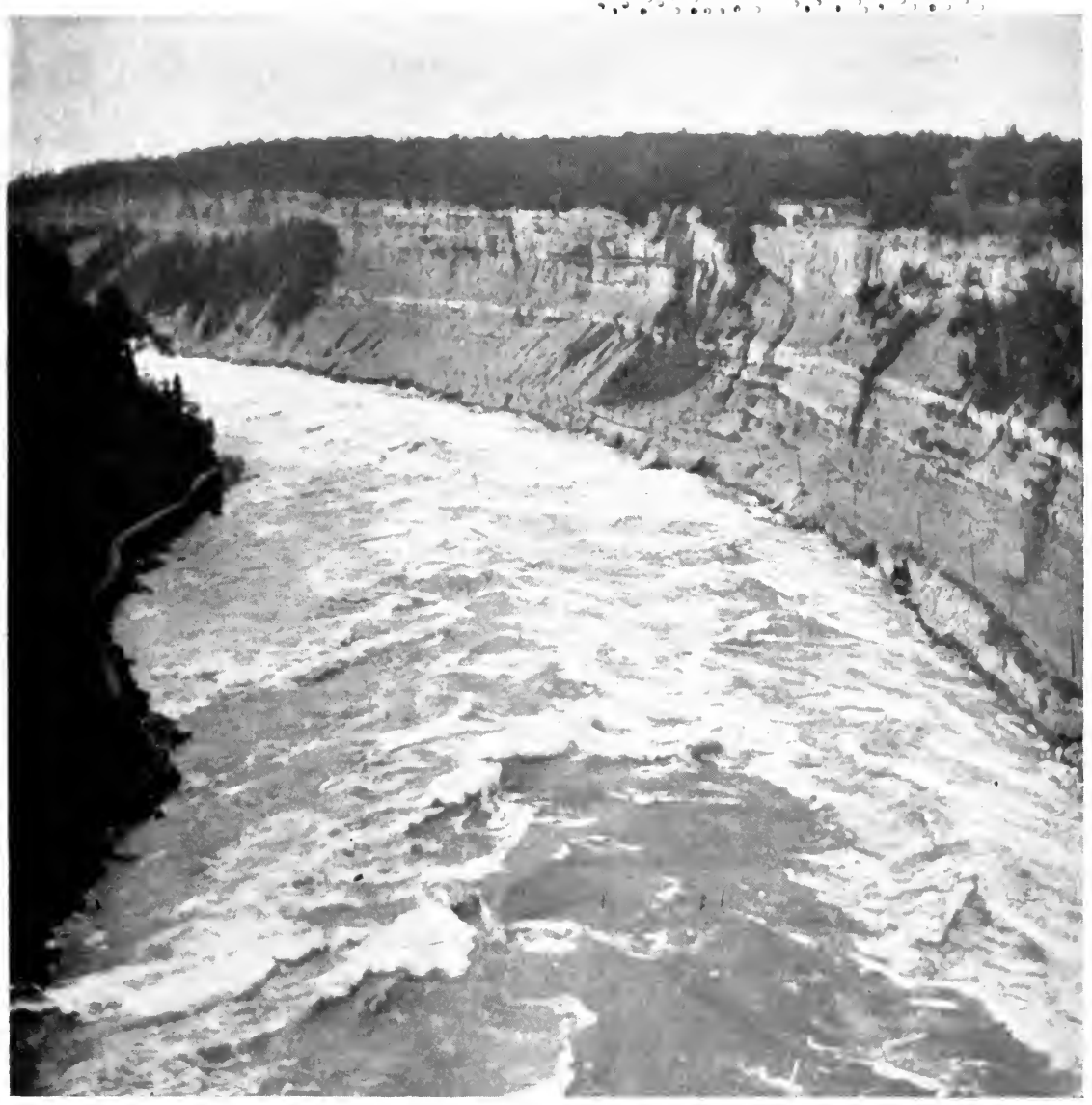

BIRD'S-EYE VIEW OF WAVES IN WHIRLPOOL RAPIDS, NIAGARA. 


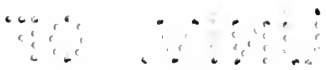

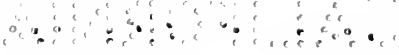


( 160 feet to 190 feet), with scarcely any fall of level, which succeeds them, I come to the second rapids of the Niagara River, called the Whirlpool Rapids, from the pool at their lower end. The fall is 50 feet per mile, nearly $I$ in 100 . The width of the Rapids is only about 350 feet, the depth is stated to be 35 feet to 50 feet, and the reputed velocity is 30 miles per hour.I The course of the river here is curved, the apex of the curve being approximately at the "Whirlpool Rapids" station of the Niagara Gorge Light Railway, situated on the right bank. A very fine general view of these rapids is obtained from the footpath of the high level railway bridge at their upper end, and an excellent view of the waves near the railway station is obtained from the cliffs of the left bank opposite thereto. Waves commence a little above the bridge, where the gradient of the bottom increases and the water begins to flow more swiftly. There are two sets of waves originating from the right and left bank respectively. The first few waves are smoothly rounded in form and practically steady in position. Lower down, where sets of waves originating from the opposite banks extend sufficiently far out to meet each other, they are

× G. K. Gilbert : "Explanation of United States Geological Survey Map of Niagara River." 
often cusped and foaming, and they shift somewhat rapidly for a short distance up and down about a mean position.

Numerous standing waves originate from successive positions on the banks, the position being determined doubtless by changes of pressure and, consequently, of velocity. Such change of pressure and velocity is obviously produced in some places by rocky obstructions, but in some instances, particularly opposite the railway station, the change of direction of the current probably contributes to the effect. No long and regular trains of waves can be observed, except just at the commencement, but the positions of the principal mounds of water are perfectly definite, so that (as long as the river remains at a certain level) these waves are recognisable individuals. Nevertheless, I noticed from my elevated stations on the bridge and the cliffs that in this terrible rapid (where the combined depth, speed, and volume are so unusually great) the throbbing, which is so slight a feature in most wavy streams, had developed to a remarkable extent. The stationary waves of the river differed from those of quieter streams in the same way that the bowwave of a steamer in a heavy sea differs from the bow-wave in smooth water. In the latter the bow- 


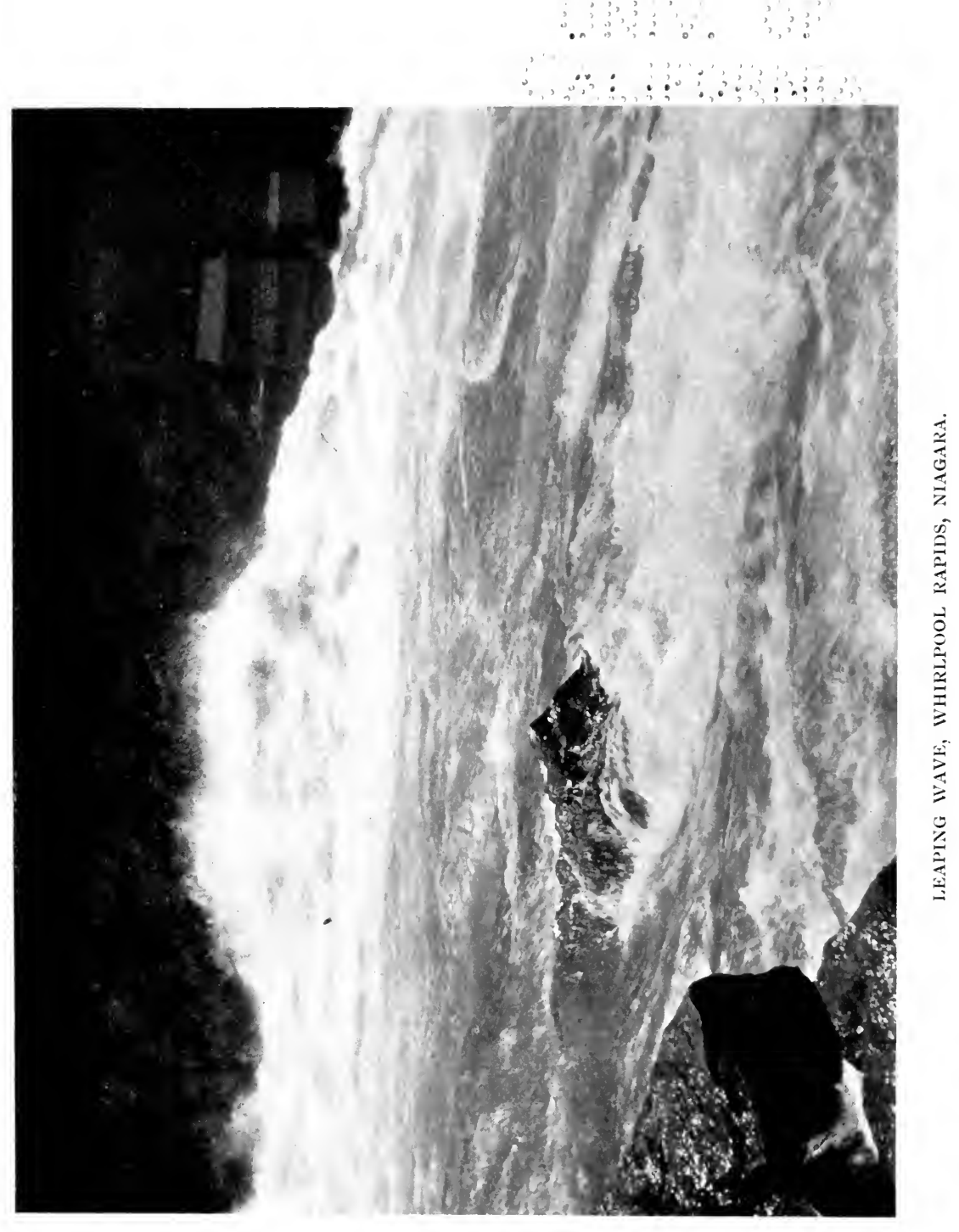




$$
\begin{aligned}
& \because y^{\prime}
\end{aligned}
$$

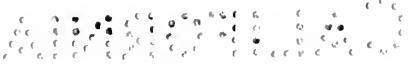




\section{AND OTHER WATER WAVES 281}

wave is constant in size and steady in position, but in a heavy sea the vessel throws off from her bows a succession of waves. Similarly, I saw the standing waves near each shore periodically wax and wane (though never waning to less than, say, three-fourths of their maximum), and as each passed its maximum it disengaged a conspicuous and considerable travelling wave, which surged forward (facing diagonally up-stream) towards the centre of the stream. The waves travelling outwards from each bank met in the middle of the stream with much commotion and throwing up of spray, after which they could be clearly seen to have passed right through each other, and to continue each its course towards the opposite shore. The wave, however, is drifting down-stream all the time; the resulting motion of the mound of foaming water being more down-stream than across stream, for the current velocity is greater than the wave velocity relatively to the bank.

Viewed from the edge of the torrent at Whirlpool Rapids Station, the great standing mounds of water in the centre of the stream towered up above the line of sight. They are formed (as I knew from my bird's-eye reconnaissance) where the standing waves, diverging from the banks, cross one another. They fluctuated continually in height 
(from 15 feet to 20 feet I estimated) 1 and also in position, but the amount of shifting was not great - perhaps one-half of the length of the mound of water. This staggering and heaving conveys the notion of efforts so great that some breakdown must soon occur. And while I watched enthralled the breathless heavings of the standing waves, a surge came rushing upon the shore where I stood, as if the river would suddenly rise and overwhelm me. I drew back, realising that my post of observation was unsafe. Acting on the ordinary experience of rivers as flowing with practically steady motion, I had not sufficiently allowed for the amount of throbbing in the Niagara Rapids. Of course, the rush of water which drove me back was not the commencement of a continuous rise, but merely the discharge of a wave, and the water receded again with a somewhat more deliberate motion, only to make way for another dashing surge. The surge was timed by the covering and exposure of a rock:

Number of Times Rock Covered.

$\begin{array}{ccccc}\text { First } & \text { Second } & \text { Third } & \text { Fourth } & \text { Fifth } \\ \text { Minute. } & \text { Minute. } & \text { Minute. } & \text { Minute. } & \text { Minute. } \\ 3 & 5 & 4 & 4 & 5 \\ & \text { Average period, } \mathrm{I}_{4} \cdot 3 & \text { seconds. } & \end{array}$

I The late Mr. T. V. Welch, formerly Superintendent of the New York State Reservation at Niagara, informed me that they are estimated at 30 feet when at their highest. 


\section{AND O'THER WATER WAVES 283}

Such a surge is well shown in cinematograph views of the Rapids. The vertical rise and fall of this surge upon the shore was about 2 feet. It is easy to realise that it is connected with the sway and heave of the standing waves, and recollecting what I had seen from above, I naturally connected it with the travelling waves which come from near the opposite shore.

My feeling that the standing waves were heaving and swaying too much for permanence was presently justified. After watching for a time the seething and roaring waters, the great billow before me suddenly leaped into the air, scattering its waters in showers of spray, which fell to leeward upon the river with a "swish," whilst a much diminished mound was seen where the explosion occurred. It was, however, only a matter of seconds for the standing wave to grow again to its normal dimęnsions. I have called this phenomenon the "leaping wave." Doubtless it may be seen in many places on Niagara, and in other such tumultuous waters, but the best place, as far as I know, for observing the phenomenon is at the Whirlpool Rapids Station. Presumably, the spot for the station was selected on account of its being opposite the place of greatest turbulence.

I was, fortunately, able by actual observation to 
trace the phenomenon to its cause; for, returning to the cliffs on the Canadian side directly above the spot, I saw travelling waves buffeting their way to mid-stream from either side (but swept down-stream, so that their resulting course was inclined at an acute angle with the current) meet together just where the crossing of the standing waves made one of the great mounds of water opposite the railway station. When the two travelling waves met each other and the great standing wave, the water leaped high into the air, shattering and scattering all regularity of form or structure. After seeing the thing from this point of vantage, I was able on another occasion to recognise the process from the nearer but lower point of view close to the railway station. My eye having become accustomed to the maze of motion (acquiring thus a temporary efficiency far beyond one's ordinary powers of seeing), I actually saw several waves converge at the same time to produce a leaping wave.

I may add that I never noticed any great leaping. up of the water except the leaping of a standing wave when progressive waves converged upon it.

In the voyage from Kingston, Ontario, to Montreal, passing through many rapids, including: those of Lachine, I was able to make my observations under another set of conditions-viz., while 

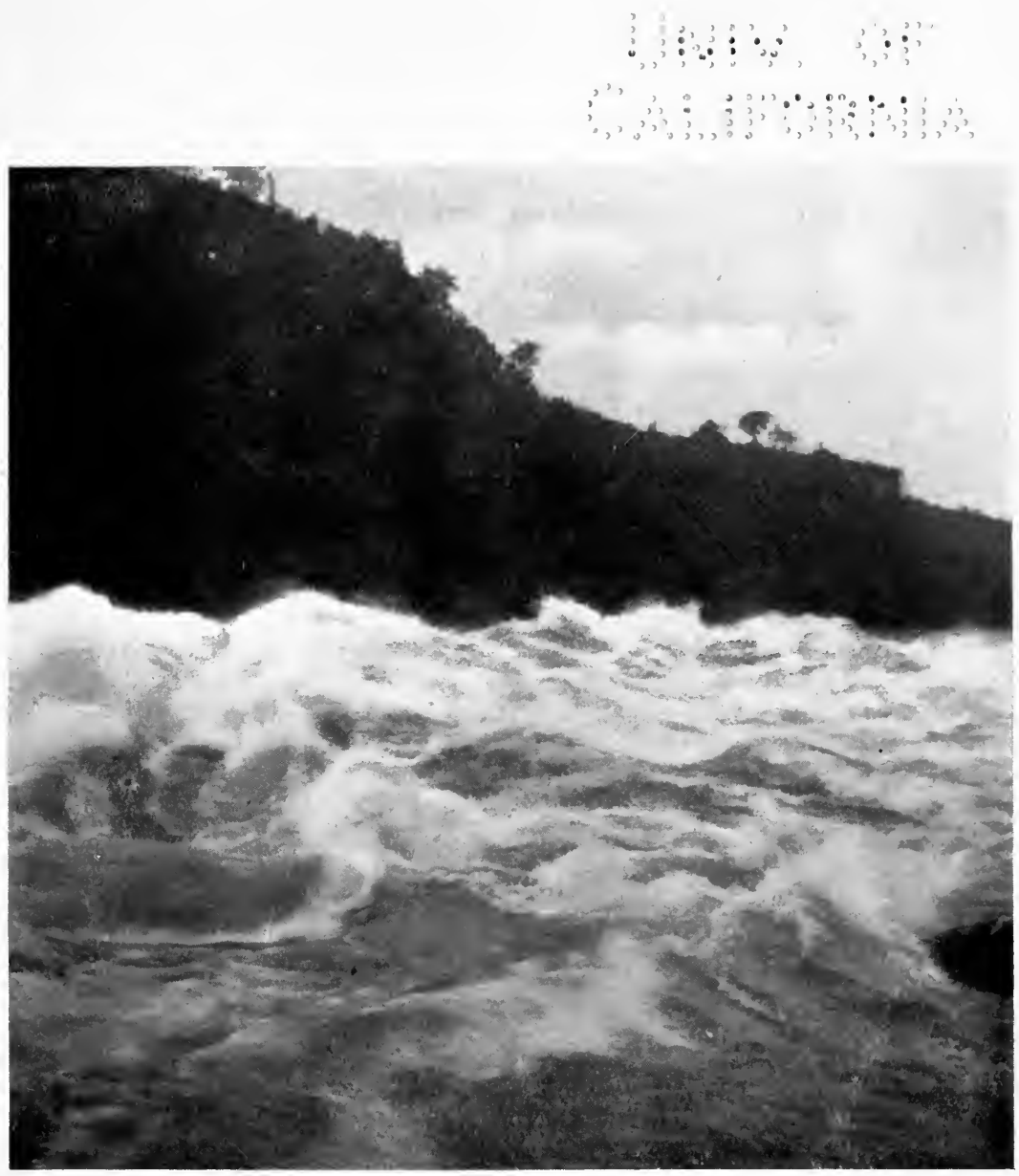

WAVES IN WHIRLPOOL RAPIDS, NIAGARA. 


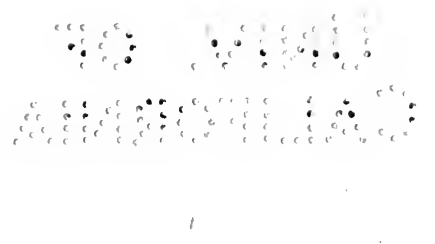




\section{AND OTHER WATER WAVES 287}

sharing the motion of the current, so that the only movement of the water which the eye had to follow was its periodic or wave motion. The changed conditions of vision are well indicated by the photographs then taken, in which there is no indication of the shutter being too slow, for the particles of foam, \&c., travelled along at the same speed as the camera. As we passed through one after another of the St. Lawrence rapids, I noticed repeatedly that the first few waves were rounded in form, unbroken in surface, constant in size, and practically fixed in position. Lower down, however, where two or more trains of waves intersected one another, they became cusped and foaming, breaking also and sometimes fluctuating.

Some part of this difference may be due to increased speed in the lower part of the rapid, but it was fairly evident that the changed character of the waves was, mainly due to superposition.

The most conspicuous billows, or apparent waves, in torrents are usually of small lateral extension, for they are produced where two standing waves cross, and each standing wave is usually inclined at about $20^{\circ}$ to the direction of the current. In the Niagara Rapids below the Whirlpool, opposite Foster's Flats (Devil's Hole Station), there is a splendid series of such combination standing waves. The course of 
the river being here straight, there is less irregularity than at the bend of the Whirlpool Rapids. The distance from crest to crest in the direction of the current was I oo feet, but this is not a true "wave-length" in the physical sense.

It is now incumbent to explain the co-existence of the ordinary diagonal standing waves of rivers with travelling waves facing diagonally up-stream in the rapids of Niagara and the St. Lawrence.

The absolute steadiness of standing waves can only be secured by absolute steadiness of current. In a river with a rough bed and a crooked course it is impossible that the motion should be perfectly steady if the current be even moderately swift, for (to take the principal and most evident cause of fluctuation) eddies are alternately formed and released. By this means a standing wave is caused to fluctuate as the "unwinding scrolls" and other irregularities follow one another down the stream. Generally speaking, the fluctuations so produced in a wave near the right bank will not synchronise with those of a wave near the left bank, for such irregularities of flow of the river are generally partial, not affecting simultaneously the whole cross-section of the stream.

Wave-motion is essentially differential, and if the rate of change of motion be slow, the effect 


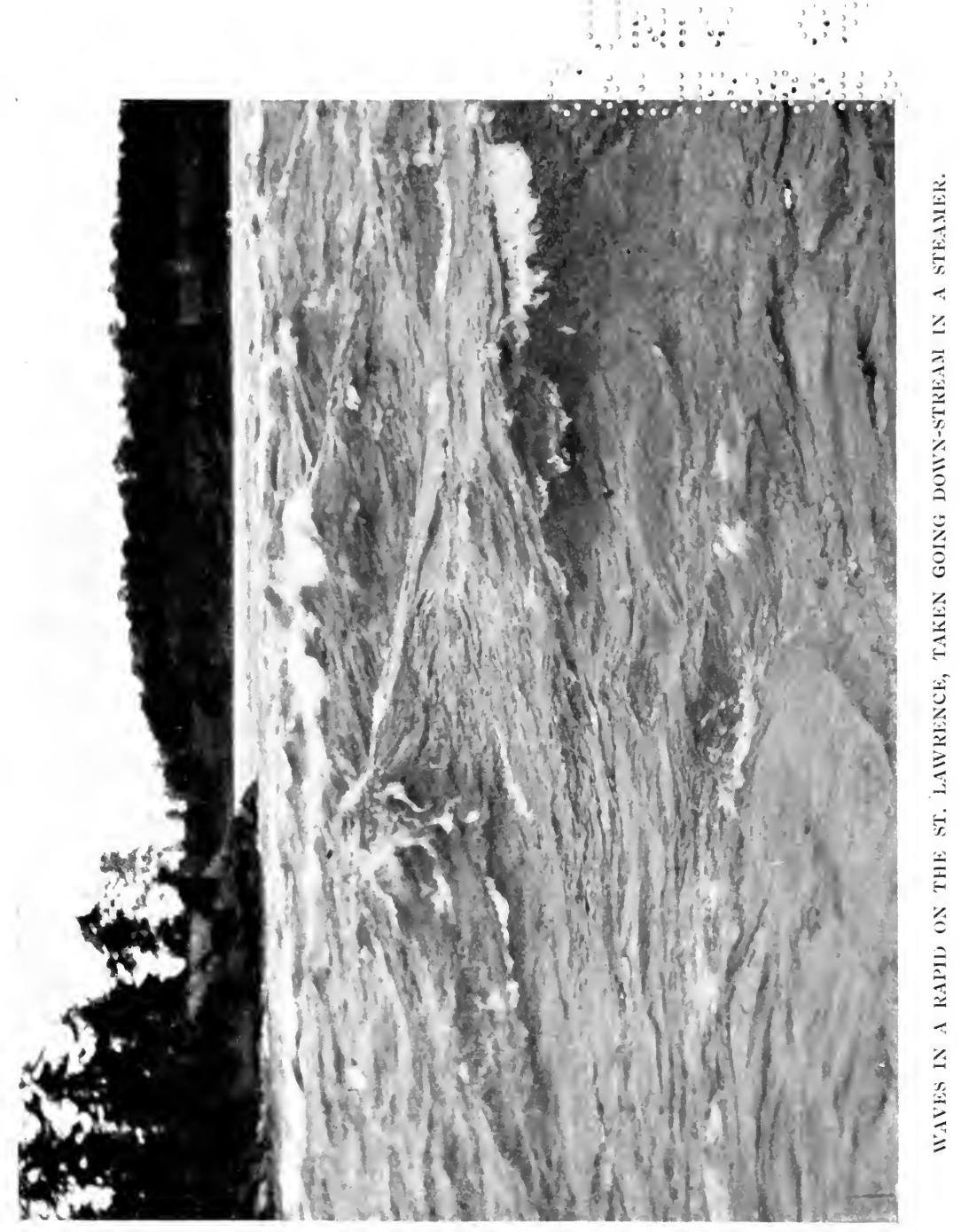




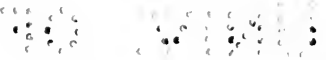

$$
\begin{aligned}
& \therefore
\end{aligned}
$$




\section{AND OTHER WATER WAVES 291}

on a wave is slight. Thus, such fluctuations of current generally only produce a flicker in the stationary waves, as described in the earliest observations recorded above. But if wave be superimposed upon wave, the effect of such fluctuation is intensified in a very high ratio. The combination wave may be regarded as a "higher power" of the original quantity, and the effect of an inequality of current as affecting the fluctuation of the combined system will increase in a rapid ratio. The fluctuation of a waved wave (as I may term it) is much more sharp and sudden than that of a simple wave. The effect will also be more marked when the standing waves are themselves steep and high relatively to their wave-length.

Thus the fluctuation of the standing waves of the Whirlpool Rapids becomes sufficiently great for the disengagement of visible travelling waves. The independence of various causes of unequal flow in different parts of the stream makes the travelling waves arise independently in different places, and their synchronisms are, therefore, irregularly timed. Great leaping waves are only caused when a number of them (in their resultant drift) converge simultaneously upon a combination standing wave.

These cross-stream progressive waves do not, however, exhaust the possibilities of progressive 
waves in rivers, and I was on the look-out more particularly for waves facing down-stream and progressing through the water in a down-stream direction. Such waves would, of course, pass the bank more rapidly than the water itself, for their apparent velocity would be that of the current plus the proper motion of the wave.

Near Devil's Hole Station, opposite to Foster's Flats, on the rapids below the Whirlpool, I observed that from time to time freshets came down the river, raising the level of the water on the bank for as much as 90 seconds. Thus at II hours 26 minutes 5 seconds a large freshet arrived, raising the general level of the water about 12 inches. Duration of high water, $1 \frac{1}{2}$ minutes.

I I hours 32 minutes 5 seconds, another freshet; high water, $\mathrm{I} \frac{1}{2}$ minutes.

I I hours 37 minutes 5 seconds, a small freshet.

I I hours 42 minutes 5 seconds, a small freshet.

I could not, however, perceive any visible travelling wave, nor was there anything to indicate that these freshets travelled faster than the current. If they had been due to "long waves" progressing in the direction of the stream, they would have been travelling at some much greater velocity, perhaps twice as fast, for the depth here is very considerable. I am inclined to think, therefore, that this 


\section{AND OTHER WATER WAVES 293}

kind of swelling of the river, which co-existed with the shorter period waves which were coming in on the shore all the time, is due to the intermittent disengagement of masses of swirling water from the great whirlpool up above. Some confirmation of this view is afforded-first, by watching the upwellings which take place in the whirlpool near the exit, and also by the appearances of such masses of swirling water lower down the Foster's Flats Rapids, where there are fewer standing waves. It is not uncommon here to see a cyclone and an anticyclone of water drifting down-stream side by side with a difference of level (reckoned from the crown of the anticyclone to the pit of the cyclone) of probably 5 feet or 6 feet. In these there is horizontal circulation of water about vertical axes.

Thus in the deeper waters of Niagara I never saw any repetition of down-stream progressive waves such as I believed I had detected in the shallow water above the American Falls. This might be explained either by their non-existence or by their being too flat to be visible in deep. water.

In the next chapter I shall give an account of the circumstances under which a stream of water flows in a series of down-stream bores. 


\section{CHAPTER XI}

On streams which flow as a series of roll-waves-Observations on a conduit from Territet to Glion-Observations on the conduit of the Grünnbach (Merlingen, Thunersee)-Observations on the conduit of the Guntenbach (Gunten, Thunersee).

On Streams which flow as a Series of Roll-waves

ON June I I, I 904, I walked from Grindelwald to view the Apbach Waterfall. Alongside the sheet of water which leaped from the overhanging part of the rock was a small body of water sliding down the precipitous, but not vertical, part of the rock. The water here would have been only a small fraction of an inch in depth if it had been uniformly spread, but it was, on the contrary, flowing in detached portions, having the form of small, wedgeshaped, progressive "solitary" waves, miniature bores, about $\frac{1}{8}$ inch in amplitude, separated by portions of rock which were covered by a film of merely capillary thickness.

The same phenomenon was seen on another occa- 
sion, on a slightly larger scale, where the water of the little Pfanenbach flows down a precipitous rockface near Gunten, on the Thunersee. Here, again, the runnels of water were not wide, and the wavefront of the progressive waves was $\mathbf{V}$-shaped.

Water flowing in a broad, thin sheet upon a sloping platform goes in progressive wavelets, which have a widely extended wave-front, presenting a series of parallel ridges, which recall the typical form of surface waves more forcibly than the $\mathbf{V}$-shaped wavelets of a film flowing in a narrow runnel. I have detected the progressive-wavelet form of flow on the face of a vertical slab of smooth stone down which water flowed, but have seen it better upon the sloping, polished marble slab of a fishmonger's shop when being washed down with water flowing from a pipe. The outflow from the pipe may not have been absolutely. steady; but any unsteadiness there may have been was certainly slight, whereas the flow of the sheet of water rapidly formed itself into a procession of progressive wavelets, which were both conspicuous and regular. The ridges were about 9 inches apart. The same thing can be seen where the street pavement or a ship's deck is flushed from a large hose. 
From Territet (on the Lake of Geneva) to Glion, about 800 feet above, there runs a funicular railway, with an average ascent of nearly $I$ in 2 . On the east of the line is a cement conduit, I 4 inches wide, with flat bottom and nearly vertical sides, which carries off small quantities of water overflowing from the machinery, as well as, perhaps, a little drainage water. The regularity of the conduit is interrupted above the bridge which crosses it on a level with the Church of Les Planches, and the water there flows in the ordinary manner. It is only from the place where the cement floor commences that the waves become noticeable. The slight, rapid, and confused inequalities of the flickering flow here become regularised into transverse progressive waves in the course of a few yards, and these waves dash past the bridge and go foaming on as far as the railway station in an orderly and regular procession, dozens of frothy. crests being simultaneously visible.

On February 9, I 905, I measured the depth at the crests of the waves and found it to be 0.2 inches, and at the troughs $0 . \mathrm{I}$ inch. The apparent period (that is to say, the interval of time separating the passage of two succeeding crests past the observer 


\section{AND O'THER WATER W AVES 297}

on the bank) was 0.4 second on one occasion and 0.7 second on another. The wave-length attains a maximum of about 18 inches or 2 feet before the end of the run is nearly reached. The reason why the waves soon attain a uniform maximum size is that the increase of depth at the crests is accompanied by a corresponding diminution of depth at the troughs where the water becomes too far reduced for further growth. On one occasion I have seen the sudden accession of a little more water (from the passing train) greatly increase the size of the waves. On another occasion, however, near the Glion Station, when much water was poured into the conduit at the end of the journey, the progressive waves vanished altogether. There appeared instead diagonal stationary waves, originating from both sides of the conduit. When the excess of water ran off, the shallower stream ceased to be steady, and again ran in a series of progressive waves.

The cement floor and sides of the conduit are not, of course, nearly so smooth as the polished marble slab above referred to, but their surface is plain, uniform, and free from palpable excrescences. The course is straight, and of uniform gradient for considerable distances. The steepness of the gradient is immensely greater than in rivers. 
The wave phenomena in the conduit are absolutely different from those normal to rapid rivers of considerable depth. In the latter, any cause which retards the flow gives rise to waves stationary as regards the bank, with their steeper face upstream, and travelling through the water in a direction more or less directly up-stream. In the conduit, on the contrary, the waves, which have their steep face down-stream, travel through the water down-stream, as I proved by measurements, to be quoted later. In rivers of moderate depths where standing waves arise, the dominant factor in wave-making is pressure, the effects of friction being relatively very small. Thus, where pressure is increased, the stream-lines open out and the level of the surface rises, in the manner and for the reasons which have been set forth by many authors who have dealt with the theory of ship-waves.

The total depth is greater at the crest of the waves, and here the flow is slower; less at the troughs where the flow is quicker; and a state of continuous flow is thus maintained, an equal quantity of water passing each cross-section of the river in each unit of time.

But in the conduit, where the depth is initially very small, the frictional resistance of the bed be- 
comes the dominant factor in determining the rate of flow. If this small depth be increased, the rate of flow is at once greatly accelerated, for the upper layers flow with considerable freedom upon a couch of water, whereas the lowest layer clings to the bed. Thus a momentary retardation of flow at any spot, by increasing the depth there, enables the water which then arrives to flow with much greater speed. The excrescence caused by any momentary check therefore dashes down-stream. Thus every retardation quickly causes acceleration. This condition necessitates the substitution of a gushing for a continuous flow. The more highly developed are the down-stream progressive waves, or roll-waves, the more gushy is the stream.

I shall now give some account of observations of these spontaneous roll-waves in shallow streams (generally artificial conduits) which I made in Switzerland during 1904 and 1905. The waves in the conduits, which are much easier to observe than the corresponding waves in natural channels, throw some light upon occurrences which are confused and obscured under natural conditions.

When looking at water flowing past in a shallow channel, I find that the eye is generally fixed by stationary features of the surface, such as diagonal standing waves originating from the banks. When 
the gaze is thus fixed, the surface of the flowing water has either a smoothed-out appearance or that of stationary streaks or stripes. If, however, the eye can be trained to follow the water in its flow, it will be seen that its surface is usually covered with travelling inequalities. This habit of vision is somewhat difficult to acquire, and the movement of the eye is always liable to be arrested involuntarily by some fixed object. If, however, a small dead leaf, or a short piece of straw, or some such light thing, be cast upon the stream, the eye follows it in its drift naturally and with ease; and then, in shallow channels with a steep gradient, the surface of the water, instead of having a smoothedout or striped look, is found to be covered with rounded excrescences travelling at about the speed of the stream. The smoothed surface is, in fact, an optical illusion. An excellent opportunity of following up this observation was afforded me by journeying up and down on the funicular cars from Territet to Glion, and from Vevey to Mont Pélerin. The appearance of the water when coming down (the car sometimes travelling at almost exactly the speed of the current) was very. different from that when going up, or when standing on the banks. On the Mont Pélerin funicular, when going up, the only surface inequalities visible 
were diagonal standing waves. Coming down, a knobbly surface travelled along with us, one of the knobs of water occasionally bursting. There were no regular roll-waves in this case, but in that of the Territet-Glion conduit I was able from the car, which travelled down at nearly the same speed as the roll-waves, to observe that, in addition to the larger waves with front extending the whole breadth of the stream, there were innumerable embryo waves, which seemed to be in continual course of production. How embryo waves become united into relatively large roll-waves, regular in form and travelling in orderly procession, can be better explained from the phenomena observed in the conduit of the Grünbach, at Merlingen, on the Thunersee, Switzerland, during 1904 and 1905 .

Observations on the Conduit of the Grünnbach (Merlingen, Thunersee)

The Grünbach is the torrent flowing through the great gorge of the Justisthal to the Thunersee. The lower portions are first controlled by a series of weirs causing waterfalls, and, finally, for the last I,360 feet, the stream is carried in a straight, paved conduit about 7 feet deep and I 5 feet wide, with nearly vertical sides, the form and structure being: 
shown on the Plate. The lip of the conduit is several feet above the highest level of the lake, and the water leaps the outflow as a waterfall. The object of a structure so considerable as this conduit is, not the accommodation of the usual flow of water, but the provision for the great rush which takes place when a thunderstorm bursts over the Justisthal, especially in springtime before the snows are melted. Under ordinary conditions, even in wet weather, the average depth of water in the conduit is seldom more than 3 inches. The speed is so great, however, on a slope nowhere less than I in I4, that the discharge is not insignificant. With a depth of about 2 inches, the speed is about I o feet per second; but if the depth were increased to 3 feet or 4 feet, the speed would, no doubt, be very much greater.

The last of the series of waterfalls above the conduit discharges the stream into a pool, whence it flows over a piece of slightly hollowed pavement for $5 \mathrm{I}$ feet, when it enters the rectangular channel. The discharge of the upper waterfall is steady, in the sense that there is no cadence, the minor flickerings of one part neutralising those of another. The pool is of irregular depth, and the discharge from it has no regular pulsation. Nevertheless, as the water rushes over the slightly 


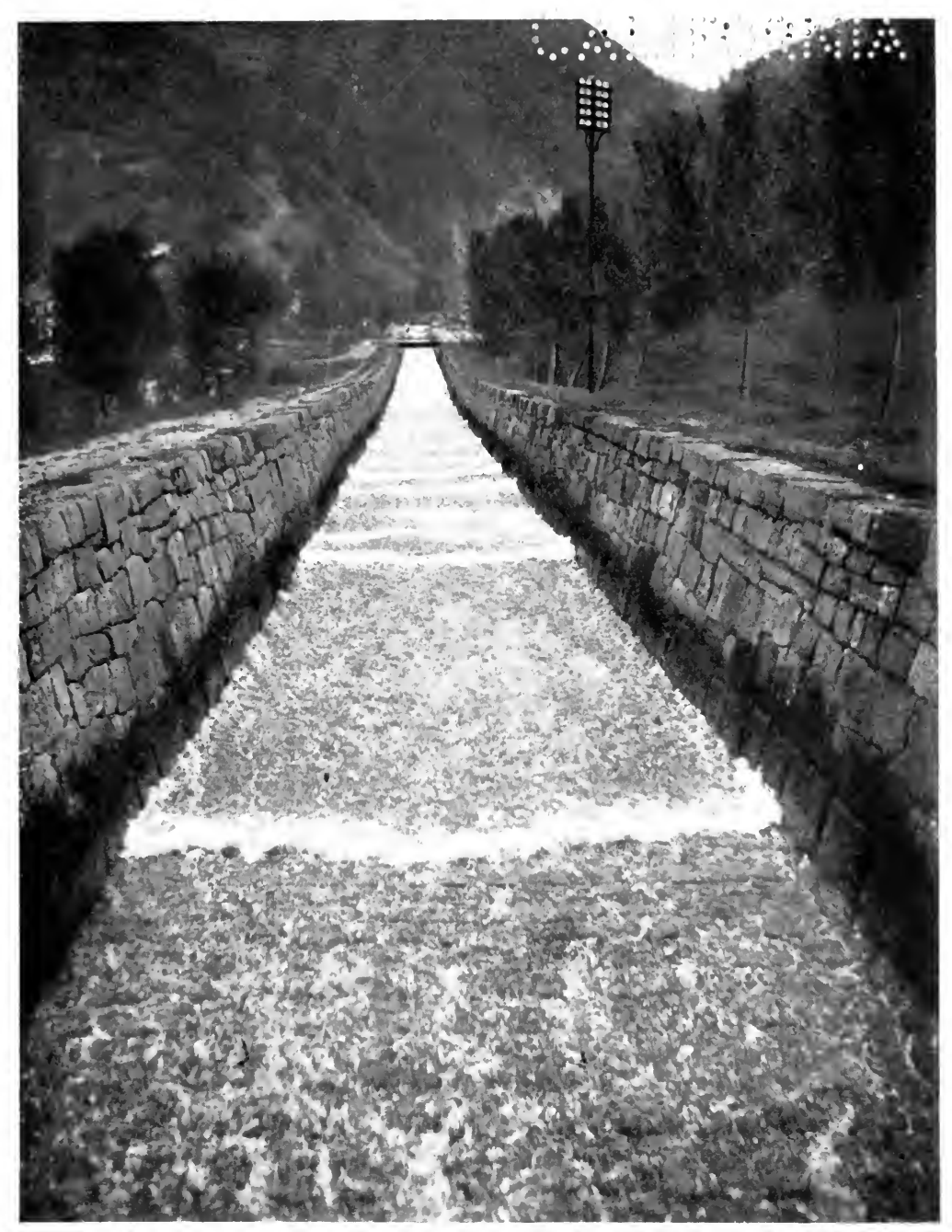

ROLL-WAVES IN THE GRÜNNBACH CONDUIT, LOOKING UP-STREAM. 


$$
\begin{array}{lll} 
\\
\hdashline & \ddots & \ddots
\end{array}
$$

$\therefore$\begin{tabular}{c}
$\therefore$ \\
\hdashline
\end{tabular} 


\section{AND OTHER WATER WAVES 305}

hollowed piece of pavement, it can be seen to flow gushingly, for the greater regularity of crosssection to some extent co-ordinates the flickerings, and the smaller depth tends to increase the gushiness of flow, as has already been explained.

At the entrance to, and for the first few yards of, the rectangular, flat-bottomed, paved channel these embryo roll-waves pass the eye in too rapid succession to be accurately. counted, but there are about 120 per minute. They are here little more than ripples, and the fronts, which face downstream, are free from white froth. As we walk down the bank of the conduit, we observe that a regularising process is at work, which, in a short distance, produces from this hurried and confused crowd of progressive wavelets an ordered series of roll-waves of greater amplitude, with foaming fronts facing down-stream, extending across the channel in a straight line at right angles to its axis. On June 6, I 904, at 465 feet from the entrance to the paved channel, there were notable larger waves; but there were many minor ones also, and the appearance was still somewhat confused. At a distance of 567 feet from the entrance to the paved channel there was no more confusion, a distinct series of waves, 33 per minute, passing the observer; whilst after travel- 
ling another 554 feet (or I; I 2 I feet in all), there were 20 waves passing every second; the height and length of the waves having increased proportionately, and the depths at the troughs being correspondingly diminished. The current is much accelerated at and near the crests, and considerably diminished in speed at the troughs, as is readily seen by watching the progress of small floating bodies.

At the outfall into the lake, a further distance of 240 feet, or I,36I feet in all, the waves were 17 per minute. The outfall of water is often twice or three times as great when a roll-wave crest arrives as at other times. The fall of the roll-wave is accompanied by a booming noise, and the flash of the outflowing water is sometimes visible at a distance of 2 miles.

On September I6, I 904, with a uniform depth in the upper part of the channel of 3 inches to $3 \frac{1}{2}$ inches, as nearly as could be determined, the water at the outflow had a depth of 8 inches at the crests and $I \frac{1}{2}$ inches at the troughs of the waves. The time of flow of the water from entrance to exit of the paved channel was 90.2 seconds-a short time indeed for the evolution of such a cadence from a mere flicker, and for the development of a wave amplitude from, say, $\frac{1}{20}$ inch to at least 6 


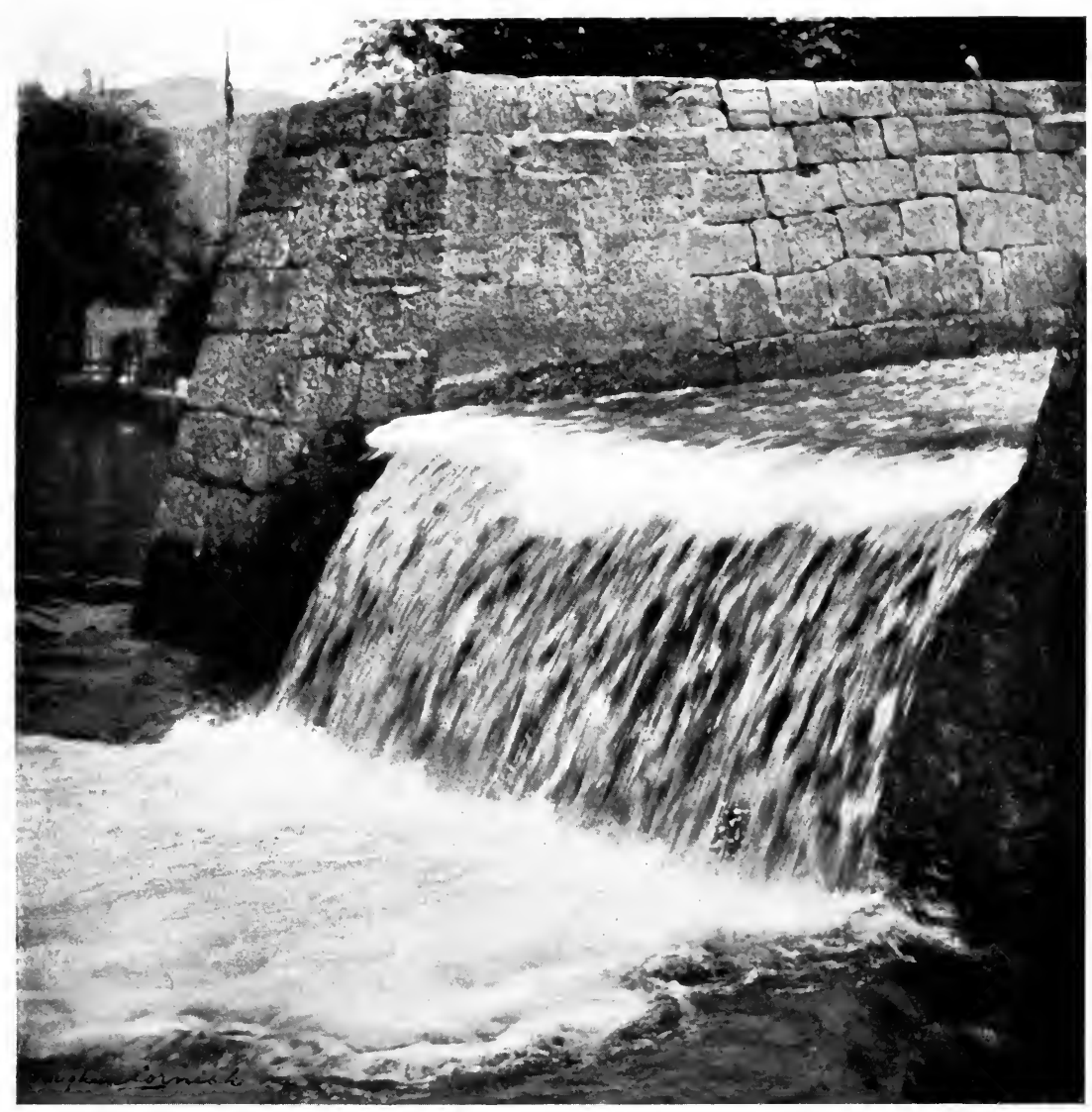

ROLL-IVAVE LEAPING THE OUTFALL OF THE GRÜNNBACH CONDUIT. 


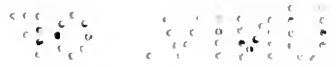

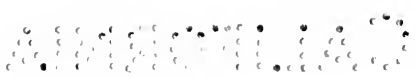




\section{AND O'THER WATER WAVES 309}

inches. The distance between the wave-crests in the lower part of the channel was on this day 66 feet.

The process of growth is easily observed, the larger wave-crests catching up the smaller and incorporating them, the wave-velocity being greater where the depth is greatest. As soon as the difference of depth between troughs and crests of the larger waves becomes considerable, the process of incorporation of the smaller wave-crests is much hastened ; for when they are situated in the troughs of the larger waves their total speed is much diminished.

On several days the speed of the current and the rate at which, the waves travelled past the observer were determined. The latter, which may be called the apparent speed of the waves, is the velocity of the current plus the rate at which the wave travels through the water in a downstream direction. Deducting the velocity of the current from the apparent velocity of the wave, we obtain the true velocity of the wave. If this should be found to be nearly the same as the calculated velocity of a long wave (viz., $\mathrm{V}=\sqrt{\mathrm{g} h}$, where $\mathrm{V}=$ velocity, $g=$ acceleration of gravity, and $h=$ depth, all expressed in feet and seconds), it may be safely concluded that these roll-waves 
progress by gravitational transmission of pressure in the manner postulated in the theory of long waves. The conditions are so different from those usually contemplated for long waves that such a test is far from superfluous.

True Velocity of Roll-Waves in the Grünnbach Conduit.

\begin{tabular}{|c|c|c|c|c|}
\hline Date. & $\begin{array}{l}\text { Observed } \\
\text { Depth } \\
\text { at Crest. }\end{array}$ & $\begin{array}{c}\text { Observed } \\
\text { Depth } \\
\text { at Trough. }\end{array}$ & $\begin{array}{c}\text { Observed } \\
\text { Speed } \\
\text { (F.P.S.). }\end{array}$ & $\begin{array}{l}\text { Calcu- } \\
\text { lated } \\
\text { Speed } \\
\text { (F.P.S.) }\end{array}$ \\
\hline 6, 1904 & $\ldots 2.5$ in. & I in. & 2.06 & $2 \cdot 5^{8}$ \\
\hline 8,1904 & $\cdots 4^{\circ} \circ$, & I " & 3.275 & 3.27 \\
\hline 15,1905 & ... 4.5, & $2 "$ & 3.54 & 3.47 \\
\hline
\end{tabular}

There was, however, one observation which did not agree with the theoretical numbers, and was also out of accord with the other three observations, viz. :

\begin{tabular}{|c|c|c|c|c|}
\hline & $\begin{array}{l}\text { Observed } \\
\text { Depth } \\
\text { at Crest. }\end{array}$ & $\begin{array}{l}\text { Observed } \\
\text { Depth } \\
\text { at Trough. }\end{array}$ & $\begin{array}{c}\text { Observed } \\
\text { Speed } \\
\text { (F.P.S.). }\end{array}$ & $\begin{array}{l}\text { Calcu- } \\
\text { lated } \\
\text { Speed } \\
\text { (F.P.S.). }\end{array}$ \\
\hline & $\ldots 8$ in. & $1 \cdot 5$ in. & 3 & $4^{\cdot 60}$ \\
\hline
\end{tabular}

Or, putting it the other way, the calculated depth at crest for the observed speed is only 4.6 inches, the difference from the observed depth of 8 inches being too great for error of observation. This was the occasion of greatest observed wave development on the Grünbach, the depth of I. 5 inches at trough being certainly small for the 
transmission of a wave with an amplitude from trough to crest of 6.5 inches. I think the discrepancy, however, is to be explained not so much by this circumstance as by an error introduced by the determination of the velocity of the current. I made a note at the time that the floating objects which I was observing were several times caught and pushed along by the foaming front of the waves. Thus their speed was probably greater than the average velocity of the current, making the wave-velocity come out too low.

On some occasions the failure of the stream just before the arrival of the crest was distinctly noticeable-a fact in itself, and apart from the measurements, indicating that the waves differ more in appearance than in essence from ordinary waves. The waves had not completed their growth when they reached the outflow; but if the length of the conduit could be much increased, we should doubtless see the last part of the course traversed by a series of waves of uniform height, length, and speed, as occurred after a short run in the shallower, but smoother, conduit of the TerritetGlion Funicular Railway.

The following table shows the number of wavecrests passing per minute at different distances from' the entrance of the channel, taken on several days, 
with the depth of water in the upper portion of the channel varying from 1.5 inches to 3 inches or 3.5 inches.

\begin{tabular}{|c|c|c|c|c|}
\hline Date. & $\begin{array}{c}\text { Distance in } \\
\text { Feet from } \\
\text { Origin. }\end{array}$ & $\begin{array}{l}\text { Period in } \\
\text { Seconds. }\end{array}$ & $\begin{array}{l}\text { Distance } \div \\
\text { Period. }\end{array}$ & $\begin{array}{l}\text { Ratio of } \\
\text { Period to that } \\
\text { at Outfall. }\end{array}$ \\
\hline 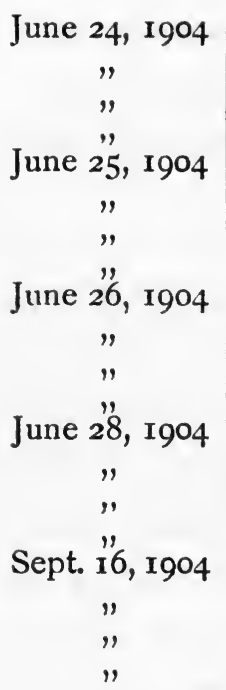 & $\begin{array}{r}465 \\
567 \\
1121 \\
1361 \\
465 \\
567 \\
1121 \\
1361 \\
465 \\
567 \\
1121 \\
1361 \\
465 \\
567 \\
1121 \\
1361 \\
465 \\
567 \\
1121 \\
1361\end{array}$ & $\begin{array}{l}2 \cdot 14 \\
- \\
4 \cdot 00 \\
4 \cdot 67 \\
- \\
2 \cdot 00 \\
3 \cdot 16 \\
4 \cdot 29 \\
- \\
1 \cdot 82 \\
3 \cdot 00 \\
3 \cdot 53 \\
1 \cdot 97 \\
- \\
- \\
4 \cdot 76 \\
1 \cdot 50 \\
- \\
- \\
3 \cdot 65\end{array}$ & $\begin{array}{c}217^{\circ} 3 \\
280^{\circ} 2 \\
291^{\circ} 4 \\
- \\
283^{\circ} 5 \\
354^{\circ} 7 \\
37^{\circ} 2 \\
- \\
311^{\circ} \cdot 5 \\
373^{\circ} 7 \\
385^{\circ} 6 \\
26^{\circ} 0 \\
- \\
285^{\circ} 9 \\
310^{\circ} 0 \\
- \\
370^{\circ} 0\end{array}$ & $\begin{array}{l}\frac{0.45^{8}}{0.856} \\
1 \cdot 000 \\
- \\
0.467 \\
0.737 \\
1 \cdot 000 \\
- \\
0.513 \\
0.851 \\
1 \cdot 000 \\
0.414 \\
- \\
- \\
I \cdot 000 \\
0.411 \\
- \\
I \cdot 000\end{array}$ \\
\hline
\end{tabular}

The period on any one occasion-i.e., for a particular depth of water-is proportional to the wave-length. If the wave-lengths were proportional to the distance run, for a particular depth of water, then the distance run divided by the period in seconds would be a constant quantity, 


\section{AND O'THER WA'TER WAVES 313}

for any one day. The figures show a less simple relationship, the period increasing somewhat slowly at first, although towards the end of the course the increase is more nearly proportional to distance run.

It will be seen from the tables that the rate of increase of period is nearly the same on different days when the depths differed by moderate amounts. In order to make a thoroughly satisfactory examination of such relationship it would be necessary to know, not only the distance run by the wave relatively to the bank, but also the distance travelled through the water, which was not determined on every occasion.

The following figures show the degree of irregularity in the intervals between successive wavecrests at the outfall. This measurement, made with a stop-watch, is very easily taken, and is free from the uncertainties which attended the measurement of depth, and, to some extent, of the velocity of current.

The intervals between Successive Wave-crests at Outfall of the Grünnbach. In Seconds.

$$
\begin{aligned}
& \text { 5, 3, 4, 8, 4, 7, 4, 4, 2, I, } \\
& 5,4,5,6,4,5,3,3,4, \mathbf{1} \\
& 6,3,4,2,4,4,3, \mathbf{1}, 7,2, \\
& 7,9,2,9,8, \mathbf{1}, \mathbf{1 0}, 5,6, \\
& \text { I, 4, 9, I, 6, I, 2, 6, 7, 4, }
\end{aligned}
$$


6 waves had a period of 1 second$$
6
$$

$6 " \quad " \quad 2$ seconds

$5 \quad " \quad, \quad 3 \quad$

$14 \quad, \quad, \quad 4 \quad$,

$6 \quad " \quad, \quad 5 \quad$ "

$5 ", \quad " \quad 6 \quad$,

$+\quad " \quad " \quad 7 \quad$ "

$2 \quad, \quad " \quad 8 \quad$,

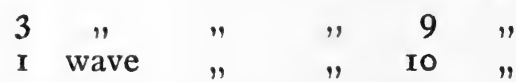

Reverting from figures to the description of appearance, I may note the following additional circumstances observed in the Grünnbach conduit, which tend to elucidate the origin and mode of growth of the train, or series, of roll-waves.

The first noticeable agency of growth is the catching up of the smaller waves by the larger, due to more rapid motion of the latter; but a new factor (not possible on the cement floor of the Glion conduit) is the increase of amplitude as the front passes over each transverse ridge of the flag pavement. It appears, therefore, that we have here a case of a progressive wave increased, not merely by friction with a flat bed, but also by passing over perceptible transverse inequalities. The depths being small, the reasoning previously employed to explain discontinuous flow as resulting from local increase of depth still holds good. 


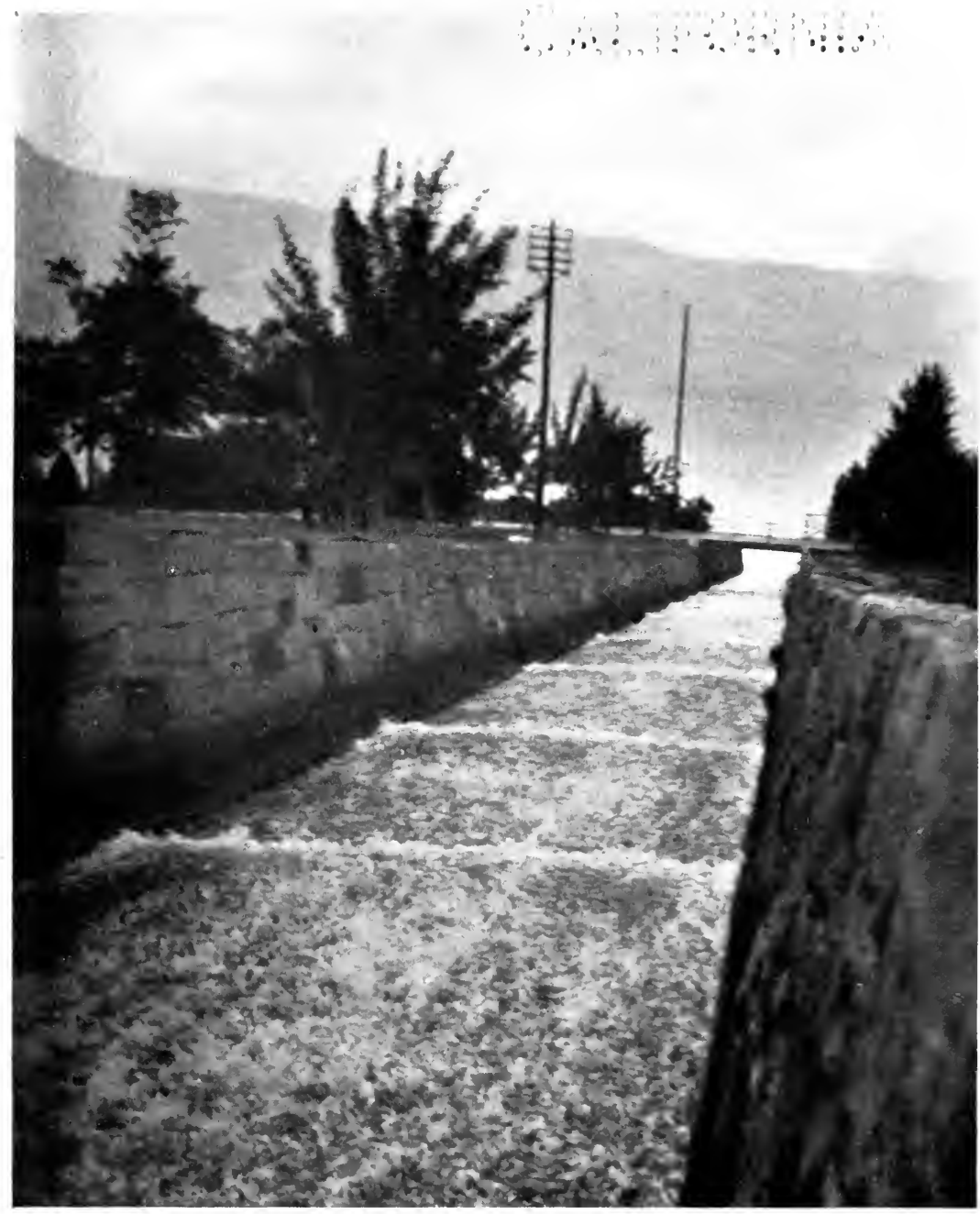

ROLL-IWAYES IN THE GRÜNNBACH CONDUTT, LOOKING DOWN-STREAM. 


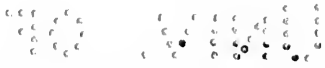

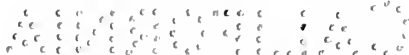


There is one portion of the conduit paved more smoothly, in larger and better trimmed blocks, than the rest. Here, when there was little water, the wave development proceeded best; afterwards, on entering the rougher part, the wave was somewhat broken up. But when the depth of water was greater, there was but little growth of the wave in passing over the smoother pavement, the growth becoming more rapid when the wave began to ride over the transverse joints of the rougher pavement. Thus, for the best development of the wave, there should exist a certain proportionality between the amplitude of the transverse corrugation and the depth of the water.

The longitudinal joints of the pavement tended somewhat to destroy the transverse wave, especially when any irregularity of channel caused the wave to pass somewhat obliquely across them.

There was a good deal of lateral wave motion, which sent a considerable wash against the sides of the channel; but these, being nearly vertical, reflected the wave back again, and thus tended to keep the front transversal. About half-way down the conduit the slope is somewhat abruptly diminished, remaining thereafter less than in the upper half. It was always a matter of surprise to 
me that no obvious change in the waves occurred when the gradient diminished.

The uniformity of depth in this conduit is, of course, a most important factor in preserving the transverse waves, and the unequal depth (in crosssection) in natural streams equally tends to prevent their development. I saw an excellent example of this at St. Maurice, in the Rhône Valley, where a paved conduit terminated in a channel encumbered by gravel, through which the stream had made for itself the usual winding course, with unequal depths on the two sides. The conduit delivered strong transverse roll-waves at intervals of a few seconds, each of which vanished almost instantaneously upon entering the winding channel of unequal depths in cross-section.

Since the velocity of the wave relatively to the banks is that of the current plus the true wavevelocity, and the latter is greater for deep water, it follows that the wave-front loses its transversality when the cross-section of the stream is not uniform, and this is more marked in downstream roll-waves than in up-stream bores (where current and wave oppose one another). This is one reason why down-stream progressive waves are so much less familiar than up-stream bores. 


\section{AND OTHER WATER WAVES 319}

Observation of Roll-waves in the Conduit of the

Guntenbach, Gunten, Thunersee, Switzerland

The Guntenbach, which drains a smaller valley than the Grünbach, runs for the last 1,000 feet of its course in a paved conduit, with a practically uniform gradient of $I$ in 22 , as measured with a small Abney level. The sides of this conduit are sloping, not vertical, as in the Grünnbach; the paving-stones are more irregular in form, and the depressions at their joints are deeper, as well as less regular. No roll-waves were ever seen in the upper part of the conduit ; ${ }^{\mathrm{I}}$ they originated suddenly lower down, generally at or below the lowest bridge, which was 370 feet from the outfall. Thus the course of events differed considerably from that in the Grünnbach, where the waves could be watched through all their stages of development. On the roughly-paved Guntenbach it took much watching to discover the origin of the roll-waves. I would stand near by where they generally commenced, watching the water closely; then, to the right or to left of where I was looking, I would hear a sudden sound like that of the word "flop," and,

- The upper part of the conduit has in many places deep longitudinal grooves in the central paving-stones. The crosssection of the lower part is more nearly uniform. 
on turning quickly, there would be a fully-formed roll-wave extending transversely across the whole channel. Once formed, they were never subsequently dissipated, but, on the contrary, grew quickly as they travelled through the water. The reason for their growth was not evident from mere observation. The outfall into the lake was in fairly regular cadence, the phenomenon being similar to that of the Grünnbach, though not so crisp. This want of crispness was evidently due partly to the sloping sides, which did not keep the wave-front so perfectly transverse as the Grünbach. The Plate is from photographs taken at intervals of a few seconds, the first photograph showing the outfall of the Guntenbach at a wave-trough, the second at a wave-crest.

After watching for three months, I came to the conclusion that the mode of origin of the waves in the Guntenbach was entirely different from that in the Grünbach. In the former there were some slight, long depressions extending the whole width of the pavement which were almost masked by its general roughness. The most marked depression was under the lowest bridge, and somewhat concealed thereby. I found that the roll-wave started here more often than at any other point, and I noticed that up-standing edges of the pavement 

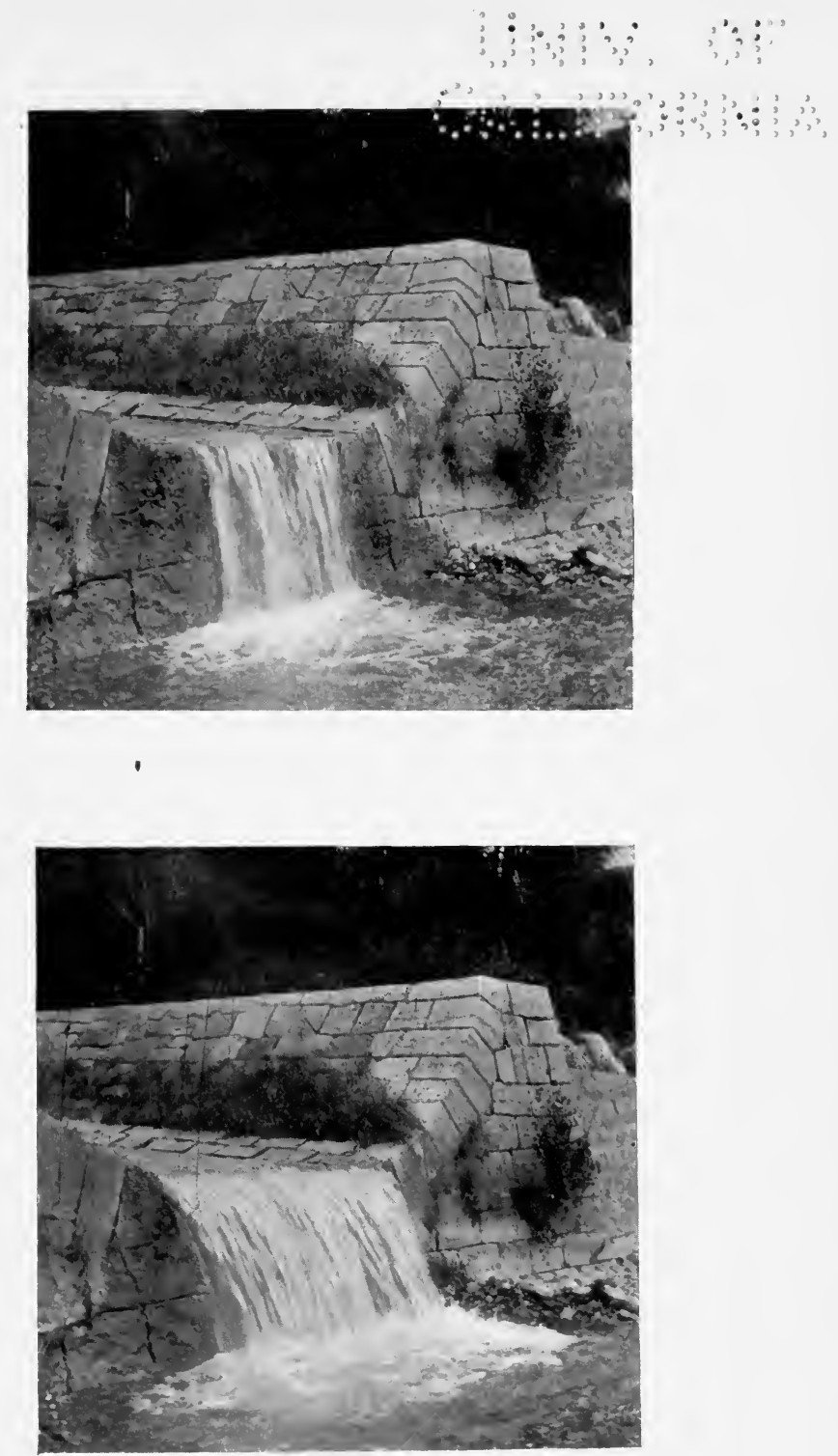

OUTFALL OF THE GUNTENBACH AT THE IVAVETROUGH, AND (A FEW SECONDS LATER) AT THE WAVE-CREST. 


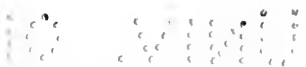

$$
\begin{aligned}
& \text { a }
\end{aligned}
$$




\section{AND OTHER WATER WAVES 323}

stones made something resembling a dam at the lower end of what was, in fact, a pool. Here the wave seemed to originate by the sudden emptying of the pool. The depth being very small (generally not more than $1 \frac{1}{2}$ inches or 2 inches on the sill), and the pool being several yards long, there was great sensitiveness to the slight flicker always perceptible in this and similar streams. Wherever in the course of these irregular flickerings a slight deficiency was followed suddenly by a slight excess, the latter would have to burst a way across the shallow sill as a small wave with a steep front; and this, clearing the way before it, drained the pool considerably, thus preparing for the formation of a second wave. This reasoning, I repeat, is only valid for a certain scale of things. If the dimensions be greatly changed, the relative importance of the factors would also be changed. This origin of the wave by the filling and emptying of a sort of pool accounts for the fact that the interval between successive waves on the Guntenbach was never less than several seconds, whereas on the Grünbach the period at first was much less than a second. When the Guntenbach was flowing sluggishly, with less water than usual, the period was always a long one, for it took a long time to fill and empty the 
pool. When there was very little water, the formation of the waves appeared to be capricious, a long interval occurring, during which the stream flowed steadily, to be succeeded by a fairly regular series of waves. On the small conduit of St. Maurice, ${ }^{1}$ already referred to, this capriciousness was still more marked, and more obviously depended upon some slight variations in the strength of the stream, caused one knows not how. It is evident that in this case we have something rather like the roll-waves of the Tees on a minute scale. The average depth in the conduit of the Guntenbach was difficult to determine on account of the inequalities of the pavement, but 2 inches was a usual amount. The speed of the current was determined at 8.5 feet per second, and the true speed of the wave at approximately 2.25 feet per second. On one occasion the depth at crest at outflow was estimated at 3.5 inches, and at the trough 2 inches.

On more than one occasion a thunderstorm filled the conduit to a depth of from 5 inches to 9 inches, and then there was absolutely no roll-wave or

${ }^{x}$ Average period of waves, 13.5 seconds. The conduit was only 3 feet wide, and paved with blocks extending the whole width, so that there were no longitudinal joints, which in the Guntenbach tend to spoil the wave by making unequal depths in cross-section. 

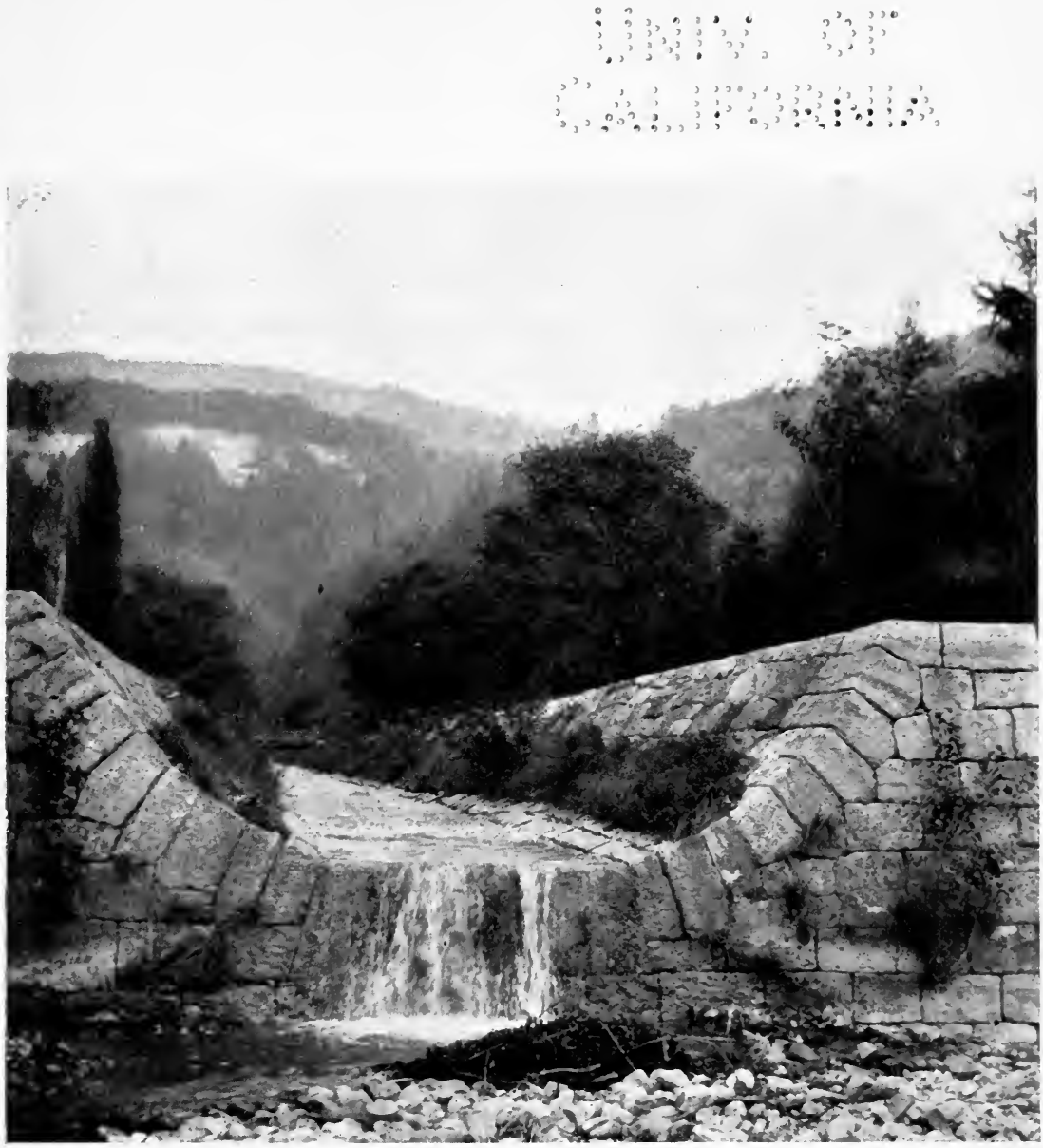

THE GUNTENBACH IVITH TWO ROLL-WAVES. 


$$
\begin{aligned}
& \because \because \because \quad \because \because \because \vdots \vdots
\end{aligned}
$$

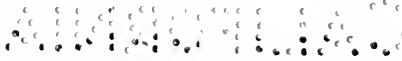


cadence in the outflow. The depth was, therefore, apparently too great for the effect of frictional resistance to produce an intermittent flow, and the pools of the pavement were now too insignificant to act as they did with a smaller depth of water.

I have never seen a stream with a uniform depth of more than 4 inches adopt spontaneously the intermittent flow in a series of roll-waves. The conduit of the Chauderon River at Montreux, with a depth of 6 inches, did not flow thus; neither did the much larger Veveyse River, in its conduit at Vevey, flowing, swiftly at the time of snowmelting, with a depth of 48 inches.

Nevertheless, I found (after my eyes had been trained by watching well-marked roll-waves for some months) that waves progressing down-stream through the water co-exist with stationary waves in shallow streams, and may even be detected in deep ones, although they do not (except if caused by floods) there develop or grow so as to become conspicuous or important relatively to the other phenomena of flow. Thus (commencing with the Guntenbach), on looking closely at a standing wave (in which the depth of water was only about 2 inches) I noticed that the water here flowed gushily-i.e., the excrescence of the bottom, which 
caused a stationary wave, also caused progressive waves. Close to Schloss Ralligen (between Gunten and Merlingen) is a short and very steep conduit, 3 feet wide, with a pavement of ribbed form, each rib extending quite across the conduit. The distance from the summit of one rib to that of the next is 6 inches, and the line of the crest of the ribs is about 0.3 inches above the line of their troughs. The depth of water covering the crests of the ribs was 0.5 inch. The appearance of the whole is that of a cascade with transverse bars of white foaming water, situated at the summit of each rib, these transverse bars showing (as is usual in cascades and waterfalls of small dimensions) a longitudinal striping, so that the form of the standing waves caused by each rib is that of a comb, the back of the comb representing the principal transverse line of white water, and the teeth the smaller longitudinal lines of white water. This, with a slight flicker, was all that I saw in 1904 . But in 1905 , being now aware how stationary objects fix the eye so that it cannot distinctly see moving things, I I tried the expedient,

- Conversely when moving bodies are many and conspicious the attention is distracted from stationary objects. A good example of this may be obtained by visiting the vicinity of the Mansion House in the City of London early on a Sunday morning. Those who think that they are familiar with the sur- 
which I had often found useful, of half-closing the eyes, so as to render the outlines of the stationary objects indistinct. I saw immediately that roll-waves extending the whole breadth of the conduit were dashing down the channel all the time with great speed, and at intervals of not more than half a second. Thus by varying the method of looking, it became possible to appreciate clearly the dual aspect of the phenomena of the flow. The roll-waves were no insignificant part of the whole flow, the apparent predominance of the stationary waves being due more to optical advantage than physical superiority. I made a similar observation in the roughly-paved steep conduit which carries the Verraye torrent at Veytaux (Switzerland) in the lower part of the course below the lower road.

In deep streams the down-stream progressive waves are difficult to observe, but I have no doubt that they are normally present wherever waves exist at all. If the eye be allowed to follow the stream, it is often easy to see some travelling inequalities of surface in the deep water, especially when the light is low, but it is not always clear whether they are truly waves;

rounding buildings from frequent, or even daily, visits will probably notice many architectural features which escaped their attention during the hours of busy traffic. 
still less is it usually possible to know if they are travelling through the current down-stream. If, however, the streams have gently shelving shores, and especially if these be smooth, the direction of the waves which come in upon them facing diagonally, but on the whole down-stream, indicates clearly that there are in the deep water progressive down-stream waves invisible only on account of their flatness.

Should I have the opportunity to revisit the Niagara Whirlpool Rapids, I might perhaps detect the existence of down-stream waves there, although I could not do so before I had daily practice in their detection. The fact that waves which have not a length great as compared to the depth continually multiply themselves, would of itself account for the fact that such waves tend to die out rather than to increase in deep streams. Unequal depth of cross-section, as has already been mentioned, also tends to do away with them, causing them to discharge themselves upon the banks. 


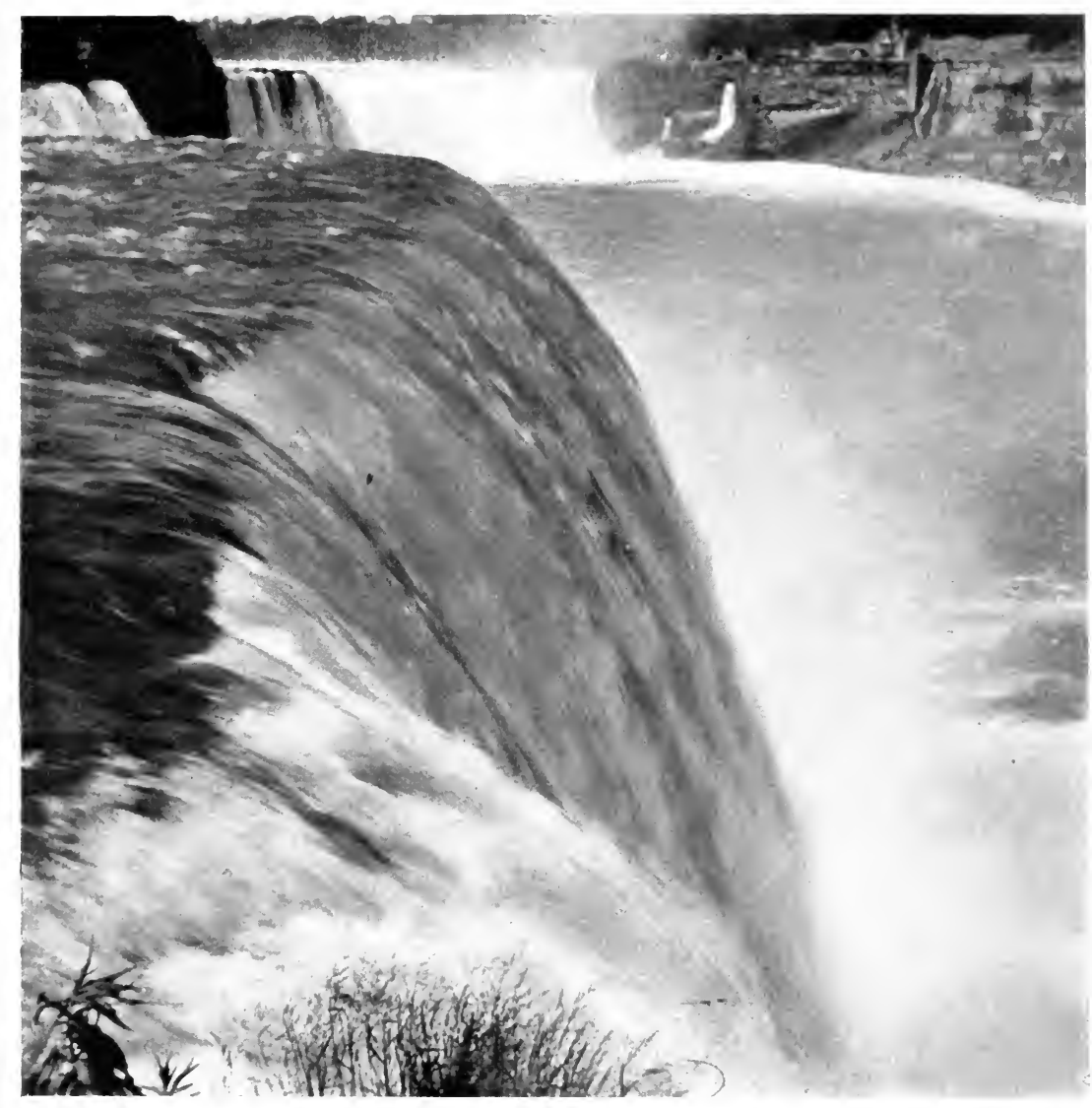

UPPER PART OF FALLS AT NIAGARA, SHOWING UNBROKEN WATER. 


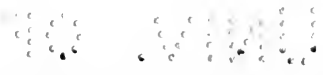

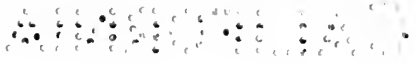




\section{CHAPTER XII}

The sounds of running water-The gushing motion of cataracts - Conical structures produced by the break-up of a waterfall-The wave-track of a ship.

\section{On the Sounds of Running Water}

WHEN we watch the standing waves of a shallow stream and think, perhaps, of the steady state to which it is supposed to have attained, the pleasant but irregular sounds which greet the ear are evidence of momentary variations in this state, and of disturbances passing down-stream. The sound of the foaming cusped wave, if continuous, would, indeed, indicate a steady condition, although the motion at that spot is "discontinuous" in the sense that the thread of the stream is there broken; but the breaking of the cusped wave is, as a rule, intermittent. From time to time also a pretty tinkle catches the ear, a single sound, presently repeated in another place. A careful study of these sounds will greatly assist the eye in discovering the details of the stream's motion. It is upon the sounds as 
much as the appearance that the poetical student of Nature has relied for conveying his impressions of these scenes. Tennyson's phrase to "babble on the pebbles" is a familiar example. When he speaks of the "drumming thunder" of a great waterfall, he records by ear the partial intermittence superimposed upon a steady motion, which will be dealt with in the next section of this paper.

On Gushing Motion in Cataracts and on the Conical Structures produced by the Breakup of a Waterfall

We have seen how in a swift shallow stream the frictional retardation of the layers next to the bed imparts a gushing motion to the water, which, when the channel is straight and of uniform crosssection, produces a train of long waves of the bore form with foaming fronts transverse to the current, following one another in regular succession down the stream. In cataracts and waterfalls there is also a gushing motion, but it is irregular. In hilly or mountainous districts the noisy cataract of white water replaces the clear babbling brook with standing waves which is characteristic of undulating country, or the silent stream of the plain with its curling currents and 


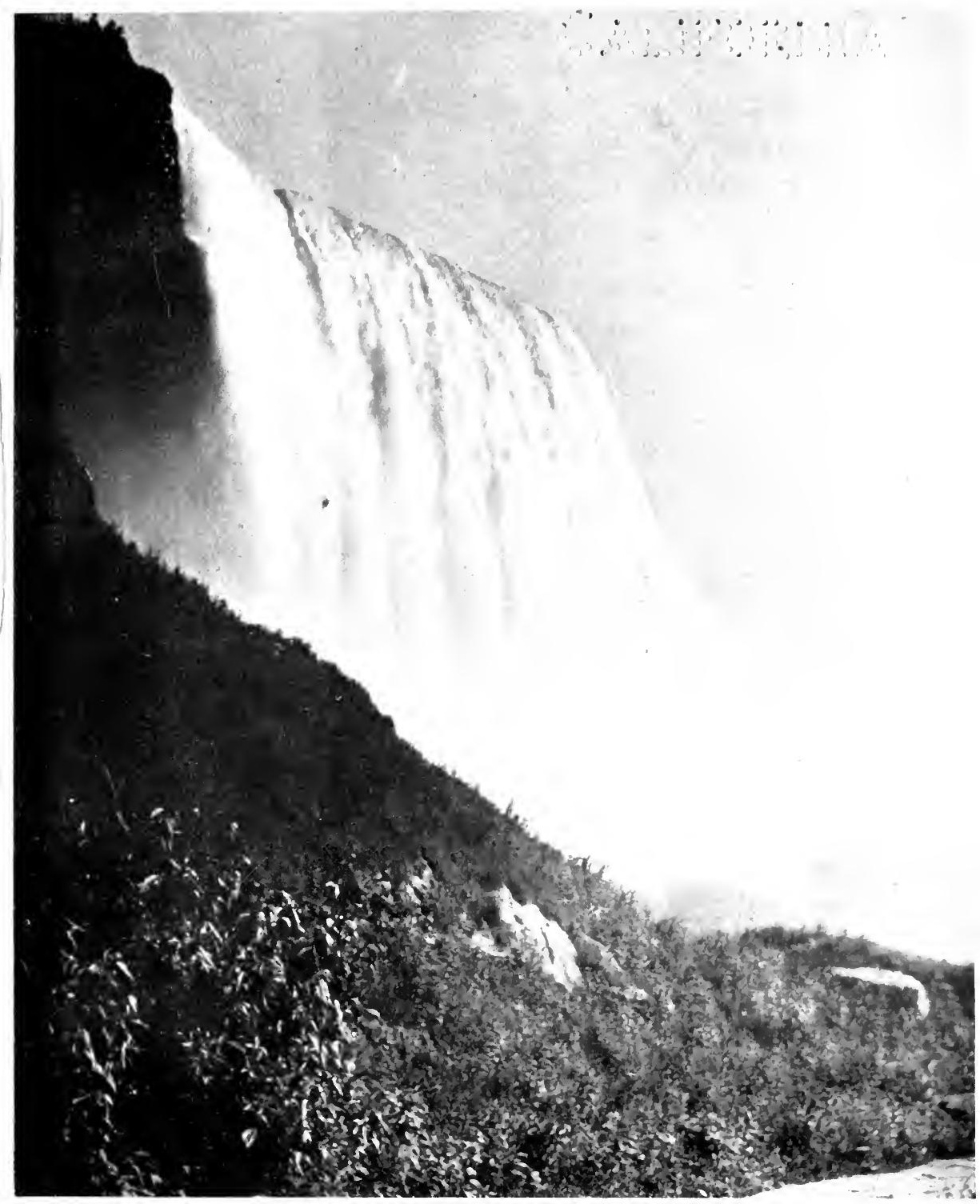

NIAGARA FALLS, SHOWING FLEECY APPEARANCE PRODLCEI BY THE BREAKING OF THE FALLING WATER. 


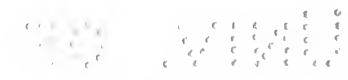

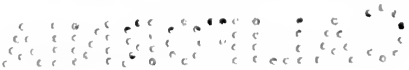


smooth surface. The broken water of the cataract passes too swiftly for the eye to follow its motion, and the streaky appearance is evidently due to this circumstance. On thrusting my hand into the flying water of a small cascade which comes foaming down through the Forest of Chillon I found that the real intermittence of the optically continuous motion was at once apparent, for instead of being subjected to a pressure, as from a current, the hand experienced a succession of sharp buffets.

In a cataract descending the right bank of the Gorge of the Chauderon, at Montreux, I saw well the transition from the rush of the cataract to the leap of the waterfall. Along reaches of lesser steepness the water kept to its bed, yet all whitely. foaming, being torn to drops by friction with its bed; but steeper reaches were leaped by the shower of water, the leap being what one calls a waterfall. By a cataract I mean that extreme case of a torrent in which the water is all foaming.

A low waterfall of I foot or 2 feet in height, unless delivering water already in violent motion, generally presents to the eye a number of brilliant vertical stripes, having a lustre as of polished metal, continuous from top to bottom, and practically steady in position. 
The appearance of the water in a high waterfall is quite different, for the water is more opaque or milky, there are none of these brilliant stripes, and (especially if the eye be allowed to follow the water in its fall) it is seen to be patchy, the patches being more or less conical or V-shaped. Photographs of waterfalls sometimes show them, when the shutter of the camera works with sufficient rapidity. Livingstone thus describes these characteristic bodies as he saw them at the Victoria Falls of the Zambesi: I "On the left side of the island we have a good view of the mass of water... as it leaps quite clear of the rock, and forms a thick, unbroken fleece all the way to the bottom. Its whiteness gave the idea of snow, a sight I had not seen for many a day. As it broke into (if I may use the term) pieces of water, all rushing on in the same direction, each gave off several rays of foam, exactly as bits of steel, when burned in oxygen gas, give off rays of sparks. The snow-like sheet seemed like myriads of small comets rushing in one direction, each of which left behind its nucleus rays of foam. I never saw the appearance referred to noticed elsewhere. It seemed to be the effect of the mass of water leaping at once

x "Missionary Travels in South Africa." 

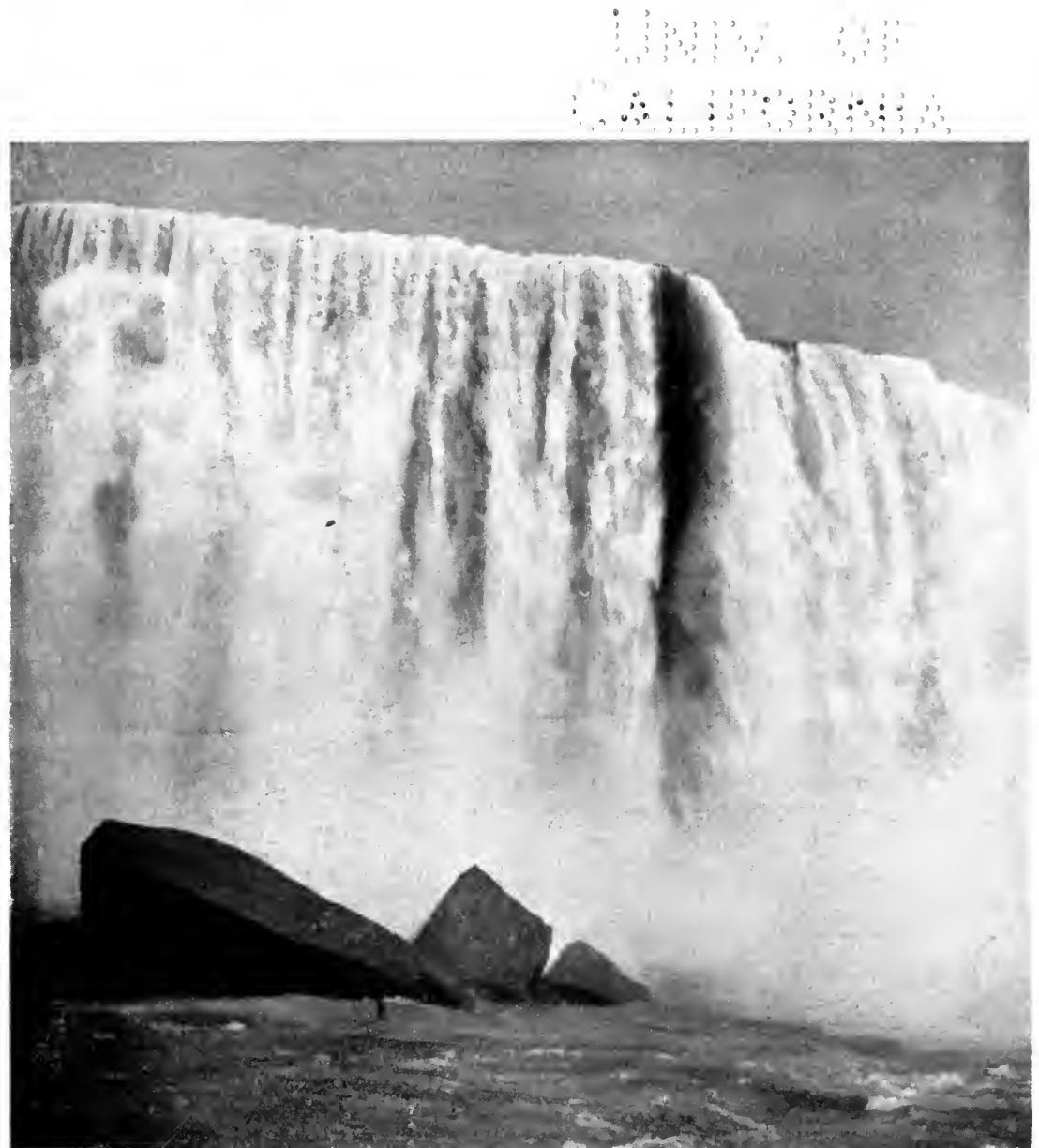

THE BREAKING WATER OF NIAGARA FALLS, TAKEN FROM S.S. MAID-OF-THE-MIST. 


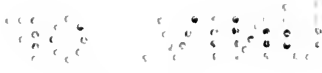

$\therefore \quad 9$ 


\section{AND O'THER WATER WAVES 341}

clear of the rock, and but slowly breaking up into spray."

The phenomenon is very noticeable in the comparatively thin sheet of water which forms the American Falls at Niagara, but the 20-feet-thick green water at the "Horse-shoe" retains its homogeneity much better. This fact indicates that the partial break-up of a waterfall is not due so much to friction with the air as to other causes, chief among which is, presumably, the dynamically unstable condition of a sheet of water falling under the constant acceleration of gravity. This partial breaking up, which, as Livingstone well indicates, is an early stage of the process by which the water will, if it falls far enough, be finally resolved into spray, must be greatly hastened in the case of a waterfall fed by a stream already markedly intermittent in its motion. I have already described (p. 273) the unsteady motion of the shallow water in the rapids above the American Falls. The late Professor J. Tyndall says ${ }^{x}$ of the Falls : " The descent finally resolves itself into a rhythm, the water reaches the bottom of the fall in periodic gushes." And Captain Basil Hall, in the Cave

x "Niagara," a discourse delivered at the Royal Institution of Great Britain, April 4, 1873, published in the Fragments of Science (p. 178$)$. 
of the Winds, behind the falling sheet of water, found that the barometer pulsated. The cones in the American Falls appeared to follow one another in swift succession, but in watching the fall of the water of the Tschingelbach, at Burglauenen, near Grindelwald, Switzerland, May 22, 1904, where the cones were very perfect, but the volume of water small, I concluded that the apparent swiftness at Niagara was due to the great number of cones passing confusedly. So also do snow-flakes seem to pass the eye rapidly when we look through a long column of air, standing out of doors, but if we watch from the interior of a room, so that no flakes pass close to the eye, it is seen that for the most part they are subsiding slowly through the air.

The conclusion was confirmed when I next viewed the Tschingelbach Fall. The amount of water was then much diminished, and the fall was coming down in several separate threads of water instead of in a broad sheet. The cones in each of these threads of falling water followed one another in an orderly and unhurried manner, ${ }^{1}$ the

I In a narrow waterfall at Isetwald, on the Lake of Brienz, I saw the cones, which were close together near the commencement, become widely separated as their velocity increased under the action of gravity. 


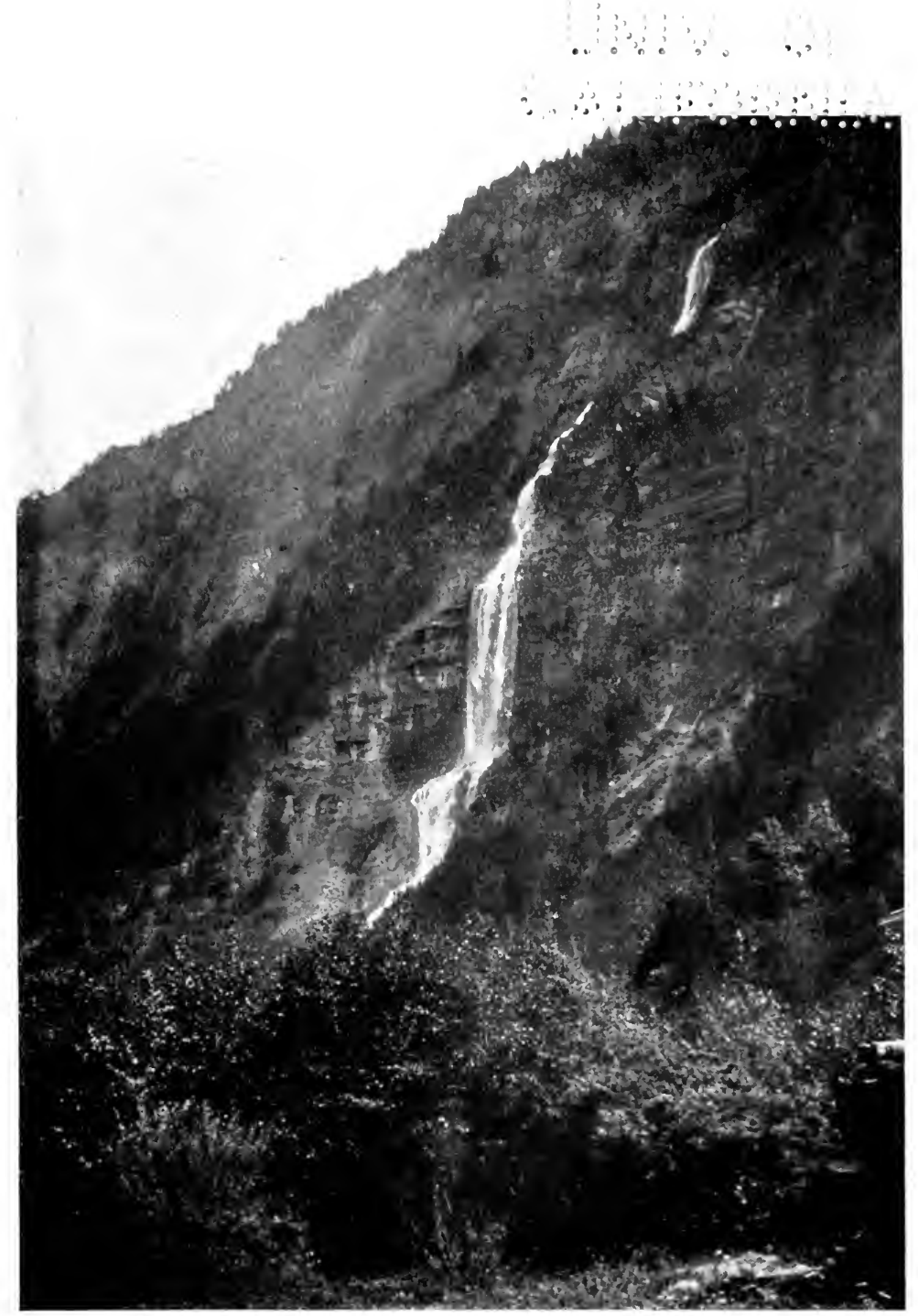

FALLS OF THE TSCHINGELBACH, BURGLAUENEN. 


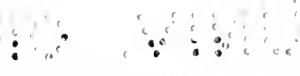

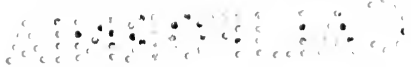


speed of each individual cone increasing as it fell, the pointed shape sometimes becoming more pronounced, until at last the forces making for disintegration dissipated the structure in spray.

This appearance is closely paralleled in the case of the snow avalanches seen from Grindelwald when they leap the edge of precipices on the Eiger or the Mettenberg. There is the same appearance of cones amidst the white clouds of snow, the cones increasing in speed, with sharpening points, and finally bursting in 'dust. The drawing out to finer lines as the cone descends is easily understood if we remember the acceleration of gravity, and the air-resistance at the edges, and the greater retardation of the finer particles. In water it is the same. When jets are thrown upwards, as from the "Horse-Shoe" at Niagara, the sharpening of a cone proceeds still more quickly.

On visiting the Tschingelbach in June, I905, I saw the water-cones in very fine development, and they were even united into roughly transverse bands. Between these the veil of misty spray was thin and semi-transparent. I then perceived that there was a local cause for their unusually fine development in the last big leap of the fall, for the water above slides over a steep face of rock, where it goes into fairly well defined roll-waves. 
The ranging of the water-cones in roughly transverse bands is due to this cause; they gradually lose their transversality as they descend.

Below a waterfall near Matten, Grindelwald, the waters flow steeply over a bed of rock, which gives a uniform, small depth to the stream, which flows in roll-waves owing largely to the initially discontinuous character of the motion of the falling water.

Below one of the principal leaps of the Giessbach Falls (Lake of Brienz) I also saw down-stream waves, which, however, soon lost their transversality on entering the swift channel of exit from the pool.

When any waterfall or cascade discharges into still, deep water, progressive trochoidal waves proceed outwards in all directions, as may be prettily seen, for instance, in the ornamental waters of the public gardens at Buxton.

On the Wave-track of a Ship as seen on the Swiss

\section{Lakes}

The late Lord Kelvin described ' the dual system of waves which originates at the bow of a ship. They are the diverging series, the fronts of which x "Popular.Lectures and Addresses." 


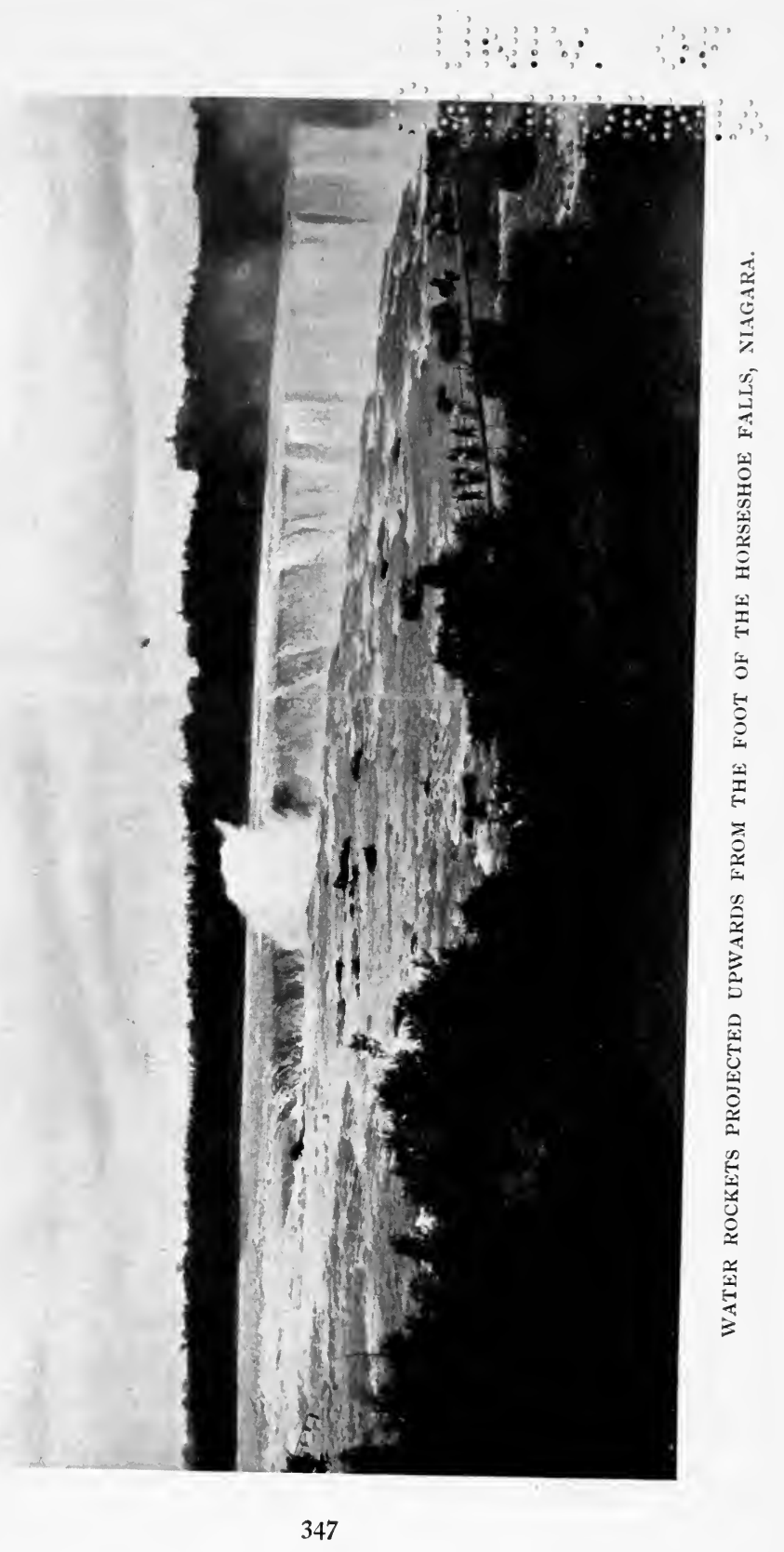




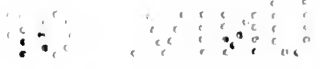

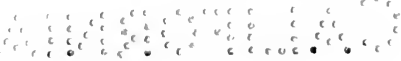




\section{AND OTHER WATER WAVES 349}

make an angle with the ship's course, and the transverse series which lie across her course, travelling in the same direction. Leaving out of account the first two or three diverging bow-waves, every wave of this series has a front concave to the direction of advance. The transverse series have fronts convex to the direction of their advance. They are flatter than the diverging waves, and therefore less conspicuous if the water be ruffled. This whole system of waves is bounded on the right and left by two imaginary straight lines, each making an angle of $19 \frac{1}{2} \circ$ with the ship's course. A similar dual series of waves originates from the stern. The pattern of waves originating from the bow or from the stern, as deduced mathematically, satisfies all that is usually visible at sea.

Being anxious to see ship-waves undisturbed by the waves of swell or wind, I decided to make observations on the placid waters of Swiss lakes. I began on the Thunersee during the fine summer weather of 1904, and continued the observations at Montreux, on the Lake of Geneva, in the spring of 1905. On still mornings the surface of the Thunersee was frequently as smooth as plate-glass, without any ruffle or darkening by even the gentlest breeze.

Under these conditions I found that the thwart 
waves are more conspicuous relatively to the diverging waves than in rougher water, and that their relative prominence is further increased when the wave-track is viewed from a height. At altitudes of from 300 to 800 feet on the steep slope above Gunten, opposite to Spiez, the number of visible thwart-ship waves in a single series must have amounted to hundreds, the water looking like corded silk. Unfortunately, the condition of glassy water is often accompanied by a slight haze, which makes it impossible then to obtain a strong photograph.

I saw nothing in the appearance of the train of thwart waves different from that indicated by Lord Kelvin's diagram, and nothing different from what is seen at sea, except their greater distinctness. The case of the diverging waves, however, was very different. Only the outer edge of the group. presents the uninterrupted concave fronts of the diagram. Behind this comes a row of notches in the wave-fronts, which row appears from a distance as a strongly marked band, light or dark according to the circumstances of reflection. Standing near the stern of a steamer, I was able to see distinctly that the first notch occurred where a diverging wave of the bow series was crossed by the first diverging wave of the series which 

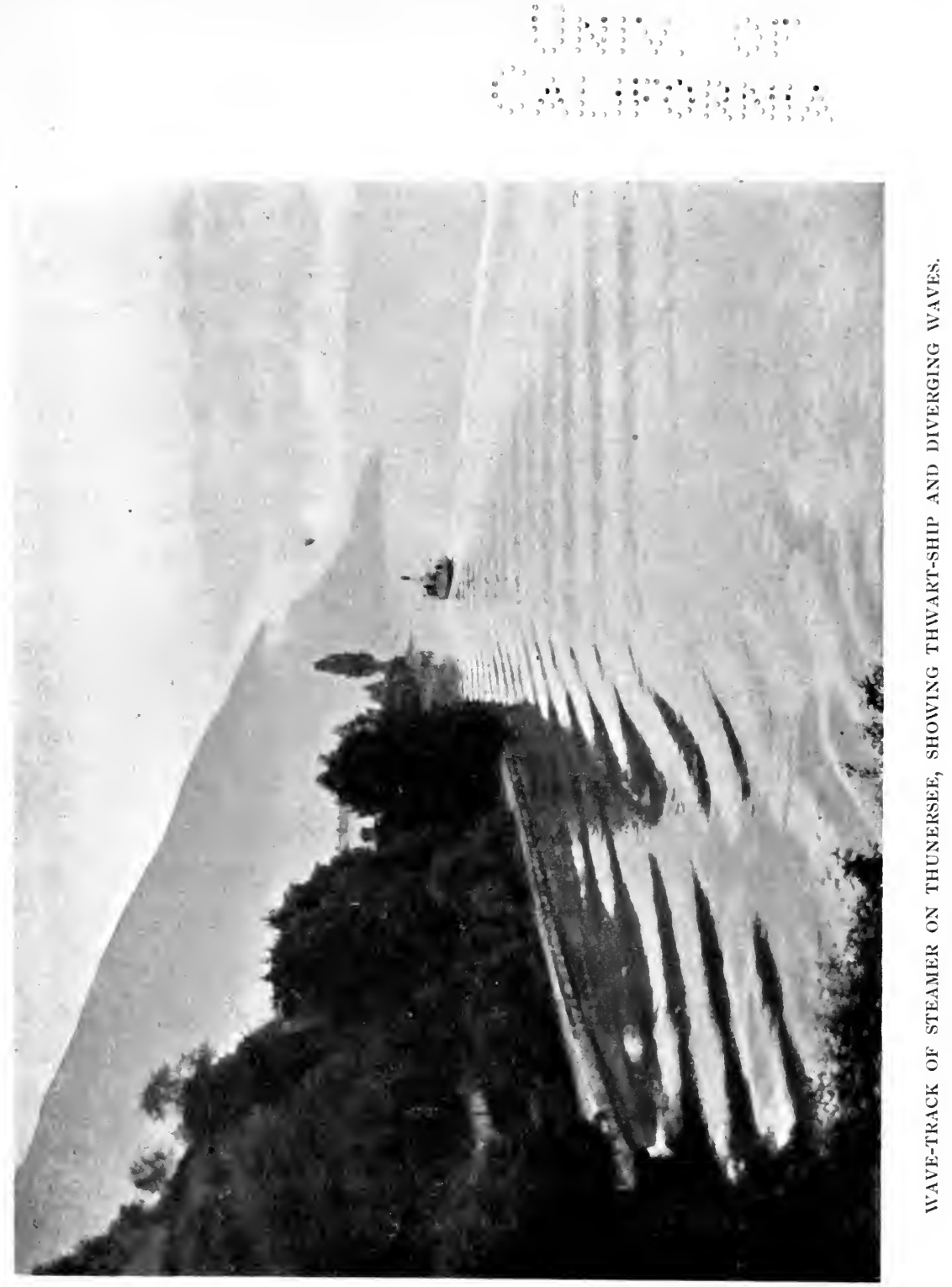


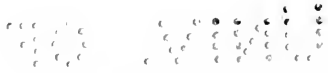

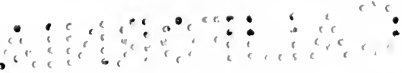




\section{AND OTHER WATER WAVES 353}

originates at the stern. The steamer which showed this best was the Spiez, a small screw vessel, the others being paddle steamers. Behind this row of notches (i.e., nearer to the line of the ship's course) were many other rows. I have counted in a good light as many as eighteen of these " interference bands" as I term them. When the water is quite glassy they are sometimes more conspicuous than the individual waves. The photograph reproduced in the Plate on page 361 was taken on Coniston Water. It shows, not only the notches in the wave fronts, but, on the right, the vertical inflection on the crests of the diverging waves caused by interference. This causes the crest of the diverging waves to appear as a pair of dark stripes separated by a broader bright stripe. The circumstance under which the photograph was obtained was peculiar. There was a fine drizzling rain when I started for a tour down the lake by the steam gondola, so I left my camera behind out of concern for its welfare. I found that the whole surface of the lake was covered with a thin scum, which appeared to consist of a very slight film of oily soot, possibly from the smoke of the furnaces and factories which are some miles distant at Ulverston and Barrow. The surface being in this condition, the vessel left a wonderful 
train of waves behind. This suggests that by dripping oil out behind a vessel one might succeed in showing the detailed pattern of the ship-waves even when there is a slight breeze on a lake. I had to do the double journey before I could get my camera, and the photographs were taken on the second journey down the lake.

The effect of interference between the diverging waves from bow and stern was noticeable in the series of breakers which came in upon the beaches near Gunten after the passage of a steamer on the Thunersee. The surf was found to be interrupted by lulls during which the breakers were much smaller.

When observing from the ship, or from a position near her, the strong curvature of the fronts of the individual diverging waves is a marked feature of the wave-track. When, however, I went to a considerable height upon the hillsides in order to obtain a bird's-eye view of the wave-track I often passed the distance where the waves were individually distinct or even discernible. Curved lines then ceased to be seen and were entirely replaced by lines which were of rigid straightness whenever the ship was running a straight course. When we are near, the case is similar to that described in the phrase "one cannot see the wood 


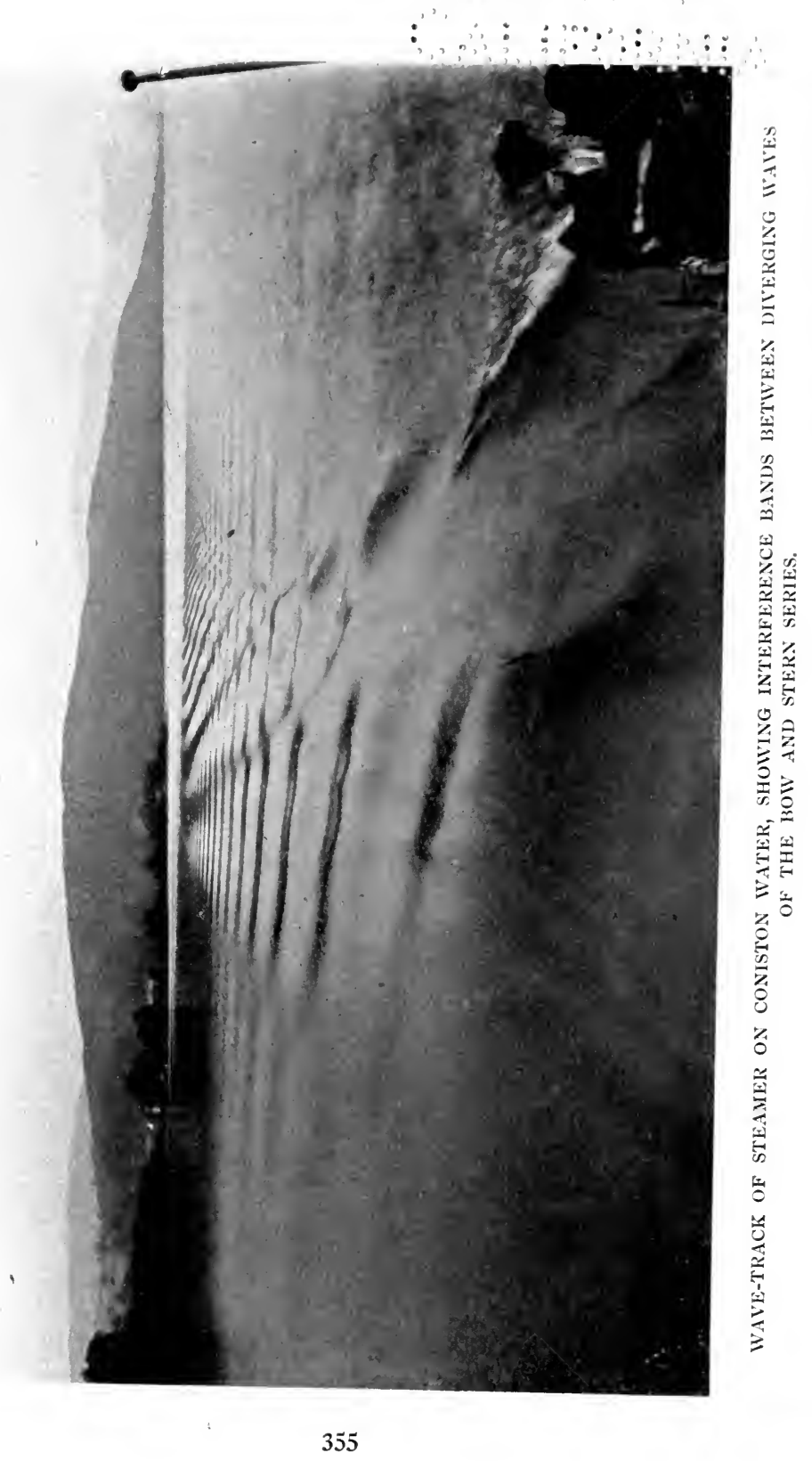




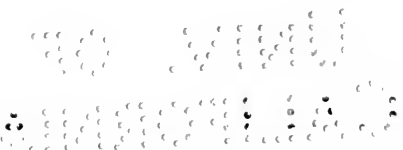




\section{AND OTHER WATER WAVES 359}

for the trees"-i.e., one cannot see the group for the waves. At a distance, when the trees are no longer individually discernible, one makes out the size and shape of the wood. Similarly, when one can no longer distinguish individual curved waves one sees at once in startling distinctness Lord Kelvin's straight-lined boundary, marking the limit to which the waves appreciably extend. In addition to this group-line there is another, also originating at the ship, which marks the rear of the diverging series of waves. Thus the wave-track of the ship is generally reduced at a distance to four straight lines, radiating from the ship, two on either side.

When this is the appearance presented to the naked eye a pair of field-glasses reveals the individual diverging waves. Sometimes also, especially when the ship is directly receding, the space between the inner boundaries of the diverging waves is seen to be filled up by a cross-barring of the flatter and broader thwart waves.

The visibility of the waves depends upon circumstances of reflection, and these vary much with the direction of the ship's course relatively to the observer and to the bright and dark parts of the sky and land. Thus, it sometimes occurs that the straight line forming the outer boundary of the 
visible diverging disturbance is not the outer edge of the bow-waves, but the first interference band of these and the stern-waves. On the approach of the vessel to Gunten on her way from Spiez I have noticed individual curved bow-waves come into view beyond the straight line which had formed the visible boundary at a greater distance. On examining the line of the inner boundary of diverging disturbance with the field-glasses I have seen it as a band, skew-barred by the individual diverging waves. These, I presume, are the rear members of the stern-waves, which ought to extend within the limits of the bow-waves. They here make a somewhat small angle with the ship's course and are consequently much crowded, with a very small wave-length.

I have never detected any rearward boundaryline to the system of transverse waves, nor have I seen light or dark bands indicative of interference between those originating from the fore-part and after-part of the ship respectively.

Ship-waves, which maintain their form unchanged and keep the same positions relatively to the moving agent which produces them, are classed as stationary or standing waves. A curious progressive condition is, however, seen among them when two steamers pass one another 


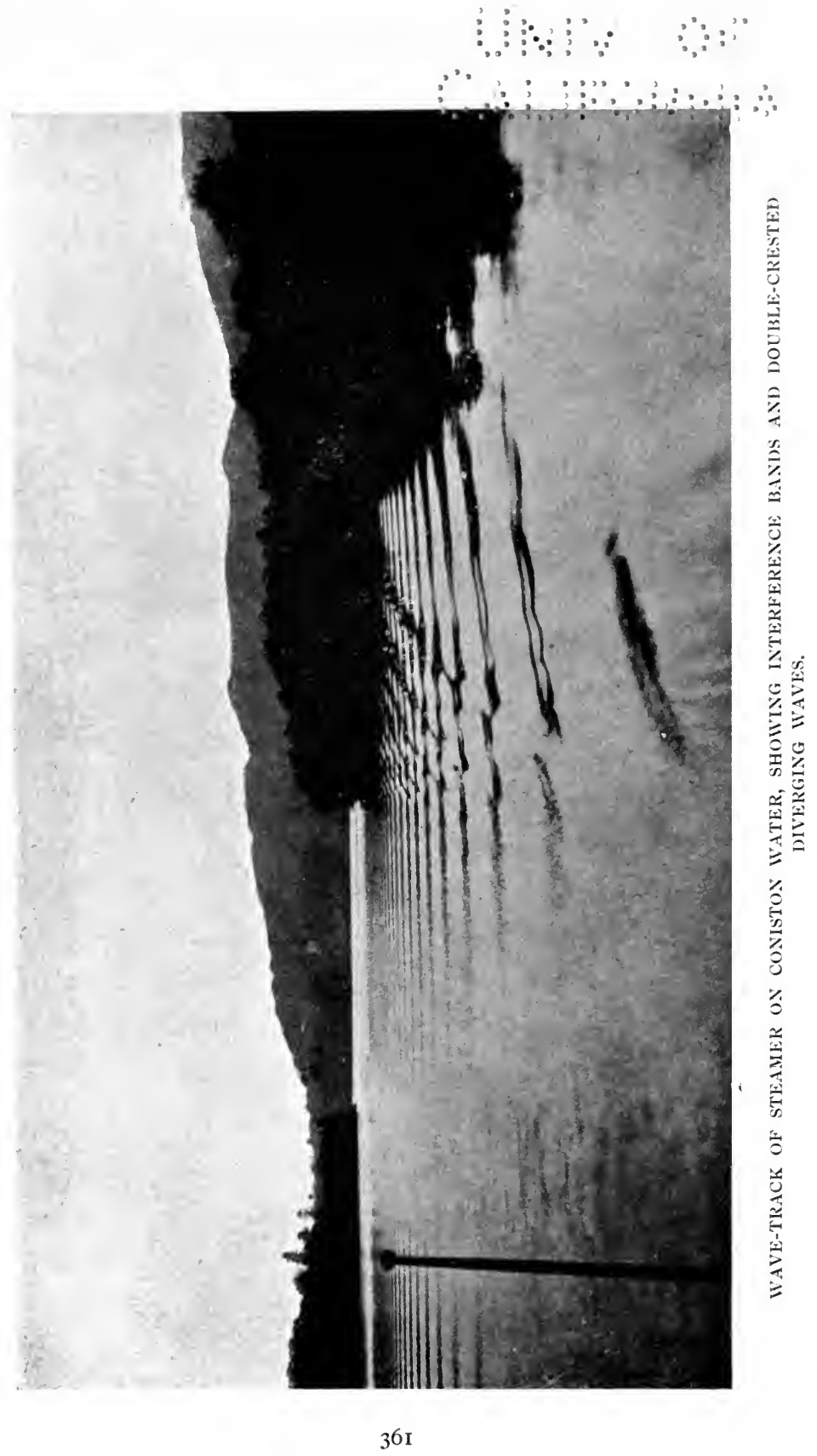




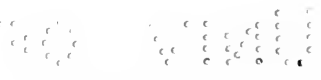

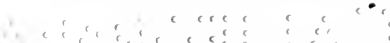

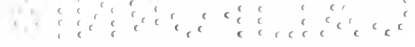



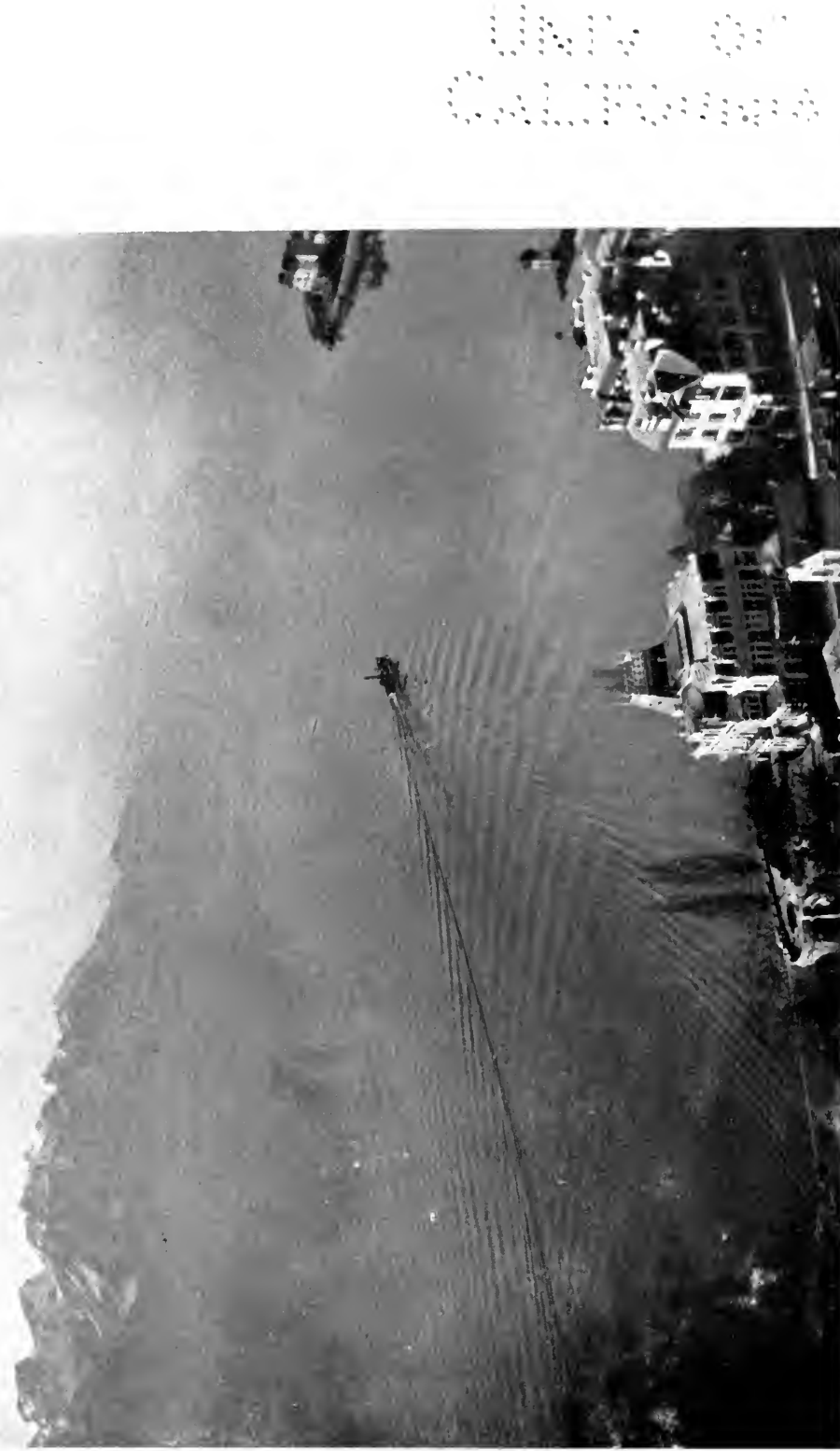

资 
"द

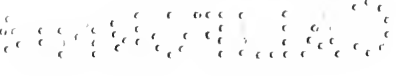



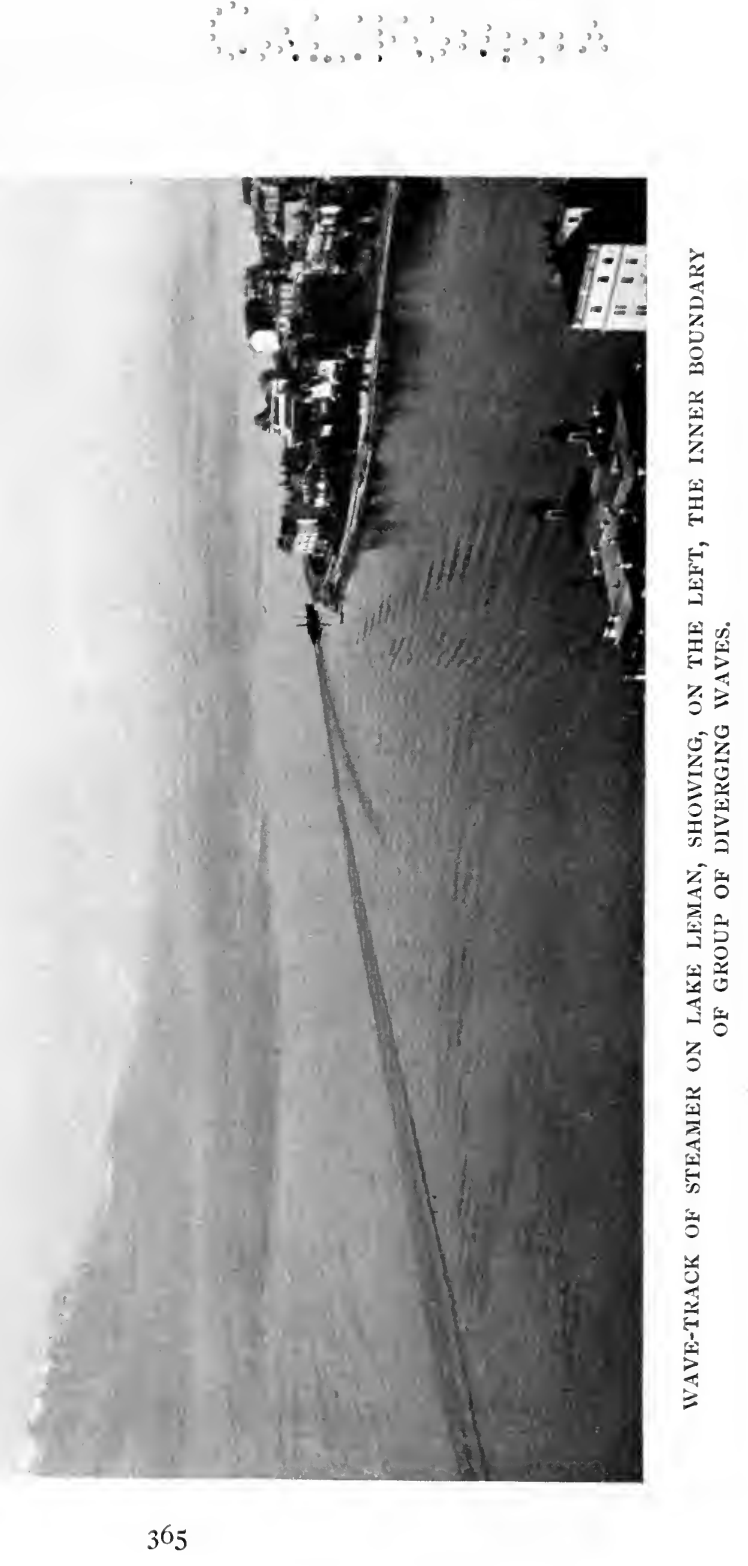



\section{AND O'THER WATER WAVES 367}

on opposite courses at such a distance that the outer boundaries of their wave-tracks meet at a small angle. On the glassy waters of the Thunersee, and on a bright day, the new disturbances of reflection run along the line of meeting in short bars of light which flash across the water at almost lightning speed, by which I mean a speed much greater than that of any railway train or of any bird in flight. 



\section{INDEX}

Abercromby, the Hon. Ralph, observations by, 77

Abernethy, Mr. G. A., on littoral drift, 187

Atlantic Ocean, North, 42, et seq.

Atlantic Ocean, South, 68

Avalanche, conical structures in, 345

Baillie, Captain C. W., II4

Bertin, M., on the period of swells, I20

Bore-

In shallow water of seashore, 165

Tidal, 230-262

Tidal, cinematograph of, 254

Bournemouth, observation of period of breakers near, 87-93

Brodie, Mr. F. J., on gales on the coasts of the British Isles, II9

Buckland, Mr. Frank, on the Severn Bore, 245

Cataracts, gushing motion of, 334-346

Cheret, Captain T. G. K., observations by, 138 note

Chesil Beach, I86-206

China Sea, 40

Coniston Water, waves on, 28

Coode, Sir John, on the Chesil Beach, 204

Currents, vertical and horizontal-

Of waves, 146-154

Of tides, 180 , et seq.

Curtis, Mr. R. H., on velocities of wind, rog

Cyclones, rate of advance as influencing the character of waves, $12 \mathrm{I}-128$ 
DARwin, Sir G. H., on the theory of tidal bores, 232

Darwin, Major Leonard, observations by, 72

David, Captain Hugh F., observations by, 73

Depth-

To which wave-agitation extends, $\mathrm{I} 4 \mathrm{I}-\mathrm{I} 46$

In which waves break, I70

Of water as affecting speed of waves, 85

Duluth, waves in canal at, 34

EDDY of air between wave-crests, 105

FLOOD, mode of advance over dry ground, 229

Forel, Dr. F. A., observations by, 3I

Formulæ for calculations relating to waves, 25, 86, 309

"Fulls," or beach ridges-

Of shingle, ${ }^{1} 5^{8}$

Of sand, $\mathbf{r} 6 \mathbf{r}$

Gaillard, Colonel D. D., U.S.A.-

On the height of waves on Lake Superior, 33

On the depth in which waves break, I7I

On the wave-front of a flood, 229

Geneva, Lake of, size of waves, 3I

Glyn, Mr. F. R., observations by, 223

Groynes, note on, 199

Grünnbach, roll-waves in conduit of, 30I-318

Guntenbach, roll-waves in conduit of, 319-330

HamiL, Mr., observations by, 29

Helmholtz, H. von, on the steepest wave, 136

Hepworth, Captain Campbell, II4

Howe, Captain Percy, observations by, 75

INDIAN Ocean, South, 68 
Kelvin, Lord-

Observations by, 24, 60

On use of the word "ripples," 236 note

On ship-waves, 346

Lamb, Prof. Horace, on waves of permanent type, 136

Langmaid, Captain C. P., observations by, $13^{8}$ note

Lions, Gulf of, height of waves, 40

Mediterranean, Western, size of waves, 35

Montrose, N.B., pulsative rise of tide at, 253

Mud, transport of by waves, $141-146$

NiagaRA Falls, break up of water in, 34I

Niagara, River, cross-stream progressive waves in, 273-293

Ogilvie, Mr. G. T., observations by, 76

Owens, Dr., 184

\section{Pacific Ocean-}

North, waves in, 6r

South, waves in, 76-78

Paris, Lieut, observations by, 24, 41, 68

Percolation, effect of, to promote the building of beaches,

157

Ponds, size of waves on, 25

Portland, tides at, 208

Prestwich, Sir J., on the Chesil Beach, 192

REynolds, Prof. Osborne-

On group-velocity, 94 note

Model estuaries, $25^{2}$

Richardson, Mr. Nelson B., an experiment on the movement of shingle, 190

Russell, Mr. J. Scott, on group-velocity, 95 note 
St. LAWRENCE River, waves on, 284

St. Maurice, Rhône Valley, roll-waves in conduit, 318

Sand, movement of, by waves, $15^{8-166}$

Sand-bank-

The Shambles, 206-2 ro

The Skerries, 2 Ir

Sand-banks, shifting of, effect on tidal bores. See Severn River Scoresby, the Rev. William, observations by, 42

Severn River, tidal bore in, 232-262

Shingle-

Action of waves to drive shorewards, I44

Effect of undertow on, 166

'Longshore transport of, 178

Ship-waves, 346

Possible effect on apparent wave-length of waves observed

Soundsat sea, 72

Of running water, 333

Of waterfalls, 334

Southwold, drift of shingle at, 184

Stevenson, Mr. Thos., table of height of waves as related to length of fetch of wind, 32

Stokes, Sir G. G.-

Observations on swell by, 93

On the symmetry of waves of permanent type, 135

On the steepest wave, 136

Swell. See Waves

TEES, River, roll-waves in, 223

Territet-Glion, roll-waves in conduit, 296

Tides-

In relation to transport of shingle, 180

At Portland, 208

Tschingelbach, falls of the, 342

Tyndall, Prof. J., 34I

UNDERTOW, effect on transport of shingle, 166

Ure, River, roll-wave in, 225 


\section{WATERFALL-}

Sounds of, 334

Breaking of water in, 334-346

Waves of the sea-

Height of, in relation to length of fetch of wind, 67

Height of "swell" during storms, 96

Average height in relation to velocity of wind, I Io. See

also under localities, as "Atlantic," "Pacific," \&c.

Length of, discrepancy between wave-lengths determined

by simultaneous and by successive observations of wave-crests, 78

Length of swell which reaches the shore after storms, 85 Co-existence of waves of different lengths, ror

Calculation of wave-length. See under Formulæ. See also under localities, as "Atlantic," "Pacific," \&c.

Mountainous appearance of, 137

Number of, in a single series. See under localities, also pp. 88-96, І26-1 27

Period of, mathematical relation to wave-length, 25

Periods of swells observed from near Bournemouth, $87-93$

Periods of swells observed from north coast of Ireland, 93-96. See also under localities, as "Atlantic," "Pacific," \&c.

Undertow of, $\mathbf{1 6 6}$

Velocity of storm waves in relation to average velocity of wind, III

Velocity of swiftest swells in relation to highest windvelocity, II9

Velocity of waves and swell in relation to rate of advance of a cyclone, I2I

Velocity in relation to depth of water, 85

On group-velocity, 94, II9

Action of, to transport mud, I4I

Action of, to transport sand, 158

Action of, to transport shingle, 146, 176 
Waves of the sea (continued)-

Action of, to arrange shingle according to size. See Chesil Beach

Action of, to form patches of shingle upon a sandy beach, 2 II

Vertical and horizontal currents of, $\mathbf{1} 46$

Waves of rivers-

The flood-wave in, 221-229

Tidal bores in, $230-262$

Stationary waves in, 265-273

Cross-stream progressive, 273-293

Leaping waves of Niagara rapids, 283

Down-stream progressive waves, or roll-waves, other than those caused by flood, 294-330. See also Tees, Ure, Nikko torrent, Severn, Niagara, St. Lawrence, Grünnbach, and Guntenbach

Velocity of long-wave in, 22 I

Waves, of ships. See Ship-waves

Wheeler, Mr. W. H., on littoral drift, 188

Wind-

Effective length of fetch of, in North Atlantic, 63

Relation of length of fetch to height of waves, 67

Table of velocities of, 109

Relation of velocity of, to average height of waves, IIO

Relation of velocity of, to velocity of waves, II I

Velocity of, in gales on coasts of British Isles, II9

Velocity of, in gusts, II 9

Direction in cyclones, 122. See also Squalls, also under the different localities, as "Atlantic," "Pacific," \&c.

Veering of, effect on waves, 132

On- and off-shore, effect on breakers and on undertow, I75

Eddies of between wave-crests, 105 
Large Crown 8vo, cloth, 6/- net.

\title{
The Age of the Earth, and other Geological Studies
}

\author{
By W. J. SOLLAS, LL.D., D.Sc., F.R.S.
}

Professor of Geology in the University of Oxford.

\section{Illustrated.}

THIS volume, while written by one of the foremost of 1 English geologists, will be found interesting and attractive by the reader who has no special knowledge of the science. The essay which gives the book its title sets forth the bearing of the doctrine of evolution on geological speculation, and particularly on the vexed question of our planet's antiquity. The subjects of the other studies include the following: The Figure of the Earth, and the Origin of the Ocean; Geologies and Deluges; the Volcanoes of the Lipari Isles; the History and Structure of a Coral Reef; the Origin and Formation of Flints; the Evolution of Freshwater Animals; and the Influence of Oxford on Geology.

"They range over a great variety of subjects, including many which are of sufficiently wide interest to bring the geologist into sympathetic touch with the general reader. What educated man can fail to be interested in such subjects, for instance, as the age of the earth, the building of coral islands, the cause of volcanic action, or the Deluge? Of all these matters the Professor discourses pleasantly and well, writing with command of much scientific learning, yet always readably, sometimes with brilliancy of diction, and occasionally with a touch of humour."-A thenoum.

LONDON : T. FISHER UNWIN. 
(THE SOUTH AMERICAN SERIES, Vol. II.)

\section{PERU}

Its Former and Present Civilization, History and Political Conditions, Topography and Natural Resources, Commerce and General Development.

BY C. REGINALD ENOCK, F.R.G.S., Author of "The Andes and the Amazon."

With an Introduction by MARTiN HUMr, a Map, and Numerous Illustrations. Demy 8vo, cloth, 10s. 6d. net.

\section{OPINIONS OF THE PRESS}

"An important work. . . The writer possesses a quick eye and a keen intelligence; is many-sided in his interests, and on certain subjects speaks as an expert. The volume deals fully with the development of the country, and is written in the same facile and graphic style as before. Illustrated by a large number of excellent photographs." -The Times.

"Mr. C. Reginald Enock's elaborate and well-studied descriptive treatise would be sure of a welcome even were it less well done than it is. The work unites in the happiest way the best qualities of an official manual and a personal description. Plentifully illustrated, well informed, and written throughout in an agreeable style, the book will prove interesting reading." -Scotsman.

"Mr. Enock's book contains much material necessary for our enlightenment of Peru. In every part of his book one finds the evidences of independent personal observation directed by a mind trained for such work. The book may be commended to all students, not only of the West, but of the East." -Morning Post.

"The author treats of Peru as a political and commercial entity, and we find it even more interesting than his previous work."-The Economist.

"An able and exhaustive study of Peru; its past, its present, and interesting matter upon which to estimate its future. As one reads through page after page of clear, concise, graphic description, one feels that one has actually travelled with Mr. Enock. All will find in this charming volume matter of interest." -New York Herald.

"The book is a valuable contribution to the literature of Peru, and a trustworthy summary of our knowledge of the country. The illustrations are excellent, and give an admirable idea of the scenery."-Manchester Guardian.

"Mr. Enock's admirable book will certainly direct attention to the country. No one can read this able and delightful volume without acquiring much information and great interest in a country of which so little is known."-Aberdeen Free Press.

"We have read the present book from cover to cover, and it seems to tell just what is wanted about one of the most interesting countries in the world. Mr. Enock's ways as a traveller commend him to us."-Country Gentlemar. 
(THE SOUTH AMERICAN SERIES, Vol. II.)

\section{PER U}

Its Former and Present Civilization, History and Political

Conditions, Topography and Natural Resources,

Commerce and General Development.

By C. REGINALD ENOCK, F.R.G.S., Author of "The Andes and the Amazon."

With an Introduction by MARTIN Homr, a Map, and Numerous Illustrations. Demy 8vo, cloth, 10s. 6d. net.

\section{OPINIONS OF THE PRESS.}

"Mr. Enock's work is of the highest value as a careful account of the existing conditions of Peru. The book is as interesting as it is instructive."-Truth.

"A magnificent collection of information on this interesting country. The author's vivid and eloquent description invests it for us with some of the glamour it possessed for the Conquistadores of the sixteenth century. And on closing the book the reader feels tempted to set out at once for Peru."-Yorkshire Observer.

"A glowing and detailed account, with a mass of information which will prove of immense service alike to students, travellers, and traders." Daily Graphic.

"Mr. Enock's former work was so good that any new effort of his was bound to attract notice. In the present volume we find all his best qualities-picturesqueness, literary skill, a dexterous combination of fact and suggestiveness, a succinct historical survey, and a clearly-drawn picture of existing social conditions-a book of unusual excellence."Birmingham Post.

"The author is already favourably known, and he writes with the same thoroughness about Peru. One rises from the perusal of so lucid and exhaustive a survey with a vivid impression. Many fine illustrations heighten the appeal of this thoroughly practical and welcome volume."Standard.

"Mr. Enock has turned out an admirable addition to 'The South American Series.' Many will welcome his admirable résumé of the story of the Inca Empire and the history of the Spanish Conquest and occupation of this wonderful country."-Glasgow Herald.

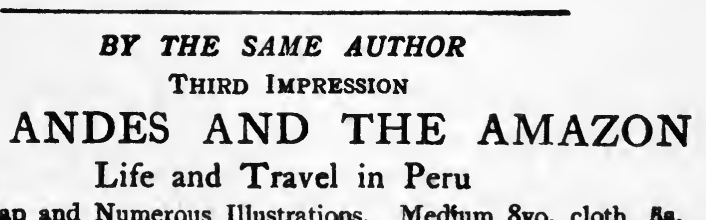

\section{THE ANDES AND THE AMAZON \\ Life and Travel in Peru \\ With a Map and Numerous Illustrations. Medfum 8vo, cloth, 8s.}




\section{A Literary History of the ' English People} BY J. J. JUSSERAND.

VOLUMES I., II. \& III. NOW READY.

\section{OPINIONS OF THE PRESS.}

"The execution of the task so far as it has proceeded at present is masterly. M. Jusserand's erudition is vast, but it does not overwhelm his sense of proportion nor distort his fine critical sense. . . . M. Jusserand has many advantages over Taine. His learning and his industry are certainly not less conspicuous, his critical method is less rigid and mechanical, his English sympathies are stronger and based on a much more familiar knowledge of English habits and English modes of thought; at the same time, like Taine, he is independent of purely English prejudices, and his literary judgments are those of a citizen of the great republic of letters which knows nothing of national or political boundaries. Altogether, the work is full of a rare attraction."-Times.

"I envy this man his style, his subtlety, his lightness of touch, his thoroughness. ... At last we have-or rather shall have when the vork is complete-a real History of literature."-Dr. AugusTus JESSOPP in the Illustrated London News.

"M. Jusserand's qualifications for the task which he has undertaken are of a high order. ... We cordially commend both to English and French readers this brilliant and thoughtful book, and shall look forward with high expectation to the appearance of its successor."-Athenceum.

"We may say, without contradiction, that the marvellous story of our literature in its vital connection with the origin and growth of the English people has never been treated with a greater union of conscientious research, minute scholarship, pleasantness of humour, picturesqueness of style, and sympathetic intimacy."-Daily Chronicle.

"The success which has been attained by $M$. Jusserand, one of the most accomplished of modern French students of this country, in his latest enterprise is exceedingly remarkable. He brings to the task which he has undertaken not merely a deep erudition, but an extraordinary insight into and sympathy with our national modes of thought and expression."-Daily Telegraph.

"We have no work at once so trustworthy and so captivating. . . . M. Jusserand knows, in a judicial way, what is and what is not evidence and authority ; he is fresh, animated, eager, yet he never speculates without a warrant. It is his method that is practically an innovation. . . As we follow his skilful guidance, we see almost in action the making of England, of English character, and of English literature."-Speaker.

LONDON : T. FISHER UNWIN. 
Illustrated. Large crown 8vo, cloth, 7s. 6d.

\title{
The English Novel in the Time of Shakespeare
}

\author{
BY J. J. JUSSERAND.
}

Translated by Elizabeth LeE.

\section{OPINIONS OF THE PRESS.}

"All lovers of Elizabethan literature will welcome M. Jusserand's new book. ... No Englishman who has written on the period has shown himself more completely in touch with his subject, or more fully and widely read in the authors with whom he deals. Want of accuracy or of literary insight is never apparent, and it is very rarely that even the smallest feature is missed because of a 'foreigner's standpoint.' ... M. Jusserand's book and its exquisite engravings form a most valuable contribution to the study of English literature."-Standard.

"The handling has all the traditional (and sometimes rather imaginary) Gallic lightness, combined with an accuracy and precision of fact and reference which is traditionally (there is some, though less, of the courtesy of imagination here also) German. And in particular $M$. Jusserand is very happy in his historical citations serving as parallels to the novel. In short, it is an excellent book in all ways for the student." -Manchester Guardian.

"A contribution of permanent value to the history of Elizabethan literature. The points of interest about this book are so numerous that it would be impossible to deal with them in detail here. But those who read for amusement only may be as safely recommended to procure it as the smaller class who seek to extend their knowledge of the Elizabethan epoch."-A thenaum.

"We hasten to invite the attention of the reader to one of the brightest, most scholarly, and most interesting volumes of literary history which it has been our good fortune to meet with for many a long day."-Speaker.

"M. Jusserand's book is scientific in the best sense of the word; it shows that he has thoroughly explored the literary province he sets forth to describe, and that he possesses in a high degree the faculty of critical co-ordination. Yet so lucid is his style, so happy his power of seizing upon the salient and characteristic features of his subject, that he never becomes tedious or needlessly discursive. To the general reader, and even to many who would call themselves students of our literary renascence, his work will prove a valuable corrective of false preconceptions."-Pall Mall Gazette.

"A work of solid value. The book is full of suggestiveness, and shows by a variety of incidental remarks the author's mastery of the subject."Spectator.

LONDON : T. FISHER UNWIN. 
Crown 8vo, limp cloth, silk sewn, 3s. $6 d$.

\title{
The Coming of the Friars
}

\author{
And other Mediæval Sketches
}

\section{BY AUGUSTUS JESSOPP, D.D.}

\author{
Fourteenth Impression.
}

\section{OPINIONS OF THE PRESS.}

"The papers which show Dr. Jessopp at his best are, without doubt that on 'Village Life Six Hundred Years Ago' and the two on 'The Black Death in East Anglia.' These reveal that historic imagination, that power of making the past live again, of taking one beyond the record of the court roll to the man who signed the deed or the suitors who formed the court, and finding out how they lived and what they did, which Dr. Jessopp possesses, perhaps, in a unique degree. Nothing can be more telling than these essays, with their light touches of humour."-Athenaum.

"The antiquarian information is conveyed in the most attractive form by a writer who has nothing of a dry-as-dust in his composition except the zeal and the patience of investigation, while the East Anglian colouring gives that individuality and precision to the descriptions which materially assist the imagination to realise with distinctness the required pictures. Another peculiar charm of Dr. Jessopp's writings is the freshness of his sympathies. . . Always lively, picturesque, and suggestive, he is in living touch with existing realities, and uses his historic gleanings to illustrate by contrast or by resemblance some present condition of modern society."-Guardian.

"In the present volume Dr. Jessopp has developed a power almost equal to that of the author of 'John Inglesant,' of catching the tone of a generation that has passed away, and of depicting the condition of England in the Middle Ages, unhidden by a veneer of modern conventionalism. ... It would be difficult to find a more graphic picture of old English life, or one in which even the driest facts of history are presented in a more attractive garb."-Morning Post.

"It is delightful to have them thus collected, for few writers have Dr. Jessopp's gift of painting to the life. His 'Village Life Six Hundred Years Ago' is as graphic and as truthful as one of Richard Jefferies's sketches of to-day. His papers on 'The Black Death' and on 'The Building of a University' are full of teaching; and no one has ever discassed with more intelligent appreciation that mediæval Salvation Army of which Franciscans and Dominicans were the two main corps." - Graphic.

"The glimpses into the social life of the past afforded by these essays will impress all who reflect for a moment upon the marvellous growth of England."-Daily Chronicle. 


\section{By J. CAMPBELL OMAN, D.Lit.}

\section{THE MYSTICS, ASCETICS, AND SAINTS OF INDIA}

Fully Illustrated. Cheaper Edition. Demy 8vo, cloth, 7s. 6d. net.

"A work of the first importance. ... In the work of analysis and description Mr. Campbell Oman has no superior in authority, at least as far as the races of the Punjab are concerned."-Daily Chronicle.

"A volume of peculiar, almost painful interest."-Observer.

"The able and learned monograph before us will certainly add to his reputation."-Glasgow Herald.

"A most uncommon and fascinating book."-Birmingham Daily Post.

"A book of genuine value."-Times.

"The fullest study of Indian asceticism from the most modern and recent aspect which has appeared."-Academy.

"A moriumental work."-Civil and Military Gazette.

\section{THE BRAHMANS, THEISTS AND MUSLIMS OF INDIA}

Fully Illustrated. Demy 8vo, cloth, 7/6 net.

This book deals with interesting phases of Indian religious and social life at the present time. The religion (goddess-worship) of the Bengalis, who have of late been so much before the world, has a chapter to itself in which some strange facts in respect to esoteric rites practised by these people are narrated. The dominant position of the Brakmans is brought into prominence in a careful study of the Hindu caste system; while Religious and Social Reformers, as well as the results achieved by them, are reviewed in some detail. Descriptive sketches of some curious festivals and ceremonies are included in this volume. Muslim India has two chapters devoted to it. As in his previous books the Author has incorporated in this one various stories and legends, and has drawn largely upon his own somewhat exceptional experiences. The photographs and the illustrations supplied by Mr. W. Campbell Oman are designed specially to elucidate the text.

London: T. FISHER UNWIN, Adelphi Terrace. 


\section{The Modern Travel Series.}

CHEAP EDITIONS OF STANDARD WORKS OF TRAVEL AND ADVENTURE.

ILLUSTRATED WITH PHOTOGRAPHS OF THE PLACES AND SCENES DESCRIBED.

Large Crown 8vo, cloth, 5s. per volume.

\section{LIST OF VOLUMES.}

Through Savage Europe. By HARRY DE WINDT.

In Dwarf Land and Cannibal Country. By ALBerT B. LLoyd.

In the Land of the Blue Gown. By Mrs. ARchibald Litrle.

Links in My Life on Land and Sea. By Commander J. W. GAMBIER, R.N.

The Andes and the Amazon. Life and Travel in Peru. By C. REginald ENOCK.

In Search of El Dorado. A Wanderer's Experiences. By Alexander Macdonald, F.R.G.S.

Adventures on the Roof of the World. By Mrs. AUBREY LE Blond (Mrs. Main).

Present-Day Japan. By A. M. CAmpberl Davidson.

John Chinaman at Home. By the Rev. E. J. HARDY, Author of "How to be Happy though Married."

Other Volumes in Preparation. Please Write for Complete List. ON SALE AT ALL BOOKSELLERS.

T. FISHER UNWIN, I, Adelphi Terrace, London. 


\section{CLASSIFIED CATALOGUE}

\section{OF \\ T. FISHER UNWIN'S \\ PUBLICATIONS.}

\section{CONTENTS.}

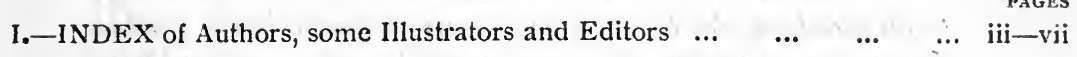

II.-INDEX in order of Titles, including a list of Mr. Unwin's various series $\begin{array}{lllllllllll}\text { of books } & \ldots & \ldots & \ldots & \ldots & \ldots & \ldots & \ldots & \ldots & \ldots & \text { viii- } \mathrm{xv}\end{array}$

III.-CATALOGUE, classified under the following subject-headings :-

$\begin{array}{lllllllll}\text { I. Literary History } & \ldots & \ldots & \ldots & \ldots & \ldots & \ldots & \ldots & 1-2\end{array}$

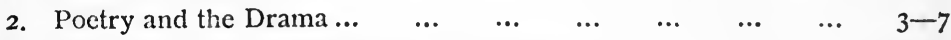

3. Novels, Humorous Works, Short Stories, \&c. $\quad \ldots \quad$... $\quad \ldots \quad 8-32$

4. Essays, Criticisms, Philosophy, \&c. ... $\quad \ldots \quad \ldots \quad \ldots \quad \ldots . \quad \ldots \quad 33-34$

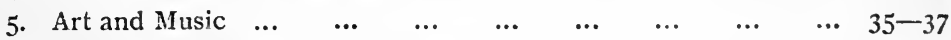

6. Biography, Memoirs, Correspondence, \&c... $\quad \ldots \quad \ldots \quad \ldots \quad \ldots \quad 38-46$

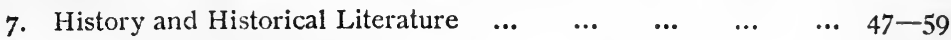

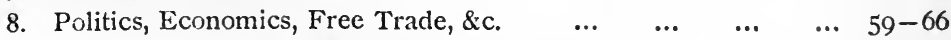

9. Geography, Travel, Mountaineering, \&c. ... $\quad \ldots . \quad \ldots \quad$.. $66-74$

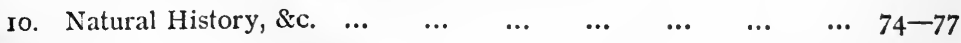

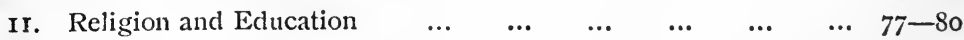

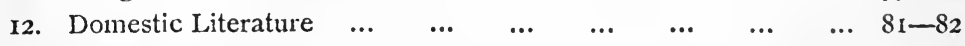

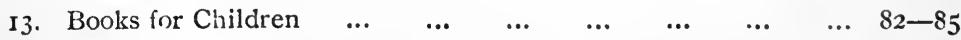

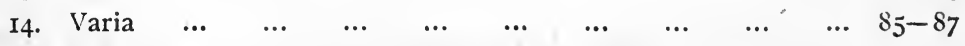

15. "The New Irish Library" "The Welsh Library" and "The

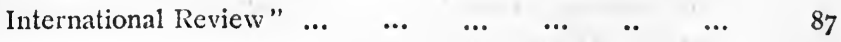


Bonk Buyers are requested to order any volumes thry may require from their bookseller. On receipt of a postcard, Mr. Fisher Unwin will be pleased to furnish the address of the nearest local bookseller where the works detailed in this list may be inspected.

Should any difficulty arise, the Publisher will be happy to forward any book in the list to any country in the Postal Union, on receipt of the price marked and a sufficient sum to cover postage, together with full Postal Address. Any amount forwarded in excess will be returned to the sender.

Remittances may be made by Cheque, draft on Londin, Money Orders, or Stamps.

After reading this Catalogue, kindiy pass it on to some book-buling friend, or send an address to which this or future editions may be sent. 


\section{INDEX of AUTHORS, some}

\section{ILLUSTRATORS, and EDITORS.}

\section{PAGE}

Abrahams, Israel.......... 7 , 79 Adam, Mme. Edmond ...... $3^{8}$ Adams, Arthur H. ........ 86 Adams, Francis ..........66 66

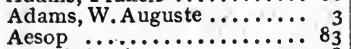
Abo, Juhani $\ldots \ldots \ldots \ldots \ldots \ldots \ldots . . \ldots 8$

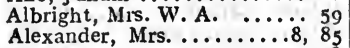
Alexander, Mrs. ........ 8 , 85
Alien $\ldots \ldots \ldots \ldots \ldots \ldots \ldots \ldots .8$ Allardyce, Paul ........... 77 Amber, Miles $\ldots \ldots \ldots \ldots \ldots \ldots . . .8$ Andrews, Katherine....... 8 Arbuthnot, Sir A. J . . . . . 39 Archer, Laura M. Palmer .... 8 Archer, T. A............ 47 Archer, William $\ldots \ldots \ldots \ldots \ldots$.......... 8 Armstrong, 1. J .......... Aronson, V. R. ......... 59 Askew, Alice and Claude ..8, 87 Austin, Mrs. Sarah ....... 43 Axon; William E. A. ........ 6

Bacheller, Irving $\ldots \ldots \ldots \ldots 9$

Badham, F. P............ 77

Bailey, E. E. J. ..........

Baillie-Saunders, Margaret... 9

Baker, Errest, A..........666

Baker, H. Barton ..........

Baker, James ..............

Bamford

Banfield, E. J.............. 66

Baring-Gould, S. ......... 47

Barlow, Jane ............

Barnett, Canon ........... 59

Barr, Walter ............ ro

Barry, William................. 47

Barth, Dr. Theodor ........ 60

Bartram, George .......... ro

Basile, Giambattista ....... 82

Bastian, H. Charlton ....... 74

Bateson, Mary .......... 47

Batey, John............ 85

Bealby, J. T. ............ Io

Beauclerk, Lady Diana ...... 35

Beaumont, Francis ........ 5

Beavan, Arthur Hr ....... 74

Beazley, C. Raymond ...... 39

Becke, Louis........... Io, 43

Beckman, Ernest ..........82, 83

Beckworth, James P .....46

Beers, Henry A. .......... I

Bell, Robert.............. 74

Bellermann, Ludwig ...... 7

Benjamin, S. G. W. ...... 47

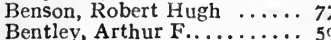

PAGE

de Benyowsky, Count ......4 46

Bernhard, Oscar .......... 85

Berry, T. W. ..........77, 85

Besant, Annie ............. $3^{8}$

Bigelow, John .......... 33

Bindloss, Harold ......... 66

Birch, Walter de Gray ...... 47

Blacker, J. F. ............ 35

Blake, Bass ............ II

Blake, B. C. ............ II

Blind, Mathilde .......... 74

Bliss, Rev. Edwin M.......... 47

Blond (See Le Blond).

Bloom, J. Harvey ......... 35

Blount, Mrs. George ......... II

Blunt, Wilfrid Scawen $\ldots .48,59$

Blyth, Edmond Kell ........ 77

Bodkin, M. McDonneli ........ I

Boissier, Gaston ........... 66

Boland, Mary A. ........... 8

Bölsche, Wilhelm ........ 4 I

Bolt, Ben ............... II

Bon (See Le Bon):

Bond, J. A. Walpole-....... 77

Bonner, Hypathia Bradlaugh 38

Booth, Eva Gore.......... 65

Boulger, Demetrius C. ....... $4^{\circ}$

Bourget, Paul ........... I

Bourinot, Sir John G. ........ $4^{8}$

Bousset, W.............. 77

Boutmy, Emile ............. 33

Bowack, William Mitchell ... 59

Bowen, Ivor $\ldots \ldots \ldots \ldots$. 59

Bowen-Rowlands, Lilian .... I I

Bowles, Thomas Gibson ..... 59

Boxall, G. E. $\ldots \ldots \ldots 74,48,59$ Boyesen, Prof. Hjalmar H.... $4^{8}$ Bradley, Henry .......... 48

Brainerd, E. H. ........... II

Bray, Reginald A..........60, 77

Breda, G. H. ............ ii

Brentano $\ldots \ldots \ldots \ldots \ldots \ldots 8_{2}$

Brereton, Austin $\ldots \ldots \ldots 4^{8}$

Bridgett, T. E. ......... 77

Bright, Allan H. ...........6

Brightwen, Mrs. $\quad \ldots \ldots \ldots .38,74$

Broda, Rodolphe ........8 87

Bromley, A. W. .......... 85

Brooke, Magdalene ......... I I

Brooke. Rev. Stopford A. ... 33

Brookes, L. Elliott......... 85

Brookfield, Arthur $\ldots \ldots \ldots \ldots .83$

Brown, Charles Reynolds 60,77

Brown, Francis ..........60

Brown, Madox …...... $8_{3}$

Browne, Prof. Edw. G. ....... I

Browne, Gordon ......... 84

Browne, Haji A........... $4^{8}$

Browne, H. Morgan ........ 60

Bruce, Mary L. ............ 44
PAGE

Brunetière, Ferdinand $\ldots \ldots$. I

Buchanan, A. J..........6.67

Buchanan, Alfred ......... II

Buchanan, Robert ............ I I

Buckmaster, J. C. ........6 60

Buel, Clarence C.......... 48

Bulfin, w.................67

Bullen, Frank T........... II

Burne-Jones, Edward ........ 5

Burns, John ............. 63

Burns, Robert .............

Burrard, W. Dutton ......... ri

Burton, E. de Witt.......... 77

Butler, Lewis ............ $4^{8}$

Butler, W. F. .............. 48

Byles, Rev. John ......... 82

Byrde, Margaretta .......... II

Byron, Lord ........... 70

Cable, G. W............. 46

Cadbury, Edward ............. 60

Caddick, Helen .............. 67

Caird, Lindsay H. ......... 85

Caird, Mona.............6 67

Callahan, James Horton ..... 60

Cameron, $v$. Lovett. ......... 46

Campbell, R. J.......... 77

Campbell, Mrs. Vere ......... Iz

Canning, Albert S. G. ......... I

Capes, Bernard .......... 4

Capuana, Luigi.$\ldots \ldots \ldots \ldots .8_{3}$

Carey, Charles ............ I2

Carducci, Giosué.............

Carlile, w. and Victor $w . . .6$ 6o

Carroll, Lewis ............ 35

Carse, Roland ..........48, 53

Cartwright, Mrs. Edward .... I2

Caryl, Valentinc ........... I2

Cayley, George john......... 67

Cayley-Webster, H. ....... $7_{2}$

de Cervantes, Miguel.......... $1_{3}$

Cesaresco, Countess Martinengo.....34, 39, 49, 67, 75

Chamberlain, Charles J. ....75

Chambers, R. W........... 12

Chapman, George ......... 5

Chesson, Nora ........... I2

Chevalier, Albert ........... 39

Chomley, C. H. ........... 12

Choyce, James .............. 46

Chrichfield, George W. ...... 49

Christy, Robert ............. 33

Church, Prof. Alfred J. ...... 49

Clare, Austin ........... 12

Clark., H. A. .......... 7

Clayden, $\mathrm{P} . \mathrm{W}, \ldots \ldots \ldots \ldots \ldots . . .49$

Cleeve, Lucas .............. I2

Clerigb, Arthur .......... 49

Clifford, Hugh ............ 67

Clifford, Mrs. W. K. ......... I 3 


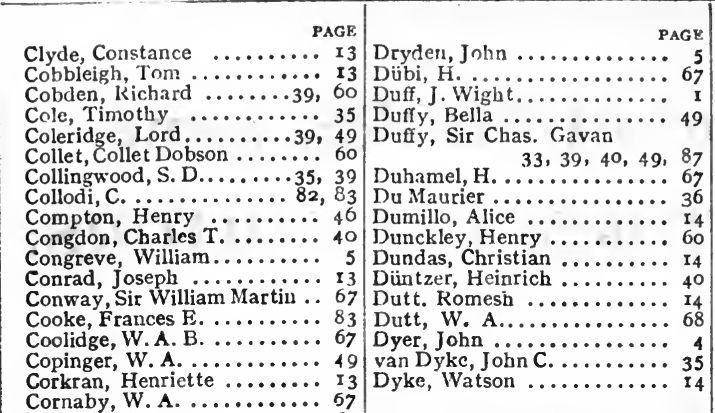

Cornaby, W. A.......... 67 Costelloe, Ray............... I 3 Cotterell, Constance ....... I3 Courlander, Alphonse ...... r 3 Courtney, Leonard .........6.60 Cowper, William ......... 4 Cox, Harold ..........6\%, 6 I Cox, Palmer ........... 83

Cox, Rev. Samuel ......... 77 Crampton, George ......... I3 Crawford, F. Marion ........
de Crespigny, Mrs. Philip de Crespigny, Mrs. Philip Crockett, S. R........... I Crompton, Henry ........6r Crottie, Julia M............ Cruikshank, George ....... 82 Cruso, H. A. A. ...........

Dale, T. F.

Dalin, Talmage ............. r4 Dalton, Moray........... I Dalziel, James............. I Dana, Chas. A. ............ 85 Danson, John Towue........ 6 Daudet, Alphonse.......82,8 Davenport, Arthur ........6 67 Davenport, Herbert Joseph . . 6I

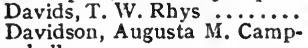
bell

Davidson, $\mathrm{L}$ illias Campbell... Davies, Mary ............ Davis, Richard Harding .... 68 Davis, Thomas ........49,87 Dawson, W. Harbutt........6 68 Dean, Mrs. Andrew ........ r r

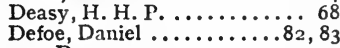
von Degen $\ldots \ldots \ldots \ldots \ldots \ldots . .$. I 4 Dekker, Thomas ...........

De la.Rey, Mrs. General ..... Dethridge, G. Olivia ........ Dew-Smith, Mrs. ...........

Dewsnup, Ernest R.

Dickeson, Alfred

Dietrich, Max.

Dietzel, $\mathrm{H}$.

Dieula foy, Marcel Auguste ...

$m \ldots \ldots \ldots$

Dittrich, Hermann $\ldots \ldots \ldots . \cdots 7^{8}$

Dodge, Walter Phelps $39,49,83$

Douglas, Sir George .........

Douglas, Prof. R. K. . . . . . . .

Dowie, Menie Muricl. ....... 46

Drachman, Holger ........... I4

Drosines, Georgios.......... $\mathrm{I}_{2}$, 8

Drury, Robert .......... 46 von Ebner-Eschenbach, Marie Echegaray, Don José ........ Edwards, Owen M. . . . . .49, 87 van Eeden, F. . ............ I

Egerton, Hugh E. ........... 43

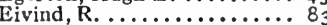

Elias, Frank ................ 6 r

Eliot, George .............6. 68

Elizabeth of England, Prin-

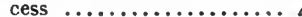
Ellenberger, Professor ...... 35 Elliott, Ebenezer ........... 6

Ellis, Havelock ............. 56 Elphinstone, Lady.......... 78

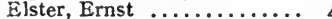
Emerson, Ralph Waldo ...... 40 Enock, C. Reginald ....... 68 Erskine, Mrs. Steuart........ 35 Escott, T. H. S.........49, 6r Evans, Howard ......... 42 Evans, S. Hope ........... 83 Evans, Thomas W........ 40 Evans, IV. Sandford ........ 8 Ewald, Alex. C. .......... Eyre-Todd, George ......... 44

Faguet, Emile.

Falconer, Lanoe Farge (See La Farge).

Farquhar, George

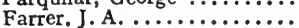
Farrow, G. E............. Fawcett, Mrs. Henry........ 65 Fegan, Bertie ............ 86 Ferguson, Sir Samuel.... I4, 87 Ferri, Prof. Enrico........ 33 Field, Michael........... 4 Findlay, Frederick R. N. ... 68 Fisher, Harrison......... 35 Fisher, Lala ............. I I Fitz-Gerald, E. A...........6 68 Fitzmaurice-Kelly, J. ..... 40 Flammarion, Camille ...... 75 Fletcher, J.S. ............ I 5 Fletclier, John ............ Flowerdew, Herbert Fogazzaro, Antonio Ford Douglas ...... Foreman, John .......... Forrest, J. Dorsey ......... Forrest, R. E. ............ I 5 Forster, L. M............ 8 Foster, George Burman...... 78 Foster, J. J............. Foster, Sir Michael......... $3^{8}$
Eastwick, Robert W.

Eckenstein, Oscar ..........68 Fitzgerald, Percy ... 15, 35, 41, 50

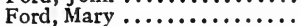

Frapan, Il

Fraser, jolin $\ldots \ldots \ldots \ldots \ldots \ldots$ I5

Frazer, R. W............, 50

Frederic, Harold .......... I5 Freeman, Prof. E. A......... so French, Henry Willard ...... I 5 Fuller, Margaret .......... 40 Furness, Annette .......... 15 Furniss, Harry........... 36

Gaggin, John ...........68 68 Gambier, J. W. ......... 40 Ganconagh (IV. B. Yeats) .... 24 Gannon, John P. ......... 50 Gardiner, A. G. .........6 62 Gardiner, J. H. ......... 78 Gardner, W. J. .......... 50 Garnett, Richard ........4, 45 Gebuza ............... 6r Geen, Philip ........... 85 George, E. A........... ;8 Gertrude, f funt .......... 82 Gibb, E. J. W. ............ 52 "Gil " .............. 13 Gilman, Arthur ....... 50, 52 Gilman, Daniel Coit ......... 78

Gissing, George .......... I5

Glover, John R. .......... 42 Goethe, W. ............ 4

Gomme, G. Lawrence ....50, 6r Goodenough, Rev. G. ...... 86 Gordon, Charles .......... 50 Gordon, H. I aing ........ 44 Gordon, Lady Duff ........ 43 Gordon, Wiiliam Clark ...... 33

Gorky, Maxim ........... I5 Gosse, Edmund ............. 6 Gould, F. Carruthers ....6r, 84 Gould, G. M. ........... 40 Grace, R. W. .......... 84 Graham, R. B. Cunninghame. 68 Grant, Daniel ............ 62 Graves, Alfred Perceval....43, 87

Gray, E. Conder .......... 40 Gray, Thomas .......... 50, 73 Greeley, Horace .......... 40

Green, Anna Katherine ...... 16 Greene, Robert .......... 5 Gregory, Lady ............ 34

Gribble, Francis ........... 68 Grieve, Ed. B. ............ 86 Griffiths, D. R.......... 16 Griffiths, Arthur ........ 6 , 50 Guarracino, Beatrice ....... 8r Guest, Lady Charlotte..... 6,87 Guyer, Michael F........ 75 Gwynn, Stephen ............ 36 Gyp ................ I 6

Hackwood, F. W. ........86 86 Haldane, Richrad Burton.... 62 Hale, Susan .............. 50 Hales, A. G. ............ 16 Hall, Charles Cuthbert ..... 78 Hall, Moreton ........... ${ }_{68}^{4}$ Hall, R. N. ............ 68 Halperine-Kaminski, H. .... 46 Hamilton, Cosmo .......... 15 Hamilton, Lord Ernest ...... I4 Hannah, J. E. ........... 50 Hardie, J. Keir ........... 65 Harding, Ellison........... I5 Hardy, Rev. E. J. I $6,4 \mathrm{r}, 68,78,8 \mathrm{x}, 87$ Harland, Marian ......... 8 r Harper, S. Eccleston......... 32 Harper, William Rainy...... 78 Harrison, Mrs. Burton....... 16 
PAGE

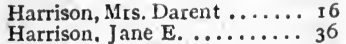

Harting, J. E. ........... 75

Harvie-Brown, J. A.......... 75

Hasen, Ch. Downer........... 50

Hasler, G. ........... 67

Hatfield, Henry Rand ..... 86

Hauff, Wilhelm .......... 83

Hawkesworth, Alfred....... 69

Hay, John ........... 42

Hay, William ........... I6

Hayden, Arthur .......... $3^{6}$

Heine, Heinrich ............

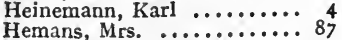

Hemans, Mrs. ........... 87

Henshaw, Julia W. ........ I6

Henson, H. Hensley ..... 78

Henty, G. A. ......... I6, 8

Herford, C. H. .......... 5

Herrick, Christine Terhune ... 8I

Herring, Frances E. ....... 69

Hertz, Gerald Berkeley ...... 50

Hertz-Garten, Theodor...... I6

Heywood, Thomas.........

Heywood, William......... 69

Hicks, John W. ......... 86

Hill, Edmund L. ..........

Hill, Geoffry

Hill, George Birkbeck ......

Hill, Robert T. ............6 6

Hindlip, Lord .......... $6 g$

Hinkson, H. A. ........... I7

Hirst, Francis W. ........ 62

Hobbes, John Oliver ..4, I7, 69

Hobhouse, L. T. ........ 62

Hobson, J. A..........63, 69

Hocking, Silas K......... I 7

Hodgson, W. B. ......... $66_{2}$

Hogan, James Francis . . . . . . 62

Holdsworth, Annie E. ..... I7

Holmes, Timothy.

Holyoake, George Jacob 4 i , 62,86

Honeyman, C. van Doren .... 69

Hornby, F. M........... 33

Horne, H. P.

Horniman, Roy .............. I 8

Horridge, Frank............ 4 I

Horrwitz, Ernest .........

Horton, R. F. ........... 78

Hosmer, Prof. James K. .... 50

Houghton, Louis Seymore.... 50

Howard, George Elliott..5I, 78

Howe, Frederic C. ....... 62

How ell, George ............6 62

Hueffer, Ford $H . \ldots \ldots \ldots 62,3_{3}$

Hudson, W. H. ......... $t 8$

Hug, Lina .............. sI

Hugessen, Knatchbull ..... $88_{3}$

Hulbert, H. B........... 73

Hulme, F. E. .......... 75

Hume, Martin. A. $\dot{S} . \cdots 43,5 \mathrm{r}, 72$

Humphrey, Frank Pope ...... I 8

Humphrey, Mrs.......... r8, 8r

Hungerford, Mrs. .......... r 8

Hyde, Douglas .... 2, 5, 78,87

Ibsen, Henrik

Indicus.

Ingersoll E...............

Iron, Ralph (Olive Schreiner). 75

Irving, Edward ........... 75

Irving, Fanny Belle ........ I8, 85

Irwin, H. C............. I 8

James, David $\mathrm{H}$.
Jane, L. Cecil

PAG:

I I Alex. H.......... $4 \mathrm{I}$ Liddell, Arthur R......... 8 avelle, Emile ........... 69 Lilly, W. S............ 52 Jay, Harriett .......................... $3^{8}$ Jebb, Louisa ........................... 52 Jeffery, Wálter ....... I 18,43 Little, Mrs. Archibald ....20, 70 Jenkins, Rhys .......... 86 Lloyd, Albert B......... 70 Jenks, Edward ............. 5I Lloyd, H. D. .............63 Jennings, Edward W. ...... I 8 Lloyd, Wallace..........20 Jephsou, Henry ........... o2 Locke, James ........... 20 Jephson, Julie ........... 38 Loeb, Jacques .......... 75 Jepson, Edgar........ 8, 84, 87 Lombroso, Prof. C........ 34

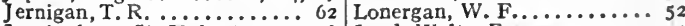
Jerningham, Sir Hubert ..... I8 Lord, Walter Frewen....... 42 Jessopp, Augustus ....18, 33, 51 Lorraine, Rupert ........ 20 Jewett, Sarah Orne ........ 5I Low, Sidney ........... 63 Johnson, Robert U. ........ 5I Lowes, Mrs............. 36 Johnson, T. Broadwood..... og Lucas, Alice ........... 79 Jones, David Brynmor ..... 5 5 Lumsden, James ......... 70 Jones, H. Stuart.......... 5I Lunn, Henry S......... 63

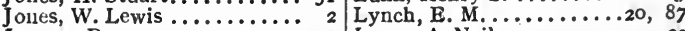

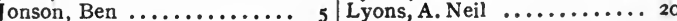
Jusserand, J. J. ...... 33, 52 Lyons, Albert E.......... 20 de Kantzow, Alfred ........ 3 Lyttelton, Edith......... 5

Keary, C. F. ............ I8 Keene, Charles ............. 37 Keller, Gottfried ............ I8 Kelly, J. D. J. ........... 52 Kempster, Aquila .......... 18 Kerr, S. Parnell ..........6 69 Kettle, Rose Mackenzie ...19, 85 Kiesow, E. L. ............. 85

Kildare, Owen ............. I9

King, Clarence ............. 69

King, Irving $\ldots \ldots \ldots \ldots \ldots, 78$

King, Joseph .......... 62

King, Richard Ashe $\ldots .44,87$ Kingsford, C. L.......... 47

Kinross, Albert .......... r

Kitson, Arthur ...........6 63

Knight, William.......... 39

Ko, Ta Sein.............. 78 Korolenko, V. ........... I9

Kroeker, Kate Freiligrath .. 83

Kruger, Paul ........... 4 I

Kruger, Gustav $\ldots \ldots \ldots \ldots \ldots$
Kurz, Louis $\ldots \ldots \ldots \ldots \ldots \ldots$

La Farge .............6 69

Lambe, J. Law rence ......... rg

Landon, Mary............ r 9

Lane, Ralph ..............6 63

Lane-Poole, Stanley ....... 52

Langbridge, Rosamond ...... 19

Langland, William ........

Latane, John H. .......52, $6_{3}$

Lanyon, H. St. Martin...... I 9

Laurenson, Arthur ........ 4

Laverton, Mrs. H. S. ....... I9

Law, Alice ............. 3

Lawless, Emily ........... 53

Lawton, Frederick $\ldots \ldots .36 \quad 42$

Lear, Edward ........... 45

Le Blond, Mrs. Aubrey....69, 70

Lebon, André ............. 52

Le Bon, Gustave .......... 33

Lee, Vernon ........ 19, 33, 52

Lee-Hamilton, Eugene ...... 19

Legge, Helen Edith ......... $3^{6}$

Leigh, M. Cordelia ......... 79

Leland Ch. G. ("Breitmann") I 9

Len theric, Charles $\ldots \ldots \ldots \ldots$ 70

Leroy-Beaulieu, P. ........ 60

Levy, Amy .............. 5

I Lewis, Frank C: ............ 20
Mac, J. .............. 70

McAulay, Allan ..........20

MacBride, Mack enzie...... 20 McCarthy, Justin $\ldots \ldots .42,52$ McClelland, J. ...........6

McCormick, A. D. .......... 67

MacDonagh, Michael ..39, 40, 87

Macdonald, Alexander ..... 70

Macdonald, George.......... 20

Macdonald, Leila ..........

Macdonald, Robert........ 84

von $\mathrm{Mach}$, Richard.........6 63

McIlraith, J. R.......... 58

Mcllwraith, J. N. ......... 83

McKendrick, John G. ...... 4

Mackintosh, C. W. ......... 39

Mackin tosh, John ......... 53

McMahan, A. Benneson......77

McManus, Blanche ........ 84

MacManus, James ......... 20

McManus, L............2 20

Macpbajl, Andrew ......... 79

Macy, Jesse ............. $6_{3}$

Maddison, $F$. ........... 42

Mahaffy, Prof. J. P. ........ 53

Mallik, Manmath C......34, 70

Mann, Mary E. ........2 21, 87

Marble, Annie Russell ..... 2

Mario, Jessie White .....44, 53

Mark, H. Thiselton ........ 79

Marlowe, Christopher ........ 6

Marquis, T.G. ........ 2 I

Marsh, Richard ........... 2 I

Marshall, Thomas .......... 34

Martin, Alfred J. ......... 79

Martyn, Edward ........... 2 I

Martyn, Ethel K. .......... 33

Mason, Eugen ........... 5

Maspero, G.............. 53

Massey, Gerald .......... 53

Massinger, Philip .......... 6

Massingham, H. W........ $66_{3}$

Masson, Gustave.......... 53

Masterman, C. F. G.....34, 62

Mathews, Shailer .......77, 79

Maude, Edwin............ 42

Maugham, W. Somerset..... 21

Maurice, C. Edmund ....... 53

du Maurier, G. .............. 36
MacDermott. Martin.....34, 87

Magnay, Sir William .......... 20

Malet, Lucas ............. 34

Mallet, Sir Louis .......60, 6366 
PAGE

Mayne, Ethel Colburn ...... 2 r

Mazzanti, C. ............ 83

Meade, Mrs. L.'T. ...... 21, 85

Meakin, Budgett.............6 63

Meirion, Ellinor ................ 2 I

Mencken, Henry L. ....... 34

Middleton, Thomas ......... 6

Mikoulitch, V.

Milford, L. S. ............ 53

Millar, J. $\mathrm{H}$.

Miller, Frank Justus $\ldots \ldots \ldots$.

Miller, William ........53, 70

Mills, E. J. ............

Mills, Wesley ............ 75

Milne, James ........... 2 I

Milyoukov, Paul .......... 63

Minns, Ellis $\mathrm{H}$.

Mistral, Frédéric

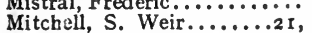

Moffat, John Smith ....... 42

Molesworth, Mrs.......... 83

de Molinari, G. ........... 63

de Montagnac, Noël........ 7 I

Montagu, Lily H........... 2 I

de Montalban, D. J. P. ...... 40

Montgomery, K. L......... 2 I

Moore, A. W. ............. 53

Moore, George ......6, 21, 34

Morel, B. D............. 63

Morfill, W. R. ........ 34

Morley, John ........... 39

Morris, Mrs. Frank......... 83

Morris, Lydia J. .......... 42

Morrison, W. Douglas.... 34, 54

Moscheles, Felix .......... 36

Mosso, Angelo .......... 36, 7 I

Mottram, William ......... 2

Mügge, M. A. ........... 34

Muir, Robert James....... 22, 34

Mummery, A. F. ........ 7 I

Murray, David.......... 54

Murray, J. Clark............ 22

Myron, A. Kiel.

Needham, Raymond ...... 54

Negri, Gaetano ......79, 4r, 54

Nelson, Jane.............. 22

Nesbit, B. ............22, 84

Newman, Edward ......... 75

Nicholson, Brinsley........... 6

Nicholson, F. C. ...........

Nicholson, L.

Nicholson, R. A ...........

Nicolay, John G

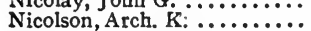

Nietzsche, Friedrich........ 34

Nieuwenkamp, W. O. J! ..... 37

Noble, M. A: ........... 86

Noel, Roden ..........6, 64

Nordau, Max ............ 36

Norman, Henry .......... 71

Norman-Neruda ............ 7I

Normyx ............... 22

Norris, W: E: ............ 22

Northcote, James......... 36

Ober, F. A.

O'Brien, R: Barry........ 64,83

O'Clerigh, Arthur ........4 49

O'Connor, T. P.. …... 38,54

O'Donnell, C. J.............. 64

Ogilvie, Will H. .......... $7 \mathrm{I}$

O'Grady, Standish...22, 83, 87

Olcott, Lucy ............6 69

Oliphant, Mrs..........22, 8

Oliver, S: P. $\ldots \ldots \ldots \ldots \ldots$ 4

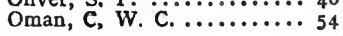

\section{PAGE}

Oman, Iohn Camplell ...... 79

Omond, G. W. T. ........ 22

Oppenheim, A. I. ........ 75

Orczy, Baroness......... 22

Otway, Thomas.......... 6

Ouida................ 22

Owen, Charles ........... 22

Page, H. A. . .

.......... 4 I

Pankhurst Mrs.......... 54

Parke, A. J............. 37

Parker, Theodore ............ 79

Parsons, John Denham...... 76

Paulscn, Friedrich .........79

Payne, J. F............. 44

Pennell, Charles .......... 37

Pennell, Elizabeth Robins.... 36

Pennell, Joseph ......... 36

de Pentheny, S. .......... 22

Perrin, F............. 67

Pfleiderer, Ot to ......... 79

Phelps, William Lyon.......

Philpott, Hugh B. ........ 80

Pidgin, Charles F. .......... 22

Pike, G. Holden.....39, 43, 45

Pike, Oliver G. ......... 76

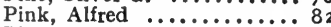

Pinnock, James ........... 7

Pinsent, Ellen F............. 22

Pinto, Ferd. Mendez ....... 46

Pitt-Lewis, G. ...........4 4

Playne, C. E. ............ 22

Plowden, A. C...........4 43

de Polen, Narcisse ........ 23

Porter, C................

Potapenko, J............. 23

Pott, F. L. Hawks ......... 54

Power, D'Arcy ............ 4

Praed, Mrs. Campbell ....23, 43

Presland, John ..........

Prichard, K. and Hesketh.... 23

Proal, Louis ............ 34

Pryce, G. ............. 23

Pullen-Burry, B...........

Pusey, S. E. Bouverie...... 5

Pyle, Howard ........... 46

de Quevedo, Francisco ..... 37

Quin, Ethel............ 7 r

Ragozin, Zénaïde A

Ravenshear, A. F.......

Ravenstein, G. E......... 80

Rawlinson, Professor George . 55

Rea, Thomas ...........

Read, C. Stanford ........ 82

Reeth, Allan ............. 25

Reid, Forrest ........... 25

van Rensselaer, Mrs. ........ 37

Rey, Guido .............. 7

Rhead, G. Woolliscroft ....... 37

Rhys, Ernest ...........

Rhys, John ............ 55

Richardson, Mrs. Aubrey .... 25

Richardson, E. .........

Richings, Emily.............. 25

Richmond, Mrs. .......... 76

Riley, Thomas ............ 83

Rita ............... 25

Robinson, A. Mary F....... 6

Ruche, James Jeffrey ....... 46

Rodgers, Joseph........... 7

Rodway, James ..........55, 72
PAGE

Rogers, Thorold ......55, 64 Ronald, Mary ............ 82 Roosevelt, Florence ....... 25 Roosevelt, Theodore ........ 72

Rosegarth, Brian............ 25

Rosegger, Peter ........... 25

Ross, Janet ............ 34

Rossetti, Dante Gabriel..... 34 Rowbotham, F. Jameson $25,55,84$

Rowlands, Lilian Bowen ....2 25

Rowsell, Mary............. 83

Roxby, Percy M. ........... 40

Rudaux, L.............. 76

Russell, Charles E........... 64

Russell, Sir Edward...... 34

Russell, George W. E. ...... 34

Russell, T. Baron .......... 34

Russell, W. Clark ........... 25

Rutherford, Mark ........ 25

Ryley, J. Horton . ...........

Ryves, K. C. ...........26

Sabatier, Paul.........64, 80

St. Hilaire, Philippe ........ 26

St. John, Sir Spencer........ $3^{8}$

Saintsbury, George......... 65

Sala, George Augustus...... 26

Sanders, Newton .......... 26

Santayana, George......... 7

Sarnia ................ 26

Scaife, A. H..................... 55

Schallenberger, V......... 26

Schiller, Friedrich .........

von Schlicht, Baron .......... 26

Schmidt, Max ........... 34

Schmidt, Rudolph ......... 76

Schreiner, C. S. Cronwright .. 65

Schreiner, Olive........26, 65

Schuller, Leo Sarkadi. . . .....

Scidmore, Eliza Ruhamah... 72

Scotson-Clark ........... 37

Scott, Sir Walter ............ 26

Scott-Elliott, G. F............. 72

Scully, W. C.............. 26

Searelle, Luscombe . . . . . . . . 72

Seccombe, Thomas ........4 43

Segantini, Giovanni....... 37

de Segovia, Pablo .......... 37

Seignobos, Charles......... 55

Selleck, W. C .......... 80

Sellon, B. Mildred ......... 84

Sergeant, Lewis ........... 55

Service, Robert W..........

Seymour, Fredcrick H. A..... 37

Seym vur, Major-General .... 72

Seymc: $r$, Lady ......... 43

Shadweil, Thomas ........... 6

Shakespeare, William....... 7

Shaw, Albert ............6.6 65

Sheehan. Rev. P. A......... 26

Sheeby-Skeffington, F. .....43

Shelley, Percy............. 70

Shenstone, Mildred.......... 26

Sheppard, Arthur ......... 86

Shervinton, Kathleen ....... 44

Sherwood, A. Curtis ....... 26

Shipp, John .............. ${ }_{46} 6$

Shirley, James.............. 6

Sholl, Anna Maclure...... 26

Shuckburgh, B. S. ....... 55

Shuddick, R. .......... 86

Sibley, N. W. ...........65

Sibree, James .............72

Sidney, Margaret .........8 84

Sigerson, George.......... 7

Sillard, Robert M. .......... 44

Simpson, Wm. (Crimean S.) .. 24

Small, Albion W. ......... 65

Smith, F. Clifford........... 26 
Smith F. PAGR

Smith, Goldwin ..........,

Sinith, Isabella............ 26

Smith, John............. 27

Smith, Mrs. S. H. ....... 44

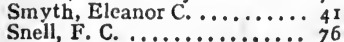

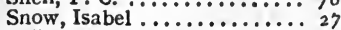

Sollas, W. J. $13 \ldots \ldots . . \ldots \ldots 7^{76}$

Spelling, T. C.............65

Spence, Ca therine ......... 2

Spicer, Howard $\ldots \ldots \ldots \ldots \ldots$. 86

Stacpoole, H. de Vere $\ldots . .2 \%, 87$

Stanley, Edward........... 55

Stead, Alfred .............. 72

Stead, Richard ........... 51

Stead, W. T. ............. 65

Steele, Richard ............ 6

Stein, M. Aurel . .......... 72

Stephens, H. Morse ......... 55

Stevens. Nina ............. 27

Stillman, W. J..............

Stokes Sir William........... 44

Stopes, Mrs. C. C. .......... 65

Stott, Beatrice ........... 27

Strachey, John St. Loe....5, 76

Strain, B. H............. 27

Strasburger, Eduard ....... 72

Stratilesco, Tereza ........... 72

Street, Eugene E........... 72

Stuart, C. Douglas ........... 37

Stubbs, Chas. William........ 80

Sturgis, Russell .......... 37

Stuttard, John............ 76

Summers, Dorothy ........... 27

Sutcliffe, Halliwell .......27, 72

Svenske, Anders.......... 65

Swain, A. E. H. ...........

Swift, Dean ............... 44

Swift, Benjamin ........... 27

Swinburne, Algernon Charles.

Symonds, John Addington .. 6

Symonds, Margaret ........ 72

Symons, Arthur $\ldots \ldots \ldots \ldots$
Synge, Mrs. Hamilton.......

Tadema, L. Alma......... 59

Taine, Adolphe Hippolyte.... 72

Tayler, F. Jenner.......... 28

Taylor, Austin $\ldots \ldots \ldots \ldots \ldots 65$

Taylor, Ellen ............. 28

Taylor, J. F.........43, 87

Taylor, Mrs. John......... 43

Tetley, J. George $\ldots \ldots \ldots \ldots, 44$

Theal. Dr. G. McCall........ 57

Thomas, Edward .......... 8

Thomas, Emile..........
Thomas, William J. PAG

Thompson, Helen Bradford ... 76

85 Watson, John ............77

............ 34 32

Thynne, R............. 28 Watson, Margaret ........ 32

Tirebuck, William ........... 44 Watson, R. Spence $\ldots \ldots .4566$

Todhunter, Dr. John ....44, 87 Watson, William........ 7,46

Tomson, Graham R. ....... 4 Watts, Henry Edw........ 58

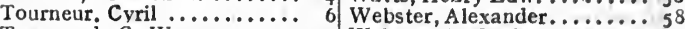

Townsend, C. W......... 72 Webster, H. Cayley ....... 73

Townshend, Dorothea..... 43 Webster, John............ 6

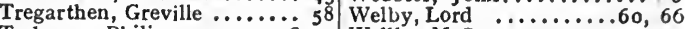

Treherne, Philip.........28, 44 Wellby, M.S. .............. 73

Trelawny, Edward J........ +6 Wells, H. G................ 34

Troubridge, Lady ........ 28 Wendell, Barrett.......... 3

Trowbridge, W. R. H..28, 49, ${ }^{8} 8$ Werner, A................

Truscott, L. Parry ......... 28 Westell, W. Percival ......... 77

Tucker, Géneviève ....... 82 Whadcoat, Gordon Cuming .. 82

Tuin, W. J.................. 37 Whistler, J. McNeill.....

Tunison, Joseph S......... 7 Whitaker, Samuel F. G..... 7

Turnbull, A. R. R........ 73 White, Hester........... 32

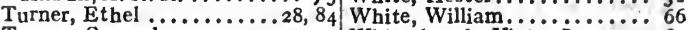

Turner, Samuel ..................... 73 Whitechurch, Victor 87

Turguan, Joseph............ 58 Whitehouse, $H$. Remsen $\ldots . .38$

Twain, Mark ............ 65 Whitman, Sidney........ 58

Tweeddale, John.......... 28 Whitty, E. M............ 59

Tynan, Katherine ...................... 7 Wiel, Alathea

Tyrrell, George ......... 80 Wilberforce. William........ 45

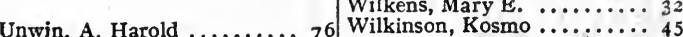

Unwin, Mrs. Cobden ........ 6 62 Williams, Leonard ......... 83

Usher, Sir Thomas ........ $4_{2}^{2}$ Williams, Meta .......... $8_{3}$

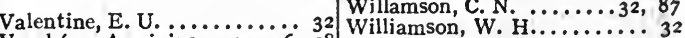

Vambéry, Arminius $44,46,58$ Willmore, Edward ...........

Vanbrugh, Sir John ........ of Wilson, Claude ........... 73

Vanderlip, Washing ton B.... 73 Wilton, Jos................ 32

Vaughan, Henry ........ 87 de Windt, Harry............. 73

Veldheer, J. G. ........ 37 Witchell, Charies A...... 77

Verga, Giovanni......... $3^{2}$ Witt, Paul............. 32

Verity, A. W. ........... 5 Wood, Katharine B........ 82

Viele, Herman K......... $3^{2}$ Woods, H. C. ........... 73

Vierge, Daniel........... 37 Worsley, A...............

Villari, Luigi .......37, 65, 73 Workman, Fanny Bullock.... 73

Villari, Pasquale $\ldots .42,43,58$ Workman, William Hunter... 73

Villars, P......................... 86

Villiers, Brougham ....... 65 Wright, H. K.............. 35

Villiers, Chas. Pelham ...66, 66 Wright, H. M........... 73

Vincent, Arthur ........ 45 Wycherley, William.......... 6

Voigt, J.C. ....................... W $3^{8}$

Volkhovsky, Felix .........8 83

Wagner, Charles .......... 8o

Walpole, Sir Spencer......... 45

Walpole-Bond, J. A. ....... 77

Walsh, C. M. ............ 7

Ward, Mrs. Humphry $\ldots \ldots .85$

Ward, w. c............ 6 Zimmermann, Jeremiah $\ldots 73$

Warden, Florence ......... 32 Zimmern, Alice.... 59, 83, 85

Waring, Henry F. ........ 80 Zimmern, Helen ....... 59,85 Warren, Algernon...$\ldots \ldots$......... 86 Z Zurbriggen, Mattias..... 


\section{INDEX in order of Titles.}

Abbot (The) ........... rAGe Abyssinia (Sport and $\ddot{\text { Fravel). }} 69$ Adam (Robert) Artist...... 35 Addresses

Adelphi Library (The).

Admiral Pbillip ........... 4 AdmiralVernon and the Navy 44 Adula Alps of the I.eopuntine Range (Tlie)

Adventure Series (The) $\cdots . .67$ Adventures of a Elockade Runner

Adventures of 2 Supercargo... Adventures of a Younger Son Adventures of a Dodo ......

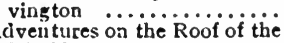

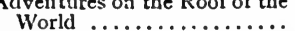
Esop's Fables .............. 83 Aga Mirza (The Adventures of) 18 Age of the Earth (The)...... 76 Alexander's Empire ....... 53 Alfred the Great............ Almayer's Folly ............ I 3 Along the Labrador Coast .. 72 Alpine Memories ........6.69 Alps (My Climbs in the) .... 7 Alps to the Andes (From the) 73 Amazing Duke (The)........20 Amaranthus ............ Amaryllis

Ambassador $(\mathrm{The}) \ldots \ldots \ldots \ldots$ America (Literary History of) American Civil War (Battles and Leaders of the) ...... 5 1

American Commerce American Literature (Ḧ̈ralds of)

American Literature (Short History of) ............. American Opinion of the French Revolution........ American Railway Organization .............. 6 r American Scholar (The) .... 79 American Workman (The) ... 63 Among the Man-Eaters $\ddot{\text { Among the People of British }}$ Columbia ............6 Among the Syringas ......... 2 r Andes and the Amazon (The) 68

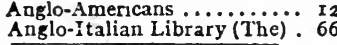

Anglo-Saxon (The) ...... 48 Animal Micrology .......... 75 Animals I Have Known ... . . . 74 Anne of Geierstein ........... Letters ............... Another View of Industrialism 59 Another Wicked Woman .... 22 Antiquary (The) $\cdots \ldots \ldots$ Bible

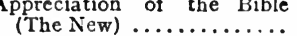
Arabs (LiteraryHistory of the) Arcady : for Better for Worse 5 Arden Miassiter ............ ro Aristotle's Theory of Conduct 34 Armaments (The Burden of). 6o Arms Reform...........62 Art and Artists $(\mathrm{On}) \ldots \ldots \ldots .36$

\section{Artist Songs}

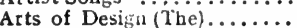

As a Tree Falts ............

Ascent of Mall (The) ...... 74

As Others See Us............ I4

Aspirate (The) ...........

Assisi (Golden Sayings of Giles of ) ........... 80

Assyria ............... 54

Astronomy for Amateurs
Atrocities of Justice under

British Rule

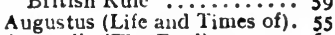
Australia (The Real)

Australian Bushrangers ( $\mathrm{His}$ -

tory of) $\ldots \ldots \ldots \ldots \ldots \ldots$

Australian Commonwealth

(The)

Australian Girlhood (My).... Australian Sheep and Wool..

Austria .................. 58

Autumn Leaves............... 19

Avocat Patelin (L').........

A wakening of a Race (The) . 59

Baboo English............ 8

Bachelor in Arcady (A) ..... 27

Bachelor Maid (A) ........ I6

Baile's Strand (On) .........

Baldwin ...................

Balfour's Pamphlet (A Reply)

Balfourism .............

Balkans (The) ............

Bamford's Passages ......... . .

Barbara Cunliffe............

Barbarian Invasions in Italy...

Barbary Corsairs (The)..... 52

Bards of Gael and Gall........

Battles and Leaders of the American Civil War...... 5

Beach and Bogland (By)....

Beaconsfield (Lord) ..........

Beauclerk (Lady Diana) ..... .

Beauty Adorned .......... I8

Beckwourth (James $\ddot{P}$., Life and Adventures of) .....4 46 Beetle (The) ............

Before I Forget ........... 39 Begliojoso : A Revolutionary Princess .............. 38 Behind the Arras (From) ..... 13

Belcaro ............... 33

Belle Marie (La) ........... I9

Belle Nivernaise (La) ....... . 83

Bending of the Bough (The).. Benyowsky (Memoirs and Travels of ) ............ Bergen Worth ............... 20 Bernard (Claude) ................. 38 Bernese Oberland ( $\mathrm{T}$ he $) \ldots \ldots .667$ Besant (Anne) ...................... Betrothed (The) .........26

Bible as English Literature (The) ..............

Big Game Shooting in South Africa ............... Birdland $($ In $) \ldots \ldots \ldots \ldots \ldots \ldots$. $\ldots \ldots \ldots$

Bird Life (British) ....... 77 Bird Life in Wild Wales...... 77 Birds I Have Known ........ 74

Bird Skinning and Bird Stuffing ............ 75 Bird's Nest $(\mathrm{Th}$ ) . ........... 77 Kishop Doyle .........40,87 Black Dwarf ............... 26
PAGE

Black Mary ............ 2

Black Shilling (The)......... Blue Gown (In the Land of the) $\ldots \ldots \ldots \ldots \ldots \ldots, 70$ Blue Lagoon (The) $\ldots \ldots \ldots 27,87$ Blue Lilies ............. 12 Bog of Stars (The) .......22, 87 Bohemia ................ 53 Bohemia with Du Maurier (In) 36 Bonaparte in Egypt .......4 48 Bond of Blood (The)........ rs Bossism and Monopoly .... 65 Bourgeois (The) $\ldots \ldots \ldots \ldots 27$ Boy and the Angel (The).... 82 Bradlaugh (Charles) ........ 38 Brahmans (The) .......... 79 Brand .................. 5 Breachly (Black Sheep)...... Io Breakfast, Dinner, and Supper (Quickest Guide to) ...... 82 Breitmann in Germany-Tyrol 19 Bride of Lammermoor (The).. 26 Bright Days in Merrie England ................. 69 Brightwen, Mrs. (Life and Thoughts) ............ $3^{8}$ Brightwen Series (The)..... 76

Britain (Early) ..........4 49

British Bird Life $\ldots \ldots \ldots \ldots$ 77

British City (The) .........6 62

British Columbia (Among the People of)..$\ldots \ldots \ldots \ldots$ ug British Diplomacy (The Story of) $\ldots \ldots \ldots \ldots \ldots \ldots \ldots \ldots$

British East Africa..........6 6 British History (Literary Influence in) ..............

British India ............ 50 British Industries under Free Trade ............... 6o British Political Leaders .... $4^{2}$ British Regiments (Famous).. 50 British Writers on Classic Lands ................. Brodie (Sir Benjamin)........... $3^{8}$ Brooke (Rajah) ............. $3^{8}$ Brown (Captain John)....... 3s Brown Owl (The).......... 83 Brown, V.C. .........8, 85 Brownies in the Philippines .. 83 Buccaneers and Marooners of America (The) .........46 Buchanan (Robert) ........ $3^{8}$ Budapest .............. 72 Buddhist India ..........49 Builders of Greater Britain.. $3^{8}$ Bulgarian Exarchán (Tne). . 63 Bundle of Life (A)......... 17 Burden of Armaments (The). to Buried City of Kenfig ...... 50 Burmese Language (Handbook of the) Burton(The Real Sir Richard) 39 Bush Honeymoon (A)...... 8 Business of Life (The)...... 8r Butterfly (The) $\ldots \ldots \ldots \ldots \ldots 76$ Bygones Worth Remembering $4 \mathrm{I}$ Byron in Italy ......... 70 Byzantine Empire (The).... 54 Cabot (John and Sebastian). . 39 Cameo Series (The)........ 3 Camera in the Fields (The).. 76 Canada (Children's Study) .. 83 Canada (Story of the Nations) 48 
Cana:la in Harvest Time

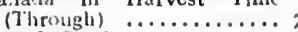
Canada To-day ............ Canal System of England.. Canon in Residence(The)..32,
Cape Colony (Everyday Life). Captain of the Lccusts ( $\mathrm{Ch}$ ) .. 7 Captain Sheen............. 22 Capture of Paul Beck (The).. Cardinal's Pawn (The) ...... 2 I Carding Mill Valley ........ r 9 Carlyle (Thom:s) .......... 39 Carpathian to Pindus (From) 72 Carroll, Lewis (Life of)...... Carroll Picture Book (The Lewis) ............. 35 Carthage ............... 49 Cartoons in Rhyme and Line.. 63 Case of Miss Elliott (The).... 22 Case of Wagner (The) ...... 34 Castle Dangerous.......... 26 Cat and Rird Stories......... 76 Catharine Furze .......... 2 Caucasus (Fire and Sword in the) ...

Cause and Effect............ Cause of Discontents in India ${ }_{4}$ Cause of IndustrialDepression 63 Cavalleria Rusticana ...... 32 Cecilia's Lover $\ldots \ldots \ldots \ldots . . . .99$ Celtic Twilight (The) Century Cook-Book (The)...... $_{82}$ Century Invalid Cookery Book 8r Century Library (The)...... r2 Century Scott (The) ....... 26

Certain Personal Matters.... $3^{2}$ Chaldea .............. 54 Charing Cross to Dellhi(From) 69 Chats on Book-Plates ..... 35 Chats on Costume........ 37 Chats on Earthenware...... 36 Chats on English China ..... 36 Chats on Old Furniture...... 36 Chats on Old Lace......... 36 Chats on Old Miniatures .... 35 Chats on Old Prints ....... 36 Chats on Oriental China .... 35 Chats Series (The)......... 35 Chaucer's Maytime (In)...... 25 Chelsea Window Gardening.. 8I Children of Endurance (The)... I 2 Children's Library (The) 82,83 Children's Study (The)...... 83 Chile .............. 72 Chillagoe Charlie........... 84 China (Story of the Nations).. 49 China Cup (The).......... $8_{3}$ China from Within ........ 67 Chinaman (John) at Home .. 68 China under the Searchlight.. 67 China's Business Methorls.... 62 Chinese History (A Sketch of) 5.1 Chinkie's Flat ............ ro Christ and the Nation ..... 78 Christian Belief........... 78

Christian Democracy......... 78 Christian Origins ......... 79 Christianity and the Bible .. 80 Christmas Berries ......... Traffic (The) ......... 59 Cinderella .............. I3 City (The) . ............. 62 Civilisation (The History of) 55 Clearer Vision (The)........ 2 I Cliff Days .............. 25 Climber's Note Book (The).. . 7
Climbing in the KarakoramHimulayds ...........6.6 Climbs in the Alps (My).

Climbs in New Zealand Alps. 68 Dawn of Pay (The)............ Climbs of Norman-Neruda 7I Dawn of the rgth Century in Clive (Lord) $\ldots \ldots \ldots \ldots \ldots$. Bngland (The)......... 47

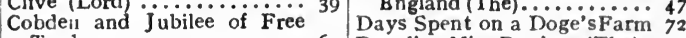
Trade

Cobden as a Citizen ............. 60 Cobden, Richard (Life of) ...

Cobden (The Political Writings of $\ldots \ldots \ldots \ldots \ldots \ldots$.............. Cobden's Work and Opinions.
Cogne (The Mountains of).... Coillard of the Zambesi .... Colette

Colonise Eng.……... 26

Comedy of Three (A) ......... 26 Coming of Friars (The)...... 51 Coming of Parliament (The).. Coming of Sonia (The)........ Command of the Prince (By). Commerce (American)....... 86 Cornmercial Travelling ...... 86 Commissioner Kerr ........ 4 I Concerning Cats $\ldots \ldots \ldots \ldots 4$ Concerning Himself ....... 32 Confessions of a Beachcomber 66 Confessions of a Caricaturist 36 Confessions of a Match-Making Mother $\ldots \ldots \ldots \ldots \ldots \ldots \ldots$ r Congo (The) …......... Convict Days (Old)......... 10 Co-operation (The History of) 62 Corner of Asia (A,$\ldots \ldots \ldots \ldots$...... Cornish Whiddles......... 83 Corn Law Rhymes.........6 6r Counsels of the Night (The) .. 12 Count Robert of Paris...... 26 Countess Kathleen (The) ..... 7 Country of Horace and Virgil 66 Country Parson (Trials of a) 51 Court Beauties of old White-

Court Beauties of Old WhiteCourt Cards ............... Creek and Gully (By) .......

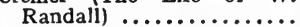
Crete (The Palaces of $\ldots \ldots \ldots$..... Cricket ............. 86 Cricket on the Brain.......... Crimean Simpson's Autobiography

Criminal Appeal $\ldots \ldots \ldots \ldots$. 65 Criminal Justice (Our) ....... 6r Criminal Scciology.......... 33 Criminology Series (The).... 33 Crimson Azaleas (The) ...... 27 Cromwell and His Times..... 39 Crowd (The) $\ldots \ldots \ldots \ldots . . . .33$ Cruise of the Wild Duck (The) I4 Crusades (The) $\ldots \ldots \ldots \ldots \ldots 47$ Cuba and International $\mathrm{Re}$. lations

Cuba and Porto Rica........ 69 Cults of India.......... 79 Curiosities ..............22 Curzon (Lord). The Failure of. 6I Cut off from the World...... Ir

Daugnter of Patriclans (A)... 26 Daughter of the Fen (A)..... Io Dauphiny (The Central Alps of

the) $\ldots \ldots \ldots \ldots \ldots$. 67 David the King........... 49 Davidson (Memorials of

Thomas)............ 39
Divis (Thomas) A Short PAGE of 87 40 Dazzling Miss Davison (The). 32 Dazzling Reprobate (A)..... 28 Deeps of Deliverance (The).. I 4 Deidre.............. z Democracy and Reaction.... 62 Derwent (Sir Frederick) .... I 9 Desert Ways to Baghdad(By) 69 Desmonde, M.D........... 15 Destroyer (The)..........27 Development of Christianity. 79 Development of Western Civilization............ 50 Devil's Half Acre (The)..... of a) .............. 49

Dianas Hunting........... II

Diarv of a Dreamer......... 14 U S.A. and Spanish America 52 Disciple (The).$\ldots \ldots \ldots \ldots$ I Discourse of Matters $(\ddot{A}) \ldots 79$ Discovery of the Future (The) 34 Disdainful Maiden (The).... 83 Disestablishment in France.. 64 Divine Presence (The)..... 79 Divorce................ II Doctor (The) ............27 Doctor Gordon .......... 32 Dog Book (The) .......... 75 Don Quichote .......... 12, 37 Double Choice (A) ......... 9 Double Marriage (A) ....... I 2 Douht and Faith ........... 78 Drama of Sunshine (A)... .. 25 Dramatic Traditions of the Dark Ages .............. Dream and the Business (The) 17 Dream Life and Real Life.... 26 Dream Woman......... 32 Dreams ........... 26 Driven ............... 32 Dutch and Flemish Masters (Old) $\ldots \ldots \ldots \ldots \ldots \ldots \ldots \ldots \ldots \ldots \ldots$ Dutch Towns (Oidi)............ 37 Dwarf-land and Cannibal Country (In) .......... yo Dyer, John (Works of) ...... 87 Barly Mountaineers (The).... 68 East Africa (British) .......6 69 East Africa (Sport and Travel) 69 Eastern Asia (A Brief History of) ................. 50 Ebbing of the Tide (The)..... 10 Econ Holden ................. Studies ............. 6r Rconomic Interpretation of History .............. 64

Editor's Sermons (An) ...... 34 Education (Trend in Higher). 78 Edward Barry.............. ro Effie Hetherington.......... II Egypt (Ancient) .........53, 55

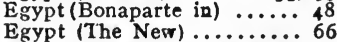
Egypt (The New) .......... 66 Egypt (Secret History of the English Occupation of) .... $4^{8}$ Eighteenth Century Painter (Memorials of an) .........36 Dog Stories ............. 76

Earl's Cedars ............ r 
INDEX IN ORDER OF TITLES.-continued.

El Dorado (In Search of) PAGE Eleanor Lambert (The Story of) $\ldots \ldots \ldots \ldots \ldots \ldots$ I Elgivia, Danglster of the Thegn 16 Eliot, George (True Story of) Elizabeth (Graudmother's advice to) (................. to) $\ldots \ldots \ldots \ldots \ldots \ldots \ldots$

Elizabeth of England (Princess) Correspondence of .... . Enchanted Castle (The) .... 8

Enchanted Garden (An) ..... $8_{3}$ Ending of My Day (The)..... 23

England (Children's Study).. 8

England (Bright Days in Merrie)

England (Dawn of the rgth

Century in)
England (The Governance of $)$ England (The Industrial History of)
England's Title in ireland $\ldots$

England (Mediæval) ........47 England (Mcdern) $\ldots . . . \ldots{ }^{52}$

England (The Monarchs of

England $\cdots$ (Parliamentary) (1660-1 832$)$. ............
ngland (Socialist Movement

England (Socialist Movement

Fngland under the Coalition... ${ }^{6} 8$

English Cathedrals.......... 37 book of)

English China (Chats on) ... 37 English Essays from a French

English Novel in the Time of Shakespeare (The) ........

English People (The) ......
English People (Literary HisEnglish People (Literary History of the)

English Public Opinion ...... 50

English Sports (Old) ....... 86

Epistles of A tkins (The) ......

Epoch in Irish History (An)... 53

Escalades dans les Alps (Mes) $7 \mathrm{I}$

Escapes of Latude and Casanova (The) .........4 46

Essays in Puritanism....... graphical...............

Ethiopia in Exile......... 71

Euphorion ............... of Hindustan ........... European Relations $\ldots \ldots$ (Memoirs of Thomas) ............. 40 Evelyn Innes . . . . . 21 Every Day Life in Cape Colony 68 Bve's Apple $\ldots \ldots \ldots \ldots \ldots \ldots$. ${ }^{1} 3$ Evolutions of World and Man 74 Bxpositions..$\ldots \ldots \ldots \ldots .77$

Fabian's Tower ........... Face and How to Read it (The) 75 Facing the Future ......... 28 Failure of Lord Curzon (The). Fair Maid of Perth (The).... 26 Fairy Tales (Irish) .......... Fairy Tales from Brentano (New)

Faith of a Modern Protestant (The) ............ 77 Falls of the Loder (The)...... r 9 Fanny Lambert ............ 27 Far East (Peoples and Politics in the $\ldots \ldots \ldots \ldots \ldots \ldots$,
Far in the Forest....... PAGK

Fast Miss Blount (That) .... r 8

Father Alphonsus.........

Father Felix's Chronicles ... I

Father of $\operatorname{Six}(A) \ldots \ldots \ldots \ldots 23$

Feather (The) $\ldots \ldots \ldots \ldots .8$

Female Offender (The)........

Filibusters (The Story of the) 46

Filigree Ball (The)......... I

Finality of Christian Religion 78
Finn and His Companions.... 83

Finnish Legends......... 83

Fire to Fortune (Through)....

First Aid to the Injured..... 85

First Fleet Family .......... I I

First Novel Library (The)....

First Watch (In the) ...... I4

Fiscal Problem (The) ........6 63

Fiscal Reform Sixty Years

Ago $\ldots$..................

Fisher Book (The Harrison). 35

Fishing in Ireland......... 85

Fishing in Scotland...... 85

Fishing (What I have Seen

While) $\ldots \ldots \ldots \ldots \ldots \ldots 75$, 85

Fitch (Ralph) .......... 40

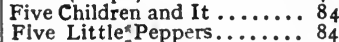

Five Talents of Women (The) $8 \mathrm{I}$

Flame and the Flood (The).. I9

Flamma Vestalis............

Florence (The History of ${ }^{\prime} \ldots 5_{5}$

Flute of: $\mathrm{Pan}$ (The) ........ I7

Foma Gord yeeff ........... I5

Fool-Killer (The) $\ldots \ldots \ldots \ldots$ 12

Fool's Tax (The) ......... I2

Football, Hockey, and Lacrosse 86

For Better? For Worse?.. 34

Forest Trees (Future) ...... 76

Fortunes of Nigel (The)..... 26

Four Philanthropists (The) ..18

France (Children's Study).... 83

France (Journeys Through).. 72

France (Literary History of $)$.

France (Mediæval) ........ 5

France (Modern)............. 52

Franks (The) ........... 55

Free Food and Free Trade.... 6

French Ambassador (A) .......

French Court (Dames and

Daughters of the) ...........
French Court (Pictures of the Old)

French Literature (Essays in)

French Literature (Manual of)

French Masters (Modern)....

French Society (Heroines of), 47

Frivola ........... 8 , cles of $\ldots \ldots \ldots \ldots \ldots \ldots$.

Froissart in roo2-03.06 .......

From One Man's Hand to Another ................. Fuller (Margaret) Love Letters of $\ldots \ldots \ldots \ldots \ldots$ Furniss (Harry) at Home....

Furze Blossoms ...........

Gael and Gall (Bards of the) .?

Gaelic Literature (Story of Early) ...............

Game of Consequences (A) ...

Gardening for the Million .....

Genealogy of Morals (A) ......

General's Daugh ter (The)....

Generation of a Norfolk House: (One)

Gentleman Upcott's Daughter

German Education ........
German-English Conversation

Book ................ so

German Love Songs (Old) .. 6

Germany (Children's Study).. 83 Germany (Story of the Nations) $\ldots \ldots \ldots \ldots \ldots \ldots 47$ Germany (The Evolution of Modern) ${ }^{r}$.................6 68

Ginette's Happiness......... I6

Girl of the Multitude (A)..... 28

Gladstone Colony (The)...... 62

Glads tone (My Memory of)... 40

Glimpses in to Plant Life..... 74

God and the People........ \&o

God's Scourge.............

Gods, Some Mortals, and

Lord Wickenham ......... I7

God's Will ............... I5

Goethe's Werke ........... 4

Goethe (Life of) .......... 40

Gogmagogs (On the) ........ I 4

Golden Sayings (The)...... 80

Good Men and True........ 4I

Good Reading about Man Books

Gordon (General) The Life of. 40

Gospels of Anarchy........ 33

Goths (The) ............ $4^{8}$

Gould-en Treasury (The) .. 62

Governance of England (The) 63 Governace of London (The). 50

Grain or Chaff............43

Grand Old Hilis "Ünder

the) $\ldots \ldots \ldots \ldots \ldots \ldots$ 19, 85

Grand Relations........... 15

Grandmother's Advice to

Elizabeth ............ I6

Grattan (Henry) ............. 49

Great Minds at One....... 33

Great Minds in Art ......... 44

Great Noodleshıre Election .. 14

Great Pillage (Before the).... 5I

Greater Love (The) ....... 26

Greece (Story of the Nations) 55

Greece (Old Tales from)...... 83

Greek Anthology (A Chaplet

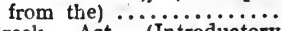

Greek Art (Introductory

Studies in) $\ldots \ldots \ldots \ldots \ldots 36$

Greek Sculptors (Ancient).... 36

Green Cloth Library ........ 28

Green Tea .............. 26

Grey Man (The) ..........13

Guiana Wilds (In)......... 72

Guy Mannering..........26

Gwilym (Dafydd ap) ...... 2

Haeckel, Ernst (Life of) ..... I $^{\text {I }}$

Haileybury College ........ 53

Halls (The) .............. 37

Handbook of the Philippines. 73

Handy-Man Afloat and Ashore 86

61 Hansa Towns (The) ........ 59

Happy-go-Lucky Land ...... 34

Harvey (William).......... 4 I

Haunts of Men (The)........ 12

Hawaii and Japan (Vacation

Days in)........... 72

36 Health at its Best $v$. Cancer 74

Hearn (Cencerning Lafcadio) $4^{\circ}$ Heart of the Empire (The).. 62

Heart of Midlothian (The).... 26

Heavy Laden ............ Is

7 Hebrew Lesson Book (A) .... 79

Hebrew Life and Thought... 50

Heine's Werke ............ 4

Helen Adair .............. 10

Hellenism (The Progress of).. 53

von Helmboltz (Hermann) ... 4I Hemans' Welsh Melodies (Mrs.) ............ 87

Herb Moon (The).......... 17 
Herb of Love (The) .......... I4 India (Vedic) ........... 55

Herbert (TheWorks of $\mathrm{George}) 87$ India (Winter) ........... 872

Hermit of Carmel (A) ....... Heroic Adventurt

Heroic Tales

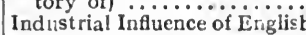
Herridge of Reality Swainp. I He that had received the

Five Talents Patent System .......... Industrial Depression (Cause of) $\ldots \ldots \ldots \ldots \ldots \ldots \ldots$ High Life in the Far East ... High Policy ............. Highland Widow

4 Industrial History of England 64 8 Industrial Rivers of the U.K. Garden ...................... Inner Life of the House of Hill (Sir Rowland) ........ Hillesden on the Moor....... Himalaya (In the !ceWorld of) 73 Historic Americans ...... 79 History in Scott's Novels ... iistory of Co-operation ('The)

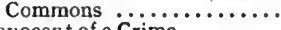
In Insane Root (The) $\ldots \ldots \ldots$..... Inspiration and the Bible.... International (The) $\ldots \ldots \ldots .87$ History of Jamaica............. History of the Holy Eucharist 77 Holland ............. 55 Holland House (The Pope of) 43 Home of the Dragon (The) ... 24 Hon. Stanbury (The)....... 24 Honour of the Flag (The) .... 25 Hookey ............... 20

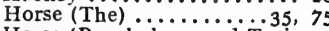
Horse (Psychology and Training of the $\ldots \ldots \ldots \ldots \ldots$ 75 Hotel d'Angleterre (The) .... I4 Hour Glass (The) $\ldots \ldots \ldots \ldots$. 7 House of Arden (The) ...... House of Commons (Inner Housewife's What's What ... 8I How to Arrange with your Creditors

How to become a Commercial

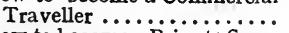

How to become a Private SecreHow to become a Teacher.... How to be Happy Thoing Married ............................ How to Buy a Business .... 85 How to get Married....... Heavens ............. How to Punctuate (Stops) ..... How to Study the Stars .... 7 Hugh Wynne............ Humours of Donegal $(\mathrm{The}) \ldots 2$... Humorous Rhymes of Historical Times

Hundred Riddles of the Fairy Bellaria

Hundred Years Hence $(\dot{A}) \ldots . .34$ Hungary(Story of theNations) 58 Hungary: Its People..... 5 I Hungry Forties (The) ........ $6_{2}$ Hunter (John) ............. 4 I Husband of no Importance $\ldots 2$ Ideas of Good and Evil .... 7 Idle Hour Series (The)....... r8 Illustration of Books (The)... 36 Impossible Person (An) ....... I 3 Impressions of a Wanderer... 70 Increase of the Suburbs (The) 63 India (The Brahmans of) .. 79 India (British) ........... 50 India (Buddhist) ........... 49 India (Cults of) .......... 79 India (Imperial) $\ldots \ldots \ldots \ldots \ldots$. . . . 69 India, Medireval............ India ("Prosperous" $\because$ British) $\ldots \ldots \ldots \ldots \ldots \ldots \ldots$

Interpreters (The) $\ldots \ldots \ldots \ldots$ I I

Ipane (The) $\ldots \ldots \ldots \ldots \ldots \ldots .68$

Ireland (Children's Study) $\ldots 8_{3}^{4}$

Ireland (England's Title in) . . 64

Ireland (Story of the Nations) $\mathbf{5 2}$

Ireland (History of) .......4 49

Ireland (Literary History of).

Ireland (I.ove Songs of).......

Ireland (the Past History of $\vec{f}$.

Ireland: The Patriotic Parliament

Ireland (Yoün) $\ldots \ldots \ldots \ldots \ldots$

Irish Fairy Tales ..........

Irish History (A Review of $\cdots 5$

Irish Library (The New) ..... lish Tongue ............

Irish Literature (The Revival of) $\ldots \ldots \ldots \ldots \ldots \ldots \ldots \ldots$

Irish Memories...........

Irish Poems of Perceval Graves Irish Song Book (The) $\quad .36,87$

Iron Gates (The) ......... I

Irving (Sir Henry) .............

Isle of Man (The Story of the).

Is Liberty Asleep ?.........

I talian Masters (Old).........

Italians (Lives of Great) . .... Italy (Ancient) ........... 5

Italy (The Birth of Modern) . 53 Italy (Modern) . . . . . . . . Italy (Studies in the $\mathrm{r} 8 \mathrm{th}$ Cen-
tury in) $\ldots \ldots \ldots \ldots \ldots \ldots \ldots$ Italy (The Barbarian Invasions of ) ............ I, Thou, and the Other One $\ldots$ Ivanhoe ............. 26

Jamaica as It Is .... ...... 7

Jamaica (A History of) .... James Sherving ton .......... I Japan (Story of the Nations) . Japan (An Artist's Letters from ) ..............6 6 Japan, Our New Ally ....... Japan (Present-Day)........ 6 Japan (The Real) .......... Java, the Garden of the East . Jews (The) ........... Jews under Roman Rule (The) 5 Jewish Literature (Short History of)

Jilt's Journal $\ddot{(A)} \ldots \ldots \ldots \ldots \ldots . . . .2$

Job (The Original Poem of) .. 78

John Jones, Curate ....... 23

John Sherman ........... 32

Johnson Club Papers........8 86

Josephine's Troubles ...... 15

9 Journeys of Artonia (The) ... r 4

Julian the Apostate ......4I, 54

Juvenile Offenders........... 34
J uvenilia $\ldots \ldots \ldots \ldots \ldots \ldots, 33$

Kafir Stories................ 26

Karakoram-Himalayas(Climb-

ing, \&c., in the).........6 67

Karakorams and Kashmir ...66 68

Keene (Charles), The Work of 37

Keith's Crime (Mrs.) ......... I3

Kenfig (Buried City of) .... 50

Kenilworth ............. 26

Khotan(Sand-Buried Ruins of) 72

King Leopold's Soliloquy.. 65

Kingdom of Twilight $\ldots \ldots \ldots, 25$

Kit Kennedy $\ldots \ldots \ldots \ldots \ldots$ r ${ }^{3}$

Kitty Costello ............ 8 , 85

Kolokotrones : Klepht and

Warrior $\ldots \ldots \ldots \ldots \ldots 4^{4}$

Kruger (Paul), The Memoirs of $4 \mathrm{r}$

Labour and Other Questions in South Africa ...........6 69

Labour ald Protection ........ 63

Labour and Victory $. . . \ldots \ldots, 4$ I

Labour Legislation.............62

Labour Movement (The)..... 62

Labour Party (The)........ 64

Lady from the Sea (The)..... 5

Lady Jean................. 50

Lady Killer (The)............. 27

Lady Mary of the Dark

House ............. 32, 87

Lady Noggs, Peeress (The)

Lady's Honour (A)......... r r

Lake of Palms (The).......... r4

Lally of the Brigade......... 20

Land of the Blue Gown (In

the) $\ldots \ldots \ldots \ldots \ldots \ldots$ 70

Langland's Vision of Plowman 2

Last Hours with Nature....7 75

Last Mackenzie of Redcastle I9

Last Step to Religious Equality

(The) .................77

Latter-day Sweethearts .... I6

Laura's Legacy........... 27

Laurenson (Arthur) The Me-

moirs of $\ldots \ldots \ldots \ldots \ldots 4$ 4

Law of God (The) ........... 79

Lays of the Red Branch ... $x_{4}, 87$

Leader of Society (A).......4 47

Leaders of Men ............ 43

Lear (Letters of Edward) ... 4 I

Leaves from the Life of an Eminent Fossil.......... I r

Legend of Montrose (The) ... 26

Legend of St. Mark (The)..... 82

Legions of the Dawn (The). 25

Leithay's Banks (On)...... rg

Leopontine Alps (The) ....... 67

Lesser's Daughter........... r4

Lessons from the World ..... 79

Letters of Her Mother to Eliza-

beth ............. 28

Lewell Pastures ............ r9

Library of Literary History 2

Life and To-morrow....... I7

Life in a Crack Regiment. . . . 26

Life in the Open $\ldots \ldots \ldots \ldots . .7$ r

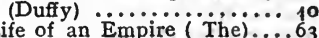

Life of Man on the High Alps...70

Life of Christ (The) ....... 77

Light Eternal (The)........ 25

Lilac Sunbonnet (The)....... I3

Lincoln (Abraham) ........ 42

Lindsay $0^{\prime}$ the Dale $(\mathbf{A}) \ldots . .$. I 6

Links in My Life (Gambier). 40

Lion's Whelp (The) .......... 9

Literary History of America 3

Literary History of France...

Literary History of India (A). 
Litcrary History of Literary History of Persia (A) Literature History of Rome. Literary History of Russia.. Literary History of Scotland Literary History of the Adelphi (The).

Literary History of the Arabs

Literary History of the Eng. lish People (A) .

Literary Influence in British Literary Life (My) (Mme. Adam).$: \because \because, \because$ Pen (The).......

Lithography and Lithograph-

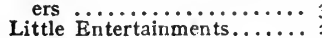

Little Glass Man (The)....... 8

Little Indabas ........... 70

Little Novels $\ldots \ldots \ldots \ldots \ldots$ 20

Lives Worth Living Series(The) 42

Living Buddha (The) ........

Living Matter (Nature and Origin of) .

Liza of Lambeth........... 7

Locum Tenens (The) ...... 32

Log of a Jack Tar (The)

(James Choyce) .........

Lombard Communes (The).. $4^{8}$

Lombard Studies ........ 48

London at School........... so

London (The Governance of) 50

London Lovers .............

London Plane Tree (A) ......

Lonely Way (The) ...........

Long Vigil (The).

Lord Maskelyne's Daughter

Lost Heir (The)

Lost Land (The) ........... Men ..................

Love and the Soul Hunters... I I

Love Cure (A)

Love is not so Light........... I

Love in the Lists ...........

Love Letters of Margaret Fuller.

Love Songs of Ireland ........

Love Songs of Robert Burns...

Love Triumphant ........2I, 8

Lucas Malet Birthday Book.. 32

Lucie and I.............. $1_{3}$

Luncheons ............... 82

Lyrics (M. F. Robinson) ..... 6

M.A.B

Mabinogion (The) .......... 87

Mabinogion (Tales from the)..

Machiavelli, Niccolo (Life of)

Madagascar (Robert Drüy)...

Madagascar before the Con-

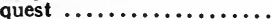

Mademoiselle Ixe ..............

Mad Sir Uchtred............ 13

Magic Oak Tree (The) ........ 83

Magic of the Pine Woods..... r 19

Maid of Maiden-lane (The).... 9

Maitland (Sir Thomas)....... 42

Major Weir ............. $2 \mathrm{I}$

Makar's Dream........... r 9

Making of a Saint (The)...... 2

Man and Maid ........... 22

Man-Eaters (Among the)...... 68

Man in the Street (The) ...... 12

Man's Love (A) .......... 27

Man's Mind (In a)............ 32

Man who was Afraid (The) ... 15

Manners for Girls $\ldots \ldots \ldots \ldots$ 8r
PAGE

Manors of Suffolk (The) $\dddot{\mathrm{Dau}}$ -

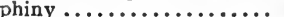

Margaret Foster ................ 26

Margaret Grey .............. 9

Margaret Hetherton ........ 85

Marguerite de Roberval .... 2I

Mariana ............... 4 Marionettes (The)...........

Marozia ............... r 6 Marriage by Capture (A) ..... II

Marriage de Convenance (A).. I 8

Marsena ............. I5

Master Mariner, $\mathrm{A}$ : Eastwick ${ }_{46}$

Master Missionaries ........4 4 I

Master Passions ............ 16

Masters of Medicine ......... 42

Match-Making Mother (The Confessions ot ) ...........

Mating of a Dove (The)...... History of $\ldots \ldots \ldots \ldots \ldots \ldots 51$

Matterhorn (The) ........ 7r

Mawkin of the Flow (The).... r 6

Meadowsweet and Rue ...... I7

Me and Myn ............. r 3

Media, Babylon, and Persia .. 55

Melpomene Papers (The) .... I5

Memoirs of Charles Boner (The) If

Memoirs of Constantine Dix 22

Memoirs of Dr. Thomas Evans 40

Mental Traits of Sex (The) .. 76

Meredith (Novels of George).

Mermaid Series (The) ........

Messianic Hope (The) .......

Mexico ......................

Mexico (S. A. Series).........

Mid Pleasures and Palaces...

Millionaire (The) .........

Milly and olly ..............

Minister's Experience (A) ...

Minister's Guest (The).......

Minor Poet (A) .............

Mirabeau the Demi-God...44, 5

Miréio

Miriam's schooling ......... 25

Mischief of a Glove (The) .... I I

Miserrima ............. 22

Mis-rule of Three (The) ...... 2

Missing Friends............ 46

Mister Bill : A Man......... 20

Mistress of Langdale Hall.19, 8

Model.Factories ..........6 63

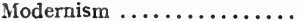

Modern Monarch (A) ........ 20

Modern Travel Series (The).

Moff

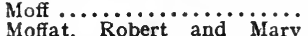

Moffat, Robert and Mary

(Lives of) $\ldots \ldots \ldots \ldots \ldots, 42$

Molly Darling $\ldots \ldots \ldots \ldots \ldots$ r 8

Monarch Series (The) .......

(The)

Monastery (The) $\ldots \ldots \ldots \ldots \ldots$.

Monism (Concepts of) ..... 80

Mousieur Paulot.......... 18

Mont Blane (The Chain of) ... 67

Moonlight .............. 20

Moce and Feil (By) ........ 72

Moors, Crags of the High Peak 66

Moors in Spain (The) ....... 52

More about Wild Nature..... 74

Mother, Baby, and Nursery.. 82

Mother Goose (The True) .... 8

Motherhood ................ 28

Mother of Pauline (The).... 28

Motor Car (The) .......... 85

Motor Cars ............... 86
PAGE

Motor Cracksman (The) ..... 12

Motorists' A B C .......... 85

Mountain Adventure (True

Tales of ) $\ldots \ldots \ldots \ldots \ldots 696$

Mountaineering in the Land of the Midnight Sun .... 70

Mountaineering in the Sierra Nevada .............. 69

Municipal Government in Continental Europe ..........6 65

Municipal Government in Great Britain ...........65

Municipal Lessons from $\mathrm{S}$.

Germany............. 63

Musical Composers (Famous). 42

Mutineer (The) .......... Ir

My Home in the Shires .... I9

My Lady's Garden (In) .... 76

Myra of the Pines ........ 32

Mysterious Psychic Forces .. 75

Mystery of Laughlin Islands II

Mystery of Muncraig (The)... 22

Mystery of Sleep (The) ..... 33

Mystery of the Campagna (A). I4

Mystics, Ascetics and Saints of India (The) .......... 79

Nancy Noon ........... 27

Naomi's Exodus............ 2 I Napoleon's Court (A Queen of) 47 Napoleon's Last Voyages .. 42 Natal (Tales from) ........ 73

National Cook Book ........ 8 8

National Credit........... 62

National Finance ......... 59

National Finance, $1908 \ldots . .50$

National Liberal Federation (The)

Native Wife (His) ............ ro

Naturalist (Life and Thoughts of a) ............... 38

Naturalist (Recreations of a) 75

Naturalist (Travels of a)..... 75

Nature and Origin of Living Matter .....................

Nature and Purpose in the Universe............ 76

Nature Studies .............. 76

Nature's Story of the Year ... 77

Near East (Traveis and Politics in the)

Need and Use of Irish Litera.

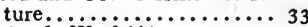

Ne'er-do-Weel $(\ddot{A}) \ldots \ldots \ldots \ldots$ r 2

Negro-Nobodies .......... 70

Neigh bours ............... I4

Neru, and other Plays....... 6

New Arcadia (The) ........ 6

New Chronicles of Don Q... 23

New Bgypt (The) ......... 66

New England Cactus (A)..... I 8

New Guinea (Through) ...... 73

Newspaper Making (The Art

of) $\ldots \ldots \ldots \ldots \ldots \ldots \ldots$ 8s

New Spirit of the Nation

(The) ........... 34, 87

New Zealand Alps (Climbs in

the) $\ldots \ldots \ldots \ldots \ldots \ldots \ldots 68$

Nietzsche: His Life and

Work . .............. 34

Nietzsche (The Philosophy of

Friedrich)

Nine Unlikely Tales........... 84

Noble Haul (A) ........... 25

No Place for Repentance .... 22

Norfolk and Suffolk Coast

(The) ...............66 68

Norman-Neruda (The Climbs

of) $\ldots \ldots \ldots \ldots \ldots \ldots \ldots$ 7r

Normans (The) ........... sI 
PAGE Nun-Ensign (The)

Nutcracker and Mouse King 83

Nyria .................. 23

Of Una

Old Bailey.

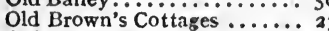

Old Hall (The) ............ I9

Old Man's Darling $(\ddot{A}) \ldots$.... 12

Old Mortality .............. 26

Old Tales from Greece $\ldots \ldots .83$

Old Tales from Rome ....... 85

Old Time Aldwych ......... s

Old Time and New ....... 44

Omnibus, De............ 22,8

Once Upon a Time......... 8

O'Neill, Owen Roe ....... 43, 8

Only a Kitten $\ldots \ldots \ldots \ldots . . . . .64$

Opportunity of I.iberalism

pean Furloughs...........

Orientations $\ldots \ldots \ldots \ldots \ldots \ldots$ 2r

Original Poem of $\mathrm{job}$ (The) ... 7

Ottilie ................. r 9

Outcast of the Islands $(A n) \ldots$.

Outcasts (The) ..............

Overseas Library (The) .......

\section{Pacific Tales}

Pagan's Love (A)

Pages from a Journa......

Pages from a Journal ....... 25

Painter's Hnneymoon $(\mathrm{A})$.....

Palaces of Crete (The).......

Panama Canal To-day (The). 67

Papacy (The) ............ 78

Papal Monarchy (The) .....4 47

Paris (Forty Years of $\ldots \ldots \ldots$.... 52

Parish Providence (A) .... 20, 87

Paris-Parisien ............ 7r

Parker, Dr., and his Friends.. 43

Parnell Movement (The)..... 5 54

Parthia ................

College (The) ............

Party Organisation .............

Passion of Mahael (The) .......

Passports

Pathless West (In the) .......

Patriot Parliament of 1689

(The) ............. 49,

Patriotism under three Flags.

Patsy

Patten Experiment (The) .... 27

$\mathrm{Pax}$ and Carolina .......82, 83

Peculiar History of Mary Ann

Susan (The) .......... Ir

Peers or People ..............

Peking Garden (Round Äbout My)

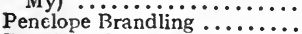

Pennine Alps (Centrai) ....... 6 \%

Pennine Alps (Eastern) $\ldots \ldots \ldots 6$

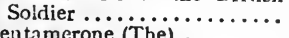

Pentamerone (The) ........ 8

People of Clopton ...........

Peoples and Politics in the

Far East ............

Perccval (Spencer)

Peril in Natal (The)

Perils of Josephine

Perils of Sympathy (The) ....

Persia ....................

Persia (Literary History of) ..
Personal Matters (Certain) ... 32 Personal Story of the Upper House, (The)

\section{Peru.}

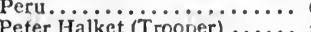

Peveril of the Peak .........26

Philippine Islands (The).... 68 Phœenix and the Carpet (The) 8

Philosopher in Portugal .... 72

Phœnicia............... 55

Physiology(Studies in General) 75

Pillage (Before the Great)....5 5

Pinto, Ferd. Mendez, the Portuguese Adven turer ........ 46

Pirate (The) ............... Thought ..............

Plant Histology (Methods in) 75

Plato's Dream of Wheels .... 34

Plays of Beaumont, \&c...... see Index of Authors

Please M'm, the Butcher I.... Selection from)

Poems of Mathilde Blind.(The complete) .............

Poems of Giosnè Carducci..

Poems of William Cowper (The Unpublished)

Poems of John Dyer (The) ...

Poems of M. F. Robinson (The Collected)

Poems (W. B. Yeats) ...........

Poet and Penelope (The) .....

Poland .......................

Policy of Free Imports (The) .

Political Advertiser (The) .....

Political Crime....$\ldots \ldots \ldots$.

Political Situation (The) Pope of Holland House (The)

Pope of Holland House (The)
Pope's Mule (The) ..........

Popular Copyright $\dddot{\text { Novels }}$.

Port Arthur (Siege of).......

Portent (The) $\ldots \ldots \ldots \ldots \ldots$. 20

Porter, Endymion (Life and

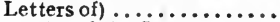

Portraits of the Sixties ...... 42

Portugal $\ldots \ldots \ldots \ldots \ldots \ldots$

Portugal (A Philosopher in) ..

Power of Charactor (The) .. 7

Prince's Marriage (Tarables 79

Prisoners of Conscience ......

Prison Escapes of the Civil

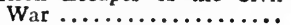
Problem of Existence (The) .. 34 Problem of Prejudice (The) ... I Process of Government (The) 59 Professions for Girls ..........
Programme of Modernism

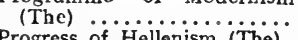
Progress of Hellenism (The) Progress of Priscilla (The) .... "Prosperous "' British India. Protection and Employment Protection (Side-Lights on)
Provence(Romantic Cities of) Proverbs, Maxims, \&c., of all Ages ................ Psalms and Litanies .......... Pseudonym Library (The) 23 , Psychology and Training of Psychology of Child Develop. ment (The).

Public Purse and the War Office

Public Speaking and
Queen of a Day (The) ... IS Queen of Napoleon's Court (A) 47 Quentin Durward .........2 26 Quests of Paul Beck (The).. II Qulet Hours with Nature .... 74 Quincy Adams Saw yer ...... 22 Quotations for Occasions..... 82

Raffles (Sir Stamford)

Raiders (Thc) .............

Rainy June (A) .......... 22

Raleigh (Sir Walter) $\ldots \ldots \ldots 4,43$ Ranch Life and the Hunting

Trail .............. 72

Random Roaming .......... sx

Ranger's Lodge (The)...... 19

Recipes for the Million ..... 82

Recreations of a Naturalist .. 75

Red Cloth Library (The) .... 30

Redgaun tlet ............ 26

Red Laugh ............. 8

Red-litten Windows (Through

the) $\ldots \ldots \ldots \ldots \ldots \cdots \cdots \cdots \cdots \times \cdots$

Red Rubber ................6 63

3 Red Sphinx (The) ........ 32

Red Star.(The) .............. 20

3 Reef and Palm (By) ........ ro

4 Reformer's Bookshelf (The) .. 64

Religion and the Higher Life 78

4 Religion and Historic Faiths 79

4 Religion of the Plain Man.. 77

Religious Songs of Connacht 5,78

Religious Equality (The Last

Step to) $\ldots \ldots \ldots \ldots \ldots \ldots$ 77

Renaissance Types ........ 52

Renunciation ..............27

Retaliatory Duties ........ 6r

Retrospect ............. 6

Revelation and the Bible .... 78

Revolution in Tanner's Lane 25

Rhodesia (Pre-Historic) ....68

Rhymer (The) ...........20

Ricroft of Withens........... 27

Ridan the Devil ........... ro

Riding, Driving, and kindred

Sports ............. 86

Rights of Man in America .. 79

Riviera (Rambles on the) ... 72

Riviera (The) ........... 70

Robert Orange ............ 17

Robinson Crusoe ........82, 83

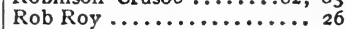

Rock and $\mathrm{Pool}(\mathrm{By}) . . . \ldots \ldots$ xo

Rock Garden of Ours (That) 75

Rodin (Life and Work of

Auguste) ........... 36

Rodman the Boatsteerer .... 10

Romance of the Fountain(The) is

Romance of a Hill Station... I9

Romance of a King's Life... 52

5 Romance of a Lonely Woman 22

Romance of a Midshipman .. 25

80 Roman Empire (The) ........ 51

53 Roman Life under the Cæsars. 58

2 Rome (Children's Study)....8 83

68 Rome. (Story of the Nations): so

6r Rome and Pompeii ....... 66

65 Rome (Literary History of) $x$

67 Rome (Mediæval) ..........5 53

Rome (Old Tales from)....59, 85

33 Romola ................. 68

8. Rose Geranium (The) ....... r 2

Rose, Shamrock and Thistle 19

Rosemonde .............27

5 Rossetti (Dante Gabriel)

(Letters of) ............ 43

Rousing of Mrs. Potter (The). 22

Royal Quartette (A) .....4 47

59 Royal Rascal (A) ........... I6

Rus Divinum $\ldots \ldots \ldots \ldots \ldots \ldots$
Russia $\ldots \ldots \ldots \ldots \ldots$ 
Russia and its Crisis ........ 63 Russia (Literary History of)... Russia Under the Great Shadow ..........., 5,73

Russian Priest (A) ......... 23 Rutherford, Mark (The Autobiography of)

Rutherford's Deliverance .... 25

Sacrifice (The) ......... r3 Saghalien Convict (The) .... r 9 Saints in Society ........... St. Mark (The Legend of) $\ldots$ Mark's Indebtedness to Matthew

St. Ronan's Well ............ 26 St. Stephen in the Fifties .. 59 Sambain ............... 34 Sand-Buried Ruins of Khotan 72 Sanitary Evolution of London (The)

Saracens (The) ........... so Sarah P. G.............. 19 Sarsfield (Patrick) (Life of) 43, 87 Savage Club (The) ....... 45 Savage Europe (Through)... 73 Savonarola, Girolamo (Life of) …............... 43 Schiller's Dramas in England 3 Schiller's Werke ............ School for Saints (The) ...... r 7

School of Art (The) ........ 27 School Out-of-Doors (Our) .... 79 Schulz Steam Turbine (The)
Scott's Novels (History in)... Scotland (Children's Study) .. 83 Scotland (Story of the Nations) $\ldots \ldots \ldots \ldots \ldots \ldots$. 53 Scotland (Literary History of) Scot tish Literature (Short History of)

Scottish Seals (History of $). .$. ...

Scrambles in the Eastern Graians $\ldots \ldots \ldots \ldots \ldots \ldots \ldots$ 73

Sea and the Moor (The) ...... I9

Sea Children ............. 83 Search of El Dorado (In) .. 70 Searchers (The) $\because \ldots \ldots \ldots \ldots$. $\ldots$. Occupation of Egypt ....

Secret of Petrarch (The) .....

Secret Rose (The)...........

Segantini (Giovanni) ........ 37

Segovia (Pablo de) .......... 37

Seneca (Tragedies of) ........

Sentinel of Wessex (The)..... 32

Seven Nights in a Gondola. 12

Seven Spiendid Sinners ....

Seventeenth Century Men of Latitude $\ldots \ldots \ldots \ldots \ldots \ldots 78$

Sex and Society .......... 34

Shacklett $\ldots \ldots \ldots \ldots \ldots \ldots$ ro

Shadowy Waters (The) ....

Shakespeare in France.......

Shakespeare the Man ......

Shakespeare's Church ........

Shakespearc's Complete Sonnets

Shakespeare Studied in Eight Plays .................. Shakespeare Studied in Six Plays

Shakespeare Studied in Three Plays

Shameless Wayne ............

She Loved Much ........... I

Shelley in Italy (IVith) ....

Shen's Pigtail (The)......... 2
Shervintons (The) $\ldots \ldots \ldots \ldots 44$ Sherwood Forest (The Scenery of) Reprints of Standard

Shilling Reprints of Standard Shipp (Memoirs of the Military Career of John) .....4 Shorter Plays............ 7 Shulamite (The).......8,8,87 Siberia ................ 73 Sibcrian Klondyke (In Search of a) ............. 73 Sicily .................. 50 Side-Lights on Protection .. 65 Siege of Port Arthur (The) ... 5 5 I Siena (Guide to) ..........6. 6 Siena and her Artists ....... 37 Sierra Nevada (Mountaineering in the) $\ldots \ldots \ldots \ldots \ldots$ 69 Sign of the Peacock (At the) 26 Silas Strong ............ 9 Silk of the Kine........... 20 Silver Age of the Greek World 53 Silver Christ (The)........ 22 Simon Ryan the Peterite..... I 8 Simpson (Sir James Y.)..... 44 Sinner's Comedy (The) ...... I7 Sins and Safeguards (The).. 79 Siren's Net (The) ......... 25 Sister of Marie Antoinette(A) 47 Sister Teresa............ 22 Sisters of Napoleon (The) .. 58 Sisters of Ombersleigh...... I9 Situations of Lady Patricia.. 28 Six Girls............. 8,85 Sixpenny Editions......... 3 Sixty Years of an Agitator's Life............4r, 62 Skipscy (Joseph)......... 45 Slave Power (The) ….... 79 Slave to College President (From) $\ldots \ldots \ldots \ldots \ldots \ldots 4$ Sleeping Fires .......... 15

Slight Indiscretion (A) $\ldots \ldots$ I2 Smith and Modern Sociology (Adam)

Smugglers and Foresters ... r Social Classes in a Republic. 79 Social Ideas of Alfred Tennyson .................... Pulpit ..............60

Social Reform (Towards).... 59 Socialist Movement.inEngland 65 Society in a Country House .. 49 Society in the New Reign.... 34

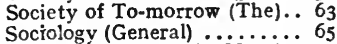
Some Emotions and a Morai.. r Somerset House ........... 54 Son of Arvon (A) . . . . . . . 23 Son of Don Juan (The) ....... Song of a Single Note (A) ....
Songs of a Sourdough......

Songs of the Uplands ......

Sorrow's Gates (Through).... 27

3 Soul of a Priest (The)......20

Soul's Departure (The) .......

Souls of Passage .............

South Africa (Story of the Nations) $\ldots \ldots \ldots \ldots \ldots$

South Africa (Big Game Shooting) $\ldots$.................... the History of ) ............ South Africa, Labour and Other Questions ...........

Sonth Africa (Little History of) 57 South African History (The Beginning of ) ...........
South American Republics (Rise of the)..........4 49 South American Series (The) .72 Spain (Children's Study) .... 83 Spain (Story of the Nations). 58 Spain and her People..... 73 Spain (The Bridle Roads of) 67 Spain (Modern) ........... 5 Spain (The Moors in) ....... 52 Spain (Saunterings in)...... 72 Specimen Spinster (A) … $3^{2}$ Spectre of Strathannan (The) 22 Speeches on Questions of Public Policy ...........6 60 Sphere of "Man "; (The) ..65 Splendid Cousin (A) ....... I4 Spoiled Priest (A) ......... 26 Sport and Travel: Abyssinia and British East Africa .... 69 Sports Library (The)....... 86 Squire Hellman $\ldots \ldots \ldots \ldots 8$ Squire to Prince (From)..... 49 Stansfeld (James) $\ldots \ldots \ldots$ to 44 Starry Heavens (How to Know the) $\ldots \ldots \ldots \ldots \ldots$..... 75 Stars of Destiny...........2

Stem of the Crimson Dahlia (The) $\ldots \ldots \ldots \ldots \ldots \ldots \ldots 20$ Stephen Kyrle............. 8

Stickit Minister (The)....... $1_{3}$

Stokes (William).......... 44

Stolen Waters ........... 12

Stops, or, How to Punctuate.. 77

Stories from Fairyland ....82, 83 Story of the Amulet (The).. 84 Story of a Crystal Heart(The) 23 Story of a Devonshire House 39,49 Story of an Estancia (The) .. 13 Story of a Puppet (The) $\ldots 82,83$ Story of My Struggles (Vambery) $\ldots \ldots \ldots \ldots \ldots \ldots, 44$ Story of the Nations (The) 56,57 Stray Thoughts of R. Williams ............... 80 Stronger than Love ......... 8 Stuarts (The)............. 50 Studies by a Recluse ........ 5 I Stuảıes Historical and Critical 53 Studies in Piography ..... 45 Studies in Black and White.. 86 Studies in General Physiology 75 Study in Colour (A) ........ 27 Study of Temptations (A).... I7 Suburbs (The Increase of the) 63 Suffolk (The Manors of) ..... 49 Sullivan (Barry)............ 44 Summer Shade (In) ...21, 87 Sunny Days of Youth (The).. 8r Supreme Moment (A) ....... 27 Surgeon's Daughter (The).... 26 Susannah .............. 20 Swanwick (Anna)........... 44 Sweden's Rights .......... 65 Swift, Dean (Unpublished Letters of . ..........44 Swift in Ireland $\ldots \ldots \ldots 44,87$ Swiss Democracy (The) ... 63 Switzerland ............ 5 Sword and Pen (With) ....... r 8

Sydenham (Thomas) ....... 44 Sylvia in Society ......... II

Tale of a Town (The) ...... 21 Tales about Temperaments ... I7

8 Tales from Natal......... 72 Tales from Plutarch .....25, 84 69 Tales from Spenser ...... 84 Tales of John Oliver Hobbes I7 Tales of the Pampas ....... 67 57 Tales of the Transvaal ..... 72 
Tales of Unrest . PAGr Ta!es told in the $Z$ oo ........ 84 Talisinan (The) ............ 26 Talks about the Border Regiment

Taxes on Knowledge.......... 60 Teacher and the Child (The) .. 79 Temple (The) ...........4, $7^{8}$ Tempting of Paul Chester

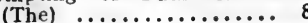

Ten Sermons ........... 79 Tenants of Beidornie (The) ... Ig Terror of the Macdurghotts

(The) $\ldots \ldots \ldots \ldots \ldots \ldots .22$ Tessa $\ldots \ldots \ldots \ldots \ldots \ldots \ldots \ldots$. t I

Theism and Atheism....... 79

They Twain ............ 25

Third Experiment (The)..... I9

Thomas Atkins (Mr.) .... I6, 87

Thousand Pities (A) ....... 28

Three Dukes ........... 32

Three Generations of Englishwomen

Three of Them .......... I5

Threshing Floor (The) ........ I

Thursday Mornings at the

City Temple ........... 77

Thus Spake Zara thustra.... 34

Thyra Varrick ........... Io Tibet and Chinese Turkestan 68 Tibet (Through Unknown)... 73

Tödi (The Range of the) .....667

Tom Gerrard..............

Tongues of Gossip ........ 26

Tormentor (The).......... 27

Tourgueneff and his French

Circle ............... 4

Towards the Heights ........ 80

Towards Social Reform .... 59

Town and Jungle (Through).. 73

Town Child (The)........6 60

Toxin ................ 22

Traitor's Wife (The) ...... 32

Tramps Round the Mountains of the Moon

Transient andPermanent ( $\mathrm{Th}$ e) 79

Transplanted Daughters..... I 6

Transvaal (First Annexation of the $\ldots \ldots \ldots \ldots \ldots \ldots 52$

Transvaal (Tales of the $\ldots \ldots . . .72$

Travels of a Naturalist...... 75

Treasure Seekers (The) ...... 84

Treasure Seekers (New) ...... 84

Trend in Higher Education .. 78

Trinity Bells...............

Trinity College (Particular Book of) ........... 5 53 Triple Entanglement (A) ..... I Trooper Peter Halket....... 26 Tropic Skies (Under) ........ I I True Tales of Mountain Ad.

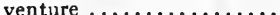

Turbines (Steam) ......... 85 Turf Smoke (Through the) ... 20

Turkey .............. 52 Turkey and the Armenian A trocities ............ 4

Tuscan Republics, with Genoa 49 Tussock Land ............. 8 Twelve Bad Men (Lives of) ... 43 Twelve Bad Women ........ 45 Two Countesses (The) ....... I4 Two Standards (The)........ Io Two Strangers (The) ....... 22
Tychiades .... PAG $\mathrm{B}$

Uganda to Khartourn ........ 7o

Ultima Verba.............

Uncle Jem .............. $3^{32}$

Under the Chilterns..........24

Under the Pompadour...... I 18 U.S.A. and Spanish America (Diploma tic Relations of) ...

University Problems in the U.S.A. . . . . . . . . . . Unprofessional Tales ....... 22 Untilled Field (The)........ 22 Unwin's Green Cloth Library 28 Unwin's Red Cloth Library ... 30 Unwin's Sixpenny Editions.. 3I Unwin's Half-Crown Standard Library of History and Biography ............. Unwin's Nature Books .... 76 Unwin's Popular Series for Boys and Girls........ 8 Unwin's Shilling Reprints of Standard Novels ......31, 87 Unwin's Theological Library Up from the Slums.......... Upper Berth (The) ......... Uprising of the Many (The).. 6 Up-to-Date Beginner's Table Book

Up-to-date-Tables (Weights, \&c.)................. 79

\section{Vagrant Songs}

Valois Queens (Lives and Times

of the Early)............

Value and Distribution....... $6 \mathrm{I}$ Vambéry (Arminius) His Life 44 Vanity ............... 25 Vanity Fair (In).......... I Variety Stage ............ 37 Vaughan (Henry) .......... 87 Vedic India ...............

Veld t and Kopje (By) ......

Venice $\ldots \ldots \ldots \ldots \ldots \ldots$

Village Politician (A) ........

Vineyard (The) $\ldots \ldots \ldots \ldots$. 17

Vocations for Our Sons ....... 86

Vulture's Prey iThe) .......

Wagner (The Case of)........

Wakefield (Edward Gibbon)..

Wales (Story of the Nations)..

Wales (A Short Story of) .... 4

Wales (Mediaval) ......... 52

Wales (The Statutes of) .... 59

Wanderer (A), and Other

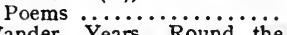

Wander Years Round the World ............... Warp and Woof................ War to Date (The) ......... 5 Washed by Four Seas ...... 73 Washington Society (Forty Years of).

Washing ton (The Youth of).. 45 Was it Right to Forgive ?.... IO Watcher on the Tower ...... I6 Waterloo (Before and After). Waverley

Way to Keep Well (The) .... Ways of Men (The) ............

Wellington's Operations 1808 .
PAGE

Well-Sinkers (The) $\ldots \ldots \ldots \ldots$ II

Welsh Fairy Book (The) ... 84

Welsh Library (The)....... 87

Welsh Literature (Short History of) ............87

Welsh People (The) ....... 58

Wer Ist's............... 86

Wesley and his Preachers .... 45

IVest African Empire (The Advance of Our) ........73

West Indies and the Spanish

Main ................ 55

West Indies (A Guide to).... 7r

Westminster Cathedral (The) 37

What I Have Seen While

Fishing $\ldots \ldots \ldots \ldots \ldots 75,85$

What is Religion ?.........77

When Wheat is Green ...... 32

Where There is Nothing ..... 7

Which is Absurd .......... 16

White-Headed Boy (The) .... ro

White Umbrella (A) ....... 26

WhiteWoman in Central Africa 67

Who's Who in Germany.... 86

Why not, Sweetheart ? ...... I6

Wide Dominion (A).......66 66

Wilberforce (Wm.) (Private

Papers of ) ............ 45

Wild Honey from Various

Thyme................

Wild I.ife in Southern Seas ... I4 Wild Nature Won by Kindness 75 Willowdene Will........... 27

Winning Hazard (A) ......... 8

Winter India............ 72

Wisdom of Esau (The) ...... I2

Wisdom of the Wise (The).... 4 Wise Words and Loving

Deeds ............. 40

Wistons $\ldots \ldots \ldots \ldots \ldots \ldots \ldots{ }_{8}$

Wit of the Wild (The) ...... 75

Within Four Walls ........

Wizard's Knot (The) ........ ro

Woman (The) ............. I5

Woman and the Sword (The) 20

Woman's Own Lawyer(Every) $\mathbf{8 2}$

Woman's Suffrage (The Case

for) $\ldots \ldots \ldots \ldots \ldots \ldots 65$

Woman's Wanderings (A).... 40

Woman's Work and Wages .. 60

Woman Thou Gavest (The) .. 28

Woman Who Vowed (The) . I 6

Women Adventurers (The) .. 46

Wonderful Weans ........... 20

Woodlanders and Field Folk . 77

Woodstock ............. 26

Wordsworth's Grave ........ 7

Working of the Workman's

Compensation Act...... 59

World at Eighteen (The) ... I 3

World is Round (The) ...... 20

World of Matter (The) ...... 79

Would-be-goods (The) ..... 84

Wreckers (The) ......... I9

Yarn of Old Harbour Town.. 25

Yellow Fiend (The) ........ 8

Yellow Library (The) ...... 32

Yorke the Adventurer ...... II

Yorkshire Ramblers' Club

Journal ............ 73

Young Ireland .............. 49

Young Sam and Sabina........ I $_{3}$ 


\section{LITERARY HISTORY.}

ABRAHAMS. A Short History of Jewish Literature, from the Fall of the Temple (70 C.E.) to the Era of Emancipation (1706 C.E.) By Israel Abrahams, M.A., Reader in Rabbinic Literature in the University of Cainbridge. $\mathrm{Cr} .8$ vo, cloth. net

BAILEY. The Novels of George Meredith. By E. E. J. Bailey, Cr. 8vo, cloth.

BEERS. A Short History of American Literature. By Henry A. Beers. Large cr. 8vo, cloth. net

BRERETON (Austin). The Literary History of the Adelphi and its Neighbourhood. See under "History."

BROWNE. A Literary History of Persia. Vol. I. From the Earliest Times until Firdawsi. By Edward G. Browne, M.A., M.B., Fellow of Pembroke College. With Photogravure Frontispiece. (Library of Literary History.) Demy 8vo, cloth.

A Literary History of Persia. Vol. 2. From Firdawsi until Sa'di (A.D. 1000-I290). By Edward G. Browne. With Photogravure Frontispiece. (Library of Literary History.) Demy 8vo, cloth.

BRÜCKNER. A Literary History of Russia. By Professor A Brückner, of Berlin. Edited by Ellis H. Minns, M.A. Translated by H. Havelock, M.A. With Plotogravure Frontispiece. (Library of Literary History.) Demy 8vo, cloth.

BRUNETIĖRE. Essays in French Literature. A Selection, translated by $D$. Nichol Smith, with a Preface by the Author specially written for this, the authorised English translation. Large cr. 8vo, cloth.

Manual of the History of French Literature. By Ferdinand Brunetière. Demy 8vo., cloth.

NING. Shakespeare Studied in Eight Plays. By the Hon. Albert S. G. Canning. Demy 8vo, cloth.

Shakespeare Studied in Six Plays. By the Hon. Albert S. G. Canning. Demy 8vo, cloth.

Shakespeare Studied in Three Plays. By the Hon. Albert S. G. Canning. Demy 8vo, cloth.

Literary Influence in British History. By the Hon. Albert S. G. Canning. Demy Svo, cloth.

History in Scott's Novels. By the Hon. Albert S. G. Canning. Demy 8 vo, cloth.

British Writers on Classic Lands. By the Hon. Albert S. G. Canning. Demy 8vo, cloth.

net

DUFF. A Literary History of Rome. From the Origins to the Close of the Golden Age. By J. Wight Duff, M.A. With Photogravure Frontispiece. (Library of Literary History.) Demy 8vo, cloth.

FAGUET. A Literary History of France. By Emile Faguet, Member of the French Academy. With Photogravure Frontispiece. (I,ibrary of Literary History.) Demy Svo, cloth. net $12 / 6$

FRAZER. A Literary History of India. By R. W. Frazer, LL.B., I.C.S. Frontispiece. (Library of Literary History.) Demy 8vo, cloth. net

HORRWITZ. A Shor History of Indian Literaiure. By Ernest Horrwitz. With an Introduction by Professor T. IV Khỵs Davids. Cr. 8vo, cloth. 
HYDE. A Literary History of Ireland. By Douglas Hyde, LL.D. IIith Photogravure Frontispiece. (Library of Literary History.) Demy 8vo, cloth.

The Story of Early Gaelic Literature. By Douglas Hyde, LL.D. (New Irish Library. Vol.6.) Sm. cr. 8vo, paper covers, 1/-; cloth

JONES. Dafydd ap Gwilym: A Welsh Poet of the rourtcenth Century. By W. Lewis Jones, M.A., Professor of English Language and Literature, University College of North Wales. Large cr. 8vo, cloth. [In Preparation.]

JUSSERAND. The English Novel in the Time of Shakespeare. By I. J. Jusserand, Conseiller d'A mbassade. Translated by Elizabeth Lee. Second Edition. Revised and enlarged by the Author. Illus. trated. Large cr. 8vo, cloth.

A Literary History of the English People. Vol. I. From the Origins to the Renaissance. By J. J. Jusserand. With Photo. gravure Frontispiece. Demy \&vo, cloth.

A Literary History of the English People. Vol. 2. From the Renaissance to the Civil War. I. By J. J. Jusserand. Wi h Photogravure Frontispiece. Demy 8 ro, clotb.

A Literary History of the English People. Vol. 3. From the Renaissance to the Civil War II. By J. J Jusserand. With Photogravure Frontispiece. Demy 8vo, cloth.

Shakespeare in France. By J. J. Jusserand. Illustrated. Demy 8vo, cloth.

LANGLAND'S (William) Vision of Piers Plowman. Edited by Kate Warren. Second Edition, revised. Cloth.

EHBRARY OF LITERARY HISTORY, THE. Each with Photogravure Frontispiece. Demy $8 \mathrm{vo}$, cloth.

Published :[For full Titles see under Authors' names.]

(I) India. By Professor R. W. Frazer.

(2) Ireland. By Dr. Douglas Hyde.

(3) America. By Professor Barrett Wendell.

(4) Persia. Vol. I. From the Earliest Times untilFirdawsi By Professor E. G. Browne.

In Preparation:-

Rome. By J. Wight Duff.
(5) Scotland. By J. H. Millar.

(6) Persia. Vol. 2. From Firdawsi until Sa'di. By Professor E. G. Browne.

(7) The Arabs. By R. A. Nicholson.

(8) France. By Emile Faguet.

(9) Russia. By Professor A. Brückner.

The Jews. By Israel Abrahams, N.A.

MARBLE Heralds of American Literature. By Annie Russell Marble. Illustrated. $\mathrm{Cr} .8 \mathrm{vo}$, cloth.

AR. A Literary History of Scotland. By J. H. Millar, Balliol College, Oxford. With Photogravure Frontispiece. (Library of Literary History.) Demy 8 vo, cloth gilt.

Also a Fine Edition, limited to 25 copies, on hand-made paper. net $42 /$ -

A Short History of Scottish Literature. By J. H. Millar. Cr 8 vo, cloth. [In Preparation.]

MILLS. The Secret of Petrarch. By E. J. Mills. With I3 Photogravure Plates, one in colour. Demy $8 \mathrm{vo}$, cloth. net

MOTTRAM. The True Story of George Eliot in relation to "Adam Bede." By William Mottram. Illustrated. Demy 8 vo, cloth. 
NICHOLSON. A Literary History of the Arabs. By R. A. Nicholson, M.A., Lecturer in Persian in the University of Cambriclyc. With Coloured Frontispiece. (Library of Literary History J Demy Evo, cloth.

REA. Schiller's Dramas and Poems in England. By Thomas Rea, M.A., Lecturer in German and Teutonic Philology, University College of North Wales. Cr. 8vo, cloth.

net

SMITH. Shakespeare the Man: An Attempt to Find Traces of the Dramatist's Personal Character in his Dramas. By Professor Goldwin Smith. 8vo, cloth gilt.

WENDELL. A Literary History of America. By Barrett Wendell, Professor of English at Harvard College. With Frontispiece. (Library of Literary History.) Demy 8ro, cloth.

[For reference see also under "Biography."]

\section{POETRY and the DRAMA.}

ADAMS. The Lonely Way, and Other Poems. By W. A. Adams, M.A. Demy I2mo, cloth.

Rus Divinum. (Poems.) By Auguste Smada. (W. A. Adams.) Demy I $2 \mathrm{mo}$, parchment binding.

Bards of the Gael and Gal!. See under "Sigerson."

BLIND. The Complete Poems of Mathilde Blind. Edited by Arthur Symons. With an Introduction by Dr. Garnett. Cr. 8vo, cloth gilt.

A Selection from the Poems of Mathilde Blind. Edited by Arthur Symons. Portrait. Fcap. 8vo, parchment gilt. Edition de Luxe, in Japan paper, in vellum.

BURNS. The Love Songs of Robert Burns. Selected and Edited, with Introduction, by Sir George Douglas, Bart. WVith Frontispiece Portrait. (Cameo Series. Vol. II.) Demy I2mo, half-bound, paper boards.

CAMEO SERIES, THE. Demy I2mo, with Frontispiece, half-bound. Paper boards, 3/6 each; vols. 14-20, each, net

Also an Edition de Luxe, limited to 30 cupies, printed on Japan paper. Prices on Application.

[For full Titles see under Author's names.]

(I) The Lady from the Sea. By Henrik Ibsen.

(2) Iphigenia in Delphi. By Richard Garnett.

(3) A London Plane Tree. By Amy Levy.

(4) Wordsworth's Grave. By William Watson.

(5) Miréio. By Frederic Mistral.

(6) Lyrics. Selected from the Works of A. Mary $F$. Robinson.

(7) A Minor Poet. By Amy Levy.

(8) Concerning Cats.

(9) A Chaplet trom the Greek Anthology. By lichard Garnett.

(Io) The Countess Kathleen. By IV. B. Yeats.
(II) The Love Songs of Robert Burns.

(I2) Love Songs of Ireland. Collected by K. Tynan.

(13) Retrospect. By A. Mary F. Robinson.

(I4) Brand. By Henrik Ibsen.

(I5) The Son of Don Juan. By Don José Echegaray.

(I6) Mariana. By Don José Echegaray.

(I7) Flamma Vestalis. By Eugene Mason.

(I8) The Soul's Departure. By E. Willmore.

(19) The Unpublished and Uncollected Poems of William Cowper.

(20) Ultima Verba. By Alfred de Kantzow. 
CAPES. Amaranthus. A Book of Little Songs. By Bernard Capes. Small cr. 8vo, cloth.

net

CARDUCCI. Poems by Giosuè Carducci. Selected and Translated, and with an Introduction by Maud Holland. $\mathrm{Cr}$. 8vo, halfparchment.

net

Concerning Cats. A Book of Verses by many Authors. Edited by Graham R. Tomson. Illustrated. (Cameo Series. Vol, 8.) Demy I 2mo, half-bound, paper boards.

COWPER. The Unpublished and Uncollected Poems of William Cowper. Edited by Thomas Wright. Frontispiece. (Cameo Series. Vol. 19.) Demy I2mo, paper boards, half-bound. net

CRUSO. Sir Walter Raleigh. A Drama in Five Acts. By H. A. A. Cruso. Cr. 8vo, cloth.

net

DYER. The Poems of John Dyer. Edited by Edward Thomas. With Portrait of J. D. (Welsh Library. Vol. 4.) Fcap. 8vo.

Paper covers, $1 /$ - ; cloth

ECHEGARAY. Mariana. An Original Drama in 3 Acts and an Epilogue. By Don José Echegaray. Translated into English by James Grahain. With a Photogravure of a recent Portrait of the Author. (Cameo Series. Vol. 16.) Demy 12mo, half-bound, paper boards.

net

The Son of Don Juan. An Original Drama in 3 Acts. By Don José Echegaray. Translated into English, with Biographical Introduction by James Graham. With Etched Portrait of the Author by Don B. Maura. (Cameo Series. Vol. I5.) Demy 12mo, halfbound, paper boards.

FIELD: Wild Honey from Various Thyme. By Michael Field. Cr. 8 vo, cloth.

GARNETT. A Chaplet from the Greek Anthology. By Richard Garnett, LL.D. (Cameo Series. Vol. 9.) Demy I2mo, half-bound, paper boards.

Iphigenia in Delphi. A Dramatic Poem. With Homer's "Shield of Achilles" and other Translations from the Greek. By Richard Garnett, LL.D. Frontispiece. (Cameo Series. Vol. 2.) Demy I2mo, half-bound, paper boards.

GOETHE'S Werke. Mit Goethe's Leben Bildnis and Faksimile, Einleitungen und Anmerkungen. Unter Mitwirkung mehrerer Fachgelehrter herausgegeben von Professor Dr. K, Heinemann. I5 vols., large cr. 8vo cloth.

GRAVES. The Irish Poems of Alfred Perceval Graves. In two volumes.

Cloth, each, net 2/- ; leather, each, net

HALL. God's Scourge. A Drama in Four Acts. By Moreton Hall. Cr. 8vo, cloth.

net

HEINRICHHEINE'S Samtliche Werke. Herausgegeben von Professor Dr. Ernst Elster. Kritisch durchgesehene und erläuterte Ausgabe. With Frontispiece and Facsimile. 7 vols., large cr. 8vo, cloth, net

HERBERT. The Temple. By George Herbert. Sacred Poems. Facsimile Reprint of the First Edition, I633. With an Introduction by J. H. Shorthouse. Sixth Edition. Fcap. 8vo, cloth. net

HILL. Altred the Great. A Play in Three Acts, wrought in Blank Verse. By Edmund L. Hill. Demy 12mo, cloth. net

HOBBES. The Ambassador: A Comedy in 4 Acts, By John Oliver

Hobbes. With Frontispiece. Cr. $8 \mathrm{vo}$, paper, net $2 /-$; cloth, net
The Wisdom of the Wise: A Comedy in 3 Acts. By John Oliver Hobbes. Cr. 8vo. Paper covers, net $2 /-$; cloth, net 
HYDE. The Religious Songs of Connacht. By Douglas Hyde, LL.D., M.R.I.A. Author of "A Literary History of Ireland," "Love Songs of Connacht," \&c. 2 vols., cloth. net

IBSEN. Brand: A Dramatic Poem. By Henrik Isben. Translated by F. Edmund Garrett. With Frontispiece. (Cameo Series. Vol. I4.) Demy I2mo, half-bound, paper boards. net

The Lady from the Sea. By Henrik Ibsen. Translated by Eleanor Marx-Aveling. With Critical Introduction by Edmund Gosse. Third Edition. Portrait. (CameoSeries. Vol. I.) Demy I2mo, half-bound, paper boards.

LAW. Songs of the Uplands. By Alice Law. $\mathrm{Cr} 8 \mathrm{vo}$, cloth, net

LEVY. A London Plane Tree. By Amy Levy. Illustrated by Bernard Partridge. (Cameo Series. Vol. 3.) Demy 12mo, half-bound, paper boards.

A Minor Poet. By Amy Levy. With Frontispiece. Second Edition. (Cameo Series. Vol. 7.) Demy I2mo, half-bound, paper boards.

LYTTELTON. Warp and Woof. A Play. By Edith Lyttelton. Cr. 8vo, cloth. net

MACDONALD. A Wanderer, and Other Poems. By Leila Macdonald. Cr. 8vo, white cloth, gilt.

net

MASON. Flamma Vestalis, and Other Poems. By Eugene Mason. Frontispiece after Sir Edward Burne-Jones. (Cameo Series. Vol. I7.) Demy I2mo, half-bound, paper boards.

net

MERMAID SERIES (THE): The Best Plays of the Old Dramatists. Literal Reproductions of the Old Text. With Photogravure Frontispieces. The volumes may now be obtained bound in the following styles :

I. Cr. 8vo, uncut. Brown paper boards, with label.

2. Cr. 8vo, uncut. Green cloth, with gilt lettering on ink panel.

3. Cr. 8vo, uncut top. Brown cloth, with gilt lettering and decorative design in brown.

4. Cr. 8vo. Full vellum, with gilt lettering and gilt top.

The Thin Paper Edition is also obtainable in cloth at $2 / 6$ net; and in leather, at

Beaumont. The Best Plays of Beaumont and Fletcher. Introduction and Notes by J. St. Loe Strachey. 2 vols.

No :

Chapman. The Best Plays of George Chapman. Edited by William Lyon Phelps, Instructor in English Literature at Yale College.

Congreve. The Complete Plays of William Congreve. Edited by Alex. C. Ewald.

Dekker. The Best Plays of Thomas Dekker. Notes by Ernest Rhys.

Dryden. The Best Plays of John Dryden. Edited by George Saintsbury. 2 vols.

Farquhar. The Best Plays of George Farquhar. Edited, and 24, 25 with an Introduction, by William Archer.

Fletcher. See Beaumont.

Ford. The Best Plays of John Ford. Edited by Havelock Ellis

Greene. The Complete Plays of Robert Greene. Edited with Introduction and Notes by Thomas H. Dickinson.

Heywood. The Eest Plays of Thomas Heywood. Edited by A W. Verity. With Introduction by J. A. Symonds.

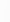


MERMAID SERIES, THE-continued.

Jonson. The Best Plays of Ben Jonson. Edited, with Introduction and Notes, by Brinsley Nicliolson and C. H. Herford.l 3 vols.

Marlowe. The Best Plays of Christopher Marlowe. Edited, with Critical Memoir and Notes, by Havelock Ellis ; and containing a General Introduction to the Series by John Addington Symonds.

Massinger. The Best Plays of Philip Massinger. With Critical and Biographical Essay and Notes by Arthur Symons. 2 vols.

Middleton. The Best Plays of Thomas Middleton. With an Introduction by Algernon Charles Sivinburne. 2 vols.

Nero, and Other Plays. Edited by H. P. Horne, Arthur Symons, A. W. Verity, and H. Ellis.

Otway. The Best Plays of Thomas Otway. Introduction and Notes by the Hon. Roden Noel.

Shadwell. The Best Plays of Thomas Shadwell. Edited by George Saintsbury.

Shirley. The Best Plays of James Shirley. With Introduction by Edmund Gosse.

Steele. The Complete Plays of Richard Steele. Edited, with Introduction and Notes, by G. A. Aitken.

Tourneur. See Webster.

Vanbrugh. The Select Plays of Sir John Vanbrugin. Edited, with an Introduction and Notes, by A. E. H. Swain. Introduction and Notes by John Addington Symonds.

Wycherley. The Complete Plays of William Wycherley. Edited, with Introduction and Notes, by W. C. Ward.

MILLER. The Tragedies of Seneca. By Frank Justus Miller. Large cr. 8vo, cloth.

MISTRAL. Miréio : A Provençal Poem. By Frederic Mistral. Translated by H. W. Preston. Frontispiece by Joseph Pennell. (Cameo Series. Vol. 5.) Demy I2mu, half-bound, paper boards.

MOORE. The Bending of the Bough. (Drama.) By George Moore. Cr. 8vo, cloth.

net

MYRON. Of Una, and other African Memories. (Poems.) By A. Kiel Myron. Cr. 8vo, cloth.

NICHOLSON (F. C.). Old German Love Songs Translated from the Minnesingers of the I2th-I4th centuries. By F. C. Nicholson, M.A. Large cr. 8vo, cloth.

(L.). Vagrant Songs. By L. Nicholson. Crown 8vo, cloth. net

PRESLAND. The Marionettes. A Puppet Show in Two Acts. With other Poems. By John Presland. Cr. 8vo, half-parchment. net

RICHARDSON. Artist Songs. By E. Richardson, LL.A., Author of "Sun, Moon, and Stars," and "Songs of Near and Far Away." Illustrated. Fcap. 8vo, cloth.

ROBINSON. The Collected Poems of Mary F. Robinson. $\mathrm{Cr}$. 8 vo, cloth.

Lyrics. Selected from the Works of A. Mary F. Robinson. (Cameo Series. Vol. 6.)

The New Arcadia. (Poems.) By A. Mary F. Robinson (Mme. James Darmesteter). Cr. 8vo, paper covers.

Retrospect, and Other Poems By A. Mary F. Robinson. (Cameo Series. Vol. I3.) Demy I2mo, half-bound, paper boards. 
SANTAYANA. A Hermit of Carmel, and other Poems. By George Santayana, Author of "The Life of Reason," \&c. Cr. 8vo, cloth. net

SCHILLER'S Werke. Herausgegeben von Ludwig Bellermann. Kritisch durchgesehene und erläuterte Ausgabe. With frontispiece and facsimile. 8 vols., cr. $8 \mathrm{vo}$, cloth.

SCHULLER. Within Four Walls, and Children at Play. Tv'o Plays. By Leo Sarkadi Schuller. Cr. 8vo, cloth. net

SERVICE. Songs of a Sourdough. By Robert W. Service. Small cr. $8 \mathrm{vo}$, cloth.

net

SHAKESPEARE. The "First Folio" Shakespeare. The Conplete Works of William Shakespeare, reprinted from the First Folio. Edited, with an Introduction to each play, Complete Glossaries, and Variant Readings, by C. Porter and H. A. Clark, and with a General Introduction by John Churton Collins, M.A., D.Litt. In 13 volumes (sold in sets only). Cr. 8vo. the set, net

RSON. Bards of the Gael and Gall : Examples of the Poetic Literature of Erinn, done into English after the Metres and Modes of the Gael. By George Sigerson, M.D., F.R.U.I. Second Edition, Revised and Enlarged. Large cr.8vo, cloth. net

TUNISON. Dramatic Traditions of the Dark Ages. By Joseph S. Tunison. Large cr. 8vo, cloth.

net

TYNAN. Love Songs of Ireland. Collected and Edited by Katherine Tynan. (Cameo Series. Vol. I2.) Demy r2mo, half-bound, paper boards.

WALSH. Shakespeare's Complete Sonnets. A new arrangement. With Introduction and notes by C. M. Walsh. Cr. 8vo, cloth. net

WATSON. Wordsworth's Grave, and Other Poems. By William Watson. (Cameo Series. Vol. 4.) Demy I2mo, half-bound, paper boards.

WHITAKER, L'Avocat Patelin. A Comedy in Three Acts. Adapted by the Abbé Brueys, from the Famous Farce of the Fifteenth Century. Translated by Samuel F. G. Whitaker. Cr. 8vo, imitation parchment wrapper.

WILLMORE. The Soul's Departure, and Other Poems. By E. Willmore. With Frontispiece. (Cameo Series. Vol. I8.) Demy I2mo, paper boards.

net

YEATS. The Countess Kathleen. A Dramatic Poem. By W. B. Yeats. With Frontispiece by J. T. Nettleship. (Cameo Series. Vol. Io.) Demy I2mo, half-bound, paper boards.

Poems. By W. B. Yeats. A New Edition entirely revised and reset. Large cr. 8vo, cloth.

Poems. I899-I905. By W. B. Yeats. Large cr. 8vo,

net

The Secret Rose. By W. B. Yeats. Large cr. 8vo.

net

- The Celtic Twilight. By W. B. Yeats. Large cr. 8vo.

Ideas of Good and Evil. By W. B. Yeats. Large cr. 8vo.

6/-

6/-

6/-

The Shadowy Waters. (Ist Version). By W. B. Yeats. Large cr. 8vo.

$3 / 6$

Where There is Nothing. By W. B. Yeats, Large cr. 8vo. net

$3 / 6$

Shorter Plays. By W. B. Yeats. Large cr. 8 vo.

net $3 / 6$

The King's Threshold, and On Baile's Strand. By W. B. Yeats. Large cr. 8vo.

net $3 / 6$

Deirdre. By W. B. Yeats. Large cr. 8vo.

net $3 ; 6$

The Hour Glass. Acting version, in paper covers.

$6 d$.

Tha Shadowy Waters. Acting version, in paper covers.

id.

On Baile's Strand. Acting version, in paper covers.

$6 d$. 


\section{NOVELS, HUMOROUS WORKS, SHORT STORIES, \&C.}

ADAMS. Tussock Land. By Arthur H.' Adams. (First Novel Library.) Cr.8vo, cloth.

THE ADELPHI LIBRARY. Standard Fiction. Cr. 8vo, cloth, each rol.

(1) Through Sorrow's Gates. By Halliwell Sutcliffe.

2) The Canon in Residence. By Victor L. Whitechurch.

(3) Evelyn.Innes. By George Moore.

4) The Portent, and Other Stories. By George Macdonald.

(5) The Beetle. By Richard Marsh.

In Preparation:-

Sister Teresa. By George Tales of Unrest By Joseph Moore. Conrad.

The Haunts of Men. By R. W. The Tales of John Oliver Chambers.

Willowdene Will. By Halliwell The Shulamite. By Alice and Sutcliffe.

\section{Claude Askew.}

AHO (Juhani). Squire Hellman. Sce Pseudonym Library. No. 25. ALEXANDER. Brown, V.C. By Mrs. Alexander. (Unwin's Green Cloth Library.) Cr. 8vo, cloth.

Popular Series for Boys and Girls. Illustrated, cloth.

Also (Popular Copyright Novels), cr. 8vo, cloth.

Kitty Costello. By Mrs. Alexander. With a Memorial Note by Isa Duffus Hardy. (Unwin's Red Cloth Library.) Cr. 8vo, cloth. Popular Series for Boys and Girls. Cloth.

Stronger than Love. By Mrs. Alexander. (Unwin's Red Cloth Library.) Cr. 8vo, cloth.

Also (Popular Copyright Novels), cr. 8vo, cloth.

Through Fire to Fortune. By Mrs. Alexander. '(Unwin's Green Cloth Library.) Cr. 8vo, cloth.

Also (Popular Copyright Novels), cloth.

A Winning Hazard. By Mrs. Alexander. (Popular Copyright Novels.) Cr. 8vo, cloth.

The Yellow Fiend. By Mrs. Alexander. (Unwin's Green Clath Library.) Cr. 8vo, cloth.

ALIEN. The Devil's Half Acre. By "Alien." (Unwin's Green Cloth Library.) Cr. 8vo, cloth.

AMBER. Wistons. A Story in Three Parts. By Miles Amber. (First Novel Library.) Crown 8vo, cloth.

ANDREIEF. The Red Laugh. By Leonidas Andreief. Translated by A. Linden. With Portrait of the Author. Cr.8vo, paper cover. net

ANDREWS. Stephen Kyrle. By Katherine Andrews. Cr.8vo, cloth.

ARCHER. A Bush Honeymoon, and Other Australian Stories. By Laura M. Palmer Archer. (Unwin's Red Cloth Library.) Cr. 8vo, cloth.

ARMSTRONG. Passports. See under "Little Novels." No. 9.

ASKEW: The Shulamite. By Alice and Claude Askew. Illustrated. Crown 8vo. (Green Cloth Library.)

Also (Tive Adelphi Library), cloth.

Also in picture wrapper.

The Tempting of Paul Chester. By Alice and Claude Askew. Cr. 8vo, cloth. 
AUTONYM LIBRARY, THE. Uniform in style and price with "The Pseudonym Library." "Paper covers, each, $1 / 6$; cloth, each

(I) The Upper Berth. By F. (10) Kafir Stories. By W. C. Marion Crawford.

(2) Mad Sir Uchtred of the Hills. By S. R. Crockett.

(3) By Reef and Palm. By Louis Becke.

(4) The Play-Actress. By S. R. Crockett.

(5) A Bachelor Maid. By Mrs. Burton Harrison.

(6) Miserrima. By G. W. T. Omond.

(7) The Two Strangers. By Mrs. Oliphant.

(8) Another Wicked Woman. By S. De Pentheny.

(9) The Spectre of Strathannan. By IV. E. Norris. Scully.

(11) Molly Darling. By Mrs. Huiigerford.

(12) A Garre of Consequences. By Albert Kinross.

(13) Sleeping Fires. By Gtorge Gissing.

(14) The Red Star. By L. Mc.llanus.

(1.5) A Marriage by Capture. By Robert Buchanan.

(16) Leaves from the Life of an Eminent Fossil. By W. Dutton Burrard.

(I7) An Impossible Person. By Constance Cotterell.

(I8) Which is Absurd. By Cosmo Hamilton.

BACHELLER. Eben Holden. By Irving Bacheller. Cr. 8vo, cloth, net Also paper covers.

Silas Strong. By Irving Bacheller. Cr. 8vo, cloth. (Unwin's Green Cloth Library.)

BAILLIE-SAUNDERS. London Lovers. By Margaret BaillieSaunders, Author of the Prize Novel, "Saints in Society." Cr. 8vo, cloth. Decorative binding.

Saints in Society. By Margaret Baillie-Saunclers. floo prize novel. Cr. 8vo, cloth. (First Novel Library.)

Also paper covers.

BAKER (H. B.). Margaret Grey. See under "Litt!e Novels." No. 4. BAKER (J.). A Double Choice. By James Baker. (Unwin's Green Cloth Library.) Cr. Svo, cloth.

BARLOW. By Beach and Bogland. By Jane Barlow, Author of "Irish Idylls," \&c. With Frontispiece. Cr. 8vo, cloth. (Unwin's Green Cloth Library.)

BARR (A. E.). The Black Shilling. By Amelia E. Barr. (Unwin's Red Cloth Library.) Cr. 8vo, cloth.

Cecilia's Lover. By Amelia E. Barr. Cr. 8vo, cloth. (Unwin's Red Cloth Library.)

- 1, Thou, and the Other One. By Amelia E. Barr. (Unwin's Green Cloth Library.) Cr. 8vo, cloth.

Also (Popular Copyright Novels), cloth.

The Lion's Whelp. By Amelia E. Barr. (Unwin's Green Cloth Library.) Cr. \&vo, cloth.

The Maid of Maiden Lane. By Amelia E. Barr. Fully Illustrated. (Unwin's Green Cloth Library.) Cr. 8vo, cloth.

Prisoners of Conscience. By Amelia E. Barr. Cr. 8vo, cloth.

Popular Series for Boys and Girls. Illustrated, cloth.

Also (Popular Copyright Novels), cloth.

A Song of a Single Note. By Amelia E. Barr. (Unwin's Red Cloth Library.) Cr. 8vo, c!oth.

Souls of Passage. By Amelia E. Barr. (Unwin's Green Cloth Library.) Cr. 8vo, cloth. 
BARR (A. E.) Thyra Varrick. By Amelia E. Barr. (Unwin's Red Cloth Library.) Cr. 8vo, cloth.

Trinity Bells. A Tale of Old New York. By Amelia E. Barr. Fully Illustrated in handsome decorated cover. $\mathrm{Cr}$. 8vo, cloth gilt.

Was it Right to Forgive? A Domestic Romance. By Amelia E. Barr. (Unwin's Green Cloth Library.) Cr. 8vo, cloth.

Also (Popular Copyright Novels), cloth.

BARR (W.). Shacklett. The Evolution of a Statesman. By Walter Barr. Large cr. 8vo, cloth.

BARRY. Arden Massiter. By William Barry. (Unwin's Green Cloth Library.) (r. 8vo, cloth.

The Dayspring-A Romance.
Red Cloth Library.) Cr. 8vo.

The Two Standards. By William Barry, D.D. (Unwin's Green Cloth Library.) Cr. 8vo, cloth.

The Wizard's Knot. By William Barry, (Unwin's Green Cloth Library.) Cr. 8vo, cloth.

BARTRAM. People of Clopton. By George Bartram. (Unwin's Green Cloth Library.) Cr. 8vo, cloth.

The White-headed Boy. By George Bartram. (Unwin's Green Cloth Libraiy.) Cr. 8vo, cloth.

BEALBY. A Daughter of the Fen. By J. T. Bealby. (Unwin's Green Cloth Library.) Cr. 8vo, cloth.

BECKE. The Adventures of a Supercargo. By Louis Becke. (Unwin's Red Cloth Library.) Cr. 8vo, cloth.

Breachley : Black Sheep. By Louis Becke. (Unwin's Red Cloth Library.) Cr. 8vo, cloth.

By Reef and Palm. See Autonym Library. Vol. 3.

By Reef and Palm, and Other Stories. By Louis Becke. (Popular Copyright Novels.) Cr. 8vo, cloth.

By Rock and Pool. By Louis Becke. (Unwin's Green Cloth Library.) Cr. 8vo, cloth.

Chinkie's Flat, and Other Stories. By Louis Becke. (Unwin's Red Cloth Library.) Cr. 8vo, cloth.

The Ebbing of the Tide. By Louis Becke. (Unwin's Green Cloth Library.) (r. 8vo, cloth.

Edward Barry: South Sea Pearler. By Louis Becke. (Unwin's Green Cloth Library.) Cr. 8vo, cloth.

Helen Adair. By Louis Becke. (Unwin's Red Cloth Library.) Cr. 8vo, cloth.

His Native Wife. By Louis Becke. (Century Library. No. 4.)

Also paper covers.

Paper covers, $1 / 6$; cloth

Old Convict Days. Edited by Louis Becke. Cr. 8vo, cloth.

Pacific Tales. By Louis Becke. Frontispiece Portrait of the Author. (Unwin's Green Cloth Library.) Cr. 8vo, cloth.

Ridan the Devil, and Other Stories. By Louis Becke. (Unwin's Green Cloth Library.) Large cr. 8vo, cloth.

Rodman the Boatsteerer. By Louis Becke. (Unwin's Green Cloth Library.) Cr. 8vo, cloth.

The Strange Adventure of James Shervington, and Other Stories. By Louis Becke. (Unwin's Red Cloth Library.) Cr. $8 \mathrm{vo}$, cloth.

Also (Popular Copyright Novels), cloth. 
BECKE. Tessa, and the Trader's Wife. By Louis Becke. (Popular Copyright Novels.) Cr. 8vo, cloth.

Tom Gerrard. By Louis Becke. (Unwin's Red Cloth Library.) Cr. 8vo, cloth.

- Under Tropic Skies. By Louis Becke. (Unwin's Red Cloth Library.) Cr. 8vo, cloth.

Wild Life in the Southern Seas. By Louis Becke. Cr. 8vo, cloth.

Yorke the Adventurer, and Other Tales. By Louis Becke. (Unwin's Green Cloth Library.) Cr. 8vo, cloth gilt.

BECKE and JEFFERY. A First Fleet Family. By Louis Becke and Walter Jeffery. (Unwin's Green Cloth Library.) Cr. 8vo, cloth.

The Mutineer. By Louis Becke and Walter Jeffery. (Unwin's Green Cloth Library.) Cr. 8vo, cloth.

The Mystery of Laughlin Islands. By Louis Becke and Walter Jeffery. (Yellow Library. Vol. 3.) Paper covers, 1/- ; cloth

BLAKE (Bass). A Lady's Honour. By Bass Blake. (First Novel Library.) Cr. 8vo, cloth.

BLAKE (B. C.) The Peculiar History of Mary Ann Susan. By Bernard C. Blake. Cr. 8vo, cloth.

BLOUNT. Sylvix in Society. By Mrs. George Blount ("Mrs. George Norman'). With a Frontispiece. Sm. demy 8vo, cloth. net

BODKIN. The Quests of Paul Beck. By M. McDonnell Bodkin, K.C. With 8 Illustrations. Cr. 8vo, cloth.

The Capture of Paul Beck. By W. McDonnell Bodkin, K.C. Cr. 8vo, cloth.

BOLT (Ben). Anthony Jasper. See Pseudonym Library. No. 52. BOURGET. The Disciple. A Novel. By Paul Bourget. Cr. 8vo, cloth. - Divorce. By Paul Bourget. Cr. 8vo. (Red Cloth Library.)

BOWEN-ROWLANDS. The Passion of Mahael. By Lilian BowenRowlands. Cr. 8vo, cloth.

BRAINERD. In Vanity Fair. A Tale of Frocks and Femininity. By Eleanor Hoyt Brainerd. Cr. 8vo, cloth.

BREDA. From One Man's Hand to Another. By G. H. Breda. (First Novel Library.) Cr. 8vo, cloth.

BROOKE (Magdalene). Eleanor Lambert. See Pseudonym Library. No. 2.

BUCHANAN (A.). She Loved Much. By Alfred Buchanan, Author of "The Real Australia," "Bubble Reputation," \&c. Cr. 8vo, cloth.

BUCHANAN. Diana's Hunting. By Robert Buchanan. Demy I2mo.

Effie Hetherington. By Robert Buchanan. (Popular Copyright Novels.) Cr. 8vo, cloth. 2/6.

Also paper covers

$6 d$.

A Marriage by Capture. By Robert Buchanan. (The Autonym Library.)

Paper covers, $1 / 6$; cloth

BULLEN. Cut Off from the World. By Frank T. Bullen. Cr. 8vo, cloth.

BURRARD (W. Dutton.) Leaves from the Life of an Eminent Fossil. See Autonym Library. Vol. I6.

By Creek and Gully. Edited by Lala Fisher. Cr. Svo, cloth.

BYRDE. The Searchers. A Story in Four Books, By Margaretta Byrde. (First Novel Library.) Cr. 8vo, cloth.

The Interpreters. By Margaretta Byrde. Cr. 8vo, cloth. 
CAMPBELL. The Problem of Prejudice. Sec "Little Novels." No. 3.

CAREY. The Motor Cracksman. By Charles Carey. Cr. 8vo, cloth. Also paper covers.

CARTWRIGHT. A Slight Indiscretion. See "Little Novcls." No. 7. CARYL (Valentine). Ne'er-Do.Weel. See Pseudonym Library. No.54. CENTURY LIBRARY, THE. With specially designed covers, printed in coiours, by William Hyde.

Paper covers, $1 / 6$; cloth

(1) Toxin. By Ouida. Illust.

(2) Moff. By John 'Tweeddale.

3) Monsieur Paulot. By Sir

(4) His Native Wife. By Louis Becke. Frontispiece by Hubert Jerningham.

Leslie Brooke.

CERVANTES. Don Quixote. By Miguel de Cervantes. With 260 Drawings by Daniel Vierge. 4 volumes, super royal 8 vo, cloth, with leather label and gilt lettering. Edition limited to 155 copies.

Fine Edition (limited to ro copies) on Imperial Japan paper, with 2 additional Illustrations and a duplicate set of the full-page plates (proofs after letters). Full vellum with gilt back.

CHAMBERS. The Haunts of Men. By R. W. Chambers. (The Adelphi Library.) Cr.8vo, cloth.

CHESSON. Father Felix's Chronicles. By Nora Chesson. With a new portrait of the Author, reproduced in Photogravure, and an Introduction by W. H. Chesson. $\mathrm{Cr}$. 8vo, cloth.

CHOMLEY. The Wisdom of Esau. By C. H. Chomley and R. L. Outhwaite. (Unwin's Green Cloth Library.) Cr, 8vo, cloth.

CLARE. Court Cards. By Austin Clare. (Unwin's Red Cloth Library.) Cr. 8vo, cloth.

CLEEVE. Anglo-Americans. By Lucas Cleeve. (Unwin's Red Cloth Library.) Cr. 8vo, cloth.

Blue Lilies. By Lucas Cleeve. (Unwin's Green Cloth Library.) Cr. 8vo, cloth.

The Children of Endurance. By Lucas Cleeve. (Unwin's Red Cloth Library.) Cr. 8vo, cloth.

Counsels of the Night. By Lucas Cleeve. (Unwin's Red Cloth Library) Cr. 8vo.

A Double Marriage. By Lucas Cleeve. Cr. 8vo, cloth. (Unwin's Red Cloth Library.)

The Fool-killer. By Lucas Cleeve. (Unwin's Red Cloth Library.) Cr. 8vo, cloth.

The Fool's Tax. By Lucas Cleeve. Cr. 8vo, cloth.

The Man in the Street. By Lucas Cleeve. (Unwin's Red Cloth Library.) Cr. 8vo, cloth.

The Progress of Priscilla. By Lucas Cleeve. (Unwin's Red Cloth Library.) Cr. 8vo.

Seven Nights in a Gondola. By Lucas Cleeve. (Unwin's Red Cloth Library.) Cr. Svo.

Stolen Waters. By Lucas Cleeve. (Unwin's Red Cloth Library.) Cr. 8vo, cloth. 
CLIFFORD. Mrs. Keith's Crime. By Mrs. IV. K. Clifford. (Unwin's Green Cluth Library.) Cr. 8vo, cloth

CLYDE. A Pagan's Love. By Constance Clycie. (Unwin's First Novel Library.) Cr. 8vo, cloth.

$6 /-$

COBBLEIGH (Tom). Gentleman Upcott's Daughter. See Pseudonym Library. No. I9.

Young Sam. See Pseudonym Library. No. 40.

CONRAD. Almayer's Folly: A liomance of an Eastern River. By Joseph Conrad. (Unwin's Green Cloth Library.) Cr. 8vo, cloth.

An Outcast of the Islands. By Joseph Conrad. (Unwin's Green Cloth Library.) Cr. 8vo, cloth.

Tales of Unrest. By Joseph Conrad. (Unwin's Green Cloth Library.) Cr. 8vo, cloth.

Also (The Adelphi Library). Cloth.

CORKRAN. Lucie and I. By Henriette Corkran. Cr. 8vo, cioth

COSTELLOE. The World at Eighteen. By Ray Costelloe. Cr. 8vo, cloth.

COTTERELL. An Impossible Person. By Constance Cotterell. (The Autonym Library.)

Paper covers, $1 / 6$; cloth

$6 /-$

$6 /-$

$6 /-$

$3 / 6$

6/-

$3 / 6$

$2 /-$

Love is Not so Light. By Constance Cotterell. (Unwin's Green Cloth Library.) Cr. 8vo, cloth.

COURLANDER. Eve's Apple. By Alphonse Courlander. With Frontispiece. Cr. 8vo, cloth.

The Sacrifice. By Alphonse Courlander. With a coloured Frontispiece. (Green Cloth Lib:ary.) Cr. 8vo.

CRAMPTON. The Story of an Estancia. By George Crampton. Cr. 8vo, cloth.

CRAWFORD (F. Marion.) The Upper Berth. See Autonym Library. Vol. I.

CRESPIGNY. From Behind the Arras. By Mrs. Philip Champion de Crespigny. (First Novel Library.) Cr. 8vo, cloth.

The Mischief of a Glove. By Mrs. Philip Champion de Crespigny. (Unwin's Red Cloth Library.) Cr. 8vo, cloth.

Also paper covers

Cricket on the Brain. By M. C. C. Illustrated by "Gil." Fcap. 4to, paper covers.

CROCKETT. Cinderella. By S. R. Crockett. (Unwin's Green Cloth Library.) With 8 Illustrations. Cr. $8 \mathrm{vo}$, cloth.

The Grey Man. By S. R. Crockett. (Unwin's Green Cloth Library.) Cr. 8vo, cloth, gilt tops.

Also an Edition de Luxe, cr. 4to, cloth gilt.

Kit Kennedy: Country Boy. By S. R. Crockett. (Unwin's Green Cloth Library. Cr. 8vo, cloth gilt.

The Lilac Sunbonnet. By S. R. Crockett. (Unwin's Green Cloth Library.) Cr. 8vo, cloth, gilt tops.

Mad Sir Uchtred of the Hills. See Autonym Library. Vol. 2.

Me and Myn. By S. R. Crockett. (Unwin's Green Cloth Library.) Cr. 8vo.

The Play Actress. See Autonym Library. Vol. 4.

The Play Actress and Mad Sir Uchtred. By S. R. Crockett. With a new Preface. (Popular Copyright Novels.) Cr. 8vo, cloth.

The Raiciers. By S. R. Crockett. (Unwin's Green Cloth Library.) Cr. 8vo, cloth, gilt tops. 
CROCKETT. The Stickit Minister. By S. R. Crockett. (Unwin's Green Cloth Library.) Crown 8vo, cloth, gilt tops.

Cheap Edition. (Popular Copyright Novels.) Cloth. Also cr. 8vo, cloth. 1/- net.

CROTTIE. The Lost Land. By Julia M. Croltie. (Unwin's Green Cloth Library). Cr. 8vo, cloth.

Neighbours: Being Annals of a Dull Town. By Julia M. Crottie. Cr. 8vo, cloth.

DALIN (Talmage). European Relations. See Pseudonym Library. No. 9.

DALTON. Olive in Italy. By Moray Dalton. Cr. 8vo, cloth.

DALZIEL. In the First Watch, and Other Engine-Room Stories. By James Dalziel. Cr. 8vo, cloth.

High Life in the Far East. By James Dalziel. Cr. 8vo, cloth.

DAVIDSON. The Confessions of a Match-making Mother. By Lillias Campbell Davidson. (Idle Hour Series. No. 6.)

Paper covers, $1 /$ - ; cloth

DEAN (Mrs. Andrew). Splendid Cousin. See Pseudonym Library. No. 20.

Lesser's Daughter. See Pseudonym Library. No: 43.

von DEGEN. Mystery of the Campagna. See Pseudonym Library. No. 3 .

DEW.SMITH. Diary of a Dreamer. By Mrs. Dew-Smith. Cr. 8vo, cloth gilt.

DICKESON. Tychiades. A Tale of the Ptolemies. Written in the Third Century, B.c., by Ornithovius, and now faithfully translated out of the Original by Alfred Dickeson. Cr. 8vo, cloth.

DRACHMANN (Holger). Cruise of the "Wild Duck." See Pseudonym Library. No. 24.

DROSINES (Georgios). Amaryllis. See Pseudonym Library. No. 5. Herb of Love. See Pseudonym Library. No. 16.

DUMILLO (Alice). On the Gogmagogs. See "Little Novels." No. Io. DUNDAS. The Journeys of Antonia. By Christian Dundas. (Unwin's Red Cloth Library.) Cr. 8vo.

T. The Lake of Palms. By Romesh Dutt, C.I.E. With Frontispiece. Cr. $8 \mathrm{vo}$, cloth.

DYKE. - As Others See Us. By Watson Dyke. (Unwin's Green Cloth Library.) Cr. 8vo.

von EBNER-ESCHENBACH (Marie). Two Countesses. See Pseudonym Library. No. 27.

van EEDEN. The Deeps of Deliverance. By F. Van Eeden. (Unwin's Red Cloth Library.) Cr. 8vo, cioth.

FALCONER (Lanoe). Mademoise!le Ixe. See Pseudonym Library. No. I.

Hotel d'Angleterre. See Pseudonym Library. No. 6.

Mademoiselle Ixe, The Hotel d'Angleterre, and Other Stories. By Lanoe Falconer. Popılat Ed. Cr. 8vo, cloth. net

FARRER. The Great Noodleshire Election. A Comedy of Political Life. By J. A. Farrer. Cr. 8vo, cloth.

FERGUSON. Lays of the Red Branch. By Sir Samuel Ferguson. (New Irish Library.) Small cr. 8vo. Paper covers, 1/- ; cloth 
FIRST NOVEL L!BRARY, THE. First Novels of New Authors. Cr. 8vo, cloth.
(I) Wistons. By Miles Amber.
(2) The Searchers. By Mar- garetıa Byrde.
(3) A Lady's Honour. By Bass Blake.
(4) From Behind the Arras. By Mrs. Philip Champion de Crespigny.
(5) The Flame and the Flood. By Rosamond langbridge.
(6) A Drama of Sunshine. By Mrs. Aubrey Richardson.
(7) Rosemonde. By Beatrice Stott.
(8) The Cardinal's Pawn. By K. L. Montgomery.
(9) Tussock Land. By Arthur H. Adams.

(I0) The Kingdom of Twiligh? By Forrest Reid.

(II) A Pagan's Love. By Constance Clyde.

(12) Saints in Society. By Margaret Baillie-Saunders.

(13) At the Sign of the Peacock. By K. C. Ryves.

(I4) From One Man's Hand to Another. By G. H. Breda.

(I5) Woman and the Sword. By Rupert I,orraine.

FITZGERALD. Josephine's Troubles. A Story of the FrancoGerman War. By Percy Fitzgerald. Illustrated. Cr. 8vo, cloth.

FLETCHER. Grand Relations. By J. S. Fletcher. Author of "The Arcadians." (Unwin's Red Cloth Library.) Cr. 8vo, cloth.

Also paper covers.

Paradise Court, By I. S. Fletcher. Cr. 8vo, cloth.

The Queen of a Day. By I. S. Fletcher. (Unwin's Red Cloth Library.) Cr. 8vo.

The Threshing Floor. By J. S. Fletcher. Cr. 8vo, cloth.

FLOWERDEW. The Ways of Men. By Herbert Flowerdew. Cr. 8vo, cloth.

FOGAZZARO. The Woman (Malombra). By Antonio Fogazzaro. Translated by F. Thorold Dickson. Cr. 8vo, cloth.

FORREST. The Bond of Blood. See under "Little Novels." No. 6.

FRAPAN (llse). Heavy Laden. See Pseudorym Library. No. I3.

— G'sa's Will. See Pseudonym Library. No. 3 I.

FRASER. Death, the Showman. By John Fraser. (Unwin's Green Cloth Library.) Cr. Svo.

FREDERIC. Marsena. By Harold Frederic. (Yellow Library. Vol. 2.)
Paper covers, 1/-; cloth

FRENCH. Desmonde, M.D. By Henry Willard French. (Popular Copyright Novels.) Cr. 8vo, cloth.

FURNESS. The Melpomene Papers. By Annette Furness. Cr.8vo, cloth.

GISSING (George). Sleeping Fires. See Autonym Library. Vol. I3. GORKY. Foma Gordyeeff. By Maxim Gorky. Illustrated and unabridged. (Unwin's Green Cloth Library.) Cr. 8vo, cloth.

The Man who was Afraid (Foma Gordyeeff). By Maxim Gorky. Popular Edition. Cr. Svo, cloth. net

The Outcasts, and Other Stories. By Maxim Gorky. Cr. 8vo, cloth.

Contents:-The Outcasts, and Waiting for the Ferry. Translated by Dora B. Montefiore. The Affair of the Clasps. Translated by Vera Volkhovsky.

New Popular Edition. Cr. 8vo, cloth.

Three of Them. By Maxim Gorky. Cr. 8vo, cloth.

New Popular Edition. Cr. 8vo, cloth.

net 
Grandmother's Advice to Elizabeth. See under "Truwbridge."

GREEN. The Filigree Ball. By Anna Katherine Green, Author of "The Leavenworth Case." (Unwin's Red Cloth Library.) Cr. 8vo, cloth. Also paper covers.

GREEN CLOTH LIBRARY. See Unwin's Green Cloth Library.

GRIFFITHS (Arthur). A Royal Rascal. By Major Arthur Griffiths. Cr. 8vo (Unwin's Red Cloth Library).

Also paper covers.

GRIFFITHS (D.R.) E'giva, Daughter of the Thegn. By D. R. Griffiths. Cr. 8vo, cloth gilt.

GUEST (Lady Charlotre). See under "Mabinogion."

GYP. Ginette's Happiness. By Gyp. Translated by Ralph Derechef. (Popular Copyright Novels.) Cr.8vo, cloth.

HALES. A Lindsay o' the Dale. By A. G. Hales. With a Frontispiece by Stanley L. Wood. Crown 8 vo, cloth.

Marozia. By A. G. Hales. Cr. 8vo, cloth.

The Watcher on the Tower. By A G. Hales. (Unwin's Red Cloth Library.) Cr. 8vo, cloth.

Also paper covers.

HAMILTON (Cosmo). Which is Absurd. See Autonym Library. Vol. I8.

HAMILTON (E.). The Mawkin of the Flow. By Lord Ernest Hamilton. (Unwin's Green Cloth Library.) Cr. 8vo, cloth.

Outlaws of the Marches. By Lord Ernest Hamilton. (Unwin's Green Cloth Library.) Cr. 8vo, cloth.

The Perils of Josephine. By Lord Ernest Hamilton. (Unwin's Green Cloth Library.) Cr. 8vo, cloth.

HARDING. The Woman Who Vowed (The Demetrian). By Ellison Harding. Cr. 8vo, cloth.

HARDY, Pen Portraits of the British Soldier, By the Rev. E. J. Hardy. Illustrated. Demy I2mo, cloth, decorated cover.

Mr. Thomas Atkins. A study in Red, Blue, Green and Khaki. By the Rev. E. J. Hardy, M.A.

Also decorative paper covers.

HARRISON (B.). Latter-day Sweethearts. By Mrs. Burton Harrison, Cr. Sro, cloth.

A Bachelor Maid. See Autonym Library. Vol. 5.

HARRISON (D.). Master Passions. By Mrs. Darent Harrison. Cr. $8 \mathrm{vo}$, cloth.

HAY. Herridge of Reality Swamp. By William Hay. Cr. 8vo, cloth.

HENSHAW. Why Not, Sweetheart? By Julia W. Henshaw. Cr. 8 vo; cloth.

HENTY. The Lost Heir. By G. A. Henty. Cr. 8vo, cloth.

Also Popular Series for Boys and Girls. Illustrated, cloth.

HERTZ-GARTEN (Theodor). Red-Litten Windows. See Pseudonym Library. No. Ir. 
HINKSON. Father Alphonsus. By H. A. Hinkson. Cr. 8vo, cloth. 6/HOBBES A Bundle of Life. See Pseudonym Library, No. 34.

- The Dream and the Business. By John Oliver Hobbes. With a cover design by Aubrey Beardsley. Cr. 8vo, cloth.

The Flute of Pan. By John Oliver Hobbes. (Unwin's Red Cloth Library.) Cr. 8vo, cloth.

The Gods, Some Mortals, and Lord Wickenham. By John Oliver Hobbes. (Unwin's Green Cloth Librar.) Cr. r.vo, cloth. Also (Idle Hour Series. No. 3). Paper covers, $1 /-$; cloth

$6 /-$ 2/Also paper covers.

$6 d$.

The Herb-Moon. By John Oliver Hobbes. (Unwin's Green Cloth Library.) Large cr. 8vo, cloth.

Also (Popular Copyright Novels).

Love and the Soul Hunters. By John Oliver Hobbes. (Unwin's Red Cloth Library.) Cr. 8vo, cloth.

Popular Edition. Cr. 8vo. Paper covers, net, 6d. ; cloth, net

Robert Orange: A Sequel to "The School for Saints." (Unwin's Green Cloth Library.) Cr. 8vo, cloth.

Also paper covers.

$6 d$.

The School for Saints. By John Oliver Hobbes. (Unwwin's Green Cloth Library.) Large cr. 8vo, cloth.

Also paper covers.

The Sinner's Comedy. See Pseudonym Library, No 28.

Some Emotions and a Moral, and The Sinner's Comedy. By John Oliver Hobbes. Cr. 8vo, cloth. net

Some Emotions and a Moral. See Pseudonym Library, No. 8. Also paper covers.

A Study in Temptations, and A Bundle of Life. By Jchn Oliver Hobbes. Cr. 8vo. Paper covers, net, 6d. ; cloth, net

A Study in Temptations. See Pseudonym Library, No. 23.

Tales about Temperaments. By John Oliver Hobbes. Cr. 8 vo, cloth gilt.

The Tales of John Oliver Hobbes. Portrait of the Author. (Unwin's Green Cloth Library.) Large cr. 8vo, cloth.

Contents :-Some Emotions and a Moral. A Bundle of Life. A Study in Temptations.

The Sinuer's Comedy.

Also (The Adelphi Library), cloth.

The Vineyard. By John Oliver Hobbes. (Unwin's Red Cloth Library.) With Six Illustrations. Cr. 8vo, cloth.

Also paper covers.

Life and To-morrow. Selections frem the Writings of John Oliver Hobbes. Edited by Zoe Procter. Cr. 8vo, cloth.

HOCKING. Meadowsweet and Rue. By Silas K. Hocking. (Unwin's Red Cloth Library.) Cr. 8vo, cloth.

HOLDSWORTH. The Iron Gates. By Annie E. Holdsworth. (Unwin's Green Cloth Library.) Cr. 8vo, cloth. 
HORNIMAN. That Fast Miss Blount. A Novel. By Roy Horniman. (Unwin's Red Cloth Libraiy.) Cr. 8vo, cloth.

Also paper corers.

The Living Buddha. By Roy Horniman. (Unwin's Red Cloth Library.) Cr. 8vo, cloth.

HUdSON. A Crystal Age. By W. H. Hudson. Cr. 8vo, cloth, decorative binding.

HUMPHREY (Frank Pope). New England Cactus. See Pseudo. nym Library, No. 15 .

HUMPHREY (Mrs.) Beauty Adorned. By Mrs. Humphrey. Long 8vo, cloth, decorated cover.

HUNGERFORD (Mrs.) Molly Darling. See Autonym Library. Vol. II.

IDLE HOUR SERIES, THE. Cr. Svo.

(I) Another Englishwoman's Love Letters. By Barry Pain.

(2) The Letters of $\mathrm{Her}$ Mother to Elizabeth, By W. R. H. Trowbridge.

(3) The Gods, Some Mortals, and Lord Wickenham. By John Oliver Hobbes (Mrs. Craigie).

(4) De Omnibus. By the Conductor (Barry Pain).
Paper covers, $1 /$; cloth

(5) Certain Personal Matters. By H. G. Wells.

(6) The Confessions of a Match-making Mother. By Lillias C. Davidson.

(7) The Grandmother's Advice to Elizabeth. By W. R. H. Trowbridge.

(8) Hookey. By A. Neil Lyons.

(9) The Adventures of Prince Aga Mirza. By Aquila Kempster.

IRVING. Six Girls. By Fanny Belle Irving. Illustrated. (Unwin's Popular Series for Boys and Girls.) Cloth.

IRWIN. With Sword and Pen. A Story of India in the Fifties. By H.

C. Irwin. (Unwin's Red Cloth Library.) Cr. 8vo, cloth.

JEFFERY (Walter). See "Becke (Louis)."

JENNINGS. Under the Pompadour. A Romance. By Edward W. Jennings. Cr. 8vo, cloth.

JEPSON. The Lady Noggs, Peeress. By Edgar Jepson. With 8 Illustrations. Cr. 8vo, cloth.

Also decorative paper covers. 1/- net.

The Four Philanthropists. By Edgar Jepson. Crown 8vo, cloth.

JERNINGHAM. Monsieur Paulot. By Sir Hubert Jerningham. (Century Library. No. 3.)

JESSOPP. Frivola, and Simon Ryan the Peterite. By Augustus Jessopp, D.D. New Edition, Revised and Expanded. With portrait. Cr. 8vo, limp cloth, silk sewn.

Simon Ryan the Peterite. By Augustus Jessopp, D.D. (Yellow Library. Vol. I.)

Paper covers, $1 /$ - ; cloth

KEARY. High Policy. By C. F. Keary. (Unwin's Red Cloth Library.) Cr. 8vo, cloth.

A Mariage de Convenance, By C. F. Keary. (Unwin's Green Cloth Library.) Cr. 8vo, cloth.

KELLER (Gottfried). A Selectlon of his Tales. Translated, with a Memoir, by Kite Freiligrath Kroeker. With Portrait. Cr.8vo. cloth.

KEMPSTER. The Adventures of Prince Aga Mirza. By Aquila Kempster. (Idle Hour Series. No. 9). Paper covers, $1 /$ - ; cloth 
KETTLE (Rosa Mackenzie), THE WORKS OF.

Cr. 8vo, cloth.

Highland Sister's Promise.

Magic of the Pine Woods.

Rose, Shamrock and Thistle.

Earl's Cedars.

Fabian's Tower.

Hillesdon on the Moor.

Carding Mill Valley.

$$
\text { Cr. 8vo, cloth. }
$$

Smugglers and Foresters.

The Old Hall Among the each 6/Water Meadows.

My Home in the Shires.

The Ranger's Lodge.

Cr. 8vo, cloth.

Lewell Pastures.

La Belle Marie.

The Falls of the Loder. Last Mackenzie of Redcastle.

The Tenants of Beldornie.

Autumn Leaves.

Summer Shade and Winter

Sunshine Poets.

Cr. 8vo, cloth.

Lord Maskelyne's Daughter.

each 4/-

On Leithay's Banks.

By Sea and Moor.

The Wreckers.

Sir Frederick Derwent.

The Memoirs of Charles Boner (2 vols.):

The Mistress of Langdale Hall Under the Grand Old Hills.

Sisters of Ombersleigh.

Furze Blossoms.

Cr. 8vo, cloth.

Christmas Berries and Sunmer Roses.

$3 / 6$

$2 / 6$

KILDARE. Up from the Slums. By Owen Kildare. Large cr. \&vo, cloth.

KINROSS (Albert). A Game of Consequences. See Autonym Library. Vol. I2.

KOROLENKO(V). Makar's Dream. Sce Pseuclonym Library. No. I4.

- Saghalien Convict. Sce Pseudonym Library. No. 18.

LAMBE. By Command of the Prince. By J. Lawrence Iambe. Cr. Svo, cloth.

LANDON. Mid Pleasures and Palaces. By Mary Landon. With 16 Illustrations. Cr. 8vo, cloth.

LANGBRIDGE. The Flame and the Flood. By Rosamond Langbridge. (First Novel Libiary.) Cr. Svo, cloth.

- The Third Experiment. By Rosamond Langbridge. (Unwin's Red Cloth Library.) Cr. 8vo, cloth.

LANYON. "Sarah P. G." A Novel. By H. Sant Martin-Lanyon. Cr. 8vo, cloth gilt.

LAVERTON. The Romance of a Hill Station. And Other Stories. By Mrs. H. S. Laverton (Valete). Illustrated. Crown 8vo, cloth.

LEE (Vernon). Ottilie. See Pseudonym Library. No.22.

- Penelope Brandling. See Pseudonym Library. No. 55.

LEE-HAMILTON. The Romance of the Fountain. By Eugene Lee-Hamilton. Cr. 8vo, cloth.

LELAND. Hans Breitmann in Germany-Tyrol. By Charles

Godfrey Leland. Frontispiece and Decorated Title-page. Fcap. 8 vo, cloth.

The Hundred Riddles of the Fairy Bellaria. By Charles Godfrey Leland ("Hans Breitmann").

Also a Fine Edition.

Paper covers, 1/- ; cloth

net 
Letters of Her Mother to Elizabeth. See under Trowbridge.

I.EWIS. A Modern Monarch. By Frank C. Lewis. Cr.8vo, cloth. 6/LITTA. The Soul of a Priest. By the Duke Lilta. Cr. 8vo, cloth. 6/LITTLE. A Millionaire's Courtship. By Mrs. Archibald Little. Cr. 8vo, cloth. "(Red Cloth Library.)

$6 /-$

LITTLE NOVELS. Demy 8 vo, printed in bold type.

Paper covers, 6d. ; cloth

(I) The World is Round. By Louise Mack.

(2) No.Place for Repentance. By Ellen F. Pinsent.

3) The Problem of Prejudice. : By Mrs. Vere Campbell.

(4) Margaret Grey. By $\mathrm{H}$. Barton Baker.

(5) A Painter's Honeymoon. By Mildred Shenstone.
(6) The Bond of Blood: By R. is. Forrest.

(7) A Slight Indiscretion. By Mrs. Edward Cartwright.

(8) A Comedy of Three. By Newton Sanders.

(9) Passports. ByI.J.Armstrong

(I0) On the Gogmagogs. By Alice Dumillo.

(II) A Noble Haul. By W. Clark Russell.

LLOYD. Bergen Worth. By Wallace Lloyd. Cr. 8vo, cloth.

LOCKE. The Stem of the Crimson Dahlia. By James Locke. With

a Coloured Frontispiece. Cr. 8vo, cloth.

LORRAINE. The Woman and the Sword. By Pupert Lorraine. B) (First Novel Library. Vol. 15.) Cr. 8vo, cloth.

LYNCH. A Parish Providence. By E. M. Lynch. '(New Irish Library.) Small cr. 8vo.

Paper covers, $1 /-$; cloth

LYONS (A. E.). Mister Bill : A Man. By Albert E. Lyons. Cr. 8vo, cloth.

LYONS. Hookey. By A. Neil Lyons. (Idle Hour Series. No. 8.) Cr. 8vo.

Paper covers, $1 /$ - ; cloth

$2 /-$

MABINOGION, THE. Translated from the Red Book of Hergest by

Lis Lady Charlotte Guest. 3 vols. (Welsh Library. Vols. I-3.) Fcap. 8vo.
Paper covers, 1/- ; cloth, each

Popular One-Volume Edition, cloth; $i \quad$ net

McAUlAY. Black Mary. By Allan McAulay. (Unwin's Green Cloth Library.) Cr. 8vo, clotb.

The Rhymer. By Allan McAulay. (Unwin's Green Cloth Library.) Cr. 8vo, cloth.

MAC BRIDE. Wonderfu' Weans : Sketches from Living Models. By Mac Kenzie Mac Bride. With a cover designed by John Duncan. Cr. 8 vo.

net

MACDONALD. The Portent and Other Stories. By George Macdonald. (Adelphi Library.) Cr. 8vo, cloth.

MACMANUS (J.). The Humours of Donegal. By James MacManus ("Mac"). Cr. 8vo.

Paper covers, $1 /$ - ; cloth

$2 \hat{1}$

Through the Turf Smoke. By Seumas MacManus ("Mac"). Cr. 8vo.

Paper covers, $1 /$ - ; cloth

$2 /-$

McMANUS (L.). Lally of the Brigade. By L. McManus. (Popular Copyright Novels.) Cr. 8vo.

- The Red Star. By L. McManus. (The Autonym Library.)

Paper covers, $1 / 6$; cloth

Silk of the Kine. By L. McManus (C. MacGuire) Cr. 8vo, cloth.

MAGNAY. The Amazing Duke. By Sir William Magnay, Bart. Cr. 8vo, cloth. 
MANN. Among the Syringas. By Mary E. Mann. (Unwin's Green Cloth Library.) Cr، 8vo.

- In Summer Shade. By Mary E. Mann. Cr. 8vo, cloth. Also in decorative paper covers.

The Mating of a Dove. By Mary E. Mann. (Unwin's Green Cloth Library.) Cr. 8vo, cloth.

Moonlight. By Mary E. Mann. (Unwin s Green Cloth Library.) Cr. 8vo.

The Patten Experiment. By Mary E. Mann. (Unwin's Green Cloth Library.) Cr. 8vo, cloth.
Susannah. By Mary E. Mann. (Unwin's Green Cloth Library.) Cr. 8vo, cloth.

MARQUIS. Marguerite de Roberval. By T. G. Marquis. Cr. 8vo, cloth.

MARSH. The Beetle. A Mystery. By Richard Marsh. With Illustrations by John Williamson. Cr. 8vo, cloth.

Also (The Adelphi Library), cloth.

MARTYN. The Tale of a Town and an Enchanted Sea. By Edward Martyn. Cr. 8vo, cloth.

MAUGHAM. 'Liza of Lambeth. By W. Somerset Maugham. Cr.8vo. cloth.

Also paper covers.

The Making of a Saint. By W. Somerset Maugham. (Unwin's Green Cloth Library.) Cr. 8vo, cloth.

Orientations, and Qther Stories. By W. Somerset Maugham. Cr. 8vo, cloth.

MAYNE. The Clearer Vision. By Ethel Colburn Mayne. Cr. 8vo, cloth gilt.

MEADE. Love Triumphant. By Mrs. L. T. Meade. (Unwin's Red Cloth Library.) Cr. 8vo, cloth.

Also Popular Series for Boys and Girls. Jllustrated, cloth.

MEIRION (Ellinor). Cause and Effect. See Pseudonym Library. No. 49.

MIKOULITCH (V.). Mimi's Marriage. See Pseudonym Library. No. 35.

MILNE. The Epistles of Atkins. By James Milne. With I2 Illustrations from War Sketches. Cr. 8vo, cloth.

MITCHELL. Hugh Wynne. By S. Weir Mitchell. (Unwin's Green Cloth Library.) Cr. 8 vo.

Far in the Forest. By S. Weir Mitchell. Cr. 8vo, cloth.

MONTAGU. Naomi's Exodus. By Lily H. Montagu. Cr. 8vo, cloth.

MONTGOMERY. The Cardinal's Pawn. By K. L. Montgomery. (First Novel Library. No. 8.) Cr. 8vo, cloth.

Also paper covers.

Major Weir. By K. L. Montgomery. With 8 Illustrations. (Unwin's Red Cloth Library.) Cr. 8vo, cloth.

MOORE. Evelyn Innes. By George Moore. (Unwin's Green Cloth Library.) Cr. 8vo, cloth. 
MOORE. Sister Teresa. A Novel. By George Moore. (Unwin's Green Cloth Library.) Cr. 8vo, cloth.

Also (The Adelphi Library). Cloth.

Paper covers.

The Untilled Field. By George Moore. (Unwin's Red Cloth Library.) Cr. 8vo, cloth.

MUIR. The Mystery of Muncraig. By Robert James Muir. Cr. 8vo, cloth gilt.

MURRAY. He that had Received the Five Talents. By J. Clark Murray. (Unwin's Red Cloth Library.) Cr. 8vo, cloth.

NELSON (Jane). The Rousing of Mrs. Potter. See Pseudonym Library. No. 36.

NESBIT. Man and Maid. By E. Nesbit. Cr. 8vo, cloth.

NESBIT'S Children's Stories. See under "Books for Children."

NORMYX. Unprofessional Tales. By Normyx. Cr. 8vo, cloth.

NORRIS (W. E.). The Spectre of Strathannan. See Autonym Library. Vol. 9.

O'GRADY. The Bog of Stars, and Other Stories of Elizabethan Ireland. By Standish O'Grady. (New Irish Library. No. 2.) Small cr. 8vo.

OLIPHANT (Mrs.). The Two Strangers. See Autonym Library. Vol. 7.

OMOND (G. W. T.). Miserrima. See Autonym Library. Vol. 6.

ORCZY. The Case of Miss Elliott. By the Baroness Orczy, Author of "The Scarlet Pimpernel," \&c. With I6 Illustrations. Cr. 8vo, cloth.

OUIDA. A Rainy June and Don Gesualdo. By Ouida. (Popular Copyright Novels.) Cr. 8vo, cloth.

The Silver Christ, and Other Stories. By Ouida. (Unwin's Green Cloth Library.) Cr. 8vo, cloth.

See also Pseudonym Library. No. 4I.

Toxin. See Century Library. No. I.

OWEN. Captain Sheen. By Charles Owen. Cr.8vo, cloth.

PAIN. Another Englishwoman's Love Letters. By Barry Pain. (Idle Hour Series. No. I.)

Paper covers, $1 /-$; cloth

Curiosities. By Barry Pain. Paper covers.

De Omnibus. By The Conductor (Barry Pain). Paper covers, 1/Cloth.

De Omnibus and Another Englishwoman's Love Letters. By Barry Pain. Paper covers

Little Entertainments. By Barry Pain. Cr. 8vo. Paper covers, 1/Cloth.

The Memoirs of Constantine Dix. By Barry Pain. Cr. 8vo, cloth

Also in decorative paper covers. 1/- net. Also paper covers

de PENTHENY (S.) Another Wicked Woman. See Autonym Library. Vol. 8.

PIDGIN. Quincy Adams Sawyer. By Charles F. Pidgin. Cr. 8vo, cloth.

PINSENT. No Place for Repentance. See under Little Novels. No. 2.

PLAYNE. The Romance of a Lonely Woman. By C. E. Playne. Cr. 8vo, cloth.

The Terror of the Macdurghotts. By C. E. Playne. Cr. Sro, cloth 
de POLEN. Clairice: The Story of a Crystal Heart. By Narcisse Lucien de Polen. Cr. 8vo, cloth.

POPULAR COPYRIGHT NOVELS. Cheap re-issue. In cr. 8vo, cloth gilt.

ALEXANDER (MRS.).

Brown, V.C.

Stronger than Love.

Through Fire to Fortune.

A Winning Hazard.

BARR (AMELIA E.).

I, Thou, \& the Other One.

Prisoners of Conscience.

Was it Right to Forgive?

BECKE (LOUIS).

By Reef \& Palm.

The Strange Adventures of James Shervington.

Tessa and The Trader's Wife.

BUCHANAN (ROBERT).

Effie Hetherington.

CROCKETT (S. R.).

The Play Actress and Mad Sir Uchtred.

The Stickit Minister.

CROMMELIN (MAY).

Half Round the World for a Husband.

FRENCH (H. W.).

Desmonde, M.D.

GYP. each $2 / 6$

Ginette's Happiness.

HOBBES (JOHN OLIVER). P GUM?

The Herb-Moon.

McMANUS (L.).

Lally of the Brigade.

OUIDA.

A Rainy June.

RITA.

The Ending of My Day.

Vanity! The Confessions of a Court Modiste.

RUSSELL (W. CLARK).

The Romarice of a Midshipman.

SALA (GEORGE AUGUS. A 710 TUS).

Margaret Forster.

SCHREINER (OLIVE).

Trooper Peter Halket.

POTAPENKO (J.). Russian Priest., See Pseudonym Library. No. 7.

General's Daughter. See Pseudonym Library. No. I7.

Father of Six. See Pseuclonym Library. No,26.

PRAED. The Insane Root. By Mrs. Campbell Praed. (Unwin's Green

Cloth Library.) Cr. 8vo, cloth.

- Nyria. By Mrs. Campbell Praed. (Unwin's Red Cloth Library.)

Cr. 8vo, cloth.

PRICHARD. The New Chronicles of Don Q. By K. and Hesketh

Prichard. Illustrated. Cr. 8vo, cloth.

PRYCE. John Jones, Curate. By G. Pryce. (Unwin's Green Cloth: Library.) Cr. 8vo, cloth.

A Son of Arvon. A Welsh Novel. By Gwendolen Pryce.
(Unwin's Green Cloth Library.) Cr. 8vo.

A Son of Arvon. A Welsh Novel. By Gwendolen Pryce.
(Unwin's Green Cloth Library.) Cr. 8vo.

PSEUDONYM LIBRARY, THE. 24mo. Paper covers, $1 / 6$; cloth, each $2 /$ -

(I) Mademoiselle Ixe. By (6) The Hotel d'Angleterre. Lanoe Falconer.

By Lanoe Falconer.

(2) The Story of Eleanor Lambert. By Magdalene Brooke.

(7) A Russian Priest.... By J. Potapenko, Translated by W. Gaussen.

(3) A Mystery of the Cam. pagna. By von Degen.

(4) The School of Art. By Isabel Snow.

(5) Amaryllis. By Georgios Drosines.

(8) Some Emotions and a Moral. By John Oliver Hobbes.

(9) European Relations. A J9 Tirolese Sketch. By Talmage Dalin. 30 7० 
PSEUDONYM LIBRARY, THE.-continued.

(Io) John Sherman, \& Dhoya. By Ganconagh (W.B. Yeats).

(II) Through the Fed-Litten Windows. By Theodor Hertz-Garten.

(I2) Green Tea. A Love Story. By V. Schallenberger.

(13) Heavy Laden, and Old Fashioned Folk. By Ilse Frapan. Translated by Helen A. Macdonell.

(14) Makar's Dream, and Other Russian Stories. By V. Korolenko, and Others.

(15) A New England Cactus. By Frank Pope Humphrey.

(16) The Herb of Love. By Georgios Drosines. Translated by Eliz. M. Edmonds.

(17) The General's Daughter. By J. Potapenko. Translated by W. Gaussen.

(18) The Saghalien Convict, and Other Russian Stories. By V. Korolenko, and Others.

(19) Gentleman Upcott's Daughter. By Tom Cobbleigh.

(20) A Splendid Cousin. By Mrs. Andrew Dean.

(2I) Colette. By Philippe St. Hilaire.

(22) Ottilie. By Vernon Lee.

(23) A Siudy in Temptations. By John Oliver Hobbes.

(24) The Cruise of the "Wild Duck." By Holger Drachmann.

(25) Squire Hellman, and Other Finnish Stories. By Juhani Aho. Translated by $R$. Nisbert Bain.

(26) A Father of Six, and An Occasional Holiday. By J. Potapenko. Translated by W. Gaussen.

(27) The Two Countesses. By Marie von EbnerEschenbach. Translated by Mrs. Waugh.

(28) The Sinner's Comedy. By John Oliver Hobbes.

(29) Cavalleria Rusticana, and Other Tales of Sicilian Peasant Life. By Giovanni Verga. Translated by Alma Strettell.
(30) The Passing of a Mood, and Other Stories. By V. O. C. S.

(3I) God's Will, and Other Stories. By llse Frapan. Translated by Helen A. Macdonell.

(32) Dream Life and Real Life. By Ralph Iron (Olive Schreiner).

(33) The Home of the Dragon. A Tonquinese Idyll. By Anna Catharina.

(34) A Bundle of Life. By John Oliver Hobbes.

(35) Mimi's Marriage By V. Mikoulitch.

(36) The Rousing of Mrs. Poiter, and Other Stories. By Jane Nelson.

(37) A Study in Colour. By Alice Spinner.

(38) The Hon. Stanbury. By Two.

(39) The Shen's Pigtail, and Other Stories of AngloChina Life. By Mr. M-.

(40) Young Sam and Sabina. By Tom Cobbleigh.

(4I) The Silver Christ, and a Lemon Tree. By Ouida.

(42) A Husband of No Importance. By Rita.

(43) Lesser's Daughter. By Mrs. Andrew Dean.

(44) Helen. By Oswald Valentine.

(45) Cliff Days. By Brian Rosegarth.

(46) Old Brown's Cottages. By John Smith.

(47) Under the Chilterns. By Rosemary.

(48) Every Day's News. By R. E. Francis.

(49) Cause and Effect. By Ellinor Meirion.

(50): A White Umbrella, and Other Stories. By Sarnia.

(5I) When Wheat is Green. By Jos. Wilton.

(52) Anthony Jasper. By Ben Bolt.

(53) As a Tree Falls. By L. Parry Truscott:

(54) A Ne'er-Do-Weel. By Valentine Caryl.

(55) Penelope Brandling. By Vernon Lee. 
RED CLOTH LIBRARY. See Unwin's Red Cloth Library.

REETH. Lezions of the Dawn. By Allan Reeth. Cr. 8vo, cloth.

REID. The Kingdom of Twilight. By Forrest Reid. (First Novel Library.) Cr. 8vo, cloth.

RICHARDSON. A Drama of Sunshine-Played in Homburg. By Mrs. Aubrey Richardson. (First Novel Library.) Cr. 8vo, cloth.

They Twain. By Mrs. Aubrey Richardson. (Unwin's Red Cloth Library.) Cr. 8vo, cloth.

RICHINGS. In Chaucer's Maytime. By Emily Richings. (Unwin's Red Cloth Library). Cr. 8vo, cloth gilt.

RITA. The Ending of My Day. By Rita. (Popular Copyright Novels.) Cr. 8vo, cloth gilt.

A Husband of No Importance. See Pseudonym Library. No. 42.

A Jilt's Journal. (Unwin's Green Cloth Library.) Cr. 8vo, cloth.

Vanity: The Confessions of a Court Modiste. By Rita. Cr.8vo, cloth.

Also (Popular Copyright Novels), cloth.

ROOSEVELT. The Siren's Net. By Florence Roosevelt. (Unwin's Red Cloth Library.) Cr. 8vo, cloth.

ROSEGARTH (Brian). Cliff Days. See Pseudonym Library. No. 45 .

ROSEGGER. The Light Eternal. By Peter Rosegger. Cr. 8vo, cloth. ROWBOTHAM. Tales from Plutarch. By F. Jameson Rowbotham. Fully illustrated. Cr. 8vo, cloth.

ROWLANDS. The Passion of Mahael. See under "Bowen-Rowlands."

RUSSELL. The Honour of the Flag. By W. Clark Russell. Demy I2mo, cloth.

A Noble Haul. See under "Little Novels." No. II.

The Romance of a Midshipman. By W. Clark Russell. (Popular Copyright Novels.) Cr. Svo, cloth.

The Yarn of Old Harbour Town. A Sea Romance. By W. Clark Russell. (Ünwin's Red Cloth Library.) Cr. 8vo, cloth.

RUTHERFORD. The Autobiography of Mark Rutherford. Edited by Reuben Shapcott. Cr. 8vo, cloth.

Catherine Furze: A Novel by Mark Rutherford. Cr. 8vo, cloth.

Clara Hopgood. By Mark Rutherford. Cr. 8vo, cloth.

Miriam's Schooling, and Other Papers. By Mark Rutherford. With Frontispiece by Walter Crane. Cr. 8vo, cloth.

The Revolution in Tanner's Lane. Cr. 8vo, cloth.

Pages from a Journal. By Mark Rutherford. Cr. 8vo, cloth.

A New Popular Edition. Each vol. cr. 8vo, cloth gilt, each, net 1/List of VOLUMES.
(I) The Autobiography of Mark Rutherford.
(3) The Revolution in Tanner's Lane.
(2) Mark Rutherford's De- liverance.
(4) Miriam's Schooling.
(5) Catherine Furze.
(6) Clara Hopgood. 
RYVES. At the Sign of the Peacock. By K. C. Ryves. (First Novel Library.) Cr.8vo, cloth.

ST. HILAIRE (Philippe). Colette. See Pseudonym Library. No. $2 \mathrm{r}$.

SALA. Margaret Forster: A Novel. By George Augustus Sala. (Popular Copyright Novels.) Cr. 8vo, cloth gilt.

SANDERS. A Comedy of Three. See under "Little Novels." No. 8.

SARNIA. White Umbrella. See Pseudonym Library. No. 50.

SCHALLENBERGER (V.). Green Tea. See Pseudonym Library. No. 12.

von SCHLICHT. Life in a Crack Regiment (Erstklassige Menschen). A Novel of German Military Manners and Morals. By Baron von Schlicht. Translated by F. B. Low. Cr. 8vo, cloth.

Also paper covers.

SCHREINER. Dream Life and Real Life. By Olive Schreiner. Cloth.

(RALPH IRON). Dream Life and Real Life. See Pseudonym Library. No. 32.

Dreams. By Olive Schreiner. Demy I2mo, cloth.

Trooper Peter Halket of Mashonaland. By Olive Schreiner. Frontispiece. (Popular Copyright Novels.) Cr. 8vo, cloth gilt.

Cheap Edition, cr. 8 vo, cloth.

SCOTT (Sir Walter). The "Century" Scott. In 25 vols. Fcap. 8 vo ( 6 by 4$)$. Each with Collotype Frontispiece, and with book plate, title-pages, binding, and devices in two colours by James Allen Duncan.

Decorative cloth, 1/- ; green leather

\section{List oF Volumes.}

Ivanhoe.

Waverley.

Guy Mannering.

Old Mortality.

Rob Roy.

The Antiquary.

The Heart of Midlothian.

The Monastery.

The Abbot.

Kenilworth.

The Pirate.

Peveril of the Peak.

The Legend of Montrose and Black Dwarf.
The Bride of Lammermoor. The Fortunes of Nigel.

Quentin Durward.

St. Ronan's Well.

Redgauntlet.

The Betrothed and Highland Widow, \&c.

The Talisman.

Woodstock.

The Fair Maid of Perth. Anne of Geierstein.

The Surgeon's Daughter and Castle Dangerous.

Count Robert of Paris.

SCULLY (W. C.). Kafir Stories. See Autonym Library. Vul. Io.

By Veldt and Kopje. By W. C. Scully. Cr. 8vo, cloth.

SHEEHAN. A Spoiled Priest, and Other Stories. By the very Rev. P. A. Sheehan, D.D. Illustrated. Cr. 8vo, cloth.

SHENSTONE. A Painter's Honeymoon. See under "Little Novels." SHERWOOD. Tongues of Gossip. By A. Curtis Sherwood. Cr. $8 \mathrm{ro}$ SHOLL. The Greater Love. By Anna McClure Sholl. Cr. 8vo, cloth SMITH (F. C.). A Daughter of Patricians. By F. Clifford Sn:ith. Illustrated. Cr. 8vo, cloth.

SMITH (I.). The Minister's Guest. By Isabella Smith. (Unwin's Green Cloth Library.) Cr. 8vo, cloth. 
SMITH (John). Old Brown's Cottages. See Pseudonym Library, 46. SNOW (Isabel). School of Art. See Pseudonym Library. No. 4. SPINNER (Alice). Study in Colour. See Pseudonym Library, 37.

STACPOOLE. The Bourgeois. By H. de Vere Stacpoole. (Unwin's Green Cloth Library.) Cr. 8vo, cloth.

The Blue Lagoon A Romance. By H. de Vere Stacpoole. Cr. 8vo, cloth.

Also in decorative paper covers.

The Crimson Aza!eas. By H. de Vere Stacpoole. Cr.8vo, cloth. Also paper covers.

The Doctor. By H. de Vere Stacpoole. (Unwin's Green Cloth Library.) Cr. 8vo, cloth gilt.

Fanny Lambert. By H. de Vere Stacpoole. (Unwin's Red Cloth Library.) Cr. 8vo, cloth.

Also Paper covers.

The Lady-Killer. By H. de Vere Stacpoole. (Unwin's Red Cloth Library.) Cr. Svo.

$6 d$.

Patsy. By H. de Vere Stacpoole. With Frontispiece. Cr.8vo, cloth

The Vulture's Prey. By H. de Vere Stacpoole. Cr. $8 \mathrm{vo}$, cloth

STEVENS. The Perils of Sympathy. By Nina Stevens. : (Unwin's Red Cloth Library.) Cr. 8vo, cloth.

STOTT. Rosemonde. By Beatrice Stott. (First Novel Library.) Cr. $8 \mathrm{vo}$, cloth.

STRAIN. Laura's Legacy. By E. H. Strain. (Unwin's Red Cloth Library.) Cr. 8vo, cloth.

SUMMERS. Renunciation. By Dorothy Summers, Cr. 8vo, cloth.

A Man's Love. By Dorothy Summers. Cr. 8vo, cloth.

$6 /-$

SUTCLIFFE. A Bachelor in Arcady. By Halliwell Sutcliffe. With Frontispiece. (Unwin's Green Cloth Library.) Cr. 8vo, cloth. Also a Presentation Edition. net

By Moor and Fell : Landscape and Lang-Settle Talk in West Yorkshire. By Halliwell Sutcliffe. Cr. 8vo, cloth.

Mistress Barbara Cunliffe. By Halliwell Sutcliffe. (Unwin's Green Cloth Library.) Cr. 8vo, cloth.

$6 /-$

$6 /-$

$6 /-$

Ricroft of Withens. By Halliwell Sutcliffe. (Unwin's Green Cloth Library.) Cr. 8vo, cloth.

Paper covers.

Shameless Wayne. By Halliwell Sutcliffe. (Unwin's Green Cloth Library.) Cr. 8vo.

Through Sorrow's Gates. A Tale of the Wintry Heath. By Halliwell Sutcliffe. (Unwin's Green Cloth Library.) Cr. 8vo, cloth Also (The Adelphi Library), cloth.

Willowdene Will. By Halliwell Sutcliffe. (Adelphi Library.) Cloth

SWIFT. The Destroyer. By Benjamin Swift. (Unwin's Green Cloth Library.) Cr. 8vo, cloth.

Nancy Noon. By Benjamin Sivift. (Unwin's Green Cloth Library.) Cr. 8vo, cloth.

The Tormentor. By Benjamin Swift. (Unwin's. Green Cloth Library.) Cr. 8vo, cloth.

SYNGE. The Coming of Sonia. By Mrs. Hamilton Synge. Cr. 8vo, cloth.

A Supreme Moment. By Mrs. Hamilton Synge. (Unwin's Green Cloth Library.) Cr. 8vo, cloth. 
TAYLER. The Long Vigil. By: F, Jenner Tayler. (Unwin's Red Cloth Library.) Cr, 8vo, cloth.

TAYLOR. A Thousand Pities. By Ellen Taylor. Cr. 8vo, cloth. ' $2 / 6$

THYNNE. Facing the Future; or, the Parting of the Ways. By R. Thynne. Cr. 8vo, cloth.

TREHERNE. A Love Cure. By Philip Treherne. Cr. 8vo, cloth. 3/6 TROUBRIDGE. The Millionaire. By Lady Troubridge. Cr. 8 vo, cloth. 6/The Woman Thou Gavest. By Lady Troubridge. Cr. 8vo, cloth. 6/Also paper covers.

$6 d$.

TROWBRIDGE. A Girl of the Multitude. By W. R. H. Trowbridge. Cr. 8vo, cloth.

A Dazzling Reprobate. By W. R. H. Trowbridge. (Unwin's Red Cloth Library.) Cr. 8vo.

The Grandmother's Advice to Elizabeth. A companion volume to "The Letters of Her Mother to Elizabeth." (Idle Hour Series. No. 7.) Paper covers, $1 /$; cloth

The Letters of Her Mother to Elizabeth. A Series of Smart Letters for Admirers of "The Visits of Elizabeth." (Idle Hour Series. No. 2.) $5^{3}$ Paper covers, $1 /-$; cloth

Also an Edition in paper covers.

The Situations of Lady Patricia: A Satire for Idle People. By W. R. H. Trowbridge. (Unwin's Red Cloth Library.) Cr. 8vo, cloth.

TRUSCOTT. As a Tree Falls. See Pseudonym Library. No. 53.

- The Mother of Pauline. By L. Parry Truscott. Paper covers.

bd.

Motherhood. By L. Parry Truscott. (Unwin's Red Cloth Library.) Cr. 8vo, cloth.

The Poet and Penelope. By L. Parry Truscott. Cr. 8vo, cloth.

Stars of Destiny. By L. Parry Truscott. (Unwin's Red Cloth Library.) Cr. 8vo, cloth.

TURNER. That Girl. By Ethel Turner (Mrs. Curlewis). With 25 Illustrations by Frances Ewan. Large cr. 8vo, cloth.

TWEEDDALE. Moff. By John Tweeddale. (Century Library. No. 2.) Paper covers, $1 / 6$; cloth

UNWIN'S GREEN CLOTH LIBRARY. In uniform green cloth, gilt tops. each

ALEXANDER (MRS.).

The Yellow Fiend.

Through Fire to Fortune.

"ALIEN."

The Devil's Half-Acre.

ASKEW (ALICE and MAUDE).

The Shulamite.

BACHELLER (IRVING).

Silas Strong.

BAKER (JAMES).

A Double Choice.

BARLOW (JANE).

By Beach and Bogland.
BARR (AMELIA E.).

Was it Right to Forgive?

I, Thou, and the Other One.

Souls of Passage.

The Maid of Maiden Lane

The Lion's Whelp.

BARRY (WILLIAM).

Arden Massiter.

The Two Standards.

The Wizard's Knot.

BARTRAM (GEORGE).

The People of Clopton.

The White-Headed Boy. 
UNWIN'S GREEN CLOTH LIBRARY-continucd.

BEALBBY (J. 'T.).

A Daughter of the Fen.

BECIE (LOUIS)

By Rock and Pool.

Edward Barry.

Rodman, the Boatsteerer.

Yorke the Adventurer.

Ridan the Devil.

The Ebbing of the Tide.

Pacific Tales.

BECKE (L.) and WALTER JEFFREY.

A First Fleet Family.

The Mutineer.

CHOMLEY (C. H.).

The Wisdom of Esau.

CI,EEVE (LUCAS).

Blue Lilies.

CLIFFORD (MRS. W. K.).

Mrs. Keith's Crime.

CONRAD (JOSEPH).

An Outcast of the Islands.

Alrnayer's Folly.

Tales of Unrest.

COTTERELL (CONSTA.ICE).

Love is not so Light.

COURLANDER (ALPHONSE).

The Sacrifice.

CROCKETT (S. R.),

Kit Kennedy.

The Stickit Minister.

The Lilac Sunbonnet.

Cinderella.

The Raiders.

The Grey Man.

Me and Myn.

CROTTIE (JULIA M.).

The Lost Land.

DYKE (WATSON).

As Others See Us.

FRASER (JOHN).

Death the Showman.

GORKY (MAXIM).

Foma Gordyeeff.

HAMILTON (EIRNEST).

Outlaws of the Marches.

The Perils of Josephine.

The Mawkin of the Flow.

HOBBES (JOHN OLIVER).

The Herb-Moon.

The Gods, Some Mortals, and Lord Wickenham.

The School for Saints.

Robert Orange.

The Tales of John Oliver Hobbes.
HOLDSIVORTH (ANNIE E.)

The Iron Gates.

KEARY (C. F.).

Marriage de Convenance

MCAULAY (ALLAN).

Black Mary.

The Rhymer.

MANN (MARY E.).

Moonlight.

Susannah.

The Patten Experiment.

Among the Syringas.

The Mating of a Dove.

MAUGHAM (W. SOMERSET).

The Making of a Saint.

Orientations.

MITCHELL (S. WEIR).

Hugh Wynne.

MOORE (GEORGE).

Evelyn Innes.

Sister Teresa.

NESBIT (E.)

The Treasure Seckers.

OUIDA.

The Silver Christ.

PRAED (MRS. CAMPBELL).

The Insane Root.

PRYCE (GWENDOLEN).

A Son of Arvon.

John Jones, Curate.

RITA.

A Jilt's Journal.

SMITH (ISABELLA).

The Minister's Guest.

STACPOOLE (H. DE VERE).

The Doctor.

The Bourgeois.

SUTCLIFFE (HALLIWELL).

Ricroft of Withens.

Shameless Wayne.

Mistress Barbara Cun. liffe.

Through Sorrow's Gates

A Bachelor in Arcady.

SWIFT (BENJAMIN).

Nancy Noon.

The Tormentor.

The Destroyer.

SYNGE (MRS. HAMILTON).

A Supreme Moment.

WATSON (J. R.).

In a Man's Mind.

WATSON (MARGARET). 
UNWIN'S RED CLOTH LIBRARY.

ALEXANDER (MRS).

Kitty Costello.

Stronger than Love.

ARCHER (L. M. PALMER).

A Bush Honeymoon.

BARR (AMELIA E.).

The Black Shilling.

A Song of a Single

Thyra Varrick.

Cecilia's Lovers.

BARRY (WILLIAM).

The Dayspring.

BECKE (LOUIS).

Breachley, Black Sheep.

Chinkie's Flat.

Adventures of a Supercargo.

Helen Adair.

The Strange Adventure of James Shervington.

Tom Gerrard.

Under Tropic Skies.

BOURGE'T (PAUL).

Divorce.

CLARE. (AUSTIN).

Court Cards.

CLEEVE (LUCAS).

Anglo-Americans.

Children of Endurance.

Counsels of the Night.

Progress of Priscilla.

Stolen Waters.

The Fool-killer.

The Man in the Street.

A Double Marriage.

Seven Nights in aGondola

DE CRESPIGNY (MRS. P.

CHAMPION).

The Mischief of a Glove.

DUNDAS (CHRISTIAN).

Journeys of Antonia.

VAN EEDEN (F.)

TheDeeps of Deliverance.

FLETCHER (J. S.)

Grand Relations.

The Queen of a Day.

GREEN (A. KATHERINE).

The Filigree Ball.

GRIFFITHS (MAJ. ARTHUR.)

A Royal Rascal.

H.ALES (A. G.).

The Watcher on the Tower.

HOBBES (JOHN OLIVER).

The Flute of Pan.

Love and the Soul Hunters.

The Princess of Bene-

The Vineyard. [vento.
Cr. 8vo, cloth. each 6/-

HOCKING (SILAS K.).

Meadow-sweet and Rue.

HORNIMAN (ROY).

That Fast Miss Blount.

The Living Buddha.

IRWIN (H. C.).

With Sword and Pen.

KEARY (C. F.).

High Policy.

LANGBRIDGE (ROSAMOND).

The Third Experiment.

LITTLE (MRS. ARCHIBALD).

A Millionaire's Courtship.

MACK (LOUISE).

An Australian Girl in London.

MEADE (L. T.)

Love Triumphant.

MONTGOMERY (K. L.).

Major Weir.

MOORE (GEORGE).

The Untilled Field.

MURRAY (J. CLARK).

Five Talents.

PRAED (MRS. CAMPBELL). Nyria.

RICHARDSON (MRS.

AUBREY).

They Twain.

RICHINGS (EMILY).

In Chaucer's Maytime.

ROOSEVELT (FLORENCE).

The Siren's Net.

RUSSELL (W. CLARK).

Yarn of Old Harbour Town.

STACPOOLE (H. DE VERE).

Fanny Lambert.

The Lady Killer.

STEVENS (NINA).

The Perils of Sympathy.

STRAIN (E. H.).

Laura's Legacy.

TAYLER (F. JENNER).

The Long Vigil.

TROWBRIDGE (W. R. H.).

A Dazzling Reprobate.

The Situations of Lady Patricia.

TRUSCOTT (L. PARRY).

Motherhood.

Stars of Destiny.

VIELE (HERMAN K.).

Myra of the Pines.

WHITECHURCH.

The Canon in Residence.

YEIGH (KATE WESTLAKE).

A Specimen Spinster.

YSTRIDDE (G.).

Three Dukes. 
UNWIN'S SHILLING REPRINTS

Cr. 8vo, cloth.

CROCKETT (S. R.).

The Stickit Minister.

FALCONER (LANOE).

Mademoiselle Ixe, and the Hotel d'Angleterre.

GORIKY (MAXIM).

Three of Them.

The Outcasts, and other Stories.

The Man who was afraid (Foma Gordyeeff).

HOBBES (JOHN OLIVER).

Love and the Soul Hunters.

Some Emotions and a Mioral, and The Sinner's Comedy.

UNWIN'S SIXPENNY EDITIONS.

Canon in Residence, The. By Victor L. Whitechurch.

Cardinal's Pawn, The. By K. L. Montgomery.

Crimson Azaleas, The. By H. cle Vere Stacpoole.

De Omnibus and Another Englishwoman's Love Letters. By Barry Pain.

Eben Holden. By Irving Bacheller. 393rd Thousand.

Evelyn Innes. By Geo. Moore.

Fanny Lambert. By $H$. de Vere Stacpoole.

Filigree Ball, The. By Anna Katherine Green.

Gods, Some Mortals, and Lord Wickenham, The. By John Oliver Hobbes (Mrs. Craigie)

Grand Relations. By J. S. Fletcher.

His Native Wife. By Louis Becke.

House by the River, The. By Florence Warden.

How to be Happy though Married. By E. J.Hardy.

Lady Mary of the Dark House. By Mrs. C. N. Williamson.

Lady Noggs, The. By Edgar Jepson.

Letters of Her Mother to Elizabeth. 63rd Thousand.

Life in a Crack Regiment. By Baron Von Schlicht.

OF STANDARD NOVELS.

each, net

$1 /-$

HOBBES (JOHN OLIVER).

A Study in Temptations, and A Bundle of Life.

RUTHERFORD (MARK).

The Autobiography of Mark Rutherford.

Mark Rutherford's Deliverance.

The Revolution in Tanner's Lane.

Miriam's Schooling.

Catherine Furze.

Clara Hopgood.

SCHREINER (OLIVE).

Trooper Peter Halket of Mashonaland.

In paper covers.

each

$6 d$.

Liza of Lambeth. By $W$. Somerset Maugham. Revised Edition.

Memoirs of Constantine Dix, The. By Barry Pain.

Mischief of a Glove, The. By Mrs. Philip Champion de Crespigny.

Mother of Pauline, The. By L. Parry Truscott.

Motor Cracksman, The. By Charles Carey.

Ricroft of Withens. By Halliwell Sutcliffe.

Robert Orange. By John Oliver Hobbes.

Royal Rascal, A. By Major Arthur Griffiths.

Saints in Society. By Margaret Baillie-Saunders.

School for Saints, The. By John Oliver Hobbes.

Sister Teresa. By George Moore. Revised Edition.

Some Emotions and a Moral. By John Oliver Hobbes.

Stickit Minister, The. By S. R. Crockett.

Stolen Waters. By Lucas Cleeve.

That Fast Miss Blount. By Roy Horniman.

Vineyard, The. ByJohn Oliver Hobbes.

Watcher on the Tower, The. By A. G. Hales.

Woman Thou Gavest, The. By Lady Troubridge. 
UNWIN'S SHILLING NOVELS. A new series of high-class Novels by popular writers. In paper covers (see page 87). Each net

VALENTINE. The Red Sphinx. By E. U. Valentine and S. Eccleston Harper. Cr. 8vo, cloth.

VERGA (Giovanni). Cavalleria Rusticana. - See Pscudonym Library. No. 29.

VIELE. Myra of the Pines. By Herman K. Viele. (Unwir's Red Cloth Library.) Cr. 8vo, cloth.

WARDEN. The Dazzling Miss Davison. By Florence Warden. Cr. 8vo, cloth.

The House by the River. By Florence Warden. Cr: $8 \mathrm{vo}$, cloth. Also paper covers.

The Mis-Rule of Three. By Florence Warden. Cr. 8vo, cloth.

WARRY. The Sentinel of Wessex. By C. King Warry. Cr. 8vo, cloth

WATSON (M.). Driven! By Margaret Watson. (Unwin's Green Cloth Library.) Cr. 8vo,

WATSON (J. R.). In a Man's Mind. By John Reay Watson. (Unwin's Green Cloth Library.) ' Cr. 8vo, cloth.

WELLS. Certain Personal Matters. By H. G. Wells. (Idle Hour Series. No. 5.)

Paper covers, $1 /-; \operatorname{cloth}_{H} 2 /-$

WHITE. Uncle Jem. By Hester White. Cr. 8vo, cloth.

WHITECHURCH. The Canon in Residence. By Victor L. Whitechurch. - (Unwin's Red Cloth Library.) Cr. 8vo, cloth.

Also (The Adelphi Library), cloth.

Also decorative paper covers. 1/- net.

Also paper covers

Concerning Himself. By Victor L. Whitechurch. Cr. 8vo, cloth The Locum Tenens. By Victor L. Whitechurch.' Cr. Svo, cloth WILKINS. Doctor Gordon. By Mary E. Wilkins. Cr. 8vo, cloth.

WILLIAMSON. Lady Mary of the Dark House. By. Mrs: C. N. Williamson. Cr. 8vo, cloth.

Also decorative paper covers. 1/- net.

Also paper covers

$6 /-$

$6 /-$

$3 / 6$

$6 d$.

$6 /-$

$6 /-$

6/-

$6 /-$

$6 d$.

WILLIAMSON (W. H.). The Traitor's Wife. By W. H. Williamson. Cr. 8vo, cloth.

The Prince's Marriage. By W. H. Williamson. Cr. 8vo, cloth.

$6 /-$

WILTON (Jos.). When Wheat is Green. See Pseudonym Library. $5 \mathrm{r}$.

WITT. Innocent of a Crime. By Captain Paul Witt. Cr. 8vo, cloth gilt.

WYLWYNNE. The Dream Woman. By Kythe Wylwynne. Cr. 8vo, cloth.

YEATS, (W. B.). John Sherman and Dhoya. See Pseudonym Library, No. Io.

YEIGH. A Specimen Spinster. By Kate Westlake Yeigh. (Unwin's Red Cloth Library.) Cr. 8vo, cloth.

YELLOW LIBRARY. A bijou series printed on yellow paper $\left(6 \frac{1}{2}\right.$ by $3 \frac{3}{8}$ inches).

Paper covers, $1 /-$; cloth
(I) Simon Ryan the Peterite. By Canon Augustus Jessopp, D.D.
(3) The Mystery of the Laugh- lin Islands. By Louis Becke and Walter Jeffery.

(2) Marsena. By Harold Frederic.

YSTRIDDE. Three Dukes. By G. Ystridde. (Unwin's Red Cloth Library.) Cr. 8vo, cloth. 


\section{ESSAYS, CRITICISM, PHILOSOPHY, \&c.}

BIGELOW. The Mystery of Sleep. By John Bigelow, LL.D. Cr. 8vo, cloth. $\quad$ net

BOUTMY. The English People: A Study of their Political Psychology. By Emile Boutmy, Membre de l'Institut. Translated by E. English. With an Introduction by J. E. C. Bodley. Demy 8 vo, cloth gilt.

BROOKE. The Need and Use of getting Irish Literature into the English Tongue. By the Rev. Stopford A. Brooke. 1/-; cloth

CHRISTY. Proverbs, Maxims, and Phrases of all Ages. Classified subjectively and arranged alphabetically. By Robert Christy. One vol. Cr. 8vo, cloth.

CRIMINOLOGY SERIES, THE. Large icr. 8vo, cloth. each

(1) The Female Offender. By (3) Juvenile Orfenders. By

Professor Lombroso.

(2) Criminal Sociology. By

Professor Enrico Ferri.
W. Douglas Morrison.

(4) Political Crime. By Louis Proal.

\section{[Fol full Titles see under Authors' names.]}

DETHRIDGE. The "Llicas Malet" Birthday Book. By G. Olivia Dethridge. Large cr. I2mo, cloth.

DUFFY. The Revival of Irish Literature. A Series of Addresses by Sir Chas. Gavan Duffy, and others. Paper covers, 1/-; cloth

FERRI. Criminal Sociology. By Professor Enrico Ferri. With Preface by W. Douglas Morrison. M.A. (Criminology Series. Vol. 2.) Large cr. 8vo, cloth.

Good Reading About Many Books. Nos, I, 2, and 3. By their Authors. With Portraits and Facsinile Autographs. Demy I2mo. Paper covers, $1 /$ - each net ; cloth, each net

GORDON. The Social Ideals of Alfred Tennyson. By William Clark Gordon. Large cr. 8vo, cloth.

net

HORNBY. Great Minds at One. A Year's Parallels in Prose and Verse. Compiled by F. M. Hornby. Fcap. 8vo, cloth.

JESSOPP. Frivola. By Augustus Jessopp, D.D. See also "The Yellow Library." Cr. 8vo, cloth.

Frivola, Simon Ryan, and other Papers. By Augustus Jessopp, D.D. Cr. 8vo, limp cloth.

JUSSERAND. English Essays from a French Pen. By J. J. Jusserand. Photogravure Frontispiece and 4 other full-page Illustrations. Large cr. 8vo, cloth.

LE BON. The Crowd: A Study of the Popular Mind. By Gustave Le Bon. Cr. 8vo, cloth.

Also in "Reformer's Bookshelf." Large cr. 8vo, cloth.

LEE. Baldwin : Being Dialogues on Views and Aspirations, By Vernon Lee. Demy 8vo, cloth.

Belcaro: Being Essays on Sundry Esthetical Questions. By Vernon Lee. Cr. 8ro, cloth.

Euphorion: Studies of the Antique and the Medireval in the Renaissance. By Vernon Lee. Fourth Impression، Cheap Edition. Deiny 8vo, cloth.

Gospels of Anarchy, and other Cuntemporary Studies. By Vernon Lee. Demy 8vo, cloth.

Juvenilia. Essays on Sundry Asthetical Questions. By Vernon Lee. Two vols., leather. 
LOMBROSO. The Female Offender. By Professor Iombroso. Edited, with Introduction, by W. Douglas Morrison, M.A. Illustrated. (Criminology Series. Vol. I.) Large cr. 8vo, cloth.

MALET. The "Lucas Malet" Birthday Book. Compiled by G. Olivia Dethridge. Cloth, large cr. I2mo.

MALLIK. The Problem of Existence: Its Mystery, Struggle, and Comfort in the Light of Aryan Wisdom. By Manmath C. Mallik. Demy 8vo, cloth.

MARSHALL. Aristotle's Theory of Conduct. By Thomas Marshall. Medium 8vo, cloth.

MARTINENGO-CESARESCO. The Place of Animals in Human Thought. IBy Countess Martinengo-Cesaresco. Illustrated. Demy Svo, cloth.

MASTERMAN. In Peril of Change. Essays written in Time of Tranquillity. 'By C. F. G. Masterman. Large cr. 8vo, cloth.

MENCKEN. The Philosophy of Friedrich Nietzsche. By Henry L. Mencken. Demy 8vo, cloth.

net

MORRISON. Juvenile Offenders. By W. Douglas Morrison, M.A. (Criminology Scries. Vol.3.) Large cr. 8vo, clotl.

MÜGGE. Nietzsche : His Life and Work. By M. A. Mügge, Ph.D. Demy 8vo, cloth.

MUIR. Plato's Dream of Wheels: Socrates, Protagoras, and the Hegeleatic Stranger. With an Appendix by certain Cyclic Pocts. By R. J. Muir, Magd. Coll., Oxon. Cr. Svo, cloth. net

New Spirit of the Nation, The. Edited by Martin MacDermott. (New Irish Library.) Small cr. 8vo. Paper covers, 1/-; cloth

NIETZSCHE. The Works of Friedrich Nietzsche. Uniform demy $8 \mathrm{vo}$, cloth gilt.
(I) A Genealogy of Morals and Poems.
(3) The Case of Wagner. Nietzsche contra Wagner.
(2) Thus Spake Zarathustra. A Book for All and None. The Twilight of the Idols. The Anti-Christ.

\section{(4) The Dawn of Day.}

PROAL. Political Crime. By Louis Proal. (Criminology Series. Vol. 4.) Large cr. 8vo, cloth.

RUSSELL (E.). An Editor's Sermons. By Sir Edward Russell. With an Introduction by the Lord Bishop of Hereford. Large cr. $8 \mathrm{vo}$, cloth.

RUSSELL (G. W. E.). "For Better? For Worse?": Notes on Social Changes. By George W. E. Russell. Cr. 8vo, cloth gilt.

SELL (T. Baron). A Hundred Years Hence. The Expectations of an Optimist. By T. Baron Russell. Large cr. 8vo, cloth.

SAMHAIN : An Occasional Review. Edited by W. B. Yeats. Contributors : J. M. Synge, Lady Gregory, Douglas Hyde, George Moore, Edward Martyn, and others. First Number(October, I901). Second Number (October, I902). Third Number (September, 1903). Paper covers.

net

Fourth Number (December, I904). Fifth Number (December, 1905)

SCHMIDT. Happy-Go-Lucky Land. England Through German Glasses. By Max Schmidt.

Paper covers, $1 /-$; cloth

Society in the New Reign. By A Foreign Resident. With Photogravure Frontispiece. Demy 8vo, cloth.

THOMAS. Sex and Society. Studies in the Social Psychology of Sex. By William J. Thomas. Large cr. 8vo, cloth. net

THRING. Addresses. By Edward Thring, M.A. With Portrait. Second Edition. Small cr. 8vo, cloth.

WELLS. The Discovery of the Future. A Discourse delivered before the Royal Institution by H. G. Wells. Paper covers, $1 /$ - ; cloth 


\section{ART and MUSIC.}

BLACKER. Chats on Oriental China. By T. F. Blacker. With a Coloured Frontispiece and about 70 other Illustrations. (Unwin's "Chats" Series. Large cr. 8vo, cloth. net $5 /=$

BLOOM. Shakespeare's Church, Otherwise the Collegiate Church of the Holy Trinity of Stratford-on-Avon. An Architectural and Ecclesiastical History of the Fabric and its Ornaments. By J. Harvey Bloom, M.A. Illustrated from photographs by L. C. Keighley-Peach. Large cr. 8vo, cloth.

net

CARROLL. The Lewis Carroll Picture Book. Edited by Stuart Dodgson Collingwood. Profusely illustrated. Large cr. 8vo, cloth.

THE "CHATS" SERIES. Practical Guides for Collectors. Each volume fu'ly Illustrated. Large cr. 8vo, cloth.

(I) Chats on Enf̧lish China. By Arthur Hayden.

net $5 /-$

(2) Chats on Old Furniture. By Arthur Hayden.

(3) Chats on Old Prints. By Arthur Hayden.

(4) Chats on Costume. A Practical Guide to Historic Dress. By G. Woolliscroft Rhead.

(5) Chats on Old Miniatures. By J. J. Foster, F.S.A.

(6) Chats on SId Lace and Needlework. By Mrs. Lowes.

(7) Chats on Oriental China. By J. F. Blacker.

In Preparation:-

Chats on Book-Plates. By H. K. Wright.

Chats on Earthenware. By Arthur Hayden.

DITTRICH. Tha Horse : A Guide to its Anatomy for Artists. IIo Drawings (reproduced by Photo Lithography) by Hermann Dittrich, with Explanatory Notes by Prof. Ellenberger and Prof. Baum. In portfolio, quarto.

van DYKE. Modern French Masters. A series of Biographical and Critical Reviews. By American Artists. With 37 Wood Engravings by Timothy Cole and others, and 28 Half-Tone Illustrations. Edited by John C. van Dyke. Royal 8vo, elegantly bound in cloth gilt.

Old Dutch and Flemish Masters. The Text by John C. van Dyke, and the Notes on the Pictures by Timothy Cole. Imp. 8vo, cloth elegant.

ERSKINE. Lady Diana Beauclerk: Her Life and Work. By Mrs. Steuart Erskine. Illustrated with Coloured Flates, and many reproductions in halt tone. Royal 4 to.

Also a Fine Edition.

FISHER. The Harrison Fisher Book. A Collection of Drawings in Colours and Black and White. With an Introduction by James B. Carrington. Quarto

FITZGERALD. Robert Adam, Artist and Architect: His Works and his System. By Percy Fitzgerald, M.A., F.S.A. With collotype plates, and many other illustrations. Cr. 4to, cloth. net 10/6

FOSTER. Chats on Oid Miniatures. By J. J. Foster, F.S.A. Copiously illustrated with examples from celebiated collections. (Unwi:1's "Chats" Series.) Large cr. 8vo, cloth. net Special Large Paper Edition. Medium 8vo. With 8 Illustrations in Coloured Collotype and about 100 reproductions in Black and White. 
FURNISS. Harry Furniss at Home. By Himself. With over 120 Illustrations. Medium $8 \mathrm{vo}$, cloth gilt.

The Confessions of a Caricaturist. Being the Reminiscences of Harry Furniss. Illustrated with over 300 Illustrations, many made specially for the volume. In 2 vols. Super royal 8 vo. New and Cheap Edition in I vol., medium 8vo, cloth.

GRAVES. The Irish Song Book, with Original Irish Airs. Edited by Alfred Perceval Graves. Eighth Impression. (New Irish Library.)

Paper covers, $1 /$ - ; cloth

$2 /-$

GWYNN. Memorials of an Eighteenth Century Painter (James Northcote). By Stephen Gwynn. Fully Illustrated with Photogravures, \&c. Demy 8vo, cloth gilt.

HARRISON. Introductory Studies in Greek Art. By Jane E. Harrison. Fourth Edition. Map and ro Illustrations. Large cr. 8 vo, cloth.

HAYDEN. Chats on English China. By Arthur Hayden. Illustrated with over 100 Specimens of Old China, and with over 150 China Marks. Three-colour Frontispiece. (Unwin's "Chats" Series.) Large cr. 8vo, cloth gilt.

Chats on Old Furniture. By Arthur Hayden. With Io6 illustrations. (Un win's "Chats" Series.) Large cr. 8vo, cloth, net

Chats on Earthenware. [In Preparation.]

Chats on Old Prints. By Arthur Hayden. With a Coloured Frontispiece and 70 full-page Plates. (Unwin's "Chats" Series.) Large cr. 8vo, cloth.

LA FARGE. An Artist's Letters from Japan. See under "Geography:"

LAWTON. The Life and Work of Auguste Rodin. By Frederick Lawton. With many Illustrations. Demy 8vo, cloth. net

LEGGE. Some Ancient Greek Sculptors. By H. Edith Legge, With a Preface by Professor Percy Gardner, and illustrated by about 40 Plates. Cr. 8vo, cloth.

LOWES. Chats on Old Lace and Needlework. By Mrs. Lowes. With a Coloured Frontispiece and about 70 other Illustrations. (Unwin's "Chats" Series.) Large cr. 8vo, cloth.

MOSCHELES. In Bohemia with Du Maurier. By Felix Moscheles. Illustrated with 63 Original Drawings by G. Du Maurier. Third Edition. Demy 8vo, cloth.

MOSSO. The Palaces of Crete and their Builders. By Angelo Mosso, Author of "The Life of Man on the High Alps." With. I87 Illustrations and 2 Plans. Royal 8vo, cloth.

NORDAU. On Art and Artists. By Max Nordau. With a Portrait Frontispiece. Large cr. 8vo, cloth.

net

PENNELL. The Illustration of Books: A Manual for the use of Students. By Joseph Pennell, Lecturer on Illustration at the Slade School, University College. With Diagrams. Cr. 8vo, cloth.

Lithography and Lithographers: Some Chapters on the History of the Art. With Technical Remarks and Suggestions by Joseph and Elizabeth Robins Pennell. Lithographic Frontispiece Portrait of Mr. Pennell by J. McNeill Whistler, and numerous Illustrations and Plates. Large royal 4 to.

Also a Fine Edition, on Japan paper. net $315 /$ - 
PENNELL The Work of Charles Keene. Introduction and Notes by Joseph Pennell, many pictures illustrative of the artist's method and vein of humour, and Bibliographical Notes by IV. H. Chesson. Large royal 4 to.

Fine Edition. net $315 /$ -

de QUEVEDO. Pablo de Segovia. By Francisco de Quevedo. Illustrated by Daniel Vierge. Introduction by Joseph Pennell. Super royal 4 to, cloth.

van RENSSELAER. English Cathedrals. Described by Mrs. van Rensselaer, and Illustrated by Charles Pennell. Royal 8vo, cloth elegant.

Hand-Book of English Cathedrals. By Mrs. van Rensselaer. Fully Illustrated. Cr. 8vo, cloth.

RHEAD. Chats on Costume : A Practical Guide to Historic Dress. By G. Woolliscroft Rhead, R.E., A.R.C.A., Lond. With a Coloured Frontispiece and many lllustrations. (Unwin's "Chats" Series.) Large cr. 8vo, cloth.

net $5 /-$

SCOTSON-CLARK. The "Halls." A Collection of Portraits of eminent Music Hall Performers, Drawn in 3 Colours by ScotsonClark. Introduction by George Gamble. Imperial 8vo, decorated title, \&c., buckrain, gilt.

SEYMOUR. Siena and Her Artists. By Frederick H. A. Seymour, Author of "Saunterings in Spain." With I6 Illustrations. Large cr. 8 vo, cloth.

STILLMAN. Old Italian Masters. By W. J. Stillman. Engravings and Notes by T. Cole. Royal 8 vo, cloth elegant.

STUART and PARKE. The Variety Stage. By C. Douglas Stuart and A. T. Parke. Cr. 8vo, cloth.

STURGIS. The Arts of Design. By Russell Sturgis, M.A., Ph.D., Fellow of the National Sculpture Society, \&c. With ro7 lllustrations. Royal 8vo, cloth.

net

VELDHEER. Old Dutch Towns and Villages of the Zuiderzee. By J. G. Veldheer. With Illustrations by J. F. Veldheer, W. J. Tuin, and W.O.J. Nieuwenkamp, and with Decorative Initials. Imperial cloth.

VIERGE. Don Quixote. By Miguel de Cervantes. With 260 Drawings by Daniel Vierge. 4 vols. Super royal 8vo. Edition limited to 155 copies.

Fine Edition (limited to ro copies) on Imperial Japan paper, with extra set of fult-page Plates.

The Nun-Ensign. Translated from the Original Spanish with an Introduction and Notes by James Fitzmaurice-Kelly, Fellow of the Brilish Academy. Also La Monja Alferez, a Play in the Original Spanish by D. Juan Perez de Montalban. With Illustrations by Daniel Vierge, Illustrator of "Pablo de Segovia" and "Don Quixote." Large cr. 8vo, cloth.

net

VILLARI. Giovanni Segantini: His Life and Work. Edited by Luigi Villari. With upwards of 80 Illustrations reproduced direct from the original paintings. In one volume. With Photogravure Frontispiece. Imperial 8 vo, with specially designed cover, and boxed, net 21/-

The Westminster Cathedral. A Free Criticism. By an Architectural Student. With 9 Plates. Quarto, cloth. 


\section{BIOGRAPHY, MEMOIRS, CORRESPONDENCE, \&C.}

ADAM. My Literary Life. By Madame Edmond Adam. (Juliette Lamber). 8vo, cloth, gilt top, with Portraits. net

Robert Adam, Artist and Architect. By Percy Fitzgerald. See under "Art."

ADVENTURE SERIES, The. See at the end of this Section.

AUSTIN (Mrs. Sarah). See Ross, "Three Generations."

BAMFORD'S Passages in the Life of a Radical. See under "Politics."

BEACONSFIELD. Lord Beaconsfield. By T. P. O'Connor. Popular Edition. With Frontispiece. Large cr. 8vo, cloth. net BEARNE (Mrs.) Works. See under "History."

BEAUCLERK (Lady Diana). By Mrs. Steuart Erskine. See under "Art."

BELGIOJOSO. A Revolutionary Princess : Christina BelgiojosoTrivulzio. Her Life and Times (1808-1871). By H. Remsen Whitehouse. With Photogravure Frontispiece and many other Illustrations. Demy 8vo, cloth.

$8 / 6$

BERNARD. Claude Bernard. By Sir Michael Foster. With Photo-
gravure Frontispiece. (Masters of Medicine. Vol. 6.) Large cr. 8 vo, cloth.

BESANT. Annie Besant: An Autobiography. New Edition, with a new Preface. Illustrated. Large cr. 8vo, cloth. net

BRADLAUGH. Charles Bradlaugh: A Record of His Life and Work. By His Daughter, Hypatia Bradlaugh Bonner. 2 vols. (Reformer's Bookshelf.) Large cr. 8vo, cloth.

Also in Unwin's Half-Crown Standard Library. I vol. Cloth. net

BRIGHTWEN. The Life and Thoughts of a Naturalist. Mrs. Brightwen. Edited by W. H. Chesson. With Portrait and Illustrations, and an Introduction by Edmund Gosse. Large cr. 8vo, cloth.

BRODIE. Sir Benjamin Brodie. By Timothy Holmes. With Photogravure Frontispiece. (Masters of Medicine. Vol. 5.) Large cr. Svo, cloth.

BROOKE. Rajah Brooke: The Englishman as Ruler of an Eastern State. By Sir Spencer St. John, G.C.M.G. With Frontispiece and Maps. (Builders of Greater Britain. Vol. 7.) Large cr. 8vo, cloth.

BROWN. Captain John Brown of Harper's Ferry. By John Newton. Fully Illustrated. Cr. 8vo, cloth.

"John Brown's body lies a 'mould'ring in the grave But his soul's marching on."

Also (Lives Worth Living Series).

BUCHANAN. Robert Buchanan: Some Account of His Life, His Life's Work, and His Literary Friendships. By Harriett Jay. Illustrated with Portraits and from other sources. Demy 8vo, cloth. net

BUILDERS OF GREATER BRITAIN. Edited by H. F. Wilson. A Set of 8 volumes, with Photogravure Frontispiece and Maps to each. Large cr. 8vo, cloth. each. Large cr. 8vo, cloth.
(I) Sir Walter Ralegh.
(2) Sir Thomas Maitland.
(3) John and Sebastian Cabot.
(4) Edward Gibbon Wakefield.
(5) Lord Clive.
(6) Admiral Phillip.
(7) Rajah Brooke.
(8) Sir Stamford Raffles.

\section{$5 /-$


BURTON. The Real Sir Richard Burton By Walter Phelps Dodge. With a Frontispiece. Large cloth. 2 net

CABOT. John and Sebastian Cabot; the Discovery of North America. By C. Raymond Beazley, M.A. With Frontispiece and Maps. (Builders of Greater Britain. Vol. 3.) Large cr. 8vo, cloth.

CARLYLE. The Story of Thomas Carlyle. By A.S. Arnold: With 6 Illustrations. (Lives Worth Living Series. Vol. II.) Cr. 8vo, cloth.

CARROLL. The Life and Letters of Lewis Carroll (G. L. Dodgson). By S. D. Collingwood. With about 100 Illustrations. Large cr. 8 vo, cloth.

CESARESCO. Italian Characters in the Epoch of Unification. By Countess Martinengo Cesaresco. Cheap Edition. Demy 8vo, cloth.

CHEVALIER. Before I Forget. Being the Autobiography of a Chevalier d'Industrie. Written by Albert Chevalier. Very fully Illustrated. Demy 8vo.

CLIVE. Lord Clive: The Foundation of British Rule in India. By Sir A. J. Arbuthnot, K.C.S.I., C.I.E. With Frontispiece and Maps. (Builders of Greater Britain. Vol. 5.) Large cr. 8vo, cloth.

COBDEN. The Life of Richard Cobden. By the Right Hon. John Morley, M.A. (Oxford), Hon. LL.D. With Photogravure Portrait from the Original Drawing by Lowes Dickinson. Jubilee Edition. (Reformer's Bookshelf.) 2 vols. Large cr. 8vo, cloth.

New Binding. Demy 8 vo, cloth.

New Popular Unabridged Edition in I vol. Large cr. 8vo, cloth. net

The "Free Trade" Edition. Popular Re-issue, abridged. Demy 4to. Paper covers.

Special Edition, in 5 Parts. Demy 8vo, paper covers. Each, net Cobden as a Citizen. A Chapter in Manchester History. Containing a facsimile of Cobden's pamphlet, "Incorporate Your Borough !" with an Introduction and a complete Cobden Bibliography, by William E. A. Axon. With 7 Photogravure Plates and 3 other Illustrations. Demy 8vo, full vellum or buckram. net Richard Cobden and the Jubilee of Free Trade. See under "Politics."

Cobden's Work and Opinions. By Welby and Mallet. See under "Politics."

The Political Writings of Richard Cobden. See under "Politics."

COILLARD. Coillard of the Zambesi. The Lives of François and Christina Coillard, of the Paris Missionary Society (1834-1904). By C. W. Mackintosh. With a Photogravure Frontispiece, a Map, and $6+$ other Illustrations. Demy $8 \mathrm{vo}$, cloth.

COLERIDGE. The Story of a Devonshire House. By Lord Coleridge, K.C. Illustrated. Demy 8 vo, cloth.

CREMER. Life of W. Randal, See page 42.

CROMWELL. Oliver Cromwell and His Times. By G. Holden Pilie. Cr. 8vo, cloth. Illustrated: Also "Lives Worth Living" Series.

DSON. Memorials of Thomas Davidson the Wandering Scholar. Collected and Edited by William Knight, LL.D., formerly Professor of Moral Philosophy in the University of St. Andrews. With a Portrait. net Duffy. (New Irish Library. Vol. Io.) Small cr. \&vo.

Paper covers, $1 /-$; cloth 2/- 
DAVITT. Michael Davitt: Revolutionary, Agitator, and Labour Leader. See "Sheehy-Skeffington."

DE LA REY. A Woman's Wanderings and Trials During the Anglo-Boer War. By Mrs. (General) De La Rey. Illustrated. 2nd Edition. Cr. 8 vo, cloth.

DOYLE. Bishop Doyle. By Michael MacDonagh. (Nerv Irish Library. Vol. II.) Small cr. 8vo. Paper covers, 1/ ; cloth

DUFFY. My Life in Two Hemispheres. By Sir Charles Gavan Duffy, K.C.M.G. Two vols. demy 8 vo, cloth.

Cheap Edition. 2 vols. (Reformer's Bookshelf.) Large cr, 8vo, cloth. DU MAURIER. By Felix Moscheles. See under "Art."

ELIZABETH. The Correspondence of Princess Elizabeth of England, Landgravine of Hesse-Homburg, for the most part with Miss Louisa Swinburne. With Portraits, and Edited with Preface by Philip C. Yorke, M.A., Oxon. With a Photogravure and other Illustrations. Demy 8vo, cloth.

EVANS. The Memoirs of Dr. Thomas W. Evans. Recollections of the Second French Empire. Edited by Edward A. Crane, M.D. Illustrated. 2 vols. Demy 8vo, cloth.

FITCH. Ralph Fitch: England's Pioneer to India and Burma. His Companions and Contemporaries. By J. Horton Ryley, Member of the Hakluyt Society. With I6 full-page and 3 smaller Illustrations. Large cr. 8vo, cloth.

FITZMAURICE-KELLY. The Nun-Ensign, Translated from the Original Spanish with an Introduction and Notès by James Fitzmaurice-Kelly, Fellow of the British Academy. Also La Monja Alferez, a Play in the Original Spanish by D. Juan Perez de Montalban. With Illustrations by Daniel Vierge, Illustrator of "Pablo de Segovia" and "Don Quixote." Large cr. 8vo, cloth. net

FULLER. The Love-Letters of Margaret Fuller (1845-1846). With an Introduction by Julia Ward Howe. To which are added the Reminiscences of Ralph Waldo Emerson, Horace Greeley, and Charles T. Congdon. With Portrait. I2mo, cloth, gilt top. net

FURNISS (Harry). Confessions of a Caricaturist. See under "Art."

At Home. See under "Art."

GAMBIER. Links in My Life on Land and Sea. By Commander J. W. Gambier, R.N. With Frontispiece and 7 other Illustrations. Demy 8 vo, cloth.

Cheap Edition, with Frontispiece. (Modern Travel Series.) Large cr. 8vo, cloth.

GLADSTONE. My Memory of Gladstone. By Goldwin Smith. With Portrait. Cr. Svo, cloth

net

GORDON. The Life of General Gordon. By Demetrius C. Boulger. Illustrated. New and Cheaper Edition. Demy 8vo, cloth.

(Lady Duff). See Ross, "Three Generations."

GOETHE. Life of Goethe. By Heinrich Düntzer. Transiated by Thomas W. Lyster, Assistant Librarian, National Library of Ireland. With Authentic Illustrations and Facsimiles. (Unwin's Half-Crown Standard Library.) Large cr. 8vo, cloth. net

GOULD. Concerning Lafcadio Hearn. By G. M. Gould, M.D. With
5 Illustrations. Demy 8vo, cloth.

GRATTAN. Henry Grattan. (The Gladstone Prize Essay in the University of Oxford, 1902.) By Percy M. Roxby, Scholar of Christ Church. With Frontispiece. Cr. 8vo, cloth.

GRAY. Wise Words and Loving Deeds. See under "Lives Worth Living." 
HAECKEL. Haeckel: His Life and Work. By Wilhclm Bölsche. Translated and with an Introduction and Supplementary Chapter by Joseph McCabe. With four Coloured Frontispieces and many other Illustrations. Demy 8vo, cloth.

HARDY. The Love Affairs of Some Famous Men. By the Rev. E. J. Hardy, M.A. Imp. I6mo, cloth.

Cheaper Edition, cr. 8vo. cloth.

HARVEY. William Harvey. By D'Arcy Power. With Photogravure Frontispiece. (Masters of Medicine. Vol. 2.) Large cr. 8vo, cloth.

HELMHOLTZ. Hermann von Helmholtz. By Prof, John G. McKenclrick. With Phologravure Frontispiece. (Masters of Medicinc. Vol. 7.) Large cr. 8vo, cloth.

HILL. Sir Rowland Hill. The Story of a Great Reform. Told by his Daughter, Eleanor C. Snisth. IVith a Photogravure Frontispiece and 16 other Illustrations. Large cr. 8 ro, clotb. net

HOLYOAKE. Bygones Worth Remembering. A Sequel to "Sixty Years of au Agitator's Life." By George Jacob Holyoake. With a Photogravure Frontispiece, and 18 other Portraits. 2 vols. Demy 8 vo, cloth.

Also Reforiner's Bookshclf, 2 vols. Large cr. 8 vo, cloth.

Sixty Years of an Agitator's Life. George Jacob Holyoake's Autobiograpliy. 2 vols. (Reformer's Bookshelf.) Large cr. 8vo, cloth.

Also in Unwin's Half-Crown Standard Library. I vol. cloth. net

HORRIDGE. Lives of Great Italians. By Frank Horridge. Illustrated. Large cr. $8 \mathrm{vo}$, cloth.

Prize Edition.

HUNTER. John Hunter. By Stephen Paget. With Pliotogravure Frontispiece. (Masters of Medicine. Vol. I.) Large cr. 8vo, cloth.

IRVING. Sir Henry Irving. A Biography. By Percy Fitzgerald. With a Photogravure Frontispiece and 35 other Illustrations. Demy Svo, cloth.

JAPP. Master Missionaries. See under "Lives Worth Living."

- Labour and Victory. See under "Lives Worth Living."

Good Men and True. See under "Lives Worth Living."

JULIAN The Apostate. A Historical Study. By Gaetano Negri. Translated by the Duchess Lita-Visconti-Arese. With an Introduction by Professor Pasquale Villari. Illustrated, 2 vols. Demy 8vo, cloth.

KEENE (Charles). By Joseph Pennell and W. H. Chesson. Sec under "Art."

KERR. Commissioner Kerr-An Individuality. By G. Pitt-Lewis, K.C. With Photogravure and half-tone Portraits. Demy 8vo, cloth.

KRUGER. The Memoirs of Paul Kruger. Four Times President of the South African Republic. Told by Himself. Translated by A. Teixeira de Mattos. WVith Portraits and Map. 2 vols. Demy 8vo, cloth gilt.

Also a Fine Edition on Japan paper. Price on application.

LAURENSON. Memoirs of Arthur Laurenson. Edited by Catherine Spence. With Portrait. Cr. 8vo, cloth.

LEAR. The Letters of Edward Lear (Author of "The Book of Nonsense") to Chichester Fortescue, Lord Carlingford, and Frances, Countess IValdegrave (I848 to 1864). Edited by Lady Strachey (of Sutton Court). With a Photogravure Frontispiece, 3 Coloured Plates, and many other Illustrations. Demy $8 \mathrm{vo}$, cloth.

net $15 /$ - 
LINCOLN. Abraham Lincoln. A History. By John G. Nicolay and Colonel John Hay. With many full-page Illustrations,' Portraits and Maps. Io vols. Royal $8 \mathrm{vo}$, cloth.

"LIVES WORTH LIVING," THE, Series of Popular Biographies. Illustrated. Cr. 8vo, cloth extra, gilt edges. per vol.

(I) Leaders of Men. By H. (7) Good Men and True. A. Page.

(2) Wise Words and Loving Deeds. By E. Conder Gray. By Alex. H. Japp, LL.D.

(8) Famous Musical Composers. By Lydia Morris.

(3) Master Missionaries. studies in Heroic Pioneer Work. By A. H. Japp.

(4) Labour and Victory. By A. H. Japp, LL.D.

(5) Heroic Adventure. Chapters in Recent Explorations and Discovery. Illustrated.

(6) Great Minds in Art. By William Tirebuck.

(9) Oliver Cromwell and $\mathrm{His}$ Times. ByG. Holden Pike.

(IO) Captain John Brown. By John Nervton.

(II) Story of Thomas Carlyle. By d. S. Arno!d.

(12) Wesley and His Preachers. By G. Holden Pike.

(13) Dr.Parker \& His Friends. By G. Holden Pike.

McCARTHY. British Political Leaders. By Justin McCartlyy. Illustrated from Photographs. I,arge cr. 8 vo, cloth, gilt top. net Popular Edition.

Portraits of the Sixties. By Justin McCarthy, M.P., Author of "A History of our Own Times," \&c. Illustrated. Demy 8vo, cloth. net $3 / 6$

MACHIAVELLI. Life and Times of Niccolo Machiavelli. By Pro-

MACHIAVELLI. Life and Times of Niccolo Machiavelli. By Pro-
fessor Pasquale Villari. Revised Edition. Translated by Linda Villari. Illustrated. Demy 8vo, cloth.

Also in Unwin's Half-Crown Standard Library. I vol., cloth. net

MADDISON. The Life of W. Randal Cremer, M.P. By Fred Maddison, M.P., and Howard Evans.

MAITLAND. Sir Thomas Maitland: The Mastery of the Mediterranean. By Walter Frewen Lord. With Frontispiece and Maps. (Builders of Greater Britain. Vol. 2.) Large cr. 8vo, cloth.

MASTERS OF MEDICINE. Edited by C. Louis Taylor. Cr. 8vo, cloth. For full Titles sce under:
(I) John Hunter.
(5) Sir Benjamin Brodie.
(2) William Harvey.
(6) Hermann von Helmholtz.
(3) Sir James Y. Simpson.
(7) Claude Bernard.
(4) William Stokes.
(8) Thomas Sydenham.

MAUDE. Oriental Campaigns and European Furloughs. The Autobiography of an Indian Mutiny Veteran. By Colonel Edwin Matde, late H.M. 2nd (Leinster) Regiment. Witl a Photogravure Frontispiece. Demy 8vo, cloth. net

MOFFAT. The Lives of Robert and Mary Moffat. By their Son, John Smith Moffat. Illustrated. Cr. 8vo, cloth.

Also in Unwin's Half-Crown Standard Library. I vol, cloth. net

MORRIS. Famous Musical Composers. See under "Lives Worth Living."

NAPOLEON. Napoleon's Last Voyages. Being the Diaries of Admiral Sir Thomas Usher, R.N., K.C.B. (on board the "Undaunted") and John R. Glover, Secretary to Rear-Admiral Cockburn (on board the "Northumberland"). New Edition, with Introduction and Notes by J. Holland Rose, Litt.D., Author of "Life of Napoleon I.," \&c. Illustrated. Demy 8vo, cloth. net

NORTHCOTE (James). By Stephen Gwynn. See under "Art." 
O'NEILL. Owen Roe O'Neill. By J. F. Taylor, K.C. (New Irish Library. Vol. 8.) Small cr. 8vo. Paper covers, 1/- ; cloth

PAGE. Leaders of Men. See under "Lives Worth Living."

PARKER. Dr. Parker and his Friends. By G. Holden Pike. With Portraits. Cr. 8vo, cloth.

Also "Lives Worth Living" Series, cr. 8vo, cloth.

PHILLIP. Admiral Phillip; the Founding of New Sonth Wales. By Louis Becke and Walter Jeffery. With Frontispiece and Maps. (Builders of Greater Britain. Vol. 6.) Large cr. 8vo, cloth.

PLOWDEN. Grain or Chaff? The Autobiography of a Police Magistrate. By A. C. Plowden. With Photogravure Frontispiece. Demy 8 vo, cloth gilt.

Popular Edition, cloth.

PORTER. Life and Letters of Mr. Endymion Porter. By Dorothea Townshend. Illustrated. Demy $8 \mathrm{vo}$, cloth.

PRAED. My Australian Girlhood. By Mrs. Campbell Praed. With many Illustrations. Demy 8vo, cloth.

Popular Edition, cloth.

RAFFLES. Sir Stamford Raffles; England in the Far East. By Hugh E. Egerton. With Frontispiece and Maps. (Builders of Greater Britain. Vol. 8.) Large cr. 8vo, cloth.

RALEGH. Sir Walter Ralegh; the British Dominion of the West. By Martin A. S. Hume. With Frontispiece and Maps. (Builders of Greater Britain. Vol. x.) Large cr. 8vo, cloth.

Also in Unwin's Half-Crown Standard Library. I vol., cloth. net

RODIN. The Life of Auguste Rodin. By Frederick Lawton. With many Illustrations. Demy $8 \mathrm{vo}$, cloth.

ROSS. Three Generations of Englishwomen : Memoirs and Correspondence of Mrs. John Taylor, Mrs. Sarah Austin, and Lady Duff Gordon. By Janet Ross. New Edition, Revised and Augmented. With Portraits. Large cr. 8vo, cloth.

ROSSETTI. Letters of Dante Gabriel Rossetti to William Allingham (1854-70). Edited by George Birkbeck Hill, D.C.L., LL.D. Illustrated. Demy Svo, cloth.

SARSFIELD. Life of Patrick Sarsfield. By Dr. John Todhunter. (New Irish Library. Vol. 7.)

SAVONAROLA. The Life and Times of Girolamo Savonarola. By Prof. Pasquale Villari. Translated by Linda Villari. Fully Illustrated. Large cr. 8vo, cloth.

Also in Unwin's Half-Crown Standard Library. I vol., cloth. net

SECCOMBE. Lives of Twelve Bad Men. Edited by Thomas Seccombe, M.A. Second Edition. Cr. 8 vo, cloth.

SEGANTINI (Giovanni). By Luigi Villari. See under "Art."

de SEGOVIA (Pablo). By F. de Quevedo. Illustrated by Daniel Vierge. See under "Art."

SEYMOUR. The "Pope" of Holland House. By Lady Seymour. Biographical Introduction and Supplementary Chapter by W. P. Courtney. With a Photogravure Frontispiece and 8 other Illustrations. Demy 8vo, cloth.

SHEEHY-SKEFFINGTON. Michael Davitt: Revolutionary, Agitator, and Labour Leader. By F. Sheehy-Skeffington. With an Introduction by Justin McCarthy and a Portrait., Demy 8vo, cloth. net 
SHERVINTON. The Shervintons-Soldiers of Fortune. By Kathleen Shervinton. Illustrated. Small demy 8vo. net 10/6

SIMPSON. Sir James Y. Simpson.W By H. Laing Gordon. With Photogravure Frontispiece. (Masters of Medicine. Vol. 3.) Large cr. 8vo, cloth.

SIMPSON. The Autobiography of William Simpson, R.I. (Crimean Simpson). Edited by George Eyre-Todd. Illustrated with many Reproductions of his Pictures. Royal 8vo, cloth. net 21/-

Also a Fine Edition, limited to roo copies, printed on Arnold's unbleached, hand-made paper, with Plates on Japan paper. net

SKIPSEY (Joseph). A Memoir. See "Watson."

SMITH. Forty Years of Washington Society. From the Letters and Journals of Mrs. Samuel Harrison Smith (Margaret Bayard). Edited by Gaillard Hunt. With numerous Illustrations and Portraits. Demy 8vo, cloth. net

STANSFELD. James Stansfeld. By Jessie. White Mario. Demy Svo, cloth.

STOKES. William Stokes. By Sir William Stokes. With Photogravure Frontispiece. (Masters of Medicine. Vol. 4.) Large cr: 8 vo, cloth.

SULLIVAN. Barry Sullivan and his Contemporaries. By Robert C: 2 M. Sillard. 2 vols. Illustrated. Demy 8vo.

SWANWICK. Anna Swanwick. A Memoir and Recollections.

85 By Mary L. Bruce. Illustrated with a Photogravure Portrait; and

five others in half-tone. Cr. 8vo, cloth. net

SWIFT. Unpublished Letters of Dean Swift. Edited by George Birkbeck Hill, D.C.L., LL.D. Illustrated. Demy 8vo, cloth.

Switt in Ireland. By Richard Ashe King, M.A. (New Irish Library.) Small cr. 8vo. Paper covers, 1/- ; cloth

SYDENHAM. Thomas Sydenham. By J. F. Payne. With Photogravure Frontispiece. (Masters of Medicine. Vol. 8.) Large cr. Svo, cloth.

TAYLOR (Mrs. John). See Ross, "Three Generations."

TETLEY. Old Times and New. By J. George Tetley, D.D., Canon Residentiary of Bristol. With Frontispiece. Demy 8vo, cloth. net

TIREBUCK. Great Minds in Art. See under "Lives Worth Living."

TOURGUENEFF. Tourgueneff and his French Circle. Edited by $\mathrm{H}$. Halpérine-Kaminsky. Translated by Ethel M. Arnold. $\mathrm{Cr}$. 8 vo, cloth.

TREHERNE, Spencer Perceval. A Biography. By Philip Treherne. With portraits. Cr. 8vo, cloth. net

TROWBRIDGE (W. R. H.). Works. See under "History."

TROWBRIDGE. Mirabeau the Demi-God. Being the True and Romantic Story of his Life and Adventures. By.W. R. H. Trowbridge. With a Photogravure Frontispiece and 32 other Illustrations. Deiny 8vo, cloth.

VAMBERY. The Story of My Struggles. The Memoirs of Arminius Vambery, C.V.O. With Photogravure and other: Illustrations. 2 vols. Demy 8 vo, cloth.

Popular. Edition in I vol. Demy 8vo, cloth.

net $21 /$ net $7 / 6$

Arminius Vambery: His Life and Adventures. By Himself. Imperial I6mo, cloth.

Boys' Edition, cr. 8vo, cloth gilt, gilt edges.

VERNON. Admiral Vernon and the Navy. A Memoir and Vindication, with Sundry Sidelights. By Douglas Ford. Illustrated. Demy 8 vo, cloth.

net $10 / 6$ 
VINCENT. Twelve Bad Women: A Companion Volume to "Twelve Bad Men." Edited by Arthur Vincent. Illustrated. Large cr. 8vo, cloth.

WAKEFIELD. Edward Gibbon Wakefield; the Colonisation of South Australia and New Zealand. By R. Garnett, C.B., LL.D. With Frontispiece and Maps. (Builders of Greater Britain. Vol. 4.) Large cr. 8vo, cloth.

WALPOLE. Essays Political and Biographical. By Sir Spencer Walpole, K.C.B. Edited by Francis Holland, IVith a Memoir by his Daughter, and a Photogravure Frontispiece. Demy 8vo, cloth. net Studies in Biography. By Sir Spencer Walpole, K.C.B. With Photogravure Frontispiece. Demy 8vo, cloth. net

WASHINGTON. From Slave to College President. Being the Life Story of Booker T. Washington. By G. Holden Pike. With Frontispicce. Cr.8vo, half-bound cloth.

- The Youth of George Washington. Told in the form of an Autobiography. By S. Weir Mitchell. Large cr. 8vo, cloth.

WATSON. The Savage Club. A Medley of History, Anecdote and Reminiscence. By Aaron Watson. With a chapter by Mark Twain, and a Photogravure Frontispiece, 4 Coloured Plates, and 64 other Illustrations. Meclium 8vo, cloth. net

WATSON. Joseph Skipsey, a Memoir. By the Rt. Hon. Robert Spence Watson. With 3 Portraits. Crown 8vo, cloth. net

WESLEY and his Preachers: Their Conquest of Britain. By G. Holden Pike. Fully Illustrated. Cr. 8vo, cloth.

Also "Iives Worth Living" Series.

WILBERFORCE. The Private Papers of William Wilberforce. Collected and Edited by A. M. Wilberforce. Illustrated. Demy 8 vo, cloth.

WILKINSON. The Personal Story of the Upper House. By Kosmo Wilkinson. Demy 8vo, cloth.

UNWIN'S HALF-CROWN STANDARD LIBRARY OF HISTORY AND BIOGRAPHY. Illustrated. Large $\mathrm{cr} .8 \mathrm{vo}$, cloth. each, net $2 / 6$

(1) The Life of Richard Cobden. By the Right Hon. John Morley.

(2) The Life of Girolamo Savonarola. By Professor Pasquale Villari.

(3) The Life of Niccolo Machiavelli. By Professor Pasquale Villari.

(4) The Lives of Robert and Mary Moffat. By John Simith Moffat.

(5) The History of Florence (for the first two centuries). By Prof. Pasquale Villari.

(6) English Wayfaring Life in the Middle Ages (XIVth Century). By J. J. Jusserand.

(7) Lord Beaconsfield. By T. P. O'Connor.
(8) Rome and Pompeii : Archaeological Rambles. By Gaston Boissier.

(9) Hol, oake : Sixty Years of an Agitator's Life. By George Jacob Holyoake.

(10) Sir Walter Ralegh. By Martin A. S. Hume.

(II) The Dawn of the Nineteenth Century in Eng. land. By John Ashton.

(12) Life of Goethe. By Heinrich Düntzer.

(13) Charles Bradlaugh. By Hypathia Bradlaugh Bonner

(14) Augustus. The Life and Times of the Founder of the Roman Empire. By E. S. Shuckburgh. 
ADVENTURE SERIES, THE. Popular Re-issuc. Large cr. 8 vo, fully Illustrated, cloth.

Per vol.

(I) Adventures of a Younger Son. By Edward J. Trelawny. Introduction by Edward Garnett.

(2) Madagascar; or, lir be $t$ Drury's Journal during his Captivity on that Island. Preface and Notes by Captain S. P. Oliver, R.A.

(3) Memoirs of the Extraordinary Military Career of John Shipp. Written by Himself. Introduction by H. Manners Chichester.

(4) The Buccaneers and Marooners of America. Edited and Illustrated by Howard Pyle.

(5) The Log of a Jack Tar: Being the Life of James Choyce, Master Mariner. Edited by Commander V. Lovett Cameron.

(6) Ferdinand Mendez Pinto, the Portuguese Adventurer. New Edition. Annotated by Prof. Arminius Vambéry.

(7) Adventures of a Blockade Runner. By William Watson. Illustrated by Arthur Byng, R.N.
(8) The Memoirs and Travels of Count de Benyowsky in Sibcria, Kamtschatka, Japan, the Liukiu Islands, and Formosa. Edited by Caplain S. P. Oliver, R.A.

(9) The Life and Adventures of James P. Beckwourth. New Edition. Edited and with Preface by C. G. Leland ("Hans Breitmann")

(Io) A Particular Account of the European Military Adventurers of Hindustan (1784-1803). Compiled by Henry Compton. New and Cheaper Edition. Maps and Illustrations.

(II) A Master Mariner. The Life of Captain Robert W. Eastwick. Edited by Herbert Compton.

(12) Kolokotrones: Klepht and Warrior. Translated from the Greek by Mrs. Edmonds. Introduction by M. Gennadius.

(13) Missing Friends. The Adventures of an Emigrant in Queensland.

The following Volumes are done at 5/- only.

The Escapes of Latude and Casanova from Prison. Edited, with Introduction, by P. Villars.
The Story of the Filibusters. By James Jeffrey hoche. And, The Life of Colonel David Crockett.

The following Volumes are done at $7 / 6$ each.

The Women Adventurers. Edited by Menie Muriel Dowie.

The Life and Adventures of James Beckwourth. Mountaineer,Scout, Pioneer, and Chief of the Crow Nation of Indians. Edited by Charles G. Leland " Hans Breitmann").
A Particular Account of the European Military Adventurers of Hindustan (1784. 1803). Compiled by Henry Compton. New and Cheaper Edition. Maps and Illustrations.

Famous Prison Escapes of the Civil War. Edited by G. W. Cable. 


\section{HISTORY and HISTORICAL LITERATURE.}

ARCHER and KINGSFORD. The Crusades: The Story of the Latin Kingdom of Jerusalem. By T. A. Archer and Charles Lethbridge Kingsford. Third Impression. With $5^{8}$ Illustrations and 3 Maps. (Story of the Nations. Vol. 40.) Large cr. 8vo, cloth.

ASHTON. The Dawn of the Nineteenth Century in England : A Social Sketch of the Times. By John Ashton. Third Edition. Illustrated. Large cr. 8vo, cloth.

Cheap Edition, "England Ioo Years Ago."

Also in Unwin's Hall-Crown Standard Library. I vol., cloth. " net

BARING-GOULD. Germany. By S. Baring-Gould, M.A. Seventh Impression. With I08 Illustrations and Maps. (Story of the Nations. Vol. 3.) Large cr. 8vo, cloth.

BARRY. The Papal Monarchy : From Gregory the Great to Boniface VIII. (590-I303). By William Barry, D.D. With 6r Illustrations and Maps. (Story of the Nations. Vol. 58.) Large cr. 8vo, cloth.

BATESON. Mediæval England (1066-1350). By Mary Batèson, Associate and Lecturer of Newnham College, Cambriclge. With 93 Illustrations. (Story of the Nations. Vol. 62.) Large cr. 8vo, cloth.

BEARNE. Heroines of French Society in the Court, the Revolution, the Empire, and the Restoration. By Mrs. Bearne. With inany Illustrations. Large cr. 8vo, cloth.

A Leader of Society at Napoleon's Court (Laura Permon). By Mrs. Bearne. Filly Illustrated. Large cr. 8vo, cloth.

Lives and Times of the Early Valois Queens. By Mrs. Bearne. Illustrated by E. H. Bearne. Small demy, cloth.

Pictures of the Old French Court. By Mrs. Bearne. Second Edition, Revised. Illustrated. Small demy 8vo, cloth.

A Royal Quartette. By Mrs. Bearne. Fully Illustrated. Large cr. $8 \mathrm{vo}$, cloth.

A Sister of Marie Antoinette. The Life Story of Maria Carolina, Queen of Naples. By Mrs. Bearne. Fully Illustrated. Large cr. 8vo, cloth.

A Queen of Napoleon's Court: The Life Story of Désirée Bernadotte. By Mrs. Bearne. Fully Illustrated. Large cr. 8vo, cloth.

BENJAMIN. Persia. By S. G. W. Benjamin, late U.S. Minister to Persia. Fourth Edition. With 56 Illustrations and Maps. (Story of the Nations. Vol. I7.) Large cr. 8vo, cloth.

BIRCH. History of Scottish Seals, from the Eleventh to the Seventeenth Century. By Walter de Gray Birch, LL.D., F.S.A,; of the British Museum. With many Illustrations derived from the finest and most interesting examples extant. Vol. I, 'The Royal Seals of Scotland. Crown 4 to, buckram, gilt top.

Also a Fine Edition on large paper.

BLISS. Turkey and the Armenian Atrocities. By Edwin M. Bliss. Introduction by Frances E. Willard. Cloth gilt. 
BLUNT. Secret History of the English Occupation of Egypt. Being a Personal Narrative of Events. By Wilfrid Scawcn Blunt. Second Edition; Revised, with an Introduction by Sir William F, Butler, K.C.B. With a Photogravure Frontispiece. Demy 8vo, cloth.

BOISSIER (Gaston). The Country of Horace and Virgil. See under "Geography."

Rome and Pompeii. See under "Geography."

BOURINOT. Canada. By Sir Joln Bourinot, K.C.M.G. With 63 Illustrations and Maps.: New Edition, with a new Map, and revisions and a supplementary chapter by Edward Porritt. (Story of the Nations. Vol. 45.) Large cr. 8vo, cloth.

BOXALL. The Anglo-Saxon : A Study in Evolution. By George E. Boxall. Crown 8vo, cloth.

The History of the Australian Bushrangers. By G. E. Boxall. Large cr. 8vo, cloth.

BOYESEN. A History of Norway. From the Earliest Times. By Professor Hjalmar H. Boyesen. With a Chapter by C. F. Keary. With 77 Illustrations and Maps. (Story of the Nations. Vol: 55.) Large cr. 8vo, cloth.

BRADLEY. The Goths. From the Earliest Times to the End of the Gothic Dominion in Spain. By Henry Bradley. Fifth Edition. With 35 Illustrations and Maps. (Story of the Nations. Vol. 12.) Large cr. 8vo, cloth.

BRERETON. The Literary History of the Adelphi and its Neighbourhood. By Austin Brereton. Wilh a new Introduction, a Photogravure Frontispiece, and 26 other full-page Illustrations. Demy 8vo, cloth.

BROOKS. Dames and Daughters of the French Court. By Geraldine Brooks. With a Photogravure Frontispiece and 1o other Illustrations. Large cr. $8 \mathrm{vo}$, cloth.

net

BROWNE. Bonaparte in Egypt and the Egyptians of To-day. By Haji A. Browne. With Frontispiece. Demy 8vo, cloth. net 10/6 BUEL (Clarence C.). See "Johnson."

BUTLER. The Lombard Communes. A History of the Republics of North Italy. By W. F. Butler. W'ith Maps and Illustrations. Demy 8vo, cloth.

BUTLER. Wellington's Operations in the Peninsula (1808-1814): By Captain Lewis Butler. With Maps. 2 vols. Demy 8vo, cloth. net Also in Six paper Parts.

each, net

CARSE. All the Monarchs of Merry England. William I. to Edward VII. By Roland Carse. With 40 full-page Coloured Illustrations by W. Heath Robinson. 252 pages, bound in full leather and gold-blocked.

The Monarchs of Merry England. William I. to Richard III. By Roland Carse. With 20 full-page Coloured Illustrations by W. Heath Robinson. I24 pages, bound in full cloth.

Also bound in art picture boards, cloth back.

More Monarchs of Merry England. Henry VII. to Edward VII. By Roland Carse. With 20 full-page Coloured Pictures by W. Heath Robinson. 128 pages, bound in full cloth.

Also bound in picture boards, cloth back.

The Monarchs of Merry England. In Four Parts, each containing Io full-page Coloured Illustrations by W. Heath Robinson. 60 pages, bound in art picture boards, cloth back.

Part I. William I, to Henry III.

2. Edward I. to Richard III.

" 4. James I. to Edward VII. 
CESARESCO. Lombard Studies. By Countess Evelyn Martinengo Cesaresco. Photogravure Frontispiece, and many other Illustra. tions. Demy $8 \mathrm{vo}$, cloth.

CHURCH. Carthage; or, the Empire of Africa. By Professor Alfred J. Church, M.A. Eighth Edition. Will the Collaboration of Arthur Gilman, M.A. With 43 Illustrations and Maps. (Story of the Nations. Vol. 4.) Large cr. 8vo, cloth.

Early Britain. By Professor Alfred J. Church, M.A., Author of "Carthage," \&c. Sixth Impression. Vith 57 Illustrations and Maps. (Slory of the Nations. Vol. 2r.) Large cr. 8vo, cloth.

CLAYDEN. England Under the Coalition: The Political History of England and Ireland from 1885 to 1892 . By P. W. Clayden. Sinall demy 8 vo, cloth.

CLERIGH. History of Ireland to the Coming of Henry II. By Arthur Ua Clerigh, M.A., K.C. Demy $8 \%$, cloth.

COLERIDGE. The Story of a Devonshire House. By Lord Coleridge, K.C. Illustrated. Demy Svo, cloth.

COPINGER. The Manors of Suffolk. Notes on their History and Devolution and their Several Lords. The Hunclreds of Babergh and Blackbourn. By IV. A. Copinger, LL.D., F.S A., F.R.S.A. Illustrated. Folio, cloth.

net 21/-

CRICHFIELD. The Rise and Progress of the South American Republics. By George W. Crichfield. Illustrated. 2 vols. Royal $8 \mathrm{ro}$, cloth.

DAVIDS Buddhist India. By T. W. Rhys Davids, LL.D., Ph.D. IVith 57 Illustrations and Maps. (Story of the Nations. Vol. 6r.) Large cr. Svo, cloth.

DAVIS. The Patriot Parliament of 1689 , with its Statutes, Votes and Proceedings. By Thomas Davis. Edited by Ch. G. Duffy. Third Edition. (New Irish Library. Vol. I.) Small cr. 8vo.

Paper covers, $1 /-$; cloth

DIEULAFOY. David the King: An Historical Inquiry. By Marcel Auguste Dieulafoy. (Membre de l'Institut.) Translated by Lucy Hotz. Small demy 8vo, cloth. net

DODGE. From Squire to Prince: Being the Rise of the House of Aiksena. By Walter Phelps Dodge. Illustrated. Demy 8vo, cloth

DOUGLAS. China. By Prof. Robert K. Douglas. Third Edition. With a new preface and a chapter on recent events. With 5 I lllustrations and a Map. (Story of the Nations. Vol 5i.) Large cr. 8vo, cloth.

DUFFY (B.). The Tuscan Republics (Florence, Siena, Pisa, and Lucca) with Genoa. By Bella Duffy. With 40 Illustrations and Mups. (Story of the Nations. Vol. 32.) Large cr. 8vo, cloth.

Also Tourist Edition in Baedeker Binding.

DUFFY (Ch. G.). Young Ireland: A Fragment of Irish History. By the Hon. Sir Charles Gavan Duffy. Illustrated. Two Parts, in stiff wrapper.

In one Volume, demy $8 \mathrm{vo}$, cloth.

EDWARDS. A Short History of Wales. By Owen M. Edwards, Lecturer on Modern History at Lincoln College, Oxford. With Maps. Cr. 8vo, cloth.

net

Wales. By Owen M. Edwards. IVith 47 Illustrations and 7 Maps. (Story of the Nations. Vol. 56.) Large cr. 8vo, cloth.

ESCOTT. Society in the Country House. Anecdotal Records of Six Centuries. By T. H. S. Escott, Author of "King Edward and His Court," \&c. With Photogravure Frontispiece. Demy 8vo, cloth. 
FITZGERALD. Lady Jean : The Romance of the Great Douglas Cause. By Percy Fitzgerald, F.S.A. With Photogravure Frontisplece and other Illustrations. Demy 8vo, cloth.

FORREST. The Development of Western Civilization. By J. Dorsey Forrest. Large cr. 8vo, cloth:

FOSTER. The Stuarts. Being Outlines of the Personal History of the Family from James V. to Prince Charles Edward. By J. J. Foster, F.S.A. Illustrated with 30 full-page Photogravure Plates. Cloth. net

FRAZER. British India. By R. IV. Frazer, LL.D. Third Edition. With 30 Illustrations and Maps. (Story of the Nations. Vol. 46.) Large cr. 8vo, cloth.

FREEMAN. Sicily: Phœnician, Greek, and Roman. By Prof. Edward A. Freeman, M.A., Hon. D.C.L., LL.D., Oxford. Third Edition. With 45 Illustrations. (Story of the Nations. Vol. 3I.). Large cr. 8 vo, cloth.

Also Tourist Edition in Baedeker Binding.

GANNON. A Review of Irish History in Relation to the Social Development of Ireland. By John P. Gannon. 288 pp., cr. 8vo, green buckram.

GARDNER. A History of Jamaica. "From its discovery by Christopher Columbus to the year 1872. By W. J. Gardner. Large cr. 8vo. net

GILMAN. Rome: From the Earliest Times to the End of the Republic. By Arthur Gilman, M.A. Third Edition. With 43 Illustrations and Maps. (Story of the Nations. Vol. I.) Large cr. 8vo, cloth.

The Saracens: From the Earliest Times to the Fall of Bagdad. By Arthur Gilman, M.A. Fourth Edition. With 57 Illustrations and Maps. (Story of the Nations. Vol. 9.) Large cr. 8vo, cloth.

GOMME. The Governance of London. Studies of the place of London in English Institutions. By G. Lawrence Gomme, F.S.A. With Maps. Demy 8vo, cloth.

GORDON. The Old Bailey and Newgate. By Charles Gordon. With about 100 Illustrations and a Frontispiece in tint. Med. 8vo, cloth. net

Old Time Aldwych, Kingsway, and Neighbourhood. By Charles Gordon. Fully Illustrated and with Map. Medium 8vo, cloth, net Popular Edition. Fully illustrated and with Map. Medium 8vo, cloth.

GRAY. The Buried City of Kenfig. By Thomas Gray. With a Map and Illustrations. Demy 8vo, cloth.

GRIFFITHS. Famous British Regiments. By Major Arthur Griffiths. Fully Illustrated. Cr. 8vo, cloth gilt.

HALE. Mexico. By Susan Hale. Third Impression. With 47 Illustrations and Maps. (Story of the Nations. Vol. 27.) Large cr. 8vo, cloth

HANNAH. A Brief History of Eastern Asia. By I. C. Hannah, M.A. Cr. 8vo, cloth.

HASEN. Contemporary American Opinion of the French Revolution. By Charles Downer Hasen. Demy 8vo, cloth. net

HERTZ. English Public Opinion after the Restoration. By Gerald Berkeley Hertz. Cr. 8vo, cloth. net

HOLYOAKE (G.T.). History of Co-operation. Sce under "Politics."

HOSMER. The Jews: In Ancient, Medizeval, and Modern Times. By Prof. James K. Hosmer. Seventh Edition. With 37 Illustrations and Maps. (Story of the Nations. Vol. 2.) Large cr. 8vo, cloth.

HOUGHTON. Hebrew Life and Thought. Being Interpretative Studies in the Literature of Israel. By Louis Seymore Houghton. Large cr. 8vo, cloth.

net 
HOWARD. A History of Matrimonial Institutions. By George Elliott Howard, Ph.D., University of Chicago. 3 vols. Super royal $8 \mathrm{vo}$.

HUG and STEAD. Switzerland. By Lina Hug and Richard Stead, B.A. Third Impression. With over 54 Illustrations, Maps, \&c. (Story of the Nations. Vol. 26.) Large cr. 8vo, cloth.

Also Tourist Edition in Baedeker Binding.

HUME. Modern Spain (1878-1898). By Martin A. S. Hume, F.R.H.S., Second Impression. With 37 Illustrations and a Map. (Story of the Nations. Vol. 53.) Large cr.8vo, cloth.

HUNGARY. Its People, Places and Politics. The Journey of the Eighty Club in I906. With 60 Illustrations. Demy 8vo, cloth."

JAMAICA (A History of). See "Gardner."

JAMES. The Siege of Port Arthur. Records of an Eye-Witness. By David.H. James, Special War Correspondent for the London Daily Telegrapl with the Third Japanese Army. With 4 Maps and Plans and 6 1llustrations. Demy 8vo, cloth.

JANE. The Coming of Parliament. (England from I350 to I660.) By L. Cecil Jane. With $5 \mathrm{r}$ Illustrations and I Map. (Story of the Nations. Vol. 63.) Large cr. 8vo, cloth.

JENKS. Parliamentary England. The Evolution of the Cabinet System. By Edward Jenks, M.A. With 47 Illustrations. (Story of the Nations. Vol. 6o.) Large cr. 8vo, cloth.

JESSOPP. Arcady: for Better, for Worse. By Augustus Jessopp, D.D. Seventh Edition. Cr. Svo, limp cloth, silk sewn.

Before the Great Pillage, with other Miscellanies. By Augustus Jessopp, D.D., Cr. 8vo, cloth.

New Cheap Edition, cr. 8vo, cloth.

The Coming of the Friars, and other Medizeval Sketches. By Augustus Jessopp, D.D. Cr. 8vo, limp cloth, silk sewn.

Frivola, Simon Ryan and other Papers. By Augustus Jessopp, D.D. Cr. 8vo, limp cloth.

One Generation of a Norfolk House. A contribution to Elizabethan History. By Augustus Jessopp, D.D. Large cr. 8vo, cloth.

Random Roaming, and other Papers. With Portrait. By Augustus Jessopp, D.D. Cr. 8vo, limp cloth, silk sewn.

Studies by a Recluse: In Cloister, Town, and Country. By Augustus Jessopp, D.D. Cr. 8vo, limp cloth, silk sewn.

The Triais of a Country Parson: Some Fugitive Papers. By Augustus Jessopp, D.D. Cr. 8vo, limp cloth, silk sewn.

JEWETT. The Story of the Normans. Told Chiefly in Relation to their Conquest of England. By Sarah Orne Jewett. Third Impression. With 35 Illustrations and Maps. (Story of the Nations. Vol. 29.) Large cr. 8vo, cloth.

JOHNSON and BUEL. Battles and Leaders of the American Civil War. By Robert U. Johnson and Clarence C. Buel. An Authoritative History written by Distinguished Participants on both sides, and Edited by the above. Four volumes, royal 8vo, elegantly bound. Fully Illustrated.

JONES (David Brynmor). See "Welsh People."

JONES (H. S.) The Roman Empire, B.C. 29-A.D. 476. By H. Stuart Jones, M.A. With a Map and many Illustrations. (Story of the Nations. Vol. 65.) Large cr. 8vo, cloth. 
JUSSERAND. English Wayfaring Life in the Middle Ages (XIVth Century). By.J. J. Jusserand, Conseiller d'Ambassáde. Translated from the French by Lucy. A. Toulmin Smith. With over 60 Illustrations. Large cr. 8vo, cloth./

Also in Unwin's Half-crown Standard Library. I vol. Cloth. net $2 / 6$

A French Ambassador at the Court of Charles II., Le Comte de Cominges. From his unpublished Correspondence. By 'J. J. Jusserand, Conseiller d'Ambassade. Second Edition. Large cr. 8vo, cloth.

The Romance of a King's Life. By J. J. Jusserand. With Illustrations. Fcap. 8vo, cloth.

LANE-POOLE. The Barbary Corsairs. By Stanley Lane-Poole. With Additions by J. D. J. Kelly. Fourth Edition. With 39 Illustrations and Maps. (Storv of the Nations. Vol. 22.) Large cr. 8vo, cloth.

Mediæval India under Mohammedan Rule (A.D. 712-1764). By Stanley Lane-Poole. With 59 Illustrations. (Story of the Nations. Vol. 59.) Large cr. 8vo, cloth.

The Moors in Spain. By Stanley Lane-Poole. With Collaboration of Arthur. Gilman, M.A. Eighth Edition. With 29 Illustrations and Maps. (Story of the Nations. Vol. 6.) Large cr. 8vo, cloth.

Turkey. By Stanley Lane-Poole. Assisted by E. J. W. Gibb and Arthur Gilman. New Edition. With a new chapter on recent events. (Ig08.) With 43 Illustrations, Maps, \&c. (Story of the Nations. Vol. I4.) Large cr. 8vo, cloth.

LATANE. The Diplomatic Relations of the United States and Spanish America. By John H. Latane. Large cr. $8 \mathrm{vo}$, cloth. net

LAWLESS. Ireland. By the Hon. Emily Lawless. Seventh Impression. With some Addition by Mrs. Arthur Bronson. With 58 Illustrations and Maps. (Story of the Nations. Vol. 10.) Large cr. 8vo, cloth.

LEBON. Modern France (1789-1895). By André Lebon. With 26 Illustrations and a Chronological Chart of the Literary, Artistic, and Scientific Movement in Contemporary France. (Story of the Nations. Vol. 47.) Large cr. 8vo, cloth.

LEE. Studies in the Eighteenth Century in Italy. By Vernon Lee. New Edition, with a new Preface, a Photogravure Frontispiece, and 40 other Illustrations selected by Dr. Guido Biagi, of the Laurentian Library, Florence. Super royal 8vo, half-bound.

LEYDS. The First Annexation of the Transvaal. By W. J. Leyds; LL.D., formerly State Secretary of the South African Republic. Demy 8vo, cloth.

LILLY. Renaissance Types. By W. S. Lilly. Demy 8vo, cloth.
LITTLE. Mediæval Wales, Chiefly in the Twelfth and Thirteenth Centuries. By A. G. Little, M.A., F.R.Hist.S. With Maps and Plans. Cr. 8vo, cloth.

LONERGAN. Forty Years of Paris. By W. F. Lonergan. With 32 Portraits of Leading Frenchmen. Demy 8vo, cloth.

McCARTHY. Modern England (Vol. I.). Before the Reform Bill. By Justin McCarthy, M.P. Author of "The History of Our Own Times," \&c. : With 3I Illustrations. (Story of the Nations. Vol. 50.) Large cr. 8vo, cloth.

Modern England (Vol. II.). From the Reform Bill to the Present Time. By.Justin McCarthy, M.P. Second Edition. With 46 Illustrations. (Story of the Nations. Vol. 52.) Large cr. 8vo, cloth. 
MACKINTOSH. Scotland: From the Earliest Times to the Present Day. By John Mackintosh, LL.D., Author of "History of Civilisation in Scotland," \&c. Fifth Impression. With 60 Illustrations and Maps. (Story of the Nations. Vol. 25.) Large cr. 8vo, cloth.

MAHAFFY. Alexander's Empire. By John Pentland Mahaffy, D.D. With Collaboration of Arthur Gilman, M.A. With 43 Illustrations and Maps. (Story of the Nations. Vol. 5.) Eighth Impression. Large cr. 8vo, cloth.

- An Epoch in Irish History: Trinity College, Dublin, Its History and Fortunes (I59I-I660). By J. P. Mahaffy, D.D., Mus. Doc. Dublin; Hon. D.C.L., Oxon.; sometime Professor of Ancient History in the University of Dublin. Demy 8vo, cloth.

Cheap Eclition. Demy 8 vo, cloth.

net

The Particular Book of Trinity College, Dublin. A facsimile in collotype of the original copy. Edited by J. P. Mahaffy, D.D. A Companion Volume to "An Epoch in Irish History." Demy 4to.

The Progress of Het

The Progress of Hellenism in Alexander's Empire. By John Pentland Mahaffy, D.D. Large cr. 8vo, cloth. net

- The Silver Age of the Greek World. By J. P. Mahaffy. Large cr. $8 \mathrm{vo}$, cloth.

MARIO. The Birth of Modern Italy. The Posthumous Papers of Jessie White Mario. Edited with Introduction, Notes, and Epilogue, by the Dake Litta-Visconti-A rese. Illustrated. Demy' 8 vo, cloth. net

MASPERO. New Light on Ancient Egypt. By G. Maspero, DirectorGeneral of the Service of Antiquities in Egypt. Translated by Elizabeth Lee. Illustrated. Demy 8vo, cloth.

net $12 / 6$

MASSEY. Ancient Egypt, the Light of the World. A Work of reclamation and Restitution in Twelve Books. By Gerald Massey. With Diagrams. 2 vols. Super royal 8 vo, cloth.

net $42 /$ -

MASSON. Mediæval France : From the Reign of Hugues Capet to the Beginning of the Sixteenth Century. By Gustave Masson, B.A. Fifth Edition. With 48 Illustrations and Maps. (Story of the Nations. Vol. 16.) Large cr. 8vo, cloth.

MAURICE. Bohemia: From the Earliest Times to the Fall of National Independence in 1620 ; with a Short Summary of later Events. By C. Edmund Maurice. Second Impression. With $4 \mathrm{I}$ Illustrations and Maps. (Story of the Nations. Vol. 43.) Large cr. 8 vo, cloth.

MILFORD. Haileybury College. By Rev. L. S. Milford. Illustrated.

MILLER. The Balkans: Roumania, Bulgaria, Servia and Montenegro. By William Miller, M.A., Oxon. New Edition, with a new chapter containing their History from I 896 to I908. With 39 Illustrations and Maps. (Story of the Nations. Vol. 44.) Large cr. 8vo, cloth.

- Mediæval Rome : From Hildebrand to Clement VIII. I073-I535. By William Miller, M.A. With 35 Illustrations. (Story of the Nations. Vol. 57.) Large cr. 8vo, cloth.

MONARCH SERIES, THE.

Humorous Rhymes of Historical Times. By Roland Carse. With Illustrations in colour and black and white by $W$. Heath Robinson. Size $8 \frac{1}{2}$ in. by II in. (For titles of volumes see under "Carse.")

MOORE. The Story of the Isle of Man. By A. W. Moore, M.A. Illustrated. Cr. 8vo, cloth. 
MORFILL. Poland. By IV. R. Morfill, M.A., Professor of Russian and Slavonic Languages in the University of Oxford. Third Impression. With 5o Illustrations and Maps. (Story of the Nations. Vol. 33.) Large cr. 8vo, cloth.

Russia. By W. R. Morfill, M.A. Fourth Edition. WVith 60 Illustrations and Maps. (Story of the Nations. Vol. 23.) Large cr. 8 vo, cloth.

War Edition. Brought up to date and with Supplementary Chapters on the Present Situation, and Large War Map. Cloth.

MORRISON. The Jews Under Roman Rule. By IV. D. Morrison. Second Impression. With 6I Illustrations and Maps. (Story of the Nations. Vol. 24.) Large cr. 8vo, cloth.

MURRAY. Japan. By David Murray, Pl.D., LL.D., late Adviser to the Japanese Minister of Education. Third Edition. With 35 Illustrations and Maps. (Story of the Nations. Vol. 37.) Large cr. 8vo, cloth.

War Edition, with New Chapter by Joseph H. Longford, formerly British Consul at Nagasaki, and Large War Map. Cloth.

NEEDHAM. Somerset House, Past and Present. By Raymond Needham and Alexander Webster. With Photogravure Frontis. piece and many Illustrations. Demy $8 \mathrm{vo}$, cloth.

NEGRI. Julian the Apostate. A Historical Study. By Gaetano Negri. Translated by the Duchess Litta Visconti Arese. With an Introduction by Professor Pasquale Villari. Illustrated. 2 vols. Demy 8vo, cloth.

O'BRIEN. Irish Memories. By R. Barry O'Brien, Author of "The Life of Charles Stuart Parnell." With Plans. Cr. 8vo, cloth. net

O'CONNOR. The Parnell Movement: Being the History of the Irish Question from the Death of O'Connell to the Suicide of Pigott. By T. P. O'Connor, M.P. Cr. 8vo. Paper covers, $1 /-$; cloth boards

OMAN. The Byzantine Empire. By C. W. C. Oman, M.A., F.S.A., Oxford. Third Edition. With 44 Illustrations and Maps. (Story of the Nations. Vol. 30.) Large cr. 8vo, cloth.

ORSI. Modern Italy (1748-1898). By Pietro Orsi, Professor of History in the R. Liceo Foscarini, Venice. Translated by Mary Alice Vialls. With over 40 Illustrations and Maps. (Story of the Nations. Vol. 54.) Large cr. 8vo, cloth.

PAIS. Ancient Italy. Historical and Geographical Investigations in Central Italy, Magna Græcia, Sicily, and Sardinia. By Ettore Pais, Professor in the University of Rome, formerly Director of the Naples Museum. Translated by C. D. Curtis. Demy 8vo, cloth. net

Patriot Parliament of 1689, with its Statutes, Votes and Proceedings, The. (New Irish Library. Vol. I.) See under "Thomas Davis."

POTT. A Sketch of Chinese History. By the Rev. F. L. Hawks Pott, D.D. Demy 8vo, cloth.

PUSEY. The Past History of Ireland. By S. E. Bouverie-Pusey. Small cr. 8vo.

Paper covers

RAGOZIN. Assyria: From the Rise of the Empire to the Fall of Nineveh. (Continued from "Chaldea.") By Zénaïde A. Ragozin. Sixth Edition. With 8I Illustrations and Maps. (Story of the Nations. Vol. I3.) Large cr. $8 \mathrm{vo}$, cloth.

Chaldea: From the Earliest Times to the Rise of Assyria. Treated as a General Introduction to the Study of Ancient History. By Zénaïde A. Ragozin. Seventh Impression. With 80 Illustrations and Maps. (Story of the Nations. Vol. II.) Large cr. 8vo, cloth. 
RAGOZIN. Media, Babylon, and Persia: From the Fall of Nineveh to the Persian War. Including a Study of the Zend-Avesta, or Religion of Zoroaster. By Zénaïde A. Ragozin. Fourth Edition. With $7 \mathrm{I}$ Illustrations and Maps. (Story of the Nations.' Vol. 19.) Iarge cr. 8vo, cloth.

Vedic India. As Embodied Principally in the Rig.Veda. By Zénaỉde A. Ragozin. Third Edition. With 36 Illustrations and Maps. (Story of the Nations. Vol. 4I.) Large cr. 8vo, cloth.

RAWLINSON. Ancient Egypt. By Prof. Georze Rawlinson, M.A. Tenth Edition. With 50 Illustrations and Maps. (Story of the Nations. Vol. 7.) Large cr. 8vo, cloth.

Parthia. By Prof. George Rawlinson, M.A. Third Impression. With 48 Illustrations and Maps. (Story of the Nations. Vol. 34.) Large cr. $8 \mathrm{vo}$, cloth.

Phœnicia. By Prof. George Rawlinson, M.A. Third Edition. With 47 Illustrations and Maps. (Story of the Nations. Vol. I8.) Large cr. 8vo, cloth.

RHYS (John). See "IVelsh People."

RODWAY. The West Indies and the Spanish Main. By James Rodway, F.L.S. Third Impression. With 48 Illustrations and Maps. (Story of the Nations. Vol. 42.) Large cr. 8vo, cloth.

ROGERS. Holland. By Prof. James E. Thorold Rogers. Fifth Edition. With 57 Illustrations and Maps. (Story of the Nations. Vol. I5.) Large cr. 8vo, cloth.

The Industrial and Commercial History of England. By Prof. Thorold Rogers. 2 vols. (Reformer's Bookshelf.) Large cr. 8 vo, cloth.

ROWBOTHAM. Tales from Plutarch. By F. Jameson Rowbotham. Fully Illustrated. Cr. 8vo, cloth.

SCAIFE. The War to Date (to Majuba Day.) By A. H. Scaife. Illustrated. Cr. 8vo, cloth.

SEIGNOBOS. History of Ancient Civilization. By Charles Seignobos; Doctor of Letters of the University of Paris. Large cr. 8vo, cloth. net History of Mediæval Civilization and of Modern to the End of the Seventeenth Century. Large cr. 8vo, cloth.

net History of Contemporary Civilization.

net

SERGEANT. The Franks. From their Origin as a Confederacy to the Establishment of the Kingdom of France and the German Empire. By Lewis Sergeant. Second Edition. With 40 Illustrations and Maps. (Story of the Nations. Vol. 48.) Large cr. 8vo, cloth.

SHUCKBURGH. Augustus. The Life and Times of the Founder of the Roman Empire (B.C. 63-A.D. I4.) By E. S. Shuckburgh Demy 8 vo, cloth gilt. Illustrated.

Popular Edition. Illustrated. Large cr. $8 \mathrm{vo}$, cloth. - net

Also in Unwin's Half-Crown Standard Library. One vol., cloth. net

The Story of Greece, from the Coming of the Hellenes to A.D. 14. By E. S. Shuckburgh. With 2 Maps and about 70 Illustrations. (Story of the Nations. Vol. 64.) Large cr. 8vo, cloth. 5/-

THE SOUTH AMERICAN SERIES. See under " Geography."

STANLEY. Before and After Waterloo. By Edward Stanley, sometime Bishop of Norwich. Edited by J. H. Adeane and Maud Grenfell. With 5 Photogravures and 5 Coloured Plates, and 27 other Illustrations. Medium 8vo, cloth.

STEPHENS. Portugal. By H. Morse Stephens, M.A., Oxford. New Edition with a new Chapter by Major Martin Hume and 5 new illustrations. With 44 Illustrations and Maps. (Story of the Nations. Vol. 28.) Large cr. 8vo, cloth. 
STORY OF THE NATIONS, THE. - The volumes occupy about 400 pages each, and contain respectively, besides an Index and Coloured Map, a great many Illustrations. The size is large $\mathrm{cr}$. 8 vo. There are published now (Autumn, I908) 65 volumes, which are to be had in the following bindings :-

Ordinary Edition. Fancy cloth, gold lettered.

Half-morocco, gilt.

Subscription Edition. Special cloth binding. On Subscription only.

Subscription Edition.-A set of 65 volumes, newly printed on specially prepared paper, and containing 2,500. full-page and other Illustrations. Now offered cloth bound for a preliminary payment of $15 \mathrm{~s}$., and 18 subsequent monthly payments of Ios. each, or a cash payment of $f 95 \mathrm{~s} .3 \mathrm{~d}$. ; or bound in half morocco, for a preliminary payment of $25 \mathrm{~s}$. and I7 further payments of $20 \mathrm{~s}$. each, or a cash payment of $£ \mathrm{I} 7$ 7s. Delivered free in the London Postal district.

\section{LIST OF VOLUMES.}

[For full Titles see under Authors' names.]

(I) Rome: From the Earliest Times to the End of the Republic. By Arthur Gilman, M.A.

(2) The Jews. By Prof. James K. Hosmer.

(3) Germany. By S. BaringGould, M.A.

(4) Carthage. By Professor Alfred J. Church, M.A.

(5) Alexander's Empire. By John Pentland Mahaffy, D.D.

(6) The Moors in Spain. By Stanley Lane-Poole.

(7) Ancient Egypt. By Prof. George Rawlinson, M.A.

(8) Hungary. By Professor Arminius Vambéry.

(9) The Saracens: From the Earliest Times to the Fall of Bagdad. By Arthur Gilman, M.A.

(Io) Ireland. By the Hon. Emily Lawless.

(I I) Chaldea: From the Earliest Times to the Rise of Assyria. By Zénaïde A. Ragozin.

(12) The Goths. By Henry Bradley.

(I3) Assyria : From the Kise of the Empire to the Fall of Nineveh. (Continued from "Chaldea.") By Zénaide A. Ragozin.

(I4) Turkey. By Stanley LanePoole.
(15) Holland. By Prof. J. E. Thorold Rogers.

(16) Mediæval France. By Gustave Masson, B.A.

(I7) Persia. By S. G. W. Benjamin.

(I8) Phœnicia. By Prof.George Rawlinson, M.A.

(I9) Media, Babylon and Persia: From the Fall of Nineveh to the Persian War. By Zénaide A. Ragozin.

(20) The Hansa Towns. By Helen Zimmern.

(2I) Early Britain. By Prof. Alfred J. Church, M.A.

(22) The Barbary Corsairs. By Stanley Lane-Poole.

(23) Russia. By W. R. Morfill, M.A.

(24) The Jews under Roman Rule. By W. D. Morrison.

(25) Scotland. By John Mackintosh, LL.D.

(26) Switzerland. By Lina Hug and R. Stead.

(27) Mexico. By Susan Hale.

(28) Portugal. By H. Morse Stephens, M.A.

(29) The Normans, By Sarah Orne Jewett.

(30) The Byzantine Empire. By C. W. C. Oman, M.A.

(3I) Sicily: Phœenician, Greek, and Roman. By Prof.' E. A. Freeman. 
STORY OF THE NATIONS, THE.-continued.

(32) The Tuscan Republics, with Genoa. By Bella Duffy.

(33) Poland. By W. R. Morfill.

(34) Parthia. By Prof. Geo. Rawlinson.

(35) The Australian Commonwealth. (New South Wales, Tasmania, Western Australia, South Australia, Victoria, Queensland, New Zealand.) By Greville Tregarthen.

(36) Spain: Being a Summary of Spanish History from the Moorish Conquest to the Fall of Granada (7II-J492 A.D.). By Henry Edward Watts.

(37) Japan. By David Murray, Ph.D., LL.D.

(38) South Africa. By George McCall Theal.

(39) Venice. By Alethea Wiel.

(40) The Crusades: The Story of the Latin Kingdom of Jerusalem. By T. A. Archer and C. L. Kingsford.

(41) Vedic India. By Zénaîle A. Ragozin.

(42) The West Indies and the Spanish Main. By James Rodway, F.L.S.

(43) Bohemia: From the Earliest Times to the Fall of National Independence in 1620 ; with a Short Summary of later Events. By C. Edinund Maurice.

(44) The Balkans. By W. Miller, M.A.

(45) Canada. By Sir John Bourinot, C.M.G.

(46) British India. By R. W. Frazer, LL.D.

(47) Modern France. By André Lebon.
(48) The Franks. By Lewis Sergeant.

(49) Austria. By Sidney Whitman.

(50) Miodern England before the Reform Bill. By Justin McCarthy.

(5I) China. By Prof. R. K. Douglas.

(52) Modern England under Queen Victoria. By Justin McCarthy.

(53) Modern Spain, 1878. 1898. By Martin A. S. Hume.

(54) Modern Italy, 1748-1898. By Prof. Pietro Orsi.

(55) Norway. By Professor Hjalmar H. Boyesen.

(56) Wales. By Owen Edwards.

(57) Mediæval Rome, 1073. 1535. By William Miller.

(58) The Papal Monarchy: From Gregory the Great to Boniface VIII. By William Barry, D.D.

(59) Mediæval India under Mohammedan Rule. By Stanley Lane-Poole.

(60) Parliamentary England: From 1660-1832. By Edward Jenks.

(6I) Buddhist India. By T. W. Rhy Davids.

(62) Mediæval England. By Mary Bateson.

(63) The Coming of Parliament. (England 1350-I660.) By L. Cecil Jane.

(64) The Story of Greece (from the Earliest Times to A.D. I4.) By E. S. Shuckburgh.

(65) The Story of the Roman Empire (B.C. 29 to A.D. 476). By H. Stuart Jones.

THEAL. The Beginning of South African History. By Dr. George McCall Theal. With Maps and Illustrations. Demy 8vo, cloth.

A Little History of South Africa. By Dr. George McCall Theal. Third Edition. Cr. 8vo.

South Africa. (The Cape Colony, Natal, Orange Free State, South African Republic, Rhodesia, and all other Territories south of the Zambesi.) By Dr. George MicCall Theal, D.Lit., LL.D. Ninth Impression (Sixth Edition). With 39 Illustrations and Maps. (Story of the Nations. Vol. 38.) Large cr. 8vo, cloth. 
THOMAS. Roman Life under the Cæsars. By Emile Thomas. Numerous Illustrations. Small demy 8vo, cloth.

TREGARTHEN. The Australian Commonwealth. (New South Wales, Tasmania, Western Australia, South Australia, Victoria, Queensland, New Zealand.) By Greville Tregarthen. Fourth Impression. With 36 Illustrations and Maps. (Story of the Nations. Vol. 35.) Large cr. 8vo, cloth.

TROWBRIDGE. Court Beauties of Old Whitehall. By IV. R. H. Trowbridge. With a Photogravure Frontispice and many other Illustrations. Demy 8vo, cloth.

Mirabeau, the Demi-God. Being the True and Romantic Story of his Life and Adventures. By WV. R. H. Trowbridge. With a Photogravure Frontispiece and 32 other Illustrations. Demy 8 vo, cloth.

Seven Splendid Sinners. By W. R. H. Trowbridge. With a Photogravure Frontispiece and other Illustrations. Demy 8vo, cloth.

TURQUAN. The Sisters of Napoleon. Edited from the French of Joseph Turquan by W. R. H. Trowbridge. Illustrated. Demy 8vo, cloth.

VAMBÉRY. Hungary : In Ancient, Mediæval, and Modern Times. By Prof. Arminius Vambéry. With Collaboration of Louis Heilprin. Seventh Edition. With 47 Illustrations and Maps. (Story of the Nations. Vol. 8.) Large cr. 8vo, cloth.

VILLARI. The Barbarian Invasions of Italy. By Prof. Pasquale Villari. Translated by Linda Villari. With Frontispiece and Maps. 2 vols. Demy 8 vo.

The History of Florence. (The First Two Centuries of Florentine History.) By Prof. Pasquale Villari. Translated by Linda Villari. Illustrated. Demy 8vo, cloth.

Also in Unwin's Half-Crown Standard Library. I vol., cloth. net

Studies Historical and Critical. By Professor Pasquale Villari, Author of "Girolamo Savonarola," \&c. With 7 Photogravure Plates. Demy 8vo, cloth.

VOIGT. Fifty Years of the History of the Republic in South Africa (1795-1845). By J. C. Voigt, M.D. With Coloured Maps, Sketches, and Diagrams. Maps and Plans. 2 vols. Demy 8 vo. net

WATTS. Spain : Being a Summary of Spanish History from the Moorish Conquest to the Fall of Granada (7I I-I492, A.D.). By Henry Edward Watts. Third Edition. With 36 Illustrations and Maps. (Story of the Nations. Vol. 36.) Large cr. 8vo, cloth.

WEBSTER (Alexander). See "Needham."

WELSH PEOPLE, THE: Their Origin, Language, and History. Being Extracts from the Reports of the Royal Commission on Land in Wales and Monmouthshire. Edited, with Additions, Notes and Appendices, by John Rhys, Principal of Jesus College, and Professor of Celtic in the University of Oxford, and David Brynmor Jones, K.C., M.P. Second Edition, Revised. Demy 8vo, cloth.

Also a cheap Edition. Large cr. 8vo, cloth.

WHITMAN. Austria. By Sidney Whitman. With the Collaboration of J. R. McIlraith. Third Edition. With 35 Illustrations and a Map. (Story of the Nations. Vol. 49.) Large cr. 8vo, cloth. 
WHITTY. St. Stephen's in the Firties. By E. M. Whitty. With an Introduction by Justin McCarthy. And Notes by H. M. Williams. With Frontispiece. Demy 8 vo, cloth. net $10 / 6$

Also in Reformer's Bookshelf. Large cr. 8vo, cloth. ${ }^{\top}$.A

WIEL. Venice. By Alethea Wiel. Fourth Edition. With 6r Illustrations and Maps. (Story of the Nations. Vol. 39.) Large cr. 8vo, cloth.

Also Tourist Edition in Baedeker Binding.

WILKINSON. The Personal Story of the Upper House. See under "Biography."

ZIMMERN. The Hansa Towns. By Helen Zimmern. Third Edition. With 5I Illustrations and Maps. (Story of the Nations. Vol. 20.) Large cr. 8vo, cloth.

Heroic Tales. Retold from Firdusi the Persian. By Helen Zimmern. With two etchings by L. Alma-Tadema, R.A., and a Prefatory Poem by Edmund W. Gosse. Third Edition. Cr. 8vo, cloth.

Old Tales from Rome. By Alice Zimmern, Author of "Old Tales from Greece." Cr. Svo, clotl,. Fully illustrated.

\section{POLITICS, ECONOMICS, FREE TRADE, \&C.}

ALBRIGHT. The Churches and the Liquor Traffic., By Mrs. W. A. Albright. Cr. 8vo, paper cover.

net

$6 d$.

ARONSON. The Working of the Workmen's Compensation Act, 1906. By V. R. Aronson, Barrister-at-law. Demy 8 ro, cloth. net 15/-

BAMFORD'S Passages in the Life of a Radical. Edited, and with an Introduction, by Henry Duckler ("Verax"). 2 vols." (Reformer's Bookshelf.) Large cr. 8vo, cloth.

BARNETT. Towards Social Reform. By A. S. Barnett, M.A., Canon of Westninster. Cr. 8va, cloth.

BENTLEY. The Process of Government. A Study of Social Pressures. By Arthur F. Bentley. Demy 8vo, cloth. net

BLISS (Rev. E. M.). Turkey and the Armenian Atrocities. See under "History."

BLUNT. Atrocities of Justice under British Rule in Egypt. By Wilfred Scawen Blunt. Paper cover.

BOWACK. Another View of Industrialism. By William Mitchell Bowack. Large cr. 8vo, cloth.

BOWEN. The Statutes of Wales. Collected, arranged and edited by Ivor Bowen, Barrister-at-law, of the South Wales Circuit: Demy 8 vo, cloth.

BOWLES. National Finance : An Imminent Peril. By Thomas Gibson Bewles. Paper cover.

National Finance. In 1908 and after. By Thomas Gibson Bowles. Paper Boards.

net

The Public Purse and the War Office. By T. Gibson Bowles. Royal 8\%o, paper cover.

BOXALL. The Awakening of a Race. By George E. Boxall. Large cr. 8 vo, cloth.

BRADLAUGH (Charles). A Record of his Life. See under "Biography." 
BRAY. The Town Child. By Reginald A. I3ray, L.C.C., Author of XCO "The Children of the Town" in "The Heart of the Empire," "The Boy and the Family" in "Studies of Boy Life," \&c. Demy" 8vo, cloth. ") of net

BRIGHT. Is Liberty Asleep. Glances-Historical and Political. By Allan H. Bright. Cr. 8vo, paper covers.

British Industries Under Free Trade. Essays by various writers. Edited by Harold Cox. Large cr. 8vo, cloth.

Also (Reformer's Bookshelf) cloth.

BROWN (Ch. R.). The Social Message of the Modern Pulpit. By Charles. Reynolds Brown, Pastor of the First Congregational Church, Oakland, California. Cr. 8vo, cloth. net

BROWN (F.): Political Parables. By the Westminster Gazelte Office. Boy (Francis Brown). Small royal 8vo. Paper, net $1:-$; cloth, net

BROWNE (H. M.).' Balfourism. A Study in Contemporary Politics. By H. Morgan Browne.

net

BUCKMASTER. A Village Politician. Edited by J. C. Buckmaster. With an Introduction by the Right Hon. A. J. Mundella, M.P. Large cr. 8vo, cloth.

Burden of Armaments, The. A Protest of the Cobden Club. Cr. 8vo, cloth.

CADBURY. Women's Work and Wages. A Phase of Life in an Industrial City. By Edward Cadbury, M. Cécile Matheson, and George Shann, M.A.; F.R.G.S: Large cr. 8vo, cloth.

6/-

CALLAHAN. Cuba and International Relations. A Historical Study in American Diplomacy. By James Horton Callahan, Ph.D.' Demy $8 \mathrm{vo}$, cloth.

CARLILE:" The Continental Outcast : Land Colonies and Poor

bio Law Relief.'By the Rev. W. Carlile, Hon. Chief Secretary, and Victor W. Carlile, Hon. Organising Secretary, of the Church Army. With 8 Illustrations. Cr. 8vo. Paper, net 1/- ; cloth, net

COBDEN. The Political Writings of Richard Cobden. New Edition. With Preface by Lord Welby and Introductions by Sir Louis Mallet and William Cullen Bryant. With Frontispieces. 2 vols. (Reformer's Bookshelf.) Large cr. 8vo, cloth.

Richard Cobden and the Jubilee of Free Trade. By P. LeroyBeaulieu, Henry Dunckley ("Verax"), Dr. Theodor Barth, the Right Hon. Leonard Courtney, M.P., and the Right Hon. Charles Villiers, M.P. Wiih introduction by Richard Gowling. Uniform in style with the Jubilee Edition of "Richard Cobden. Cr. 8vo, cloth.

Cobden as a Citizen. A Chapter in Manchester History. Being a facsimile of Cobden's pamphlet, "Incorporate Ycur Borough !" with an Introduction and a complete Cobden Bibliography. By William E. A. Axon.

Speeches on Questions of Public Policy. By Richard Cobden. Edited by John Bright and James E. Thorold Rogers. With a Preface by James E. Thorold Rogers, and Appreciations by J. E. Thorold Rogers and Goldwin Smith, and 2 Photogravure Portraits. Fifth Impression. 2 vols. Large cr. 8vo, cloth. (Uniforin with the Jubilee Edition of Morley's "Life of Cobden.")

COLLET. Taxes on Knowledge: The Story of their Origin and Repeal. By Collet Dobson Collet. With an Introduction by George Jacob Holyoake. Large cr. 8vo. 2 vols.

Also 2 vols., cloth. 
COX. Mr. Balfour's Pamphlet: A Reply. By Harold Cox. Medium $8 \mathrm{vo}$, paper covers.

net

$2 d$.

The Policy of Free Imports. By Harold Cox. A Paper read at Liverpool on February I6th, 1903, to the New Century Society. Large cr. 8vo.

Paper covers, 1d.; cloth, net

Protection and Employment. By Harold Cox, formerly Secretary of the Cobden Club. Paper covers.

CROMPTON. Our Criminal Justice. By Henry Crompton. With an Introduction by Sir Kenelm Digby, K.C.B.

net

DANSON. Economic and Statistical Studies, 1840-1890. By John Towne Danson. With a brief memoir by his daughter, Mary Norman Hill, and an Introduction by E. C. K. Gonner, M.A., Brunner, Professor of Economic Science, Liverpool University. With a Photogravure Froniispiece, 2 other Portraits, and 31 Plates. Small royal 8 \%o, cloth.

DAVENPORT. Value and Distribution. A Critical and Constructive Study. By Herbert Joseph Davenport, Associate Professor of Political Economy in the University of Chicago. Demy 8vo, cloth.

DAWSON. The Evolution of Modern Germany. See under "Travel." $6 d$. $6 d$.

6d.

DEWSNUP. American Railway Organization and Working. Lectures by Prominent Railway Men. Edited by Ernest R. Dew'snup. Large cr. 8vo, cloth.

DIETZEL. Retaliatory Duties. By H. Dietzel. Professor at the University of Bonn. Translated by D. W. Simon, D.D., and W. Osborne Brigstocke, Member of the Unionist Free Trade Club. Cr. 8vo, cloth.

net $2 / 6$

ELIAS. The Political Advertiser. By Frank Elias. Illustrated. Fcap. 4to, paper covers.

net $1 /$ -

ELLIOTT. Corn Law Rhymes and Other Verses. By Ebenezer Elliott. $12 \mathrm{mo}$.

Paper covers, 2d. ; cloth limp

ESCOTT. The Story of British Diplomacy: Its Makers and Movements. By T. H. S. Escott, Author of "Society in the Country House," \&c., \&c. With a Photogravure Frontispiece. Demy 8 vo, cloth.

Failure of Lord Curzon, The. A Study in Imperialism. An Open Letter to the Earl of Rosebery. By "Twenty-eight Years in India." Cr. 8 vo, cloth.

net

$6 d$.

GEBUZA. The Peril in Natal. By Gebuza. Demy 8vo, paper covers. net

GOMME. The Governance of London. Studies of the place of London in English Institutions. By G. Lawrence Gomme, F.S.A., Clerk to the London County Council. With Maps. Demy 8vo, cloth.

GOULD. The Modern Chronicles of Froissart. Told and Pictured by Sir F. Carruthers Gould. With special Cover Design, Decorated Title, and 44 Illustrations. Fifth Impression. Fcap. 4 to.

Froissart in 1902. Told and Pictured by Sir F. Carruthers Gould. With special Cover Design and Coloured Frontispiece. Fcap. 4to.

Also a Fine Edition (limited to 50 copies) on Japan paper, numbered and signed.

F.C.G.'s Froissart, 1903-1906. Told and Pictured by Sir F. Carruthers Gould. With special Cover Design, and 50 Illustrations, Fcap. 4to, cloth.

Also a Fine Edition (limited to 50 copies) on Japan paper, numbered and signed.

net $21 /$ -

See also "Lawson" 
GOULD. The Gould-en Treasury. With 34 Illustrations by Sir.F. Carruthers Gould. Fcap. 4to.

GRANT. Free Food and Free Trade. By Daniel Grant, Ex-M.P. Paper covers.

HALDANE. Army Reform and Other Addresses. By the Right Hon. Richard Burton Haldane, M.P. Iarge cr. 8vo, cloth. net

Heart of the Empire, The. Studies in Problems of Modern City Life in England. Large cr. 8vo, cloth.

HIRST. National Credit and the Sinking Fund: How to make $£ 500,000,000$. By Francis W. Hirst. Paper covers.

HOBHOUSE. Democracy and Reaction. By L. T. Hobhouse. Cr. $8 \mathrm{vo}$, cloth.

A'so a revised Edition in paper ccver:

The Labour Movement. By L. T. Hobhouse, M.A. (Reformer's Bookshelf), larie cr. 8vo, cloth.

Also a New and Cheaper Edition. Cr. 8vo, paper covers. net

HODGsON. To Colonise England. A Plea for a Policy. By W. B. Hod gson, C. F. G. Masterman and Other Wri ers. Edited by A. G. Gardiner. Cr. 8vo. Paper, net $2 / 6$; cloth, net

HOGAN. The Gladstone Colony. By James Francis Hogan, M.P. Demy 8 vo, cloth.

Also (Reformer's Bookshelf), cloth.

HOLYOAKE. Sixty Years of an Agitator's Life: George Jacob Holyoake's Autobiography. 2 vols. (Reformer's Bookshelf.) cloth.

Also :n $\mathrm{I}$ vol. (Unwin's Half-Crown Standard Library.) net

The History of Co-operation. Its Literature and its Advocates. By G. J. Holyoake. Illustrated. 2 vols. Demy 8 vo, cloth. net

Also a Popular Edition in I vol. Illustrated. Large cr. 8vo, cloth.

net

Bygones Worth Remembering. See under "Biography."

Public Speaking and Debate. A Manual for Advocates and Agitators. By George Jacob Holyoake. New Edition.

Paper covers, net $1 /$ - ; cloth, net

HOWE. The City, the Hope of Democracy. By Frederic C. Howe, Ph.D. Large cr. 8vo, cloth.

net

The British City. By F. C. Howe, Author of "The City, the Hope of Democracy." Large cr. 8vo, cloth.

net

HOWELL. Labour Legislation, Labour Movements, and Labour Leaders. By George Howell. Demy 8vo, cloth.

Also 2 vols. Large cr. 8vo, cloth. (Reformer's Bookshelf.)

Hungry Forties, The. An Account of Life under the Bread Tax from the Letters of Living Witnesses. With an Introduction by Mrs. Cobden Unwin. Illustrated. Large cr. 8vo, cloth.

Also (Reformer's Bookshelf), cloth.

People's Edition. Paper covers.

JEPHSON. The Sanitary Evolution of London. By Henry Jephson. Demy 8vo, cloth.

JERNIGAN. China's Business Methods and Policy. By T. R. Jernigan, Ex-Consul-General of the United States of America at Shanghai. Demy 8 vo, cloth.

KING. Electoral Reform. An Inquiry into our System of Parlia. mentary Representation. By Joseph King. Cr. 8vo, cloth. net 
KITSON. The Cause of Industrial Depression. A Lecture delivered at the New Reform Club. By Arthur Kitson. Paper covers.

Labour and Protection. Essays by Various Writers. (John Burns, 1 A 4 ? G. J. Holyoake, \&c.) Edited by H. W. Massingham. Large cr. 8vo, cloth.

Also (Reformer's Bookshelf).

LANE. Patriotism under Three Flags: A Plea for Rationalism in Politics. By Ralph Lane. Cr. 8vo, cloth.

LATANE. The Diplomatic Relations of the United States and Spanish America. By J. H. Latane, Ph.D. Demy 8 vo, cloth. net

LAWSON. Cartoons in Rhyme and Line. By Sir Wilfrid Lawson, Bart., M.P. Illus. by Sir F. Carruthers Gould. Fcap. 4to, cloth. net

Edition de Luxe, signed by Author and Artist. Printed on hand-made paper.

LEVASSEUR. The American Workman. By Prof. R. Levasseur. Translated by Thomas S. Adams, and Edited by Theodore Marburg. Demy 8 vo, cloth.

LLOYD. The Swiss Democracy. A Study of a Sovereign People. By H. D. Lloyd and John A. Hobson. Large cr. 8vo, cloth. ? net

- The Governance of England. By Sidney Low, B.A., late Lecturer on Modern History, King's Collegre, London. Demy 8vo, cloth.

Cheap Edition. Large cr. 8vo, cloth.

The Increase of the Suburbs. By Sidney Low. Cr. 8vo, paper covers.

net

LUNN. Municipal Lessons from Southern Germany. By Henry S. Lunn, M.D., J.P. With an Introduction by the Rt. Hon. Sir John Gorst, and 7 Illustrations. Medium 8vo, cloth.

von MACH. The Bulgarian Exarchate: Its History and the Extent of its Authority in Turkey. From the German of Richard von Mach. With a Map. Demy 8vo, cloth. net

MACY. Party Organisation and Machinery in the United States. By Jesse Macy, Professor of Political Science at Iowa College. Cr. 8vo, cloth.

McCleLLAND. The Fiscal Problem. With Diagrams. By J. McClelland. Cr. 8vo.

MALLET (Sir Louis). See Welby ("Cobden's Work").

MEAKIN (B.). Model Factories and Villages. Ideal Conditions of Labour and Housing. By Budgett Meakin, Lecturer on Industrial Betterment. With about 200 Illustrations. Large cr. 8vo, cloth.

MEAKIN (W.). The Life of an Empire. By Walter Meakin, B.A., LL. B. Large cr. 8vo, cloth.

YOUKOV. Russia and Its Crisis. By Professor Paul Milyoukov. With 6 Maps. Demy 8vo, cloth.

MOLINARI. The Society of To-Morrow: A Forecast of its Political and Economic Organisation. By G. de Molinari, Membre de l'Institut and Editor of Le Fournal des Economistes. Translated by P. H. LeeWarner. With a Prefatory Letter by Frédéric Passy, and an Introduction by Hodgson Pratt. Cr. 8vo, cloth.

MOREL. Red Rubber. The Story of the Rubber Slave Trade on the Congo. By E. D. Morel. With an Introduction by Sir Harry H. Johnston, G.C.M.G., K.C.B., and a Frontispiece. Cr. $8 \mathrm{vo}$.

Popular Edition, paper covers.

Paper boards, net $2 / 6$; cloth, net net

MORLEY (John). Life of Richard Cobden. See under "Biography." 
NOEL. The Labour Party: What it is and What it Waits. By the Rev. Conrai Roden Noel. Cr. 8vo.' Paper; net $1 /-$; cloth, net 2/O'BRIEN. England's Title in Ireland: A Letter Addressed to the $A$ Ha Lord Lieutenant. By R. Barry O'Brien. Paper covers. 6d.

Irish Memories." By R. Barry O'Brien., See under "History."

O'CONNOR (T. P.). The Parnell Movement. See under "History." O'DONNELL. The Causes of Present Discontents in India. By C. J. O'Donnell, M.P. Demy 8vo, cloth. net

RAVENSHEAR. The Industrial and Commercial Influence of the English Patent System. By A. F. Ravenshear. Large Cr.8vo. not REFORMER'S BOOKSHELF, THE, Large cr. 8vo, cloth. each

The Labouir Movement. By L. T. Hobhouse, M.A. Preface by R. B. Haldane, M.P.

Sixty Years of an Agitator's Life. G. J. Holyoake's Autobiography. 2 vols.

Banford's Passages in the Life of a Radlcal. Edited and with an Introduction by Henry Dunckley. 2 vols.

The Economic Interpretation of History. By. Professor Thorold Rogers. 2 vols.

The Industrial and Commer. cial History of England. By Professor Thorold Rogers. 2 vols.

Charles Bradlaugh: A Record of his Life and Work. By his Daughter Hypathia Bradlaugh Bonner. 2 vols.

The Inner Life of the House of Commons. Selected from the Writings of William White.

The Life of Richard Cobden. By John Morley. 2 vols.

The Political Writings of Richard Cobden, A New Edition. With Preface by Lord Welby, and Introduction by Sir Louis Mallet and William Cullen Bryant, and a Bibliography. With Frontispieces. 2 vols.
The Gladstone Colony. By James Francis Hogan, M.P.

British Industries under Free Trade. Edited by Harold Cox.

My Life in Two Hemispheres. By Sir Charles Gavan Duffy, K.C.M.G. 2 vols.

Labour Legislation, Labour Movements, and Labour Leaders. By George Howell. With Frontispiece. 2 vols.

St. Stephen's in the Fifties. By E. M. Whitty. With an Introduction by Justin McCarthy.

The Crowd: A Study of the Popular Mind. By Gustave Le Bon.

Juvenile Offenders. By W. Douglas Morrison, LL.D.

Bygones Worth Remembering. A Sequel to "Sixty Years of an Agitator's Life." By George Jacob Holyoake. With a Photogravure Frontispiece and 18 other Portraits. 2 vols.

The Hungry Forties. An account of Life Under the Bread Tax. With an Introduction by Mrs. Cobden Unwin. Illustrated.

ROGERS. The Economic interpretation of History: Lectures on Political Economy and its History, delivered at Oxford, I887-I 888. By Professor Thorold Rogers. 2 vols. (Reformer's Booksl ilf.) Large cr. 8 vo, cloth.

The Industrial and Commercial History of England. see under "Historical Literature."

RUSSELL. The Uprising of the Many. By Charles E. Russell. With 32 Illustrations. Large cr. 8vo, cloth.

SABATIER. Disestablishment in France. By Paul Sabatier. Translated (with an Introduction) by Robert Dell. With' Portraits of the Author and the Abbé Loisy ; and the complete text (both in French and English) of the Law for the Separation of the Churches and the State, with explanatory notes. Cr. 8vo, cloth. net 
SCHREINER, The Political Situation. By Olive Schreiner and $\mathrm{C}$. S. Cronwright Schreiner. Cr. 8vo, cloth.

SHAW. Municipal Government in Continental Europe. By Albert Shaw. Demy 8 vo, cloth.

Municipal Government of Great Britain. By Albert Shaw. Demy 8vo, cloth.

net

SIBLEY. Criminal Appeal and Evidence. By N. W. Sibley, B.A., LL.M. Trin. H. Camb. and B.A. London; Barrister-at-Law of Lincoln's Inn ; Joint Author of "International Law as Interpreted during the Russo-Japanese War," and "The Aliens Act, I905." Demy 8vo, cloth.

net $15 /$.

SMALL. General Sociology: An Exposition of the Main Development in Sociological Theory, from Spencer to Ratzenhofer. By Albion W. Small, Professor and Head of the Department of Sociology in the University of Chicago. Demy 8vo, cloth. net

Adam Smith and Modern Sociology. A Study in the Method. ology of the Social Sciences. IBy Albion W. Small, Professor and Head of the Department of Sociology in the University of Chicago. Cloth.

net

SMITH (Goldwin). My Memory of Gladstone. See under "Biography."

SMITH. International Law as Inierpreted during the RussoJapanese War. By F. E. Smith, B.C.L., and N. W. Sibley, LL.M. Second Edition, Revised. Royal 8vo, cloth.

SPELLING. Bossism and Monopoly. By T. C. Spelling. Large cr. 8vo, cloth. net

STEAD. Peers or People? The House of Lords Weighed in the Balances and Found IVanting. An Appeal to History. By W. T. Stead. Cr. 8vo.

Paper boards, net $2 / 6$; cloth, net

STEVENI. The Scandinavian Question. By William Barnes Steveni. With a Map. Large cr. 8vo, cloth.

net

STOPES. The Sphere of "Man" in Relation to that of "Woman" in the Constitution. By Mrs. C. C. Stopes, Author of "British Frecwomen." Large cr. 8vo, paper covers.

net

$6 d$.

SVENSKE. Sweden's Rights and the Present Political Position. By Anders Svenske. Cloth.

net

TAYLOR. Side-Lights on Protection. The History of a Vanished Industry. By Austin Taylor, M.P. Paper covers.

TWAIN. King Leopold's Soliloquy. A Defence of his Congo Rule. By Mark Twain. With a Preface and Appendices by E. D. Morel, Author of "Red Rubber." Cr. 8vo. Paper, net 1/- ; cloth, net

VILLARI. Russia Under the Great Shadow. By Luigi Villari. With 84 Illustrations. Demy 8vo, cloth.

net $10 / 6$

VILLARI (Pasquale). Niccolo Machiavelli. See under "Biography."

VILLIERS (B.). The Opportunity of Liberalism. By Brougham Villiers. Paper covers.

net

The Case for Woman's Suffrage. A volume of essays by Mrs.
Henry Fawcett, Mrs. Pankhurst, J. Keir Hardie, M.P., Miss Eva
Gore Booth, Miss LI. Davies, Miss Margaret McMillan, and others.
Edited with an Introduction by Brougham Villiers. Cr. 8vo.
Paper boards, net $2 / 6$; cloth, net

The Case for Woman's Suffrage. A volume of essays by Mrs.
Henry Fawcet, Mrs. Pankhurst, J. Keir Hardie, M.P., Miss Eva
Gore Booth, Miss Ll. Davies, Miss Margaret McMillan, and others.
Edited with an Introduction by Brougham Villiers. Cr. 8vo.
Paper boards, net $2 / 6$; cloth, net

The Case for Woman's Suffrage. A volume of essays by Mrs.
Henry Fawcet, Mrs. Pankhurst, J. Keir Hardie, M.P., Miss Eva
Gore Booth, Miss Ll. Davies, Miss Margaret McMillan, and others.
Edited with an Introduction by Brougham Villiers. Cr. 8vo.
Paper boards, net $2 / 6$; cloth, net

The Case for Woman's Suffrage. A volume of essays by Mrs.
Henry Fawcett, Mrs. Pankhurst, J. Keir Hardie, M.P., Miss Eva
Gore Booth, Miss Ll. Davies, Miss Margaret McMillan, and others.
Edited with an Introduction by Brougham Villiers. Cr. 8vo.
Paper boards, net $2 / 6$; cloth, net

The Case for Woman's Suffrage. A volume of essays by Mrs.
Henry Fawcet, Mrs. Pankhurst, J. Keir Hardie, M.P., Miss Eva
Gore Booth, Miss Ll. Davies, Miss Margaret McMillan, and others.
Edited with an Introduction by Brougham Villiers. Cr. 8vo.
Paper boards, net $2 / 6$; cloth, net The Socialist Movement in England. "By Brougham Villiers, 
VILLIERS (Ch. P.). Fiscal Reformation Sixty Years Ago : Passages from the Speeches of the Rt. Hon. Charles Pelham Villiers, M.P. for Wolverhampton, 1835-1898. Selected by Wilbrahain Villiers Cooper. Paper covers.

WATSON. The National Liberal Federation from its Commencement to the General Election of 1906. By R. Spence Watson, LL.D., President of the Federation 1890-1902. With a Photogravure Frontispiece from a Portrait by Sir George Reid, and an Introduction by the Right Honourable Augustine Birrell. Cr. $8 \mathrm{vo}$, cloth.

net

WELBY and MALLET. Cobden's Work and Opinions. By Lord Welby and Sir Louis Mallet. Imitation Calf covers. net

WHITE. The Inner Life of the House of Commons : Selected from the Writings of William White, with a Prefatory Note by his Son, and an Introduction by Justin McCarthy. 2 vols. (Reformer's Bookshelf.) Cr. 8vo, cloth.

WILKINSON. The Personal Story of the Upper House. See under "Biography."

[For reference see also "Biography" and "History."]

\section{GEOGRAPHY, TRAVEL, MOUNTAINEERING, \&C.}

ADAMS. The New Egypt. By Francis Adams. Large cr. 8vo, cloth.

ANGLO-ITALIAN LIBRARY, THE. Each volume fully illustrated. Large cr. 8 vo, cloth.

With Shelley in Italy. A Selection of Poems and Letters relating to His Life in Italy. Edited, with an Introduction, by Anna Bcnneson McMahan.

With Byron in Italy. A Selection of Poems and Letters relating to His Life in Italy. Edited by Anna Benneson McMahan.

Romola. By George Eliot. A Historically Illustrated Edition. Edited, with Introduction and Notes, by Guido Biagi, Librarian of the Laurentian and Riccardi Libraries, Florence. 2 vols.

The four volumes may also be obtained in Florentine white vellum binding. Price 10/6 net each.

BAKER, Moors, Crags, and Caves of the High Peak and the Neighbourhood. By Ernest A. Baker, M.A. With about 40 Illustrations and 2 Maps. Demy 8vo, cloth gilt. net

BANFIELD. The Confessions of a Beachcomber. Scenes and Incidents in the Career of an Unprofessional Beachcomber in Tropical Queensland. By E. J. Banfield. With a Map and 48 Illustrations. Demy 8vo, cloth.

BINDLOSS (Harold). Wide Dominion. See Overseas Library. No. 7. BLOND (Mrs. Aubrey Le). See under "Le Blond."

BOISSIER. The Country of Horace and Virgil, By Gaston Boissier. Translated by D. Havelock Fisher. Large cr. 8vo, cloth.

Rome and Pompeii. By Gaston Boissier. Translated by $D$. Havelock Fisher. (The only authorised version in English of "Les Promenades Archæologiques.") Maps and Plans. Large cr. 8vo, cloth.

Also in Unwirl's Half-Crown Standard Library. Cloth. 
67 GEOGRAPHY, TRAVEL, MOUNTAINEERING, \&c.-continued.

BUCHANAN. The Real Australia. By A. J. Buchanan. Cr. 8vo. 6/BULFIN (W.). Tales of the Pampas. See Overseas Library. No. ro. CADDICK. A White Woman in Central Africa. By Helen Caddick. I6 Illustrations. Cr. 8vo, cloth.

CAIRD. Romantic Cities of Provence. By Mona Caird, Author of "The Pathway of the Gods," \&c., \&c. Illustrated witl Sketches by Joseph PennelI and Edward M. Synge. Small royal 8vo, cloth. net

CAYLEY. The Bridle Roads of Spain (Las Alforjas.) By George John Cayley. New edition. With an Introduction by Martin Hume, M.A., and Recollections of the Author by Lady Ritchie and Mrs. Cobden Sickert, and a Photogravure Frontispiece. La. cr. 8vo, net

CESARESCO. Lombard Studies. By Countess Evelyn Martinengo Cesaresco. Photogravure Frontispiece and many other Illustrations. Demy $8 \mathrm{vo}$, cloth.

CLIFFORD (Hugh). A Corner of Asia. See Overseas Library. No. 5.

CONWAY, Climbing and Exploration in the KarakoramHimalayas. By Sir William Martin Conway, M.A., F.S.A., F.R.G.S. 300 Illustrations by A. D. McCormick, and Maps. Super royal $8 \mathrm{vo,}$ cloth.

Supplementary Volume. With Frontispiece of the Author. Super royal $8 \mathrm{vo}$, cloth.

CONWAY AND COOLIDGE'S CLIMBERS' GUIDES. Edited by Sir William M. Conway and Rev. W. A. B. Coolidge. Gilt lettered, with pocket, flap, and pencil. 32mo, limp cloth, each.

(I) The Central Pennine Alps.

By Sir William Martin Conway.

(2) The Eastern Pennine Alps. By Sir William Martin Conway.

(3) The Lepontine Alps (Simplon and Gotthard). By W. A. B. Coolidge and Sir William M. Conway.

(4) The Central Alps of the Dauphiny. By W. A. B. Coolidge, H. Duhamel, and F. Perrin. Second Edition. Thoroughly revised. Small 8vo, cloth. $7 / 6$ net.

(5) The Chain of Mont Blanc. By Louis Kurz.

(6) The Adula Alps of the Lepontine Range. By

W. A. B. Coolidge.
(7) The Mountains of Cogne. By George Yeld and W. A. B. Coolidge. With Map.

(8) The Range of the Tödi. By W. A. B. Coolidge.

(9) The Bernese Oberland. Vol. I. From the Gemmi to the Mönchjoch. By G. Hasler.

(Io) The Bernese Oberland. Vol. 2. From the Mönchjoch to the Grimsel. By W. A. B. Coolidge.

(II) The Bernese Oberland. Vol. 3. The West Wing. By H. Dübi.

(I2 \& I3) The Bernese Oberland. Vol. 4 (Parts I and 2). From the Grimsel to the Uri Rothstock. By H. Dübi.

Also a Series of Six Coloured Maps of the Alps of the Dauphiny, mounted on linen, and strongly bound in cloth case, the set.

COOLIDGE (W. A. B.). See under Conway and Coolidge's Climbers' Guides.

CORNABY. China under the Searchlight, By W. A. Cornaby. Cr. 8vo, cloth.

CORNISH. The Panama Canal To-day. By Vaughan Cornish. Cloth. 
DAVIDSON. Present-Day Japan. By Augusta M. Campbell Davidson, M.A. Fully Illustrated. Medium 8vo, cloth.

Cheap Edition (Modern Travel Series), cloth.

DAVIS. The Congo and the Coasts of Africa. By Richard Harding Davis. Illustrated. Large cr. 8vo, cloth. net

SON. The Evolution of Modern Germany. By W. Harbutt Dawson, Author of "German Life in Town and Country." net 21/.

DEASY; In Tibet and Chinese Turkestan. By Captain H. H. P. Deasy. Being the Record of Three Years' Exploration. With Appendices, Maps, and 80 Illustrations. Demy 8vo, cloth gilt. net 21/Also a Cheap Edition.

DIGBY. "Prosperous" British India, By William Digby, C.I.E. With Diagrams and Maps. Demy 8vo, cloth.

DUTT. The Norfolk and Suffolk Coast. By W. A. Dutt. With about 40 .llustrations. Cr. 8vo, cloth.

ECKENSTEIN. The Karakorams and Kashmir: The Story of a Journey. By Oscar Eckenstein. Cr. 8vo, cloth gilt.

ELIOT. Romola. By George Eliot. A historically illustrated edition. Edited, with Introduction and Notes, by Guido Biagi, Librarian of the Laurentian and Riccardi Libraries, Florence. With I6o Illustrations. 2 vols. (The Anglo-Italian Library.) each, net

ENOCK. The Andes and the Amazon. Life and Travel in Peru. By C. Reginald Enock, F.R.G.S. With a Map and numerous Illustrations. Medium 8vo, cloth.

Peru. Its Former and Present Civilization, Topography and Natural Resources, History and Political Conditions, Commerce and Present Conditions. By C. Reginald Enock, F.R.G.S. With an Introduction by Martin Hume, a Map, and numerous Illustrations. (The South American Series.) Demy 8vo, cloth. net

Mexico. By C. Reginald Enock, F.R.G.S. (Volume 3 of the South American Series.) Demy 8vo, cloth.

Everyday Life in Cape Colony. By a late Resident. Illustrated. Cr. 8vo, cloth:

FARGE. An Artist's Letters from Japan. See under "La Farge."

FINDLAY. Big Game Shooting and Travel in South and East Africa. By Frederick R. N. Findlay. Fully Illustrated, and with Map. Medium 8vo.

net $15 /$.

FITZ-GERALD. Climbs in the New Zealand Alps: Being an Account of Travel and Discovery. By E. A. Fitz-Gerald, F.R.G.S. Cloth, size $9 \frac{1}{2}$ by $6 \frac{1}{2}$.

FOREMAN. The Philippine Islands. A Political, Ethnographical, Social and Commercial History of the Philippine Archipelago. By John Foreman, F.R.G.S. With Maps and Illustrations. Royal 8 vo; cloth.

GAGGIN (John). Among the Man-Eaters. See Overseas Library. No. 8. GRAHAM (Cunninghame). The Ipane. See Overseas Library. No. I. GRIBBLE. The Early Mountaineers: The Stories of their Lives. By Francis Gribble.' Fully Illustrated. 'Demy' 8vo, cloth gilt.

HALL. Pre-Historic Rhodesia. An Examination of the Ethnological and Archæological Evidences as to the Origin and Age of the Rock Mines and Stone Buildings, with a Gazetteer of Mediaeval SouthEast Africa. By R. N. Hall. With Illustrations, Maps and Plans. Medium 8vo, cloth.

HARDY. John Chinaman at Home. By the Rev. E. J. Hardy. Author of "How to be Happy though Married." With 36 Jllustrations. Demy $8 \mathrm{vo}$, cloth. net $10 / 6$ Cheap Edition (Modern Travel Series), cloth. 
69 GEOGRAPHY, TRAVEL, MOUNTAINEERING, \&o.-continued.

HARVIE-BROWN. Travels of a Naturalist in Northern Europe. By J. A. Harvie-Brown. See under "Natural History."

HAWKESWORTH. Australian Sheep and Wool. A Practical and Theoretical Treatise. By Alfred Hawkesworth, Lecturer in Charge of "Sheep and Wool" Department, Technical College, Sydncy. Second Edition, Revised and Enlarged. With 55 Illustrations. Demy 8vo, cloth.

net

HERRING. Among the People of British Columbia: Red, White, Yellow and Irown. By Frances E. Herring. Fully Illustrated from Original Photographs. Cr. 8vo, cloth.

- In the Pathless West. By Frances E. Herring. With I4 Illustrations. Cr. 8 vo, cloth.

HEYWOOD. Guide to Siena. History and Art. By William Heywood and Lucy Olcott. Cr. 8vo, cloth. net

HILL. Cuba and Porto Rico: With the other Islands of the West Indies. By Robert T. Hill. 500 pages, with 250 Illustrations and Maps. Demy 8vo.

HINDLIP. British East Africa : Past, Present, and Future. By Lord Hindlip, F.R.G.S., F.Z.S. Cr. 8vo, cloth.

net

- Sport and Travel: Abyssinia and British East Africa. By Lord Hindlip, F.R.G.S., F.Z.S. With Maps and more than 70 Illustrations. Demy 8vo, cloth.

HOBBES. Imperial India: Letters from the East. By John Oliver Hobbes. Cr. 8vo.

Paper covers, $1 /$ - ; cloth

HOBSON. Canada To-Day. By J. A. Hobson, M.A., Author of "The Evolution of Modern Capitalism," \&c. Cr. 8vo, cloth. net

HONEYMAN. Bright Days in Merrie England. By C. Van Doren Honeyman. Cr. 8vo, cloth.

INDICUS. Labour and other Questions in South Africa. By "Indicus." Cr. 8vo, cloth.

JAVELLE. Alpine Memories. By Emile Javelle. Small demy, cloth. JEBB. By Desert Ways to Baghdad. By Louisa Jebb. With many Illustrations from Photographs taken by the Author. Demy 8vo, cloth.

JERNIGAN. China's Business Methods and Policy. See under "Politics."

JOHNSON. Tramps Round the Mountains of the Moon and through the Back Gate of the Congo State. By T. Broadwood Johnson, M.A., of the Uganda Mission. With 30 Illustrations from Photographs. Large $\mathrm{cr}^{\circ}$. $8 \mathrm{vo}$, cloth.

KERR. From Charing Cross to Delhi. By S. Parnell Kerr. With 65 Illustrations. Demy 8 vo, cloth.

KING. Mountaineering in the Sierra Nevada. By Clarence King. Cr. 8vo, cloth.

KURZ (Louis). See under Conway and Coolidge's Climbers' Guides.

LA FARGE. An Artist's Letters from Japan. With many Illustrations. Demy 8vo, cloth.

LE BLOND. Adventures on the Roof of the World. By Mrs. Aubrey Le Blond (Mrs. Main). With over Ioo Illustrations, Demy Svo, cloth. net

Cheap Edition (Modern Travel Series), cloth.

True Tales of Mountain Adventure for Non-Climbers, Young and Old. By Mrs. Aubrey Le Blond (Mrs. Main). With numerous Illustrations and Frontispiece. Demy 8vo, cloth.

net $10 / 6$

Cheap Edition (Modern Travel Series) cloth. 
LE BLOND. Mountaineering in the Land of the Midnight Sun. By Mrs. Aubrey Le Blond (Mrs. Main). With many lllustrations and a Map. Demy 8vo, cloth.

LENTHERIC. The Riviera, Ancient and Modern. By Charles Lentheric. Translated by C. West. With 9 Maps and Plans, Large cr. 8vo, cloth.

LITTLE. In the Land of the Blue Gown. By Mrs. Archibald Little, Author of "Intimate China." With over roo Illustrations. Medium 8 vo.

Also a Cheaper Edition. Cloth.

net

Round About My Peking Garden. By Mrs. Archibald Little. Author of "Li Hung Chang, His Life and Times," "A Marriage in China," \&c., \&c. Fully Illustrated. Demy 8vo, cloth. net

LLOYD. In Dwarf-Land and Cannibal Country, By Albert B. Lloyd. Illustrated and with 3 Maps. Demy 8vo.

Also a Cheaper Edition. Cloth.

net

Uganda to Khartoum. Life and Adventure on the Upper Nile. By Albert B. Lloyd. With a preface by Victor Buxton. With a Map and 8I Illustrations. Demy 8vo, cloth.

LUMSDEN. Through Canada in Harvest Time : A Study of Life and Labour in the Golden West. By James Lumsden. Fully Illustrated, and with Map. Large cr. 8vo, cloth gilt.

MAC (J.) Little Indabas. See Overseas Library. No. 9.

MACDONALD. In Search of EI Dorado: A Wanderer's Experiences. By Alexander Macdonald. With 32 Illustrations. Demy 8vo, cloth.

Cheap Edition (Modern Travel Series), cloth.

McMAHAN. Byron in Italy. A Selection of Poems and Letters relating to His Life in Italy. Edited by Anna Benneson McMahan. With more than 60 Illustrations from Photographs. Large cr., 8vo, cloth.

net

With Shelley in Italy. A Selection of Poems and Letters relating to His Life in Italy. Edited, with an Introduction, by Anna Benneson McMahan. With 64 Illustrations from Photographs. Large cr. 8vo, cloth.

MALLIK. Impressions of a Wanderer. By Manmath C. Mallik, of the Middle Temple, Barrister-at-Law. Crown 8vo, cloth. net

MILLER. Travels and Politics in the Near East. By William Miller, Author of "The Balkans." With 100 Illustrations and a Map. Demy 8vo, cloth.

ERN TRAVEL SERIES, THE. Each Volume illustrated. Large cr. 8 vo, cloth.

(I) True Tales of Mountain Adventure. By Mrs. Aubrey le Blond (Mrs. Main). With many illustrations from photographs by the Author.

(2) In Search of EI Dorado. A Wanderer's Experiences. By A lexand er Macdonald, F.R.G S. With an Introduction by Admiral Moresby. With 32 Illustrations.

(3) Adventures on the Roof of the World. By Mrs. Aubrey le Blond (Mrs. Main). With more than roo illustrations.

(4) John Chinaman at Home. By the Rev. E. J. Hardy, Author of "How to be Happy though Married," lately Chaplain to H.M. Forces at Hong Kong. With 36 Illustrations.

(5) Present Day Japan. By A. M. Campbell Davidson. With 32 Illustrations.

(6) Links in my Life on Land and Sea. By Commander J. W. Gambier, R.N. With a Frontispiece. 
de MONTAGNAC (Noel), Negro Nobodies. See Overseas Library. No. 6.

MOSSO. Life of Man on the High Alps: Studies made on Monte Rosa. By Angelo Mosso. Translated from the Second Edition of the Italian by E. Lough Kiesow, in Collaboration with F. Kiesow. With numerous Illustrations and Diagrams. Royal 8vo, cluth.

MUMMERY. Mes Escalades Dans les Alpes et le Caucase. Par A. F. Mummery. Traduit de l'Anglais par Maurice Paillon. With a new Preface and Notice on Mummery as a Climber. Illustrated by a Portrait of the Author in Collotype, 24 full-page Plates, and 4 Maps. Paper covers.

net $8 /=$

My Climbs in the Alps and Caucasus. By A. F. Mummery. With Photogravure, Coloured and Half-Tone Illustrations by Joseph Pennell and others. New Edition, with Introductions by Mrs. Mummery and I. A. Hobson. Super-royal 8vo, cloth. net

NORMAN. The Peoples and Politics of the Far East. Travels and Studies in the British, French, Spanish, and Portuguese Colonies; Siberia, China, Japan, Korea, Siam, and Malaya. By Sir Henry Norman, M.P. With many Illustrations. Sixth Impression. Small demy $8 \mathrm{vo}$, cloth.

The Real Japan. By Sir Henry Norman, M.P. Profusely Illustrated. Large cr, 8vo.

net

NORMAN-NERUDA. The Climbs of Norman-Neruda. Edited, with an Account of his last Climb, by May Norman-Neruda. Demy 8 vo, cloth.

OBER. A Guide to the West Indies and Bermudas. By F. A. Ober. With Maps and many Illustrations. Small cr. 8vo, cloth. net

OGILVIE. My Life in the Open. By Will H. Ogilvie, Author of "Fair Girls and Gray Horses." With Portrait. Large cr.8vo, cloth. net

OLCOYT. Guide to Siena. Sce Heywood.

OVERSEAS LIBRARY, THE. At the End of this Section.

PARIS-PARISIEN. A Complete Guide to Paris. French Text. I.--What to See. II. - What to Know. III.-Parisian Ways. IV.Practical Paris. Large demy I2mo, limp leather.

PINNOCK. Wander Years Round the World. By James Pinnock. With over 70 Illustrations and about 20 special Maps. Demy 8 vo. cluth.

PULLEN-BURRY. Jamaica as it is, By B. Puller-Burry. With a Map and 8 Illustrations. Cr. 8vo, cloth.

net $6 /=$

Ethiopia in Exile: Jamaica Revisited. By B. Pullen-Burry. Cr. 8vo, cloth.

QUIN (Ethel). Well-Sinkers. See Overseas Library. No. 4.

REY. The Matterhorn. By Guido Rey. Illustrated by Edoardo Rubino. With a Preface by Edmondo de Amicis. Translated from the Italian by J. E. C. Eaton. With I4 Coloured Plates, 23 Pen Drawings, and II Photographs. Super royal 8vo, cloth. net

Fine Paper Edition (Limited to Fifteen Copies.) Price on application.

RODGERS. The Scenery of Sherwood Forest. With some Account of the Eminent Families once resident there, and an Essay on Robin Hood. By Joseph Rodgers. With Illustrations of the Magnificent Trees and Characteristic Scenery, from Drawings by the Author, and with Portraits in Photogravure. Super royal 8vo, cloth.

net $21 /$ - 
RODWAY (James). In Guiana Wilds. See Overseas Library. No 3.

ROOSEVELT. Ranch Life and the Hunting Trail, By Theodore Roosevelt, late President of the United States. Illustrated by Frederick Remington. Royal 8vo, cloth.

SCIDMORE. Java: The Garden of the East. By Eliza Ruhamah Scidmore. With nearly 40 full-page Illustrations. Cr. $8 \mathrm{vo}$.

Winter India. By Eliza Ruhamah Scidmore. Fully Illustrated. Medium 8vo, cloth.

SCOTT-ELLIOTT. Chile. By G. F. Scott-Elliott, F.R.G.S. With an Introduction by Martin Hume: Illustrated. (The South American Library. Vol. r.) Demy 8vo, cloth. net

SEARELLE. Tales of the Transvaal. By Luscombe Searelle. Illustrated by P. Frenzeny, and after Photographs. 8vo, cloth.

SEYMOUR. Saunterings in Spain-Barcelona, Madrid, Toledo, Cordova, Seville, Granada. By Major-General Seymour. Illustrated. Demy 8 vo, cloth.

SIBREE. Madagascar before the Conquest. By James Sibree. Illustrated. With Map. Demy 8vo, cloth.

SMITH. Budapest. The City of the Magyars. By T. Berkeley Smith. Fully Illustrated. Cr. 8vo, cloth.

THE SOUTH AMERICAN SERIES. Edited by Martin Hume. Each Volume Illustrated. Demy 8 vo, clotli.

Vol. I. Chile. By G. F. Scott-Elliot, F.R G.S.

Vol. 2. Peru. By C. Reginald Enock, F.R.G.S.

Vol: 3. Mexico. By C. Reginald Enock, F.R.G.S.

STEAD. Japan, Our New Ally. By Alfred Stead. With an Introduction by the Marquis Ito. Fully Illustrated. Cr. 8 vo, cloth. net

STEIN.- Sand-Buried Ruins of Khotan. By M. Aurel Stein, Indian Educational Service: With over I20 Illustrations and a Photogravure Frontispiece and large Map. Mediım 8vo, cloth. net

STRASBURGER. Rambles on the Riviera. By Eduard Strasburger, F.R.S., D.C.L. Oxon. With 87 Coloured Illustrations by Louise Reusch. Demy 8vo, cloth.

STRATILESCO. From Carpathian to Pindus: Pictures of Roumanian Country Life. By Tereza Stratilesco. With two Maps and many illustrations. Demy 8vo. cloth. net 15/-

STREET. A Philosopher in Portugal. By Eugène E. Street, F.S.A. Cr. 8vo, buckram. net $5 /-$

SUTCLIFFE. By Moor and Fell. Landscape and Lang-Settle Talk in West Yorkshire. By Halliwell Sutcliffe, Author of "Ricroft of Withens," \&c. With many Illustrations. Cr. 8vo, cloth.

SYMONDS. Days Spent on a Doge's Farm. By Margaret Symonds (Mrs. Vaughan). With a Photogravure Frontispiece and many other Illustrations from Sketches and Photographs. New Edition. Demy 8 vo, cloth.

net $10 / 6$

TAINE. Journeys through France: Being the Authorised Translation of "Carnets de Voyage." By Adolphe Hippolyte Taine. Cr. 8vo, cloth.

TAYLOR. Vacation Days in Hawaii and Japan. By Charles M. Taylor. Illustrated. Large cr. 8vo, cloth. net

TOWNSEND. Along the Labrador Coast. By Charles Wendell Townsend, M.D. With 40 Illustrations and a Map. Large cr. 8vo, cloth. 
TURNBULL. Tales from Natal, By A. R. R. Turnbull. Cr. 8vo, cloth $3 / 6$

TURNER. Siberia: A Record of Travel, Climbing, and Exploration. By Samuel Turner, F.R.G.S. With more than 100 Illustrations and 2 Maps. Demy 8vo, cloth. net

VANDERLIP. In Search of a Siberian Klondike. By Washington B. Vanderlip and H. B. Hulbert. IVith 48 Illustrations, Large cr. cloth. net

VILLARI. Russia Under the Great Shadow. By Luigi Villari, Author of "Giovanni Segantini," "Italian Life in Town and Country," \&c. With 84 Illustrations. Demy 8vo, cloth. net

Fire and Sword in the Caucasus. By Luigi Vallari. Illustrated. Demy 8vo, cloth. net $10 / 6$

WALLIS. The Advance of our West African Empire. By Captain Braithwaite Wallis. Fully Illustrated. Medium 8vo, cloth.

WATSON (JOHN). Woodlanders and Field Folk. Sketches of Wild Life in Britain. See "Natural History."

net

WEBSTER. Through New Guinea and the Cannibal Countries. By H. Cayley-IVebster. Very fully Illustrated from Photographs, and with Maps, Diagrams, and Photogravure Frontispiece. Medium $8 \mathrm{vo}$, cloth gilt.

WELLBY. Through Unknown Tibet. By Captain M. S. Wellby. Photogravure and many other Illustrations, also Maps and Appendices of Flora, \&c. Medium $8 \mathrm{vo}$, cloth gilt.

WERNER (A.). Captain of the Locusts. Sce Overseas Library. No. 2.

WILSON. The Climber's Note Book. By Claude Wilson, M.D. Waistcoat pocket size. Buckram, gilt. net

de WINDT. Through Savage Europe. By Harry de Windt, Author of "Siberia as it is," "From Paris to New York by Land," \&c., \&c. With more than 90 Illustrations. Demy 8 ro, cloth.

net $10 / 6$

WOODS. Washed by Four Seas. By H. C. Woods, F.R.G.S., formerly of the Grenadier Guards. With an Introduction by Sir Martin Conway, 66 Photographs and a Map. Demy 8vo, cloth. net

WORKMAN. In the Ice World of Himalaya. By Fanny Bullock Workman and William Hunter Workman. With 4 large Maps and nearly Ioo Illustrations. Demy $8 \mathrm{vo}$, cloth gilt.

Cheap Edition, with 2 Maps and 65 Illustrations.

- Through Town and Jungle: Fourteen Thousand Miles Awheel among the Temples and People of the Indian Plain. By William Hunter Workman and Fanny Bullock Workman. With Map and 202 Illustrations. Super royal 8vo, cloth.

WRIGHT. A Handbook of the Philippines. By Hamilton M. Wright. Illustrated. Cr. Svo, cloth.

YELD. Scrambles in the Eastern Graians. By George Yeld. Editor of the Alpine Fournal. Illustrated, and with a Map. Large cr. 8vo.

Yorkshire Ramblers' Club Journal, The. Edited by Thomas Gray. Illustrated. 8vo, paper covers.

ZIMMERMAN. Spain and her People. By Jeremiah Zimmerman. With many Illustrations. Demy 8vo, clotli.

ZURBRIGGEN. From the Alps to the Andes. Being the Autobiography of a Mountain Guide. By Mattias Zurbriggen. Translated by Mary Alice Vialls. Fully Illustrated. Demy 8vo, cloth. net

[For reference see also "History."] 
OVERSEAS LIBRARY, THE. Decorative Cover by W. H. Cowlishaw. Cr. 8vo.

(I) The Ipane. By R. B. Cunninghame Graham.

Paper covers, $1 / 6$; cloth, each

(5) A Corner of Asia. By Hugh Clifford.

(2) The Captain of the Locusts, and Other Stories. By A. Werner.

(3) In Guiana Wiids. By James Rodway.

(6) Negro Nobodies. By Nöel de Montagnac.

(7) A Wide Dominion. By Harold Bindloss.

(8) Among the Man-Eaters. By John Gaggin.

(4) The Well-Sinkers. By Ethel Quin.

(9) Little Indabas. By J. Mac.

(Io) Tales of the Pampas. By IV. Bulfin.

\section{NATURAL HISTORY, SCIENCE, \&C:}

BASTIAN. The Nature and Origin of Living Matter. By $\mathrm{H}$. Charlton Bastian, M.A., M.D. (Londou), F.R.S., F.L.S., Emeritus Professor of the Principles and Practice of Medicine, and of Clinical Medicine at University College, London. With 76 Illustrations. Medium 8vo, cloth.

BEAVAN. Animals I Have Known. By Arthur H. Beavan. With about 50 lllustrations. Cr. 8vo, cloth.

Cheap Edition. (Unwin's Nature Books. Vol. 10.) Cloth.

Birds I Have Known. By Arthur H. Beavan. With 39 Illustrations. Cr. 8 ro, cloth.

Cheap Edition. (Unwin's Nature Books. Vol. 9.) Cloth.

Fishes I Have Known. By Arthur H. Beavan. With about 40 Illustrations. Cr. 8vo, cloth.

Cheap Idition. (Unwin's Nature Books. Vol. II.) Cloth.

BELL. Health at its Best v. Cancer and other Diseases. By Robert Bell, M.B., M.D., F.F.P.S., \&c., formerly Senior Physician to the Glasgow Hospital for Women, Author of "Cancer: Its Cause and Treatment without Operation," \&c., \&c. Cr. 8vo, cloth. net

BLIND. The Ascent of Man. An Edition de Luxe, limited to 250 Copies. By Mathilde Blind. With an Introduction by Alfred Russel Wallace. Heliogravure Medallion Portrait printed on Japan paper. Fcap. 4to.

BOXALL. The Evolution of the World and of Man. By G. E. Boxall. Cr. 8vo, cloth.

BRIGHTWEN. Glimpses into Plant Life: An Easy Guide to the Study of Botany. By Mrs. Brightwen. Illustrated. Cr. 8vo, cloth.

Cheap Reissue. (Unwin's Nature Books. Vol. 4.) Cloth.

Inmates of my House and Garden. By Mrs. Brightwen. With 32 Illustrations by Theo. Carreras. Crown 8vo, imitation leather, in box.

Also a Cheap Edition. (Unwin's Nature Books. Vol. 3.) Cloth.

More about Wild Nature. By Mrs. Brightwen. With Portrait of the Author and many other full-page Illustrations. Cr. 8vo, imitation leather, gilt lettered, gilt edges, in box.

Also a Cheap Edition. (Unwin's Nature Books. Vol. 2.) Cloth.

Quiet Hours with Nature. By Mrs. Brightwen. Fully Illustrated. Cr. 8vo, cloth.

Also a Cheap Edition. (Unwin's Nature Books. Vol. 7.) Cloth. 2/- 
BRIGHTWEN. Wild Nature Won by Kindness. By.Mrs. Brightwen. Revised Edition, with additional Illustrations. Cr. 8vo, imitation leather, gilt lettered, gilt edges, in box.

Also a Cheap Edition. (Unwin's Nature Books. Vol. I.) Cloth.

Last Hours with Nature. By Mrs. Brightwen, F.Z.S., F.E.S., Edited by W. H. Chesson. With Illustrations. Cr. 8vo, cloth. net

THE BRIGHTWEN SERIES. See "Unwin's Nature Books."

CESARESCO. The Psychology and Training of the Horse. By Count Eugenio Martinengo Cesaresco. With Photogravure Frontispiece. Demy Svo, cloth.

CHAMBERLAIN. Methods in Plant Histology. By Charles J. Chamberlain, A.M., Ph.D. With many Illustrations from Photomicrographs. Demy 8 vo, cloth.

DITTRICH. The Horse: A Pictorial Guide to its Anatomy. Iro Drawings (reproduced by Photo. Lithography) by Hermann Dittrich, with Explanatory Notes by Prof. Ellenberger and Prof. Baum. In portfolio, 4 to.

FLAMMARION. Astronomy for Amateurs. By Camille Flammarion. Authorised Translation by Francis A. Welby. With 84 Illustrations. $\mathrm{Cr}$. 8vo, cloth.

Mysterious Psychic Forces. An Account of the Author's Investigations in Psychical Research, together with those of other European Savants. By Camille Flammarion. With 2I Illustrations. Demy 8 vo, cloth.

net

GEEN. What I Have Seen While Fishing. By Philip Geen. See under "Varia."

GUYER. Animal Micrology. Practical Exercises in Microscopical Methods. By Michael F. Guyer, Ph.D. Demy 8vo, cloth. net

HARTING. Recreations of a Naturalist. By J. E. Harting. With numerous Illustrations. Demy 8 vo, cloth.

HARVIE-BROWN. Travels of a Naturalist in Northern Europe. By J. A. Harvie-Brown, F.R.S.E., F.Z.S. With 4 Maps, 2 Coloured Plates, and many lllustrations, 2 vols. Small royal $8 \mathrm{vo}$, cloth.

HULME. That Rock Garden of Ours. By F. E. Hulme, F.L.S., F.S.A. With Coloured Illustrations. Demy 8 vo, cloth.

INGERSOLL. The Wit of the Wild. By Ernest Ingersoll. Illustrated. Cr. \&vo, cloth.

net

IRVING. How to Know the Starry Heavens. An Invitation to the Study of Suns and Worlds. By Edward Irving. With Charts, Coloured Plates, Diagrams, and many Engravings of Photographs. Demy 8vo, cloth.

LOEB. Studies in General Physiology. By Jacques Loeb. With numerous Illustrations. 2 vols., royal $8 \mathrm{vo}$, cloth.

MILLS. The Dog Book: The Origin, History, Varieties, Breeding, Education, and General Management of the Dog in Health, and his Treatment in Disease. By Wesley Mills, M.A., M.D., D.V.S., \&c. With 43 full-page Cuts, one Coloured Plate, and numerous other Illustrations. Large cr. 8vo, cloth.

NEWMAN. Bird Skinning and Bird Stuffing. By Edward Newman. Cr. 8vo.

OPPENHEIM. The Face and How to Read it. By Annie Isabella Openheim, F.B.P.S. Illustrated. Cr. 8 vo, cloth.

net $2 / 6$ 
PARSONS. The Nature and Purpose of the Universe. By John Denham Parsons. Demy 8vo, cloth.

PIKE. In Bird-Land with Field-Glass and Camera. By Oliver G. Pike. With over 80 Photographs of British Birds. Photogravure Frontispiece. Cr. 8vo, cloth gilt.

Cheap Reissue. (Unwin's Nature Books. Vol. 5.) Cr. 8vo. cloth.

RICHMOND. In My Lady's Garden. By Mrs. Richmond (late

B. Garden Editor of The Queen). With a Coloured Frontispiece and other Illustrations. Demy 8 vo, cloth.

RUDAUX. How to Study the Stars. By L. Rudaux. Profusely Illustrated. Cloth. net

SCHMIDT. Pain: Its Causation and Diagnostic Significance in Internal Diseases. By Dr. Rudolph Schmidt. Translated and Edited by Karl M. Vogel, M.D., and Hảns Zinsser, A.M., M.D., Demy 8vo, cloth.

SNELL. The Camera in the Fields. A Practical Guide to Nature Photography. By F. C. Snell. With 80 Illustrations. Cr. 8vo, cloth.

Cheap Re-issue. (Unwin's Nature Books. Vol. I2.)

Nature Studies by Night and Day. By F. C. Snell. With about 90 Photographs taken direct from Nature. Cr. 8vo, cloth.

SOLLAS. The Age of the Earth, and other Geological Studies. By W. J. Sollas, LL:D., D.Sc., F.R.S., Professor of Geology in the University of Oxford. Illustrated. Demy 8vo, cloth. net $10 / 6$

Cheap Edition. Large cr. 8vo, cloth. net $6 /$ -

STRACHEY. Cat and Bird Stories from "The Spectator." With an Introduction by John St. Loe Strachey. Cr. 8 vo, cloth.

- Dog Stories from "The Spectator." With an Introduction by J. St. Loe Strachey. Cr. 8vo, cloth.

STUTTARD. The Butterfly: Its Nature, Development, and Attributes. By John Stuttard. Illustrated. Fcap. 8vo, limp cloth.

THOMPSON. The Mental Traits of Sex. An Experimental Investigation of the Normal Mind in Men and Women. By Helen Bradford Thompson, Ph.D. With many Diagrams, Large cr. 8vo, cloth.

net

UNWIN. Future Forest Trees. The Importance of German Experiments in the Introduction of North American Trees. By A. Harold Unwir, D. Oec. Publ. (Munich). With 4 Illustrations. Demy 8vo, cloth.

net

UNWIN'S NATURE BOOKS (Formerly The Brightwen Series.) Each volume fully Illustrated. Cr. 8vo, cloth. each

(I) Wild Nature Won by Kindness. By'Mrs. Brightwen.

(2) More about Wild Nature. By Mrs. Brightwen.

(3) Inmates of my House and Garden. By Mrs. Brightwen.

(4) Glimpses into Plant Life. By Mrs. Brightwen.

(5) In Birdland with FieldGlass and Camera. By Oliver G. Pike.

(6) Bird Life in Wild Wales. By J. A. Walpole-Bond.
(7) Quiet Hours with Nature. By Mrs. Brightwen.

(8) Nature's Story of the Year. By Charles A. Witchell.

(9) Birds I Have Known. By Arthur H. Beavan.

(I0) Animals I have Known. By Arthur H. I3cavan.

(II) Fishes I Have Known. By Arthur H. Beavan.

(12) The Camera in the Fields. By F. C. Snell. 
WALPOLE-BOND. Bird Life in Wild Wales. By J. A. WalpoleBond. With 60 Illustrations from photographs by Oliver G. Pike.

Large cr. 8vo, cloth.

Cheap Re-issue. (Unwin's Nature Books. Vol. 6.)

WESTELL. British Bird Life. By W. Percival Westell, M.B.O.U., F.R.H.S., \&c. With over 60 Illustrations. With an Introduction by Sir Herbert Maxwell, Bart. Large cr. 8vo, cloth.

Cheap Edition, Large cr. 8vo, cloth.

WATSON. Woodlanders and Field Folk. Sketches of Wild Life in Britain. By John Watson, author of "Poachers and Poaching," and Blanche Winder. Illustrated. Large cr. 8vo, cloth. net

WITCHELL. Nature's Story of the Year, By Charles A. Witchell. Fully lllustrated. Cr. 8vo, cloth.

Cheap Re-issue. (Unwin's Nature Books. Vol. 8.) Cr. 8vo, cloth.

\section{RELIGION and EDUCATION.}

ALLARDYCE. Stops; or, How to Punctuate. A Practical Handbook for Writers and Students. By Paul Allardyce. Fcap. 8vo, cloth.

BADHAM. St. Mark's Indebtedness to St. Matthew. By F. P. Badham. $\mathrm{Cr}$. 8vo, cloth.

BENSON. The Religion of the Plain Man. By Father Robert Hugh Benson. Cr. 8vo, cloth.

BERRY. How to Become a Teacher. By T. W. Berry. Fcap. 8vo, cloth.

BLYTH. The Last Step to Religious Equality. By Edmond Kell Blyth. Cr. 8vo, paper covers.

BOUSSET. What is Religion? By Professor W. Bousset. Translated by F. B. Low. Cr. 8vo, cloth.

The Faith of a Modern Protestant. By Professor W. Bousset. Translated by F. B. Low. Cr. 8vo, cloth.

net

BRAY. The Town Child. By Reginald A. Bray, L.C.C., Author of "The Children of the Town" in "The Heart of the Empire,"

"The Boy and the Family" in "The Studies of Boy Life," \&c. Demy 8vo, cloth.

net

BRIDGETT. A History of the Holy Eucharist in Great Britain. By T. E. Bridgett, C.S.S.R. A New Revised and Illustrated Edition. Edited, with notes, by Herbert Thurston, S.J. Royal Folio, cloth. net

BROWN. The Social Message of the Modern Pulpit. By Charles Reynolds Brown. Cr. 8vo, cloth.

BURTON. The Life of Christ. An Aid to Historical Study, and a Condensed Commentary on the Gospels. By Ernest de Witt Burton and Shailer Mathews, Professors in the University of Chicago. Large cr. 8vo, cloth.

CAMPBELL. Thursday Mornings at the City Temple. By the Rev. R. J. Campbell, M.A. Cr. 8vo, cloth.

COX. The Bird's Nest, and Other Sermons for Children of all Ages. By Samuel Cox, D.D. Fourth Edition, imp. I6mo, cloth.

Expositions. By Samuel Cox, D.D. In 4 vols. Demy 8vo, cloth, each. 
DILLON. The Original Poem of Job. Translated from the Restored Text. By E. J. Dillon, Doc. Orient. Lang., Author of "The Sceptics of the Old Testament," \&c. To which is appended "The Book of Job According to the Authorised Version." Crown 8vo, cloth.

ELPHINSTONE. The Power of Character, and Other Studies. By Lady Elphinstone. Wilh a Preface by Canon J. G. Tetley. Cr. 8vo, cloth.

net

FOSTER (G. B.). The Finality of the Christian Religion. By George Burman Foster, Professor of the Philosophy of Religion, Chicaro. Demy 8vo, cloth.

GARDINER. The Bible as English Literature. By J. H. Gardincr. Cr. 8vo, cloth. net $5 /=$

GEORGE. Seventeenth Century Men of Latitude. Precursors of Liberal Theology. By E. A. George. With Portraits. Cr. 8vo, cloth.

GILMAN. University Problems in the United States. By Daniel Coit Gilman, LL.D. Demy 8vo, 320 pp., cloth.

HALL. Christian Belief Interpreted by Christian Experlence. By Charles Cuthbert Hall. With an Introductory Note by the ViceChancellor of the University of Bombay. Deny Svo, cloth. net

HARDY. Doubt and Faith. By Rev. E. J. Hardy, M.A. Cr. 8vo, cloth.

HARPER. Religion and the Higher Life. By WVilliam Rainy Harper, D.D., LJ.D. Large cr. 8vo, cloth.

The Trend in Higher Education in America. By William Rainy Harper, D.D., LL.D. Cr. 8vo, cloth. net

HENSON. Christ and the Nation. Westminster and other Sermons. By H. Hensley Henson, Canon of Westminster, and Rector of St. Margaret's. Cr. 8vo, clcth.

HERBERT (George). A Country Parson. See under "Philosophy, Essays," \&c.

The Temple. Sacred Poems. By Gcorge Herbert. Facsimile Reprint of the First Edition (I633). With an Introduction by J. H. Shorthouse, Author of "John Inglesant." Fcap. 8vo net

HILL. The Aspirate ; or, the Use of the Letter " $\mathrm{H}$ " in English, Latin, Greek, and Gaelic. By Gecffry Hill, M.A. Cr. 8vo, cloth. net

HORTON. Revelation and the Bible. By R. F. Horton, M.A., D.D. Third Edition. Cr. 8vo, cloth.

Inspiration and the Bible: An Inquiry. By R. F. Horton, M.A., D.D. Crown 8vo, cloth.

Popular Edition, cr. 8vo.

Paper, net, 1/- ; cloth, net

HOWARD. A History of Matrimonial Institutions. By George Elliott Howard, Ph.D. See under "History."

HYDE. The Religious Songs of Connacht. By Douglas Hyde, LL.D., M.R.I.A., Author of "A Literary History of Ireland," "Love Songs of Connacht," \&c. 2 vols. Cr, 8vo, cloth.

JEPHSON. Christian Democracy. A Church for Our Day. By Julie Jephson. Cr. 8vo, paper covers.

KING. The Psychology of Child Development. By Irving King. With an Introduction by John Dewey. Cr. 8ro, cloth. net

KO. Elementary Handbook of the Burmese Language. By Taw Sein Ko, M.R.A.S., F.A.I., F.S.A. Boards. net

KRUGER. The Papacy: The Idea and its Exponents. By Gustav Kruger. Crown 8vo, cloth.

net 
LEIGH. Our School Out-of-Doors. By the Hon. M. Cordelia Leigh, Author of "Simple Lessons from Nature," \&c. Illustrated. Cr. 8 vo, cloth.

LUCAS and ABRAHAMS. A Hebrew Lesson-Book. By Alice

Lucas and Israel Abrahams. Cr. 8vo, cloth.

MACPHAlL. Essays in Puritanism. By Andrew Macphail. Large cr. 8vo, cloth.

MARK. The Teacher and the Child. Elements of Moral and Religious Teaching in the Day School, the Home, and the Sunday School. By H. Thiselton Mark, Master of Method, the Owens College, Manchester. With Frontispiece. Cr. 8vo, cloth.

net $1 /$ -

MARTIN'S Up-To-Date Tables: Weights, Measures, Coinage. For Use throughout the Empire. By Alfred J. Martin, F.S.I. With I8 Diagrams and 3 Maps. Demy r6mo, cloth.

net $2 / 6$

-Up-to-Date Beginners' Table Book. For Schools and Home Teaching. Twenty-ninth Thousand. In papcr covers.

$1 d$.

MATHEWS. The Messianic Hope in the New Testament. By Shailer Mathews. Demy 8vo, cloth.

net $10 / 6$

MAZZINI (Joseph). See Stubbs.

NEGRI. Julian the Apostate. By Gaetano Negri. See under "Biograplyy."

OMAN. The Mystics, Ascetics, and Saints of India. By John Campbell Oman. Fully Illustrated. Medium 8vo, cloth. net 14/-

Cheaper Edition. Demy 8vo, cloth.

net $7 / 6$

The Brahmans, Theists and Muslims of India. By John Campbell Ounan, D.Lit. Illustrated. Medium 8vo, cloth. net

$14 /-$

Cults, Customs, and Superstitions of India. Being a Revised and Enlarged Edition of "Indian Life, Religious and Social." By J. Campbell Oman, D.Lit., M.R.A.S. Illustrated. Demy 8vo, cloth.

net $14 /-$

PARKER. The Complete Works of Theodore Parker. Crown 8vo, cloth.

each 5/-

(I) A Discourse of Matters Pertaining to Religion.

(2) The World of Matter and the Spirit of Man.

(3) The American Scholar.

(4) The Transient and Permanent in Christianity.

(5) Ten Sermons on Religion.

(6) Historic Americans.

(7) The Sins and Safeguards of Society.

(8) Social Classes in a Republic.

(9) Prayers, Poems'and Parables.

(10) Lessons from the World of Matter and of Man.

(II) Theism and Atheism.

(I2) The Divine Presence.

(r3) The Slave Power.

(14) The Law of God and the Statutes of Man.

(15) The Rights of Man in America.

(16) A Minister's Experience.

PAULSEN. German Education, Past and Present, By Friedrich Paulsen, Ph.D. Translated by T. Lorenz, Ph.D. Crown 8vo, cloth.

net $5 /$ -

PFLEIDERER. Religion and Historic Faiths. By Otto Pfleiderer, D.D., Professor of Theology in the University of Berlin. Crown 8 vo, cloth.

net

- Christian Origins. By Otto Pfleiderer, D.D. Crown 8vo, cloth. net The Development of Christianity. By Otto Pfleiderer. Cr. 8vo, cloth. net $5 \%$ 
PHILPOTT. London at School: The Story of the School Board, 1870-1904. By Hugh B. Philpott. Illustrated. Cr. 8vo, cloth.

PIKE. Wesley and his Preachers. By G. Holden Pike. See under "Biography."

RAVENSTEIN. A Pocket German-English Conversation-Dictionary. By G. E. Ravenstein. (Meyer's' Sprachführer.) 500 pages. $16 \mathrm{mo}$, cloth.

net

ROBINSON. The Golden Sayings of the Blessed Brother Giles of Assisi. Newly 'Translated and Edited, together with a Sketch of his Life, by Father Paschal Robinson, of the Order of Friars Minor. - With 6 Illustrations. Crown 8vo, cloth. net

SABATIER. Modernism. The Jowett Lectures of 1908. By Paul Sabatier. With a Preface and Notes, and the full text of the Encyclicals Pieni l'Anmio, Lamenlabili, and Pascendi Dominici Gregis. Translated by C. A. Miles. Crown 8vo, cloth. net

Disestablishment in France. See under "Politics."

SELLECK. The New Appreciation of the Bible. A Study of the Spiritual Outcome of Biblical Criticism. By W. C. Selleck, D.D. Crown 8vo, cloth.

STUBBS. "God and the Peoplel" The Religious Creed of a Democrat. Being Selections from the Writings of Joseph Mazzini. By Charles William Stubbs (Dean of Ely): Second Edition. Cr. 8vo.

TYRRELL. The Programme of Modernism. A Reply to the Encyclical Pascendi of Pius X. Translated from the second Italian Edition (with the author's latest additions), by George Tyrrell, M.A. With an Introduction by A. L. Lilley, M.A., Vicar of St. Mary's, Paddington Green. Crown 8vo, cloth.

UNWIN'S THEOLOGICAL LIBRARY.

Crown 8vo, cloth.

Each Volume. net

I Modernism. The Jowett Lectures of 1908. By Paul Sabatier.

2 What is Religion? By Professor W. Bousset.

3 The Bible as English Literature. By Professor J. H. Gardiner.

4 The Programme of Modernism. A Reply to the Encyclical Pascendi of Pius X.

5 Christian Origins. By Professor Otto Pfleiderer.

6 Religion and Historic Faiths. By Professor Otto Pfleiderer.

7 The Development of Christianity. By Otto Pfleiderer.

WAGNER. Courage. By Charles Wagner, Author "The Simple Life," \&c. Medium I2mo. Paper, net 1/- ; cloth, net

Towards the Heights. By Charles Wagner. Medium I2mo. Paper, net 1/- ; cloth, net

WARING. Christianity and its Bible. By Henry F. Waring. Large cr. 8vo, cloth.

WILLIAMS. Psalms and Litanies, Counsels and Collects for Devout Persons. By Rowland Williams, D.D. New Edition. Cr. 8vo, cloth.

Stray Thoughts from the Note-Books of Rowland Williams, D.D. New Edition. Cr. 8vo, cloth.

SLEY. Concepts of Monism. A Critical Comparison of all Systems of Monism, both Asiatic and European. By A. Worsley. Demy 8vo, cloth

See also under "Biography" for Oliver Cromwell, Robert and Mary Moffat, Dr. Parker, Girolamo Savonarola, Wesley, and others. Also Japp ["Master Missionaries,"] \&c. 


\section{DOMESTIC LITERATURE.}

BOLAND. The Century Invalid Cookery Book. By Mary A. Boland. Edited by Mrs. Humphrey ("Madge" of Truth). Cr. 8vo, cloth.

DAVIES. The Housewife's What's What. A Hold-All of Useful Information for the House. By Mary Davies. Large cr. $8 \mathrm{vo}$, cloth. net Popular Edition, large cr. $8 \mathrm{vo}$, cloth net

FORSTER. Chelsea Window Gardening; or, Some Notes on the Management of Pot Plants and Town Gardens. By L. M. Forster. Cr. 8vo, paper covers.

2d.

GUARRACINO. "Please, M'm, the Butcherl" A Complete Guide to Catering for the Housewife of Moderate Means, with Menus of all Meals for a Year, numerous Recipes, and Fifty-two additional Menus of Dinners without Meat. Illustrated. By Beatrice Guarracino. Large cr. $8 \mathrm{ro}$, cloth.

Cheap Edition, cloth.

HARDY. The Business of Life: A Book for Everyone. By the Rev. E. J. Hardy, M.A. Square imperial I6mo, cloth.

Presentation Edition, bevelled boards, gilt edges, in box.

The Five Talents of Woman: A Book for Girls and Young Women. By the Rev. E. J. Hardy, M.A. Popular Edition, small cr. 8 vo, cloth.

Presentation Edition, bevelled boards, gilt edges, in box.

How to be Happy though Married: Being a Handbook to Marriage. By the Rev. E. J. Hardy, M.A. Presentation Edition, imperial $16 \mathrm{mo}$, white vellum, cloth, extra gilt, bevelled boards, gilt edges, in box.

Popular Edition, cr. 8vo, cloth, bevelled boards.

Large cr. 8vo, green cloth with white label, flat back.

New Edition, 83rd thousand, small cr. $8 v 0$, cloth.

net

Small cr. 8vo, paper cover.

Also a Sixpenny Edition.

net

How to Get Married. By the Rev. E. J. Hardy, Author of "How to be Happy though Married. Cr. 8vo, paper covers. net

"Manners Makyth Man." By the Rev. E. J. Hardy, M.A. Presentation Edition, imperial I6mo, cloth, bevelled boards, gilt edges, in box.

Popular Edition, small square 8vo, cloth.

cloth,

The Sunny Days of Youth: A Book for Boys and Young Men. Square imperial I6mo, cloth.

Presentation Edition, elegantly bound, bevelled boards, gilt edges, in box.

HARLAND and HERRICK. The National Cook-Book: A Thousand Recipes carefully prepared in the light of the Latest Methods of Cooking and Serving. By Marian Harland and Christine Terhune Herrick. I2mo, cloth.

HUMPHREY. Manners for Girls. By Mrs. Humphrey. Long 8vo, cloth, decorated cover. 
PINK. Gardening for the Million. By Alfred Pink. Iarge cr. 8vo, cloth.

Recipes for the Million Alfred Pink. Twelfth Thousand. Cr. 8vo, cloth.

Quickest Guide to Breakfast, Dinner, and Supper, The. By Aunt Gertrude. Paper boards.

READ. The Way to Keep Well. Practical Home Hints on Common Ailments. By C. Stanford Read, M.B. (Lond.), London County Council Lecturer. Cr. $8 \mathrm{vo}$, cloth.

RONALD. The Century Cook-Book. By Mary Ronald. Fully Illustrated. Demy 8vo, cloth.

Luncheons: A Cook's Picture Book. A Supplement to "The Century Cook-Book." With many Illustrations. By Mary Ronald. Large cr. 8vo, cloth.

TUCKER. Mother, Baby, and Nursery : A Manual for Mothers. By Genevieve Tucker, M.D. Illustrated. Large cr. 8vo, cloth.

Paper covers, $1 /-$; cloth.

WHADCOAT. Every. Woman's Own Lawyer. A Legal Adviser for Ladies. By Gordon Cuming Whadcoat, Solicitor, Author of "The Balance," and other novels. Cr. 8vo, cloth. net

WOOD. Quotations for Occasions. Compiled by Katharine B. Wood. Large cr, 8vo cloth.

\section{BOOKS Por CHILDREN.}

BRENTANO. New Fairy Tales from Brentano. By Kate Freiligrath Kroeker. A New Edition. With Coloured Frontispiece and eight Illustrations by F. C. Gould. Fcap. 4 to, cloth.

BYLES. The Boy and the Angel: Discourses for Children. By Rev. John Byles. Cr. 8vo, cloth.

- The Legend of St. Mark: A New Series of Sunday Morning Talks to Children. By Rev. John Byles. Crown 8vo, cloth.

CHILDREN'S LIBRARY, THE. Illustrated. Fcap.8vo. The following in cloth, Pinafore binding, floral edges.

BASILE. The Pentamerone; or, the Story of Stories. By Giambattista Basile. Translated from the Neapolitan by John Edward Taylor. New Edition, revised and edited by Helen Zimmern. Illustrated by George Cruik. shank.

BECKMAN. Pax and Carlino. By Ernest Beckman.

COLLODI. The Story of a Puppet. By C. Collodi. Translated from the Italian by M. A. Murray. Illustrated by C. Mazzanti.
DAUDET. The Pope's Mule, and Other Stories. By Alphonse Daudet. Translated by A. D. Beavington. Atkinson and D. Havers. Illustrated by Ethel K. Martyn.

DEFOE. The Adventures of Robinson Crusoe. Edited with Illustrations by George Cruikshank.

DROSINES. Stories from Fairyland. By Georgios Drosines. Illustrated by Thomas Riley. 
CHILDREN'S LIBRARY, THE-continned.

EIVIND. Finnish Legends. Adapted by R. Eivind. Illustrated from the Finnish text.

EVANS. Sea Children. By S. Hope Evans. Illustrated.

HAUFF. The Little Glass Man, and Other Stories. Translated from the German of Wilhelm Hauff. Illustrated by James Pryde.

HUEFFER. The Feather. By Ford H. Hueffer. Frontispiece by Madox Brown.
IUUGESSEN. The Magic Oak Tree, and Other Fairy Stories. By Knatchbull Hugessen (Lord Brabourne), Author of "Prince Marigold," "Queer Folk" \&c,

MORRIS. Cornish Whiddles for Teenin' Time. By Mrs. Frank Morris. Illustrated by Arch. K. Nicolson.

WILLIAMS. Tales from the Mabinogion. By Meta IVilliams.

Popular Re-issue, Fcap. 8vo, decorated bindings. Illustrated. each B ROOK F I E I. D. AEsop's Fables for Little People. Told by Mrs. Arthur Brookfield. Pictured by Henry J. Ford.

BECKMAN. Pax and Carlino. By Ernest Beckman. Illustrated by Florence K. Upton.

CAPUANA. Once Upon a Time. By Luigi Capuana. Illustrated by C. Mazzanti.

COLLODI. The Story of a Puppet; or, The Adventures of Pinocchio. Illus. trated by C. Mazzanti.

DAUDET. La Belle Nivernaise. By Alphonse Daudet. Illustrated by Montegut.

DROSINES. Stories from Fairyland. By Georgios Drosines. Illustrated by Thomas Riley.

HOF F M N N. Nutcracker and Mouse King, and Other Stories. By E. T A. Hoffinann. Translated from the German by Ascott R. Hope.

HUEFFER. The Brown Owl. By Ford H. Hueffer. Illus. trated by Madox Brown.

MOLESWORTH. An Enchanted Garden. By Mrs. Molesworth. Illustrated by J. W. Hennessey.

O'GRADY. Finn and His Companion. By Standish O'Grady. Illustrated by Jack B. Yeats.

VOLKHOVSKY. The China Cup, and Other Stories. By Felix Volkhovsky. Illustrated by Malischeff.

YEATS. Irish Fairy Tales. Edited by W. B. Yeats. Illustrated by Jack B. Yeats.

CHILDREN'S STUDY, THE. Long $8 \mathrm{vo}$, cloth, gilt top, with Photogravure Frontispiece.

(I) Scotland. By Mrs. Oli.

( phant.

2) Ireland. Edited by Barry O'Brien.

(3) England. By Frances E. Cooke.

(5) Old Tales from Greece. By Alice Zimınern, Author of "Old Tales from Rome."

(6) France, By Mary Rowsell.

(7) Rome. By Mary Ford.

(4) Germany. By Kate Freiligrath Kroeker.

(8) Spain. ByLeonard TVilliams

(9) Canada. J. N. McIlwraith.

COX. The Brownies in the Philipnines. By Palmer Cox. Large 4to. Copiously illustrated.

DEFOE. The Adventures of Robinson Crusoe. By Daniel Defoe. Newly Edited after the Original Editions. ro full-page Illustrations by Kauffmann. Large cr. $8 \mathrm{vo}$, cloth extra, gilt edges.

DODGE. The Disdainful Maiden, A Fairy Story. By W. Phelps Dodge, Author of "Piers Gaveston," \&c. Parchinent, grey covers, cr. r2mo. 
FARROW. The Adventures of a Dodo. By G. E. Farrow, Author of "The Wallypug of Why," \&c. With 70 Illustrations by Willy Pogany, Crown 8vo, cloth.

GOULD. Tales Told in the Zoo. By F. Carruthers Gould and his son, F. H. Carruthers Gould. Fully Illustrated by "F. C. G." Cr. 4 to.

GRACE. Tales from Spenser. By R. W. Grace. 'With I2 Illustra. tions. Cr. 8vo; clóth.

JEPSON. The Lady Noggs, Peeress. By Edgar Jepson, Author of "The Admirable Tinker." Children's Edition. With I6 Illustrations by Lewis Baumer. Large crown 8vo, cloth.

MACDONALD. The Secret of the Sargasso. By Robert $M$. Macdonald. Profusely lllustrated. Large cr.8vo.

Chillagoe Charlie:/. By Robert M. Macdonald. Profusely' Illus: trated. Large cr. 8 vo.

McMANUS. The True Mother Goose. Songs for the Nursery; or, Mother Goose's Melodies for Children. With Notes and Pictures in two colours, by Blanche McManus. Cr. 4to, cloth. net

MONARCH SERIES, THE. Humorous Rhymes of Historical Times. By Roland Carse. Illustrations in coluur and black and white by W. Heath Robinson. Size $8 \frac{1}{2}$ in. by $I I$ in. See under "History.

NESBIT. The House of Arden. By E. Nesbit. With 32 Illustrations by H. R. Millar. Large crown 8vo.

The Phoenix and the Carpet. By E. Nesbit. With 48 Illustrations. Large crown 8vo.

Five Children and It. By E. Nesbit.: With 46 Illustrations by H. R. Millar. , Cr. 8vo, cloth. Illustrations.

By E. Nesbit. With 27

The Story of the Treasure Seekers. By E. Nesbit. Fifth Impression. With 15 Illustrations by Gordon Browne and 2 by Lewis Baumer. Large cr. 8vo, cloth.

New Treasure Seekers. By E. Nesbit. With about 40 Illustrations by Gordon Browne and Lewis Baumer. Cr. 8vo, cloth.

The Would-be-Goods. Being the Further Adventures of the Treasure Seekers. By E. Nesbit. With I8 Illustrations. Cr. 8vo, cloth gilt.

The Enchanted Castle. By E. Nesbit. With 48 Illustrations by H. R. Millar. Large crown 8vo, cloth.

The Story of the Amulet. By E. Nesbit. With 48 Illustrations by H. R. Millar. Large crown 8 vo, cloth.

ROWBOTHAM. Tales from Plutarch. By F. Jameson Rowbotham. Fully illustrated. Cr. 8vo, cloth.

SELLON: Only a Kitten, and Other Stories. By E. Mildred Sellon. Cr. 8vo, cloth.

SIDNEY, Five Little Peppers and How they Grew. By Margaret Sidney. Illustrated.

THOMAS. The Welsh Fairy Book. By W. Jenkyn Thomas, With a Coloured Frontispiece and about 200 Illustrations by Willy Pogany. Sinall Demy Svo, cloth.

TURNER. That Girl. By Ethel Turner (Mrs, Curlewis). With 25 Illustrations. Large cr. 8vo, cloth. 
UNWIN'S POPULAR SERIES FOR BOYS AND GIRLS. Illus: trated. Cr. 8vo, cloth.

(I) Brown, V.C. By Mrs. Alexander.

Each volume

(2) The Lost Heir. By G. A. Henty.

(3) The Mistress of Langdale Hall. By Rosa Mackcuzie Kettle.

(4) Margaret Hetherton. By E. Lough Kiesow.

(5) Love Triumphant, By $\mathbf{L}$. T. Meade.

(6) Under the Grand Old Hills. By Rosa Mackenzie Kettle.

(7) Prisoners of Conscience. By Amelia E. Barr.

(8) Kitty Costello. By Mrs. Alexander.

(9) Six Girls. By Fanny Belle Irving.

WARD. Milly and Olly, or A Holiday Among the Mountains. By Mrs. Humphry Ward. New Edition. Illustrated by Willy Pogany. I arge crown 8vo, cloth.

ZIMMERN (A.). Old Tales from Rome, By Alice Zimmern. Fully lllustrated. Cr. 8vo, cloth.

ZIMMERN (H.). Herioc Tales. Retold from Firdusi the Persian. By Helen Zimmern. With two Etchings by L. Alma-Tadema, R.A., and a Prefatory poem by Edmund W. Gosse. Third Edition. $\mathrm{Cr}$. $8 \mathrm{vo}$, cloth.

\section{VARIA.}

BATEY. The Motor Car and its Engine. A practical Treatise for Motor Engineers, including Owners and Chauffeurs. By John Batey. Demy $12 \mathrm{mo}$, cloth.

BERRY. Professions for Girls. By T. W. Berry. Cr. 8vo, cloth, net BERNHARD. First Aid to the Injured. By Dr. Oscar Bernhard. Cr. 8vo, cloth.

BROMLEY. How to Buy a Business. A Guide to the Purchase of Retail and other Businesses, Professional Practices, \&c. With a Chapter on Partnership. By A. W. Bromley. Cr. 8vo, cloth. net

BROOKES. The Motorist's A B C. A Practical Handbook for the use of owners, operators, and automobile mechanics. By L. Elliott Brookes. With more than 100 illustrations. net

CAIRD. Talks about the Border Regiment. By Major Lindsay $H$. Caird. Author of "A History of Corsica." Paper covers. net

DANA. The Art of Newspaper Making. Three Lectures. By Chas. A. Dana. Fcap. 8vo, paper boards.

DIETRICH. The Schulz Steam Turbine, for Land and Marine Purposes, with special reference to its application to War Vessels. By Max Dietrich, Marine-Engineer of the German Navy. With 43 lllustrations and Diagrams, and 6 Tables. Royal 8vo, cloth. T net

EVANS. The Canadian Contingent. By W. Sandford Evans. Profusely Illustrated from Photographs, and with several Maps. Cr. 8vo, cloth.

GEEN. What I have Seen while Fishing, and How I Have Caught. my Fish. By Philip Geen, for twenty-seven years President of the London Anglers' Association. With 73 Illustrations. Second Edition. Demy 8vo, cloth. net

Fishing in Ireland (being Vol. I of "What I have Seen while Fshing"). net

Fishing in Scotland and the Home Counties (being Vol:2 of the above). By Philip Geen. Fully Illustrated. Demy 8vo, cloth. net 
GOODENOUGH. The Handy Man Afloat and Ashore. By the Rev. G. Goodenough, R.N. Fully Illustrated. Cr. 8vo, cloth.

GRIEVE. How to Become a Commercial Traveller. By Ed. B. Grieve. Fcap. 8vo, cloth.

HACKWOOD. Old English Sports. By F. W. Hackwood. With 6 Coloured Plates, and 32 other full-page Illustrations. Demy $8 \mathrm{vo}$, cloth.

HATFIELD. American Commerce and Finance. Lectures delivered at the University of Chicago by representative Business Men. Edited by Henry Rand Hatfield. First Series. Large cr. 8vo, cloth. net

HICKS Vocations for Our Sons. By John W: Hicks, F.R.A.S. Cr. $8 \mathrm{vo}$, cloth.

net

HOLYOAKE. Public Speaking and Debate: A Manual for Advocates and Agitators. By George Jacob Holyoake. Cri 8 vo, cloth.

Cheap Edition, cloth, 2/- net ; paper covers.

Industrial Rivers of the United Kingdom. By various well-known Experts. Illustrated. Second Edition. Cr. 8vo, cloth.

JENKINS. Motor Cars, and the Application of Mechanical Power to Road Vehicles. By Rhys Jenkins, Memb. Inst. Mech. Eng. IVith over roo Illustrations. Medium 8vo, cloth.

JOHNSON CLUB PAPERS. By Various Hands, Copper-plate Frontispiece and fully Illustrated. Large cr. $8 \mathrm{vo}$, cloth. net

SHEPPARD. How to Become a Private Secretary : Qualifications, Training, Work. By Arthur Sheppard. Fcap. 8vo, cloth.

SHUDDICK. How to Arrange with Your Creditors. By R. Shuddick. Fcap. 8vo, cloth. is

SOMERSET. Studies in Black and White. By Lady Henry Somerset. Oblong $24 \mathrm{mo}$, sewed.

SPORTS LIBRARY. Edited by Howard Spicer. Each volume fully Illustrated. Cr. 8vo cloth. each

Vol. I. Riding, Driving, and Vol. 3. Cricket. By M. A. Kindred Sports. By T. F. Dale.

Vol. 2. Football, Hockey, and Lacrosse. By Bertie Fegan, Tindsley Linkley, J. C. Isard, and J. H. Battersby. Noble, A. Ward, P. F. Warner, Lord Harris, C. W. Alcock," S. Apted, T. C. Collins, and others.

THOMPSON. The Canal System of England: Its Growth and Present Condition, with particular reference to the Cheap Carriage of Goods. By H. Gordon Thompson, Victoria University, \&c.

Paper covers, net, $1 / 6$; cloth, net

WARREN: Commercial Travelling: Its Features Past and Present. By Algernon Warren. Cr. 8vo, cloth.

Who's Who in Germany (Wer Ist's)? Edited by Hermann A. L. Degener. Cloth.

WRIGHT. Baboo English as 'tis Writ. Curiosities of Indian Journalism. By Arnold Wright. Second Edition. Demy I6mo. 
THE NEW IRISH LIBRARY. Edited by Sir Charles Gavan Duffy, K.C.M.G., Assisted by Douglas Hyde, LL.D., and R. Barry O'Brien. Small cr. 8vo.

(I) The Patriot Parliament of 1689, with its Statutes, Votes and Proceedings. By Thomas Davis.

(2) The Bog of Stars, and Other Stories of Elizabethan Ireland. By Standish O'Grady.

(3) The New Spirit of the Nation. Edited by Martin MacDermott.

(1) A Parish Providence. By E. M. Iynch.

(5) The Irish Song Book. Edited by Alfred Perceval Graves.

Paper covers, $1 /$ - each ; cloth, $2 /$ -

(6) The Story of Early Gaelic Literature. By Douglas Hyde, LL.D.

(7) Life of Patrick Sarsfield. By Dr. John Todhunter.

(8) Owen Roe O'Neill. By J. TAH F. Taylor, K.C.

(9) Swift in Ireland. By Richard Ashe King, M.A.

(10) A Short Life of Thomas Davis. By Sir Charles Gavan Duffy.

(11) Bishop Doyle. By Michael MacDonagh.

(12) Lays of the Red Branch. By Sir Samuel Ferguson.

THE WELSH LIBRARY. Edited by Owen M. Edwards, Author of

"Walcs." Each volume fcap. 8vo.

Vols. 1-3. The Mabinogion. Translated from the Red Book of Hergest by Lady Charlotte Guest. 3 vols.

Vol. 4. The Works of John Dyer. Edited by Edward Thomas, M.A., Author of "Hor:e Solitarize."

Paper covers, $1 /$ - ; cloth, 2/In preparation:

A Short History of Welsh Literature. By Owen M. Edwards.

The Works of George Herbert. Edited by Miss Louise I. Guiney.

Henry Vaughan.

Mrs. Hemans' Welsh Melodies.

THE INTERNATIONA!. A Review of the World's Progress. Etiled by Rodo!phe Broda. Published Montily. Royal 8vo. net 1/-

M. A. B. (Mainly about Books). An Illustrated Monthly Guide to the best New Books.

THE LITERARY " $U$ " PEN. In book box.

UNWIN'S SHILLING NOVELS. A new series of higli-class Novels by Popular Writers. Bound in Picture Wrappers. Each net
(1) In Summer Shade. By Mary E. Mann.
(5) The Blue Lagoon. By $H$. de Vere Stacpoolc.
(2) Lady Mary of the Dark House. By Mrs. C. N. Williamson.
(6) The Lady Noggs, Peeress. By Edgar Jepson.
(3) The Shulamite. By Alice and Claude Askew.
(7) The Canon in Residence.
(4) "Mr. Thomas Atkins." By the Rev. E. J Hardy. By Victor L. Whitechurch.
(8) De Omnibus. By the Conducior (Barry Pain). 


\section{BAEDEKER'S GUIDE BOOKS}

\section{(Joist of Volumes in Englisf.)}

Published Prices are NET.

Austria-Hungary including Dalmatia and Boswia. With 33 Maps and 44 Plans. Tenth edition. 1905. Net 88 .

The Eastern Alps including the Bavarian Highlands, Tyrol, Salzburg, Upper and Lower Austria, Styria, Carinthia, and Carniala. With 6r Maps, io Plans, and 8 Panoramas. Eleventh edition. $190 \%$.

Net 10w.

Belgium and Holland including the Grand-Dichy of Luxembourg. With I5 Ilaps and 30 Plans. Fourteenth edition. 1905.

Net 6s.

The Dominion of Canada, with Neivfoundland and an Excursion to Alaska. With 13 Maps and 12 Plans. Third edition. 1907.

Net 6s.

Constantinople and Asia Minor, see Special List.

Denmark, see Norway, Sweden and Derimark.

Egypt, Lower and Upper Egypt, Lower and Upper Nubia and the Sudan. With 24 Maps; 76 Plans, and 59 Vignettes. Sixth edition. ' 1908 .

England, see Great Britain.

France :

Paris and its Environs, with Routes from London to Paris: With I4 Maps and 38 Plans, Sixteenth edition. r907. Net 8 ,

Northern France from Belgium and the English Channel to the Loire excluding Paris and its Environs. With 13 Mape and 40 Plans. Fourth edition. 1905. Net 78.

Southern France from the Loire to the Pyrenees, the Auvergne, the Clvennes, the French Alps, the Rhone Valley, Provence, the French Riviera and Corsica. With 33 Maps and 49 Plans. rifth edition. 1907. Net 88 .

\section{Germany :}

Beriin and its Envir. With 5 Maps and 20 Plans. Third edition. Igo8. Net 38 .

Northern Germany as far as the Bavar. ian and Austrian frontiers. With 49 Maps and 75 Plans. Fourteenth edition, 1904. Net 8s.

Southern Germany (Wurtemberg and Bavaria). With 30 Maps and 23 Plans. Tenth edition. rgo7.

Net 8s.

The Rhine from Rotterdam to Constance, including the Seven Mountains, the Moselle, the Volcanic Bifel, the Taunus, the Odenwald and Heidelberg, the Vosges Mountains, the Black Porest, \&cc. With 52 Mlaps and 20 Plans. Slxteenth edition. 1906.
Great Britain, England, Wales and Scotland. With 22 Maps, 58 Plans, and 2 Panorama. Sixth edition. 1906. Net 103. Lonton and its Environs. With 9 Maps and 9 Plans. Slxteenth editioa. 1909.

Net $6 \mathrm{~s}$.

Greece, the Greek Islands aud an Excursion to Crete. With I6 Maps, 30 Plans, and a Panorama of Athens. Fourth edition. rgog.

Net 8 s.

Holland, see Belgium and Holland.

Italy :

1. Northern Italy, including Leghorn, Florence, Ravenna and routes through Switzerland and Austria. With 30 Maps and 40 Plans. Thirteenth edition. 1906. Net 88 .

I1. Central Italy and Rome. With I9 Maps, 55 Plans, a view of the Forum Romanum, and the Arms of the Popes since 1417. Fifteenth edition. 1909:

Net 7s. 8d.

III. Soulhern Italy and Sicily, with Excursions to Malta, Sardinia, Tunis, and Corfu. With 30 Maps and 28 Plans. Flfteenth edition. Igo8. Net $8 \mathrm{~s}$.

Italy from the Alps to Naples. With 25 Maps and 52 Plans. Second edition. 1909. Net 8s.

Norway, Sweden and Denmark including an Excursion to Spitzergen. With 37 Maps, 22 Plans, and 3 Panoramas. Eightb edition. 1903. Net 8 s.

Palestine and Syria, including the principal routes through Mesoposamia and Babylonia. With 20 Maps, 52 Plans, and a Panorama of Jerusalem. Fourth edition. 1906.

Net 128.

Portugal, see Spain and Portugal.

Riviera, see Southern France.

Russia, see Special List.

Scotland, see Great Britain.

Spain and Portugal with Excursions to Tangier and the Balearic Islands. With 9 Maps and 57 Plans. Third edition. 1908. Net 16s.

Switzerland and the adjacent portions of Italy Savoy and Tyrol. With 69 Maps, I8 Plans, and II Panoramas. Twentysecond edition. 1907. Net 8s.

Tyrol! see The Eastern Alps.

The United States, with Excursions to Hexico, Cuba. Porto Rico and Alaska. With 33 Maps and 48 Plans. Pourth edition. 1909.

Net 150,

Complete List-English, French, and German-free on application. 


\section{THE ORDNANCE SURVEY MAPS.}

MR.T. FISHER UNWIN has pleasure in announcing that he has been appointed by His Majesty's Government sole wholesale agent for the Small Scale Ordnance Survey and Geological Maps of the United Kingdom.

UTILITY OF THE MAPS.-For general views of the structure of the country, the distribution and relation of mountains, plains, valleys, roads, rivers, and railways, the Ordnance Maps, practically the result of generations of work, are unsurpassed. Being Govern. ment publications they are the official maps from which all others have to be prepared.

LUOIDITY AND RELIABILITY.-Owing to the exceedingly fine draughtsmanship and engraving of Ordnance Maps, and the good paper they are printed upon, they will be found perfectly legible. They give a vast amount of information, yet they are easy to read and understand. They are being constantly revised and brought up to date, and may be regarded as of unimpeachable accuracy.

OONVENIENT FORM OF THE MAPS. The maps can be obtained folded in such a way that they will go easily into the pocket, and need not be opened to their full extent for inspection, but can be examined a section at a time, like the pages of a book. This greatly facilitates outdoor reference in stormy weather.

DIFFERENT SGALES AND CHARAOTERISTIOS.The maps are on the scales of $1,2,4,10$, and 15 miles to the inch. The one-mile-to-the-inch maps are ideal for pedestrian and cross. country purposes, being on a large and legible scale, with great wealth of topographical detail. The two-mile-to-the-inch maps in colour are the standard maps for all-round touring purposes, especially as road maps for motoring, cycling and walking. Special attention is directed to the new sheets of this scale on the "Layer system." The four miles, ten miles, and fifteen-miles-to-the-inch maps are practically indispensable to motorists and cyclists travelling long distances. They are also specially suitable as wall maps for educational purposes.

OATALOGUE.-The complete Catalogue containing full details of prices, with directions for ordering maps, will be sent post free to any address on request.

\section{Indian Government Publications.}

MR. T. FISHER UNWIN has been appointed Agent by I the Secretary of State for India for the sale of these publications. They include a variety of works on Indian History and Archaeology, Architecture and Art, Botany and Forestry; Grammars of the different Indian LanguagesDafla, Kurukh, Lepcha, Lais, \&c. ; and the valuable series of maps of the Indian Ordnance Survey.

Catalogues will be sent on application.

T. FISHER UNWIN, 1, Adelphi Terrace, London. 


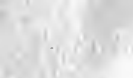

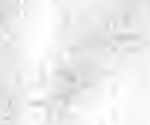


RETURN TO the circulation desk of any University of California Library

$$
\text { or to the }
$$

NORTHERN REGIONAL LIBRARY FACILITY Bldg. 400, Richmond Field Station

University of California

Richmond, CA 94804-4698

ALL BOOKS MAY BE RECALLED AFTER 7 DAYS 2-month loans may be renewed by calling

(510) 642-6753

1-year loans may be recharged by bringing books to NRLF

Renewals and recharges may be made 4 days prior to due date

DUE AS STAMPED BELOW

\section{AUG 8 1999 PETURRIE}

AU6 121994

sant ditnoy 
YC 89340

(n) 

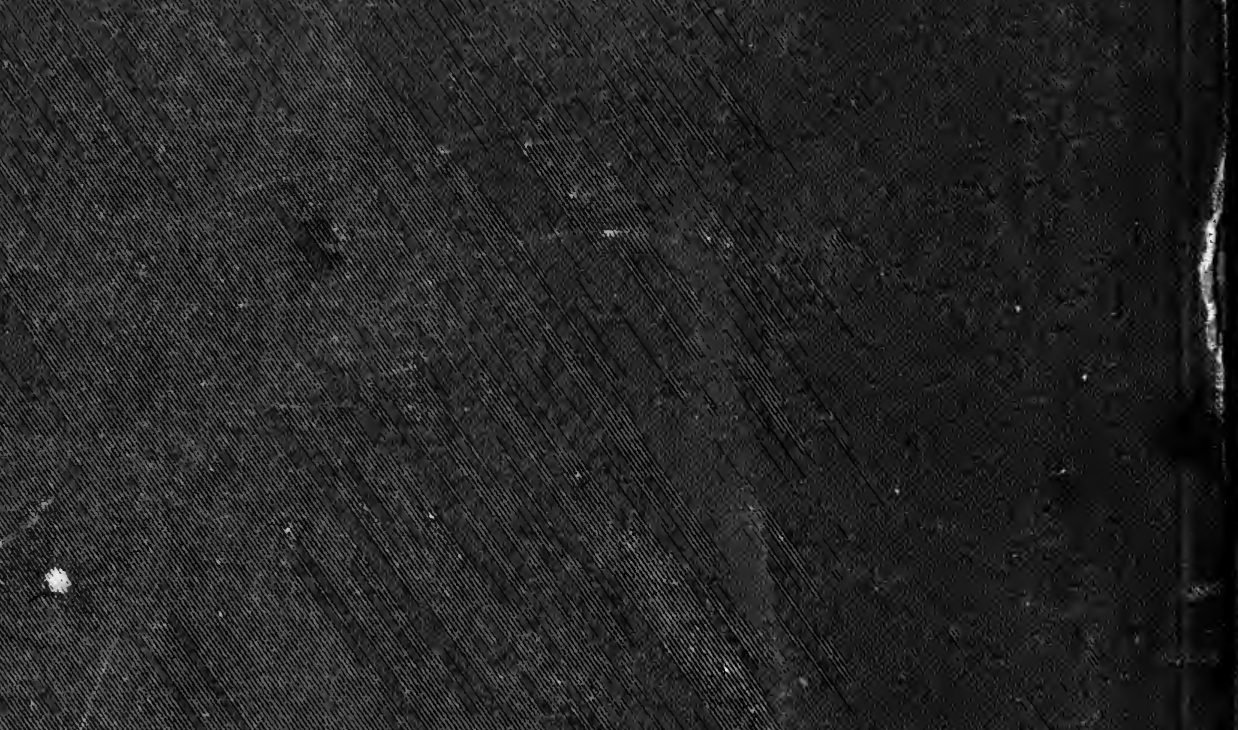

,
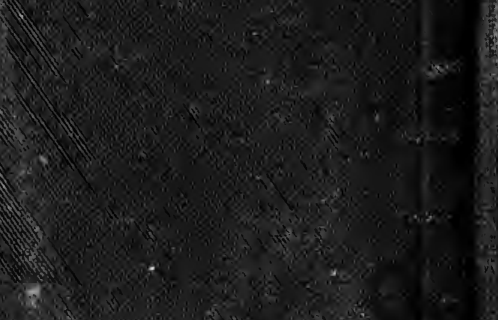